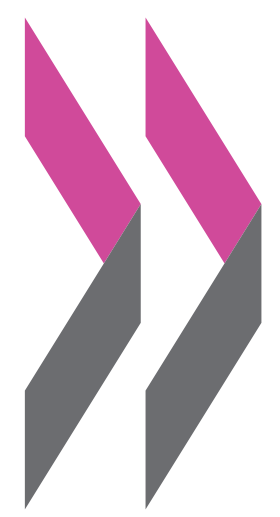

Eurostat-OECD Methodological Guide for Developing Producer Price Indices for Services

Second Edition 



\title{
Eurostat-OECD \\ Methodological Guide for Developing Producer Price Indices for Services
}

\author{
SECOND EDITION
}


This work is published under the responsibility of the Secretary-General of the OECD.The opinions expressed and arguments employed herein do not necessarily reflect the official views of OECD member countries or the European Union.

This document and any map included herein are without prejudice to the status of or sovereignty over any territory, to the delimitation of international frontiers and boundaries and to the name of any territory, city or area.

\section{Please cite this publication as:}

OECD/Eurostat (2014), Eurostat-OECD Methodological Guide for Developing Producer Price Indices for Services: Second Edition, OECD Publishing.

http://dx.doi.org/10.1787/9789264220676-en

ISBN 978-92-64-22066-9 (print)

ISBN 978-92-64-22067-6 (PDF)

European Union

Catalogue number: KS-04-14-661-EN-C (print)

Catalogue number: KS-04-14-661-EN-N (pdf)

ISBN 978-92-79-38769-2

ISBN 978-92-79-38768-5

The statistical data for Israel are supplied by and under the responsibility of the relevant Israeli authorities. The use of such data by the OECD is without prejudice to the status of the Golan Heights, East Jerusalem and Israeli settlements in the West Bank under the terms of international law.

Photo credits: Cover @ art4all/Shutterstock.com.

Corrigenda to OECD publications may be found on line at: www.oecd.org/about/publishing/corrigenda.htm.

(C) OECD/European Union, 2014

You can copy, download or print OECD content for your own use, and you can include excerpts from OECD publications, databases and multimedia products in your own documents, presentations, blogs, websites and teaching materials, provided that suitable acknowledgment of the source and copyright owner is given. All requests for public or commercial use and translation rights should be submitted to rights@oecd.org. Requests for permission to photocopy portions of this material for public or commercial use shall be addressed directly to the Copyright Clearance Center (CCC) at info@copyright.com or the Centre français d'exploitation du droit de copie (CFC) at contact@cfcopies.com. 


\section{Foreword}

The international Producer Price Index Manual (PPI Manual) published by the IMF in 2004 constituted a landmark for international standards on price measurement. It contains detailed, comprehensive information for the compilation of producer price indices as well as an extensive coverage of conceptual and theoretical issues. The joint Eurostat-OECD Methodological Guide for Developing Producer Price Indices for Services (SPPI Guide) is a complement to the PPI Manual in two ways: it focuses on service specific aspects in the PPI compilation by further developing the conceptual framework and it adds detailed descriptions of PPI measurement for a series of service industries.

Over the past decade, the field of service producer price indices (SPPI) has developed further. Considerable methodological and practical progress has been made by both European Union (EU) and non-EU OECD countries, resulting in a significant increase in the availability of SPPI. This second edition of the SPPI Guide signifies this considerable progress. It updates and replaces the first edition of the Guide that was published in 2005. It aims to help countries in developing SPPIs by sharing experiences and lessons learnt in the collection of data and the compilation of indices.

The second edition of the SPPI Guide has three objectives: first, to propose a global and comprehensive framework that improves the understanding of problems related to the specific nature of services: many services are unique, they are not repeated, at least not in a fully comparable manner, or they might be customer specific; second, to identify practical solutions implemented by countries for developing SPPIs for specific service industry (e.g. transport and storage, information and communication services, and professional, scientific and technical services); third, to promote new methodologies that in some cases are still under development (e.g. financial intermediation, insurance, human health activities) and for which the sharing of experiences and expertise will contribute to address remaining issues and challenges.

The electronic version of the second edition of the SPPI Guide is available on the websites of the OECD and Eurostat. The SPPI Guide should be considered as a 'living document'; in due course, it will be revised and updated, to incorporate additional service industries and to address particular issues in greater detail. It is hoped that this Guide will advance the development of services producer price indices in the OECD region and beyond, thus providing better information for decision-making and analysis.

We trust that this second edition of the Methodological Guide for developing producer price indices for services will foster the compilation, the understanding and the use of producer price indices for services.

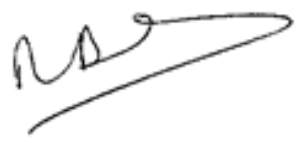

Martine Durand

OECD Chief Statistician and

Director of Statistics

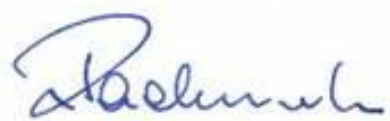

Walter Radermacher

Chief Statistician and

Director General of Eurostat 



\section{ACKNOWLEDGEMENTS}

The second edition of the SPPI Guide has been jointly produced by the OECD, Eurostat and a joint Eurostat-OECD Task Force set up to oversee the revision and updating of the 2005 edition of the SPPI Guide.

The joint Eurostat-OECD Task Force was established in 2011 and met three times: on 14-15 April 2011 (Paris, OECD), 26-27 September 2011 (Newport, U.K., Office for National Statistics) and 26-27 April 2012 (Paris, OECD). The Task Force was chaired by Nadim Ahmad (OECD) and Paul Schreyer (OECD). Delegates from Austria, Australia, Canada, France, Germany, Hungary, Israel, Japan, Korea, the Netherlands, Mexico, Poland, the United Kingdom and the United States participated in the Task Force. Several among them contributed to the Guide by providing detailed descriptions of their methodologies for compiling service PPIs; the others were represented by national experts in meetings of the Task Force.

André Loranger (Statistics Canada) officially represented the Voorburg Group on Services Statistics in the Task Force.

The first three methodological chapters in the Guide were written by the OECD and Eurostat Secretariats, under the guidance of the Task Force. Anne-Sophie Fraisse (OECD) is the principal author, with support from Thomas Jaegers (Eurostat). Niall O'Hanlon (CSO Ireland) contributed significantly.

Chapters 4 to 13 of the Guide, which mainly report country practices, were drafted under the responsibility of lead authors, again under the guidance of the Task Force: Dorothee Blang (Destatis), Paul Boling (Australian Bureau of Statistics), Johanna von Borstel (Destatis), Catherine Draper, (Statistics Canada), Anne-Sophie Fraisse (OECD), David Friedman (U.S. Bureau of Labor Statistics), Denis Gac (INSEE), Alain Gallais (INSEE), Ildikó Hamvainé Holocsy (Statistics Hungary), Christopher Jenkins (Office for National Statistics United Kingdom), Hina Kikegawa (Bank of Japan), Michael Morgan (Australian Bureau of Statistics), Bonnie Murphy (U.S. Bureau of Labor Statistics), Aspasia Papa (Office for National Statistics United Kingdom), Christian Puchter (Statistics Austria), Maria Schuch (Statistics Austria), Marcel Spanjaard (Statistics Netherlands), and Ruth Vizner (Central Bureau of Statistics Israel).

Niall O'Hanlon (CSO Ireland) acted as the editor of the SPPI Guide with contributions from Anne-Sophie Fraisse (OECD).

Eurostat and the OECD would like to thank all those who contributed by providing comments and suggestions to the improvement of this Guide. 



\section{Table of contents}

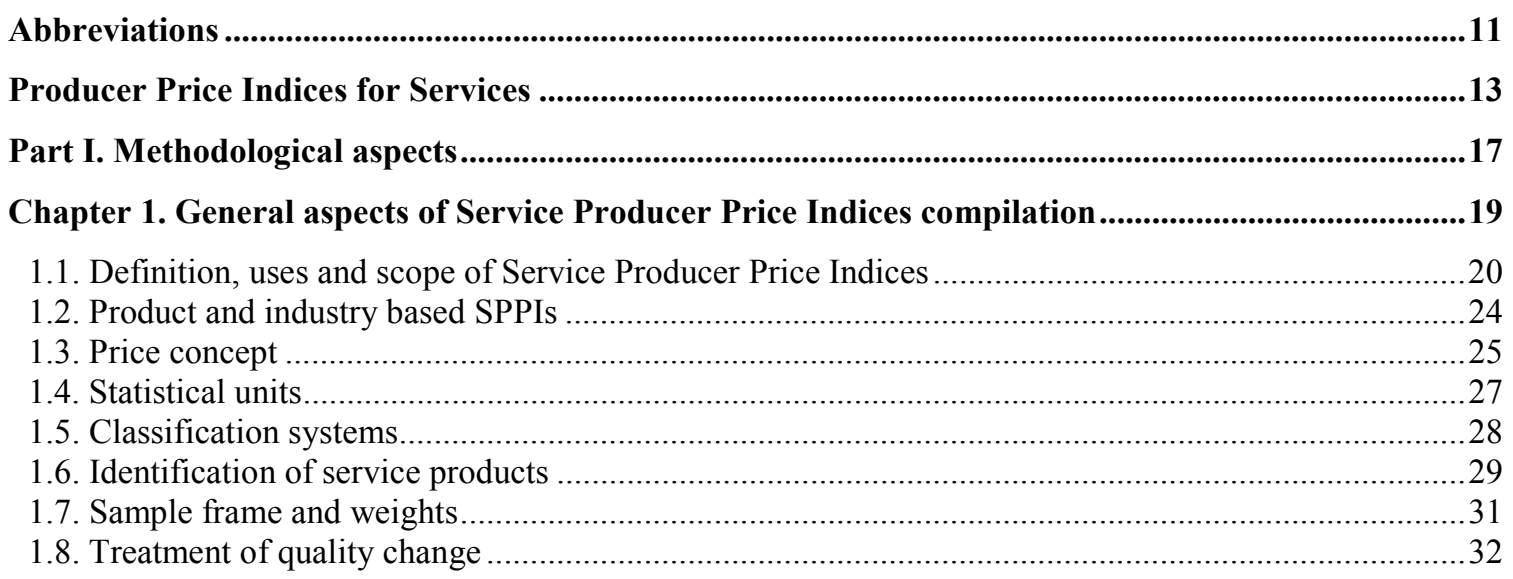

Chapter 2. Main pricing methods for Service Producer Price Indices .......................................................37

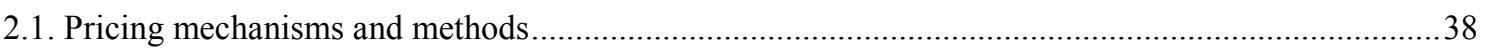

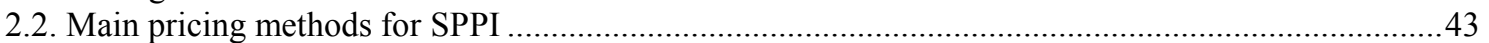

Chapter 3. Practical aspects of the development process .............................................................................69

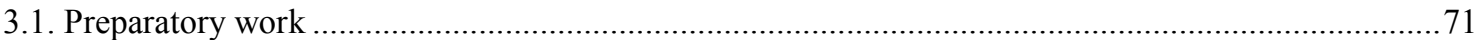

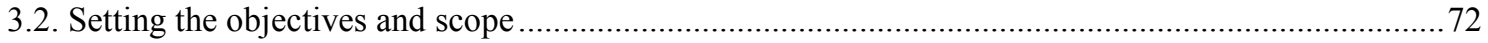

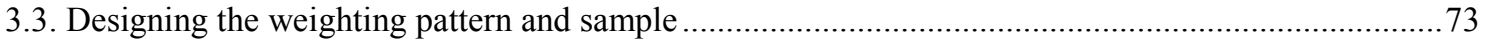

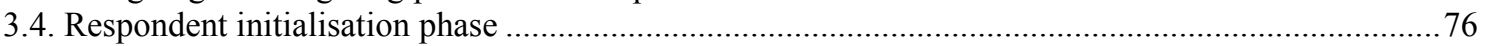

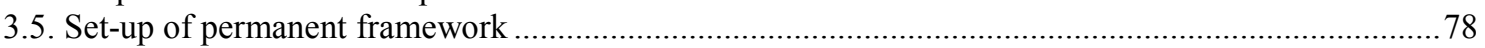

Part II. Producer Price Indices for specific service industries................................................................89

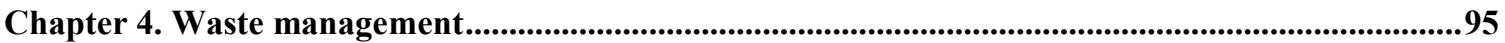

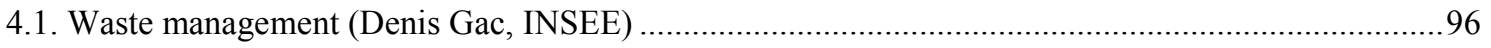

Chapter 5. Wholesale and retail trade services .....................................................................................105

5.1. Wholesale and retail trade services (Catherine Draper, Statistics Canada) ......................................106

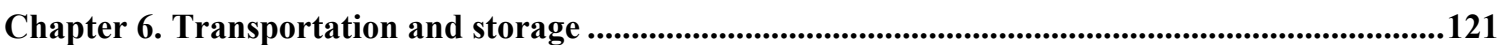

6.1. Freight transport by road (Christopher Jenkins and Aspasia Papa, Office for National Statistics United Kingdom)

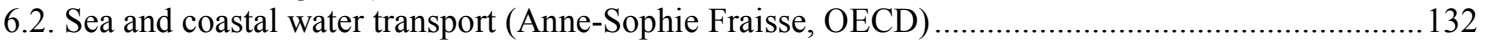

6.3. Air transport (Christian Puchter, Statistics Austria) ........................................................................ 142

6.4. Warehousing and storage (Paul Boling, Australian Bureau of Statistics).........................................149

6.5. Cargo handling (Paul Boling, Australian Bureau of Statistics) .....................................................155

6.6. Courier and postal activities (Denis Gac, INSEE \& Ildikó Hamvainé Holocsy, Statistics

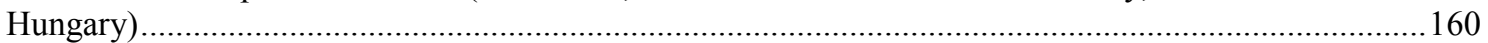

Chapter 7. Accommodation and food service activities......................................................................177

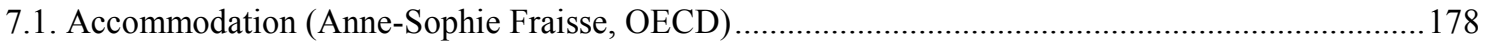


Chapter 8. Information and telecommunication ...........................................................................201

8.1. Publishing of books, periodicals and other publishing activities (Denis Gac, INSEE) ...................202

8.2. Software publishing (David Friedman, U.S. Bureau of Labor Statistics).....................................208

8.3. Telecommunications (Christopher Jenkins, Office for National Statistics U.K.) .........................2217

8.4. Computer programming, consultancy and related activity (Ruth Vizner, Central Bureau of

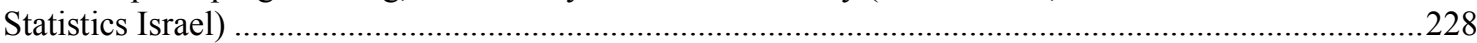

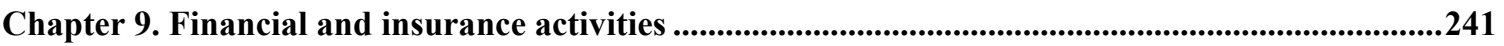

9.1. Monetary intermediation activities (David Friedman, U.S. Bureau of Labor Statistics) .................242

9.2. Investment banking (David Friedman, U.S. Bureau of Labor Statistics) .....................................252

9.3. Security and commodity contracts brokerage (Hina Kikegawa, Bank of Japan)...........................261

9.4. Insurance (David Friedman, U.S. Bureau of Labor Statistics) ..................................................2275

Chapter 10. Real estate activities..............................................................................................287

10.1. Real estate activities with own or leased property (Aspasia Papa, Office for National

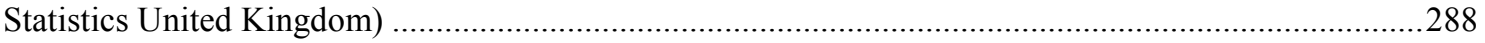

Chapter 11. Professional, scientific and technical activities............................................................299

11.1. Legal activities (Christopher Jenkins, Office for National Statistics, United Kingdom \&

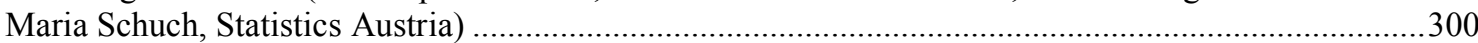

11.2. Accounting, bookkeeping and auditing activities; tax consultancy (André Loranger,

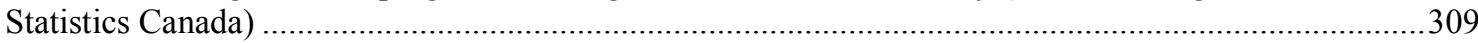

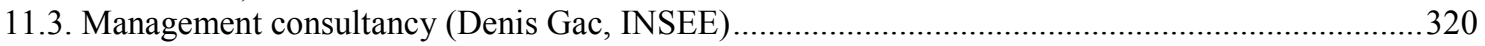

11.4. Architectural activities (Marcel Spanjaard, Statistics Netherlands) .........................................327

11.5. Engineering services and related technical consulting services (Marcel Spanjaard, Statistics

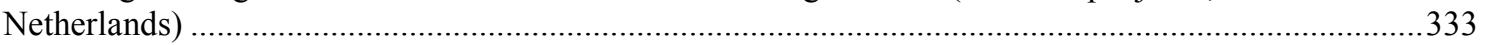

11.6. Technical testing and analysis (Ildiko Holocsy, Hungarian Central Statistical Office)....................341

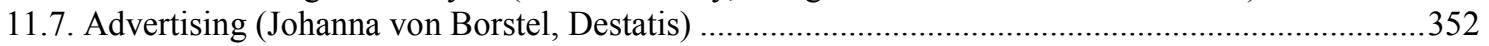

11.8. Market research and public opinion polling (Aspasia Papa, Office for National Statistics

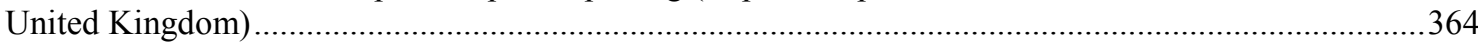

Chapter 12. Administrative and support service activities .............................................................375

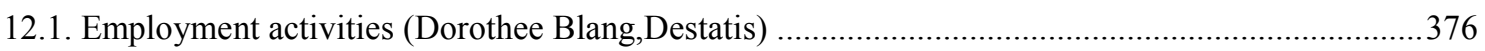

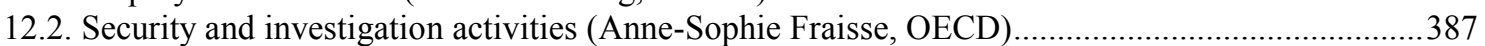

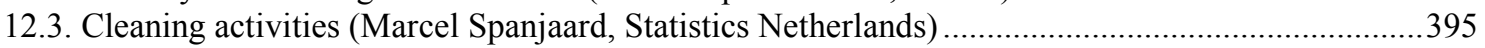

Chapter 13. Human health activities...................................................................................................405

13.1. Human health activities (Bonnie Murphy, U.S. Bureau of Labor Statistics) .............................406

Annex A. Classification systems by industry ................................................................................419

Annex B. Classification systems by product .................................................................................421

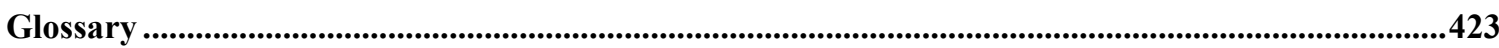

Boxes

Box 1.1. SPPI by destination - the French experience ................................................................23

Box 2.1. Classification of main pricing methods for SPPI ........................................................42

Box 2.2. Direct use of prices of repeated services: passenger car rental industry.................................44

Box 2.3. Contract pricing: Freight transport by road ....................................................................46

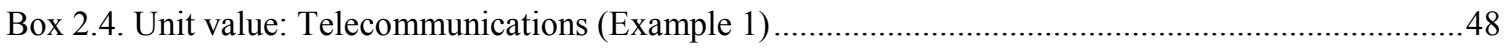

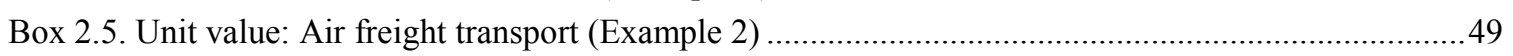


Box 2.6. Percentage fee: Leasing of office equipment (Example 1) ..................................................50

Box 2.7. Percentage fee: Real estate activities (Example 2) .................................................................51

Box 2.8. Component pricing: Telecommunications ....................................................................53

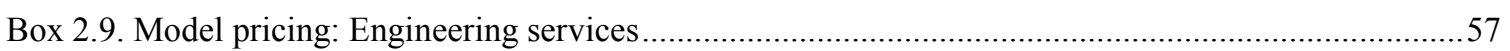

Box 2.10. Pricing based on working time / Hourly charge-out rate: Engineering activities ........................60

Box 2.11. Pricing based on working time / realised hourly rates: Engineering activities...........................61

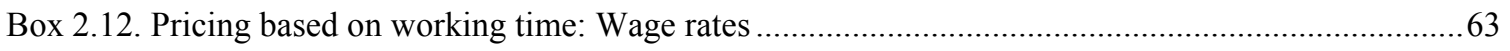

Box 3.1. Main phases of the development process ............................................................................ 70

Box 3.2. Timetable for developing an SPPI - hypothetical example.....................................................71

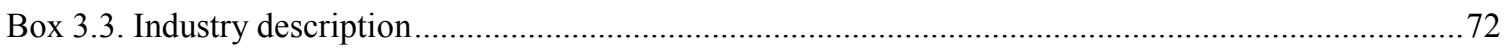

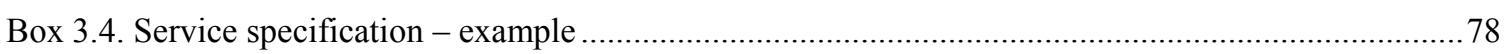

Box 3.5. Overlap method - example ................................................................................................. 80

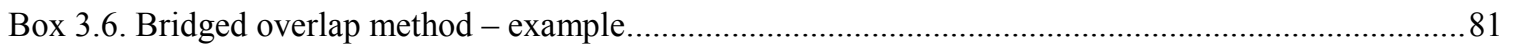

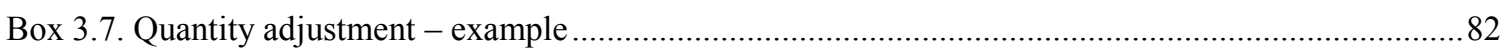

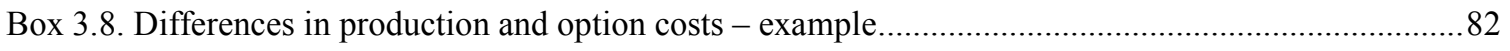

Box 3.9. Weighting example for product SPPI of 4-digit level industry ............................................8 84

Box 3.10. Assessment of SPPI for service industry ........................................................................ 85

Box 3.11. Criteria for evaluating an SPPI as a national accounts deflator.............................................86

Box 6.1.1. Example of a service description for a price quotation for road haulage services.................. 125

Box 8.1.1. French examples of types of prices collected for books.....................................................206

Box 8.1.2. French examples of types of prices collected for newspapers............................................207

Box 9.2.1. Example of a firm commitment equity underwriting transaction.......................................257

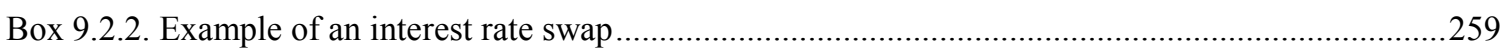

Box 9. 3. 1. Example: a customer would like to purchase securities at time 0 ....................................268

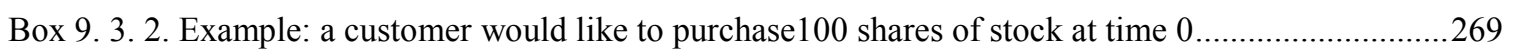

Box 9. 3. 3. Example: a customer would like to purchase securities at time 0 .......................................269

Box 9.3.4. Example of a reverse repurchase agreement ..................................................................2 271

Box 11.4.1. Model pricing for architectural activities .................................................................330

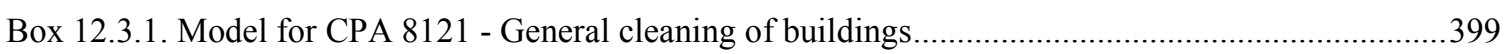

\section{Tables}

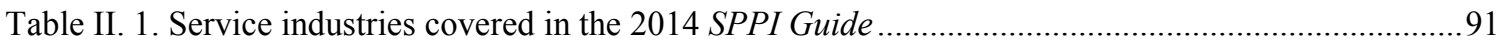

Table 8.2.1. U.S. indices for the Software Publishing industry ........................................................214

Table 8.2.2. Weighting results for CPA-products for Other software publishing (NACE 58.29),

Computer programming, consultancy and related activities (NACE 62.00), and Data processing, hosting and related activities; web portals (NACE 63.10) ............................................................216

Table 8.3.1. Summary of the Pricing Method for Telecommunications SPPI .......................................222

Table 8.4.1. Pricing methods for computer programming, consultancy and related activity ...................234

Table 9.1.1. U.S. PPI industry based publication structures for the banking industries ..........................248

Table 9.1.2. U.S. PPI product based publication structures for the banking industries ............................249

Table 9.2.1. U.S. PPI industry based publication structures for the investment banking and

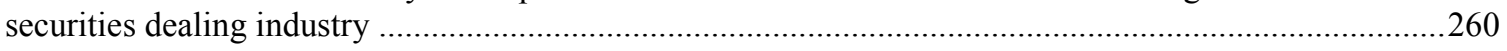

Table 9.2.2. U.S. PPI product based publication structures for investment banking services .................260

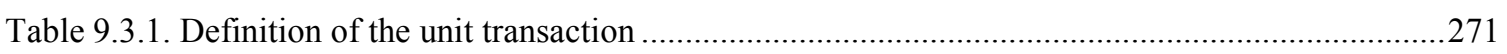

Table 9.3.2. Results of the estimated real output based on the three approaches ..................................2272 
Table 9.3.3. U.S. SPPI publication structures for securities brokerage services.....................................273

Table 9.3.4. U.S. SPPI publication structures for principal securities transaction services .........................273

Table 9.3.5. U.S. SPPI product based for securities brokerage and dealing service ....................................273

Table 9.3.6. Japan's CSPI for securities and commodity contracts brokerage ..........................................274

Table 9.4.1. U.S. PPI industry publication structures for the insurance industries .....................................281

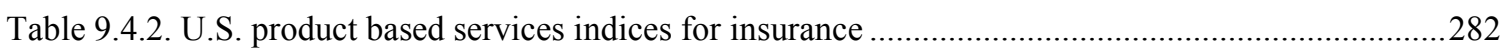

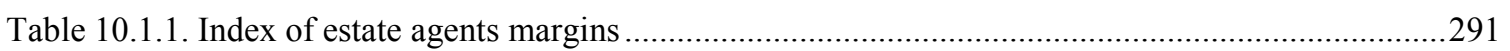

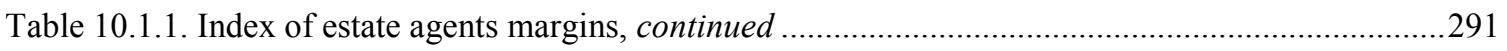

Table 12.2.1. Example of pricing methods in Security and investigation activities ....................................393

Table 13.1.1. U.S. PPI industry based publication structures for the human health activities.....................413

Table 13.1.2. U.S. PPI product based publication structures for health care services ..................................414 


\section{ABBREVIATIONS}

$\begin{array}{ll}\text { ANZSIC: } & \text { Australian and New Zealand Standard Industrial Classification } \\ \text { CPA: } & \text { Statistical Classification of Products by Activity within the European Economic Community } \\ \text { CPC: } & \text { Central Product Classification } \\ \text { CPI: } & \text { Consumer price index } \\ \text { BtoAll } & \text { Business to all users } \\ \text { BtoB: } & \text { Business to business } \\ \text { BtoC: } & \text { Business to consumer } \\ \text { BtoE: } & \text { Business to export } \\ \text { ESA: } & \text { European system of accounts } \\ \text { EU: } & \text { European Union } \\ \text { Eurostat: } & \text { Statistical Office of the European Communities } \\ \text { GDP: } & \text { Gross domestic product } \\ \text { INSEE: } & \text { Institut National de la Statistique et des Études } \\ \text { ISIC: } & \text { International Standard Industrial Classification of all Economic Activities } \\ \text { KAU: } & \text { Kind of activity unit } \\ \text { LKAU: } & \text { Local kind of activity unit } \\ \text { NACE: } & \text { Classification of Economic Activities within the European Communities } \\ \text { NAICS: } & \text { North American Industrial Classification System } \\ \text { NAPCS: } & \text { North American Product Classification System } \\ \text { NPI: } & \text { Non-profit institution } \\ \text { NSO: } & \text { National Statistical Office } \\ \text { OECD: } & \text { Organisation for Economic Co-operation and Development } \\ \text { PPS: } & \text { Probability proportional to size } \\ \text { PPI: } & \text { Producer price index } \\ \text { SNA: } & \text { System of National Accounts } \\ \text { SPPI: } & \text { Services producer price index } \\ \text { STS-R: } & \text { Short-term Statistics regulation (for EU Member states) } \\ \text { UMTS: } & \text { Universal Mobile Telecommunications Systems } \\ \text { UN: } & \text { United Nations } \\ \text { VAT: } & \text { Value-added tax } \\ & \end{array}$





\section{Producer Price Indices for Services}

\section{Why develop price statistics for services?}

In OECD countries, services account for the largest share of GDP. However, statistics on services are still partially underdeveloped when compared to statistics on goods producing industries. ${ }^{1}$ This is particularly true for producer price indices where price indices for goods by far outnumber available price indices for services. There are several reasons for this asymmetric coverage of price indices. One is simply that goods historically played a more important role than services and this has shaped statistical systems. Another reason is that developing service price indices is a difficult and expensive task. Service output may be hard to identify on purely theoretical grounds, and even more difficult to measure reliably. For example, services may be unique and have to be treated like new products (e.g. various consultancy services) or they can be tailored or bundled in different ways for different users. All this implies complexity and high costs for price measurement.

\section{What are service producer price indices (SPPIS)?}

Service producer price indices (SPPI) are intended to trace price movements that reflect the supply and demand conditions in the service markets, with a view to facilitate the analysis of macro-economic conditions and to monitoring inflationary pressures. Importantly, they are also used as deflators in national accounts to convert the value of service output into volume measures. ${ }^{2}$ Volume measures of service output of various periodicities are essential for economic analysis. Producer price indices for services are also useful to the business community in evaluating particular markets.

Why a methodological Guide for developing producer price index for services (SPPI Guide)?

The aim of the SPPI Guide is to aid countries in developing producer price indices for services. The Guide is intended to complement the Producer Price Index Manual (PPI Manual), which discusses index theory and provides general guidelines to be applied in the compilation of price indices - but does not include extensive discussion of producer price indices for particular service industries or products. ${ }^{3}$ In addition, many services have very specific features and require individual discussion. Also, the methods used to arrive at constant quality pricing are often complex and depend on the particular service industry and product. It is for all these reasons that a separate Guide on measuring producer price indices for services has been developed.

\section{Why a new edition of the SPPI Guide?}

The first edition of the SPPI Guide was developed by a joint expert group between 2002 and 2004 and published in 2005. The present edition was prepared by a joint OECD-Eurostat Task Force established in 2011, which has overseen the revision and the update of the 2005 edition of the SPPI Guide. 
The first edition of the SPPI Guide provided some conceptual guidance on producer price indices for services along with documentation of country practices. Since its publication, significant progress has been made by a number of countries in developing new SPPIs in sectors not covered in the first edition, providing strong motivation for an update and revision of the Guide. Moreover, in 2005 output prices for services became a mandatory requirement in EU countries. Indeed, since 2008 Eurostat publishes service producer price indices for all Member States on a quarterly basis. These statistics belong to Eurostat's set of Principal European Economic Indicators. These developments, as well as the updates of the 2008 System of National Accounts (SNA) and the international classification systems (ISIC Rev. 4), provided an excellent momentum for updating the SPPI Guide, thus allowing countries to capitalise on new developments and to take into account the impact of the revisions of the SNA and the international classification systems.

The new SPPI Guide: Enhancing a global and comprehensive methodological SPPI framework

The main objectives of the 2011 Task Force were to enhance the methodological background of the 2005 SPPI Guide and to provide a common methodology for service prices. The general methodological principles are presented in the first three chapters of the Guide:

Chapter 1 (General aspects of SPPI compilation) presents methodological information on the core measurement issues of SPPIs that the compiler will have to deal with when starting compilation. It provides discussions on the definition, uses and scope of SPPIs; product and industry SPPIs; the price concept underlying SPPIs; the appropriate statistical units; the international classifications; the identification of service products; the sample frame and weights; and the treatment of quality changes.

Chapter 2 (Main pricing methods for SPPI) seeks to help the compiler to develop a better understanding of the variety of pricing methods used. It characterises the various approaches within a broad conceptual framework that facilitates understanding and international comparability by providing links between the various pricing mechanisms used by service providers and the methods used by index compilers to measure price changes.

Chapter 3 (Practical aspects of the development process) addresses practical aspects related to the collection of prices and aims to describe all necessary steps to set up a price collection system.

The focus in these three chapters is on issues that are typical for services. The recommendations made in these chapters can also be applied to services that are not explicitly covered in the chapter on individual industries.

The new SPPI Guide: Relying on material developed by the Voorburg Group on Services Statistics

Although the SPPI Guide devotes some space to concepts and methodology, its main purpose remains to propose practical solutions for the development of new SPPIs and for the quality improvement of existing ones To achieve this objective, the intention of the 2011 Task Force was to also rely on material already produced by the Voorburg Group on Service Statistics ${ }^{4}$ in order to enlarge the scope of the 2005 SPPI Guide by including a broad spectrum of service industries. 


\section{The new SPPI Guide: Enlarging the scope and the range of service industries covered}

The 2005 SPPI Guide provided guidance on "business to business" (BtoB) service industries, i.e. those services that are mainly aimed at uses other than household consumption, and for which the development of price indices was considered most urgent. Selection criteria were the size of industries and the speed of technological change that is likely to affect price measurement. An important objective of the revision of the SPPI Guide was to extend the coverage by including other types of service industries, in order to produce business to all (BtoAll) indices and to consider the possibility of having subdivisions of SPPIs by destination of output (e.g., BtoB, business to consumer (BtoC), and business to export (BtoE)).

Reflecting its broader coverage and scope, the new SPPI Guide provides, in its second part, guidance for 31 service industries. This guidance is based on the premise that the service activities of a particular industry are relatively similar in different countries and therefore practices adopted in one country may be applicable in others. Consequently, the guidance draws heavily on the experience of countries already producing SPPIs and tries to identify best practices across a wide range of countries. Ideally, this information will lead to similar approaches across countries and increase the comparability of the resulting indices. When comparable SPPIs are used for deflation in the national accounts, this should also result in an enhanced comparability of volume changes in the production of services.

\section{How to compile SPPI for 31 specific service industries?}

Chapters 4 to 13 are based on country practices and describe feasible solutions for a set of 31 service industries. For each service industry, the relevant activities and possible classification issues are described. Furthermore, methodological aspects regarding the compilation of an SPPI are explained. The list of service industries covered in chapters 4 to 13 and the structure of the presentations are shown pages 91 to 93 .

\section{Notes}

1. The European Union regulation on short-term statistics provides an illustration of this: only 10 of the 38 STS indicators cover retail trade, repair and other services, 17 concern industries and 11 construction.

2. Producer price indices are the preferred measure for deflation in Eurostat's Handbook of Price and Volume Measures in National Accounts. In some market sectors (e.g. banking, insurance) and most non-market services (e.g. education) the calculation of producer price indices is particularly problematic due to the lack of observable prices. Calculations of volumes therefore often have to rely on second best methods which are described in the handbook.

3. Some examples on the compilation of SPPI can be found in chapter 10 of the PPI Manual.

4. The Voorburg Group has been the leading international forum for establishing an internationally recognised methodology for developing producer price indices for 
service industries since the late 1990's. Indeed, the Voorburg group aims to develop internationally comparable methodologies for measuring the deflated or constant dollar outputs of the service industries focusing on classification, output measures and price indices. To fully achieve this primary objective, the Voorburg Group aims to $i$ ) develop new concepts, methods and best practices; ii) maintain and improve the knowledge base, and iii) disseminate best practices and knowledge transfer. More information can be find on Voorburg Group website: http://www.voorburggroup.org/ 
PART I. METHODOLOGICAL ASPECTS 



\section{Chapter 1. General aspects of Service Producer Price Indices compilation}

This chapter gives an overview of general aspects of service producer price indices (SPPIS) compilation. The chapter presents methodological information on the core measurement issues of SPPIs that the compiler will have to deal with when starting compilation and discusses the definition, uses and scope of SPPIs; product and industry SPPIs; the price concept underlying SPPIs; the appropriate statistical units; the international classifications; the identification of service products; the sample frame and weights and; the treatment of quality changes. Efforts have been made to present discussions in line with the Producer Price Index Manual (PPI Manual) ${ }^{l}$ and to focus on service-specific aspects of producer price indices (PPIS) compilation by developing further the conceptual framework. 


\subsection{Definition, uses and scope of Service Producer Price Indices}

\subsubsection{Definition of SPPIS}

SPPIs are defined for the purposes of this Guide as output price indices for services that provide measures of the average movements of prices - valued at basic prices received by domestic service producers. SPPIs are therefore a subset of output PPIs.

\subsubsection{Uses and Objectives of SPPIS}

SPPIs serve two main functions. The first is to provide an indication of price change by producers of services, and therefore an indicator of inflationary pressure. The second is to provide a suitable deflator of nominal values of output or intermediate consumption for the compilation of production volumes in the national accounts. Notwithstanding the importance that should be attached to use of SPPIs as a timely indicator of inflationary pressures, this Guide gives preference to their use as deflators in the national accounts. This choice is in line with the PPI Manual. ${ }^{2}$

The choice of primary use of SPPIs can often dictate the way in which they are defined and constructed. The preference given here to their role in deflating current price estimates of economic activity to arrive at measures of activity in constant prices determines a number of characteristics of the indices.

First, the scope of SPPIs should, in theory, cover services provided for all uses, intermediate and domestic final consumption, and for exports. Ideally, separate SPPIs should be available for each of these end use categories, reflecting the fact that prices, and price movements, may discriminate between users. The scope and coverage of SPPIs are discussed further at section 1.1.3.

Second, SPPIs should measure change in the prices of products, rather than industries. This reflects the fact that the output of industries in most countries can typically be broken down into various products, and so measures of industry output in volume terms can be readily derived. Moreover, in order to arrive at volume estimates of value-added it is necessary to use double-deflation which requires deflating the intermediate consumption of industries, which is again typically measured on a product basis. CPIs and other price indices also measure change in the prices of products rather than industries. This approach provides greater scope for combining various price index data at an aggregate level for use in, for example, balancing supply and use tables in the national accounts and in macroeconomic analysis. The choice between product and industry SPPIs is discussed in more detail at section 1.2.

Third, SPPIs should represent all output as defined in national accounts and follow, as closely as possible, the accrual principle in recording prices. In accrual recording, the output of services in national accounts and associated prices are recorded at the date when services are provided. This can give rise to a number of practical problems in respect of the recording of prices. These are discussed further at section 1.3.2.

Normally, there is no conflict between the two main uses of SPPIs mentioned above and where they do arise they can often be reconciled in index development. However, in exceptional cases, it is important to explicitly assess how well an SPPI fits each of them. Two examples illustrate this issue which is discussed in more detail in section 1.3 in the context of the timing of price collection. 
1. In air transport, a timely indicator of price change can be based on price quotes for tickets that are bought long before the travel date. For instance, if prices of summer vacation airfares are known by April, this provides a timely indication of emerging price movements that could inform monetary policy decision making. However for deflation of production, these prices need to be reflected in the SPPI for the period in which the underlying production occurred, in this case the summer months.

2. An extreme case is provided by operational car leasing for which prices may stay fixed for several years. The correct deflator should reflect the prices that were in place over the time of the lease for all production. This means that the deflator at any point in time would be mainly composed of old lease contracts that were still running, with a relatively small weight given to the lease price in the most recent period. However, the most pertinent indicator of inflationary pressures would arguably be the price levels of new contracts.

\subsubsection{Scope and coverage}

The supply and use accounting framework focuses on the process of production and consumption and can help to answer the question "Where do products come from and how are they used?". The supply table itemises the products each industry domestically produces or imports and these are then identified in the use table where the allocation of each product between intermediate consumption and final demand (final consumption, capital formation, and exports) is recorded. Compiling supply and use tables at current values ensures consistency in the different measures of Gross Domestic Product (GDP). Changes in the values of flows of goods and services can be decomposed into two components, one reflecting changes in the price of goods and services, and the other changes in their volume.

The System of National Accounts (SNA) $)^{3}$ recommends compiling price and volume measures within the accounting framework provided by the supply and use tables because this framework provides a check on the numerical consistency and reliability of the set of measures as a whole. ${ }^{4}$

In principle, four major types of price indices, Producer Price Indices (PPIs), Consumer Price Indices (CPIs), Export Price Indices (XPIs) and Import Price Indices (MPIs) should be available to derive volume measures in the different parts of the supplyuse framework. The PPI Manual uses this national accounts framework to illustrate the relationships between different price indices. ${ }^{5}$

Services make up a sub-set of all products produced and consumed in an economy. Their supply and use, and associated price indices comprise the following sub-areas:

- Domestic output of services - SPPIs;

- Consumption of services by households - CPIs;

- Other domestic uses of services, such as intermediate consumption;

- Exports of services - XPIs;

- Imports of services - MPIs.

In this framework, SPPIs are crucial not only for measuring output of services but also for estimating price development of the use of services in areas where independent 
price indices are not available. This concerns the intermediate consumption of services and exports of services in particular. ${ }^{6}$

This Guide has adopted as a principle that the scope of SPPIs should cover all domestic production of services provided for all uses, intermediate and domestic final consumption, and for exports. The consequences in terms of the coverage of SPPIs are discussed below.

First, by definition, services provided by non-resident units are not within the scope of SPPIs which are designed to reflect price movements of domestic producers only. While the separation of resident and foreign producers (and consumers) sounds straightforward, it is not always easy to define. The 2008 SNA provides general principles for the recording of a unit by referring to its "centre of predominant economic interest". This is explained in par. 4.14 as follows: ${ }^{7}$

An institutional unit has a centre of predominant economic interest in an economic territory when there exists, within the economic territory, some location, dwelling, place of production, or other premises on which or from which the unit engages and intends to continue engaging, either indefinitely or over a finite but long period of time, in economic activities and transactions on a significant scale. The location need not be fixed so long as it remains within the economic territory. Actual or intended location for one year or more is used as an operational definition; while the choice of one year as a specific period is somewhat arbitrary, it is adopted to avoid uncertainty and facilitate international consistency. In most cases, it is reasonable to assume that an institutional unit has a centre of economic interest in a country if it has already engaged in economic activities and transactions on a significant scale in the country for one year or more, or it intends to do so. The conduct of economic activities and transactions over a period of one year normally implies a centre of interest, but the choice of any specific period of time is somewhat arbitrary and it must be emphasised that one year is suggested only as a guideline and not as an inflexible rule.

In par. 4.15 , the $2008 S N A$ provides some further guidance for the implementation of this definition:

Corporations and NPIs may normally be expected to have a centre of economic interest in the country in which they are legally constituted and registered. Corporations may be resident in countries different from their shareholders and subsidiary corporations may be resident in countries different from their parent corporations. When a corporation, or unincorporated enterprise, maintains a branch, office or production site in another country in order to engage in production over a long period of time (usually taken to be one year or more) but without creating a subsidiary corporation for the purpose, the branch, office or site is considered to be a quasi-corporation (that is, a separate institutional unit) resident in the country in which it is located.

Second, the coverage of all output implies that SPPIs comprise prices for the provision of services to all institutional sectors, financial and non-financial corporations, government units, non-profit institutions (NPISHs), households and the rest of the world. However, as mentioned above, services provided for different sectors are not necessarily the same and their price development can be different. Sub-division of an SPPI by destination of output, where possible, is therefore strongly encouraged particularly for purposes of deflation in national accounts. 
Third, there is a potential overlap between SPPIs and CPIs when it comes to the pricing of services delivered to households. There is no general rule for how the compilation of SPPIs vis-à-vis CPIs are best organised. The situation varies between service products and data sources may also differ between countries. It may be possible to use CPI information to obtain prices for services acquired by households and if so the data collection for SPPIs would be reduced to business-to-business (BtoB) and export transactions if significant. However, the price concept underlying CPIs is not the same as that underlying SPPIs. ${ }^{8}$ There may be other cases where the service output and its prices for different end users are very similar or cannot be separated in practice (e.g., economyfare air travel). In these cases it may be easier to cover service output prices to all end users in a single estimation.

Statistics by end use, like supply and use tables, are the appropriate tool to identify the relative importance of groups of purchasers (export, intermediate consumption, households) of the output of an industry.

\section{Box 1.1. SPPI by destination - the French experience}

Since May 2013, the French National Statistical Office (INSEE) publishes SPPIs disaggregated by destination of output, for a wide range of services activities (e.g. sections H, I, J, L, M and N of NACE Rev. 2).

\section{Definition}

- Domestic Business-to-Business SPPIs (BtoB) measure transaction price changes for services sold by national producers to national businesses; they cover domestic production sold to legal entities established in France (including the general government sector, French affiliates of foreign groups, etc.).

- Domestic Business-to-Consumer SPPIs (BtoC) measure transaction price changes for services sold by national producers to households in the national territory; CPIs are the main source for these indices; valued at purchasers' prices, they are however adjusted to basic prices by deducting any taxes including VAT and trade margins.

- Domestic Business-to-Export SPPIs (BtoE) measure transaction price changes for services sold by national producers to foreign markets. In the case of France, transaction prices are converted to Euros and therefore include exchange rate effects. Note that intra-group transactions are included.

- Domestic Business-to-All SPPIs (BtoAll) measure transaction price changes for services sold by national producers to all markets. INSEE obtains BtoAll SPPIs by "horizontal aggregation" (at each classification level) of BtoB, BtoC and BtoE indices.

\section{Valuation}

Measurement of SPPIs in France is conducted at basic prices; precisely by activity, including subsidies on products, but excluding VAT and other taxes on products. Intra-group transactions are included.

Additional BtoB SPPIs valued at market prices (by products, including VAT, excluding subsidies on products, including taxes on products) are also computed mainly for use in contract escalation. Intra-group transactions are excluded. 


\section{Box 1.1. SPPI by destination - the French experience, continued}

Use

The disaggregation of SPPIs by destination of output is of particular relevance to both the deflation of production figures derived from structural business statistics and also to distinguishing between the change in volume of activity and the change in prices of activity ("volume-price breakdown").

The disaggregated SPPIs also provide an indication of inflationary pressure through the economy. As mentioned above, BtoB SPPIs valued generally at market prices may be used in contract escalation.

\section{Source}

French SPPIs by destination of output are calculated on the basis of quarterly price observation (or annual observation for some respondents) of some 9,789 products collected from a representative sample of 1,725 respondents in the mandatory "Observation des Prix de l'Industrie et des Services" survey. This survey covers 59\% of the value (in 2010) of the markets and classes of products. A further $19 \%$ are derived from consumer price indices. The remaining $22 \%$ are imputed using close price indicators (from a similar market or class of products).

\section{Computation}

French SPPIs by destination of output are Laspeyres chain-linked indices. The weights at the detailed levels (strictly below the 4-digits level of NACE) are updated every five years when the sample of surveyed units in a class of products is renewed. Weights at the upper level are derived from measures of turnover by class of products and markets, and are consistent with the national accounts. These upper level weights are updated annually.

Sources: INSEE, more detailed information is available at: http://www.insee.fr/fr/themes/indicateur.asp? id $=100$

\subsection{Product and industry based SPPIs}

As previously noted, the SPPI Guide gives preference to SPPIs measuring change in the prices of products, rather than industries. In practice however, the primary goal of developing product SPPIs is often not systematically adopted because detailed output data is not available for all service products. Thus, SPPIs for a given country may be a mixture of industry and product SPPIs depending on the data sources available for various industries. In this sense, it is important to note that in general, product based statistics on outputs are less developed for service industries than for goods industries.

However, the choice between industry and product based SPPIs may be less important for services than for goods, because the share of secondary production falling under a different industrial class to the principal production tends to be smaller in the former. Exceptions exist however, with significant or growing secondary production in industries such as management consultancy.

Most countries establish individual SPPIs at the 4-digit industry level (ISIC Class level or equivalent). An industry based index is created from a sample of business enterprises classified under that industry. All of the output of these sampled units is represented, even secondary activity output that is classified under other industries in the 
international classification systems, and aggregated to form these 4-digit industry level indices.

Product based indices are created from samples of products. All service product output (obtained from lists of producers of each product) is eligible for selection, regardless of the classification of the business enterprises that produce it. Price movements for products are generally aggregated to form product Group or product Class level indices (following the CPC Ver.2 terminology) and can also be aggregated to 4-digit industry level indices.

The larger the share of industry turnover generated from the provision of secondary service activities the stronger the argument for compiling product based SPPIs.

The choice between product and industry based indices and the methodologies for compiling them are discussed further in chapter 3.

\subsection{Price concept}

\subsubsection{Valuation}

The PPI Manual recommends that PPIs should measure actual transaction prices reflecting the revenue received by the producer for products sold to customers. ${ }^{9}$ They should take into account any applicable discounts, rebates, surcharges, etc. that may apply to the customers. Because the price reflects revenue received by the producer, taxes on products should be excluded from prices whereas subsidies on products received by the producer, if there are any, should be added. In other words, the recommendation is to apply a concept of basic prices in the measurement of SPPIs. This is also recommended by the 2008 SNA for the valuation of output in the national accounts. ${ }^{10}$

\subsubsection{Accrual recording}

The PPI Manual recommends that, in line with the valuation of output in the SNA, accrual accounting rules should be followed as far as possible, so that transaction prices are recorded at the time of shipping or delivery.

Accrual accounting is defined in the 2008 SNA par. 2.55 as follows: ${ }^{11}$

The general principle in national accounting is that transactions between institutional units have to be recorded when claims and obligations arise, are transformed or are cancelled. This time of recording is called an accrual basis. Transactions internal to one institutional unit are equivalently recorded when economic value is created, transformed or extinguished. Generally speaking, all transactions, however they are described, can always be viewed as dealing with economic value.

Accrual recording, in the case of services, is explained in the 2008 SNA par. 3.170:

Services are recorded in the SNA when they are provided. Some services are special in the sense that they are characteristically supplied on a continuous basis. Examples are operating leasing, insurance and housing services (including those of owner-occupied dwellings). These services are recorded as provided continuously over the whole period the contract lasts or the dwelling is available.

There are no significant difficulties in implementing the accrual principle in price indices, providing the provision of services coincides closely with the time when the 
contract is signed or the payment made. However, there can be differences in practice between the time when services are provided and when they are paid for.

A case in point is transportation services; air transport particularly, where nonrefundable tickets purchased months in advance can be bought at lower prices. Evidently, services that have to be paid for at different points of time to when they are provided belong to different quality categories and have to be treated as different services. But how should the accrual principal be implemented in such cases?

The 2008 SNA recommendations suggest that prepayments should be recorded as "interest free loans" (rather than as purchases of tickets) from clients to service providers that are paid back at the time of service provision. The client "buys" the ticket once again at the time of service provision, which ensures consistency between supply and demand of services. ${ }^{12}$ This means that prices used for SPPIs should be based on the actual purchased values accrued and recorded to the time of service provision.

Another problematic case for application of the accrual principle arises when there are long-term contracts with up-front payments rather than payments made over the duration of the contracts. Services are provided continuously and accordingly, prices should be allocated to the whole period. Because of the up-front payment and the longterm nature of the contract it may not be possible to determine whether the price for the delivery of the service is the same throughout the period or it varies. All that is known is the average price over the entire period. However, prices of contracts should reflect supply and demand conditions at the time when services are actually provided.

One possible approach to be considered is to escalate prices over the contract period on the basis of cost development of inputs. Such a procedure is typically applied in the estimation of price development for the shipbuilding industry. ${ }^{13}$ While this method might be reasonable in individual contracts it does not capture the evolution of market conditions (or captures only supply-side conditions). It seems that there is no ideal way available to use prices of long-term contracts for SPPIs.

The examples above show that while the accrual principle is very important for services, it may be difficult to implement. Simple solutions can sometimes be useful if they are easily understood by users and bearing in mind that the accrual principle is not always rigorously implemented in the national accounts. Thus, while accrual accounting should in principle be respected, it has to be applied with flexibility in practice.

\subsubsection{Frequency of price collection}

The frequency of price collection can be monthly or quarterly. When collecting prices for a particular period, there are two basic methods: ${ }^{14}$

1. Period prices are an estimate of the average price throughout the period. A period price should take account of price changes that occurred during the period;

2. Point-in-time prices relate to the price on a particular date or sub-period. For example, it might be the nearest trading day to the midpoint of the period or the middle week of the quarter or month.

Generally, collection of period prices is to be preferred. Point-in-time prices can be considered for use only if they are expected to be representative over the entire reference period (i.e. month or quarter). They should be used with caution if the price collection frequency is greater than one month. It should be noted that the distinction between period price and point-in-time-price does not address the issue of when the service is 
provided. For instance, both period prices and point-in-time prices can be surveyed for air transport tickets either long before the actual transport, or in the same period as the transport takes place.

\subsection{Statistical units}

\subsubsection{General principles}

The PPI Manual recommends that a statistical unit should refer to a single output generating entity, analogous to the SNA establishment concept. ${ }^{15}$ Within the SNA, output measures are based on the production of establishments or local kind of activity units (LKAUs) as they are referred in the European system of national accounts (ESA 2010) terminology. ${ }^{16}$ Establishments are defined as production units that have a single location and whose production is homogeneous (subject to the limitations of obtaining production account data). Thus, enterprises might be partitioned into smaller and more homogeneous units if they are engaged in different kinds of activities or situated in different locations, and services provided by these units should be registered separately. Weighting of and sampling for, an index should in principle be organised accordingly.

In practice, the use of establishments as the basis for weighting and sampling is not always possible as there may be insufficient information available for them. In the case of services, information on turnover by enterprise rather than establishment is typically used as a basis for index compilation. There are also considerable differences between service industries in this respect.

\subsubsection{Outputs of statistical units in special cases}

A consequence of the definition of statistical units as establishments is that, for consistency, sub-contracts of services should be treated in an index in the same way as any other service, irrespective of whether a service contains sub-contracts or is in itself is a sub-contract. This also holds for any activities that may be outsourced.

This is self-evident if the contractor and sub-contractor belong to different categories in the product or activity classification, as sub-contracted activities do not differ from other activities used as intermediate consumption. However, where the sub-contractor is in the same activity classification as the contractor, it is legitimate to question whether some attempt should be made to remove the sub-contracted activity in constructing an overall SPPI for that activity as there will be some element of double counting. This reflects the fact that the contractor may pass these price changes through in the sales of its own production. However, as stated previously, the main goal of SPPIs should be to provide a price index for national accounts purposes and because output is measured on a gross basis, so too should SPPIs.

In national accounts, separate indices for contracts and sub-contracts are in principle needed for deflation purposes, but only one kind of index is normally produced. If this is the case, an index based on main contracts (that may or may not include sub-contracts) should be preferred on the grounds that it is likely to give an acceptable proxy for overall gross price movements. Equally, SPPIs based on main contracts are likely to be the appropriate deflator for the use of these services in other industries and sectors.

Outsourcing relates to the purchase by business enterprises of ancillary services they had previously conducted in-house. Because many of these services were previously produced within the non-service sector, outsourcing typically leads to growth in service 
sector value-added with corresponding falls in manufacturing value-added (mainly through compensation of employees). However, there are no specific reasons why outsourced services should not be treated like any other purchased services for inclusion in SPPIs.

Output also covers services that an establishment provides to other units of the same enterprise. ${ }^{17}$ The 2008 SNA recommends that these intra-enterprise services should be valued at current basic values that would have been received if they had been sold. ${ }^{18}$ However, in the enterprise's bookkeeping these services are often valued at reduced amounts, and sometimes not at all, rather than at current basic prices. Furthermore, the services are unique. The PPI Manual makes clear that "one of the primary goals of the PPI is to help determine the magnitude and direction of price movement on both a macroand microeconomic level and for such a use, any index containing non-market prices not paralleling market price movement is of dubious value." 19 Because the national accounts should in theory value these transactions at current market prices rather than the transferprice values recorded in the establishment and enterprise's accounts, it is preferable to exclude these types of services in compiling SPPIs. Their inclusion may introduce inconsistencies in the deflation of the national accounts.

There are also borderline cases such as the provision of services by temporary employment agencies. The 2008 SNA (par. 19.21h) recommends that persons employed by temporary employment agencies are to be included in the industry of the agency which employs them, and not in the industry of the enterprise for which they actually work. As a consequence of this recommendation, the value of services produced by the agencies amounts to all payments (including compensation of temporary employees) and not only "net fees" received by the agency. However, this may not be implemented in practice. Any decision concerning the gross or net treatment of prices underlying the SPPI for temporary employment agencies should be made in line with the national accounts practice in a given country. ${ }^{20}$ In principle the national accounts should always show nonconsolidated flows (gross) but this may not be the case for certain activities in some countries depending on national circumstances. In these cases the SPPI should be designed accordingly.

One particular activity that merits special attention relates to processor firms i.e. firms that provide processing services by manufacturing goods for clients who own part of the inputs in the production process). The 2008 SNA recommends that international transactions by these firms should follow the principle of economic ownership, bringing the treatment of processing firms that manufacture goods for foreign clients in line with that of processing firms providing manufactured goods for domestic clients. ${ }^{21}$ These manufacturing services are currently considered out of the scope of this Guide.

\subsection{Classification systems}

Classification systems provide an organising structure for reporting units and products. Once the sub-aggregates within the classification system are selected, an appropriate frame can be identified from which representative establishments and service products can be selected for inclusion in the index. The classification system also determines the structure of the index and defines the weighting system. 


\subsubsection{Classification systems by activity}

Individual countries usually collect information by activity using their own national activity classifications that reflect the structure of their economy. This may cause some degree of incomparability across countries but typically, especially at the higher levels of aggregation, national classification systems are consistent with the International Standard Industrial Classification of all Economic Activities (ISIC).

The other three main regional classification systems by activity are:

- The Classification of Economic Activities within the European Communities (NACE);

- $\quad$ The North American Industrial Classification System (NAICS);

- Australian and New Zealand Standard Industrial Classification (ANZSIC).

\subsubsection{Classification systems by product}

Individual countries may also refer to national classifications by product or commodity, which are designed to categorise products by common characteristics. Unlike their activity counterparts, national product classifications are typically less consistent with the international standard, the Central Product Classification (CPC).

The other two main regional classification systems by product are:

- Classification of Products by Activity (CPA) - the CPC equivalent European Union classification;

- North American Product Classification System (NAPCS).

Classifications are discussed at a general level in the PPI Manual ${ }^{22}$ and specific classification systems are well documented elsewhere. ${ }^{23}$ Classification aspects relating to services are discussed in chapter 10 of the PPI Manual where SPPIs for a set of service industries are introduced. It should be noted that product classifications serve as a guide and cannot in themselves be used to form the components of a weighting structure for an index. This is done by accessing information from structural statistics or information collected during the respondent initialisation process. More information on these processes is provided in chapter 3 .

\subsection{Identification of service products}

\subsubsection{General guidelines}

The identification of service products is a fundamental task in the compilation of SPPIs. It involves identifying those service characteristics that are price-relevant and distinguishing between apparently similar services. These tasks tend to be more complex for services than for goods. Similarly, services that are primarily sold to other businesses tend to be more complex than those sold mainly to households.

Factors to be taken into account in the determination of products are discussed at a general level in the $2008 S N A{ }^{24}$ These guidelines are valid for both goods and services and help to identify different products at a given point in time; they also give guidance for the index treatment of goods and services, whose characteristics change over time. A general principle is laid out in par. 15.67 of the 2008 SNA as follows: ${ }^{25}$ 
It is generally assumed in economic analysis that whenever a difference in price is found between two goods and services that appear to be physically identical there must be some other factor, such as location, timing or conditions of sale that is introducing a difference in quality. Otherwise, it can be argued that the difference could not persist, as rational purchasers would always buy lower priced items and no sales would take place at higher prices.

The 2008 SNA further states in paragraph 15.75 that "If there is doubt as to whether the price differences constitute price discrimination, it seems preferable to assume that they reflect quality differences...". ${ }^{26}$ Equally, 2008 SNA rules identify location as a price determining factor. ${ }^{27}$ Conceptually therefore, prices of the "same" service provided by a business enterprise in two locations should not be averaged but treated as different services.

However, the 2008 SNA suggests that price differences between similar service products imply quality differences between these products only on the condition that "full" information is available. For services provided to business enterprises, this condition is often not met because services are typically based on unique contracts between service providers and clients. Prices paid by different clients might vary significantly but this information is not freely available. Additional guidance is needed and the ESA 2010 summarises the general rules to be applied in situations where apparently similar products are transacted at different prices as follows. ${ }^{28}$

In practice, however, two units of a product with identical physical characteristics may be sold at different prices for two types of reasons.

(a) Two units with identical physical characteristics can be considered as not being equivalent if they are sold in different places, at different periods or according to different conditions. In this case, the units have to be regarded as corresponding to different homogeneous products.

(b) Two units with identical physical characteristics can be sold at different prices, either due to lack of information, or to restrictions brought to purchase freedom, or to the existence of parallel markets. In this case, the units have to be regarded as belonging to the same homogeneous product.

This implies that in most cases differences in prices should, at least in practice, be interpreted as price differences rather than quality differences. Specifically, the provision of services that are identical but whose prices discriminate between markets and or clients should be assumed to have the same quality.

\subsubsection{Duration of the service-provision as a service determining factor}

The delivery of services often coincides with their production. Consequently, the duration of production is of direct importance to the purchaser of services and may constitute an important price determining factor. For example, in the case of transport services the preference for faster transportation means that the duration of the production of the service often impacts on their price.

There are other services where production and consumption do not necessarily coincide (e.g. accounting services) and where duration might have less importance as a price-determining characteristic. For these services it is normally sufficient to ensure that the resulting service is well specified. In general, services where clients are directly involved in the creation of the service tend to belong more often to those cases where 
addressing duration is important. ${ }^{29}$ These are largely consumer services rather than business services. For most business services, longer or shorter duration of production is generally indicative of lower or higher productivity ${ }^{30}$ but is not relevant for the quality of the service product, and there is no need to take it into account as long as duration is not explicitly referred in the service specification.

Addressing the question of duration is particularly relevant when prices used in index compilation do not refer to a complete service product received by a client but are expressed in terms of working time, such as charge-out rates where adjustments to reflect productivity changes will be necessary. These issues are discussed in more detail in chapter 2.

\subsection{Sample frame and weights}

\subsubsection{Sample frame}

SPPIs can be established on the basis of industries, service products or both (see section 1.2). The required sample frame depends on this choice. The use of industries is in most cases easier because the information on establishments needed to construct a frame is organised by industry rather than by product. This issue is further discussed in chapter 3 of this Guide.

The sample frame represents the universe (or population) from which the sample is selected. Business registers often provide the source data for the sample frame. Ideally, the business register will be updated regularly and provide sufficient information for each unit in respect of the value of output at industry and/or product level and also contact details.

\subsubsection{Weights}

Weights determine the impact that a particular price change will have on the overall index and are key elements in the construction of SPPIs. As price change across service products is not uniform over time, the relative importance of a product, as well as its price development, must be considered in index calculation. The same holds true for establishments and industries. As the market for products and the performance of establishments evolves over time weights must be updated to reflect these changes.

The calculation of SPPIs usually proceeds in two stages which involve the use of relevant weighting at each level. In almost all countries the first stage of index aggregation results in product indices, which are then aggregated further to give both higher level product indices and/or industry indices:

- At the first stage of elementary aggregation, individual prices are combined and, where possible, each price should be weighted by the value of production which it represents. In other words if several establishments $(\mathrm{X}, \mathrm{Y}, \mathrm{Z})$ produce product $\mathrm{A}$, the weight given to the price of product $\mathrm{A}$ produced by establishment $\mathrm{X}, \mathrm{P}_{\mathrm{XA}}$ should correspond to the share of establishment X's production of $\mathrm{A}$ in the economy. Where more than one price $(i, j, k)$ for product $A$ is collected from a single establishment, the prices should be weighted using the relative production values of the establishment for the different transaction specifications $\mathrm{i}, \mathrm{j}, \mathrm{k}$. Thus, it is important to have output data at a detailed product level for all establishments in the SPPI sample; 
- These detailed product level indices are then weighted together to give higher level product indices using the values of production of the detailed products for the economy as a whole (macro-weights). Industry indices are obtained by weighting together the product indices relevant to each industry. Ideally, account should be taken of secondary products when compiling industry SPPIs, i.e., detailed product indices covering both the principal and the secondary activities (products) should be combined to give industry SPPIs with the same coverage as the service output which the SPPIs may be used to deflate.

Two approaches can be used to weight individual PPIs to form a higher aggregate, referred to here as gross and net sector weights. This Guide gives preference to gross output weights that are simply the total deliveries or sales of each service product in that sector to all consumers; whether final or intermediate consumption. However, aggregation of industry or group indices using gross weights will result in some, albeit implicit, degree of double-counting the effect of input price change.

If the indices are used to analyse how inflationary pressures are transmitted from one sector to another then net sector weights should be used in the compilation of higher level aggregates to overcome the 'double-counting' problem. Net sector weights are based on the value of sales to business enterprises outside the industry or group of industries in question (inter-industry sales only). However, the use of net weights for compiling aggregate indices for inflation monitoring needs detailed input-output tables; which implies an extra layer of complexity in the construction of SPPIs.

The need for revisions to weights depends largely on the service industries concerned. In some industries the contents and structure of service output change rapidly, requiring frequent updating of weights. These changes can be due to the emergence of new products as well as change in the pricing systems. In some other industries there is no strong need to update weights very frequently because, in general, estimated price indices are not very sensitive to small errors in weights. Different strategies can be followed in revising weights, for example upper-level weights may be updated more frequently than lower-level weights. As a general rule, the PPI Manual recommends that weights should be updated, at least once every five years to reflect changes in market structure. ${ }^{31}$

More information on this topic can be found in chapter 9 of the PPI Manual.

\subsection{Treatment of quality change}

Assessing the quality of products and adjusting price observations for quality changes are important tasks that price index compilers encounter each time an existing sampled product is replaced by a new one. Chapters 7, 8 and 21 of the PPI Manual deal with issues related to quality changes.

The PPI Manual (par. 7.75) provides a list of methods that can be used for dealing with quality changes of products.

The same quality adjustments methods can in principle be used for goods and services. In practice however, fewer options are available for services. For example, the hedonic approach is rarely applied, because the quality of services is often made up of intangible factors that are difficult to identify and to measure in quantity terms. Moreover, even where quality factors of service products can be identified, it is often hard to find suitable data to capture gradual changes in the quality of services. 
A particular challenge for the compilation of SPPIs is that business services are often unique. One might conclude that the quality of services changes over time and/or that there are differences in the quality of similar services provided by different service producers but it is not possible to quantify the quality change. In some cases, such as advertising services, the quality of a service may not be known when the service is provided but can only be determined with reference to its impact. In these situations, where the characteristics of services are not observable at the time of service provision, it may be considered helpful to use information on outcomes in the measurement of the quality of services. For example in the case of consultation services, consideration might be given to quality adjusting the services provided with reference to changes in revenues or growth of output resulting from the service received. For advertising services the quality of service may be manifested the change in the volume of sales or in the number of people actually seeing the advertisement. ${ }^{32}$

In practice however, changes in outcomes can rarely be used for quality adjustment because outcomes are heavily influenced by factors that are not directly related to the services received. Moreover, a starting point in the measurement of prices is the information available to the service provider and client when a contract is signed. In the case of advertising services, if the number of people actually seeing the advertisement is unpredictable, it may not appropriate to use the size of audience for adjustment although the size of audience per se is an important quality factor and should be used as a classification criterion for advertising services.

Quality adjustment methods that are feasible, particularly for services, are discussed further in chapter 3 of this Guide.

\section{Bibliography}

European Commission, IMF, OECD, UN and World Bank (eds.) (2009), System of National Accounts 2008, United Nations, New York.

Eurostat (2013), European system of accounts - ESA 2010, European Union, Luxembourg.

ILO, IMF, OECD, UNECE, Eurostat, World Bank (eds.) (2004 a), Consumer Price Index Manual, Theory and practice, International Labour Office, Geneva.

ILO, IMF, OECD, UNECE, Eurostat, World Bank (eds.) (2004 b), Producer Price Index Manual, Theory and practice, International Monetary Funds, Washington, DC.

ILO, IMF, OECD, UNECE, Eurostat, World Bank (eds.) (2009), Export and Import Price Index Manual, Theory and Practice (XMPI Manual), International Monetary Funds, Washington, DC.

IMF (2009), Balance of Payments and International Investment Position Manual (BPM6), International Monetary Funds, Washington, DC. 


\section{Notes}

1. See ILO et al. (2004b).

2. See PPI Manual, par. 1.10.

3. The System of National Accounts (SNA) is the internationally agreed standard set of recommendation on how to compile measures of economic activity in accordance with established accounting conventions based on economic principles. The System of National Accounts 2008 (2008 SNA) is the latest version of the international statistical standard for the national accounts, adopted by the United Nations Statistical Commission (UNSC) (European Commission, et al. (eds.) (2009)).

4. See 2008 SNA, par. 15.110-112.

5. See PPI Manual, chapter 14.

6. In national accounts based on the supply and use framework, an advantage of using SPPI data on the use side is that consistency of prices in service balances can be ensured.

7. Further information can also be found in chapter 4 of the Balance of Payments and International Investment Position Manual (BPM6) (IMF (2009)), which is fully in line with the 2008 SNA.

8. PPIs measure price change from the perspective of the domestic producers whereas the CPI measures price change from the Household purchaser's perspective. This difference of perspective implies a difference in valuation: PPIs are valued at basic prices reflecting the amount received by the producer exclusive of any taxes on products and transport and trade margins while CPIs are valued at purchaser's price including any charge incurred in order to take delivery at the time and place required by the purchaser. For further details, see PPI Manual, chapter 2 and Consumer Price Index Manual: Theory and Practice (CPI Manual), (ILO et al. 2004a), chapter 3.

9. $\quad$ See PPI Manual, par. 1.178.

10. More precisely, the 2008 SNA distinguished two valuations for output PPIs, basic prices and producer prices. The basic price is the amount receivable by the producer from the purchaser for a unit of a good or service produced as output minus any tax payable, and plus any subsidy receivable, by the producer as a consequence of its production or sale. It excludes any transport charges invoiced separately by the producer. The producer's price is the amount receivable by the producer from the purchaser for a unit of a good or service produced as output minus any VAT, or similar deductible tax, invoiced to the purchaser. It excludes any transport charges invoiced separately by the producer. Somewhat confusingly, the 2008 SNA and the PPI Manual have a preference for valuations to be measured on the basis of basic prices, rather than producer prices, as basic prices better align with the cash that producers actually receive to compensate them for expenditures on goods and services used as intermediate inputs, for labour costs and as a return to capital.

11. Further information can also be found in chapter 4 of the BPM6 Manual, (IMF (2009)) which is fully in line with the 2008 SNA.

12. The valuation principle is not fully satisfactory because prices at two different points of time cannot be held the same. Neither the present 2008 SNA or ESA 2010 explicitly discuss this issue. 
13. See PPI Manual, par. 10.123-124.

14. A more detailed description of these two methods can be found in the PPI Manual, chapter 6 .

15. See PPI Manual, par. 3.49 and 2008 SNA, par. 2.38 .

16. See Eurostat (2013).

17. See 2008 SNA par. 6.99. Note also that intra-enterprise services should not be mixed up with production of services for own consumption by an establishment (e.g. transportation, storage and maintenance services). These are produced by so-called ancillary units and are not separately identified or recorded either under the output or the intermediate consumption of the establishment/LKAU or the enterprise to which it belongs. Services provided by ancillary units are outside the scope of SPPIs.

18. See 2008 SNA, par. 6.104 .

19. See PPI Manual, par. 3.35. Discussion on the treatment of transfer prices in exports and imports can be found in chapter 18 of the Export and Import Price Index Manual, Theory and Practice (XMPI Manual), IMF, 2009.

20. No problems arise, of course, if the temporary worker is not on the payroll of the employment agency. Discussion of when a person is interpreted as an employee can be found in the 2008 SNA par. 7.28-7.37.

21. See 2008 SNA, par. 2.48.

22. See PPI Manual, par. 3.58 - 3.71 .

23. Further information on the classifications and links between them can be found in the following websites:

United Nations classification register:

http://unstats.un.org/unsd/class/family/default.asp

Eurostat's classification server:

http://ec.europa.eu/eurostat/ramon/nomenclatures/index.cfm?TargetUrl=LST_NOM\& $\underline{\text { StrGroupCode }=\text { CLASSIFIC } \& \text { StrLanguageCode }=E N}$

North American industry and product classification system:

http://www.census.gov/epcd/www/naics.html

Australian and New Zealand industry classification:

http://www.abs.gov.au/AUSSTATS/abs@.nsf/Lookup/1292.0Main+Features12006\%

20(Revision\%202.0)?OpenDocument

24. Discussion can be found in chapter 15 of the 2008 SNA.

25. The PPI Manual, chapter 8 (section D.3.1.2) discusses evolutionary and revolutionary products that differ in terms of size of changes in products. Evolutionary products can be replaced in an index without changing the weight structure whereas revolutionary products are additions to the index and require changes in weights.

26. See also discussion on price discrimination in the PPI Manual (par. 6.92-98). The discussion refers only to goods but its recommendation to investigate reasons for price differences is equally valid for service products.

27. See $2008 S N A$, chapter 15 , section 4 - Causes of price variation.

28. See ESA 2010, par. 10.14 . 
29. Still, not all individual services belong to this category. For example, duration of many personal services may vary but they can be treated as the same services when clients are not willing to pay a higher price for a more rapidly delivered service.

30. Productivity is understood here as labour productivity, i.e., a change in the working time needed to provide the same service product in two periods. A rise in labour productivity may be a result of increased intensity of service provision during one hour worked or of increased quantity of capital used per hour worked.

31. See PPI Manual, par. 4.4.

32. Outcomes have been extensively discussed in the connection of developing price and volume measurement for health and education services. See the 2008 SNA par. $15.120-121$. 


\section{Chapter 2. Main pricing methods for Service Producer Price Indices}

The primary motivation of this chapter is to help to develop a better understanding of the variety of pricing methods used. It characterises the various approaches within a broad conceptual framework that facilitates understanding and international comparability by providing links between the various pricing mechanisms used by service providers and the methods used by index compilers to measure price change. ${ }^{l}$ 
The compilation of price indices should be based on clearly specified, representative products for which prices are tracked over time with due attention to quality change. For services, this principle is often difficult to follow:

1. Pricing (or charging) arrangements or mechanisms for the sale of services are often such that it is difficult for the compiler to observe prices for a repeated service transaction;

2. Identifying quality change can be a significant task, particularly in the context of services, where the very notion of quality is often problematic. Is a haircut delivered in one hour better or worse than a haircut that takes two hours for example?

3. Many service products are unique. In these cases, prices cannot be observed over multiple periods and so assumptions on quality changes have to be made (typically, constant quality is assumed) that are mostly based on convention rather than reflecting "reality".

In practice therefore, SPPI compilers may have to use a number of pricing methods to track price changes in service products, with the methods typically depending on the producing industry or product and on the pricing mechanisms used.

\subsection{Pricing mechanisms and methods}

Pricing methods refer to the procedures put in place by index compilers to make price data suitable for use in index compilation. These procedures are carried out prior to elementary index compilation and are solely concerned with data relating to prices. ${ }^{2}$ The selection of the appropriate pricing method for a service product or industry is largely determined by the pricing mechanism employed for that product or industry.

\subsubsection{Pricing mechanisms}

Pricing mechanisms refer to charging arrangements put in place by economic operators. In practice service providers use a variety of mechanisms to price their output but these can be characterised under three broad groups defined as follows:

- An explicit fee/price for the service is charged and payable (excluding those services charged as a function of time-spent), and referred to, for convenience, as explicit output charged mechanisms;

- An explicit fee/price for the service is charged and payable as a function of timespent, referred to as time-spent mechanisms,

- No explicit fee/price is charged and the payment for the service is not explicitly identifiable but is instead bundled within the price of another good or service. Two types of services are typically priced in this way. The first reflects the output of the retail/wholesale/distribution activities and the second reflects financial intermediation services indirectly measured (FISIM). This mechanism is for convenience referred to as margin-pricing.

Price information is available for the majority of services products. However, this price information may not necessarily meet the fundamental principle underlying price indices, which is to follow prices of products with comparable quality in consecutive periods. In other words the fact that price information is observable does not, unfortunately, mean that measuring price change is a trivial task. Therefore the compiler 
must examine the available price information and determine how it can be used in index compilation.

\subsubsection{Data type in surveys}

A key factor in determining the range of appropriate pricing methods is the data available to the compiler. Therefore before giving an overview of the various pricing methods widely used in practice by countries, it is instructive to consider the typical price data available:

1. Real transaction price: the price of a service actually paid in the market, taking the form of a receipt, bank statement or electronic database. It represents the actual price paid (inclusive of any discounts, surcharges or rebates) for an individual transaction that can be observed repeatedly;

2. List price: a price quoted from the producer's price list, catalogue, Internet site, etc. It is generally the gross price exclusive of all discounts, surcharges or rebates that may apply to an actual transaction. A list price is therefore less suitable than a real transaction price for SPPI compilation. Note that list prices for fixed amounts of working time are known as standard hourly rates;

3. Revenue ${ }^{3}$ and amount sold: data on both revenue and amount sold which allows for calculation of an average price for a large number of transactions. These data may be used in several pricing methods (unit value, component pricing, model pricing, and hourly charge-out rates). The revenue corresponds to the value of output sold or the value of invoiced sales of goods or services supplied to third parties during the reference period. The amount sold is a measure of the quantity of homogeneous services;

4. Acquisition and selling prices: data on both acquisition and selling prices where the difference between the two allows for calculation of a margin price. The acquisition price is the cost to the seller of purchasing a product or a service from a supplier excluding any taxes and rebates. The selling price is the cost to the purchaser excluding any taxes and transport charges;

5. Percentage fees and related value: data on both the value of a good or service, and a percentage fee from which an actual fee (price) can be calculated. The percentage fee could in practice be taken from a list, estimated by an expert or calculated as an average from real transactions. The related value refers to that of the underlying good (or other product) to which the service relates;

6. Expert estimate: price based on the potentially subjective judgment of the expert in the responding unit who completes the survey. The estimate can reflect different types of units, for instance only components of an entire service, or prices per working time and per product;

7. Input data: Price data for all (or a number of) input components needed to produce a set amount of service output. The profit margin is always to be included as an important input component. Input data can be taken from business enterprise records based on real transactions or be estimated by an expert. Strictly speaking, the input prices can be taken from a list, estimated by an expert, or calculated as an average from real transactions. However, an input price is set apart as it is not an output price. 


\subsubsection{Introduction to pricing methods}

The following section summarises the main pricing methods used to compile SPPIs from the different types of price data. The list does not claim to be exhaustive but it does reflect an exhaustive assessment of commonly used methods:

- Direct use of prices of repeated services represents the ideal of using real transaction prices or, less preferably, list prices, of the same service product in successive survey periods. Adjustments will be needed to account for any changes that occur when the observed product is replaced or if its quality changes. The method is discussed in section 2.2.1;

- Contract pricing refers to the use of prices in long term contracts for the repeated delivery of the same (or a very similar) service. This is a special case of using real transaction prices. The contract pricing method is discussed in section 2.2.2;

- The unit value method constructs a price index based on observed revenue and quantity data. Note that the unit value method as defined here is limited to cases where price observations refer directly to service output. The method is discussed in section 2.2.3;

- The percentage fee method calculates the value of the service as the product of the percentage fee and value of the product to which the fee relates. The method is discussed in section 2.2.4;

- The component pricing method is particularly relevant when only information on total revenues and number of sales are typically available, but where the products sold are relatively heterogeneous - invalidating the unit value approach. The approach specifies a representative product and estimates its price on the basis of the prices of identifiable components that determine the overall price. The method is discussed in section 2.2.5;

- The model pricing method is typically applied in cases where the service provided is unique. The approach specifies a standardised product, that is sufficiently representative of the type of service provided, and respondents are asked to provide a price quote for this standardised product. The method is discussed in section 2.2.6;

- Time based methods reflect cases where a service is specified in terms of the time spent providing a particular service and not necessarily in terms of the actual service provided. See section 2.2.7;

- Margin pricing method: Margin prices are defined here as those prices that are not directly observable but where the value of the service can be measured as the difference between the observed acquisition and selling prices of a given product. The method is discussed in section 2.2.8. It is important to differentiate this method from pricing mechanisms that may be used by typical margin charging industries. In some cases these industries will specify the price of a service for a given delivery/provision of a product, which may also be invoiced as a percentage of the value of the underlying product. In these cases the appropriate methods are those that relate real transaction prices or percentage fees. There are however similarities in practice between the percentage fee and margin pricing methods. 
Box 2.1. shows the pricing methods as defined in this Guide. They are presented linked to pricing mechanisms and results of pricing methods (namely the price that enters into index compilation). Therefore three main classes of pricing methods are distinguished and defined as such:

- Pricing methods which result in a price of final service outputs (left-hand side of box 2.1.): price-determining factors of services are well-specified; they are fully defined in terms of all the characteristics that influence their transaction prices. Price observations refer directly to specified service outputs and result in prices of final services output;

- Pricing methods which result in time based prices: (central part of box 2.1.): price observations refer to the time used in the provision of the service rather than on the service itself. Adjustments to reflect productivity changes may be necessary;

- Pricing methods which result in margin prices (right-hand side of box 2.1.): price observations that are used in this method refer to the difference in the price that paid by the service provider for the good or service they transformed and the price paid by the final consumer.

The resulting prices derived from using each of the methods applied are emphasised as they are important in monitoring practices and in analysing price and volume developments across different countries. In particular, price indices based on final service outputs may need to be interpreted differently from time based price indices. In the first case, the volume of output is, in principle, correctly measured (albeit depending on how well price-determining factors are specified) but this is not necessarily the case for time based methods, particularly where quality changes have occurred in the output, or productivity changes impact on the input (hours spent). This issue is further discussed in section 2.2.7. 
Box 2.1. Classification of main pricing methods for SPPI
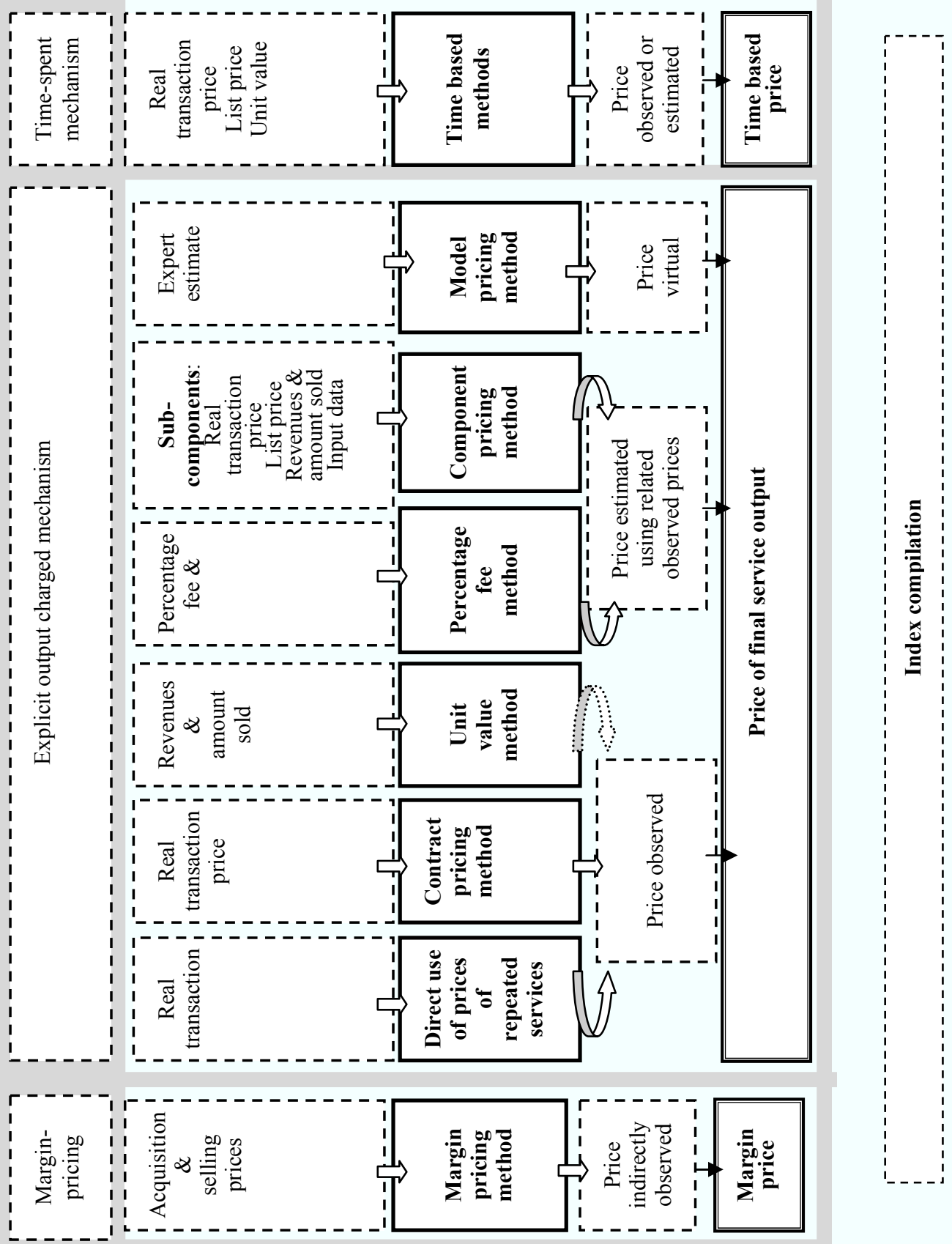


\subsection{Main pricing methods for SPPI}

\subsubsection{Direct use of prices of repeated services}

The direct use of prices of repeated services represents the ideal and refers to transaction prices for well-specified, repeated services which can be either simple services or packages of services. It corresponds to the transaction pricing typically observed in CPI and PPI compilation. This method captures price movements of real transactions of the same service products in successive survey periods.

\section{Data type in the survey}

The price data used are ideally real transaction prices (inclusive of any discounts, surcharges or rebates ${ }^{4}$ ) extracted from enterprise records or accounts in each survey period. If real transaction prices are not directly available they can be estimated by the respondent.

List prices can occasionally be used as proxies for real transaction prices. List prices are collected from standard price lists established by a business enterprise for the service products it sells. These prices may either directly match the required service specification or be as close to it as possible if prices for the exact specification are not available. List prices should only be used in an SPPI if there are good reasons to believe that they accurately reflect the evolution of actual transaction prices. This is not the case when discounts, surcharges or rebates vary over time in response to changing market conditions.

\section{Use of the direct use of prices of repeated services method}

Direct use of prices of repeated services is the preferred and easiest pricing method because indices can be directly compiled using standard PPI compilation procedures. Respondents are asked to select a number of service products that are representative of their total output. The prices of these services are observed over time, as are their characteristics in order to control for quality changes.

While the pricing of simple services is often straightforward, pricing of service packages is more difficult when their structure changes or when customers switch their purchases towards more favourable packages. For example, in the telecommunication sector a package might consist of fixed amount of phone call minutes (perhaps further split across network providers), SMS (short message service) messages and data as well as a fixed fee. New packages which provide differing amounts of phone call minutes, SMS messages and data are regularly introduced. Older packages may become less representative over time as customers switch to new ones, thereby leading to survey bias. However, replacing less representative service packages in an index with more representative ones may lead the statistician away from the pricing of repeated services to alternative methods to ensure service products remain representative while pricing is to constant quality.

The direct use of prices of repeated services is typically used for pricing the following industries: air transport, warehousing and storage, cargo handling, postal and courier activities, telecommunication, technical testing and analysis, employment activities, food $\&$ accommodation, other monetary intermediation, security and commodity contracts brokerage, insurance activities and rental and leasing activities.

As shown in box 2.2., one of the main issues when using direct use of prices of repeated services is to define and standardise the specification of the service to ensure 
that the specification continues over time. An overly tight specification entails the risk that the service may not be transacted again.

\section{Box 2.2. Direct use of prices of repeated services: passenger car rental industry}

Type of service: passenger car rental for leisure travel

Location $\mathrm{n}^{\circ}: 6437500$

Establishment number and street: 64375 BLS parkway, Cincinnati, Ohio 45260. Corporateowned establishment. Airport site. Standard rate plan.

Duration of car rental period: one day

Class : standard

Age of rental vehicle: $12-24$ months

Model/name of rental vehicle: Pontiac grand am

Passenger count of rental vehicle: five passengers

Daily rate

One-way rental (pick-up and drop-off points are at different locations), pick-up point: 64375 BLS parkway, Cincinnati, Ohio 45260. Drop-off point: 80631 Dol place, Cincinnati, Ohio 45309.

Unlimited mileage (no extra charge)

No fuel charge (for rental car with full tank of gas; returned with full tank).

Advance reservation.

The service is transacted every survey period. The price is the total daily rental.

Special case: the use of data collected for the Consumer Price Index (CPI)

The use of price data collected for the CPI can be considered as a special case of direct use of prices of repeated services. This situation arises particularly for service industries where the vast share of output from the sector goes to final demand. In other words, when services that are predominantly but not exclusively destined for household consumption such as passenger transportation, food \& accommodation or finance \& insurance, the use of CPI data may prove to be an attractive option. The use of CPI data can, in particular, help to remove or minimise the requirement for data collection.

CPI data can be used either exclusively (only CPI data are used as proxies for the SPPI) or in tandem with other producer price data not covered by the CPI, especially those relating to business users (collected by a dedicated SPPI survey). However, when using CPI data due attention should be paid to the two following issues:

1. CPI data that is used in the compilation of SPPIs must be adjusted such from valuation at purchasers' prices to basic prices by deducting any taxes including VAT and trade margins. ${ }^{5}$ Basic prices are better aligned to the remuneration that producers actually receive to compensate them for expenditures on goods and services used as intermediate inputs, for labour costs and as a return to capital; ${ }^{6}$

2. When CPI data are used as a full proxy for the SPPI, special attention needs to be given to the potential for prices charged to businesses to display different trends to those charged to household consumers. The assumption that prices for business 
users and households move in a similar trend, with a similar composition of consumption, should be tested.

3. CPIs are typically used as proxies in the compilation of BtoAll indices, such as postal and couriers activities, telecommunication, technical testing and analysis (of passenger vehicles) and food and accommodation services.

\subsubsection{Contract pricing method}

In the contract pricing method, the object of measurement is a single real transaction of service based on a contract for which prices are agreed for more than one period when the contract is signed or renewed.

Data type in the survey

Prices for the repeated delivery of the same or a very similar service in many survey periods, set out in long-term contracts are used in the contract pricing method. The method uses real transaction prices of a special kind in so far as:

- Prices in a contract are agreed for more than one period when the contract is signed or renewed;

- Prices may be the same for that period or change according to an agreed pattern.

While surveyed price data are commonly based on a "contract", this does not necessarily result in the use of the contract pricing method. In order for contract pricing to be employed the contract must cover more than one survey period, services provided in each period must be the same and prices must be agreed at the same time for more than one period.

\section{Use of the contract pricing method}

The contract pricing method works as follows:

- Specific contracts are selected during the respondent initialisation phase (see chapter 3, section 3.4.). The product description identifies the client explicitly. The nature and quantity of the service to which the price refers is also stated clearly, e.g. the total weekly or monthly service (coinciding with payment), or the price per unit of service delivery, for example one transportation trip, one days' cleaning or an hour of security provided;

- The price of this product is included in every compilation period although respondents in some industries have stated that prices change so rarely that the survey frequency should be lower than the periodicity of SPPI calculation. Where a contract fixes the period for which a constant quality service is provided for a specified price, this price can be used in index compilation for the duration of the contract;

- If there is any change in the actual service, a quality correction has to be made for which standard methods can be applied. For example, an office cleaning contract changes from 5 to 3 cleanings per week or the weight of the load of a road haulage trip increases from 10 to 14 tonnes.

Box 2.3. shows an example of contract pricing methods for freight transport by road. 


\section{Box 2.3. Contract pricing: Freight transport by road}

Respondents provide price information on relevant routes and freight types (by customer) that they have selected themselves. Prices reported by the respondent are real transaction prices.

Prices are set in advance for several survey periods. They are updated about once a year. Fuel surcharges can be added within the contract period if agreed in the contract.

Weights are not available for each service transaction but at the level of type of service activity - consequently an un-weighted geometric mean formulation is used to calculate elementary price indices.

\begin{tabular}{|c|c|c|c|c|c|}
\hline \multirow[t]{2}{*}{ Service } & \multirow[t]{2}{*}{ Unit } & \multicolumn{2}{|c|}{ Price } & \multirow[t]{2}{*}{ Price change } & \multirow[t]{2}{*}{ Weight } \\
\hline & & $t-1$ & $\mathrm{t}$ & & \\
\hline \multicolumn{5}{|l|}{ Temperature controlled transports } & 0.25 \\
\hline Customer A: Transport of meat, from A to B & $\begin{array}{l}€ / 10 \\
\text { boxes }\end{array}$ & 25 & 26 & 1.040 & \\
\hline \multirow[t]{2}{*}{ Customer B: Transport of fish, from C to D } & $\begin{array}{l}€ / 10 \\
\text { boxes }\end{array}$ & 25 & 27 & 1.080 & \\
\hline & \multicolumn{3}{|c|}{ Geometric mean } & 1.060 & \\
\hline \multicolumn{5}{|l|}{ Tank transports (fertilizers, gas etc.) } & 0.25 \\
\hline Customer A: Sludge, from A to B, $€$ /ton & $€ /$ ton & 18.25 & 18.15 & 0.995 & \\
\hline \multirow[t]{2}{*}{ Customer B: Acid, from C to D, €/ton } & $€ /$ ton & 14.15 & 14.62 & 1.033 & \\
\hline & \multicolumn{3}{|c|}{ Geometric mean } & 1.014 & \\
\hline \multicolumn{5}{|c|}{ Paper and wood industry transports (paper, cartons, pulp etc.) } & 0.5 \\
\hline Customer C: Pulp, from A to B & $€ /$ ton & 6.70 & 6.9 & 1.030 & \\
\hline \multirow[t]{2}{*}{ Customer D: Timber, from C to D } & $€ /$ ton & 8.72 & 8.94 & 1.025 & \\
\hline & \multicolumn{3}{|c|}{ Geometric mean } & 1.028 & \\
\hline \multicolumn{4}{|l|}{ Weighted price change from $\mathrm{t}-1$ to $\mathrm{t}$} & \multicolumn{2}{|l|}{1.0325} \\
\hline
\end{tabular}

Contract pricing is usually relatively easy to apply where payments are made on an accrual basis - that for each individual contract the prices are fully in line with corresponding service output.

However, it is important to note that the contract pricing method can be employed only under certain conditions. Firstly, if contract pricing is based on a real transaction as in the case of direct use of prices of repeated services, there is a fundamental difference between these two methods. Contract pricing is based on a single transaction, whereas the direct use of prices of repeated services is based on multiple transactions, possibly for different clients. A contract and its price are thus usually unique for a particular client. However, as they are repeated over many survey periods the "unique product problem" does not apply here.

Secondly, the producer-client contract must cover the repeated delivery of a service over a period of time, whether predefined (for example one year) or open ended. This pricing method requires therefore that the contract lasts over a sufficiently long period (at least a number of survey periods), and that service delivery is repeated at least once in each survey period (remembering that survey periodicity and compilation periodicity do not need to be the same). However, the price specified in the contract need not be constant but may change without an accompanying change to the output specified in the contract. Prices can change via different mechanisms, for instance by yearly renegotiation, by escalation with another index such as the CPI, or by a clause that states that the producer is allowed to pass on certain cost changes (for example a fuel 
surcharge). Payments are typically periodic, e.g. every week or month the same amount is paid.

The method should be used with caution because individual contract prices agreed in a previous period for future periods may not be representative of current price development in the industry. Therefore, a crucial concern when applying the contract pricing method is how well the resulting price index reflects price development in the industry concerned. In those service industries where contract pricing is the prevailing pricing mechanism, two issues should be considered to ensure representativeness:

1. Contracts included in the sample should preferably reflect different volumes of service deliveries because price developments may vary with the size of the customer;

2. A relatively large sample is required. Otherwise the resulting index may become too sensitive to the spread of contract periods in the sample. In other words, due attention should be paid to the temporal representativeness of the sample to capture the evolution of the market situation. It is possible that the spread of contract periods is highly seasonal, e.g. contracts are usually signed at the beginning of the year.

If there is no significant seasonal pattern in the spread of contract periods over the year and services provided by the industry are relatively homogeneous, the contract pricing method and a representative sample of contracts might result in an index that is broadly representative of the whole industry. On the other hand, if there is a strong seasonal pattern, it may be necessary to also collect prices that are based on alternative pricing mechanisms. The more prevalent other pricing mechanisms are in an industry the more important it is to enlarge the sample. This would naturally imply the use of multiple pricing methods across different respondents for the industry concerned.

Note finally, that "new sales biases" may occur when contract pricing is used. This problem arises where a new contract is won at a significantly discounted price. Once custom is secured, prices revert to regular market levels. The resulting SPPI may show an excessive price increase as the status of a customer moves from "new" to "regular". A practical solution to this problem is to avoid the inclusion of prices that are clearly discounted to win new business.

In summary, the contract pricing can only be applied if: $i$ ) the chosen unit of service ${ }^{7}$ is repeatedly provided under a single contract over many survey periods and at least once per survey period and, $i$ ) the surveyed prices reflect the same service each survey period. If these conditions are not met, the contract pricing method cannot be used:

- Long lasting contracts for unique services, like a three year engineering project, cannot be surveyed using the contract pricing method, because different services (or phases of a large service agreement) are produced in each survey period. For such services, model pricing or a time based method are the main options. Similarly, framework agreements under which different amounts of service or different services are delivered in each period are not suitable for contract pricing;

- Contract pricing is not recommended in cases where the same services are delivered in each period but payments are made less frequently (for example a large up-front payment). There is no way, other than by estimation, to allocate these payments over the contract period to determine prices for each sub-period 
and to apply the accrual principle. It is recommended to apply other pricing methods, such as model pricing, in these cases.

The contract pricing method is typically used for pricing the following industries: freight transport by road, postal and courier activities, technical testing and analysis, cleaning activities, waste management and software publishing.

\subsubsection{Unit value method}

The unit value method is based on repeated real transaction of final service output for which prices are derived using respondent data that are not output prices. Service output is subdivided into homogeneous sub-sets for which value and quantity data are available. Prices are then estimated by dividing the value of service outputs by the corresponding output quantities.

The unit value method as defined here is limited to those cases where estimated prices refer directly to final service output. Cases where unit values are employed in the estimation of hourly rates are included in the section on pricing methods based on working time (section 2.2.7). In addition, in the case of the component pricing method a sub-component might be based on unit-value. This situation is covered in the section on component pricing (section 2.2.5).

\section{Data type in the survey}

Under the unit value method, the price of a service is derived by dividing revenues from sales by volumes of services provided in respect of a large number of transactions. As shown in the telecommunications example presented in box 2.4., the 'local calling price' is the total revenue from local phone calls divided by the total volume (minutes) of local phone calls.

\section{Box 2.4. Unit value: Telecommunications (Example 1)}

U.K. Business Telecommunication: Local calls

\begin{tabular}{|c|c|c|c|c|}
\hline & Revenues (£m) & $\begin{array}{l}\text { Volumes (million } \\
\text { minutes) }\end{array}$ & $\begin{array}{l}\text { Unit Values } \\
\text { (£ per minute) }\end{array}$ & Index Value \\
\hline \multicolumn{5}{|c|}{ Year t } \\
\hline Q1 & 300 & 14,000 & 0.02143 & 100.0 \\
\hline Q2 & 280 & 13,500 & 0.02074 & 96.8 \\
\hline Q3 & 260 & 13,000 & 0.02000 & 93.3 \\
\hline Q4 & 240 & 12,500 & 0.01920 & 89.6 \\
\hline \multicolumn{5}{|c|}{ Year t+1 } \\
\hline Q1 & 220 & 12,000 & 0.01833 & 85.6 \\
\hline Q2 & 200 & 11,500 & 0.01739 & 81.2 \\
\hline Q3 & 180 & 11,000 & 0.01636 & 76.4 \\
\hline Q4 & 160 & 10,500 & 0.01524 & 71.1 \\
\hline
\end{tabular}

The unit value method may be appropriate in cases where consistent value and quantity data are available for sufficiently homogeneous services. However, in practice the homogeneity requirement is difficult to fully meet. Even a very detailed sub-division of output does not always ensure that services are homogeneous. Although the quality of specific services might be homogeneous, measures of revenues and quantities may include contracts of different sizes (which is an important price determining factor), 
undermining the feasibility of the method. Detailed sub-division of services is of the utmost importance to ensure that the impact of this problem is minimised.

There are cases, such as postal and courier services, where unit values can often be considered appropriate. ${ }^{8}$ The unit value method may also prove to be the best pricing method for certain complex services (for example telecommunications and flight transportation services). Rapid technological development and frequent changes to invoicing systems may make the implementation of other alternatives so difficult and costly that a judicious use of the unit value method offers a feasible and cost-effective option. ${ }^{9}$

Note however, that a problem sometimes encountered with unit value indices is that the required data are not available in time for inclusion in current quarter estimation. This means that unit value indices are often lagged by one quarter (or month) or alternatively, indices are published preliminarily and revised when final data become available.

The unit value method is typically used for pricing the following industries: air transport (see box 2.5.), postal and courier activities, telecommunications, advertising, accommodation, waste management, publishing of books, periodicals and other publishing activities, software publishing.

\section{Box 2.5. Unit value: Air freight transport (Example 2)}

Freight rates $(€ / \mathrm{kg})$ are a commonly employed pricing mechanism in Air freight transportation. Rates may differ from contract to contract, between customers or according to different levels of services or goods. However, as both rates and services provided can be quite homogenous a unit value approach can be used.

Total revenue and volume data is available. For their member airlines, IATA international the International Air Transport Association - runs an accounting system for Air Waybills. It collects information on turnover, transported volume (weight in $\mathrm{kg}$ ), destination and carrier. With this information, unit values can be calculated for every destination and airline that subscribes to the system (and all large international airlines do). FSO Germany receives quarterly reports from IATA containing turnover and transported volume by airline and destination, and calculates unit values out of it. For example:

\begin{tabular}{|l|l|l|}
\hline \multirow{2}{*}{ Airline A } & \multicolumn{2}{c|}{ Destination X } \\
\cline { 2 - 3 } & \multicolumn{1}{|c|}{$\mathrm{T}$} & \multicolumn{1}{c|}{$\mathrm{T}+1$} \\
\hline Turnover $(€)$ & & 181 \\
\hline Volume $(\mathrm{kg})$ & 150 & 29 \\
\hline Freight Rate $(€ / \mathrm{kg})$ & 25 & 6.24 \\
\hline Index value & 6.00 & 104 \\
\hline
\end{tabular}

The freight rates for airline $\mathrm{A}$ by destination $\mathrm{X}$ is calculated dividing turnover by transported volume. It contains multiple, variable transactions. The change in price is calculated by comparing the calculated freight rates: in this example, the price has risen by $4 \%$.

\subsubsection{Percentage fee method}

The percentage fee method is used to measure the price development of real transactions of services that are tied to transactions of products such as goods, contracts or assets.

Data type in the survey 
In this method, the percentage fee and related value of the product transacted are used to estimate the price of the final service output by multiplying the percentage and the value of the good.

The percentage fee and the value of the product value may be collected from different sources. The percentage fee can be taken from a list, estimated by an expert or calculated as an average. Often, the price (actual or index) of the good is already available to the compiler, for example in the case of a price index for leasing of office equipment rented (box 2.6.) or real estate activities (see box 2.7). In other cases both the percentage fee and product value are supplied by the respondent.

\section{Box 2.6. Percentage fee: Leasing of office equipment (Example 1)}

In the example, prices are calculated by using percentage fees and price indices. For each survey period $(\mathrm{t}-1, \mathrm{t}, \mathrm{t}+1 \ldots)$, the compiler collects data on percentage fees and combines them with price indices for the products concerned.

Service price $=1+$ percentage fee $(\%)$ x price index of the product.

\begin{tabular}{|c|c|c|c|c|}
\hline Service & Period & $\begin{array}{c}\text { Percentage fee }(\%) \\
\text { (a) }\end{array}$ & $\begin{array}{l}\text { Price index of } \\
\text { personal computer / } \\
\text { copying machines } \\
\text { (year t0 }=100 \text { ) } \\
\text { (b) }\end{array}$ & $\begin{array}{c}\text { Prices } \\
(1+a) \times(b)\end{array}$ \\
\hline \multirow{3}{*}{$\begin{array}{l}\text { Monthly fee for } \\
\text { leasing a personal } \\
\text { computer valued at } \\
250,000 \text { yen for } 3 \\
\text { year contract }\end{array}$} & $t-1$ & 3.0 & 86.5 & 89.095 \\
\hline & $\mathrm{T}$ & 3.1 & 83 & 85.573 \\
\hline & Percentage change & $+3.3 \%$ & $-4.0 \%$ & $-3.9 \%$ \\
\hline \multirow{3}{*}{$\begin{array}{l}\text { Monthly fee for } \\
\text { leasing a copying } \\
\text { machine valued at } \\
1,000,000 \text { yen for } 5 \\
\text { year contract }\end{array}$} & $t-1$ & 2.6 & 95.0 & 97.47 \\
\hline & $\mathrm{T}$ & 2.7 & 94.0 & 96.538 \\
\hline & Percentage change & $+3.8 \%$ & $-1.1 \%$ & $-1.0 \%$ \\
\hline
\end{tabular}

Use of percentage fee method

Typically, the percentage fee method is used in the real estate agencies sector where the pricing mechanism is based on real estate prices and commission rates (see box 2.7.). Other examples of services for which the method is used include the placement of advertisements, architectural services, and rental and leasing services. For this method to be employed the product to which the service is tied should be a product group rather than a strictly specified product. The latter case, where the fee for the same product for consecutive periods is targeted directly (by measurement of the difference between the acquisition and selling prices of product), is categorised as the margin pricing method. 


\section{Box 2.7. Percentage fee: Real estate activities (Example 2)}

\section{Specification of the service:}

Residential property sale/purchase. Agents and brokers services provided: listing agent. Full service. Single family cooperative apartment. Address of property: 804 River RD \#4f, Nowhere, NY. Other property identification: mls \#2205775. Number of bedrooms: 2. number of bathrooms: 1. property value: $\$ 176,000$. Commission rate: $2.00 \%$.

The exact house has not been transacted every survey period. The property value and commission rates are updated using actual data from recent sales of comparable properties.

\begin{tabular}{|c|c|c|c|c|}
\hline Period & Property value & Commission & Price & Index value \\
\hline T-1 & $\$ 182,000$ & $2 \%$ & $\$ 3640$ & 100 \\
\hline $\mathrm{T}$ & $\$ 176,000$ & $2 \%$ & $\$ 3520$ & 96.7 \\
\hline
\end{tabular}

The price, based on real transactions, is estimated using commission rate and product price.

In the percentage fee method, the price change is split into two parts, the change of the percentage fee and the change of the product price. Thus, the price of the service can be estimated by updating the price in the previous period via the following formula:

$$
P_{s}^{t}=P_{s}^{t-1} \times \frac{1+m_{t}}{1+m_{t-1}} \times \frac{P_{t}}{P_{t-1}}
$$

Where: $P_{S}^{t}$, is the price of the final service output in period $t$;

$P_{t}$, is the value of a group of contracts, assets or products in period $\mathrm{t}$;

$m_{t}$, is the percentage fee in period $t$ that applies to the value.

Capturing price development by applying the above formula is less data demanding than when fees for well-specified products are targeted directly because only the price index for the product group and percentage fee are required. However, the underlying product group should be sufficiently homogeneous over time to provide a valid price estimate.

A special application of the percentage fee method is employed where the pricing mechanism is based on a scale with varying percentages that depend on the value of the underlying product. Typically, the percentage fee decreases according to a schedule as the value of the product increases. ${ }^{10}$ In this case, only products in the same fee schedule category can be taken as homogeneous. However, the same product (although not directly observable) might, as a result of more general price inflation, move to a different fee schedule category where a different commission is applied. This scenario should be accounted for in index compilation.

It should also be noted that as a consequence of the assumption that the price of the service is related to the price of the underlying asset or product, any change to the size or quantity of products will be directly reflected as changes in the volume of services.

\subsubsection{Component pricing method}

The component pricing method individually measures the price movements of all or some output components of the final service output. In other words, the service is divided into a number of key output components of which one or more are then priced separately. 


\section{Data type in the survey}

For each output component actual respondent data are used. No subjective estimation should be used. Component pricing is fully based on real transaction prices of output components that have been combined to form or estimate a price of the final service output.

The main restriction on this method is that time based prices (such as the price of one hour of work) are not used for determining the price of components. Otherwise the pricing method belongs to time based pricing (see section 2.2.7.). This is due to the fact that often in the production of services, labour accounts for a high proportion of inputs. The importance of this principle is particularly apparent in cases where time based pricing is applied for sub-services that are subject to strong technological development. For example, the adoption of more advanced technology may lead to increased hourly rates but also to a reduction in the required working time. Consequently "real" prices and volumes of services may remain stable. A fixed weight structure, even when updated frequently, does not capture these changes and a biased sub-component price may end up contributing to the final price. ${ }^{11}$ On the other hand, assessing required working time rather than keeping it fixed would mean that the method falls into the category of model pricing where (at least some) subjective estimation is made.

The pricing method used in the reporting of each separate output component (e.g. real transaction prices, unit value, etc.) should not be considered when determining the overall pricing method used for the "total" price.

\section{Use of the component pricing method}

An advantage of component pricing is its flexibility of use. Care should be taken to ensure its representativeness over time and therefore sub-components and weight structures should be updated frequently.

In practice, the price for each individual output sub-component is provided by the respondent and the compiler then combines this information to compute a price index for the composite service. There are different ways of combining or aggregating across the elements for which prices have been collected. Methods include:

- The use of existing bills or contracts to draw up a user profile. For example, a typical bill for a telecommunications client applies different rates for local phone calls, national calls, etc., and the total volume of communication is distributed between these elements (see box 2.8.). Representative distributions of communication volumes constitute user profiles. These user profiles can provide the necessary weighting schemata to construct a composite index of communication services. Sometimes not all elements of composite prices can be covered. Where this is the case, it has to be assumed that the price of the missing element moves approximately in line with the average of the other elements. Omissions may also be acceptable if the user profile shows a very small weight for the missing element;

- The use of output or consumption weights. Composite prices can be constructed by collating prices of components using a weighting schemata provided by the respondent. This kind of pricing can be considered for use in transportation services, for example.

A total price derived during the application of the component pricing method will not necessarily correspond to the price of any transacted service because quantities of sub- 
services in the component price may differ from actually transacted services. Furthermore, some sub-services may not be covered even though it is desirable that the coverage of sub-services is as exhaustive as possible.

The component pricing method is not widely used except in telecommunication services (see box 2.8.).

\section{Box 2.8. Component pricing: Telecommunications}

\section{Pricing of local telephone services:}

(a): Average number per access line (weight) in the base period is obtained by dividing the total number of units for each type of charge by the total number of access lines.

(b): Average revenue per unit in period $t$ is obtained by dividing revenues for each type of charge by the total quantity used of each charge.

(a) $\times$ (b): Weighted revenue in period $t$ is calculated by multiplying average number per access line by average revenue per unit.

\begin{tabular}{|c|c|c|c|}
\hline Type of charge & $\begin{array}{l}\text { Average number per } \\
\text { access line } \\
\text { (a) }\end{array}$ & $\begin{array}{l}\text { Average revenue per unit } \\
\text { (b) }\end{array}$ & $\begin{array}{l}\text { Weighted revenue } \\
\qquad \begin{array}{l}\text { (a) } x(b)\end{array}\end{array}$ \\
\hline Access line & 1 & 26.7530 & 26.7530 \\
\hline \multicolumn{4}{|c|}{ Usage charges based on time: } \\
\hline Peak minutes & 162 & 0.2589 & 41.9418 \\
\hline Off-peak minutes & 133 & 0.0824 & 10.9592 \\
\hline Roaming minutes & 10 & 0.9722 & 9.7220 \\
\hline \multicolumn{4}{|c|}{ Usage charges other than time: } \\
\hline Landline, per call & 2 & 0.1500 & 0.3000 \\
\hline Other charges, daily rate & 1 & 1.5000 & 1.5000 \\
\hline \multicolumn{4}{|c|}{ Features/Options and feature packages: } \\
\hline Custom calling package & 0.65 & 3.4600 & 2.2490 \\
\hline Call waiting & 0.20 & 4.8500 & 0.9700 \\
\hline Call forwarding & 0.10 & 5.1500 & 0.5150 \\
\hline 3-way conference & 0.05 & 5.7500 & 0.2875 \\
\hline No answer transfer & 0.10 & 4.2500 & 0.4250 \\
\hline Voice messaging & 0.20 & 4.8000 & 0.9600 \\
\hline \multicolumn{2}{|l|}{ Total (Price in period $t$ ) } & \multicolumn{2}{|l|}{96.5825} \\
\hline
\end{tabular}

The price, based on real transaction of sub-components, is the sum of weighted revenues. The method used is not unit value: unit values are used for the components but it is not unit value pricing method because the various unit values are combined.

\subsubsection{Model pricing method}

\section{General features of the model pricing method}

The model pricing method is the most appropriate approach for use in industries where service outputs are predominantly unique. As the compiler requires in each period a price for a standard service with constant specifications, the method allows for estimation of the price for a standardised final service product, a model transaction which is not transacted in the comparison period. ${ }^{12}$

The model transaction represents a service product that is non-observable (virtual) at the time of data collection. Two types of model transaction can be considered as follows: 
1. A model can be a service that has never been observed as such, a fictitious single service that can be set as the re-priceable service product for a group of respondents;

2. Alternatively, a model can be a service that has been directly observed in the past, but not during the current pricing period. In other words, the specifications of a real service provided can be developed as the 'model' to price. For example, an engineering services producer is asked to select a representative contract which it has signed in the past and for each period to quote the required price to undertake that project in the survey period. When selecting a real transaction for use as a model, a recent service transaction is generally selected. A recent transaction may more accurately represent the current activity of a service producer and the price may be updated more easily.

It is important that although model prices are not based on observed market transactions, estimates should capture prices prevailing in the survey period. It is clear that this is the case for small contracts where respondents have recorded data that can be directly used in the estimation of model prices. However, the same principle applies also when a contract covers several periods, that is, estimates for all parts of a project should be made based on conditions and prices prevailing in the survey period. Deviating from this rule would mean that the accrual principle is not followed and this could imply biased measures of service volumes when SPPI are used for deflation.

Noteworthy in the case of contracts that last several periods is the fact that model prices differ from prices of actual tenders where future changes in inflation, taxation etc. might be taken into account. They are artificial in the sense that project costs and markups represent only the market situation in the current survey period although various stages of a long-term project become actual (or current) at different points in time. On the other hand, relying only on present price levels is also an advantage from a practical point of view because there are fewer uncertainties in the estimation of prices and base data used in the estimation may be directly available.

\section{Estimating model prices}

Appropriate models for different service industries will have different requirements. It is essential that the model is specified in sufficient detail; so that the respondent reports prices for a constant quality model and that no variation from the model occurs over time without notification to the compiler.

The estimation of a real transaction price is fully based on expert estimation which may be subjective. The expert might consider real transaction prices, revenue and amount sold, list prices and any input data for calculating this price. The resulting total price for the service is therefore a fictitious expert estimate. The pricing method used to form the resulting total price should not be a consideration when determining the overall pricing method.

A central task for the expert is to estimate the working time required to produce a service. An estimation based on the current market situation is needed, for instance by keeping recent tenders in mind. Indeed, pricing factors such as hours worked should be updated in model prices when there is a change in the number of hours required to provide the service. The re-evaluation of the required working time is essential in order to capture changes in the efficiency of service provision. If the working time is not evaluated but assumed unchanged, the method is not categorised as model pricing but as pricing based on working time. In other words, as prices of the same services (although 
virtual ones) are followed over time, changes in productivity must be taken into account. In practice, the difference between the methods may not be very significant if respondents cannot accurately describe how much more or less time a service provision requires compared to the previous period.

When estimating the price of the model, the expert should pay particular attention to the following factors: labour costs (staff by skill or experience and numbers of hours); overheads; and gross profit margin (the representative margin that would apply in the current competitive climate). For each pricing period, the respondent will need to "recost" each component. Special attention is needed to ensure that the model describes an output with an associated price and not a list of input components and prices.

As noted above, it is particularly important that labour input is adequately reestimated to reflect changes in productivity. The respondent must therefore detail any change in the number of hours needed for the production of the model described in output terms (for example 1,000 engineer hours were previously required, now only 930 engineer hours are needed). If this detail is not provided, the model pricing method has the same 'productivity problem' as time based methods. Models might also have to be modified from time to time to ensure that they remain representative of the type of outputs of, and production methods used by, the service producer.

The reported profit margin should reflect actual business conditions in the pricing period, and this component is therefore expected to fluctuate with market conditions (for example it will be higher in periods of market growth and lower, perhaps even negative, in periods of recession).

\section{Use of model pricing}

Models might be hypothetical and/or based on real transactions from previous periods. Perhaps the most convenient way to implement the method is to rely in so far as possible on actual data from more recent periods. A model could be, for example, based on a contract that was made in a recent period. Use of recent data has a number of advantages, for example:

- Changes in market conditions will be better accounted for;

- Constant quality of service products will most likely be better ensured;

- Representativeness of service products and prices will be better ensured;

- It is easier for respondents to estimate prices. Fresh data will be available to make appropriate adjustments in those cases when some features or characteristics of the service change.

On the whole, compared to a hypothetical or old model, model pricing from the recent period should give better quality results. This may be the case particularly if respondents have not undertaken any work in the recent past and are not tendering for any such work related to the hypothetical model. The type of data that is available for use in developing the base period model might differ depending on the service and service provider. Typically, they include data on charge-out rates applied in service projects and various data on costs. A combination of detailed respondent data from a recent period and similar data in the survey period provides the best possible framework to capture price development.

When using model pricing, the starting point is to select a specific service and adequately specify the details of that service. The respondent is asked to price the same service in $t-1$ and $t$ rather than assuming from the outset that the required working hours 
by staff category alone provides a sufficient transaction specification, as is the case in the hourly rate method (see section 2.2.7.). That means that although price changes mostly stem from changes in hourly rates, overhead and profit, some changes might also originate from changes in the number of working hours and other features.

Specifically, if a different number of hours or a different mix of personnel and their hours are required to provide the exact same service or contract in the survey period, then those factors have to be updated and the resulting changes shown as price changes. Note however that if the resulting price changes are large, then the respondent should be contacted and asked to explain why and to ensure that no changes have been made to the specified service.

Changes to a model might also result from changes in technology or to regulation such that the exact same output is provided with a change in the amount of inputs. In such cases, recording the difference as a price change is fully justified. On the other hand, if it can be concluded that the change in inputs really does result in a change in the output (or the service being provided), then a quality adjustment is required. The information can be used in updating the service description but the price must be adjusted.

Because the respondent is being asked to price the same service in period $t-1$ and $t$, the unit of measurement is actually a price movement. This differs from the normal situation where a respondent is asked to provide only a price for each sampled service product for the current period of reference. Therefore, in using this method, the reported price movements collected each period for the model should be linked together to measure the evolution of price.

Note finally that a problem with model pricing is that it can be difficult to ensure that the models employed remain representative. Also, the workload imposed on the respondent is relatively large even in cases when models are based on recently provided service products. This implies a risk that the respondent will not commit sufficient effort to ensuring accurate returns and may instead report model prices that remain unchanged for several periods. Therefore, it is important to engage with respondents to ensure that the prices reflect adequately the evolution of the market situation.

The model pricing method is typically employed for the following industries: freight transport by road, air transport, postal and courier activities, legal activities, accounting, bookkeeping and auditing activities, tax consultancy, management consultancy activities, architectural and engineering activities and related technical consultancy (see box 2.9.), technical testing and analysis, advertising, market research and public opinion polling, software publishing, insurance activities, health service industries and financial service activities (combined with percentage fee). 


\section{Box 2.9. Model pricing: Engineering services}

Specification of the service: Building related engineering services. Contract identifier: Project BLS-PPI. Billing invoice number: 123. CLIENT \#456. Multi-use building. Non-fixed (variable-hourly fee). Qualifications based selection. Monthly billing. Review soils @ excavation base; test engineered fill, backfill, observe concrete reinforcement \& masonry construction for compliance; provide proof roll of parking areas; sample \& test fresh concrete \& compressive strength; masonry grout \& prism testing.

\begin{tabular}{|l|l|l|l|}
\hline \multicolumn{1}{|c|}{ Charge Category } & \multicolumn{1}{c|}{ Hours } & Rate & Hours $\times$ Rate \\
\hline Compaction testing & 1 & $\$ 40.00$ & $\$ 40.00$ \\
\hline Special inspections, concrete & 15 & $\$ 50.00$ & $\$ 750.00$ \\
\hline Concrete testing & 25 & $\$ 40.00$ & $\$ 1,000.00$ \\
\hline Sample pick-up & 6 & $\$ 40.00$ & $\$ 240.00$ \\
\hline Special inspections, masonry & 8 & $\$ 50.00$ & $\$ 400.00$ \\
\hline Project mgmt. - Senior project engineer & 2 & $\$ 80.00$ & $\$ 160.00$ \\
\hline Total fee & & $\mathbf{\$ 2 , 5 9 0 . 0 0}$ \\
\hline
\end{tabular}

Every survey period the respondent estimates the number of hours and rates for each charge category required to provide the fixed service described in the specification. The estimated price is not a price based on working time since the number of hours is not fixed; rather the service being provided is fixed.

\subsubsection{Pricing methods based on working time}

\section{General features of pricing methods based on time worked}

Pricing based on working time differs from other pricing methods in that the price of the service finally provided is not identified but that the price of the time spent in the provision of the service is used instead. Services are assumed to correspond directly or predominantly to different types of chargeable hours worked for a client. The validity of the method depends on how realistic this assumption is; that is the extent to which the quantity and quality of chargeable hours worked remains constant over consecutive periods.

Measurements of prices based on hourly (or charge out) rates represent pricing mechanisms rather than the actual prices of real services. The price of a real service is made up of all payments to the service provider and it is this total price rather than the hourly rate that should, in ideal circumstances, be observed. The degree of appropriateness of time based pricing methods for direct use in SPPI compilation depends largely on the services concerned.

Characteristics of the methods based on prices of working time become apparent when a time based index is used in the deflation of National Accounts. If a price index is assumed to equal the development of hourly rates, the measure of volume corresponds to the time devoted to the service provision (number of worked hours) rather than the volume of services provided. No change in productivity is reflected in these measures except those stemming from changes in the staff structure - productivity development is slightly positive if the share of higher-paid staff goes up and is negative in the reverse case. Productivity change is not picked up within each staff grade.

The assumption of unchanged productivity in each staff grade is particularly strong in a situation where the staffing structure is subject to change. Changes in the staffing 
structure often mean that the content (and value) of work changes within grades. For example, with the help of new technology some tasks previously carried out exclusively by professionals may now be delivered by support staff. As a result the volume and quality of the work of support staff and perhaps professional staff change - undermining the assumptions underlying the method. An adjustment procedure is needed because of a quality change to the unit priced, the chargeable hour. It depends on each actual situation and data availability as to how adjustments are made in practice. However, this does not solve the productivity problem which would require that "real" service output should be identified.

The acquisition of, or improvements to, office machinery, software and other equipment are expected to improve real service output and productivity. The time worked to produce services may shorten and the quality of services might change. Thus, SPPIs based solely on time worked for clients, tend to be positively biased, particularly in those service industries greater amounts of equipment are used in production.

Nevertheless, hourly rates represent observable pricing mechanisms and are a natural starting point for the compilation of certain SPPIs. ${ }^{13}$ For some services it may be difficult to identify more suitable options than hourly rates. In such cases the resulting SPPI may be accurate in the short term but in the longer term it might be subject to an increasing risk of bias, depending on the type of service. There are very few market services where productivity improvements are not expected over the longer term.

The pricing methods based on worked time are in principle straightforward. Several time based methods can be distinguished and these are briefly discussed in the following sub-sections. They can be broadly classified into two main categories:

1. Methods where the resulting price is fully based on working time required to provide a service;

2. Methods that use a significant element of time based measure as part of the estimation are referred to as predominantly based on prices of working time.

Special attention needs to be paid to the sensitivity of the methods to changes in the scope of billable working hours. ${ }^{14}$ For example, if support staff is ceased to be charged separately and charge-out rates of professionals increase to account for this, then the resulting price index would increase and in theory the estimate of volume change for the industry would decrease after deflation even though the actual service output is unchanged. Put differently, savings gained by a more efficient use of staff are not reflected in prices but the index becomes upwards biased. A similar example occurs where charge-out rates for professionals increase due to the application of new technology, which allows them to complete tasks quicker thus reducing their billable hours whilst providing the same service to clients.

Thus, when using time based methods, the compiler should be vigilant to potential changes in the coverage of billable hours and, provided that the method is considered applicable in the situation, should adjust for them as appropriate (by excluding changes in charge-out rates which do not result from pure price change).

Compilers could, for example, inquire if a change in hourly rates between the current and previous period has been influenced by factors such as changing technology, administrative reorganisation or changes to billing structures. Resulting adjustments might eliminate some volatility in the index. However in order to make a comprehensive adjustment, the relevant service products have to be explicitly or implicitly identified, in 
which case the method would fall into the category of model pricing rather than belonging to time based pricing.

Where business enterprises increasingly outsource their activities the use of hourly rates may not be appropriate. The service purchaser may receive the same service as before but pay a higher hourly rate applied to a reduced number of billable hours. In such cases a deflator based on hourly rates will result in a reduced estimate of the volume of services produced. There is no obvious adjustment procedure for this situation.

\subsubsection{Resulting price fully based on time worked in the provision of service}

The target measure is the price of chargeable working time. In this pricing method the monetary amount charged to a buyer of a service, for a standard amount (e.g. one hour) of work by an employee of the producer contributing to the provision of that service is utilised. However, the method has four variants depending on the availability of price data.

\subsubsection{Hourly charge-out rate}

The hourly charge-out rate method represents the simplest case where transaction prices are available by labour categories. However, depending on the type or price data in the survey two variants exist in practice.

First, the resulting price could be estimated as a weighted average of hourly rates. In this case, respondents provide average hourly rates charged, subdivided by type of labour. This data could be taken directly from on-going projects or - more subjectively - they could reflect the respondent's estimate of the general market situation. The overall price change is a weighted average of changes of charged hourly rates in different labour categories:

$$
P_{t}=\frac{\sum_{i} h_{t}^{i} r_{t}^{i}}{\sum_{i} h_{t}^{i}} ; P_{t+1}=\frac{\sum_{i} h_{t}^{i} r_{t+1}^{i}}{\sum_{i} h_{t}^{i}}
$$

Where: $P_{t}$ is the price in period $t$;

$r_{t}^{i}$, is average hourly charge-out rates in staff class $i$ in period $t$;

$h_{t}^{i}$, is the number of hours worked in staff category $i$ in period $t$.

Box 2.10. shows an example of hourly charge-out rate in engineering activities. 


\section{Box 2.10. Pricing based on working time / Hourly charge-out rate: Engineering} activities

Respondents report of the average hourly rates of different types of personnel (total rate / total hours worked during the reference period).

\begin{tabular}{|c|c|c|c|c|c|}
\hline \multirow[t]{2}{*}{ Service } & \multirow[t]{2}{*}{ Unit } & \multicolumn{2}{|c|}{ Price } & \multirow{2}{*}{$\begin{array}{c}\text { Price } \\
\text { change }\end{array}$} & \multirow[t]{2}{*}{ Weight } \\
\hline & & t-1 & $\mathbf{t}$ & & \\
\hline \multicolumn{5}{|c|}{ Machine and process designing } & 0.25 \\
\hline Senior Consultant, Person A & $€ /$ hour & 54.5 & 55.21 & 1.013 & \\
\hline Senior Consultant, Person B & $€ /$ hour & 54.5 & 53.52 & 0.982 & \\
\hline Consultant, Person A & $€ /$ hour & 45.4 & 45.24 & 0.996 & \\
\hline Consultant, Person B & $€ /$ hour & 43.2 & 42.1 & 0.975 & \\
\hline \multirow[t]{2}{*}{ Junior Designer, Person A } & $€ /$ hour & 43.8 & 42.5 & 0.970 & \\
\hline & \multicolumn{3}{|c|}{ Geometric mean } & 0.987 & \\
\hline \multicolumn{5}{|l|}{ Electrical wiring designing } & 0.75 \\
\hline Designer, Person C & $€$ €litem & 59 & 59.2 & 1.003 & \\
\hline Junior Designer, Person A & & 54.2 & 55.2 & 1.018 & \\
\hline \multirow[t]{2}{*}{ Junior Designer, Person B } & $€ /$ item & 53 & 56 & 1.057 & \\
\hline & \multicolumn{3}{|c|}{ Geometric mean } & 1.026 & \\
\hline \multicolumn{5}{|l|}{ Weighted change from $t-1$ to $t$} & 1.016 \\
\hline
\end{tabular}

The same method is applied for business and management consultancy activities. Respondents usually report hourly-rates (Rate / hours worked) directly from their accounting systems.

A second kind of charge-out rate method uses average hourly rates for staff classes directly in the compilation of an SPPI. The price is derived by dividing revenues for service by number of hours worked.

$$
P_{t}^{i}=\frac{R_{t}^{i}}{h_{t}^{i}} ; P_{t+1}^{i}=\frac{R_{t+1}^{i}}{h_{t+1}^{i}}
$$

Where: $P_{t}^{i}$, is the price in period t;

$R_{t}^{i}$, is the total of revenues in staff category $\mathrm{i}$ in period $\mathrm{t}$;

$h_{t}^{i}$, is the number of hours worked for clients in staff category $i$ in period $\mathrm{t}$

These kinds of unit rates are called average "realised hourly rates" in the Netherlands and "fee income per grade of worker" in the U.K. (see box 2.11). Note that as with all unit value indices, the homogeneity of the classes is an issue. 


\section{Box 2.11. Pricing based on working time / realised hourly rates: Engineering activities}

The income in $€$ and the number of hours worked are provided in each period via the survey. From these, the realised hourly rate is calculated as their ratio (for instance, in the top line 147, $991 / 2,980=49.6 €$ per hour).

After calculating these realised hourly rates for both the base period and the comparison period, an item index is calculated for each item. In the example below, the hourly rate of the experienced drawer in the two periods are $€ 49.6$ and $€ 55.4$ per hour respectively. The item index for experienced drawer is $55.4 / 49.6=1.10$

\begin{tabular}{|c|c|c|c|c|c|c|c|}
\hline & \multicolumn{3}{|c|}{ Based period } & \multicolumn{3}{|c|}{ Comparison period } & \multirow{2}{*}{$\begin{array}{c}\text { Index } \\
\text { Base } \\
\text { period = } \\
100\end{array}$} \\
\hline & $\begin{array}{c}\text { Income }(€) \\
\text { (a) }\end{array}$ & $\begin{array}{c}\text { Hours } \\
\text { worked } \\
\text { (b) }\end{array}$ & $\begin{array}{c}\text { Realized } \\
\text { hourly rate } \\
\text { (income/hours } \\
\text { worked) (a) / } \\
\text { (b) }\end{array}$ & $\begin{array}{c}\text { Income }(€) \\
\text { (a) }\end{array}$ & $\begin{array}{l}\text { Hours } \\
\text { worked } \\
\text { (b) }\end{array}$ & $\begin{array}{c}\text { Realized } \\
\text { hourly rate } \\
\text { (income/hours } \\
\text { worked) (a) / } \\
\text { (b) }\end{array}$ & \\
\hline $\begin{array}{l}\text { Experienced } \\
\text { drawer }\end{array}$ & 147,991 & 2,980 & 49.6 & 100,200 & 1,809 & 55.4 & 111.7 \\
\hline $\begin{array}{l}\text { Consultant- } \\
\text { engineer }\end{array}$ & 18,000 & 226 & 79.6 & 22,456 & 313 & 71.7 & 90.1 \\
\hline Designer & 163,090 & 1,624 & 100.4 & 120,668 & 1,050 & 114.9 & 114.4 \\
\hline $\begin{array}{l}\text { Senior project } \\
\text { manager }\end{array}$ & 47,010 & 471 & 99.8 & 50,505 & 533 & 94.8 & 95 \\
\hline
\end{tabular}

\subsubsection{Hourly list rates}

When transaction prices of working hours are not available, list prices (also known as standard hourly rates) could be used to derive the price of a service. Business enterprises often compile a list of external commercial hourly rates for different staff grades. These rates can be used in the compilation of an index. The classification of labour might vary between enterprises. On the other hand, some enterprises, particularly small ones, may have individual rates per person that are typically drawn up once per year. Note however that the rates might often serve as a reference rather than as the charging rates actually transacted. If so, adjustments based on the difference between realised and implied revenues are of particular importance.

Prices could be derived as follows when using hourly list rates. Note that as in the case of hourly charge-out rates, the method can also be applied separately for individual staff category (unit rates).

$$
P_{t}=\frac{R_{t}}{R_{t}^{*}} \times \frac{R_{t}^{*}}{\sum_{i} h_{t}^{i}} ; P_{t+1}=\frac{R_{t+1}}{R_{t+1}^{*}} \times \frac{\sum_{i} h_{t}^{i} r_{t}^{i^{*}}}{\sum_{i} h_{t}^{i}}
$$

With:

$\mathrm{R}_{\mathrm{t}}=\sum_{\mathrm{i}} \mathrm{h}_{\mathrm{t}}^{\mathrm{i}} \mathrm{r}_{\mathrm{t}}^{\mathrm{i}}$, the total of realised revenues in period $\mathrm{t}$

$\mathrm{R}_{\mathrm{t}}^{*}=\sum_{\mathrm{i}} \mathrm{h}_{\mathrm{t}}^{\mathrm{i}} \mathrm{r}_{\mathrm{t}}^{\mathrm{i}^{*}}$, the estimated total revenues in period $\mathrm{t}$ 
Where:

$\mathrm{P}_{\mathrm{t}}$ is the price in period $\mathrm{t}$;

$\mathrm{h}_{\mathrm{t}}^{\mathrm{i}}$, is the number of hours worked in staff category $\mathrm{i}$ in period $\mathrm{t}$;

$\mathrm{r}_{\mathrm{t}+1}^{\mathrm{i}^{*}}$, is the average hourly list rate in staff category $\mathrm{i}$ in period $\mathrm{t}+1$.

It is of particular importance that the total of realised revenues $\left(R_{t}\right)$ used in the adjustment is consistent with estimated total revenues $\left(R_{t}^{*}\right)$. This means that data on realised revenues are accrual based rather than cash based.

Meting this requirement is often not possible and consequently the ratio of realised and implied revenues might have to be independently evaluated. In such cases the adjustment ratio to be used is an estimate of the average discount rate. As in the case of normal discounts, there is no need for adjustment if the same discounts are applied in consecutive periods.

Indices compiled, using this method, are closely comparable with those of the hourly rate method. In order for them to agree exactly, the adjustment for discounts should be made and the relative difference between real and list prices should be the same in all categories of labour.

\subsubsection{Wages rates}

If charge-out rates are not directly available then data on hourly wage rates might be used. Respondents are asked to provide data on wages for, and hours worked for clients by, a number of staff categories. Wage rates must be adjusted to correspond to revenues. This means that wages have to be multiplied by an estimate of the ratio of revenues to wages. ${ }^{15}$

$$
P_{t}=\left(\frac{R}{W}\right)_{t} \times \frac{\sum_{i} h_{t}^{i} w_{t}^{i}}{\sum_{i} h_{t}^{i}} ; P_{t}=\left(\frac{R}{W}\right)_{t+1} \times \frac{\sum_{i} h_{t}^{i} w_{t+1}^{i}}{\sum_{i} h_{t}^{i}}
$$

Where:

$\mathrm{P}_{\mathrm{t}}$, is the price in period $\mathrm{t}$;

$\left(\frac{R}{W}\right)_{t}$, is the revenue/wage ratio in period $\mathrm{t}$;

$\mathrm{w}_{\mathrm{t}}^{\mathrm{i}}$, is the average hourly wage in staff category $\mathrm{i}$ in period $\mathrm{t}$;

$\mathrm{h}_{\mathrm{t}}^{\mathrm{i}}$, is the number of hours worked in staff category $\mathrm{i}$ in period $\mathrm{t}$;

$\mathrm{R}_{\mathrm{t}}$, is the total of revenues in period $\mathrm{t}$;

The wage rate method is very sensitive to the estimation of the revenue/wage ratio and therefore a strict correspondence between revenues and wages is essential. Revenues should be accrual based to provide comparable prices for consecutive periods. With a high quality ratio, results generated by the wage rate method are closely comparable with results obtained when using the previously described time based methods. The relative accuracy of the methods depends on whether wage- or charge-out rates better reflect the differences in the performance of staff in various categories of labour.

As in the case of hourly charge-out rates and hourly list rates, the method can also be applied separately for individual staff categories (unit rates). 
Box 2.12. shows an example of the use of wages rates.

\section{Box 2.12. Pricing based on working time: Wage rates}

The wage and the revenue/wage ratio are provided in each period via the survey. If the wages change only twice a year, bi-annual surveying suffices. The revenue/wage ratio $(\mathrm{R} / \mathrm{W})$ on the other hand changes faster.

The price is the average wage multiplied by the $\mathrm{R} / \mathrm{W}$ ratio (third line).

\begin{tabular}{|l|l|l|l|l|l|}
\hline \multicolumn{1}{|c|}{ Quarter } & \multicolumn{1}{c|}{1 (base) } & \multicolumn{1}{c|}{2} & \multicolumn{1}{c|}{3} & \multicolumn{1}{c|}{4} & \multicolumn{1}{c|}{5} \\
\hline Wage & $40 €$ & $40 €$ & $41 €$ & $41 €$ & $45 €$ \\
\hline $\begin{array}{l}\text { Revenue/wage ratio } \\
\text { (R/W) }\end{array}$ & 2.00 & 1.90 & 1.85 & 1.95 & 1.90 \\
\hline Price (wage $\times \mathrm{R} / \mathrm{W})$ & $80.0 €$ & $76.0 €$ & $75.9 €$ & $80.0 €$ & $85.5 €$ \\
\hline $\begin{array}{l}\text { Price index (quarter } \\
1=100 \text { ) }\end{array}$ & 100.0 & 95.0 & 94.8 & 99.9 & 106.9 \\
\hline
\end{tabular}

\subsection{Working days}

Occasionally data on working time are not available on an hourly basis but perhaps in terms of working days. In these cases the compilation procedures are in principle the same as for hourly rates. However, the unit used in the estimation is less precise and this may influence the accuracy of results.

\subsubsection{Resulting price predominantly based on working time spent in the provision of service}

The category of "methods predominantly based on prices of working time spent in the provision of service" describes practices where a price is not directly time based but instead time based measures are used as building blocks in the estimation of price. In other words, the resulting price is not fully measured in terms of a clearly specified service.

Different situations may arise where pricing methods fall into the category of "time based methods" although price evolution of identical and clearly specified service output was initially the target measure:

- Prices are made-up of several sub-components - as defined under the component pricing method (section 2.2.5.) - including compensation for a fixed number of hours of work to produce a given service. The use of time based prices for subcomponents that are subject to significant technological development, particularly when their weight in the calculation of the price is high, imply a high risk of bias;

- Price are virtual and thus resemble model pricing (section 2.2.6.) but the working hours underlying the price are always assumed to be the same as in the previous period rather than based on genuine evaluation;

- Prices are estimated using fees that are associated with service projects or contracts (like in percentage fee method, section 2.2.4.) for which price development is measured using a time based-method.

As previously noted, an important aim of the classification of pricing methods is to monitor the characteristics of resulting price indices. Therefore, it is essential to separate 
time based methods from those methods under which the price development of identical service transactions is targeted.

\subsubsection{Margin pricing method}

The margin pricing method is used to measure price development in services that are not separately invoiced and where the service is related to the transformation in space or time of an item. The item may be a product, such as a good purchased and sold by a retailer or a loan provided by a financial intermediary. The price of the service can be estimated as the difference between the price paid by the service provider for the good or service they transformed and the price paid by the final consumer (at the same point in time). ${ }^{16}$

\section{Data type in the survey}

There are two distinct types of margin prices: those charged by retailers and wholesalers, in relation to the goods and services they sell, and those charged by financial intermediaries, in relation to the loans and deposits they provide.

In the case of wholesalers and retailers the data sources are acquisition and selling prices for selected items/products or services purchased for resale. The difference between selling and acquisition prices - both real transaction prices - results in a margin price that reflects the actual transaction price of services provided by wholesalers and retailers.

In practice the information will cover a heterogeneous mix of products. Ideally the calculation of margin prices should be based on a product list that is as detailed as possible. Separate price indices should be compiled for individual products and these should be combined by weighting in accordance with the value of sales of the individual products. In this approach, the margin price method splits the price change into two parts, a change in the margin rate (similar to a percentage fee, see section 2.2.4.) and a change in the price of the product sold. Thus, the price of the margin service for a given product can be estimated by updating the price in the previous period via the following formula:

$$
P_{s}^{t, i}=P_{s}^{t-1, \mathrm{i}} \times \frac{1+m_{t, i}}{1+m_{t-1, \mathrm{i}}} \times \frac{P_{t, i}}{P_{t-1, \mathrm{i}}}
$$

Where: $P_{s}^{t, i}$, is the price of the final service output in period $\mathrm{t}$ related to the transformation of product $\mathrm{i}$;

$P_{t, i}$, is the value of a homogeneous product (i) sold in period $\mathrm{t}$;

$m_{t, i}$ is the margin rate (the difference between the total value of homogeneous products (i) sold by the retailer/wholesaler and the value it would have to pay at time $t$ as a ratio of the latter).

And so the price index for a group of products sold can be calculated as follows:

$$
=\sum_{\mathrm{i}} \frac{\mathrm{p}_{\mathrm{s}}^{\mathrm{t}, \mathrm{i}}}{p_{s}^{t-1, i}} \times \frac{P_{t, i}}{\sum_{j} P_{t-1, \mathrm{j}}}
$$

\section{FISIM}

A special case of implicitly priced margin services relates to the measurement of financial intermediation services indirectly measured (FISIM). In layman's terms FISIM 
in the $2008 S N A$ can be described as the implicit prices charged by a financial intermediary (typically a bank), which take the form of interest rate margins incorporated in the rates charged for loans or paid on deposits. In exchange for paying a higher rate of interest on loans or accepting a lower rate of interest on deposits, customers receive the following types of services: record keeping, safekeeping, payment processing, intermediation between savers and borrowers, risk management and advice, and liquidity provision.

The 2008 SNA describes FISIM as the following (par. 6.163):

One traditional way in which financial services are provided is by means of financial intermediation. This is understood to refer to the process whereby a financial institution such as a bank accepts deposits from units wishing to receive interest on funds for which the unit has no immediate use and lends them to other units whose funds are insufficient to meet their needs. The bank thus provides a mechanism to allow the first unit to lend to the second. Each of the two parties pays a fee to the bank for the service provided, the unit lending funds by accepting a rate of interest lower than that paid by the borrower, the difference being the combined fees implicitly charged by the bank to the depositor and to the borrower. From this basic idea the concept emerges of a "reference" rate of interest. The difference between the rate paid to banks by borrowers and the reference rate plus the difference between the reference rate and the rate actually paid to depositors represent charges for financial intermediation services indirectly measured (FISIM).

At the time of writing the Intersecretariat Working Group on National Accounts (ISWGNA) Task Force on FISIM was investigating the definition of FISIM in the SNA. However, this investigation is not expected to have implications for the treatment of FISIM in the context of SPPI compilation, as the research conducted by the Task Force chiefly relates to the definition of the reference rate used in the SNA and the scope and coverage of instruments to which FISIM should be applied. Irrespective of how these issues are resolved, the recommendation on the appropriate price index (as defined below) is unaffected. The Task Force has considered whether quantity approaches to FISIM volume measurement (and so implied deflators for price measurement were possible) but these have been largely ruled out on practical grounds.

The underlying assumption behind FISIM is that there is a specific service provided to borrowers and lenders for which a price can be calculated, based on the interest paid or received on loans or deposits and an underlying reference rate. Currently SNA prescribes the use of a single reference rate for all loans and deposits irrespective of the maturity structure of the loans and deposits. The Task Force on FISIM is investigating what the most appropriate single reference rate should be and also whether specific reference rates are applicable for loans and deposits with different maturities. One other consideration of the Task Force relates to credit default risk and whether this should be removed from the calculation of FISIM (by excluding a component from the interest actually paid by borrowers). What follows therefore is a generic description of FISIM price measurement that assumes credit default risk is already removed from the interest flows. If the Task Force chooses not to remove credit default risk from the value of FISIM, it should be assumed that the interest flows correspondingly include these payments.

At time $t$, the balance sheets of financial intermediaries show assets of $\sum L_{m}$, where $L_{m}$ reflects the value of loans made by the bank with maturity m, with interest of $I_{l, m}$ reflecting the interest received on those loans. The bank also has liabilities of $\sum D_{m}$ to depositors and pays $I_{d, m}$ to depositors. 
Total FISIM in current prices

$$
=\sum\left(I_{l, m}-L_{m} \times r_{m}\right)+\sum\left(I_{d, m}-D_{m} \times r_{m}\right)
$$

Total FISIM in prices of the previous year

$$
=\sum\left(I_{l, m}-L_{m} \times r_{m}^{t-1}\right)+\sum\left(I_{d, m}-D_{m} \times r_{m}^{t-1}\right) / P^{t}
$$

Where:

$r_{m}^{t-1}$, is the reference rate in the previous year;

$P^{t}$ is a general price index (for example the CPI) for year $\mathrm{t}$ in relation to year $\mathrm{t}-1$.

The FISIM price index is therefore derived as the quotient of FISIM in current prices and FISIM in constant prices. It is important to note in the above, that even if only one reference rate is used such that $r_{m}$ is set as $r$ for all $m$, a breakdown into maturity structures will still be necessary for the calculation of constant price FISIM.

\section{Bibliography}

Buisson B., Kenessey A. \& McKenzie R. (2005), Pricing methods, $20^{\text {th }}$ Voorburg Group meeting, Helsinki, Finland available at: http://www.voorburggroup.org/Documents/2005\%20helsinki/papers/2005-32.pdf

European Commission, IMF, OECD, UN and World Bank (eds.) (2009), System of National Accounts 2008, United Nations, New York.

ILO, IMF, OECD, UNECE, Eurostat, World Bank (eds.) (2004 b), Producer Price Index Manual, Theory and practice, International Monetary Funds, Washington, DC.

Langer T. \& Murphy J. (2009), Glossary of Voorburg Group Terminology for MiniPresentations, Sector Papers, and Revisited Sector Papers, Voorburg Group available at:

http://www.voorburggroup.org/Documents/2009\%20Oslo/Papers/2009\%20\%2004.pdf

Murphy B. \& Swick R. (2006), Comments on the SPPI definition of pricing methods, BLS, $21^{\text {st }}$ Voorburg Group meeting, Wiesbaden, Germany available at: http://www.voorburggroup.org/Documents/2006\%20wiesbaden/papers/06.pdf

Voorburg Group (2007), Thesaurus of Producer Price Indices for Services (SPPIs), available at:

http://www.voorburggroup.org/Documents/2007\%20Seoul/papers/03.pdf 


\section{Notes}

1. Pricing methods are here understood as procedures applied in a "normal" situation or routine collection, not in a situation where old services are replaced by new ones and direct adjustments are used to make the service comparable. By convention, even systematically applied, adjustments are out of scope. They do not refer either to initial collection procedures.

2. The index formulae and aggregation methods needed to bring together these basic elements are not discussed in this chapter and reference is made to chapter 3 and the PPI Manual.

3. The term is often used interchangeably with "sales" and "turnover". It corresponds to the value of output sold or the value of invoiced sales of goods or services supplied to third parties during the reference period.

4. As mentioned in chapter 1, SPPIs should measure actual transaction prices reflecting revenue received by the producer for services sold to customers. Care must be taken to ensure that the prices reflect those at the time the transaction occurs, and that " $[\ldots]$ they must reflect the net prices inclusive of all discounts applied to the transactions whether they be volume discounts, settlement discounts, or competitive price-cutting discounts, which are likely to fluctuate with market conditions. Any rebates also need to be considered. The collection of nominal list prices, or book prices, is not reflective of actual transactions, is unlikely to yield reliable price indices, and may result in quite misleading results because fluctuation in market prices are not captured“, $P P I$ Manual, par. 1.328.

5. See chapter 1: section 1.1.3. and footnote $n^{\circ} 8$.

6. "The basic price is the amount receivable by the producer from the purchaser for a unit of a good or service produced as output minus any tax payable, and plus any subsidy receivable, by the producer as a consequence of its production or sale. It excludes any transport charges invoiced separately by the producer", $2008 \mathrm{SNA}$, par. 6.51.a.

7. It does not matter what the unit of 'a service' is; either 'all cleaning under one contract' can be regarded as one service, or a unit of service delivery can be chosen as e.g. one trip, one days' cleaning or a week of guarding. Another option, and easiest for practical purposes, is to adhere to what the surveyed price reflects: a price per trip, or per day, or the total price of the monthly or quarterly payment. In the last case, the unit of service can be 'quarterly charge for twice-a-week road transport'.

8. National accountants often directly use quantity indicators, where volume of output is a weighted average of quantity indices based on base year weights. The corresponding price index is the change of output divided by the resulting volume index. The method is used because detailed turnover data might not be currently available to estimate unit value prices. To give satisfactory results, a basic requirement in the method is that quantity indicators cover all output exhaustively.

9. It might also be appropriate to use the Fisher formula in the estimation of price indices for industries undergoing rapid technological changes. This would require that quantity and turnover data are collected continuously to update weights for each period. Weights of firms in the sample become quickly outdated when prices change significantly like in mobile phone and internet services. 
10. An example of this is ad valorem pricing which is often used in legal services. In this pricing mechanism fees are either based on a proportion of the value of the claim or they relate to price classes which represent the various values of claims. The fee might also change progressively. See section on legal activities.

11. It is recommended to use model pricing in this kind of situation.

12. See also PPI Manual par. 6.83 .

13. Note that methods based on working time are sometimes also used when the pricing mechanism is not time based for example in the case of ad valorem pricing. See section on legal activities.

14. Defined as the numbers of hours used to produce a good or a service billed to the client.

15. This method is sometimes referred to as wages with mark-up or input with mark-up as the mark-up includes administrative and other costs. The term mark-up is not used here to stress that it covers conceptually revenues minus wages. Thus it includes all costs (other than wages) and net operating surplus.

16. See $2008 S N A$, par. 6.146 . 


\section{Chapter 3. Practical aspects of the development process}

Each service industry presents a unique set of challenges to identifying and pricing service products. The purpose of this chapter is to outline, in a practical way, how to develop SPPIs. 
The main steps in developing a price index for a service industry are presented in box 3.1. Each of these steps is further discussed in this chapter. ${ }^{1}$ For ease of presentation the process is described here in a linear form. In practice it might be necessary to omit or repeat certain steps, to change their order or to undertake some tasks simultaneously.

\section{Box 3.1. Main phases of the development process}

\section{Preparatory work}

1.1. Review of literature (SPPI Guide, Voorburg Group papers, PPI Manual, etc.)

1.2. Discussions with industry representative organisations

1.3. Industry description

1.4. Setting the objectives and scope

\section{Designing the weighting pattern and sample}

2.1. The weighting pattern

2.2. Designing the sample

\section{Respondent initialisation phase}

3.1. The initialisation process

3.2. The initialisation questionnaire

3.3. Transaction specification

\section{Set-up of permanent framework}

4.1. Ongoing price collection

4.2. Treatment of quality change

4.3. Index calculation

4.4. Quality assessment and maintenance

The entire process of establishing an index and relevant sub-indices (from the first conceptual phase to the publication) for a specific service industry can take up to 2 years. In box 3.2., a stylised timetable is presented. The example is based on timetables for grant agreements that Eurostat concluded with several European national statistical institutes for the development of SPPIs. 


\section{Box 3.2. Timetable for developing an SPPI - hypothetical example}

\begin{tabular}{|c|c|}
\hline $\begin{array}{l}\text { Month: } \\
\text { - } 1-2:\end{array}$ & $\begin{array}{l}\text { Action: } \\
\text { - Preparatory work: Literature research, identification of industry } \\
\text { representative organisations, collection of data on size and structure of the } \\
\text { industry; }\end{array}$ \\
\hline - $3-5$ : & $\begin{array}{l}\text { - Discussion with representative organisations and with users of statistics; } \\
\text { - Visits to enterprises; }\end{array}$ \\
\hline - $6-7$ : & $\begin{array}{l}\text { - Industry description; } \\
\text { - Collection of addresses for pilot survev; }\end{array}$ \\
\hline - $8-13$ : & $\begin{array}{l}\text { - Pilot study (dispatch of pilot questionnaires, contact with respondents to } \\
\text { explain questionnaire, collection of results, evaluation, decisions concerning } \\
\text { final sample design etc.); }\end{array}$ \\
\hline - $13-14$ : & $\begin{array}{l}\text { - Finalisation of questionnaires, drawing of sample, dispatch of } \\
\text { questionnaires; }\end{array}$ \\
\hline & - Data collection, control of response rate, reminders, compiling indices; \\
\hline & - Evaluation of data quality; \\
\hline - 23 & - Publication of index, evaluation of feedback from users. \\
\hline
\end{tabular}

\subsection{Preparatory work}

\subsubsection{Review of literature}

The development of a new SPPI should begin with a review of the relevant literature. In addition to the PPI Manual and this Guide, material published by the Voorburg Group on Services Statistics is especially useful. The primary objectives of the Voorburg Group are the proper identification and definition of services industries, products and measures of turnover combined with a coordinated effort to compile producer price indices for use as deflators in order to improve the measurement of services components of GDP at constant prices. The Voorburg Group has published papers on a considerable number of Services sectors which are available on its website. ${ }^{2}$ The "Sector Papers" and "Revisited Sector Papers" will be particularly relevant to index developers.

\subsubsection{Discussions with industry representative organisations}

Early and effective contact with industry representative organisations can have a positive impact on the quality of indices. Even where the compiler develops an overview of the industry before meeting with the representative organisations, consultation with these organisations is important for the development of a high quality price index. This consultation may help compilers to better understand the industry by providing advice in respect of drafting product specifications, pricing mechanisms and changes occurring within the industry. It may also help to identify problems that can be encountered in the compilation of an SPPI for the industry. Industry representative organisations may assist with forming a more detailed sampling frame (if necessary) and encourage establishments to participate in the survey.

\subsubsection{Industry Description}

The primary output of the preliminary research and consultation process will be a description of the industry ${ }^{3}$ upon which subsequent methodological decisions can be 
based. This description may have different forms; sample information that should be included is presented in box 3.3 .

\section{Box 3.3. Industry description}

1. Identification of industry representative organisations (type of businesses represented, tasks of the organisation, contact persons);

2. Detailed review of any previous structural business surveys or other surveys on the industry undertaken by the respective national statistical institute;

3. Overview of methods used in other countries to produce SPPIs for the particular industry, overview of other methodological information (e.g. Sector Papers produced by the Voorburg Group on Services Statistics);

4. Scope of the industry (including secondary activities);

5. Size of the industry (revenue, value added, employment);

6. Structure of the industry (share of large and small business enterprises, regional distribution);

7. Description of the industry's service products and their destinations (e.g. export, BtoB);

8. Description of where service outputs are used (information that might be extracted from supply and use tables);

9. Description of pricing mechanisms employed for different industries or service products;

10. Identification of possible sources of turnover data at service product and enterprise level (if additional to Structural Business Statistics);

11. Distribution of revenue between different service products.

This industry description will help to inform decisions concerning the objectives and scope of the index and the pricing methods to be used. It should also provide initial information on how to divide the service products into the main groups and how these groups could be weighted together to obtain the total aggregate of this service industry.

\subsection{Setting the objectives and scope}

The objectives and scope of the new index must be determined. A number of considerations have already been reviewed in chapter 1 and these should be discussed with users, both internal and external. Even where an index is introduced in response to a legal requirement that already specifies scope, periodicity and other central aspects, it can be useful to discuss methodological and practical questions with other future users of the index.

As noted in chapter 1, the scope of the index should, in theory, cover services provided for all uses, intermediate and domestic final consumption, and for exports. Ideally, separate SPPIs should be available for each of these use categories, reflecting the fact that prices, and price movements, may discriminate between users.

A choice must be made between SPPIs which measure change in the prices of products (product based) or industries (industry based). This Guide gives preference to product based SPPIs although in practice industry based SPPIs are also more commonly compiled. 


\subsection{Designing the weighting pattern and sample}

\subsubsection{The weighting pattern}

SPPIs are compiled by progressively weighting price observations through successive levels of aggregation, following the chosen classification structure. There are two phases to the weighting pattern. The first phase combines individual prices to create lower level indices (or elementary aggregates). In the second phase these lower level indices are combined to form upper-level indices.

During the first phase of weighting it is recommended to use explicit weights, in other words weights that reflect the relative importance of the sampled items. This means for example, that each price observation (transaction) will be assigned a weight based on its share of sales of a product. In order to use explicit weights, product value or sales data will need to be collected, usually during the respondent initialisation process. Ideally, lower level weights will not be fixed over any predetermined period thereby allowing for flexibility in updating the sample of transactions and their weights thereby keeping the index representative.

Upper level indices are compiled by weighting together lower level indices through progressive levels of aggregation defined by the classification structure, usually employing weights for a fixed period (say one, three or five years) between index reweighting. ${ }^{4}$

There are a number of potential data sources for use as upper level weights, including; structural business/industry surveys, economic census, input-output tables and international trade statistics. ${ }^{5}$

If a product classification can be determined within a service industry (e.g. defined at4-digit level) or across various industries, then this classification can be used to form an elementary aggregate ("family tree") structure. This classification might sometimes originate from an existing classification or from a specific survey but it may also be based on the advice of the relevant industry representative organisations. Each of these elementary aggregate components is weighted according to the estimated proportion of sales for these products within the industry. Using this approach, surveyed units will contribute one or more sample price relatives to the elementary aggregate structure. ${ }^{6}$

\subsubsection{The sample}

\subsubsection{Sampling techniques}

SPPI compilers must consider sample design in respect of the selection of both producers and service products (transactions). The methodology or methodologies employed must be based on a consideration of the objectives of the survey (as a national accounts deflator or a general indicator of inflation), the availability and quality of data from which the sample will be drawn and also the level of resources allocated to the survey.

The PPI Manual (chapter 5, sections 5.7- 5.13) considers a series of questions and answers which will guide the compiler in determining which sampling methodology should be adopted.

The sampling methodologies employed can be probability or non-probability based. In the case of probability sampling, each producer and service product is drawn from a 
known universe and has a known chance of selection. There are two advantages to using a probability based sample. Producers and/or service products (transactions) are chosen impartially and it is possible to measure the quality of the survey through estimation of variance or sampling error.

Probability sampling can take the form of simple random, systematic or probability proportional to size (PPS) sampling. It can be supplemented by clustering or stratification techniques to improve survey efficiency. For SPPI compilation in the U.S., units are stratified by size and PPS sampling is then applied to each stratum to select reporting units. A set of representative service products is selected using a PPS sampling technique called disaggregation. With this process, each sampled establishment is asked to report the turnover they generate from the sales of service products within designated categories. Probabilities of selection are assigned to each category based on these turnover values. The categories selected are broken into additional detail in subsequent stages, until unique service products (transactions) are selected and specified for pricing.

In practice however, non-probability sampling is often employed, usually where insufficient data is available to establish the full universe of producers and service products or where the organisation of an industry is concentrated among a small number of large business enterprises.

In non-probability sampling (also known as judgemental or purposive sampling) the sample is chosen, with the aim of being representative, by expert judgement. It is more difficult to estimate the quality of the survey, in respect of both results and analysis of the efficiency of the sample selection, when non-probability sampling is adopted.

Cut-off sampling is a commonly employed non-probability based sampling method. In this method all units at or above a chosen threshold (usually in terms of size) will be included in the sample. While this will generally ensure a high degree of coverage among larger units it may introduce a bias into the index where smaller units have different price movements.

A combination of both probability and non-probability sampling may also be employed. For example, PPS sampling may be employed in the selection of service producers while the most representative service products for each of these producers may be purposively selected.

While the use of probability based sampling has advantages in respect of impartiality of selection and calculation of sampling error, it should be borne in mind that the risks in not employing probability sampling are relatively low in the compilation of price indices. ${ }^{8}$

That said, service industries often have low concentration ratios - there are many service producers and even where there are some larger units they only account for a relatively small proportion of output. In these industries there is a stronger case for using probability based sampling. ${ }^{9}$

\subsubsection{Sampling frame}

The situation concerning possible sampling frames may vary considerably from country to country. In many countries the business register or national accounts provide a source of sampling frames. Business registers normally have information on revenue (or turnover) and the number of employees. However, they are usually not detailed enough to provide information at the level of establishments (local kind of activity units) or revenue 
information by service categories. An additional survey may therefore be needed to derive reliable weights for establishments or the main service product groups for the industry. This survey takes place during the respondent initialisation process and is discussed under section 3.4. Industry representative organisations, regulatory authorities or market studies carried out by third parties may give additional information. In extreme cases the frame might be structured on the basis of information obtained from alternative sources such as the telephone directory or the internet.

Ideally, the sample frame should include all producing units (including those exporting) within the geographic and industry coverage required and should be updated instantly with births and deaths and any changes to contact details. ${ }^{10}$

\subsubsection{Sampling structure}

The choice of sampling structure will largely depend on what information is available in the sampling frame and on whether industry or product level statistics are required.

For industry based SPPIs, firstly each establishment is classified to a 4-digit ISIC or NACE heading based on its principal activity. A sample of establishments is then drawn from within each heading and a selection of representative transactions is priced from each sampled unit. All output of these sampled units is represented in theory (even secondary activity output classified under other industries) and aggregated to form these 4-digit industry level indices.

Product based SPPIs are created from samples of products and so should, in theory, be compiled on the basis of output information at product level from each establishment. This information is used to compile lists of producers of each product. All service product output (obtained from lists of producers of each product) is eligible for selection, regardless of the classification of the establishments that produce it. A sample of transactions is drawn from each list and these transactions are weighted to form product group or product class level indices (following the CPC terminology) and can also be aggregated to 4-digit industry level indices. It is unlikely however, at least in the case of the services sector, that sample frames will have sufficient detail at product level to allow for this approach.

Approximate product based SPPIs are compiled from samples of establishments for multiple industries. Firstly, each unit is classified to a 4-digit industry based on its principal activity. Each industry frame is then stratified by size of unit and samples are selected from each of these strata (i.e. probability proportionate to size sampling for the industry). Transactions are selected from each unit, using either probability or purposive based techniques, and these are assigned to their relevant product area. Product level SPPIs can then be calculated by weighting transactions on the basis of their product heading, irrespective of the industry in which the units are classified ("wherever made"). Industry based indices can also be produced by weighting the transactions on the basis of the industry in which they are produced ("whatever made"). While product level SPPIs compiled using this option may not be as accurate as those compiled from direct sampling of products it has the advantage of not requiring the sample frame to contain detailed information on the volume of services produced at product level. 


\subsection{Respondent initialisation phase}

\subsubsection{The initialisation process $^{11}$}

Detailed service product (characteristics) and price data are required to produce high quality price indices and the collection of these data can be difficult and expensive. The initialisation process must be detailed and precise even when resources are constrained. Ideally, initialisation of new respondents should involve a personal visit. Where this is not possible the initialisation may require pre-contact research, telephone calls and a dedicated (initialisation) questionnaire.

The initialisation process should include the ten following activities. Where personal visits are possible these may focus on activities 5-7.

1. Research: The initialisation team researches each sample unit/establishment that is being introduced as a result of new samples. This research will cover business activity, products sold, pricing mechanisms, type of customers, etc. A combination of tools including the business register, the internet, industry publications, etc. will be used to thoroughly research the sampling unit and the related business activity;

2. Verification: The team is required to verify the contact information for each establishment. This may require cross referencing information with other surveys being conducted within the National Statistical Institute;

3. Initial contact: The establishment is provided with an introduction to the SPPI survey, including an explanation of the survey purpose, uses of survey data, reporting requirements and the steps involved in the survey initialisation process;

4. "Best" contact: The "best" contact that is able to report data on behalf of the establishment sampled is identified. It may take a number of attempts and some effort to identify the best person in the establishment to provide the price data that is required. This is usually the case for larger units that may have sales, marketing and accounting departments;

5. Products and/or specifications and initialisation questionnaire: Once the "best" contact has been identified, the initialisation team works with this respondent to explain, discuss and identify the products to be reported and the detailed product specifications and/or pricing mechanisms to be used. The development of the initialisation questionnaire is discussed in more detail under section 3.4.2.;

6. Initialisation questionnaire mail-out: After a contact has been identified and the products to be reported and/or pricing mechanisms selected, the initialisation team mails out a customised initialisation questionnaire and reporting guide to the respondent;

7. Initialisation follow-up: The initialisation team schedules telephone follow-up with the respondent to ensure that they have received the initialisation questionnaire and to respond to any queries or questions they may have;

8. Collection of initialisation questionnaire data: The initialisation team ensures that the initialisation is completed and returned by the respondent in a timely manner;

9. Data analysis: The initialisation questionnaire data is verified to ensure that it is correct and that it makes sense; 
10. Assignment of initialised units to centralised collection for ongoing collection: After it has returned a correctly completed initialisation questionnaire, the respondent is transferred to centralised collection for ongoing collection. The initialisation team member responsible for initialising the respondent also reviews the first regular return made by the respondent to ensure that it is acceptable;

Specialised training on specific aspects of the survey, including pricing mechanisms and concepts should be provided to the initialisation team and the centralised collection team as required.

\subsubsection{Initialisation questionnaire}

In order to identify, collect, track and analyse the specific services that must be repriced over time, a separate initialisation questionnaire is used to introduce new sample units/products. This should be designed to minimise respondent burden while also ensuring the required information can be accurately reported and collected. The initialisation questionnaire will include detail on:

- Business activity: Confirmation of services activities;

- Service product lines/Departments: Based on sales revenue, identify the main product lines or departments and their respective share of total sales;

- Destination - Services for export: Where export sales of product lines/department export sales are sufficiently large, prices for representative export transactions should be included - again with their share of sales;

- Transactions: Specification of most representative transactions sold by the sampling unit. These should be classified within service product lines or departments. Specifications should be detailed enough to allow respondents to report constant quality prices for them. They should also include their share of total product line or department sales to allow for weighting of individual prices. Transaction specification is discussed in more detail in the following section.

\subsubsection{Transaction specification}

The target is to select transactions to represent all service product lines (primary and secondary); however, it is also important to balance the need for these data with response burden. The PPI Manual suggests that the average number of prices collected from each establishment should be around 4 or 5 . This is only a guide, but it does serve to minimise burden. If the number of transaction specifications exceeds $15-20$ per establishment, it is recommended in the manual to combine product lines in a way that seems reasonable. For product lines with very low weights, it is either advisable to combine these with another product line or to ignore them and redistribute the weight.

The purpose of a detailed service transaction specification is to ensure that a consistent price is collected from period to period, relating to the same service with the same terms of sale in each period. It will also facilitate the adjustment of prices for services which change in quality over time. ${ }^{12}$ Box 3.4. lists some of the criteria that could affect the price of a service and therefore might form part of a specification. The pricing mechanism employed by the respondent, and the pricing method chosen in response, will significantly influence the service specification. The list is not comprehensive and additional criteria may be required in different service industries or business enterprises. ${ }^{13}$ 


\section{Box 3.4. Service specification - example}

Specification: $\quad$ Explanation:

- Name of service - Respondent's name for the service within the specific service group.

- Description and - The respondent should specify in detail what the service includes. coverage of the service

- Unit of sale - Units used in describing the service (for example minutes, hours, entries, documents or tasks).

- Customer - Pricing structure might depend on customer (or the size category of the customer). A reference number can be used to maintain customer confidentiality.

- Discounts/Rebates - All applicable discounts/rebates should be described.

- Location - The price of the service may depend on the place where it is supplied (including export markets).

- Time - The price of a service may depend on the time when it is delivered (e.g. week-end or working day).

- Payment terms - Different payment or credit terms may result in different prices.

- Currency - Currency fluctuations may significantly alter the price received by the service provider.

\subsection{Set-up of permanent framework}

\subsubsection{Ongoing price collection}

Ongoing price collection should be conducted with customised forms, detailing the specifications of the transactions selected for pricing and taking account of the pricing method to be employed. As previously noted, prices reported should be actual market transaction prices.

Price observations should undergo both input and output editing. Input editing refers to edit checks on individual price observations and often involves setting tolerances around price changes. Price changes that are larger than a set threshold (for example, $+/$ $5 \%$ ) may be checked for an accompanying explanation or queried with respondents where necessary. Output editing refers to editing by comparison of price movement of similar products. Outliers (price observations which appear inconsistent with other prices) should be identified and checked.

In addition there should also be a check for prolonged non-movement of prices. Price change can be more or less frequent in different industries and consequently different tolerances for prolonged non-movement of prices may be employed.

It is also recommended to periodically check indices against alternative sources of information on price development within industries. This may involve analysis of similar price measures or media reports. Industry representative organisations may also be able to provide good market intelligence.

\subsubsection{Treatment of quality change}

A challenge for collecting price data for services (and goods) is that the products bought and sold change over time. Firstly, specific services exchanged between a producer and a customer may change (e.g. a service is delivered in less time or by a better 
qualified employee of the service producer). This is referred to as the problem of quality change. Secondly, the composition of services that are exchanged in a certain service industry will vary over time. It is important therefore to ensure that the transactions selected for pricing, and their respective weights remain representative.

The overarching principle for the treatment of quality change is that "at the most detailed level, the prices of items between any two periods may be directly compared only if the items are essentially the same". ${ }^{14}$ Two services (of a certain nature) are assumed to be of the same quality if at a given time they are exchanged for the same price. Theoretically the quality of a service is defined by a number of dimensions which are on the one hand of importance to the user and his willingness to pay for the service (known as the user-value approach) and on the other hand of importance to the seller and the costs that that he has to bear to produce the service (known as the production-cost approach). ${ }^{15}$ As a rule, there is a case for quality adjustment if clients are willing to pay more for a changed service or if they are no longer willing to pay the former price.

The practical assessment of service qualities is often problematic since observed differences in prices for two services that appear to be the same might exist for a number of reasons (e.g. market imperfections). Even if it can be assumed that price differences are related to quality differences, it might not be known which dimensions of the quality are in fact responsible for the differences. Finally, even when the differences in two services are known, it may still be difficult to separate the price changes due to the quality change from the genuine price change that a price index should reflect.

To the extent that the quality of a product depends on factors that cannot be directly observed (e.g. the preferences of the customers), drafting a description of a product which includes all the various quality aspects will be an approximation. However, in the case of (physical) goods such a description can be assembled with more confidence than in the case of services. For example, for agricultural products quality classes have been defined that guarantee a high degree of homogeneity for products within one class. In the case of technical products like computers, quality aspects that play an important role in the price setting between buyers and sellers can be objectively defined and measured (storage capacity, speed etc.). For services however, this is much more difficult. Services might differ in ways that cannot easily be observed by the compiler. Services are often much more complex than goods (e.g. giving legal advice or management consulting) and services might be unique, i.e. tailor-made for one occasion and/or for one customer. Finally, quality changes in services are not systematic; they might represent improvements or deteriorations.

As a consequence, some degree of subjectivity on the part of the compiler measuring quality change in services cannot be avoided. Therefore, it is of great importance that the reasons and methods employed are well documented.

There are frequent needs for quality adjustments and replacement of transactions for ongoing pricing. These should be an important consideration in the design of questionnaires and survey process and methodologies. The following issues should also be discussed with representative organisations and/or respondents when the survey is being developed:

1. Expected changes in the representativeness of services over time;

2. Expected changes in the quality of services;

3. Quality adjustment methods to be considered; and 
4. Data availability for implementing quality adjustments.

Chapter 7 of the PPI Manual discusses various quality adjustment methods in detail. Because of the very specific nature of certain services, only some of the methods may be applicable for some service industries.

Each method for quality adjusting has advantages and disadvantages. The choice between various methods depends on service characteristics and data availability.

The following section summarises the main points contained in chapter 7 of the PPI Manual and in the OECD's Handbook on hedonic indexes and quality adjustments in price indexes. ${ }^{16}$

\subsubsection{Direct comparison / comparable replacement ${ }^{17}$}

In the simplest case, it may be assumed (either with input from the respondent or through analyst judgement) that there are no relevant differences in the quality of an old and a new service product. In such a case, the direct comparison method (an implicit method of quality adjustment) will be used, i.e. the price of the new service products will be incorporated into the index without any adjustment and the prices for the new and the old services will be directly compared because it has been determined that there is no change in quality. A typical example of such a case is a change to the name of a service product or producer without a change of the service itself.

\subsubsection{Overlap method ${ }^{18}$}

The overlap method can be applied when old and new service products are transacted simultaneously during a certain period of time making it possible to use observations in the overlapping period as a link. The implicit assumption in the method is that the price difference between the old and new products reflects entirely differences in quality.

\section{Box 3.5. Overlap method - example}

In period 1 , the price of the old service is $€ 100$. In period 2, a similar but new service is exchanged for the first time for $€ 108$; the old service is still exchanged but the price is now $€ 90$. The old and new services are largely the same, yet the new service is delivered faster. It is assumed that the relative price difference between old and new service $(1.2=€ 108 / € 90)$ represents the price increase due to the better (faster) service. In period 3, the old service is no longer provided. The price of the new service in period 3 is $€ 144$. In order to make all three periods comparable, the new service price in period 3 is corrected using the quality factor identified in the overlap period.

\begin{tabular}{|l|l|l|}
\hline \multicolumn{1}{|c|}{ Period 1 } & \multicolumn{1}{|c|}{ Period 2 } & \multicolumn{1}{c|}{ Period 3 } \\
\hline$P_{\text {old }}=€ 100$ & $P_{\text {old }}=€ 90$ & $P_{\text {old }}=\mathrm{n} . \mathrm{a}$. \\
\hline $\mathrm{P}_{\text {new }}=\mathrm{n}$. $\mathrm{a}$. & $\mathrm{P}_{\text {new }}=€ 108$ & $\mathrm{P}_{\text {new }}=€ 144$ \\
\hline $\mathrm{P}=€ 100$ & Quality factor: $1.2(€ 108 / € 90)$ & \\
\hline & $\mathrm{P}=€ 90(€ 108 / 1.2)$ & $\mathrm{P}=€ 120(€ 144 / 1.2)$ \\
\hline & $\Delta \mathrm{p}=-10 \%(€ 90 / € 100)$ & $\Delta \mathrm{p}=33.33 \%(€ 120 / € 90)$ \\
\hline
\end{tabular}

The use of the overlap method is restricted to cases where there are old and new products that are sufficiently comparable to assume that price differences between them are quality related and where a change in quality indeed can be assumed to have occurred. A problem arises with the method when the markets for the old and the new product are not in equilibrium and so the entire price difference may not be resulting from quality 
change. In the above example, if the old service in period 2 could only be sold with a rebate because of the competition from the new service then the quality factor would be too high.

In a more extreme case, it might also happen that a service producer increases the price of the old service to deter customers from buying it and offers the new service at preferable terms to promote it. While the new service might actually be better than the old (providing increased utility to the customer), the quality factor could indicate a deterioration in quality.

A typical situation requiring the use of the overlap method is the rotation of products in a sample. For example, consider the case of outdoor advertising. The price of an advertisement is specified based on size and location. If the advertisement expires, the sample price is replaced by another. In this case, the overlap method can be used providing that the new sample price has coexisted with the old one and the price difference between them has been relatively stable in the past.

\subsubsection{Bridged overlap method ${ }^{19}$}

The overlap method requires transactions of the old and the new service during the same period, so that it is possible to collect comparable prices for both services. Where comparable prices in a common period cannot be identified, the price development of similar services (to both the replaced service and the replacement service) can be used to distinguish pure price changes from changes that are due to a different quality.

In the bridged overlap method the difference between the price of the old and the new service is compared with average price changes in similar services. If the price change between the old and the new services is different from the average price change of these "reference services" the difference is assumed to reflect a change in quality.

\section{Box 3.6. Bridged overlap method - example}

In period 1 , service $\mathrm{A}$ is provided for $€ 100$. In period 2 , the service is replaced by an improved service $B$ which costs $€ 120$. Services $C$ and $D$ are in many respects similar to services $\mathrm{A}$ and $\mathrm{B}$. Their respective qualities remain unchanged between period 1 and 2 but both prices (and thus the average price of these reference services) increase by $15 \%$.

It is therefore assumed that the price increase of $20 \%$ between service A (in period 1) and service B (in period 2) is made up of a pure price increase of $15 \%$ and a quality element of $5 \%$.

\subsubsection{Quantity adjustment ${ }^{20}$}

Quantity adjustments are used in cases where the specification of service products is based on certain measureable standards. To be applicable, it is also important that fixed costs of service provision are relatively small. In these cases, prices can sometimes be expressed as unit prices, which make it possible to establish price comparison between periods.

Examples of these kinds of services are taxi transportation and newspaper advertising, where prices are established based on given standards. The method should however, be applied with caution and only if changes in standards are relatively modest. 


\section{Box 3.7. Quantity adjustment - example}

In period 1 , a weekly cleaning service is provided for a customer with office space of 1,000 square metres. The total price is $€ 20,000$. In period 2, the customer has rented additional offices of 200 square metres and the service provider now charges a total of $€ 25,200$.

$\mathrm{P} 1=€ 20,000$ for 1,000 square metres, i.e. $€ 20$ per square metre

$\mathrm{P} 2=€ 25,200$ for 1,200 square metres, i.e. $€ 21$ per square metre

$\mathrm{P} 2 / \mathrm{P} 1=21 / 20=1.05$, i.e. prices have increased by $5 \%$

\subsubsection{Differences in production and option $\operatorname{costs}^{21}$}

The production-option cost method requires information about the additional cost (or cost savings) for the producer that accrues when an old service is replaced by a new one. The central assumption of this approach is that the changes in production costs reflect directly the quality difference between the old service and its replacement.

\section{Box 3.8. Differences in production and option costs - example}

In period 1 , a certain service is provided for the price of $€ 1,000$. In period 2 , the price increases to $€ 1,100$. However, some quality aspect of the service changes as well (e.g. shorter time for service delivery, higher frequency, or service provided by better trained personnel). According to the service producer, the increased quality has generated additional cost of $€ 130$.

The pure change in prices is therefore: $\left(\mathrm{P}_{2}-\right.$ add. cost $) / \mathrm{P}_{1}=(€ 1,100-€ 130 / € 1,000)=$ 0.97 , i.e. the price decreased by $3 \%$.

The method is applicable for services that undergo simple changes rather than change in respect of service content. While there are some similarities with the quantity method the additional quality of the service is not necessarily limited to some measurable dimension of the service (such as size, frequency etc.).

\subsubsection{Hedonic approach ${ }^{22}$}

The hedonic approach is typically used for products that are under rapid development and where sufficiently representative and robust prices cannot be found to cover overlapping periods. Instead of relying directly on prices of new and old products, a price comparison is established on the basis of the individual characteristics of products.

In market equilibrium and perfect competition, prices should reflect the importance of various characteristics of products. This makes it possible to use actual data for identifying price determining factors and for establishing a regression model. The model can then be used for estimating an overall quality change of products whose characteristics change over time. It should be noted however, that the hedonic approach requires a large pool of observation of prices and price determining characteristics.

Price determining factors for services can be difficult to identify or to measure, and therefore the hedonic method is rarely directly applicable. However, it might be used indirectly, namely in cases when services are related to goods for which price changes are estimated using the hedonic approach (such as rental of computers). 


\subsubsection{Index calculation}

The index formula chosen for the elementary aggregates ${ }^{23}$ can vary as a function of the sampling method, information available, specific nature of industry, and resource restrictions. A more extensive description of widely used elementary aggregate formulas and their justification can be found in chapter 20 of the PPI Manual.

It is recommended that where possible, explicit weights are used at all levels of aggregation. When aggregating sample price relatives ${ }^{24}$ within elementary aggregates, geometric averaging should be used when weights are not available.

The index number formula used in the aggregation of elementary aggregates should be selected as a function of the indicator's purpose. Individual countries may have different priorities and the formulas may therefore differ from country to country. In general, it is recommended that the European Union member states should use a Laspeyres-type index formula that is in line with the EU short-term statistics regulation, which specifies all relevant aspects of the collection of service producer prices in the $\mathrm{EU}^{25}$

The modified Laspeyres (short-term formulation) has a number of advantages over the standard Laspeyres (long-term formulation) in calculating the SPPI. The short-term formulation weights each short-term price relative (current price compared with previous period price) by its previous expenditure share (weight in previous period). The previous period expenditure share is equivalent to the base period value share, updated for price change to the previous period, thus providing a better representation of the dynamic nature of the weighting structure. The short-term formulation facilitates the introduction of new transactions without having to impute base period prices. When two successive prices for the replacement transaction are available, it can be used in place of the transaction that is no longer available. If a price is missing, the short-term price change of similar items can be used (as opposed to long-term price changes) for purposes of imputation. Another advantage of the short-term formulation is that it is much easier to deal with quality changes.

The weight of a sample price relative for a certain product or service will reflect the first stage weight (i.e. the inverse of its probability of being selected for the sample) of the units in which it is produced and also the share of the turnover of that product in the units' turnover (second stage weight). See box 3.9 below as an example of this weighting methodology.

An advantage of this form of index aggregation is that sub-indices for service products (i.e. which form the elementary aggregate structure) are produced which may be a useful output if deemed to be of suitable quality. A potential disadvantage of this method is that it relies on the relevance of the product classification forming the family tree structure. If this phase of the index development has not been done well then the family tree structure may not represent important product groups within the industry and the index could be of low quality. 


\section{Box 3.9. Weighting example for product SPPI of 4-digit level industry}

An industry survey showed that a particular service industry identified at 4-digit NACE level produces 4 main product groups; y1, y2, y3 and y4 with approximate shares of 20\%, 30\%, $15 \%$ and $35 \%$. This defines the elementary aggregate structure for the SPPI. The total turnover for the industry is 2,360 (the sum of the establishment group turnovers).

5 establishments are chosen in the sample for the industry using probability proportional to size (PPS) sampling. Establishment A was selected from a group of 5 establishments who have a total turnover of 500. ${ }^{(1)}$ Establishment B was selected from a group of 8 establishments who have a total turnover of 560 and so on. Larger establishments are asked to provide up to six price quotations and smaller establishments are asked to provide non more than four. The establishments have the following characteristics:

\begin{tabular}{|l|l|l|l|l|l|}
\hline $\begin{array}{c}\text { Establishment } \\
\text { (enterprise) }\end{array}$ & $\begin{array}{c}\text { Probability of } \\
\text { selection }\end{array}$ & Turnover & $\begin{array}{c}\text { Establishment group } \\
\text { turnover }\end{array}$ & $\begin{array}{l}\text { Shares of the } \\
\text { main product } \\
\text { groups in } \\
\text { turnover }\end{array}$ & $\begin{array}{c}\text { Price quotations } \\
\text { for each product } \\
\text { group }\end{array}$ \\
\hline $\mathrm{A}$ & $1 / 5$ & 100 & 500 & $0.25 ; 0.25 ; 0.5 ; 0$ & $1 ; 2 ; 3 ; 0$ \\
\hline $\mathrm{B}$ & $1 / 8$ & 70 & 560 & $0.7 ; 0 ; 0 ; 0.3$ & 4,$0 ; 0 ; 2$ \\
\hline $\mathrm{C}$ & $1 / 10$ & 40 & 400 & $0 ; 0.4 ; 0 ; 0.6$ & $0 ; 3 ; 0 ; 3$ \\
\hline $\mathrm{D}$ & $1 / 50$ & 10 & 500 & $0 ; 0.5 ; 0.5 ; 0$ & $0 ; 3 ; 3 ; 0$ \\
\hline $\mathrm{E}$ & $1 / 100$ & 4 & 400 & $0 ; 0 ; 0 ; 1$ & $0 ; 0 ; 0 ; 4$ \\
\hline
\end{tabular}

For each establishment, price quotations (specifications) within a product group have equal weights. Relative weights for each specification are aggregated geometrically to form an establishment level relative weight for the product group. These weight relatives (micro indices) must then be weighted together with other establishments' weight relatives to form the elementary aggregate (i.e. product group) indices.

\begin{tabular}{|c|c|c|c|c|c|c|}
\hline $\begin{array}{l}\text { Product } \\
\text { group }\end{array}$ & $\begin{array}{l}\text { Product group } \\
\text { weight } \\
\text { (product } \\
\text { approximate } \\
\text { share* total } \\
\text { industry } \\
\text { turnover) }\end{array}$ & Establishment & $\begin{array}{l}\text { 1st stage } \\
\text { weight (2) }\end{array}$ & $\begin{array}{c}2^{\text {nd }} \text { stage } \\
\text { weight }\end{array}$ & $\begin{array}{c}\text { Total weight } \\
\left(1 \text { st * }^{\text {nd }}\right)\end{array}$ & $\begin{array}{c}\text { Relative Weight } \\
\text { within product } \\
\text { group }\end{array}$ \\
\hline \multirow[t]{2}{*}{ Y1 } & 472 & A & 5 & $\begin{array}{l}100^{*} 0.25= \\
25\end{array}$ & 125 & $\begin{array}{l}125 /(125+392) \\
=0.24\end{array}$ \\
\hline & & $\mathrm{B}$ & 8 & $70 * 0.7=49$ & 392 & 0.76 \\
\hline \multirow[t]{3}{*}{ Y2 } & 708 & $A$ & 5 & $\begin{array}{l}100^{*} 0.25= \\
25\end{array}$ & 125 & 0.23 \\
\hline & & C & 10 & $40 * 0.4=16$ & 160 & 0.30 \\
\hline & & D & 50 & $10^{*} 0.5=5$ & 250 & 0.47 \\
\hline \multirow[t]{2}{*}{ Y3 } & 354 & A & 5 & $100^{*} 0.5=50$ & 250 & 0.50 \\
\hline & & $\mathrm{D}$ & 50 & $10^{*} 0.5=5$ & 250 & 0.50 \\
\hline \multirow[t]{3}{*}{$\mathrm{Y4}$} & 826 & $B$ & 8 & $70 * 0.3=21$ & 168 & 0.21 \\
\hline & & C & 10 & $40 * 0.6=24$ & 240 & 0.30 \\
\hline & & $E$ & 100 & $4^{*} 1=4$ & 400 & 0.49 \\
\hline
\end{tabular}

(1) Under PPS sampling, the probability of an establishment being selected in the sample is proportional to a measure of size for the establishment obtained from the sampling frame (e.g. turnover), i.e. the larger the establishment the higher the chance that it will be included in the sample.

(2) The first stage weight is equal to the inverse of its probability of selection. 


\subsubsection{Quality assessment and maintenance}

After a new SPPI for a service industry is compiled, or a pilot survey has been conducted, a quality assessment should be performed. Quality assessments should also be periodically performed on existing indices to ensure they remain representative. The quality assessment procedure is discussed here from two perspectives: firstly, the SPPI is judged as an indicator in its own right (box 3.10) and secondly, as an input into the national accounts (box 3.11).

\section{Box 3.10. Assessment of SPPI for service industry}

- Ability to approximate transaction prices;

- Objectivity (e.g. preference for actual charge out rates);

- Pricing frequency;

- Continuity (period for which a method can be applied without a change);

- Practicality (for the staff of the statistical offices);

- Response burden (e.g. time that a respondent needs to fill in the survey);

- Response rate (number of forms returned divided by number of forms sent out);

- Opinion of the pilot-study respondents;

- Transparency of the method;

- Plausibility of the results.

For a practical evaluation each method is given a certain score for each criterion; for example very positive $(++)$, positive $(+)$, neutral $(0)$, negative $(-)$, very negative $(--)$. Alternatively, points could be distributed; for example very positive (2), positive (1), neutral (0), negative (-1), very negative (-2). Since not all criteria are of equal importance, the criteria might also be given different weights. The evaluation of a method is then the result of the scores and the weights.

There is a certain element of subjectivity in this method, especially for criteria like transparency which can be difficult or sometimes impossible to measure directly (as e.g. compared to the response rate). Moreover, the evaluation grid might put more or less emphasis on certain aspects (for example, in the above box the opinion of the pilot-study respondents could be omitted because it could be argued that this information is implicitly contained in the response burden and response rate). Nevertheless this approach has the advantage that the decision in favour or against a certain method can be better justified and that the criteria and their weights can be determined in advance.

Another way of assessing SPPIs is to consider their quality as national accounts deflators. The criteria that are used in the evaluation can be divided into two groups: absolute measures that indicate how reliable the SPPI are in their own right, and relative measures that compare the SPPI to deflators that are used currently. Examples of criteria for absolute measures are presented in box 3.11. The Eurostat Handbook on price and volume measure in national accounts provides an example of a relative criteria assessment, classifying methods into A, B or C methods. 


\section{Box 3.11. Criteria for evaluating an SPPI as a national accounts deflator}

- Statistical properties of the survey;

- The definitions and specifications of the variables (should be in line with the national accounts definitions and specifications);

- Periodicity of data collection, timeliness, and length of the series;

- Quality checks (e.g. ability to explain erratic movements) and periodicity of index revisions;

- The transparency and available documentation of the production and quality assessments.

After the quality assessment has been carried out, the necessary actions to improve the survey should be undertaken. In the case of the quality assessment of a pilot survey, full-scale data collection should start only after the improvements are implemented.

The maintenance of service price quality is an important task in the compilation of price indices. Ideally, prices for a representative set of service products could be surveyed from one period to another but in practice the market changes continuously. New services appear and old services disappear, especially in services industries dominated by swift technological changes such as telecommunication. Sometimes services remain unchanged but the pricing mechanism might change and consequently, pricing methods have to be changed. Also, the business demography may change, which can necessitate a revision of the sample frame. For all these reasons, maintaining representativeness of the sample and at the same time capturing pure price changes in the survey data for an SPPI is a challenging task.

The maintenance work of service prices thus includes:

1. Evaluation of the representativeness of service products in the sample;

2. Continuous observation of sample price specifications;

3. Replacement of sample prices.

The use of representative service products and transactions in an SPPI is an essential precondition for correctly monitoring the evolution of prices. Confirmation of sample price specifications is of great importance for ensuring that the prices of the same transactions are followed over time. When sample prices are replaced, quality adjustments should be considered.

The maintenance work has to be done after the periodical price survey starts and within the cycle of the survey period to ensure that data are validated in advance of scheduled publication dates. Since not all survey response is received promptly enough to allow it to be validated within the survey period, published data may need to be revised in later periods to reflect these late reports. To ensure that the maintenance work is performed accurately, efficiently, and in a timely manner, price compilers should be prepared in advance. They will have to reserve time for discussions with respondents and possibly industry associations on changes in the market and possible solutions. Proper preparation for surveys is, in general, time consuming, and it is possible that not enough time is available for all maintenance tasks during the survey periods. Therefore, focusing 
on maintenance work outside the non-probability current periodic surveys (e.g. halfannually or annually) is a practice worth considering.

Further information on the maintenance of a price index can found particularly in chapter 8 of the PPI Manual.

\section{Bibliography}

Destatis (2009), Handbook on the application of quality adjustment methods in the Harmonised Index of Consumer Prices, Statistics and Science - Volume 13, Federal Statistical Office of Germany, Wiesbaden, Germany.

European Commission (2001), Handbook on price and volume measures in national accounts, European communities, Luxembourg, available at: http://epp.eurostat.ec.europa.eu/cache/ITY OFFPUB/KS-41-01-543/EN/KS-41-01543-EN.PDF

European Commission, IMF, OECD, UN and World Bank (eds.) (2009), System of National Accounts 2008, United Nations, New York.

ILO, IMF, OECD, UNECE, Eurostat, World Bank (eds.) (2004 b), Producer Price Index Manual, Theory and practice, International Monetary Funds, Washington, DC.

Triplett J. (2006), Handbook on hedonic indexes and quality adjustments in price indexes, OECD, Paris. A free of charge version is available at:

http://www.oecd.org/science/sci-tech/33789552.pdf

\section{Notes}

1. This chapter draws heavily on the PPI Manual which details ten basic steps to PPI development. See PPI Manual, appendix 1.1.

2. See http://www.voorburggroup.org/

3. Note that "industry" means here that service products are aggregated to the 4-digit industrial classification. In practice the index usually only covers service products principal to the industry, but in concept should also include secondary production.

4. See PPI Manual, par. 1.306.

5. See PPI Manual, par. 1.309 .

6. Note that a respondent unit will only contribute a specification to a component of the elementary aggregate structure if it has significant production for the particular 
service product in question. Thus one does not expect a respondent to contribute specifications to each component of the indices' elementary aggregate structure.

7. This section draws heavily on chapter 5 of the PPI Manual which readers should consult for a more in depth discussion.

8. $\quad$ See PPI Manual, par. 5.22.

9. See PPI Manual, par. 1.320 .

10. See PPI Manual, par. 5.36.

11. This section is largely based on a note by Draper and Loranger (unpublished) detailing the processes adopted by Statistics Canada in the initialisation of new respondents in price surveys.

12. The treatment of quality change is discussed in more detail under section 3.5.2.

13. For concrete examples of product specifications see the detailed industry chapters in this Guide. Additional information can be found in chapter 10 of the PPI Manual which deals with the treatment of specific products, in particular in sections 10.J. (Retail Trade), 10.K. (Telecommunication), 10.L. (Commercial Banking), 10.M. (Insurance), 10.N. (Software, Consultancy and Supply), 10.O. (Legal Services), and 10.P. (General Medical Hospitals).

14. See PPI Manual, section 7.2.

15. See PPI Manual, section 7.6.

16. See Triplett (2006).

17. See PPI Manual, section 7.107.

18. See PPI Manual, sections 7.80-7.89.

19. See Destatis (2009), chapter 5.2.5.

20. See PPI Manual, sections 7.113 - 7.117.

21. See PPI Manual, sections 7.118-7.125.

22. See PPI Manual, par. 7.126-7.151.

23. An elementary aggregate is generally the lowest level within an index structure for which reliable weights exist for the population of interest (e.g. relatively homogeneous group of service products), generally obtained from some source not directly related to the collection of prices (e.g. independent survey). Samples of prices are collected within each elementary aggregate.

24. Sampled price relatives are the micro indices of sampled prices contributing to the elementary aggregate.

25. All legal text concerning EU short-term statistics are available at: http://epp.eurostat.ec.europa.eu/portal/page/portal/short_term_business_statistics/legis lation 
PART II. PRODUCER PRICE INDICES FOR SPECIFIC SERVICE INDUSTRIES 



\section{General framework for replicable and harmonised guidance}

The second part of the SPPI Guide contains 10 chapters classified according to the ISIC classification that provide guidance on 31 service industries. These chapters 4 to 13 are based on country practices and deal with feasible solutions to implement SPPIs in some specific service industries.

Guidance on these 31 service industries has been developed by the Task Force based on two main criteria: first, the service industries already included in the first edition of the SPPI Guide should to be revised to reflect the impact of moving to ISIC Rev.4 and also to reflect any possible new information that needed to be incorporated - for example any advancements in compilation practices; second, to broaden the types of service industries covered (beyond only services mainly aimed at business use) and to consider the potential for extending the scope of the SPPI Guide, by discussing service industries where subdivisions of SPPIs by destination of output (BtoB, BtoC and BtoAll) may be considered.

The 31 service industries covered in the SPPI Guide are listed in the table II.1. Industry sections have been drafted by lead author(s) under the guidance of the Task Force.

Table II. 1. Service industries covered in the 2014 SPPI Guide

\begin{tabular}{|c|c|c|c|}
\hline ISIC & Section & Title & Lead Author(s) \\
\hline $37-38$ & 4.1 . & Waste management & Denis Gac, INSEE \\
\hline $46-47$ & 5.1. & Wholesale and retail trade services & Catherine Draper, Statistics Canada \\
\hline 4923 & 6.1. & Freight transport by road & $\begin{array}{l}\text { Christopher Jenkins and Aspasia Papa, } \\
\text { Office for National Statistics United } \\
\text { Kingdom }\end{array}$ \\
\hline 5012 & 6.2 . & Sea and coastal water transport & Anne-Sophie Fraisse, OECD \\
\hline 51 & 6.3. & Air transport & Christian Puchter, Statistics Austria \\
\hline 5210 & 6.4. & Warehousing and storage & Paul Boling, Australian Bureau of Statistics \\
\hline 5224 & 6.5 . & Cargo handling & Paul Boling, Australian Bureau of Statistics \\
\hline 53 & 6.6. & Courier and postal activities & $\begin{array}{l}\text { Denis Gac, INSEE \& Ildikó Hamvainé } \\
\text { Holocsy, Statistics Hungary }\end{array}$ \\
\hline 55 & 7.1. & Accommodation & Anne-Sophie Fraisse, OECD \\
\hline 56 & 7.2 . & Food and beverage service activities & Anne-Sophie Fraisse, OECD \\
\hline 581 & 8.1. & $\begin{array}{l}\text { Publishing of books, periodicals and other } \\
\text { publishing activities }\end{array}$ & Denis Gac, INSEE \\
\hline 5820 & 8.2. & Software publishing & $\begin{array}{l}\text { David Friedman, U.S. Bureau of Labor } \\
\text { Statistics }\end{array}$ \\
\hline 61 & 8.3. & Telecommunications & $\begin{array}{l}\text { Christopher Jenkins, Office for National } \\
\text { Statistics U.K. }\end{array}$ \\
\hline 62 & 8.4. & $\begin{array}{l}\text { Computer programming, consultancy and } \\
\text { related activity }\end{array}$ & $\begin{array}{l}\text { Ruth Vizner, Central Bureau of Statistics } \\
\text { Israel }\end{array}$ \\
\hline
\end{tabular}


Table II. 1. Service industries covered in the 2014 SPPI Guide, continued

\begin{tabular}{|c|c|c|c|}
\hline ISIC & Section & Title & Lead Author(s) \\
\hline 6419 & 9.1. & Monetary intermediation activities & $\begin{array}{l}\text { David Friedman, U.S. Bureau of Labor } \\
\text { Statistics }\end{array}$ \\
\hline 6499 & 9.2 & Investment banking & $\begin{array}{l}\text { David Friedman, U.S. Bureau of Labor } \\
\text { Statistics }\end{array}$ \\
\hline 6612 & 9.3 . & $\begin{array}{l}\text { Security and commodity contracts } \\
\text { brokerage }\end{array}$ & Hina Kikegawa, Bank of Japan \\
\hline 651 & 9.4 . & Insurance & $\begin{array}{l}\text { David Friedman, U.S. Bureau of Labor } \\
\text { Statistics }\end{array}$ \\
\hline 68 & 10.1. & $\begin{array}{l}\text { Real estate activities with own or leased } \\
\text { property }\end{array}$ & $\begin{array}{l}\text { Aspasia Papa, Office for National Statistics } \\
\text { United Kingdom }\end{array}$ \\
\hline 6910 & 11.1. & Legal activities & $\begin{array}{l}\text { Christopher Jenkins, Office for National } \\
\text { Statistics, United Kingdom \& Maria } \\
\text { Schuch, Statistics Austria }\end{array}$ \\
\hline 6920 & 11.2. & $\begin{array}{l}\text { Accounting, bookkeeping and auditing } \\
\text { activities; tax consultancy }\end{array}$ & André Loranger, Statistics Canada \\
\hline 7020 & 11.3. & Management consultancy & Denis Gac, INSEE \\
\hline 7110 & 11.4. & Architectural activities & Marcel Spanjaard, Statistics Netherlands \\
\hline 7110 & 11.5. & $\begin{array}{l}\text { Engineering services and related technical } \\
\text { consulting services }\end{array}$ & Marcel Spanjaard, Statistics Netherlands \\
\hline 7120 & 11.6. & Technical testing and analysis & $\begin{array}{l}\text { Ildiko Holocsy, Hungarian Central } \\
\text { Statistical Office }\end{array}$ \\
\hline 7310 & 11.7. & Advertising & Johanna von Borstel, Destatis \\
\hline 7320 & 11.8 . & Market research and public opinion polling & $\begin{array}{l}\text { Aspasia Papa, Office for National Statistics } \\
\text { United Kingdom }\end{array}$ \\
\hline 78 & 12.1 & Employment activities & Dorothee Blang,Destatis \\
\hline 80 & 12.2. & Security and investigation activities & Anne-Sophie Fraisse, OECD \\
\hline 812 & 12.3. & Cleaning activities & Marcel Spanjaard, Statistics Netherlands \\
\hline 86 & 13.1. & Human health activities & $\begin{array}{l}\text { Bonnie Murphy, U.S. Bureau of Labor } \\
\text { Statistics }\end{array}$ \\
\hline
\end{tabular}

The objective of chapters 4 to 13 is to provide an overview of key practices, experiences and issues in developing SPPIs for specific service industries. While guidance may reflect the national practice of the lead author(s) it should be noted that efforts have been made by lead authors, as far as possible, to provide replicable guidance across countries.

As such, each section of chapter 4 to 13 is subdivided into eleven (or twelve as appropriate) sub-sections in order to address the following issues:

- The coverage and classification aspects:

1. Industry description: the subsection gives a general outline of the service industry and recent developments in the nature of the industry, particularly those that present pricing difficulties;

2. Classification aspects: the subsection shows in detail the classification aspects relevant for the service industry and also highlights some specific classification issues when it is felt necessary.

3. Scope of the survey: Ideally, the subsection describes the 'ideal' (but practical) survey, and how it would accommodate an exhaustive coverage of users. In other words, the description presents the conceptual boundaries of the SPPI in terms of final users of the service industries' output and discusses the measurement difficulties related to the split between business and other users (e.g. government, household, and export). In practice however, the scope of the survey may not be 
as exhaustive as an ideal survey and so a second best approach may be described based on the scope of the survey used in the lead author's country.

4. Industry vs. Product based SPPI (when relevant): In some service industries, the decision on whether to create an industry based SPPI or a product based SPPI is an important aspect to consider and the choice of the basis for developing SPPIs depends on the priorities of individual countries. Related issues in respect of the basis for developing SPPIs and how to deal with secondary activity may also be discussed.

- The compilation issues:

5. Sample design: This subsection describes the sampling issues in price collection. National experiences are likely to dictate what is described in the sample design subsection even if efforts have been made to focus on an ideal sample with national experiences added for additional information.

6. Collection of information and specification of the services: This subsection gives an overview of price collection issues and discusses how the data collection is organised and the common types of price specifications for the service products in the particular industry.

7. Pricing methods: This subsection provides a description of the main pricing methods and their applicability to the industry. The aim is to assess the pricing methods by articulating a series of pros and cons. ${ }^{1}$

8. Quality issues: This subsection provides information on the quality determining characteristics of services in this industry and how quality changes are dealt with. As the general principles are covered in chapter 3, this subsection describes only how quality adjustments are made in practice for specific services.

9. Weighting and aggregation: This subsection provides a general description of how SPPIs for a specific service industry are calculated.

10. Specific aspects: This subsection includes discussions on service industry specific aspects such as treatment of outsourcing and sub-contracts; treatment of bundled services; future developments of the service industry, etc.

- The experience of individual countries:

11. Overview of national methods

- The sources used:

12. Bibliography 


\section{Notes}

1. The SPPI TF agreed not to classify the pricing methods according to a prescriptive nomenclature that ranked pricing methods, rather it choose to assess the pricing methods by articulating a series of pros and cons; assessments are based on specific criteria including pricing mechanisms, nature of the industry, adequacy in capturing quality changes, repeatability of the price specification, timeliness of the data collection, etc. 


\section{Chapter 4. Waste management}

This chapter presents practical guidance as well as main issues and challenges for compiling SPPI for Waste management service activities (ISIC 37-38). 


\subsection{Waste management (Denis Gac, INSEE)}

\subsubsection{Industry description (ISIC 37-38)}

Divisions 37 and 38 of the ISIC classification system combined, broadly cover waste management service activities. ISIC division 37 - Sewerage, includes: the operation, maintenance and cleaning of sewer systems or sewer treatment facilities; the collection, transportation and treatment of human, industrial and rainwater; the emptying and cleaning of sewerage from cesspools and septic tanks, sinks and pits; and the serving of chemical toilets. Division 38 - Waste collection, treatment and disposal activities; materials recovery, includes: the collection treatment and disposal of waste; and materials recovery.

In many countries, public entities, often local government, have traditionally provided a significant proportion of waste management activities although increasingly these are being provided by private operators. For example in France, the private sector now accounts for two-thirds of municipal waste management activity. In some cases the activities are funded through taxation and outsourced by government to private operators, while in other cases consumers purchase services directly from private operators. These models of service provision will require different pricing methods.

The provision of certain activities (such as the collection and disposal of household waste) is usually well regulated by government and this may make price collection relatively straightforward. On the other hand, business enterprises providing waste management services often provide a range of activities spanning across, and beyond, the two divisions (for example activities classified to ISIC division 36 - Water treatment).

Pricing mechanisms may differ significantly between activities and by type of service producers and therefore considerable effort is required in the design of the surveys, particularly at the industry research and respondent initialisation stages.

\subsubsection{Classification aspects}

\subsubsection{Industry classification}

The international industrial classifications are broadly comparable although they provide varying levels of detail (see annex A). The NACE, NAICS and ANZIC classifications all follow the organization of ISIC divisions 37 and 38 in that they distinguish between the collection (ISIC 381) and the treatment and disposal of waste (ISIC 382), as well as the recovery of materials (ISIC 383). Note that under the JSIC classification, waste management services are organised according to the source of the waste (domestic or industrial).

The classifications differ however in the treatment of remediation services. Both the ISIC and NACE classify remediation services separately under division 39 - Remediation activities and other waste management services, while they are included with waste management under a combined subsector in both the NAICS (5629 - Remediation and Other Waste Management Services) and ANZIC (2922 - Waste Remediation and Materials Recovery Services) classifications.

\subsubsection{Product classification}

There is greater variation among the international product classifications, both in terms of content and detail. In particular, both the CPC and NAPCS classifications focus 
on waste management service activities although the NAPCS does provide some limited detail on recyclable materials.

The CPA, on the other hand, covers both services and goods, and contains a detailed list of products covering waste materials, recyclable materials (goods) and secondary metals under group 38.3 - Materials recovery services; secondary raw materials. The outputs of the waste management industries, (such as recycled metals) are significant as they may offset service fees.

It is not clear therefore if only the service activities provided should be included in the SPPI, or if transactions of recyclable materials are also relevant. The question of goods versus services was raised with the Technical Subgroup of the Expert Group on International Social and Economic Classifications (TSG) during the review of the CPC. However, there was not complete agreement that waste and secondary raw materials were the only categories of tangible outputs. There can be multiple transactions from recyclable materials collection businesses to sorting businesses, to wholesalers of recyclable materials, and to processors. While some of these transactions are margin activities, others involve processing and the treatment and the basis for measurement is not as clear (Murphy, 2011).

\subsubsection{Scope of the survey}

Ideally, SPPIs for waste management service activities should include the changes in fees received by the various institutional sectors providing these services. Governments often provide waste management services in respect of the collection and disposal of nonhazardous household and commercial waste or recyclable materials. They may also provide landfill, incinerator or other disposal facilities. Where the provision of waste management services are outsourced by government to private enterprises, these transactions are within scope of the SPPI.

SPPIs for waste management service activities should distinguish between different end users of these services as they are likely to involved different prices and pricing mechanisms. Contracts between government and private enterprises for the outsourcing of these activities are likely to be complex and cover a number of years in contrast to activities provided to households over a one year period which may be priced according to published lists.

CPA division 38 - Waste collection, treatment and disposal services; materials recovery services, includes business enterprises with highly complementary activities. Service producers may be involved in several activities of the industries forming the division, often across the different stages of the waste-management process. This provides a strong argument for the compilation of indices covering all of the activities of the division including the recycling of materials. On the other hand, it may also be the case that producers of specialised recycling services do not engage in waste collection activities and derive revenue from recovering recyclable raw materials. This is particularly true of household-waste incineration plants, an aspect that can significantly influence the price of incineration services.

\subsubsection{Industry vs. Product based SPPI}

Product based SPPIs are preferable for the deflation of national accounts. In practice however, the required weighting data (such as turnover at product level) is rarely available to compilers. These data are more typically available at the industry level 
meaning that compilers are more likely to target the compilation of industry based price indices. Whilst this industry based approach is more practical, it has the disadvantage that it will miss relevant secondary activity of those establishments classified outside the waste management divisions. This disadvantage could be a significant issue in the case of services relating to sewerage.

The supply of water and sewerage activities is often offered by the same business enterprises as they share many related activities. Sewerage activities provided by business enterprises classified to division 36 - Water collection, treatment and supply, will not be included in an industry based SPPI.

\subsubsection{Sample design}

Ideally, sampling of the waste management divisions should be carried out using probability proportional to size (PPS) with turnover as the size measure. Samples are usually drawn from business registers. If additional data is available to the compiler, perhaps from the regulation of the provision of service activities, these could be used to supplement the information held on the business register.

The divisions may be heavily concentrated, with a small number of larger business enterprises responsible for a sizeable portion of output. These larger service producers could be selected with certainty. As it is possible to distinguish between a numbers of very different types of activities within each division, compilers should check to ensure that these activities are adequately represented in the sample.

In France, more than 60 units are included in the sample. All of these units produce service activities than span at least two industries. As activities are delivered regionally, it is important to ensure that the sample is representative of this industry characteristic. Industry representative organisations can provide useful information on the regional organisation of the industry.

\subsubsection{Collection of information and specification of the service}

As previously noted, pricing mechanisms may differ significantly between activities and by type of service producers. Many of the types of activities produced may be subject to regulation and this will impact both on the delivery of services and the availability of relevant and information on them. It is essential therefore that considerable effort is applied to the research and respondent initialisation phases of the survey. Each component of the waste management industries should be separately reviewed and evaluated.

The selection of products for price collection should be conducted in consultation with the respondents so as to ensure that they are representative of the service activities produced. In France, a visit is made to each respondent to identify, in detail, the activities they produce. These are identified according to the following detail:

\subsection{Collection of non-hazardous waste}

- Collection from households and equivalents

- traditional collection

- selective collection (sorted bags or voluntary drop-off points)

- collection at waste dumps

- Collection from economic activities

- Management of transfer facilities 
- Waste materials (scrap metal, cullet)

38.12 Collection of hazardous waste

- Collection of hazardous industrial waste

- Management of transit centres or facilities

- Collection of hazardous or infectious hospital waste

38.21 Treatment and disposal of non-hazardous waste

- Treatment of household waste and equivalents

- Management of sorting facilities for household waste and equivalents

- Operation of class-2 storage centres for HW

- Incineration of household waste

$\sim$ Ash, incinerators residues

- Collection of waste from economic activities

- Management of sort centres

- Management of class-2 storage centres

- Management of class-3 storage centres

38.22 Treatment of hazardous waste

- Specialised incineration

- Management of class-1 storage centres

- Co-incineration in cement plants

- Treatment of infectious hazardous medical waste

- Decontamination, remediation of contaminated facilities and soil

38.3 Energy by-products

- Energy recovery ( $\mathrm{kW}$, hot water, methane)

\subsection{Street cleaning}

\subsubsection{Main pricing methods}

A variety of pricing mechanisms are employed by producers of waste management services. Service provider type (government, business enterprise), service consumer type (government, household, enterprise) and service type, all influence the way in which specific transactions are priced.

If household waste collection or sewerage services are included as part of a package of services provided by government, and funded by taxation, then transaction prices cannot be observed. On the other hand, if households pay per collection or pay by weight, it is likely that these services are already included in the CPI and can be easily incorporated into the SPPI.

If government outsources the provision of waste management services to private operators then the relevant contracts can be used for ongoing pricing. However, care must be taken to determine whether the contracts are identical over time, with the same collection area and the same frequencies. Collection areas may widen because of the inclusion of new neighbourhoods in the collection route. It is also important to separate collection activities from treatment and disposal activities. 


\subsubsection{Waste collection}

For the collection of household waste, it is important to note that the service produced cannot usually be segmented. Waste collection effectively consists of collecting all waste left by households for collection (such as glass, organic, paper), and not just a single type. Consequently, tracking the price per volume (such as metric tonne) may not provide an adequate solution, despite its very frequent use as an indicator by private-sector operators.

In France, households are not charged on the basis of the waste they have had collected, but according to the "cadastral rental value" of their dwellings, which also serves to assess other local taxes. Some local communities are attempting to introduce "pay-as-you-throw" ("PAYT") as an incentive to increase recycling and curb waste generation, since the price to pay is no longer a flat rate, identical whatever the quantity of waste left to collect.

Where a "PAYT" pricing method is employed, it is possible to determine a unit price for the service provided although the resulting index would not take into account various quality effects such as the introduction of different collection procedures for recyclable and non-recyclable waste.

If private operators are contracted by government to provide waste management services it could be possible to measure prices based on the contracts for this outsourcing. However, it is necessary to determine whether the contracts are identical over time, with the same collection area and the same frequencies. Collection areas often widen because of the inclusion of new neighbourhoods in the collection route. One way around this problem is to measure the price of a collection hour for a given arrangement, typically one truck and two collectors. When a contract is drawn up, its value may be pegged to population size and to cost indices, typically for fuel and gross wages. However, when using a time based method it is important to note that as collection equipment becomes more sophisticated it cannot be assumed that productivity remains constant.

The price per resident could provide a stable unit-price, if the characteristics other than the collection area have not changed radically.

Recycling incentives often lead to changes in the collection process. For example, services have developed to include not only: $i$ ) the collection of unsorted waste; but also ii) the collection of bins at voluntary drop-off points for glass, paper/cardboard, and plastics; and iii) the collection of sorted waste (organic, plastic, paper etc.). As waste collection becomes increasingly segmented into different services (according to the type of waste), the observed prices should reflect this market segmentation; an average "price per specified weight" for all materials combined may no longer produce an adequate measure of price development.

\subsubsection{Waste treatment and disposal}

For waste treatment and disposal, the most appropriate solution appears to be price per quantity. Characteristics that should be taken into account include:

- Type of waste (solvent, grease, paint, radioactive material etc.);

- Format (liquid, unsorted/bulk, etc.);

- Quantity (50 g, 10 metric tons);

- Waste disposal process (storage, landfill, incineration, etc.). 


\subsubsection{Quality issues}

Improvements to the quality of service produced may require quality adjustment. The overall quality of waste collection and treatment services is not determined solely by the buyer and seller, but also by the regulatory standards concerning health, pollution, and the environment. It is important that all changes in the quality of services produced are identified and adjusted for where necessary.

For example in France, authorities are involved in regulation, setting pollutant emission standards, defining the procedures to be implemented, and setting guidelines for local policies such that compliance with EU Directives is achieved. The following targets have been set according to "Le Grenelle de l'Environnement":

- Reduce household-waste production by 7\% per year;

- Increase recycling of materials and organic substances in order to raise the share of recycled household waste and equivalents from $24 \%$ in 2004 to $35 \%$ in 2012 and $45 \%$ in 2015 ;

- Reduce incineration volume by $15 \%$ between 2009 and 2012 .

Changes to collection processes must be monitored and accounted for. A current trend that can be observed is the separation of waste-collection flows, thereby increasing total collection activity. If unit prices are tracked at a too broad level, changes in the collection process cannot be accounted for. In some localities, for example, a twice-weekly collection of unsorted waste may be changed to one collection of unsorted waste and one collection of sorted waste.

\subsubsection{Weighting and aggregation}

The extent to which suitable weights can be identified for the compilation of SPPIs for waste management services will be largely dependent on the market structure within a country. In particular, the relative importance of government as a service provider will determine the completeness of traditional sources of weights (such as structural business statistics or the national accounts). Secondary sources of weights such as the volume of waste produced or disposed of to estimate weights across institutional sectors could also be employed (Murphy, 2011).

\subsubsection{Specific aspects}

The overlap in production of water and sewerage services may present challenges to the compiler if it is not possible to separately identify prices for the services. Furthermore, it may be difficult to directly measure the price development of waste management services produced by government. Where these services are outsourced to business enterprises the contract price method can be employed.

As previously noted, it is not entirely clear how the transactions of the output of recycling of some waste should be treated in the compilation of SPPIs.

\subsubsection{Overview of national methods}

\section{Korea}

In Korea, the SPPI for waste management is limited to the collection and disposal of human, non-hazardous, hazardous and construction waste. Local governments are responsible for the collection and treatment of sewerage, although these services may be 
sub-contracted to private enterprises. Prices for waste collection, treatment and disposal are market-determined, except in the case of landfills owned by local governments, for which rates are determined by regulation.

For human waste collection \& disposal services, list prices of local governments or their licensed agencies are used. These services cover the cleaning the septic tanks of houses and buildings, and the transportation of the sludge generated, to treatment facilities. The fees for the cleaning of septic tanks are determined by local government regulation.

For business waste collection and disposal services the contract pricing method is employed. Prices are collected for the collection, treatment and disposal of general business waste, construction waste and some hazardous waste. Collection of prices for each stage of processing was attempted. However, this was not successful as contracts usually involve a single price for all the stages of processing combined.

\section{United Kingdom}

In the U.K., the SPPI for waste management covers sewerage, waste disposal and recovery of sorted materials services. Services are typically provided under long-term contract agreements where price and delivery are well-specified for a number of periods. This facilitates the use of the direct use of repeated services method. Sewerage prices are specified either per cubic meter or according a formula specified under regulation. For waste disposal services prices are specified per household, per tonne or per cubic meter.

Atypical price movements are queried with respondents by telephone. Where service transactions undergo change in quality, direct comparison, direct quality adjustment, or imputation may be employed.

\section{Bibliography}

Gac, D. (2011), SPPI on waste collection; waste treatment and disposal in France, $26^{\text {th }}$ Voorburg Group meeting, Newport, United Kingdom available at: http://www.voorburggroup.org/Documents/2011\%20Newport/Papers/2011\%20\%2046.pdf

Murphy, J. (2011), Waste management and remediation services - Turnover/output measures in the U.S., $26^{\text {th }}$ Voorburg Group meeting, Newport, United Kingdom available at:

http://www.voorburggroup.org/Documents/2011\%20Newport/Papers/2011\%20$\% 2042 . p d f$

Papa, A. (2011), SPPI for waste management, $26^{\text {th }}$ Voorburg Group meeting, Newport, United Kingdom available at: http://www.voorburggroup.org/Documents/2011\%20Newport/Papers/2011\%20\%2047.pdf 
Park, Y. (2011), SPPI for sewerage and waste management services in Korea, $26^{\text {th }}$ Voorburg Group meeting, Newport, United Kingdom available at:

http://www.voorburggroup.org/Documents/2011\%20Newport/Papers/2011\%20\%2048.pdf 



\section{Chapter 5. Wholesale and retail trade services}

This chapter presents practical guidance as well as main issues and challenges for compiling SPPI for Wholesale and retail trade services (ISIC 46-47). 


\subsection{Wholesale and retail trade services (Catherine Draper, Statistics Canada)}

\subsubsection{Industry description (ISIC 46-47)}

In general, the retailing and wholesaling industries (commonly referred to as the distributive trades sector) represent the intermediate steps in the distribution of merchandise between producers and consumers of goods. Wholesale and retail trade services are crucial to the efficient and effective flow of goods from producer to consumer.

Together the wholesaling and retailing industries account for significant portions of economic output and global employment.

- Wholesalers act as marketing intermediaries that neither produce nor consume the finished product, but instead sell to retailers, other merchants, and/or to industrial, institutional, and commercial users.

- Retailers are organised to sell merchandise (generally without transformation) in smaller quantities to the general public for personal or household consumption, and to other business and institutional clients. There are two main types of retailers: store and non-store.

Garneau et al. (2011) note that "Services Producer Price Indices for retail and wholesale trade should focus primarily on the "merchant" distributive trade services provided by establishments that purchase and re-sell goods, as measured by changes in margin prices ...".

In Canada, the SPPI program pricing methodology for the distributive trades sector is defined as the margin price per unit which represents the price of the wholesaling or retailing service. Both the wholesale and the retail services price indices strive to measure the change in the price of the service and not the price of the product. Respondents provide the purchase price and the selling price for a selected product and a margin price per unit is calculated. Margin prices represent the difference between the prices at which retailers and wholesalers purchase and sell their products. This is represented mathematically as follows:

$$
\mathrm{MP}^{\mathrm{t}} \text { unit }=\mathrm{SP}^{\mathrm{t}} \text { selling price/unit }-\mathrm{PP}^{\mathrm{t}} \text { purchase price/unit }
$$

The margin price can be used to deflate the gross margin thereby providing a measure of real output for the distributive trades sector in the System of National Accounts. Wholesale and retail services price indices can also be used to evaluate different aspects of a product value chain, for example by allowing for the measurement of value added by wholesale distribution and retailing to the final consumer. ${ }^{1}$

\subsubsection{Classification aspects}

\subsubsection{Industry classification}

In both the ISIC and NACE classification systems wholesale and retail trade services are classified under section $\mathrm{G}$ - Wholesale and retail trade; repair of motor vehicles and motorcycles including three divisions as follows:

- Division 46 comprises wholesale trade, except motor vehicles and motorcycles;

- Division 47 of retail trade, except of motor vehicles and motorcycles; 
- The wholesaling, retailing and repair of motor vehicles and motorcycles, which are outside of the scope of this section, are classified separately under Division 45 .

\section{Division 46 - Wholesale trade}

Under the ISIC classification wholesale trade is broken down into seven classes mainly according to the type of goods traded:

461 - Wholesale on a fee or contract basis;

462 - Wholesale of agricultural raw materials and live animals;

463 - Wholesale of food, beverages and tobacco;

464 - Wholesale of household goods;

465 - Wholesale of machinery, equipment and supplies;

466 - Other specialized wholesale;

469 - Non-specialized wholesale trade.

A more detailed disaggregation of classes is provided in the NACE classification.

The NAICS classifies wholesale trade under sector 41, which is broken down into nine subsectors and includes the wholesaling of motor vehicles:

411 - Farm product merchant wholesalers;

412 - Petroleum and petroleum products merchant wholesalers;

413 - Food, beverage and tobacco merchant wholesalers;

414 - Personal and household goods merchant wholesalers;

415 - Motor vehicle and motor vehicle parts and accessories merchant wholesalers;

416 - Building material and supplies merchant wholesalers;

417 - Machinery, equipment and supplies merchant wholesalers;

418 - Miscellaneous merchant wholesalers;

419 - Business-to-business electronic markets, and agents and brokers.

These subsectors are further disaggregated into a large number of industries.

\section{Division 47 - Retail trade}

In both the ISIC and NACE classifications retail trade services are classified into nine groups by type of sale outlet. These groups are further subdivided by the range of products sold or by the forms of trade in the case of sales not via stores. Again, the NACE classification provides more detailed subdivisions. The ISIC groups are:

471 - Retail sale in non-specialized stores;

472 - Retail sale of food, beverages and tobacco in specialized stores;

473 - Retail sale of automotive fuel in specialized stores;

474 - Retail sale of information and communications equipment in specialized stores;

475 - Retail sale of other household equipment in specialized stores; 
476 - Retail sale of cultural and recreation goods in specialized stores;

477 - Retail sale of other goods in specialized stores;

478 - Retail sale via stalls and markets;

479 - Retail trade not in stores, stalls or markets.

The NAICS classifies retail trade activities under sectors 44 and 45, which are broken down into twelve subsectors:

441 - Motor vehicle and parts dealers;

442 - Furniture and home furnishings stores;

443 - Electronics and appliance stores;

444 - Building material and garden equipment and supplies stores;

445 - Food and beverage stores;

446 - Health and personal care stores;

447 - Gasoline stations;

448 - Clothing and clothing accessories stores;

451 - Sporting goods, hobby, book and music stores;

452 - General merchandise stores;

453 - Miscellaneous store retailers;

454 - Non-store retailers.

These twelve subsectors are further disaggregated into a large number of industries.

A review of the different international industry classifications (ISIC, NAICS and NACE) suggests that they cover and define essentially the same activities, although there are some differences. For example, motor vehicle and parts dealers are included separately under NAICS 441 and wholesaling on a fee or contract basis (wholesale agents and brokers) is distinguished from merchant wholesaling and in-store retailing is distinguished from non-store retailing.

Store retailers operate fixed point-of-sale locations, located and designed to attract a high volume of walk-in customers. In general, retail stores have extensive displays of merchandise and use mass-media advertising to attract customers, whereas the retailing methods used by non-store retailers differ. The establishments in the non-store subsector reach customers and market merchandise via such methods as the broadcasting and publishing of direct-response advertising, electronic catalogues, door-to-door solicitation and distribution by vending machines, etc.

Issues concerning classification of activity can surface in the wholesale trade sector where it is often difficult to distinguish between wholesaling and manufacturing. This could lead to the misclassification of business enterprises. The concept of transformation is used to resolve the discrepancies between distributive trades and manufacturing. Manufacturing establishments are generally engaged in the transformation of materials into new products, whereas wholesalers are generally engaged in the breaking of bulk and/or redistribution into smaller lots. The wholesaler produces a modified version of the same product, not a new product. 


\subsubsection{Product classification}

In the CPC product classification system, wholesale trade services are classified under section 6 - Distributive trade services, accommodation, food and beverage services, division 61 - Wholesale trade services. The classification system delineates wholesale trade services into two groups according to whether the wholesaler purchases goods before selling them or negotiates wholesale commercial transactions for a fee or a commission (without taking ownership of the goods). Each of these groups is then divided into classes based on the types of goods transacted.

The CPA product classification differs slightly in that wholesale trade services on a fee or contract basis are identified as a separate group (3-digit) alongside other classes based on the type of goods transacted.

Retail trade services are classified in the CPC under section 6 - Distributive trade services, accommodation, food and beverage services, division 62 - Retail trade services. This division is split into four groups according to the type of outlet (namely; nonspecialized stores, specialized stores, mail order or internet and other non-store outlets). A fifth group provides for retail trade services on a fee or contract basis. Subclass 62281 comprises specialised store retail trade services of motor vehicles, motorcycles, snowmobiles and related parts and accessories although, as previously noted, in the ISIC classification of industry the wholesale and retail trade and repair of motor vehicles and motorcycles is classified separately under division 45.

The CPA classification differs in that it delineates retail trade services according to the type of goods sold rather than the type of outlet. No separate classification is provided for retail trade services on a fee or contract basis. Furthermore, the CPA follows the NACE and ISIC systems in respect of the classification of wholesale and retail trade and repair services of motor vehicles and motorcycles under a separate division.

Canada, the U.S. and Mexico have adopted the North American Product Classification System (NAPCS). Although NAPCS product lines are not currently used for the U.S. product-based index structure and Statistics Canada does not currently produce product indices for the distributive trades sector, product coding on a NAPCS basis may be on the horizon for retail and wholesale SPPIs in both Canada and the U.S.

\subsubsection{Scope of the survey}

The main output for retail and wholesale trade is the margin on the sale of goods within each of these sectors.

The target population for the distributive trade surveys are all establishments primarily engaged in retailing and wholesaling. For those countries following the ISIC or NACE classification systems, wholesalers and retailers of motor vehicles and motorcycles are outside the scope of the survey.

Wholesale agents and brokers, retail automobile and other motor vehicle dealers and non-store retailers are currently not in scope for the Canadian distributive trade's services price indices, but may be added at a later date. The U.S. publishes indices for wholesale agents and brokers, new car dealers, and non-store retailers under distributive trade. 


\subsubsection{Industry vs. Product based SPPI}

The U.S. publishes product based SPPIs for the wholesale and retail trades. These indices measure price for specific service products, regardless of the service provider's industry of origin.

At the time of the writing, Canada has not published retail and wholesale data at the product level. The survey is sampled at the industry level and price information is collected at the service product or product line level. However, because several industries are covered, sufficient detail is available to approximate product movements. In order to compile product level indices, it is necessary to have comprehensive weights for all of the activities in which the sampling unit is engaged. This information is currently not available for the wholesaling industry in Canada. Commodity level weights are available for retail, although their fitness-for-use remains to be assessed.

\subsubsection{Sample design}

Traditionally, most compilers adopt a 2-stage approach for designing samples that are used to collect price data for estimating a price index. Sample selection with probability proportional to size (PPS) is recommended when choosing a sample for the distributive trades sector. Sample units are selected at the 5-digit NAICS level and then further stratified based on size (e.g. establishment revenue).

Canada maintains a Business Register (BR) which is used as the sampling frame for wholesalers and retailers. The BR is the sample source for both the SPPIs and the turnover surveys. This common sampling source facilitates the compilation of comparable price and turnover statistics.

Both enterprise and establishment level sampling pose unique challenges for distributive trades. In Canada, the initial intent when designing the distributive trades surveys was to sample at the establishment level. However, the establishment level sample for the retail sector had a high degree of variability arising from the legal structure of the business entity, creating potential quality issues and implications for estimation. In some cases, major retailers were significantly over or under represented in the sample and different iterations of the same sample specifications yielded different results. The challenge of enterprise-based sampling is that there can often be multiple banners (a retail banner is a brand name under which a set of stores is operated) organised under a single enterprise.

It is important to identify the respondent enterprise's corporate structure during the initialisation process, in order to establish an appropriate reporting arrangement. Respondents may also find it difficult to aggregate price information across multiple banners to the enterprise level. This may contribute to respondent fatigue and make price collection more difficult.

In Canada, an enterprise-based resample was undertaken for the retail sample in order to minimise these issues. All establishments within a given enterprise and NAICS subsector were rolled up to determine the total revenue for that enterprise for that particular NAICS. The sampling unit from which prices are collected consists of all operations for a specific NAICS activity within the enterprise. As mentioned above, in cases of particularly large enterprises with multiple banners, caution is required to ensure that the enterprise is adequately and accurately represented in the index. 
In order to minimise the response burden imposed on smaller retailers and wholesalers and to restrict units that have a negligible impact on index calculation from entering the sample, a minimum revenue threshold can be established. Any sample units that fall below this threshold can be excluded from the target population. Subject matter experience can help reduce burden by guiding the respondent through the complexity, detail, and precision associated with reporting prices and product specifications.

\subsubsection{Collection of information and specification of the service}

\subsubsection{Timing and frequency of price collection}

In the U.S., average purchase prices (collected based on replacement costs) and average selling prices for retail and wholesale transactions are obtained on a monthly basis.

In Canada, average purchase and average selling prices for retail and wholesale are measured monthly but collected on a quarterly basis.

In Australia, sales and Cost of Goods Sold (COGS) data for a range of commodity groups to calculate retail trade margin prices are collected quarterly from retail outlets.

\subsubsection{Description of the Survey}

Respondents are asked to price select products or product lines that are representative of their business activity based on the revenue (ideally margin revenue, otherwise sales revenue) generated by these products. Ideally, the reported products should be high volume, year round sellers. In addition to the product description and specifications, the product purchase and selling prices are collected.

Respondents are requested to report for the selected products over time. Prefilled questionnaires, containing detailed product specifications and price information that was previously reported, are used to facilitate the identification and tracking of a constant quality product over time.

\subsubsection{Survey variables collected}

The main variables collected by the retail and wholesale price surveys include:

- Average purchase price: The average purchase price is defined as the cost to purchase a product/service from the supplier, excluding all taxes. In the U.S., replacement costs are used as the average purchase prices. These represent the prices that a retailer or wholesaler would pay if they were to purchase the selected products in the current period. The most recent price paid by the establishment to acquire a product from the supplier may be used as a fall-back if the respondent is unwilling or unable to identify the current period replacement cost;

- Average selling price: The average selling price is defined as the cost to the purchaser, excluding taxes and freight;

- Main reason for purchase or selling price change: Identifies the reason for a change in the purchase or selling price. Reasons can range from a change in the product, change in supplier, inflation or exchange rate fluctuations. In the U.S. this information is also obtained via phone calls to respondents; 
- Product description: Identifies specific products by name, colour or other product attribute, which can be used to uniquely identify and track the product or service through time. Other descriptors or specifications can include product code [the PLU (Price Look-Up code), UPC (Universal Product Code) or SKU (Stock Keeping Unit)]; manufacturer; size or weight; or unit of measure;

- Country of origin: If the product is imported, the country from which the product originates is identified (Canada collects this information from wholesalers only);

- Retail and/or wholesale activities: A list of activities (incidental to the sale of goods) performed by wholesalers or retailers for the services chosen. Price margins may fluctuate due to (perceived or actual) value-added by the performance of all or any of these activities.

In the U.S., in order to minimise response burden and improve the representativeness of the assortment of products that are sold, separate average purchase and selling prices per unit are collected for an entire comparable product line rather than for a single product. Comparable product lines are groupings of products sold on the same per unit basis (e.g. per unit, per package, per pound, etc.) and marketed under a similar set of conditions. However, in some cases this aggregate information is not available and single product margin prices are collected as a fall back procedure.

\subsubsection{Initialisation}

Detailed product (characteristics) and price data are required to produce high quality retail and wholesale services price indices; however it can be difficult and expensive to collect this information. This is particularly true for the distributive trade indices because they are margin indices which are often more volatile as both the sales and purchase prices may change. Additionally, since margin prices are significantly smaller than sales prices, incremental changes often cause large percentage changes (for example, an increase in a margin price from 2 cents to 4 cents is a $100 \%$ increase.) Different approaches are used to initialise respondents in the distributive trades sector:

- In the U.S., field economists identify products and collect initial margin prices, often using a personal visit;

- In Canada, personal respondent visits are expensive, limiting their use as an ongoing method for initialisation of new sample units. Furthermore, the mail out questionnaire approach did not provide the flexibility required to ensure the "right" data are collected. Consequently, specialised "initialisation unit" has been established to research and initialise new respondents on prices surveys, particularly in the wholesaling and retailing sectors. The initialisation process needs to be specific and tailored to the new units being initialised. Experience indicates that more phone follow-up interaction is needed in order for the respondent to understand the product and product specification selection method;

- In Australia, where the retail trade margins price index is under development, each selected business is initialised into the retail trade margins survey via a personal interview.

A notable issue for the initialisation process in the distributive trades sector is the variation in the types and quantities of products that potentially could be reported by retailers and wholesalers. Retailers and wholesalers carry an extremely wide and diverse assortment of products that can range from a relatively small number of unique items to 
thousands and sometimes tens of thousands of specific products. Consequently, the selection of representative products is vital. Collection of detailed product specifications is an ongoing challenge for collection in this sector as well as maintaining the integrity of the product(s) or product mix that is being reported.

When establishing a new series or identifying a product substitute, taking discount or near-zero prices should be avoided. Discount prices and prices approaching zero can cause large fluctuations in the price relative in the month that the price is first encountered and again in the month that the price reverts to normal. In Canada, margin prices close to zero are excluded from index estimation (under normal circumstances) until the product returns to its non-discount price. In the U.S., a "representative margin price" that reflects the typical margin price for the product that is discounted during the initialisation month is collected along with the average margin sale price. The "representative margin price" is a reference point that may be used as the base price for the transaction.

In the U.S., seasonal items are priced during the months they are in season. In Canada, respondents are asked to select products that are sold year round.

Closely related to the issue of seasonality, particularly for retailers, is the inclusion of high fashion items in the products being reported. High fashion items account for a significant portion of retail sales and these items are often only available for a few months before they are replaced. It is important that the respondent is able to provide a comparable product substitution with a comparable margin price serving the same market niche (for example children's clothing) in order to maintain constant quality pricing and minimise fluctuations in the margin prices.

Retailers may bundle goods and services to encourage customers to buy or commit to long-term service contracts. Often the vendor's purchase price of the product will exceed the selling price, creating a negative margin. This practice is frequently encountered for mobile phone retailers. If the margin becomes and remains consistently negative, the price has no economic meaning and the output value is zero. In Canada, items with negative margins are excluded from index calculation.

\subsubsection{Main pricing methods}

The commonly accepted pricing methodology for the distributive trades sector is the margin price per unit which represents the price of the retailing or wholesaling service. As previously noted, the retail and wholesale services PPI's strive to measure the change in the price of the distributive trade service and not the price of the product.

$$
\mathrm{MP}^{\mathrm{t}} \text { unit }=\mathrm{SP}^{\mathrm{t}} \text { selling price/unit }-\mathrm{PP}^{\mathrm{t}} \text { purchase price/unit }
$$

Products that are representative of the respondent's business activity, based on the share of total margin revenue generated are identified. Detailed specifications are recorded and prices collected and verified. The detailed specifications facilitate the identification and pricing of a constant quality product over time.

Generally, the average purchase and average selling prices that are collected reflect real transactions and are reported on a per unit basis. The reported purchase and selling prices represent an average monthly price. The margin price is then calculated from this information. Reported purchase prices should be exclusive of freight, but inclusive of discounts. Respondents are asked to continue reporting for the selected products over time. 
Margin pricing introduces a new dimension to index construction for the distributive trades sector as margin prices can behave very differently from gross sales prices (both for retail and wholesale) and must be treated accordingly.

While discounted retail prices typically reduce margins, they are legitimate prices that yield a positive return and as such should be included in the index in their correct proportion. However, prices that are set to effectively clear out unsold merchandise that no longer has any real value to the retailer or wholesaler (referred to as clearance or close-out prices) should be excluded. When clearance or close-out prices are encountered, the margin price often declines steeply and may become negative. The item drops out of the index and we must determine whether the price is a discounted or close-out price. The preferred handling would be to not accept negative prices in the first place, thus avoiding product substitution, volatility, and the downward price bias altogether.

\subsubsection{Quality issues}

There are two important issues to consider in compiling indices of constant quality service transactions. The first is "pricing to constant quality" where the focus is on pricing the wholesale or retail service to constant quality (which is determined by characteristics such as opening hours, numbers of checkouts, floor space, general ambience, temperament of staff, ease of parking, range of goods on offer, proximity to other stores etc.). The U.S. currently uses a hedonic model for the quality adjustment of services provided by one retail trade industry. The model provides estimates of quality change based on changes in numerous collected service characteristics; including total number of checkouts, hours of operation, and number of products offered for sale. While this model has been successfully implemented, its effect on the index is minimal and the associated resource costs are high. Since costs are high for minimal benefit, this method of adjusting for service quality change, while theoretically sound, is not being recommended as a best practice methodology for the distributive trades industries.

The second issue concerns the data source used to achieve trade margin pricing. Representative items (commodity/commodity groups) should be selected to enable margin prices to be calculated. Every effort should be made to ensure that changes in the quality of items sold do not influence the distributive trade indices. When an item that was being used to calculate a margin price is no longer available or representative, a product replacement, along with detailed product specifications, must be provided. An evaluation is carried out to determine if the new product is a comparable or noncomparable substitution. If the new product is retailed or wholesaled under similar conditions as the old product, then it is considered a comparable substitution and the price change is accepted. However, if the new product serves a different niche market and/or no longer has the same basic functionality, the product change is a non-comparable substitution. Where possible, the quality difference between the two non-comparable products is used for quality adjusting the margin price difference. Identification of comparable and non-comparable product replacements is a major determinant of quality change. Care must be taken to avoid introducing a non-comparable product substitute for a product after it has been given a "close-out" or "end of season" price as this can cause a downward bias in the index. Experience dictates that in order to minimise the risk of introducing a downward bias, it is preferable to find a comparable substitute whenever possible. A change in the level of service provided by either wholesalers or retailers triggers an initial attempt at valuation which can include a discussion with the respondent to see if there is some reasonable and objective value that can be assigned to the change. If this is not possible, then the alternative is to flag the change as a non-comparable 
substitution and to impute a price change for it. Some control over the quality of their product mix can be exercised by retailers and wholesalers as they are responsible for selecting the products they sell.

\subsubsection{Weighting and aggregation}

The experience of each statistical agency influences their weighting and aggregation methodologies. In Canada, the two common weighting sources for the distributive trades' services prices indices are:

- Total revenue of the sampled unit; and

- Total industry revenue (In the U.S. this is specified as the margin revenue from distributive trade activities and the sales revenue from all other activities).

Compilation of SPPIs for the distributive trades' services is a multi-stage process that includes the calculation of weights, price relatives and elementary indices; index aggregation; and imputation for missing data:

- Weights are calculated for each retail or wholesale sampling unit, usually on the basis of revenue or a combination of revenue and sampling probability;

- Price relatives are calculated for each specified service transaction. Price relatives beneath the sampling unit level are combined by geometric average. Sampling unit weights are then used to aggregate indices at a higher level;

- Margin revenues for trade activities and sales revenues for non-trade activities should be used to weight distributive trade indices;

- In Canada, a parental imputation method (use the prices movement of those units who do respond to represent the movement of those units that do not) is employed for the imputation of missing prices (see figure 5.1.). Under this method, prices are imputed using a cell mean (or parental) imputation based on the next highest level of aggregation. Thus, missing product relatives are imputed using the firm relative; missing firm relatives are imputed using a stratum index; a missing stratum index is imputed using a 5-digit NAICS index, and so on.

Other types of automated micro data imputation typically found in turnover statistics programs (donor or tax replacement) are not appropriate as they have the potential to introduce some bias to the distributive trade price indices, depending on the rate and nature of imputation. Most of the SPPI samples are relatively new and consistent reporting patterns will only emerge as collection procedures are standardised. 
Figure 5.1. Index Imputation

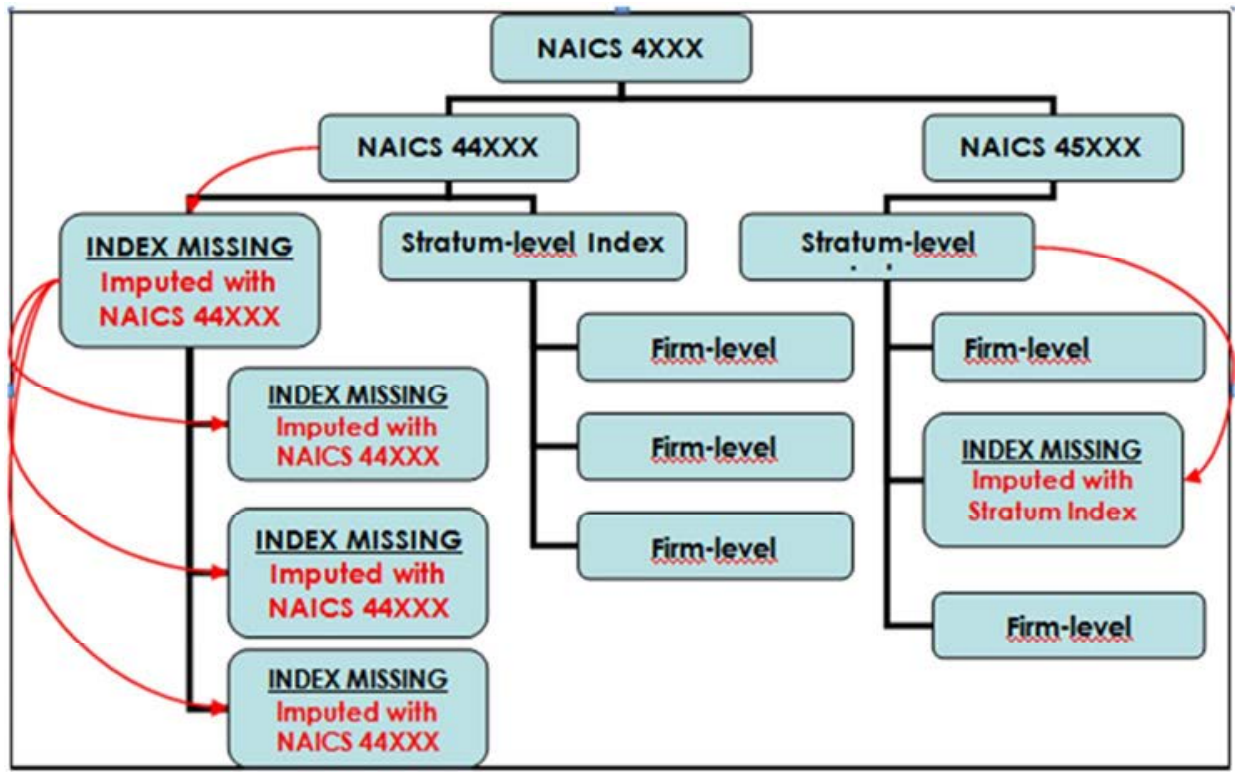

Ideally, the compiler should determine the optimal number of price observations to be collected from each respondent that will satisfy data quality standards while at the same time minimise respondent burden. Typically, if the respondent has a wide and heterogeneous product line (for example a large hardware store), then increasing the number of products for which prices are collected will improve the representative price movement. However, if the product line is narrow and homogenous (for example a timber wholesaler) then fewer products are required to measure the respondent's price change.

\subsubsection{Specific aspects}

The retail and wholesale SPPI's are important information sources for Statistics Canada's research agenda and more specifically the availability of commodity price data for the distributive trades' sector will greatly benefit the Canadian statistics program by:

- Providing a comprehensive set of indicators for distributive trades that will lead to better estimates of real output and productivity for this sector;

- Providing information on the behaviour of margin prices for wholesale and retail;

- Helping to answer questions related to the distributive trades sector in Canada;

- Providing new information source on the impact of exchange rate pass-through.

\subsubsection{Overview of national methods}

Few countries currently compile SPPIs for the wholesale and retail services. The methods described mainly reflect the Canadian and American experience. More detailed information can be found in the references cited in the bibliography section. 


\section{ANNEX CHAPTER 5 - THE PETROLEUM PRODUCT VALUE CHAIN}

Wholesale and retail services price indices can also be used to evaluate different aspects of a product value chain. For example, if we look at petroleum products which are an important commodity in terms of their economic importance to the Canadian economy, we can also see the value added by wholesale distribution and retailing to the final consumer.

The following figure illustrates the various stages of the petroleum value chain from oil and gas extraction to petroleum refining to wholesale distribution and retailing to final consumption. We can also see where the various price indices fit in this chain:

- Oil and gas extraction companies extract crude oil, which is then transported domestically via pipelines to refineries;

- Petroleum refineries transform crude oil into refined petroleum products such as gasoline, diesel, aviation fuel, etc. Refineries are generally built to serve regional markets;

- Refined fuels are stored and then distributed to wholesale terminals. The wholesale sector for distribution of petroleum products "comprises establishments primarily engaged in wholesaling crude oil, liquefied petroleum gases, heating oil and other refined petroleum products" so it also includes crude oil and natural gas;

- Wholesalers then sell auto fuel such as gasoline and diesel to retailers. The retail gasoline market is highly saturated with most service stations operating independently although they may be "branded" under a major refiner. Finally retail gasoline stations sell auto fuel to consumers. 


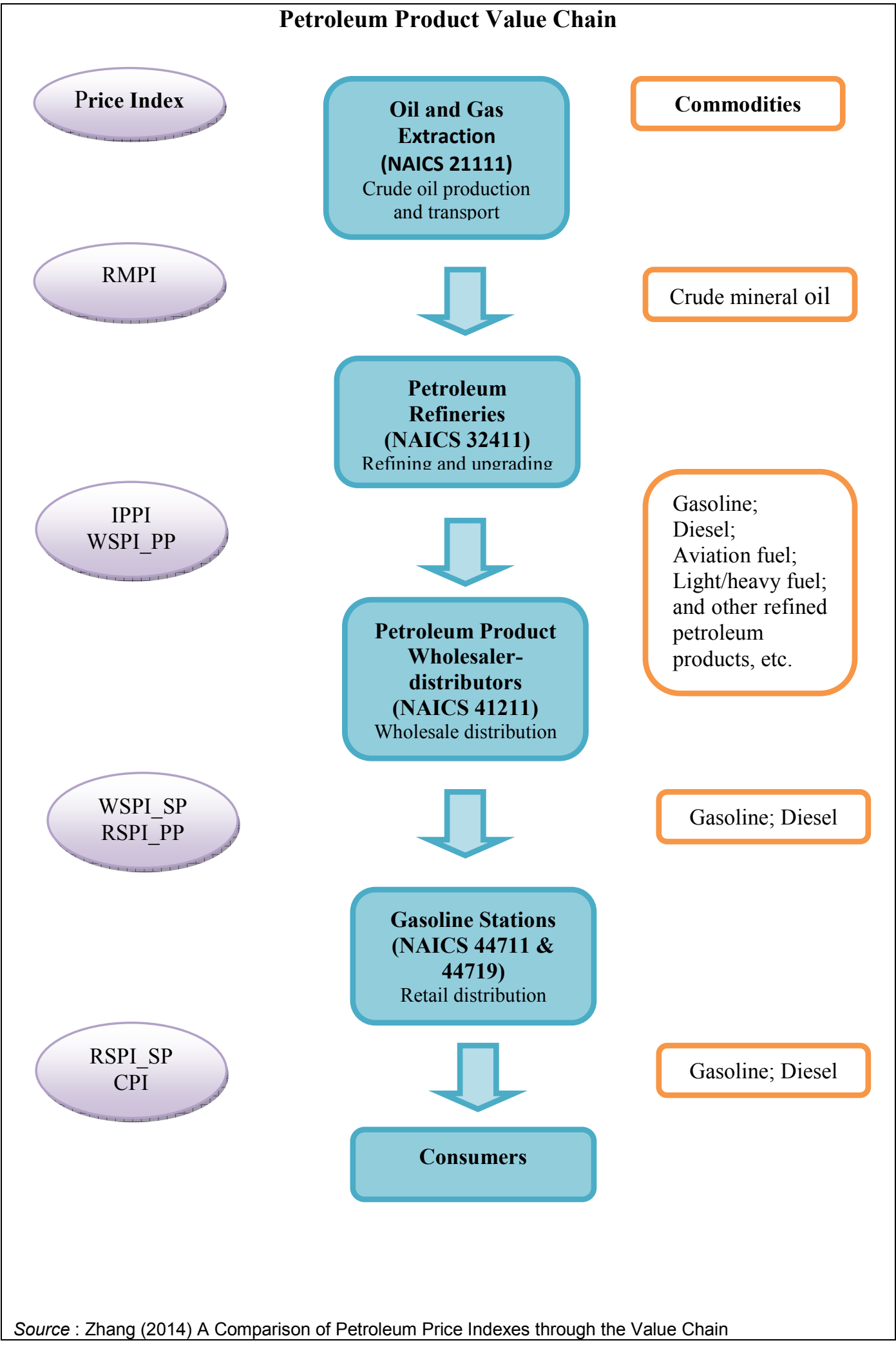


Where the wholesale and retail services indices fit in the chain:

- Raw Materials Price Index (RMPI) measures price changes for commodities purchased by manufacturers in Canada, including all charges incurred such as transportation cost, net taxes paid, custom duties and subsidies. The commodity of interest is crude mineral oil;

- Industrial Product Price Index (IPPI) measures price changes for commodities sold by manufacturers in Canada at factory gate, excluding all indirect taxes and freight. Industry PPI's are also released. PPI's of interest are for motor gasoline, diesel and the Petroleum Refineries industry;

- Wholesale Services Price Index Purchase Price and Selling Price (WSPI_PP \& WSPI_SP) measures changes in the purchase price and selling price of Petroleum Product Wholesale distributors, excluding taxes and freight;

- Retail Services Price Index Purchase Price and Selling Price (RSPI_PP \& RSPI_SP) measures changes in the purchase price and selling price of Gasoline stations, excluding taxes and freight;

- Consumer Price Index (CPI) measures changes in gasoline prices faced by consumers, including taxes.

\section{Bibliography}

Barzyk, F., (2008), SPPI for Wholesale Services in Canada. 23 ${ }^{\text {rd }}$ Voorburg Group meeting, Aguascalientes, Mexico available at: http://www.voorburggroup.org/Documents/2008\%20Aguascalientes/Papers/2008\%20 $-02019 . p d f$

Draper, C. \& Loranger, A., (2010): SPPI for Retail Services in Canada, $25^{\text {th }}$ Voorburg Group meeting, Vienna, Austria available at:

http://www.voorburggroup.org/Documents/2010\%20Vienna/Papers/2010\%20\%2067.pdf

Färnstrand, J., (2008), Turnover in the Wholesale Trade Industry in Sweden, $23^{\text {rd }}$ Voorburg Group meeting, Aguascalientes, Mexico available at: http://www.voorburggroup.org/Documents/2008\%20Aguascalientes/Papers/2008\%20\%2054.pdf

Forrest, C. (2010), Australian Retail Trade Margin Index, $25^{\text {th }}$ Voorburg Group meeting, Vienna, Austria available at: http://www.voorburggroup.org/Documents/2010\%20Vienna/Papers/2010\%20\%2069.pdf

Garneau, M.B., Kaumanns, S., Murphy, B. and Gallais, A. (2011), Issue paper on section $G$ of ISIC (Rev. 4) Wholesale and retail trade; repair of motor vehicles and motorcycles, $26^{\text {th }}$ Voorburg Group meeting, Newport, United-Kingdom, available at: 
http://www.voorburggroup.org/Documents/2011\%20Newport/Papers/2011\%20$\% 2010 . p d f$.

Gorko, J.J. and Murphy, B. (2008), Producer Price Indices for the U.S. Wholesale Trade Industries NAICS Sector 42, $23^{\text {rd }}$ Voorburg Group meeting, Aguascalientes, Mexico available at:

http://www.voorburggroup.org/Documents/2008\%20Aguascalientes/Papers/2008\%20\%2009.pdf

Kaumanns, S. (2010), Problems of measuring retail trade due to the impact of different ways of organising distribution, $25^{\text {th }}$ Voorburg Group meeting, Vienna, Austria available at:

http://www.voorburggroup.org/Documents/2010\%20Vienna/Papers/2010\%20$\% 2059 . \mathrm{pdf}$

MacDonald, M., (2010), PPD Business Process Flow, Statistics Canada, Ottawa, Canada.

Præstiin, L. \& Bolsgård, Ø., (2010), Mini presentation on the Index of Retail Sales Norway. $25^{\text {th }}$ Voorburg Group meeting, Vienna, Austria available at:

http://www.voorburggroup.org/Documents/2010\%20Vienna/Papers/2010\%20$\% 2061 . p d f$

Statistics Canada, (2001), A Guide to Deflating the Input-Output Accounts: Sources and Methods, catalogue ${ }^{\circ}$ 15F0077GIE, p. 20-21, Ottawa, Canada.

Statistics Canada, (2006), Gross Domestic product by Industry: Sources and Methods with Industry Details, catalogue $\mathrm{n}^{\circ}$ 15-548-XIE, p. 286-287, Ottawa, Canada.

Statistics Canada (2008), Guide to the Income and Expenditure Accounts, catalogue $\mathrm{n}^{\circ} 13-017$, p. 119, par. 7.43 -7.44, Ottawa, Canada.

United Nations Statistics Division (2009): International Recommendations for Distributive Trade Statistics 2008, Statistical papers, Series M, No 89.

Vizner, R. (2008), Developing SPPI for Wholesale Trade in Israel, 23 ${ }^{\text {rd }}$ Voorburg Group meeting, Aguascalientes, Mexico available at:

http://www.voorburggroup.org/Documents/2008\%20Aguascalientes/Papers/2008\%20\%2004.pdf

Zhang, S. (2014), A Comparison of Petroleum Price Indexes through the Value Chain, Statistics Canada, Ottawa, Canada.

\section{Notes}

1. A note describing the petroleum value chain is presented in the annex of this chapter as an example of how the wholesale and retail services indices fit into the product value chain. 


\section{Chapter 6. Transportation and storage}

This chapter presents main issues and challenges for compiling SPPIs for Freight transport by road (ISIC 4923), Sea and costal water transport (ISIC 5012), Air transport (ISIC 51), Warehousing and storage (ISIC 5210), Cargo handling (ISIC 5224), and Courier and postal activities (ISIC 53). 


\subsection{Freight transport by road (Christopher Jenkins and Aspasia Papa, Office for National Statistics United Kingdom)}

\subsubsection{Industry description (ISIC 4923)}

Freight transport by road is the predominant component of the freight transport industry. Business enterprises classified to this industry are primarily engaged in all landbased transport other than rail transport. The industry also includes service providers that specialise in renting trucks with drivers for road freight transport.

\subsubsection{Classification aspects}

\subsubsection{Industry classification}

On an industry basis, the various international classification systems are fairly well harmonised. Depending on the country, localised differences show up at the lower level of their respective industry classification structure. Nonetheless, there is a high degree of standardisation and integration in terms of the definition of the service being measured.

Indeed, ISIC and NACE are aligned. According to these classifications, the industry provides the efficient transportation of a wide variety of goods from source to destination, either by man or animal-drawn vehicles. These include haulage of a wide range of products, including the products of logging activities, general stock, refrigerated goods, automobiles, haulage in tanker trucks, furniture removal and transport of waste and waste materials. This class excludes log hauling within the forest, as part of logging operations (0240 ISIC), distribution of water by trucks (3600 ISIC), operation of terminal facilities for handling freight (5221 ISIC), crating and packing activities for transport (5229 ISIC), post and courier activities (5310 and 5320 ISIC) and waste transport as an integrated part of waste collection activities (3811 and 3812 ISIC).

The NAICS class 484 - Truck transportation, comprises firms primarily engaged in the truck transportation of goods. These firms may carry general freight or bulk, dry, forest or specialised freight. Specialised freight comprises goods that, because of size, weight, shape or other inherent characteristics, require specialised equipment for transportation. Firms may operate locally, that is within a metropolitan area and its adjacent non-urban area or over long distances, i.e. between metropolitan areas. Lower level industry classification focuses on long distance as opposed to local trucking, and a full truckload as opposed to less than a truckload. Whereas ISIC includes freight transport services only as a principal activity, NAICS 484 explicitly includes incidental packaging and storage services. In the U.S., these services are included in bundled freight transport transaction prices.

In a similar vein, ANZSIC 4610 consists of business enterprises engaged in the transportation of freight by road. It also includes those mainly engaged in renting trucks with drivers for road freight transport. Specifically, principal activities of this industry include delivery service, road (except courier), furniture removal service (road), log haulage service (road); road freight transport service; taxi truck service (with driver); and truck hire service (with driver).

When considering how to employ the appropriate classification systems in the compilation of the index, it is important to analyse how the industry is organised nationally. This will facilitate the identification of establishments or services within homogenous sub-classifications that can be used for the purposes of imputation and 
quality assurance. For example, establishments primarily engaged in long haul freight transport may have significantly different cost drivers and price movements to those engaged primarily in the delivery of short haul or metropolitan freight transportation. Failure to consider these factors in index compilation could lead to the introduction of biases and unrepresentative price movements.

\subsubsection{Product classification}

Unlike the industry classification comparison, product classifications are not harmonised to the same degree. The CPA and CPC classifications closely follow each other; however there are several noticeable differences when compared to NAPCS. More specifically:

- The CPA and CPC include road transport of letters and parcels (49.41.18 - Road transport services of letters and parcels and 65116 - Road transport services of letters and parcels respectively), while NAPCS places these under a different output group (492001 - Courier, parcels and local messenger and delivery services);

- The CPC has a category for freight transport by man - or animal-drawn vehicles (64334 - Road transport services of freight by man or animal-drawn vehicles) which is excluded in NAPCS for road transport.

\subsubsection{Scope of the survey}

Traditionally, the activities of business enterprises engaged in road haulage were focused on simply providing the physical means of transporting goods from point A to point $\mathrm{B}$, with a small minority having an ancillary, but less important, interest in providing storage and warehousing services for goods in transit. As a result, the task of isolating and collecting data for the total activity of contracted road freight services has been relatively straightforward with the vast majority of business enterprises being classified to 4923 of ISIC.

However, in recent years the industry structure has changed and service producers are more likely to generate a significant share of turnover from secondary activities. Increasing competition in the industry coupled with recent developments such as a shift to just-in time inventory and production management practices, have prompted business enterprises to integrate other transport-related services. In these cases, the actual transportation of goods may no longer be the principal activity. Service producers may offer clients a bundle of freight-related services, or "supply chain solutions", tailored to suit the needs of each specific client. These services may include some or all of the following:

- Freight forwarding;

- Packaging, crating, palletising and containerisation of goods;

- Cargo consolidation (groupage), management and handling;

- Stock control and re-ordering;

- Storage and warehousing;

- Transport consultancy services;

- Vehicle recovery, repair and maintenance; 
- Dealing with documentation;

- Negotiating return loads for clients' own transport;

- Information management services e.g. operating web sites linking loads to haulers and the increased use of Electronic Data Interchange (EDI);

- Courier services.

As previously noted in chapter 1, the larger the share of industry turnover generated from the provision of secondary service activities the stronger the argument for compiling product based (or approximate product based) SPPIs.

Other notable issues include the difficulty of distinguishing road freight from freight forwarding (5229 - Other transportation support activities of ISIC) and treatment of those establishments providing a range of inter-modal freight transport (see for example classes 50 - Water Transport and 51 - Air Transport of ISIC). Conceptually, the index should only capture data for pure road freight and therefore bundled services as well as the blended operations of freight forwarders fall out of scope and should be excluded. Nonetheless, in practice respondents may be unable to isolate road freight services from a bundled price containing additional logistics services and similar value added services. In Germany for example, the main providers of freight transport by road services are classified under 5229 - Other transportation support activities, of ISIC and excluding these could have a significant impact on the measurement of price movements in the industry.

In addition, subcontracting, whereby large business enterprises subcontract significant parts of their activities to other operators, is common within the road-freight industry. As previously noted in chapter 1 , sub-contracts of services should be treated in an index in the same way as any other service, irrespective of whether a service contains subcontracts or is itself a sub-contract. However, for practical reasons the subcontracted components of service activities are often excluded from price collection.

In general, the product classification of the road freight industry may be appropriately subdivided by the type of goods being transported (e.g. liquid, livestock, refrigerated etc.). As operating costs (such as fuel costs, toll charges etc.) differ across international boundaries, it is recommended that international road freight should be treated as a separate product group within the industry, so as to maintain homogeneity within product groups. It is also recommended that the ISIC and CPC classifications are used as a preliminary basis for freight transport by road. National deviations from the activities included within these classifications should be recognised and included in the national SPPI.

\subsubsection{Sample design}

As a first approach, it is recommended that probability proportional to size (PPS) sampling is applied. Options for stratified sampling, using employment or turnover as the stratification variable, may be utilised to improve efficiency of the sample by reducing variance. In selecting the appropriate sampling method, particular consideration should be given to classification issues. Indeed, because of the natural overlap between freight transport by road and other industries (such as storage and warehousing and freight forwarding), a number of road freights operators may be classified elsewhere.

Where regional variations in price movements exist, stratification by region should be applied. If national road freight is recognised to be dominated by a small number of large 
service producers, a mixture of non-probability and random sampling may be considered. This is because larger service producers are likely to offer long-standing contracts whereas smaller producers tend to be more active in the "spot hire" market (one-off contracts). Therefore, a combination of random and non-probability sampling would ensure that the leading units are always included in the sample, with the remaining units also being adequately represented in the sample.

It is also important that where possible, consideration is given to organising the sample according to homogenous establishment groups in terms of their price drivers and the nature of their work, as discussed under sub section on classification aspects. Another example might be to consider during the sample design the types of ancillary, or bundled, services that establishments provide.

\subsubsection{Collection of information and specification of the service}

The selection of service products for pricing by individual establishments should be representative of their main activities and defined and agreed with the appropriate establishment contact during the respondent initialisation process.

It is important that service specification is sufficiently detailed to ensure that a consistent price is collected from period to period, relating to the same service with the same terms of sale in each period. In an ideal situation, the following characteristics of a road freight service should also be quoted:

- Size and type of vehicle;

- Nature and weight of cargo;

- Distance of journey and/or destination;

- Routing information (distribution or joint cargo);

- Time criteria for delivery, if applicable;

- Availability of return cargo;

- Inclusion of packaging and loading/unloading services;

- Name and customer-status of the customer;

- Domestic or export category;

- Any other special conditions which might apply to the contract.

An example of a road haulage service price description is given in box 6.1.1.

\section{Box 6.1.1. Example of a service description for a price quotation for road haulage services}

- Truck and trailer 25 tonnes. From Assen to Mayer (Germany), 217 km, \pm 6.5 hours. Advance notice of 3 days.

- Excluding return cargo, including loading, unloading and reimbursement for waiting. Including German toll.

- Contract price for a fixed client $\mathrm{n}^{\circ} 10502$. Price per ton.

Source: Kirsten (2006), "The PPI for road haulage services in the Netherlands" 
However, collection of all of these attributes for every price observation provided could place an unreasonable and unwelcome burden on respondents. Therefore, a more pragmatic approach may be applied which accepts descriptions of freight services which differ from the above, but are in line with the normal business practice of the respondent. This is subject to the important proviso that the respondent is able to identify the specific contract and can supply the latest (and correct) price for that service on a regular, repeating basis. Following initialisation, respondents should be required to provide prices for the same service (as long as it remains representative), whereas any change in the service description should be noted by the respondent and the forms should be updated accordingly.

\subsubsection{Main pricing methods}

The road freight industry offers a complex variety of pricing mechanisms, which may vary depending on, for example, cargo-type (liquid, containers etc.) or distance (shorthaul, long-haul, international) etc. Within the industry, larger service producers tend to generate more turnover from repeated contract work from regular customers, while smaller producers may be more likely to operate on an ad-hoc, single contract basis. A number of different pricing methods may therefore be employed, reflecting the variety of pricing mechanisms than can be observed.

\subsubsection{Contract pricing}

Contract pricing refers to the use of prices in long term contracts for the repeated delivery of the same (or a very similar) service. This is a special case of using real transaction prices. Usually they are available for large road freight suppliers and regular customers, who negotiate discounts from the list prices through their guarantee of business volume. Respondents are asked to supply prices for the repeated delivery of the same or a very similar service in many survey periods, as set out in long-term contracts. These services should be typical and representative of the main activities of the respondent.

Contract transaction pricing places the least compliance burden on the survey respondent since the prices are relatively easy to retrieve from respondents' accounting/financial systems. The contract pricing method can be implemented such that the basic price (the per unit revenue received by the service producer, excluding taxes but including subsidies and discounts) is identified for road freight service provision. However, it is recognised that there is a potential weakness in this pricing method, as a large element of the overall market may not be fully represented, namely the one-off or spot market, where the service relates to a single journey which is unlikely to be repeated. Indeed the use of transaction prices is not suitable for smaller respondents, who compete for individual journey contracts. The transaction price is also sensitive to the volume of business that a customer can offer and it is essential that this is defined in the serviceproduct specification when using the model pricing approach.

\subsubsection{Direct use of prices of repeated services using list prices}

In the absence of actual transaction prices, list prices might also be available for use in the compilation of an SPPI. List prices are the published prices for services (usually published as rates applied, based on mileage, weight, volume and additional services) and are often used as a starting point to negotiate discounts for spot prices or transaction/contractual prices. List price collection is most appropriate for smaller road 
freight service producers and results in relatively small respondent burden. However, it does not capture the actual transaction price unless any discounts applied are known. List price collection may therefore not entirely capture price development resulting from competition in the market environment.

\subsubsection{Model pricing}

Model pricing is mostly applicable to service producers offering ad-hoc, one-off or irregular trips, such as:

- Smaller producers or those specialising on the spot markets;

- Grouped cargo where customers and payment conditions are constant overtime but the quantity and type of cargo varies;

- Transportation of heavy loads which are not repeated services.

As the compiler requires in each period a price for a standard service with constant specifications, this method allows for estimation of the price for a standardised final service product, a model transaction which is not transacted in the comparison period. The respondent may give a real transaction price in the base period and in the following periods the price is calculated as an expert estimate, because the exact same service is not being provided on an ongoing basis. If a model service is no longer considered to be representative of the typical services provided by the respondent, an alternative and representative service should be specified for ongoing pricing.

In the absence of real transaction prices, model pricing offers a suitable compromise. Model pricing can also control for quality change. This does however require a significant investment of time by the respondent and compiler to define a representative set of service models thereby increasing direct costs and compliance burden. There is also a danger, with time, that model services become outdated, which necessitates frequent monitoring of models.

\subsubsection{Quality issues}

Within the road freight industry, respondents are asked to provide details of any changes to the service provided. Furthermore, instances of unexplained price changes that are outside set thresholds (or validation gates) are checked to determine whether they have been caused by a genuine price change or a change in quality. In these cases, contact with respondents is required and explicit methods can be applied to quantify the changes that have occurred.

When a contract is discontinued or a service is no longer representative of the activity of the respondent, a replacement contract should be sought. If the service is still deemed representative but the contract has been discontinued, the replacement should be as close to the original as possible (match-models method). If the service is no longer representative then a replacement representative and repeatable service should be identified in consultation with the respondent. For the linking of the two prices, several quality adjustment methods can be applied. The preferable method is the overlap method where a price is provided for the new service in both the previous and current periods. However, if the old service stops before the new one starts, other methods can be applied, such as expert judgement and the mean imputation method.

In the U.K., a quality assurance process which monitors prices that are "too stable" is applied across a number of SPPIs. Where a price has remained static for a number of 
periods, the respondent is contacted to check that the service specification is still representative and that the price remains correct. This is even more important to carry out when model pricing is being used, so as to ensure that the respondent does not simply return the same price for a model each period.

Another important issue is that of temporarily missing products, such as the transportation of agricultural goods where prices may only be available on a seasonal basis. In Germany, an example of seasonal products is the transportation of sugar beets which are harvested between mid-September and mid-November. Price quotations of real transaction prices can only be given during these periods so for the rest of the year a suitable imputation method can be applied. Prices can, for example, be imputed by with reference to mean class imputation. Another method is to use the Rothwell price index which applies different weights for the reporting periods, so the missing product is assigned a zero weight.

\subsubsection{Weighting and aggregation}

The choice of weights to be used for weighting and aggregation depends on the availability of reliable source data. In principle, different data sources can be used, such as turnover data collected through a dedicated turnover survey, weighting data provided by an external supplier, national accounts input/output tables or a combination of the above data sources. The weighting structure below industry level will depend on the chosen classification structure, based on standard classifications and perhaps modified or extended to take account of the national organisation of the industry.

In the U.K., two sources of weights are used to aggregate the SPPI. At the elementary aggregate level, a dedicated quinquennial turnover survey of all respondents providing price data to the SPPI is carried out to collect the corresponding turnover generated for these services. This source of turnover is used to calculate elementary aggregate weights, which in turn are used to weight together the elementary aggregate price relatives to produce higher-level indices, up to and including the industry level aggregate.

At the industry level, the U.K. uses national accounts data to derive industry level weights (input/output tables). These weights are then used to aggregate the industry level price movements together to calculate a 'service sector' SPPI, although it should be noted that this aggregate is only representative of the industries which are currently included in the SPPI. This aggregate SPPI is produced on both a gross and a net basis through the adjustment of the industry weights. It should be noted that in this context, the net sector series refers to transactions between business services and other sectors excluding business services whereas the gross sector series measures transactions between business services and other sectors including business services.

\subsubsection{Specific aspects}

One of the issues that confront compilers of SPPIs for the road freight industry is the provision of bundled services. In order to respond to the increasing demand for expedited freight service, road freight service producers are increasingly providing additional "supply chain services" or "complete logistic solutions" in addition to the basic transportation services. Consequently, respondents are often unable to separate prices for pure transportation services and additional service activities such as storage and warehousing and freight forwarding. The problem of misclassification can also arise if prices are provided for inter-modal services, for which the price cannot be split between the different modes of transport. 
As previously noted, subcontracting of service provision may also create difficulties in index compilation. In addition, fuel surcharges can be an important price-determining factor, particularly in periods of rising fuel prices. Depending on how fuel surcharges are paid and collected their inclusion if often straightforward. In addition, differences in fuel costs between countries can affect prices and so the domestic or export nature of the service should be captured in the service definition.

Other common market conditions such as highway congestion, driver shortages, safety and security issues, regulation of hours worked by drivers and other legal requirements might impact on the price movements.

\subsubsection{Overview of national methods}

\section{Austria}

Austria uses the direct use of prices of repeated services method in the compilation of SPPIs for freight transport by road activities. The price collection covers domestic and cross-border transportation by different types of trucks. Price quotations for the representative service transactions selected by respondents are aggregated to form $6 \mathrm{sub}-$ indices (dangerous-, food-, tank-, silo-, building materials- and others- transportation) that are the most representative service sub-categories. These 6 main groups were selected in cooperation with the Association of freight transport. These 6 sub-indices are then aggregated to an overall SPPI for NACE 49.4 - Freight transport by road.

\section{Australia}

In Australia, non-probability sampling is employed. Initialisation interviews with prospective respondents are then conducted to assess their suitability for participation in the survey and to determine which services are most representative of their service activities.

Data is collected from respondents via mail, email or fax on a quarterly basis. Respondents are asked to provide a price for one or more of their given services. Respondents also provide reasons for reported price changes. This information is very valuable to the validation of prices. Individual specifications for repeat services on the same route or source to destination have their own weights. Weights are based on the amount of turnover of the establishment, the market segment they represent in the sample (which is established in the initial interview conducted with the respondent) and on other sources.

Basic prices including fuel surcharges are collected. The fuel surcharge is usually reported separately as fuel is a significant cost driver of price change in this industry. Respondents are required to report prices exclusive of goods and services taxes. Both contracted and non-contracted services are covered.

There are persistent issues with maintaining the quality of the index. Large establishments engaged in road freight frequently utilise other modes by substituting rail, sea or even air freight for part of the journey. Respondents are asked to separate out the road freight component where possible. Attempting to avoid quality issues by overly tightening transaction specifications might result in few or no services being performed as described in any given period. When there is a price due to a change in the modes of transport, the respondent is asked to provide either a previous period price on the same basis or estimate the change since the last pricing point. This normally occurs when the 
respondent contact has changed and there is need for some clarification as to the specific transaction to be priced.

Occasionally respondents provide inadequate reasons for a price change and further investigation and follow up is required. Contacting respondents can be difficult at times and if a query on a price cannot be resolved a new price is imputed.

Australia is not subject to the problems of import or export of road freight and the consequential differential costs of fuel between countries. However, there are differences between states in fuel excise levels, and occasional rebate schemes, which must be borne in mind.

\section{Canada}

In Canada, the survey frame is derived from the Statistics Canada Business Register which contains about 5,500 establishments in this sector. Establishments with under $\$ 1,000,000$ annual revenue were excluded from the frame. These are assumed to be owner-operators of trucks who lease themselves and their trucks out to the larger trucking companies. The units on the frame are stratified by 5-digit NAICS (48411 - General freight trucking, local; 48412 - General freight trucking, long distance; 48421 - Used household and office goods moving; 48422 - Specialised freight (except used goods) trucking, local; 48423 - Specialised freight (except used goods) trucking, long distance).

The sample is a cross-sectional design, with the sample and weighting information derived from transportation activity data obtained from the business register frame. The sample consists of trucking businesses which were selected on the basis of establishment revenue and stratified by 5-digit NAICS. Each NAICS stratum was further stratified by take-all (large units) and take-some (smaller units).

Monthly prices are collected directly from respondents once a quarter. The initialisation (or first) phase of the survey, conducted via survey forms and telephone contact, consists of identifying and collecting baseline information for typical shipment/services provided by the respondents. In the second phase and thereafter, respondents are asked to provide monthly specific shipment price information for the predetermined representative commodity groups/services offered and to identify the main reason for each reported price change.

The main pricing method employed is contract pricing. In the case of smaller sized freight carriers a mix of contract and list prices are collected. Prices are collected with reference to actual and specific contracts for the movement of goods. Respondents are asked to supply prices for specific service transactions which they consider to be typical and representative of their business for which they can provide current prices in each survey period.

When the services specified are no longer being provided or have become unrepresentative, new service transactions (and their specifications) are obtained from the respondent. In such cases an explicit adjustment is made to remove the effect of any change in quality, ensuring that we are measuring pure price change. Given the nature of the industry, frequent changes to "for-hire" trucking services specifications are not expected. Respondents are asked to provide estimates in cases where they did not provide the specific service in the selected month. Missing prices are imputed for using the average of reported prices in designated cells. Estimates are produced by calculating a weighted average of price relatives by industry, which are chained together to form an 
index series. The for-hire motor carrier freight services price index is a national index that uses establishment revenue as its weighting source.

\section{Netherlands}

In the Netherlands, almost all respondents provide prices for specific service activities on a repeated basis. Typically, this would allow for the use of the direct use of price of repeated services method of price collection. However, the model pricing method is employed as it is well suited to industries, such as freight transport by road, in which specific service transactions are not always repeated (and therefore observed) in a given period. An additional benefit to using the model pricing method is that quality issues can be easily identified. If there is a change in a specific service model, the overlap method is used to account for the difference in quality.

Prices, provided quarterly by respondents, are quality assured. Large price changes reported by more significant respondents are queried by telephone. When a smaller respondent reports a large price change, the price change is only queried if it is so large as to actually have a significant effect on the index. As a result, larger respondents are queried more often since even small changes in the prices of their services can affect the index.

\section{United Kingdom}

The U.K. SPPI for freight transport by road is split into seven main categories organised by the type of service provided: general haulage; warehousing \& distribution; tipping and construction; agriculture \& livestock; tankers; international haulage and temperature controlled transport.

Prices for freight transport by road are collected using quarterly questionnaires. Respondents are selected using a weighted stratified simple random sampling technique, where potential responders are stratified by size (employment band) and industry (according to the U.K. SIC '07 classification).

Respondents are asked to provide details of actual transactions undertaken for real clients (or for regular routes serving a number of customers with similar requirements and cargoes) as a preference. However, there are a variety of ways in which respondents set their prices and a mixture of transaction and list prices are observed. The pricing method employed is the direct use of prices of repeated services. Any atypical or extreme price changes are queried with the respondent so as to confirm that they are a genuine price change as opposed a price change resulting from a change in the quality of service defined in the contract.

\section{United States}

The U.S. publishes distinct price indices for various types of freight transport by road. These indices are differentiated on the basis of the type and amount of freight shipped and whether it is transported locally or over a long distance. During the respondent initialisation process, representative service transactions are selected and initial prices are collected through in-person visits. In subsequent periods, updated price information is provided by respondents through survey forms returned by mail, fax, or online submission. Probability proportional to size sampling (with employment as the size variable) is used to select the sample for each of the various industries.

Turnover data collected by the U.S. Census Bureau are used for index weights. Item weights are derived using sample company turnover which is obtained from the 
respondent during the respondent initialisation process, adjusted to account for accurate statistical representation of firms that were not selected in the sample.

The direct use of prices of repeated services method is employed for nearly all freight transportation by road transactions. The price for each transaction is typically set as a base rate plus a surcharge for fuel expenses, with both charges expressed on a per distance basis. In subsequent periods, respondents are asked to provide the current price for the selected transaction.

\subsection{Sea and coastal water transport (Anne-Sophie Fraisse, OECD)}

\subsubsection{Industry description (ISIC 5012)}

\section{Water transport services: recent developments}

Water transport industries play a fundamental role in globalisation, particularly as it gathers pace with the increasing international fragmentation of production. Measuring the value of water transport services, both in current and constant prices, is therefore important both for large importing economies but in particular for those economies with large maritime sectors. ${ }^{1}$

Measurement of price changes is non-trivial, complicated in large part by the organisation of business enterprises in this sector but also by the predominance of cross border trade. Therefore this Guide focuses mainly on the international dimension of water transport (water and coastal freight transport).

Water and coastal freight transport is a complex service industry that includes both short-sea and deep-sea shipping. Short-sea shipping, which should not be confused with inland water transport, is the maritime transport of goods over relatively short distances (e.g. from Lisbon to Rotterdam, Philadelphia to New Orleans). Short-sea shipping is preponderant in the European Union with $40 \%$ of the freight exchange between EU member states conducted by sea in $2010 .^{2}$ Deep-sea shipping refers to the maritime transport of goods via intercontinental routes, crossing oceans and is particularly developed in countries with large ports concentrating on intercontinental trade. ${ }^{3}$

The complexity of the industry, at least from a measurement perspective, reflects the multitude of categories of services offered. Water and coastal freight transport services are characterised either by: type of goods carried (dry bulk, chemicals; oil product, liquefied gas, etc.); mode (liner shipping, charter and tramp shipping); type of ship (oil tankers, bulk carriers, cargo incl. refrigerated, specialized cargo, Roll-on Roll-off, container ships and other ships including chemical tankers, liquefied gas carriers etc.); vessel size; and geographical regions.

Water and coastal freight transport industries are highly sensitive to developments in the world economy and international trade. In recent years, globalisation, containerisation and development of intermodal freight transport have reshaped the maritime transportation sector. The market is therefore extremely internationalised with a high level of specialisation, particularly in regions with many smaller countries like the European Union, or with large intercontinental trade activity like Asia. This is also the case, and to an even higher degree for intercontinental transport. Furthermore, the liner shipping and tramp shipping markets do not operate independently of one another. Those business enterprises active in liner shipping use, to a considerable extent, chartered vessels as an input. Each of these features of the water and coastal freight transport market can highly influence pricing. 
1. Globalisation: maritime shipping is a highly globalised industry, both in operation and ownership, with an increasing contribution made by developing countries. The contribution of various regions to world seaborne trade volumes underscores the dominance of large emerging countries: in 2010, Asia was by far the most important loading and unloading area with a share of $40 \%$ of total goods loaded and $55 \%$ of goods unloaded. Other loading areas (exports) were the Americas (21\%), Europe (19\%), Oceania (11\%) and Africa (11\%). Europe unloaded (imported) more cargo (23\%), than the Americas (16\%), followed by Africa (5\%) and Oceania (1\%). Developing countries almost entirely dominate labourintensive low-cost domains such as ship scrapping and the provision of crews. Access to cheap labour, coupled with more efficient and larger ships has led to a reduction of international transport costs; ${ }^{4}$

2. Containerisation: globalisation would not have been possible without containerisation. Container trade and major dry bulks are the main drivers in the development of seaborne trade. Since the 1990's, container trade volumes have seen a continuous expansion (containerised cargo expanded at an average rate of $8.2 \%$ between 1990 and 2010), mirrored by both the growth of containers ships and the fleet of container ships themselves. Since 2005, the dry bulk fleet has almost doubled and the containership fleet has nearly tripled. In 2010, total world containerised trade was estimated at 1.4 billion tons - an increase of around 17.6 $\%$ over the previous year. Approximately $17 \%$ of world seaborne trade in volume terms (tons) is transported in containers; ${ }^{5}$

3. Intermodal freight transportation: containerisation has also fostered the expansion of the intermodal freight transportation. Intermodal transport involves the use of two or more transport modes (ship - maritime and inland, rail and road) without any handling of the cargo itself when changing modes. Therefore, measuring price change, at least in constant quality terms, requires consideration of each of the components of the overall cost such as the transportation mode, transhipment and warehousing activities.

The use of Roll-on Roll-off cargo (Ro-Ro) has also been a key driver of intermodal transport, in particular in Europe where $14 \%$ of goods are transported in Ro-Ro units (while $12 \%$ are carried by containers). The specificity of Ro-Ro cargoes is that they facilitate intermodal transportation by design, facilitating transportation by lorry. This is in contrast to Lift-on Lift-off vessels (Lo-Lo) where cargo is loaded and unloaded by use of crane.

\section{Price determining factors and price strategies}

The price that a carrier, a ship-owner or charterer charges for transported cargo is known as a freight rate. The freight rate depends on many factors including distance covered, type and value of goods, the cost of operating the vessel (crew wages, fuel prices, maintenance and insurance), the capital costs of buying the vessel (such as deposit, interest and depreciation) and the cost of shore-side operation (which covers office personnel, rent and marketing). Freight rates are rarely all-inclusive and may be subject to numerous additions such as bunker adjustment factors, currency adjustment factors, terminal handling charges, war risk premiums, piracy surcharges, container seal fees, late fees and equipment shortage fees.

For price measurement of the freight industry sector, two main categories should be distinguished: the liner market and the tramp market. Liner shipping relates to vessels, 
primarily container ships which carry containerized cargo, between fixed ports on a strict timetable with published freight rates. Note that Ro-Ro traffic is normally liner shipping.

Tramp shipping operates predominantly on a spot market and does not have a fixed schedule or itinerary/port calls. When vessels are not chartered out on a long term basis, ship-owners and charterers, using brokers to find cargoes for their ships to carry, establish a contract to lease the vessel at individually negotiated prices. ${ }^{6}$ The service offered is therefore typically unique. The duration of contracts depends on a number of market conditions. Currently, short-term contracts of less than six months represent the majority of the total tramp shipping contracts (in 2010, they accounted for $60 \%$ having risen from $45 \%$ in 2008 and $52 \%$ in 2009). Experts assume that this is due to the current low prices and the expectation of a future price increase. On the other hand, long-term contracts of more than 24 months have tended to decline in recent years: they represented $18 \%$ of charters in 2008, 8\% and 9\% in 2009 and $2010 .{ }^{7}$ Usually the financing of very large container ships is secured through long-term leasing contracts with liner shipping companies. In comparison with liner shipping, prices for leasing of vessels are usually more volatile; this applies particularly to new leasing contracts.

\subsubsection{Classification aspects}

\subsubsection{Industry classification}

Water transport is classified in section $\mathrm{H}$ - Transport and storage, division 50 - Water transport of the ISIC classification system. It covers both sea and coastal water transport and inland water transport including a distinction between passenger and freight transport. Inland and passenger transport have relatively small weights in most countries and so SPPI compilers mainly focus on sea and coastal freight water transport. Furthermore, because passenger water transport is typically consumed by households, price movements for these services are usually captured in the CPI: ${ }^{8}$ Sea and coastal freight water transport (as defined by the ISIC classification) includes:

- Transport of freight overseas and coastal waters whether scheduled or not;

- Transport by towing or pushing of barges, oil rigs.

A review of other international classification systems by activity (NACE, NAICS and ANZSIC) shows a good concordance with the ISIC classification (see annex A). It should be noted however that the ANZSIC classification does not distinguish between sea and inland water transport.

\subsubsection{Product classification}

The corresponding products for ISIC 5012 - Sea and coastal freight water transport are classified in classes 6521 - Coastal and transoceanic water transport services of freight and 6602 - Rental services of water vessels with operator of the CPC. They are defined as follows:

- 65211 - Coastal and transoceanic water transport services of freight by refrigerator vessels. This subclass includes coastal and transoceanic water transportation of frozen or refrigerated goods in specially refrigerated compartments;

- 65212 - Coastal and transoceanic water transport services of freight by tankers. This class includes coastal and transoceanic water transportation of crude oil in 
special tankers and other bulk liquids or gases such as natural gas, methane and refined petroleum products in special tankers;

- 65213 - Coastal and transoceanic water transport services of intermodal containers by container ships. This subclass includes coastal and transoceanic water transportation of individual articles and packages assembled and shipped in specially constructed shipping containers designed for ease of handling in transport;

- 65219 - Other coastal and transoceanic water transport services of other freight. This subclass includes coastal and transoceanic water transportation of letters and parcels on behalf of postal and courier services; dry bulk goods such as cereals, flours, cement, sand, coal; towing and pushing services on the high seas and on coastal waters and towing services for oil rigs, floating cranes, dredging vessels and buoys, as well as ships' hulls and incomplete vessels, on coastal waters or the open sea;

- 66022 - Rental services of freight vessels for coastal and transoceanic water transport with operator. This subclass includes rental services of all types of selfpropelled freight vessels for coastal and transoceanic water transport with crew, such as tankers, bulk dry cargo vessels, cargo and freight vessels, tugboats and fishing vessels.

The CPA (as shown in annex B) is consistent with the CPC but provides a more detailed breakdown with a finer description of the type of cargo carried.

The NAPCS classification system used in North America provides a more detailed description of products for sea and coastal freight water transport by type of cargo (bulks liquids, bulk gases, dry bulk, automobiles, truck, livestock and waste), and type of vessel (such as tank containers, intermodal tank containers, cargo, tankers). The NAPCS (Canada) for 483002 - Water freight transportation services is defined as follows:

- 483002.1 - Transportation of bulk liquids and bulk gases in intermodal tank containers by water;

- 483002.2 - Transportation of bulk liquids and bulk gases, except in intermodal tank containers, by water;

- 483002.3 - Transportation of dry bulk, except in intermodal containers, by water;

- 483002.4 - Transportation of climate-controlled boxed, palletized and other packed goods, except in intermodal containers, by water;

- 483002.5 - Transportation of boxed, palletized and other packed goods, not climate-controlled, not in intermodal containers, by water;

- 483002.6 - Transportation of climate-controlled intermodal containers, n.e.c., by water;

- 483002.7 - Transportation of intermodal containers, not climate-controlled, n.e.c., by water;

- 483002.8 - Transportation of automobiles and light-duty trucks by water;

- 483002.9 - Transportation of livestock by water;

- 483002.10 - Transportation of waste by water; 
- 483002.11 - Transportation of other goods by water;

- 483002.11.1 - Transportation of truck trailers by water;

- 483002.11 .2 - Transportation of all other goods by water.

\subsubsection{Scope of the survey}

The ideal survey would track constant quality price change for the full range of output to all end users (such as business, household, exports and government etc.). Business customers, either resident or non-residents are the main clients of water freight transport providers and, as such, the survey could be produced on a business-to-business basis capturing separate prices for resident and non-resident clients.

The inclusion in the SPPI of establishments categorised under transport of towing or pushing of barges (included in class 5012 of ISIC) may not be necessary where they are small and unlikely to have a significant impact on the overall price index.

The collection of price data for non-scheduled freight water transport, either tramp time or tramp trip, is likely to prove difficult and resource intensive. A pragmatic decision to cover only liner shipping may therefore be appropriate, on the grounds that the contribution of non-scheduled freight water transport is of little importance and/or the price changes recorded in this sub-sector may follow price changes in non-scheduled and one-off shipping services, even if the actual prices differ. However, considerable care is necessary in using this assumption, as the experience in some countries (see below for Sweden) suggests that it may not always hold.

It is also important to bear in mind the notion of residency: the residence of the business enterprise is determined from its base of operations, rather than the point of delivery. ${ }^{9}$ In other words, the activity of the service producer is attributed to the economy in which it is resident.

\subsubsection{Sample design}

Sampling design requires decisions on sampling techniques, sampling frames, sampling structures, sample allocation between strata and methods for reducing nonsampling errors.

For liner shipping, there are typically only a small number of dominant service providers. These units should, as a rule, always be covered in the survey with smaller units selected by sampling based on turnover or number of employees. Sample rotation is advisable among smaller units in order to limit the length of time they remain on the survey panel. Rotation keeps the sample up to date and helps to alleviate the problems caused by sample depletion. Indeed, shrinking markets (in terms of the number of service providers and/or overall activity of the sector) may lead to a loss of respondents over time so the sample should be reviewed at regular intervals.

For tramp shipping, it is advisable to distinguish between one-way freight and time charter ${ }^{10}$, between small and large ships, and also between types of ship (freight) namely dry bulk, tankers and container vessels. Distinguishing between small and large ships helps to identify short sea and coastal transporters from long distance sea transporters. In the case of Sweden for example, the short sea and coastal transporters refers to freight transported in the Baltic Sea and the North Sea (a regional market with its own price developments). Long distance transports can be performed anywhere in the world and 
prices are set on the world market. The distinction between dry bulk and tanker is recommended as the price development in these two markets can differ.

Samples from service industries are usually drawn from business registers using probability proportional to size, cut-off sampling or stratified sampling. It may however be advisable in some cases (e.g. when business registers do not differentiate between establishments operating in passenger transport and those operating in freight transport), to combine business registers with data from other sources like trade institutes and representative associations. For tramp shipping in particular, prices can be collected directly from shipbrokers. In Sweden for example, much use is made of these networks (brokers and the Swedish Ship-owners' Association).

The size of the sample can vary considerably between countries according to the structure and size of the market. For example, in Germany, 600 price quotations for liner shipping and Ro-Ro services are collected from 30 respondents while 560 prices are collected for the U.S. SPPI. Norway and Singapore both collect 300 prices quotations per period. On the other hand, in Poland only 14 price quotations are collected. A number of countries collect on average between 30 and 70 price quotations per period. In the Netherlands, 129 price quotations are collected from 27 respondents. ${ }^{11}$

\subsubsection{Collection of information and specification of the service}

The selection of products for price collection should be conducted in consultation with each respondent so as to ensure that they are representative of the service activities provided. Information on the main transport activities of establishments may come from transport statistics or from commercial sources. Most prices are collected directly from the service producers. Some additional sources can also be used: e. g. Australia uses data from other government agencies; Germany (only for Ro-Ro) and Norway collect data from the Internet and, as already mentioned, shipbrokers can also be a source of price data.

The choice of whether or not to include non-scheduled water freight transport will greatly influence the way in which the price collection is organised.

Particular services are specified in as much detail level as possible, taking into account the following parameters:

- Origin and destination of the transport;

- Type of freight;

- Weight or volume for non-containerised cargo;

- $\quad$ Size and type of container (general, dangerous, refrigerated);

- Type of vessel (general, dangerous or refrigerated);

- Need for additional services (loading/unloading, storage etc.).

Ideally, non-water freight component prices that are bundled together with the transport service should be collected separately and excluded from the price of the water freight transport. On the other hand, fuel surcharges pose a specific problem when collecting prices. It may be advisable to collect fuel surcharge prices separately (as is done in Australia and Germany).

It is essential that during the respondent initialisation process detailed information is collected to ensure that specific service transactions can be priced to reflect constant 
quality in subsequent periods. It is advisable to organise personal interviews and provide tailored forms during this process. Once the base specifications have been agreed with respondents, collection of prices can be conducted on a regular basis, usually quarterly. Note however that tramp market prices can be updated on a more regular basis as is the case in Sweden where tramp market prices are collected weekly.

Any notable changes in the price or collection need to be checked with respondents to identify the reasons for change. Where a change in price has been caused by a change in service specification, the appropriate quality adjustment is carried out to ensure the service remains representative and at a constant quality.

\subsubsection{Main pricing methods}

The most commonly used pricing method is contract pricing, where the survey aims to capture prices of scheduled transport services, namely liner shipping. An alternative is the use of model pricing which is of particular relevance for tramp shipping.

\subsubsection{Liner shipping: contract pricing}

Contract pricing is the appropriate method when long-term prices for the repeated delivery of the same or very similar services can be observed. The survey should, where possible, collect actual prices including price reductions (i.e. not list prices) for transport of the same cargo between the same origin and destination, repeated on an ongoing basis for a set of regular clients. Surcharges for the client (e.g. fuel adjustment factor, port charges, war risk) should be included.

Contract pricing is commonly used for liner shipping services that operate vessels between fixed ports on a strict timetable. Difficulties may arise in cases where liner services are operated by a group of establishments, such as an alliance or consortium, which may share costs and revenues. However, in these cases the underlying principles for measuring price change remains the same.

\subsubsection{Tramp shipping: model pricing}

For non-scheduled transport, either tramp time or tramp trip, the model pricing approach is the appropriate pricing method. In practice, compilers often use market data (estimates from shipbrokers ${ }^{12}$ and international indices ${ }^{13}$ ) to estimate price trends on the tramp market. The use of market data in this instance follows the model pricing method as brokers supply an estimate of what a certain transport would cost if it was carried out. This differs from conventional model pricing in that the estimate is not made directly by the service provider. International indices are compiled from data supplied by panels of shipbrokers, ship-owners and charterers, but can still be considered as a form of model pricing.

\subsubsection{Quality issues}

Precise specification of sea and coastal water transport is necessary and must be kept constant over time. As in another transportation services, advances in technology and logistics, which may impact on prices, must be identified and appropriately dealt with. The volatility of surcharges can also have a considerable influence on price development over time.

The most common method for treating quality changes is the overlapping method. The second most common quality adjustment method is the comparable replacement 
approach. The U.K. uses a "with specification change" mechanism which revises the base period price but does not reflect a price change in the index. This is equivalent to the "linked to show no price change" method.

\subsubsection{Weighting and aggregation}

The sources of weight data vary between countries. Most countries use data from annual surveys such as structural business surveys, annual sectoral surveys and annual surveys of services for transport services. In some countries, weight data are collected using a specific SPPI survey. Australia and Netherlands use national accounts data (in the Netherlands these are combined with data collected in the SPPI survey). In Germany, turnover is estimated by multiplying price data (from the SPPI) with transportation performance data (tonne $\mathrm{km}$ ) collected for transport statistics. ${ }^{14}$

\subsubsection{Specific aspects}

The increasing share of container transport must be considered. However, a definite allocation of container freight in terms of product classification is not always possible. The index structure should therefore mainly focus on traffic routes, i.e. principle origins and destinations. A distinction by different types of goods carried is advisable only at the second level, where this information is available.

An important issue when measuring price change in the sea and water freight transport industry is price fluctuation on the tramp market. Given that the collection of price data for tramp shipping is likely to prove difficult and resource intensive, it may be advisable to concentrate price collection and measurement on liner shipping only.

Many transport services are sold as a "package" together with other services like freight forwarding and storage, or combined with other transport modes. In these cases, it can be difficult to identify a price for the actual sea and coastal water freight transport component. Care should be taken to ensure that a price index that includes elements of these bundled packages should align with the recording of the output as measured in the national accounts industry statistics.

\subsubsection{Overview of national methods}

Most services within this industry constitute international transportation. This international dimension is complicated by the fact that the residency of the service producer is not necessarily related to the ports from which any particular ship may operate. For example, Panamanian service producers (can) tender for exactly the same services as British and Indonesian producers. However, this additional complexity can provide a mechanism to assure the quality of national SPPI estimates. The high degree of international competition in the market and the flexibility with which different operators are able to provide services irrespective of their residence means that SPPIs across different countries should at least, broadly, align especially over the medium to longer term.

\section{Hong Kong}

Hong Kong is well known as a major international maritime centre and has maintained its position as one of the world's busiest container ports. An SPPI is published for maritime transport as a whole covering both sea passenger transport and sea freight transport. A separate SPPI for sea freight transport services only is not published. 
Producer prices for sea freight transport services are compiled as quarterly averages of actual transacted prices net of any discounts, premiums, rebates or allowances given to buyers, but including surcharges. Respondents provide price data for their most representative transport services based on stable and continuing transactions. These data should also be readily available to the respondent. These data should also be readily available to the respondent. Respondents are also asked for the total amount of business receipts of sea freight services plus receipts in respect of individual major services, and receipts for prominent product items of major service products.

Data are collected through the quarterly survey of service industries. The survey is based on a stratified sample of establishments engaging five or more persons. A rotational replicate sample design is adopted. Every year about one-third of the sample is rotated out and replaced by newly selected establishments.

\section{Germany}

Since 1970, the German Statistical Office has compiled monthly price indices for sea freight transport. Due to the lower economic importance of inland water transport, no official price indices for that industry are compiled. In 2003, the compilation of a separate index for tramp shipping was abandoned due to the low quality of data and the high burden of the survey. In 2006, the scope of the index was extended to cover sea and water transport as a whole as a consequence of the EU regulation on short-term statistics and data collection was extended to Ro-Ro and passenger transport.

Since 2006, the index has been compiled on a quarterly basis although prices are collected monthly. Monthly collection is necessary in order to take account of the high volatility of prices including surcharges and changes of currency exchange rates.

The main pricing method employed for liner shipping is contract pricing while for Ro-Ro shipping and passenger transport the direct use of prices of repeated services (tariff) is used.

For liner shipping, freight rates are collected monthly through a sample of 20 reporting units (shipping companies, ship brokers and agencies) for a representative selection of traffic relations and important goods.

Freight rates are calculated for each type of service with regard to a specific traffic route on a peer-to-peer basis. The objective is to capture the effective freight rate (i.e. including discounts etc.) for a total of 117 traffic routes. These routes, combined with different types of goods, give rise to 672 price observations. Detailed transport statistics (mainly physical data) and the Federal National Bank survey on "Revenue and expenditure of the German maritime shipping" are used in the calculation of the weighting structure. Additional modelling was required to convert physical data into monetary amounts for the purposes of calculating the weights.

The index of sea freight rates is divided into homeward-bound and outward-bound services. An additional regional breakdown of the index by the four traffic routes of Europe, Africa, America, and Asia/Australia is available.

The price collection for tramp shipping was discontinued in 2003 due to quality issues. In light of the difficulties in estimating the real development of sea and coastal shipping during the economic crisis of 2008 and 2009, it has become obvious that this gap in the SPPI for sea and coastal shipping has to be closed. During 2013, German compilers worked on developing a reliable picture of the relative importance of the various maritime shipping sectors. Based on this analysis it may be possible to develop a 
weighting scheme that allows for the compilation of a SPPI that utilises all the available market data (estimates from shipbrokers and international indices) in an appropriate manner.

\section{Sweden}

The Swedish water transport market mainly consists of sea and coastal transport. Sea and coastal water freight transport represents $99.6 \%$ of the turnover for freight water transportation, and $65.4 \%$ of the turnover for all water transportation (passengers and freight). The Swedish SPPI covers NACE 50.2 - Sea and coastal freight water transport, with the assumption that prices on the inland transportation market - representing $0.25 \%$ of the water transport sector's turnover in 2007 - follow price movements on the sea and coastal market. Passenger water transport is covered in the CPI and is not included in the SPPI.

The sea freight market for Sweden is international and there are several submarkets which employ different pricing mechanisms. The tramp market is dominant in terms of volume of international shipping. Line cargo shipping, in which traffic is mostly carried out by large container vessels that service particular ports, is the second largest submarket. There are numerous Swedish sea and coastal freight transport establishments but the industry is dominated by a few large ones.

The Swedish SPPI covers both liner shipping and tramp shipping. Tramp market prices are collected from shipbrokers that can provide a good overview of market prices given the role they place in the functioning of the market. Prices were initially collected on a quarterly basis but this proved problematic as prices on the tramp market are volatile, especially in the one-way freight market segment (a spot market) and a price quote at a given point in time could be unrepresentative of price development over the entire quarter. Prices are now collected weekly in order to ensure their representativeness.

When liner shipping functions as a "bus line" (where the exact route is sailed very frequently and anyone can buy the transport service) the direct use of prices of repeated services pricing method is used. List prices are collected for different kinds of standard transports. Note that in Sweden this kind of traffic is usually short-distance.

Where a ship-owner signs a contract with a customer, usually a producer of some kind of goods, to sail according to a fixed schedule during a settled period of time, contract pricing is used.

\section{United Kingdom}

The U.K. index for sea freight services is split into three main categories: coastal (domestic); near sea (Europe); and deep sea (rest of world) which have weights of $60 \%$, $2 \%$ and $38 \%$ respectively. Prices for sea $\&$ coastal water freight transport are collected using quarterly questionnaires. In selecting the sample, a weighted stratified simple random sampling technique is applied; where potential respondents are stratified by size (employment band) and industry (SIC '07 classification). Turnover data for sea \& coastal water freight transport are collected using the service turnover survey (STS).

Prices are collected either from existing ongoing contracts or using tariff rates (including discounts) charged to U.K. businesses for scheduled services on specific trade routes. The price of specific services for this industry is determined by the volume of goods and the final destination. As with the other freight industries, one-off services and regular services for repeat customers are provided. Currently 25 prices are collected from 9 respondents. 
The direct use of prices of repeated services pricing method is employed. After prices are collected, any atypical or extreme measure is queried with the respondent. This is to confirm that price movement is real, rather than resulting from change to the quality of the service defined in the contract.

\subsection{Air transport (Christian Puchter, Statistics Austria)}

\subsubsection{Industry description (ISIC 51)}

The air transport industry has become increasingly liberalised in recent decades. The liberalisation process began in the late 1970's in America and around the mid 1980's in Europe as a result of legislative change. Large airlines and strategic alliances increase their market influence and enlarge their network capacities through mergers with national carriers.

The air transport service industry may differ in size across countries, but in the majority of cases the industry is quite similar in nature. That is, a small number of large establishments provides almost all passenger air transport services, with smaller establishments providing other kinds of air transport such as air taxis and air sightseeing.

The variety of prices and offers for air transport tickets has increased as the industry has deregulated. Airlines attempt to maximise their income through use of computerdeveloped pricing mechanisms called yield management systems (YMS). These systems are based on the assumption that different consumers are willing to pay different prices at different times for the same service. Consumers who buy their tickets in advance benefit from cheaper ticket prices but may have to accept ticket restrictions and consequential extra fees for changing the ticket specification (e.g. rebooking). Conversely, consumers (perhaps business travellers) who buy their tickets closer to the date of travel are willing to pay higher prices in order to get a ticket instantly and to benefit from higher flexibility.

In recent years a number of new, mostly small, air carriers have entered the market offering lower air fares (the so-called "low-cost carriers"). These carriers compete with both existing airlines and other transportation systems in general. They can offer cheaper ticket prices by using second best airports in urban centres, maximising the daily operating time of their planes and crew and perhaps by paying lower wages and benefits for their staff.

Air transport services cover passenger air-, freight air-and space transport. However, space transport is generally not covered in SPPI compilation. Both passenger and freight flights are often sub-divided by scheduled and chartered flights.

\subsubsection{Classification aspects}

\subsubsection{Industry classification}

In the ISIC, division 51 - Air transport, is split between passenger and freight air transport. Space transport, renting of air transport equipment and general aviation are included as supplementary groups. The same differentiations apply to ANZSIC and NACE.

Only NAICS distinguishes between scheduled and non-scheduled air transportation, as was the case in earlier versions of NACE and ISIC. 


\subsubsection{Product classification}

According to the CPC classification the corresponding activities for air transport services include:

- Passenger air transportation on regular routes and on regular schedules; transportation of passenger baggage and other items that may be carried at no extra cost;

- Passenger air transportation on a non-scheduled basis supplied in aircraft of any type; sightseeing services and air taxi services by helicopters; transportation of passenger baggage and other items that may be carried at no extra cost;

- Transportation of letters and parcels by air on scheduled and non-scheduled flights;

- Air transportation of individual articles and packages assembled and shipped in specially shipped containers designed for ease of handling in transport; air transportation on freight not elsewhere classified;

- Space transportation services; launching and placing of satellites in space; services provided by space laboratories;

- Rental and leasing services of freight- or passenger-carried aircraft of any type and for any purpose with crew.

Table in annex B illustrates the appropriation of CPC codes to the corresponding ISIC codes.

\subsubsection{Scope of the survey}

As noted in chapter 1, SPPIs should comprise of prices for the provision of services to all institutional sectors, financial and non-financial corporations, government units, and non-profit institutions (NPISH), households and the rest of the world. In practice, it is often difficult to separate prices charged to different end-users of air transport services and compilers may instead calculate a single PPI covering all end users.

Air transportation of freight and space transport, where significant, should be included in the scope of the SPPI. However, it appears that in a considerable number of national indices the scope is limited to transportation of passengers only. A survey of 28 EU countries in 2010 found that approximately one third exclude freight transport services, and more than one half explicitly exclude space transport from the calculation of SPPIs for the air transportation service industry. Many countries also exclude both nonscheduled and charter services.

\subsubsection{Sample design}

The sampling frame should comprise of all producers of air transport services and business registers are normally considered a reliable source of data. It is important to ensure that establishments specialising in providing air-freight services are included in the frame. Generally, the frame could be stratified by sub-sector (for example, according to the CPC classifications presented above) or size using turnover or employment as a size variable. In theory, any available probability based sampling strategy can be used. In practice, due to the size and structure of the industry, with small numbers of large establishments dominating, stratified probability proportional to size sampling or non- 
probability sampling are more likely to be employed. Rotating samples may only be required in countries with a large number of small to medium establishments in the air transport sector, as all large establishments can be included.

\subsubsection{Collection of information and specification of the service}

Quarterly or monthly prices may be collected via establishment surveys and/or directly from airline websites. If passenger airfares are included in the national CPI, data may be shared between the surveys in order to minimise respondent burden.

As is the case for a number of other service industries, relevant data may also be provided by a national regulatory authority. Compilers may be able to minimise the costs for data collection and respondent burden in respect of freight transportation services by using data compiled by the International Air Transport Association (IATA).

Irrespective of the mode of data collection, it is important to have well trained staff and an on-going program of review of sampled prices to ensure they remain representative of both the services produced and the development of prices in the market.

It is also important that representative services for on-going pricing are as well specified as possible. Among EU countries, the most commonly used price determining characteristics for air transport are: ${ }^{15}$

- Passengers:

- Destination/route;

- Distinction business/economy;

- Fare type;

- Time of reservation;

- Type of connection.

- Freight:

- Destination/route;

- Type of good;

- Weight;

- Speed of delivery.

\subsubsection{Main pricing methods}

The direct use of prices of repeated services, the unit value method and the model pricing method appear to be the most appropriate pricing methods for this industry.

The use of the unit value method is becoming the preferred method under the prevailing yield management practice in the airline industry. The model pricing method may also be employed but it involves more burdensome data collection.

Innovations in the yield management systems allow airlines to observe real-time vacancies for each scheduled flight and to change their price quotes more dynamically in order to maximise profit. These innovations create challenges for compilers. For example, ticket prices for the same flights (and flight class) can vary significantly depending on the timing of the ticket purchase. 


\subsubsection{Direct use of prices of repeated services}

The direct use of prices of repeated services is one of the more appropriate pricing methods for passenger air transport services. Representative flights, covering destination and ticket characteristics (such as fare class, luggage allowance and travel flexibility, should be selected. The timing of the fare purchase (for example 30 days before date of travel) should also be specified and held constant as this can have a very significant impact on price. This will allow for the collection of prices for constant quality services.

\subsubsection{Unit value method}

The unit value method is also employed; primarily in response to the difficulty in pricing constant quality services sold under yield management systems. If airlines are willing to cooperate, average prices for representative routes and tickets can be surveyed for business and economy class tickets. The unit value method can also be employed for air freight transport. As in the case of passenger air transport, representative modes of transportation and destinations for air freight transportation should be selected. Additional price relevant characteristics of the services should also be defined (for example; kind of good transported, type of transport container, speed of delivery) in order to form homogeneous subgroups which are essential for the calculation of constant quality unit values. A homogeneous subgroup, and accordingly the resulting sub-index, should be constructed of services with almost identical price determining characteristics.

\subsubsection{Model pricing}

It may not always be possible to secure satisfactory cooperation from airlines. In such a circumstance, the model pricing method may substitute for the unit value method. In applying this method, the compiler is first required to identify as many key conditions relevant for yield management as possible. Suppose for example, that the compiler identifies two relevant conditions; then, the compiler should collect a two-dimensional vector of price quotes either directly from the airlines, or from their websites. The weighted average of these price quotations is regarded as a model price which approximates the unit value price. However, this method is burdensome when there are a large number of key conditions for airlines' yield management and/or the set of key conditions changes frequently.

\subsubsection{Quality issues}

It is not always clear as to how compilers should deal with changes in the characteristics and pricing structure of fares and services. Changes in pricing structure are often accompanied by changes in the quality of the service such as the introduction of charges for meals, changes to booking conditions, duration of tickets and changes to the quantity of free baggage allowed. Jenkins and Puchter (2011) examine the issues arising from quality changes in air transportation, including several clear examples of quality changes and their impacts on index development. They favour the use of the production function of the service producer rather than the utility function of the consumer as the basis for quality adjustment. However, an internationally agreed approach to these issues, as well as for the appropriate treatment of frequent flyers programs, has not yet been found. 


\subsubsection{Weighting and aggregation}

As previously noted, at the first stage of the compilation of an SPPI for air transportation a distinction should be made between passenger and freight transport. Fortunately, in most cases data for the two sub-indices can be collected from the same respondent.

Figure 6.3.1 serves as an example of a possible aggregation structure for an overall SPPI for air transportation. The first distinction is made between passenger and freight transport. At the next level of sub-indices further differentiations can be made between destinations (passenger transport) and different types of transportation (freight transportation). At the next lower level of the aggregation structure, various ticket types per destination (passenger transport) and several important freight routes (freight transport) have been chosen. The examples of "business destination 1" and "freight type cool" illustrate how disaggregation can be made. These disaggregations should be applied uniformly for all destinations and freight types covered in the example.

Figure 6.3.1. Example of an aggregation structure for an SPPI for air transport services

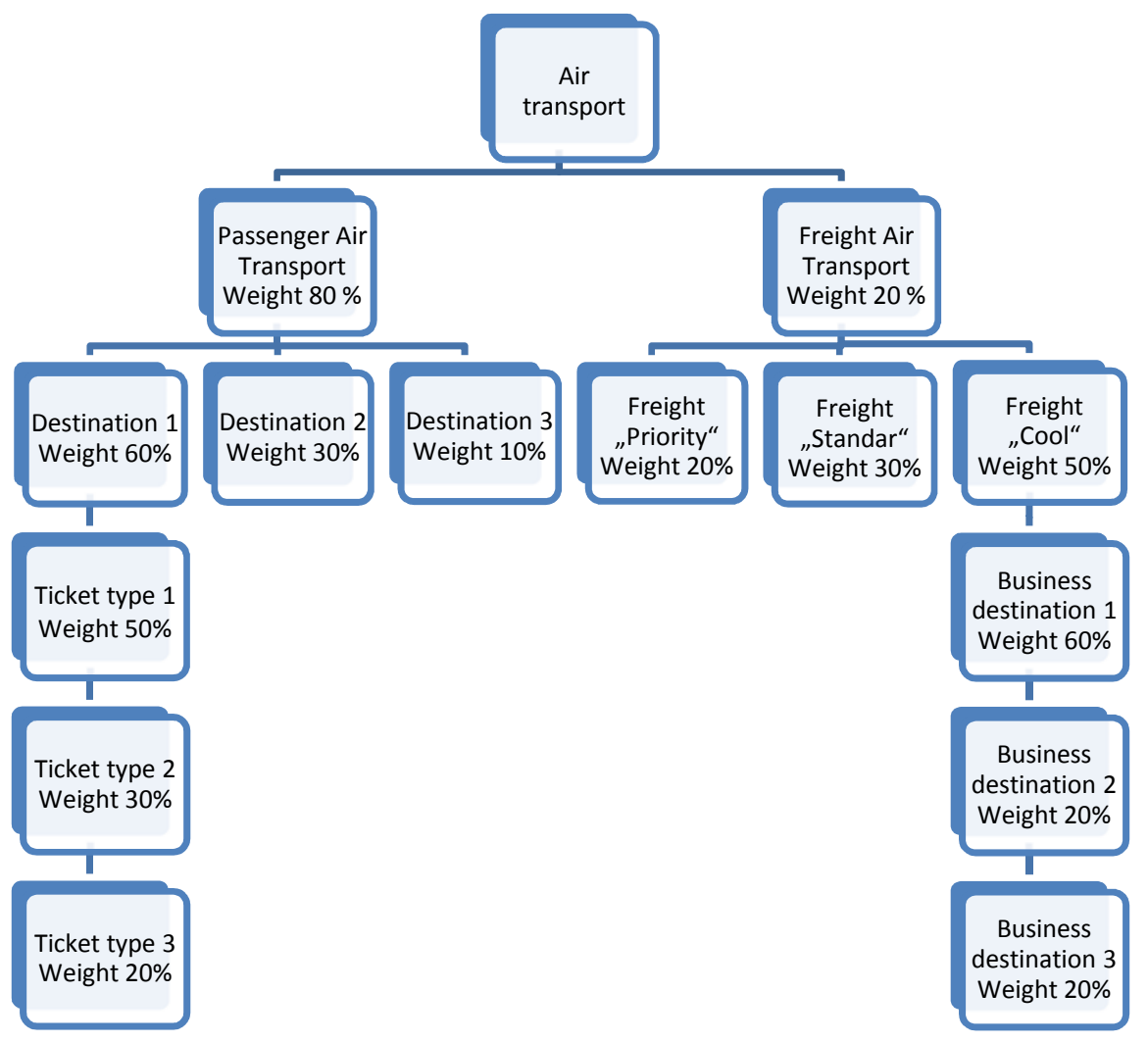

The example also shows possible available weighting information based on turnover information. Such information could be generated by respondent accounting systems. It should serve as the starting point of the index development process in that it can be used to select the most representative services for an SPPI for air transport. Using a Laspeyres 
type index, the weighting structure and the representative services for on-going pricing, should be updated at least every five years.

The design of the index aggregation structure will depend on the availability of data and the willingness of the respondents to cooperate. For example, if it were possible to obtain further weighting information in regard to the status of the traveller (business, government, and consumer) for the aggregation structure presented at figure 1, it would be possible to incorporate an additional disaggregation at the top level of the aggregation tree in order to calculate indices by type of end user.

\subsubsection{Specific aspects}

Additional charges which influence price, such as taxes and airport landing and security charges should be excluded if they are not retained by the service provider. However, surcharges imposed by respondents to cover rising input costs (e.g. fuel) must be included.

Theoretically, the price for an observed service should be recorded when the service is provided, thereby obeying the accrual principle. ${ }^{16}$ The same rule applies to the recording of output. As previously noted in chapter 1, the 2008 SNA suggests that prepayments can be recorded as "interest free loans" (rather than as purchases of tickets) from clients to service providers that are paid back at the time of service provision. The client "buys" the ticket once again at the time of service provision, which ensures consistency between supply and demand of services. However, in the case of air travel this not fully satisfactory as prices offered at two different points of time cannot be automatically be considered as relating to a constant quality service transaction.

Another specific aspect of the air transport service sector is frequent flyer programs (e.g. Miles and More) which are common amongst airlines. These programs aim to bind the consumer to one airline or one alliance of airlines by offering special premiums (e.g. free flights, upgrades) for travelled miles. Typically, several different levels of frequent flyers exist within one frequent flyer program, based on the number of miles travelled miles in the previous 12 months. Frequent flyer programs offer additional "free" services such as priority check in, access to luxury airport lounges with drinks and snacks, and additional baggage allowance. The extent to which these additional "free" services should be taken into account in the quality adjustment of prices (and the methodology for doing so) requires further discussion in the future.

In countries with only one or two domestic carriers it may not be possible to publish indices for reason of confidentiality.

\subsubsection{Overview of national methods}

\section{Austria}

Austria calculates SPPIs for both passenger and freight air transport services. The passenger air transport index is compiled using the direct use of prices of repeated services method whereas the freight transport index is compiled using the unit value method. In both indices the characteristics of the respective services (ticket type, destination, mode of freight transport, etc.) have been chosen conjointly with the respondents. Weighting information is also provided by the respondents. Due to reasons of confidentiality the indices are not published.

France 
In France an SPPI for air freight transport services is calculated by the Ministry of Transport. As in the case of Germany, data used in the compilation of the index are provided by the International Air Transport Association (IATA) in order to reduce respondent burden and the cost of compilation. The index covers $72 \%$ of the total air freight transport market and comprises of the most important carriers departing from France.

\section{Germany}

Germany compiles a BtoAll index that covers scheduled passenger air transport (national and international) and freight air transport. One of the main difficulties in the production and publication of a price index for air transport is the very small number of resident service producers. For reason of confidentiality, the SPPI for resident producers is not published but only provided to the national accounts and to Eurostat on a confidential basis. A separate SPPI for air transport services, covering both resident and non-resident service producers, is compiled and published.

The direct use of prices of repeated services method is employed for the SPPI for air passenger transport, mainly using prices that are collected for the CPI. The weighting scheme is organised by destination, by airline and by type of booking class.

For freight air transport services, the index is compiled using data supplied by IATA's Cargo IS service, which provides "standard reports" with data for the whole market and single airlines. Both unit value prices (for freight rates) and prices of repeated services (for surcharges) are provided. The sum of the freight rate and surcharges forms a per-kilo-price which is methodologically classified by the NSI as component pricing.

\section{Japan}

Japan compiles price indices for air transport services including air passenger transport and air freight transport for air passenger transport, the model pricing method is employed. Air passenger transport services selected for pricing are stratified according to international and domestic routes. Prices for international routes are further stratified into three arrival regions: North America, Europe, and Asia/Oceania. Indices are focused on BtoB transactions. For air freight transport, Japan uses the unit value method. Averagemonthly prices for freight fee per tonnage are collected for specified routes, airlines, and types of cargo. These prices are stratified according to international and domestic routes.

\section{Sweden}

Sweden currently produces quarterly indices for passenger and freight air transport. However, these indices cannot be published for reason of confidentiality. Prices for air transportation of passengers on both national and international flights are collected, differentiating between business and consumer passengers using the direct use of prices of repeated services method. For air transportation of freight model pricing is used. No distinction in respect of the end user of the service (e.g. business or consumer) can be made.

\section{United Kingdom}

The U.K. business airfares index aims to measure quarterly movements in prices charged by U.K. airlines to U.K. business passengers. However, there are difficulties distinguishing between business and leisure travel for this industry. The index therefore includes transport of leisure and business passengers, over regular routes and on regular schedules. 
The index is split into three main categories; long haul flights, European flights, and domestic flights. Long haul flights have a weight of $76 \%$ within the index, European flights $18 \%$ and domestic flights the remaining $6 \%$. The majority of prices are collected from the U.K. Civil Aviation Authority in order to reduce respondent burden. These are supplemented with prices collected from a questionnaire sent to one of the large airlines in the U.K.

The index is compiled using the direct use of prices of repeated services method. An unrestricted or business class fare is taken as the representative business customer tariff. Budget airlines and chartered flights are excluded and the U.K. does not currently produce an index for air freight transport.

\section{United States}

The U.S. SPPI for Air transportation is a BtoAll index covers passenger and freight transportation on scheduled and non-scheduled (charter), and domestic and international routes. It is based on price information obtained directly from airlines. This index only covers domestic carriers. The pricing data excludes taxes and airport fees, but includes fees that are retained by the airlines such as fuel surcharges, baggage fees, and reservation cancellation fees.

Currently, the U.S. SPPI measures the price development of scheduled air transportation of passenger services by collecting monthly average revenue (turnover) per passenger for specific seats on selected flights, i.e. the unit value method. Total passenger revenue (turnover) and total passengers for select origins and destinations for a given passenger class (for example: first class, including business or coach) are collected directly from airlines each month. Separate indices are published for domestic first class, including business; domestic coach; and international. For non-scheduled or chartered passenger and freight transportation, transaction prices based on fixed service specifications are collected. The unit of measure is usually per trip or hour (passenger) and the price per kilo, per pound, per mile, per trip, or per hour (freight).

Adjustments for baggage fees and reservation cancellation fees for scheduled air passenger transportation have only been reflected in this U.S. SPPI since 2009. This new procedure was put in place at the time when many U.S. airlines added or expanded $1 \mathrm{st}$ and 2 nd checked bag fees. Data on the amount each airline earns from baggage and cancellation fees on a per passenger basis are obtained from the U.S. bureau of transportation statistics. This amount is then added to the average revenue per passenger reported by each responding airline to get the final price used in the index. Using this fee adjustment, the U.S. SPPI now reflects all changes that are attributable to the implementation of 1 st and 2 nd checked bag fees, as well as any other bag fees (e.g. fees for oversized, overweight, or 3rd checked bags) and reservation cancellation fees. Prior to making these adjustments, the SPPI average revenue per passenger data did not include revenue attributable to bag fees or reservation cancellation fees due to data limitations at participating airlines.

\subsection{Warehousing and storage (Paul Boling, Australian Bureau of Statistics)}

\subsubsection{Industry description (ISIC 5210)}

The warehousing and storage class is one of the components of ISIC section $\mathrm{H}$ Transport and storage and covers the operation of warehousing and storage facilities for merchandise. These facilities include those for general merchandise, refrigerated 
merchandise, grain storage and other farm products, other bulk products in specialised facilities such as timber and petroleum, records management, storage of goods in foreign trade zones and blast freezing. Business enterprises for which these activities are the dominant revenue earner should be classified under warehousing and storage. Other business enterprises providing these services but where the dominant revenue earner is an additional service such as transport, or a wider range of complimentary or transport related services, should be appropriately classified elsewhere.

The market for warehousing and storage services has low barriers to entry for service providers and increasingly there are new or remodelled operations providing specialised services to cater to changed demands. Larger transport providers are increasingly likely to branch out into the provision of other modes of transport and services such as warehousing. Offering bundled services allows service providers to provide more attractive and effective services to the customer. Cross subsidisation of prices to win new business creates problems for compilers in obtaining and isolating genuine transaction prices.

In producing a fit for purpose index, the compiler must achieve a balance between ideal methods and what is actually practical, with particular reference to available resources.

\subsubsection{Classification aspects}

\subsubsection{Industry classification}

ISIC classifies warehousing and storage services under section $\mathrm{H}$ - Transport and storage, division 52 - Warehousing and support activities for transportation, group 521, class 5210 with no further breakdown. NACE provides the same classification structure.

However, other international industry classifications provide finer delineations. For example, NAICS delineates group 493 - Warehousing and storage services, by 49311 General warehousing and storage, 49312 - Refrigerated warehousing and storage, 49313 Farm product warehousing and storage, and 49319 - Other warehousing and storage. ANZSIC, provides a separate division 53 for warehousing and storage services, identical to group 530 and subdivided into two classes; 5301 - Grain storage services, and 5309 Other warehousing and storage services.

\subsubsection{Product classification}

The CPC classification includes warehousing and storage under section 6 Distributive trade services; accommodation, food and beverage serving services; transport services; and electricity, gas and water distribution services, division 67 - Supporting transport services, group 672 - Storage and warehousing services. This group is further divided into 3 classes:

- 6721 - Refrigerated storage services;

- 6722 - Bulk liquid or gas storage services;

- 6729 - Other storage or warehousing.

Only pure warehousing and storage service activities therefore are included. The CPA classification is very similar although it provides some additional detail in respect of grain storage services. 
The NAPCS classification is far more detailed and provides a broader overview of all of the services offered by the sector including auxiliary services for storage and all the range of services offered by logistics providers. In doing so it facilitates the classification of products typically offered by other industries and the compilation of approximate product based indices in addition to industry based indices.

\subsubsection{Scope of the survey}

Ideally the survey should measure price changes for warehousing and storage activities provided for hire or reward to all end users. Activities performed by businesses enterprises on their own account for their own merchandise are not typically included as obtaining genuine transaction prices may be difficult.

\subsubsection{Industry vs. Product based SPPI}

Industry based indices measure the transaction prices of activities produced by establishments classified to the industry. Product based indices measure the transaction prices of relevant service activities produced not only by establishments classified to the industry but also the transaction prices of relevant activities produced by establishments classified elsewhere as a complimentary or secondary activity.

The survey sample is usually industry based (due to the unavailability of a product level sample frame) and structured to reflect the operational practices of each part of the industry. On this basis, warehousing and storage services provided as secondary activity in other industries may be missed even though these services are often an important secondary activity of establishments classified elsewhere in the transport and logistics sector (Goldhammer, 2010). Product level indices which offer a finer level of collection detail can be structured in a more logical hierarchy than industry indices and more closely resemble how the industries operate in the market.

Consideration needs to be given to whether these secondary activities affect the market price for the principal activity and if the price is affected, whether the secondary activity is a price driver of the principal activity. Consultation with industry representative associations and service providers can provide this information.

\subsubsection{Sample design}

National registers should be used initially to select respondents. Other sources including respondent and industry representative organisation provided information may also be utilised to ensure the sample is representative of the market.

The choice of sampling method may vary depending on the organisation of the industry in each country. Where there are a limited number of large national service providers which dominate a specific market (such as grain storage) almost full enumeration could be considered. Compilers should remain aware of geographical distribution which may affect seasonality. For example, the geographic size of Australia gives the country a huge range of climatic conditions. Regional differences in crops and yields between regions may result in different price trends. In markets characterised by a larger number of smaller operators to the use of probability based sampling may be more appropriate. A mixture of probability and non-probability sampling could be employed where there are a range of large, medium and small units.

Sub-samples may be drawn to represent different sub-industries as the warehousing or storage of different merchandise may have different cost drivers. For example, a 
warehouse providing storage in respect of a defined space or volume under contract has different cost drivers to a facility providing temperature controlled short-term hire with a high throughput.

The sample size will be determined by the structure of the industry, the requirements for coverage of establishments within various size classes, burden considerations and by the availability for resources. Ideally the compiler should determine the optimal number of price observations to be collected from each respondent that will satisfy data quality standards while at the same time minimise respondent burden. Typically, if the respondent offers a wide and heterogeneous line of service activities then increasing the number of activities for which prices are collected will improve representativity. However, if the different services offered are limited in number, and homogenous, then fewer service transactions are required to measure price change.

\subsubsection{Collection of information and specification of the service}

During the respondent initialisation process, each respondent provides information about the range of services it offers and the respective shares of total turnover generated by each type of service activity. Representative service transactions are then selected for the main service activities for on-going pricing. Each transaction should be sufficiently well specified to ensure that it can be easily identified in each period so as to facilitate pricing to a constant quality. Some service transactions may be unique to a client but broadly representative of services provided to other clients.

Information which helps the compiler understand the nature of the industry and market conditions may also be collected (ideally by personal interview) during the respondent initialisation process. Industry representative associations may also be a useful source of market knowledge and perhaps even assist in questionnaire design.

A range of methods may be used to collect prices data from respondents in each survey period from respondents in a secure and cost-effective manner, while minimising the burden on the respondent. Prices data can be collected via survey forms, email, from company websites (particularly for services aimed at the consumer or small business), from administrative data such as exchange rates or from other statistical collections such as those relating to international merchandise trade. Some services activities may have published rate schedules which are updated on a regular basis.

\subsubsection{Main pricing methods}

\subsubsection{Contract pricing}

A key characteristic of the provision of warehousing and storage services is the bundling of services, often at unique rates to specific customers (Lucier, 2004). Consequently, the contract pricing method is commonly employed for this sector. This method facilitates the collection of prices for bundled services with multiple pricedetermining characteristics and is reflective of the pricing mechanism employed in the sector. Where standard services are provided to different customers at the same price the direct use of prices of repeated services method can be employed. Use of this method is facilitated by the fact that warehousing and storage services are usually easily described (Goldhammer, 2010). 


\subsubsection{Unit value method}

The unit value pricing method can also be employed where total revenue can be divided by a measure of the total volume of services provided (such as per day, per $\mathrm{m}^{2}$ ). However, it is important that the service provided must be very homogeneous and that the volume measure is reflective of the pricing mechanism employed. Furthermore, it may not be appropriate to use unit value measures based on time where fixed charges are a component of prices.

\subsubsection{Quality issues}

The SPPI should measure the change in price of a fixed basket of representative services to constant quality. Changes in the conditions, access, security and length of time warehoused or stored could all give rise to quality change. Specific service transactions priced in one period may not be available in a subsequent period either because of a change in the characteristics of the service or because it has been replace by a new service. Failure to account for quality changes will introduce a bias into the price index. Thus, if the qualities of goods or services being compared are not identical, quality adjustment is required.

The price collection instrument should require the respondent to note reasons for significant changes in price or changes to the product. These reasons may also provide signals to alert the compiler to changes in quality.

Missing values can be estimated using "class mean" imputation, wherein missing price movements are imputed using movements based on the next highest level of aggregation.

\subsubsection{Weighting and aggregation}

Weights should be based on contribution to the total industry revenue. These data may be available from different sources for different levels. For aggregates at or above the lowest level in the classification framework, values from structural business statistics or national accounts input/output tables could be used. For samples or aggregates below this level of the classification it may be necessary to use industry sourced information or data from turnover surveys or other surveys, perhaps by other organisations.

The key sources of data for upper level weights for the Australian SPPIs are the Australian national accounts input/output tables. In addition to broad data from inputoutput tables, other data sources used to construct national accounts aggregates are frequently used in the estimation of lower level weights. Whilst these data typically come from other Australian Bureau of Statistics (ABS) economic surveys, the national accounts component data are generally more complete in terms of consistent coverage and valuation basis. ABS economic surveys are also used in the production of lower level weights for the output producer price indices. These data typically provide information on type and characteristics of producers, as well as some detailed information on revenue. In addition, these ABS surveys frequently provide information regarding industry outputs in terms of quantity measures. Deriving lower level weights from these quantity data requires that they are combined with measures of average prices.

Other weighting data may be sourced from administrative data, industry associations or during the respondent initialisation process. 


\subsubsection{Specific aspects}

Warehousing and storage services are increasingly bundled with transport services and other complimentary services such as packing and stock management. Many warehousing and storage providers also offer "supply chain management" or "logistics solutions" and bundle a variety of services for their customers. In these instances business contracts may be won by discounting part of the overall bundled task with this service effectively subsidised by the remaining parts. Obtaining separate market prices for specific services can be a challenge.

Another practice within the industry is to contract for a fixed quantity or period with 'take or pay' conditions whereby the purchaser's obligation to pay is unconditional whether or not the purchased service is taken. The current turnover rate and percentage of the fixed quantity in the contract which is utilised may then have an effect on the unit price of the storage. While list prices could be used for the pricing of some services, this practice could miss price changes arising from discounting.

Increased awareness and understanding of the issues facing this sector will lead to improved methodologies and ultimately better estimates of the real output and productivity for the warehousing and storage services sector.

\subsubsection{Overview of national methods}

The U.S. includes bundled services and produces both industry and product indices. Germany and Hungary also produce both, whereas industry indices are produced by Austria, New Zealand, Poland and Australia. Product indices are produced by France, Korea, Mexico, the Netherlands and the U.K. Most countries use ISIC, or a concordant system, as the industrial classification system and update weights with a five year frequency.

All countries rely on respondents to provide information explaining how much a change in price is due to a change in quality. This information is used to determine the method and amount of appropriate quality adjustment.

In the U.S., all services provided by firms classified in this sector are covered. Any services that are not principal to warehousing and storage are considered "other receipts" and given a chance of selection at each sampled firm. When publication criteria are met, a price index for "other receipts" is published. Examples of common "other receipts" include the arrangement of freight transportation, packaging and labelling services, and supply chain management consulting.

Model pricing is used in the U.S. for bundled transactions where a firm provides additional services such as sorting, packing and crating in addition to the storage service. For these bundled transactions an actual transaction is selected in the initial data collection period. This transaction may include, for example, a charge for storing 100 boxes of a product for 60 days along with a one-time per box charge for packing and crating. For the initial price, it is essential that the same quantities of the product are used to determine both the storage charge and the packing and crating charge. If the storage fee is for 100 boxes, then 100 instances of the "per box" packing and crating fee should also be recorded so as to ensure that these services are represented in the correct proportions. In subsequent periods the respondent estimates the current storage and packing and crating fees they would charge, while the quantity of 100 boxes is held constant. Explaining the pricing methodology is often challenging as some respondents prefer to update both the rates and the quantities, when only rates should be updated. 


\subsection{Cargo handling (Paul Boling, Australian Bureau of Statistics)}

\subsubsection{Industry description (ISIC 5224)}

Cargo handling is one of the components of the transport and storage industry. This class includes the loading and unloading of goods or passengers' luggage irrespective of the mode of transport used for transportation. Stevedoring and the loading and unloading of freight railway cars are the largest components of the cargo handling industry. Stevedoring is dominated in most countries by the moving, lifting and securing of intermodal containers within the terminal facility onto or off the mode of transport. Cargo handling excludes the operation of the terminal facilities.

Cargo handling services are usually provided by large national or multi-national service providers and are concentrated in ports. Entry into the market at this level requires large areas of dockside land for container storage and transfer to other modes of transport. Handling equipment is large and requires multiple units to efficiently turn around a vessel. The capacity to secure large amounts of finance or the availability of cash is a barrier to entry to this industry.

\subsubsection{Classification aspects}

\subsubsection{Industry classification}

Cargo handling is classified under section $\mathrm{H}$ - Transport and storage, division 52 Warehousing and support activities for transportation, group 522 - Support activities for transportation of the ISIC classification system. It covers the loading and unloading of goods or passengers' luggage irrespective of the mode of transport used for transportation operation of terminal facilities, stevedoring and the loading and unloading of freight railway car but excludes the operation of terminal facilities.

A review of the international industry classification systems shows varying degrees of concordance with the ISIC classification. The NACE classification is fully aligned with the ISIC classification. However, in the NAICS classification cargo handling activities are organised according to the mode of transportation such that, for example, the handling of air cargo and baggage is classified under industry 488119 - Other airport operations, while the handling of cargo carried over the road network is classified under industry 488490 - Other support activities for road transportation. The handling of cargo transported over water is classified as an industry 488320 - Marine cargo handling. Similarly, the ANZIC classification is organised according to the mode of transportation.

\subsubsection{Product classification}

The main international product classification systems are not well aligned.

In the CPC classification, the corresponding products for ISIC are classified under section 6 - Distributive trade services; accommodation, food and beverage serving services; transport services; and electricity, gas and water distribution services, division 67 - Supporting transport services, group 671 - Cargo handling services. The classification of cargo handling service products are split between the handling of containers (class 6711 - Container handling services) and non-containerised cargo (class 6719 - Other cargo and baggage handling services). 
The European CPA classification system also differentiates cargo handling service products by the handling of container cargo and non-containerised cargo but additionally it differentiates by location - services provided at ports and not at ports.

In the NAPCS classification system cargo handling service products are classified under the warehousing and storage industry group. Cargo handling service products are in the main differentiated on the basis of the type of cargo: goods, bulk liquids and gases, dry bulks, climate-controlled goods, automobiles, project cargo and other cargo. The handling of boxed, palletised or packed goods and intermodal containers are also distinguished.

\subsubsection{Scope of the survey}

The ideal survey measures price changes for the provision of each of the different types of cargo handling services. Often, only the main service lines, on the basis of their share of the total output for the cargo handling industry, will be covered.

Furthermore, scope will be limited to those service activities performed for hire or reward as separate services. Cargo handling activities performed by enterprises on their own account for their own merchandise are typically not included as obtaining a genuine transaction price for a non-market service may be difficult.

In Australia, ANZSIC class 5211 - Stevedoring, covers the largest proportion of cargo handling and the SPPI is effectively limited to stevedoring for ship containers. The revenues generated by other types of cargo handling, such as break bulk and car carrying on Roll On-Roll Off (Ro-Ro) vessels are not significant enough to warrant their inclusion in the SPPI, given the limited resources available for survey compilation.

The market for stevedoring for ship containers currently operates as a duopoly and prices are subject to scrutiny by the Australian Competition and Consumer Commission (ACCC), under Part VIIA of the Competition and Consumer Act 2010. The ACCC monitors the prices, costs and profits of container terminal operator companies at the ports of Adelaide, Brisbane, Burnie, Fremantle, Melbourne and Sydney under the container stevedoring monitoring program. The ACCC publishes a representative price for container stevedoring services which is calculated as an average across all ports - no single port facility may actually charge that price. This price is used in the compilation of the SPPI. A third operator is in the process of building a new terminal in Brisbane.

\subsubsection{Industry vs. Product based SPPI}

Although product based SPPIs are the most appropriate measure for use in the deflation of the national accounts, they are rarely feasible as they require a sampling frame comprising of sufficiently detailed product level turnover data.

Alternatively, an industry based SPPI can be compiled from a sample of establishments classified to the cargo handling industry. All of the output of these sampled units is represented, including secondary activity output that is classified under other industries in the classification system, and aggregated to form a 4 digit industry level index.

The larger the shares of industry turnover generated from the provision of cargo handling services as secondary activities the stronger the argument for compiling product based SPPIs. Consideration also needs to be given to whether these secondary activities affect the market price for the principal activity and if so, whether the secondary activity 
is a price driver of the principal activity Consultation with industry representative associations and service providers can provide this information.

\subsubsection{Sample design}

Samples are typically drawn from business registers using either probability proportional to size sampling or a non-probability technique. Where a limited number of large national service providers dominate a specific market almost full enumeration could be considered. In markets characterised by a larger number of smaller operators the use of probability based sampling may be more appropriate. A mixture of probability and nonprobability sampling could be employed where there are a range of large, medium and small units. Sample rotation is advisable among smaller units in order to limit the length of time they remain on the survey panel. Rotation keeps the sample up to date and reduces the impact of sample depletion.

Cargo handling services for different types of merchandise can have very different cost drivers and therefore the sample should be representative different service activities. For example, the lifting of containers in a terminal from one mode of transport to another with a rate per container that is fixed irrespective of content or weight has different cost drivers to handling services for non-containerised merchandise.

\subsubsection{Collection of information and specification of the service}

During the respondent initialisation process, each respondent provides information about the range of services it offers and the respective shares of total turnover generated by each type of service activity. Representative service transactions are then selected for the main service activities for on-going pricing. Each transaction should be sufficiently well specified to ensure that they are easily identified in each period thereby facilitating constant quality pricing. Some service transactions may be unique to a client but broadly representative of services provided to other clients.

Specification parameters may include:

- Type of cargo (liquid, dry bulk, automobile, etc.);

- Containerised or non-containerised;

- Packed (box, pallet, etc.);

- Weight;

- Load on-Load off or Roll on-Roll off;

- Turn-around time;

- Security provided for cargo;

- Client.

Information which helps the compiler to understand the nature of the industry and market conditions may also be collected (ideally by personal interview) during the respondent initialisation process. Industry representative associations may also be a useful source of market knowledge and perhaps even assist in questionnaire design.

A range of methods may be used to collect prices data from respondents in each survey period from respondents in a secure and cost-effective manner, while minimising the burden on the respondent. Prices data can be collected via survey forms, email, from 
company websites (particularly for services aimed at the consumer or small business), from administrative data such as exchange rates or from other statistical collections such as those relating to international merchandise trade. Some services activities may have published rate schedules which are updated on a regular basis.

\subsubsection{Main pricing methods}

Cargo handling services are usually repeatable and priced according to a consistent mechanism. The direct use of prices of repeated services can therefore be employed in most cases.

The industry does not appear to be subject to rapid technological change and it should be possible in many cases to price repeated services of constant quality over at least a number of years.

In Australia the representative price for stevedoring services is currently calculated annually as an administrative by-product of the regulating body. It is expressed as the container lift price of a twenty foot container.

\subsubsection{Quality issues}

The SPPI should measure the changing price of a fixed basket of services. Changes to service conditions, access, security and turn-around time could all give rise to quality change. A specified service may become unavailable over time because of a change in its specification or because it has been replaced by a new service. Failure to account for quality changes can introduce a bias into the index. Therefore, a quality adjustment is required if the quality of a specified service changes.

Respondents should be required to note reasons for significant changes in price or any changes to the specified service.

\subsubsection{Weighting and aggregation}

Weights should be based on contribution to the total industry revenue. These data may be available from different sources for different levels. For aggregates at or above the lowest level in the classification framework, values from structural business statistics or national accounts input-output tables could be used. For samples or aggregates below this level of the classification it may be necessary to use industry sourced information or data from turnover surveys or other surveys, perhaps by other organisations.

The key sources of data for upper level weights for the Australian SPPIs are the Australian national accounts input-output tables. In addition to broad data from inputoutput tables, other data sources used to construct national accounts aggregates are frequently used in the estimation of lower level weights. Whilst these data typically come from other ABS economic surveys, the national accounts component data are generally more complete in terms of consistent coverage and valuation basis. ABS economic surveys are also used in the production of lower level weights for the output producer price indices. These data typically provide information on type and characteristics of producers, as well as some detailed information on revenue. In addition, these ABS surveys frequently provide information regarding industry outputs in terms of quantity measures. Deriving lower level weights from these quantity data requires that they are combined with measures of average prices. 
Other weighting data may be sourced from administrative data, industry associations or during the respondent initialisation process.

\subsubsection{Specific aspects}

Cargo handling services may be bundled with other transport services and or complimentary services such as packing and stock management. Obtaining separate market prices for specific services can be a challenge.

Increased awareness and understanding of the issues facing this sector will lead to improved methodologies and ultimately better estimates of the real output and productivity for the cargo handling services sector.

\subsubsection{Overview of national methods}

Germany, Hungary and the U.S. compile both industry and product level indices. France, Korea, the Netherlands and the U.K. compile product level indices.

\section{Korea}

In Korea the charge-out rates for cargo handling are adjusted annually as a result of labour-management negotiations. The adjustment of rates for water freight handling in each harbour requires government approval. The price data are collected from the industry representative association and government websites. Korea's SPPI for cargo handling services comprises of two elementary aggregates, for railroad loading and unloading charges and harbour loading and unloading charges. Their respective weights obtained from input/output tables and since 2013 the SPPI has been calculated as a chained index with annual updated weights.

\section{Netherlands}

In the compilation of the SPPI for cargo handling services in the Netherlands, elementary indices are calculated as geometric averages. Successive levels of aggregation are then performed company level weights (derived from the SBS survey) and then weights derived from the input/output tables. Weights are updated every 5 years although the introduction of an annual updating of weights is currently under consideration.

\section{United Kingdom}

In the U.K., SPPI compilers found that the CPA classification structure did not reflect the organisation of the cargo handling industry. Therefore a customised aggregation structure, which delineates the industry into sea, air and land cargo handling services, was developed after industry consultation. Cargo handling services represent a small part of the overall supply chain. Often a cargo handling service is arranged as a component of the whole process of moving goods from one point to another. This can lead to difficulties in identifying the price actually received for the handling element alone. Therefore, where appropriate, respondents are advised to include solely the price of cargo handling services. 


\subsection{Courier and postal activities (Denis Gac, INSEE \& Ildikó Hamvainé Holocsy, Statistics Hungary)}

\subsubsection{Industry description (ISIC 53)}

The service activities provided by the postal and courier industry are the collection and delivery of documents, letters and parcels (in general, light freight). The time between collection and delivery is one of the most important differences in quality among the variety of services.

The total turnover of postal and courier services (ISIC 53) represents approximately $1 \%$ of the European total GDP. Nearly $80 \%$ of the total turnover of this division is generated by national post activity, with the remainder generated by other postal and courier activities. In a number of countries, such as Australia and the U.S., courier services have a larger share of turnover although the provision of postal services dominates the industry.

The core definition of postal services and courier services are the same, except that postal services are rendered under a "universal service obligation" (USO). ${ }^{17}$ Postal operators are traditionally state-owned and regulated. Many countries impose requirements on the incumbent postal operator to provide prescribed services at a certain level of quality, for example requirements to provide a given frequency of deliveries or collections, to limit the maximum distance to the nearest post office, and to propose affordable offers for mail, or small parcels.

Officially, the European Commission defines the "universal service obligation" (USOs) as the obligation for holders of postal monopolies to ensure every citizen has access at least one delivery and collection of mail five days a week, at affordable prices throughout the territory. Regulatory bodies ensure that these obligations are performed (not only in the EU, but also in countries such as the U.S., Norway and New Zealand).

The postal market is, for historic reasons, usually dominated by a single producer. If there is any competition, it often exists only in certain parts of the market such as mass mail or international mail. Despite legislation to allow competition and liberalise the market, it is unlikely that full competition on all postal services will be achieved, in all countries, due to the nature of the service activities. These monopolistic situations give rise to confidentiality issues.

However, some countries have completely liberalised their postal sector (Germany, Sweden, Finland, New Zealand), while some others have retained only a small reserved area.

In direct contrast to the market for postal services, the market for courier services is highly competitive. The provision of postal and courier activities is currently undergoing change, as service providers increasingly offer diverse products, such as logistics, storage and freight transport services to their customers. In addition, establishments classified to the freight transport by road division often compete directly with couriers, by offering similar services.

The structure of the population of couriers within European countries is quite similar. Most have few employees (small and medium size sized), but the largest dominate the turnover of this activity. In other words, this sector is controlled mainly by large enterprises. However, the structure of the population of postal enterprises is even more 
extreme: one enterprise dominates the market typically accounting for at least half, but possibly much more, of the total revenue of the industry.

Both households and businesses purchase services from national post operators although businesses (including government) are by far the largest clients (in the EU their proportion is more than three-quarters of the total turnover). Courier and local messenger service producers also focus their activity on businesses. There are also some differences between the services they offer. Normally, national post services are more routine and have very specific characteristics that cannot be changed. On the other hand, courier service producers can offer 'tailor-made' services, often fixing prices with reference to the volume of documents and parcels for delivery.

Globalisation is also affecting this industry. Service producers are establishing alliances with equivalent providers abroad, in order to improve the international delivery of parcels.

\subsubsection{Classification aspects}

\subsubsection{Industry classification}

As a result of an international harmonisation process, the various international industry classifications are quite similar. As shown in annex A, the industry descriptions and parameters are broadly equivalent.

However, in several cases it is difficult to exactly classify business enterprises. Each unit is classified to a single activity, whether it is wholly or mainly engaged in that activity. Some units may have a very significant secondary activity, perhaps completely different from their main activity, and a small change in the relative importance of activities can lead to a reclassification of business.

There is an important classification issue in respect of the differentiation between courier firms and freight transport by road enterprises. As mentioned above, both can offer similar services although the weight of the goods transported is usually used to differentiate between 'courier services' and 'freight services'. However, there is no universal rule applied and the definition of these services varies between countries. Normally, transportation of items weighing up to $30 \mathrm{~kg}$ is considered as a postal and courier service and transportation of heavier items is classified as freight transport. An important requirement of couriers, which can distinguish them from service providers in similar industries, is that they must be able to provide end-to-end transportation, from origin to destination including local pick-up and delivery in a time sensitive to quality. In Germany, the size of the transport vehicles in use is used to distinguish between "courier services" and "freight transport by road." Additionally, a courier service has to provide both collection and delivery. In summary, the liberalisation of the postal market increasingly blurs the distinction between postal and courier or freight-related services (see under section 6.1.3).

The provision of "express delivery" services appears to lie between the postal and courier two activities. The core business of the express industry is the provision of doorto-door transport and delivery of next day or time-definite shipments, including documents, parcels and merchandise goods. In Germany, door-to-door transportation is the characteristic feature of courier services. Express services are mainly defined by delivery time. However, the differences in delivery time of postal and parcel services compared with express services are diminishing. A few (perhaps 4 or 5) enterprises 
dominate this industry internationally (namely, DHL, FedEX, TNT and UPS). These enterprises are referred to as "integrators", as they maintain control over all aspects of the distribution process with each item being tracked at every stage of its journey. Express transportation is achieved by using a variety of different transport modes; lorries, vans, trains, passenger aircrafts, and freight aircraft as well as on-foot.

The courier and messenger sector defined by categories 4921 and 4922 of the NAICS consists of establishments primarily engaged in providing air, surface or combined courier delivery services. Local messengers comprise of establishments primarily engaged in providing messenger and delivery services of small parcels within a single urban area. Establishments engaged in the delivery of letters and documents, such as legal documents, often by bicycle or on foot; the delivery of small parcels such as take-out restaurant meals, alcoholic beverages and groceries, on a fee basis, usually by small truck or van, are included.

\subsubsection{Product classification}

The corresponding products for ISIC 53 - Courier and postal activities, are classified in classes 6811 - Postal services, 6812 - Courier services and 6813 - Local delivery services, of the CPC.

The international product classifications are however not well aligned and harmonised, and this may imply classification and comparability problems. CPA offers further details with additional subcategories for postal services under universal service obligation related to newspapers and periodicals (53.10.11 CPA) and three for the postal and courier services. In contrast, the other international product classifications (NAPCS and ANZSPC) provide less detail. None of the international product classifications provide sufficient detail to distinguish differing drivers of price change.

\subsubsection{Scope of the survey}

Ideally, the survey would track constant quality price change for the full range of output to all and users.

The postal and courier services industry groups should be fully covered, as it is the case for many European countries. Some exceptions may however exist according to the country context; in Germany only courier activities are covered despite a full demonopolisation of the sector in 2006.

For postal services, one of the main challenges for compilers and data suppliers is the identification of domestic and non-domestic markets since the international agreements between national post offices and other postal and courier operators. ${ }^{18}$ Thus in most countries, the portion of the total turnover generated by exported services is not covered by price indices. On the other hand, postal services in several countries are limited to letters and parcels, and some services such as those related to delivery of newspapers and periodicals, counter services or food home delivery service are not included.

As previously mentioned, business and government end users consume the majority of the service output. The household share of postal services is fairly small and in most of countries it is not representative of the overall activity. As a result, an index covering only the provision of services to business and government end users may closely approximate an index including services to households. 
Additional data collected for the CPI could be used in the calculation of a BtoC, which in turn could be used in the compilation of a BtoAll. ${ }^{19}$ Generally postal activities are covered by the CPI, so there should be no extra collection work involved.

\subsubsection{Industry vs. Product based SPPI}

A primary use of SPPIs is in the deflation of the service industry output to produce relevant statistical indicators at constant (real) prices. For the calculation of an industry based volume index an industry based SPPI is sufficient. However, for national accounts purposes a product based SPPI is more appropriate.

Many establishments classified to the CPA division 53 - Postal and courier services, have relevant turnover share generated from secondary activities. For example, as well as providing postal activities under universal service obligation (53.10 CPA) the Hungarian post office provides courier, logistic, telecommunication and other monetary intermediation services as secondary activities. On the other hand, enterprises classified to the freight transport or warehousing and support industries for transportation, may also have a relevant share of turnover generated from secondary courier activity.

In Hungary, the SPPI for the industry is compiled at both industry and product level (at NACE 4-digit level and CPA 4-digit level respectively). The sample of establishments classified to the division 53 is expanded to include establishments with relevant secondary activity in "other postal and courier activities". Respondents are asked to provide prices for both principal and secondary activities.

\subsubsection{Sample design}

As previously noted, the structure of this industry is quite similar from country to country. In particular, the ISIC class 5310 - Postal activities, is made up by one dominant service provider and possibly a small number of other providers. The smaller service providers should be included in the sample if they have a significant market share.

Price development can differ by product or client type, depending on the extent of liberalisation in specific markets. For instance, if only international postal services are liberalised in a certain country, it is important to get specific price data on this submarket (as well as relevant weighting data), because price development may differ from those submarkets that have not been liberalised. In liberalised submarkets volume discounts may be afforded to larger clients like banks and insurance companies. On the other hand, if the market is free of competition, the sole provider of postal services may not see any need to offer any discounts.

For courier firms, probability proportional to size (PPS) sampling, by turnover or number of employees, is advisable. Where a small number of large units dominate, they should always be included in the sample. Another option is to include only the largest units (cut-off sampling), when they account for almost entire market (e.g. greater than $80 \%$ ) and therefore dictate the evolution of prices. This option will therefore minimise the response burden on small units. According to the Voorburg Group survey previously mentioned, cut off sampling is the predominant sampling method used among reporting countries. A census of the largest units is taken above a size threshold (or cut off line) and this may be supplement by a random or subjectively chosen sample of smaller units.

An additional consideration when designing a sample for the industry concerns the choice of submarkets and services to be sampled within the dominant/monopoly postal enterprise. The household share of postal services in most of countries is fairly small (Gac 
and Holocsy, 2010). However, for courier activities in particular, the demand from households could be significant.

\subsubsection{Collection of information and specification of the service}

Prices should be collected for a set of well specified service transactions so as to facilitate constant quality pricing. Prices should be collected on the basis of the appropriate unit of measure, such as one mail (letter, package, other).

The price of each service activity depends on various factors including; transaction partners, geography (i.e. origin and destination of service); timing of delivery (e.g. overnight or next day and other); type of the item(s) being delivered; the size of the delivery (in number, weight, and/or volume); type of service (ground, air, etc.). In some countries, consideration is given to additional criteria, such as type of packaging; insurance or registered/special delivery.

For courier services, the most important price determining characteristic is the time it takes for a package to be delivered. The customer is not concerned by the modes of transportation used, only that the package is delivered within the allocated time. Express delivery services by air are faster (and higher priced) while standard courier services are slower (and lower priced). Courier services by air often include a domestic component and international component. ${ }^{20}$

The price of a service activity can typically be expressed as follows:

$$
\text { Price }=\text { Base rate }+ \text { fuel surcharge }+ \text { other applicable surcharges }
$$

It should however be noted that a large number of transactions take place in this industry, while the item allocation is comparatively small. Major service providers account for the bulk of transactions due to high concentration levels within the industry. The term "bulk mail" refers to larger quantities of mail prepared for mailing at reduced postage.

The prices of postal and courier services are often quite stable. Therefore quarterly collection of data may be sufficient to study the evolution of producer prices. If the index of postal services shows significant change at annual intervals only (e.g. in the first month or quarter of the year), this may have implications for the frequency of price collection.

The most commonly employed methods of collecting price data on an on-going basis are by survey or from the list prices displayed on the websites of service providers (although often only the larger service providers list their prices in detail on their websites). However, it must be remembered that list prices may not include discounts, unless for example, the company provides a discount calculator relating to volume purchases. Regulatory authorities may also be able to provide some data.

\subsubsection{Main pricing methods}

When selecting the pricing method to be employed for the measurement of price change in the industry, it is important to consider the pricing mechanisms used by service providers. The most common pricing methods employed in the compilation of SPPIs for post and courier service activities are discussed below. 


\subsubsection{Direct use of prices of repeated services}

List prices for common service activities are often available, in particular for postal services, and these can be used to proxy for direct use of prices of repeated services. In some countries, large service providers may include a calculator service on their website to show the discounts that will apply to list prices based on the volume of services purchased. In such cases the observed prices may be closer to actual real transaction prices.

The use of list prices reflects the relative abundance of on-line information. However, it is important to establish the relative market share of services sold at the list price when establishing the index weighting structure to ensure they are not over represented in the index. List prices should only be used if it can be established that sufficient quantities of services are actually sold at their list prices, or in other words that the list prices are representative of real transaction prices.

In many countries certain postal and courier activities are covered by the CPI. It may therefore be possible to reuse data collected for the CPI in the compilation of SPPIs. However, these data may require certain transformations, to account for differences in survey periodicity and the treatment of taxes and subsidies. It should also be noted that prices collected for CPI compilation are unlikely to include volume discounts that may be important in the context of the provision of services to other businesses and to government. The use of CPIs as proxies for the SPPI is discussed in more detail under chapter 2 .

\subsubsection{Unit value method}

Under the unit value pricing method, the unit price index is determined as the quotient of the value (sales revenue) and quantity of services sold over a large number of transactions. The method is applicable in cases when service types in a group of services are relatively homogeneous. The units have to be defined clearly for each product or service. The units should be as homogenous as possible, e.g. letters classified by size, parcels classified by narrow weight and/or dimension categories. To ensure the homogeneity of the units, detailed specifications including the speed of delivery and destination must also be included. In defining the unit, detailed information about the quantity of units sold has to be available; this may impose a general restriction on the degree of homogeneity that can be achieved.

If the services are homogeneous and can be quality adjusted for any changes occurring, then the unit value method is an optimum choice. A drawback of this method is that information about the quantity of products sold is often not available at a sufficiently detailed level that ensures the homogeneity of the underlying services. In such cases care must be taken to ensure that the range of services grouped together (at the lowest level for which quantity data are available) are relatively homogenous - otherwise the unit value method should not be used (e.g. if the lowest level of quantity data available is 'all letters' then this is too heterogeneous to consider using the unit value method).

\subsubsection{Contract pricing}

For services provided by a dominant postal service provider to large clients, contract pricing can be employed. The service provider selects representative services that are repeatedly to specific clients under long-term contracts. 
Contract pricing is an ideal method as it measures the real transaction prices of services. However, it is difficult to apply to the full range of services provided by the industry, in particular when unique services are provided. Furthermore, the method should be used with caution because individual contract prices agreed in a previous period for future periods may not be representative of current price development in the industry

\subsubsection{Model pricing}

Under this method, bundles of service activities are described in detail and respondents provide prices for them in each survey period. The selected services have to be representative of common transactions within each relevant sub-sector of activity, and should be replaced if they become less representative over time. Usually, these models are defined on the basis of weight/size of parcels, speed of delivery and destination. Nevertheless, more characteristics could be taken into account if they influence price, for example, type of delivery, inclusion of insurance etc.

The main advantage of model pricing is that any improvements in productivity should be captured in price changes. It is important to ensure that the model remains representative and that respondents include all applicable discounts when re-pricing the model service activities each period.

\subsubsection{Quality issues}

In the past, services provided by the postal and courier industry were mainly defined by stable characteristics and consequently quality changes were relatively easy to measure. However, due to market liberalisation and the free movement of services, quality aspects have become increasingly important. In particular the increasing number of service providers offering both postal and courier services creates challenges in respect of the classification of services and service providers and strengthens the argument for product based indices.

The most commonly observed quality adjustment method for the industry is the overlap method. This method can be applied relatively successfully because new and old services are generally sold simultaneously. Where this is not the case, respondents can often provide previous period prices for new service activities. Comparable adjustment and quantity adjustment methods are also used.

In order to maintain the on-going quality of the index, significant price changes and changes to existing services should be queried with respondents and treated appropriately. Most compilers make comparisons, mainly on an ad hoc basis, with data from other sources (e.g. CPI, SPPI from other countries, regulatory or administrative data, and exchange rate movements). If service activities are performed on an ongoing basis, quality adjustment may rarely be required. However it is important to ensure that observed prices remain representative of the types of service activities provided. Prior to dissemination, the price indices should be analysed and historic trends reviewed.

\subsubsection{Weighting and aggregation}

Data used in the weighting and aggregation of the SPPI may be derived from a number of sources such as dedicated turnover surveys or the national accounts. Many countries collect turnover/revenue data on an annual basis to derive the necessary weights 
for index compilation (e.g. the Netherlands, Hungary). Regulatory authorities may also be a potential source of data.

\section{Hungarian experience}

Hungary employs two sources of turnover data for weighting. For aggregation of establishment-level and higher-level sub-indices of "large" establishments, previous year "product-level" turnover data is collected using a dedicated SPPI survey. For the industry-based SPPI, turnover data from two years prior is obtained at the 4-digit and higher levels from the SBS. Weights are updated annually.

Lower level (CPA 6-digit) indices for the national post office are first calculated as a weighted arithmetical average and as un-weighted geometrical means for other respondents. Next, the respondents' class level (CPA 4-digit) aggregates are computed as a weighted arithmetical average, followed by sub-indices for "large" (weighted) and "smaller" (un-weighted) units, which are aggregated using the share of industry data as derived from the SBS survey.

Compilation of a business to all users aggregated index can be calculated as a weighted average of the $\mathrm{BtoB}$ and $\mathrm{BtoC}$ indices in the following way:

- A weighted average from BtoB and BtoC indices is calculated by applying the relevant turnover share as weights.

- Assuming that $\mathrm{I}_{\mathrm{BtoAll}}, \mathrm{I}_{\mathrm{BtoB}}$, and $\mathrm{I}_{\mathrm{BtoC}}$ are the relevant indices, $\mathrm{W}_{\text {BtoAll }}, \mathrm{W}_{\mathrm{BtoB}}$ and $\mathrm{W}_{\mathrm{BtoC}}$ are the weights, the formula could be expressed as follows:

$$
\begin{aligned}
& \mathrm{I}_{\mathrm{BtoAll}}=\mathrm{I}_{\mathrm{BtoB}} * \mathrm{~W}_{\mathrm{BtoB}}+\mathrm{I}_{\mathrm{BtoC}} * \mathrm{~W}_{\mathrm{BtoC}}, \\
& \text { where } 1=\mathrm{w}_{\text {BtoAll }}=\mathrm{w}_{\mathrm{BtoB}}+\mathrm{w}_{\mathrm{BtoC}}
\end{aligned}
$$

\subsubsection{Specific aspects}

For most countries there have not been any notable complications in obtaining a sampling frame, and respondents are able to provide pricing data with minimal difficulty. The main challenges in developing the index for postal and courier services are described below.

The SPPI for postal services should primarily focus on the dominant (or monopoly) service activity provider, as this business enterprise largely determines the total index. Confidentiality guidelines typically prohibit publishing the index for postal services meaning that only the overall index for postal and courier services or only the courier services index can be published. In European countries, the postal SPPI is generally available only to national accountants and to Eurostat for inclusion in EU-aggregates. However some countries, such as the U.S., have mechanisms for waiving confidentiality guidelines with the respondent's assent.

It is important to distinguish between resident consumption of international courier services and service exports. Assuming that for national accounts purposes exports means "products or services sold to non-resident customers", and that according to international rules, postal offices deliver letters (parcels) coming from abroad for an agreed sum, the simplified examples - figures 6.6.1. and 6.6.2. - illustrate export/import transactions as follows: 
Figure 6.6.1. Delivery letters (parcels) from country A to the country B

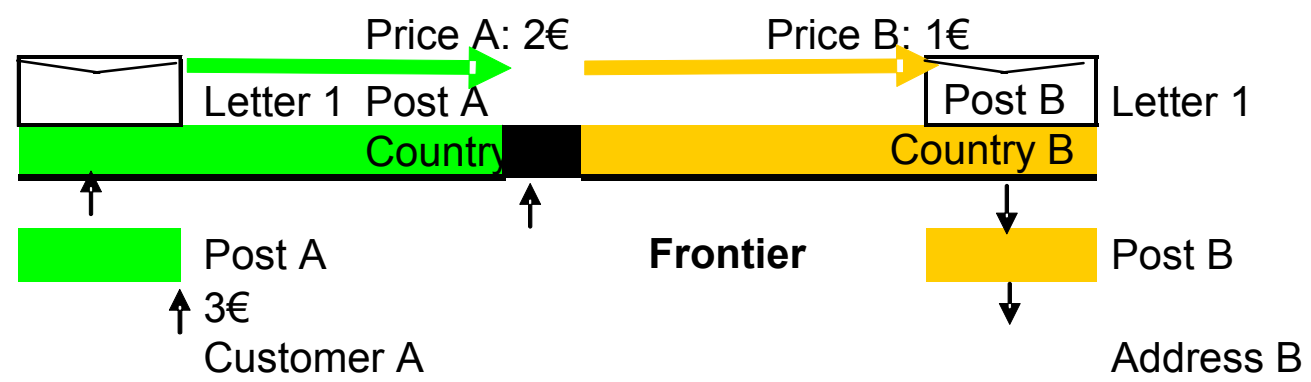

From the point of view of country A, the delivery of post as presented is a domestic service (sold to the domestic customer). The value of the domestic turnover is $3 €$, which includes an imported service (provided by the Post B located in the country B for the agreed sum) for $1 €$.

Figure 6.6.2. Delivery letters (parcels) from country B to the country A

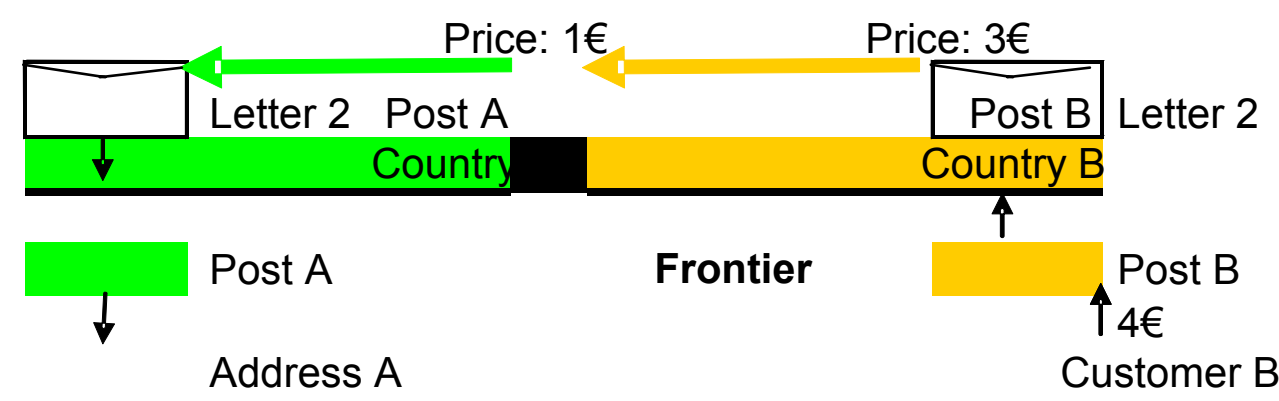

Again from the point of view of country A, the delivery of post as presented is an export service (sold to the Post B, located in the country B). The value of the export turnover is $1 €$.

\subsubsection{Overview of national methods}

Austria

For the compilation of SPPIs for postal activities under universal service obligation in Austria, data is collected from only one respondent, the national post company. On this account the index cannot be published. Currently the index calculation is based on official postal tariffs which can be obtained via the internet. The direct use of prices of repeated services pricing method is employed. The various resulting sub-indices (parcels, letters, etc.) are aggregated by turnover weights provided by the national post agency.

The direct use of prices of repeated services method is also employed for other postal and courier activities. Price determining characteristics are size, weight, destination and speed of delivery and the prices are provided by the respondents inclusive of discounts. The index for other postal and courier activities is published as there are an adequate number of respondents.

\section{Canada}


The courier and messengers service price index - CMSPI (NAICS 492) measures the change over time in prices for courier and messenger services provided by long and short distance delivery companies to Canadian based business clients. The courier service portion includes deliveries within and between Canadian cities and provinces/territories, as well as some international deliveries. The local messenger portion tracks price change for within-city deliveries only.

The sample and weighting information are derived from establishment revenue data obtained through the business register frame in Statistics Canada. The sample of courier establishments consists of five of the largest establishments accounting for approximately $80 \%$ of the operating revenue generated by the industry.

Model pricing is used taking into account the following specifications for courier services prices: geographical, type of parcel by weight and speed of delivery. For local messenger business enterprises the specifications are simpler. Several cities of each Canadian region are selected and only two services are priced: delivery in 1 hour or less, and delivery of 3 to 4 hours.

No index is compiled for NAICS 491 - Postal services.

\section{France}

In France, field-officers visit each respondent and identify representative service transactions. A mix of pricing methods is employed including, the direct use of prices of repeated services, unit values and contract pricing. The coverage of services for which prices are collected is limited to the mailing of items of correspondence up to $2 \mathrm{~kg}$ letters sent to businesses and households under USO. Unaddressed postal advertising, express delivery and urban messengers are not covered.

\section{Hungary}

In Hungary, the SPPI for postal and courier service activities covers both postal activities under USO and other postal and courier services. Data are collected by quarterly questionnaires since 2007 . The general pricing methodology with a standard product list was developed in close cooperation with respondents. A respondent initialisation survey was used to develop customised questionnaires for each respondent, based on the detailed service transaction specifications provided. Both BtoB and BtoC prices and turnover are collected from the Hungarian post office. The unit value pricing method is employed.

Other postal and courier respondents mainly provide BtoB prices. For these respondents a mixture of pricing methods is applied including; direct use of prices of repeated services, contract pricing and unit value pricing.

Currently, indices for BtoB service activities as well as BtoAll indices are compiled and transmitted to Eurostat. Sales to businesses account for about $75 \%$ of total output and the BtoB index is significantly lower than the separately compiled CPI for postal and courier services. The SBS survey was expanded to allow for the estimation of the turnover generated to $\mathrm{BtoB}$ and $\mathrm{BtoC}$ service activities. This will facilitate the calculation of a BtoAll index as a weighted average of the BtoB and BtoC indices.

Indices for both NACE 53 - Postal and courier activities, and NACE 53.2 - Courier activities, are published. Separately, the index for postal services is not published for reason of confidentiality.

\section{Spain}


In Spain the index for postal and courier includes both postal activities under USO (NACE 53.1) and other postal and courier activities (NACE 53.2). The observation units are selected using the cut-off method. The largest business enterprises are included such that a significant percentage of the turnover is covered.

The main price determining characteristics used to define representative service transactions are; destination of delivery, weight of parcels and time of delivery.

The index for postal activities under universal service obligation is calculated using official tariff prices, while the index for other postal and courier activities employs the direct use of prices of repeated services method.

\section{Sweden}

The national post index (NACE 53.1) is compiled using list prices collected from the Internet. The selection of representative service transactions was chosen in cooperation with the national postal service which also provides annual turnover data to calculate weights. This index is not published due to reason of confidentiality but it is included in higher aggregates, as well as in the overall SPPI.

In Sweden, class 53.20 of NACE - Other postal and courier activities is divided into three subclasses; other postal services, courier services and distribution of newspapers. Just over $50 \%$ of the turnover in the class comes from distribution of newspapers. Representative and constant quality service transaction prices are mainly measured through direct use of prices of repeated services. Each service transaction is specified with price determining factors, such as client, type of delivery, weight or size of delivery, time of delivery, dispatch and destination.

Only BtoB prices are collected but the index for other postal and courier activities is considered as a BtoAll index as the class covers services that are provided to consumers.

\section{The Netherlands}

Since April 2009, the key legislation regulating postal activities has been the Dutch Postal Act 2009. This Act requires a designated postal provider to perform the universal postal services in the Netherlands. The index for NACE 53.1 - Postal activities under universal service obligation, is calculated using list prices. Price quotations for the fifteen most representative services are collected and aggregated by a weighted average. Service products covered include services provided to both households and businesses. This index is not published for reason of confidentiality, but it is included in higher aggregates, as well as in the overall SPPI.

Class 53.20 - Other postal and courier activities, is divided into two subclasses: courier services and non-universal postal services. For couriers, three different types of prices are collected: list prices, fictitious (model) prices and prices of real transactions (i.e. direct use of prices of repeated services). Factors taken into account are: weight and/or size, duration between pickup and delivery, destination, insurance, tracking, inclusion of customs formalities, inclusion of extra services and bulk discounts. The index for courier services is published.

For non-universal-postal services (mainly services for the delivery of bulk letters, bulk printed matter such as advertising, magazines and unaddressed mail items) a limited number of respondents are active. The index for non-universal postal services is not published for reason of confidentiality, but it is included in higher aggregates, as well as 
in the overall SPPI. For division 53 - Postal and courier activities, only business enterprises delivering nationwide are surveyed.

\section{United Kingdom}

The provision of courier activities covers the collection from the premises of the customer of relatively small consignments of documents, parcels or lightweight freight (often single items) and delivery to the destination by a specific time. For these personalised services, customers are willing to pay a premium price for guaranteed doorto-door, secure delivery. It is estimated that about $95 \%$ of activity is produced for business users. Couriers and express freight operators utilise all forms of road vehicles (bicycles, motorcycles, cars, vans and heavier goods vehicles) and air transport (both scheduled and non-scheduled) as well as the rail network due to the growth of high speed inter-city and continental links.

The vast majority of service producers publish highly detailed tariffs for the services they provide and the geographical locations covered. The key price-determining criteria are: the nature of the consignment - mail, documents, parcels or freight; the weight of the consignment; the destination - geographical areas are divided into tariff zones, the more zones crossed the higher the charge; the timing for delivery; and any special features (highly valuable consignments or hazardous material, for example). The destination and speed of delivery also dictate the model(s) of transport required, which is another important factor. Some service producers add a charge for insurance of goods in transit as standard; others offer it as an option to the customer. The published data for courier services has shown a steady increase, for the most part, over the last five years. The main reasons for price changes in this industry are overheads, wages and fuel costs. Prices are collected in 9 categories, split by destination and timing of delivery as follows: same day, next day, other for destinations U.K., other EU, and rest of world. Prices are collected according to three methods: those based on actual contracts; those taken from quoted tariff rates (although these may not be the achieved rate in every case); or those representative of the charge companies would make for a particular delivery (a model contract).

\section{United States}

In the U.S., the direct use of prices of repeated services method is employed for both postal services and courier services. For postal services, prices are collected directly from a sample of reporting firms.

\section{Bibliography}

\section{Freight transport by road:}

Barzyk, F., (2007), Sector paper on freight transport by road (ISIC6023), $22^{\text {nd }}$ Voorburg Group meeting, Seoul, South Korea available at: http://www4.statcan.ca/english/voorburg/Documents/2007\%20Seoul/papers/06.pdf 
Goldhammer, B., and Ritter, L., (2006), SPPI for freight transport by road in Germany, $21^{\text {st }}$ Voorburg Group meeting, Wiesbaden, Germany available at: http://www4.statcan.ca/english/voorburg/Documents/2006\%20wiesbaden/papers/09.p df

Murphy, J., (2006), Road transportation of freight turnover measures and practices at the U.S. Census Bureau, $21^{\text {st }}$ Voorburg Group meeting, Wiesbaden, Germany available at: http://www4.statcan.ca/english/voorburg/Documents/2006\%20wiesbaden/papers/15.p $\underline{\mathrm{df}}$

Palmer, N., and Jones, K., (2002), Price index for freight transport by road, $17^{\text {th }}$ Voorburg Group meeting at Nantes, France, available at:

http://www4.statcan.ca/english/voorburg/Documents/2002\%20nantes/papers/2002003.pdf

Uwe, K., (2006), The PPI for road haulage services in the Netherlands, $21^{\text {st }}$ Voorburg Group meeting, Wiesbaden, Germany available at: http://www4.statcan.ca/english/voorburg/Documents/2006\%20wiesbaden/papers/11.p $\underline{\mathrm{df}}$

Williams, D., Subrail, S., Boling, P. and Eales, R., (2006), Producer price indexes for road freight services within Australia, $21^{\text {st }}$ Voorburg Group meeting, Wiesbaden, Germany available at: http://www4.statcan.ca/english/voorburg/Documents/2006\%20wiesbaden/papers/07.p $\underline{\mathrm{df}}$

\section{Sea and coastal water transport:}

Eurostat, (2012), PEEIS in focus, a summary of the services producer price index, Luxemburg.

IMF, (2009), Balance of payments and international investment position manual (BPM6), International Monetary Funds, Washington, DC.

Olsson, Th., (2009), SPPI for freight water transport in Sweden, $24^{\text {th }}$ Voorburg Group meeting, Oslo, Norway, available at:

http://www.voorburggroup.org/Documents/2009\%20Oslo/Papers/2009\%20-

$$
\text { \%2049.pdf }
$$

- $\quad$, (2010), Sector paper on water transport, 25 ${ }^{\text {th }}$ Voorburg Group meeting, Vienna, Austria, available at:

http://www.voorburggroup.org/Documents/2010\%20Vienna/Papers/2010\%20-

\%2002.pdf

Roemer, P., (2009), Producer price index for water transportation in Germany, $24^{\text {th }}$ Voorburg Group meeting, Oslo, Norway, available at:

http://www.voorburggroup.org/Documents/2009\%20Oslo/Papers/2009\%20\%2051.pdf

UNCTAD (2011), Review of maritime transport, United Nations Publication, New York and Geneva.

Air transport:

Collins, S., (2003), Producer price index for scheduled passenger air transport services a summary, $18^{\text {th }}$ Voorburg Group meeting, Tokyo, Japan, available at: 
http://www4.statcan.ca/english/voorburg/Documents/2003\%20tokyo/papers/2003$\underline{081 . p d f}$

- , (2004), Producers price index for air passenger and air freight transport services, $19^{\text {th }}$ Voorburg Group meeting, Ottawa, Canada, available at:

http://www4.statcan.ca/english/voorburg/Documents/2004\%20ottawa/papers/2004-

023.pdf

Jenkins, Ch., and Puchter, Ch., (2011), Revisited paper - Adjusting for quality change: ISIC 51 - Air transport, $26^{\text {th }}$ Voorburg Group meeting, Newport, United Kingdom available at:

http://www4.statcan.ca/english/voorburg/Documents/2011\%20Newport/Papers/2011 \%20-\%2007.pdf

Norrman, V., and Tareke, M., (2003), PPI for scheduled air transport in Sweden, $18^{\text {th }}$ Voorburg Group meeting, Tokyo, Japan, available at:

http://www4.statcan.ca/english/voorburg/Documents/2003\%20tokyo/papers/2003057.pdf

Palmer, N., and Porcu, S., (2003), The development of the corporate services price index for business airfares in U.K., $18^{\text {th }}$ Voorburg Group meeting, Tokyo, Japan, available at:

http://www4.statcan.ca/english/voorburg/Documents/2003\%20tokyo/papers/2003046.pdf

Puchter, Ch., and Auer, J., (2003), The development of a PPI for scheduled passenger air transport services, $18^{\text {th }}$ Voorburg Group meeting, Tokyo, Japan, available at: http://www4.statcan.ca/english/voorburg/Documents/2003\%20tokyo/papers/2003033.pdf

- $\quad$, (2009), Revised sector paper on air transport (ISIC 51), 24th Voorburg Group meeting, Oslo, Norway, available at:

http://www4.statcan.ca/english/voorburg/Documents/2009\%20Oslo/Papers/2009\%20\%2058.pdf

Tareke, M., (2003), Producer price index for air transport in Sweden, $18^{\text {th }}$ Voorburg Group meeting, Tokyo, Japan, available at:

http://www4.statcan.ca/english/voorburg/Documents/2003\%20tokyo/papers/2003$\underline{057 . p d f}$

- $\quad$, (2004), Producer price index for air transport in Sweden, Appendix: Sweden, $19^{\text {th }}$ Voorburg Group meeting, Ottawa, Canada, available at: http://www4.statcan.ca/english/voorburg/Documents/2004\%20ottawa/papers/2004025.pdf

Page, W. J., (2004), The U.S: Producer price index for scheduled air passenger transportation, $19^{\text {th }}$ Voorburg Group meeting, Ottawa, Canada, available at: http://www4.statcan.ca/english/voorburg/Documents/2004\%20ottawa/papers/2004$\underline{024 . p d f}$

Warehousing and Storage, Cargo handling:

Draper, C., (2012), Wholesale and retail trade services, Joint OECD - Eurostat Task Force for the revision of the Methodological Guide for developing Producer Price Indices for Services, Paris, France. 
Goldhammer, B., (2010), Revisited sector paper on ISIC Rev. 45210 -Warehousing and storage, $25^{\text {th }}$ Voorburg Group meeting, Vienna, Austria, available at: http://www4.statcan.ca/english/voorburg/Documents/2010\%20Vienna/Papers/2010\% 20-\%2015.pdf

Lucier, J. L., (2004), The U.S. producer price index for refrigerated warehousing and storage (NAICS 493120). 19 ${ }^{\text {th }}$ Voorburg Group meeting, Ottawa, Canada, available at: http://www4.statcan.ca/english/voorburg/Documents/2004\%20ottawa/papers/2004$\underline{055 . p d f}$

\section{Courier and postal activities:}

Barzyk, F., (2005), Producer price index for couriers and messengers - appendix, $20^{\text {th }}$ Voorburg Group meeting, Helsinki, Finland available at:

http://www4.statcan.ca/english/voorburg/Documents/2005\%20helsinki/papers/2005-

09.pdf

Boling, P., and Garmonsway, P., (2005), Producer price indexes for postal and courier services, $20^{\text {th }}$ Voorburg Group meeting, Helsinki, Finland available at: http://www4.statcan.ca/english/voorburg/Documents/2005\%20helsinki/papers/2005-

$$
\text { 12.pdf }
$$

Eidman, U., (2010), A comparison of methods used to compile PEEIs in short-term business statistics, Statistics in Focus 52/2010, Eurostat.

Gac, D., and Holocsy, I., (2010), Revisited sector paper on courier activities (ISIC 4.0 53.20), $25^{\text {th }}$ Voorburg Group meeting, Vienna, Austria, available at: http://www4.statcan.ca/english/voorburg/Documents/2010\%20Vienna/Papers/2010\%2 $\underline{0-\% 2017 . p d f}$

Rémond-Tiedrez, I., (2008), Service producer price indices (SPPIs): a new European economic indicator, Statistics in Focus 103/2008, Eurostat, Luxembourg.

Stark, P., (2005), The U.S. producer price index for couriers NAICS 492110, $20^{\text {th }}$ Voorburg Group meeting, Helsinki, Finland available at: http://www4.statcan.ca/english/voorburg/Documents/2005\%20helsinki/papers/200503.pdf

Tareke, M., (2005), Producer price index for couriers services in Sweden - appendix, 20th Voorburg Group meeting, Helsinki, Finland available at: http://www4.statcan.ca/english/voorburg/Documents/2005\%20helsinki/papers/2005$\underline{13 . p d f}$

\section{Notes}

1. For example water transport industries generated $30 \%$ of the value added of transportation and storage total in Norway en 2009.In the European Union in 2010, water transport services generated $0.4 \%$ of value added of non-financial business economy total and $5.0 \%$ of the transportation and storage total. However, the importance of this industry varies widely from one country to another. Indeed, in 
2009 Germany accounted for $40.3 \%$ of the EU27's value added followed by Denmark, Italy, Netherlands and the U.K.. For more detailed information on Water transport services in the EU see: http://epp.eurostat.ec.europa.eu/statistics_explained/index.php/Water_transport_servi ces statistics - NACE Rev. 2

2. Note than an active European policy to promote short-sea shipping has been established given its high efficiency in terms of environmental performance and energy efficiency in order to meet the goal of the European sustainable transport policy. More at:

http://ec.europa.eu/transport/modes/maritime/short_sea_shipping/index_en.htm

Statistical data on short sea shipping for European countries are available at: http://epp.eurostat.ec.europa.eu/statistics explained/index.php/Maritime transport st atistics - short sea shipping of goods

3. The world 20 leading container ports for 2008-2010 includes 14 ports in Asia, 3 in Europe (Rotterdam, Antwerp and Hamburg) and 3 in North America (Los Angeles, Long Beach and New York/New Jersey).

4. UNCTAD (2011), pp. 10-1 \& 166-7.

5. UNCTAD (2011), p.75.

6. The Baltic Exchange, the physical headquarters for tramp ship brokerage in London, allows co-operation between ship-owners, charterers and brokers and provide shipping market information:

http://www.balticexchange.com/default.asp?action=article \&ID=1

7. UNCTAD (2011), p.73.

8. Note that the European countries are required to deliver SSPI covering sea and coastal water transport for both passenger and freight. However, among the 18 countries that publish an SPPI for sea and coastal water transport, half exclude passenger transport. See Eurostat (2012).

9. See IMF (2009), §4.136. The BPM6 highlights however that "an institutional unit that operates ships on the high seas and various territorial waters has its residence determined according to the criteria in paragraphs 4.131-4.135, and the economy of residence is not necessarily the same as the location where the ships spend the most time or the territory of registration of the ships. Additionally, the enterprise that operates the ships is not necessarily the same as the enterprise that owns the ships, such as where the ship operator has an operating lease from the ship owner, who is resident in another economy. The residence of the enterprise that owns the ship is determined according to the criteria in paragraphs 4.131-4.135. Flags of convenience used by enterprises do not determine the residence of the operator, and indeed a single shipping operator may have ships registered in several economies. Similarly, the residence of enterprises that charter ships is determined by the location of its own base of operations, rather than the flags or locations of particular ships. The base of operations does not necessarily equate to the location from which the enterprise is managed. A company operating mobile equipment may be legally domiciled in one economy but managed from another economy".

10. The experience of Statistics Sweden shows that "the tramp market changes over time and the distribution between time charter and one-way freight is variable. When the market is booming the freight owners want to assure that they have enough transport capacity and rent ships on the time charter market that thus grows. During a freight 
market depression the freight owner's are not interested in renting ships and the ship owners choose to operate on the one-way freight market. The consequence is that the time charter market decreases and the one-way freight market grows" (Olsson (2009), p. 11).

11. See Olsson (2010), p.6.

12. For example, the Hamburg Shipbrokers' Association, also known by its German acronym, VHSS available at: http://www.vhss.de/objectives_and_services.php

13. See, for example the dry cargo freight, UNCTAD (2011), p. 72.

14. See Olsson (2010), p. 6.

15. Eurostat (2012), PEEIs in Focus; A summary for the services producer price index, Luxembourg, Office for Official Publications of the European Communities, p. 14.

16. See definition in chapter 1.

17. See: http://www.oecd.org/regreform/sectors/34343050.pdf

18. See under section 6.6.10 on specific aspects.

19. As to the appropriateness of using CPIs to deflate the output of this industry, the Handbook on price and volume measures in national accounts (European Communities, 2001, p. 89) recommends: "The use of detailed CPIs to deflate output other than that consumed by households can be a B method if price developments can be shown to be similar for households and business. However, CPIs are unlikely to be suitable for the full range of postal services, because of the availability of discounts and the different range of products consumed by businesses. Using detailed CPIs for business purchases where it is known that businesses receive discounts or purchase a different range of products than households would be a $\mathrm{C}$ method."

20. See under section 6.6 .10 on specific aspects. 


\section{Chapter 7. Accommodation and food service activities}

This chapter presents practical guidance as well as main issues and challenges for compiling SPPIs for Accommodation (ISIC 55) and Food and beverage service activities (ISIC 56). 
The accommodation and food sector is closely linked to the development of the tourism economy and makes a considerable contribution to economic growth, employment, enterprise demography and to development in rural, peripheral or lessdeveloped areas. Measuring the value of accommodation and food service activities, both in current and constant prices, is therefore particularly important for countries with significant tourism activity. The sector also serves local clients and business customers.

However, it may be difficult to measure price changes at constant quality due to the bundling of services (including secondary activities classified under other industries), complexity in the pricing mechanisms employed and the burden of data collection.

The pricing mechanisms employed in the provision of accommodation and food services differ fundamentally. Consequently, the accommodation and food service industries are separately discussed in this chapter.

\subsection{Accommodation (Anne-Sophie Fraisse, OECD)}

\subsubsection{Industry description (ISIC 55)}

The accommodation division mainly comprises the provision of short-term accommodation, typically on a daily or weekly basis, for visitors and other travellers by hotels, motels, guesthouse, holiday homes, bed and breakfast etc. It also includes the supply of short-term accommodation services by camping grounds, parks as well as the provision of space and facilities for recreational vehicles and the provision of temporary or longer-term accommodation in single or shared rooms or dormitories for students, migrant and seasonal workers and other individuals. In most countries, the provision of short-term accommodation by hotels is the main focus of the SPPI. Campsite and other accommodation services are generally excluded from coverage as they have relatively small weights.

The hotel industry is a highly segmented and competitive market. First, different hotels target different market segments with a wide range of offers from luxury to economy. Second, hotels target different types of customers: business, leisure, meeting and groups, government, foreign, etc. Third, offers are also segmented by types of rooms for each individual hotel (from suite to single room). Moreover, the growing share and size of hotel brands tend to increase competition within the market. This has led to differentiated pricing mechanisms and to aggressive pricing strategies reinforced by high income elasticity of demand and the development of IT tools and electronic sales channels.

1. A higher income elasticity of demand: Spending on tourism related services generally decreases proportionally faster than consumers' income during an economic slowdown. A downturn in economic conditions is also likely to result in reduced business activity; this in turn may be reflected in fewer business trips and nights spent in hotels, as well as less corporate entertainment. ${ }^{1}$ This can lead to some price volatility and to numerous promotions, discounts, and rebates. Furthermore, political or economic uncertainties (for example, when exchange rates change rapidly) tend to lead to a diversion of tourism demand, resulting in shifts between outbound tourism and domestic tourism.

2. IT tools and electronic sales channels: The growing importance of the Internet has led to the development of alternatives sales channels to traditional travel agencies. Hotels usually have more than one sales channel in order to increase the sales of 
rooms, e.g. direct booking (including voice, mail, own on-line sales); online travel agencies; internet companies (e.g. Booking.com, Hotel.com); Global Distribution System (e.g. Amadeus, Galileo, Sabre) which is a reservation network in real-time owned and operated as joint-ventures by major airlines, car rentals and hotel groups; and Distribution Service Providers (DSP e.g. Pegasus, Leonardo) which connect hotel's reservation systems (GDS) with distributors (e.g. travel agencies). DSP companies provide a wide range of services including central reservation systems, electronic distribution services, commission processing and payment services, property management systems, and marketing representation services. All of these sale channels tend to strengthen market competition: Hotels have a preference for bookings made directly through their own websites rather than via intermediaries, not only to reduce intermediary costs but also to develop relationships with regular customers. However, from the buyer perspective, the non-direct booking sales channels allow the customer to compare multiple booking possibilities and prices. There is competition not only between hotels therefore, but also between different sales channels.

\section{Price determining factors, pricing mechanisms and strategies}

The price for a room (the daily room rate) is dependent on many factors, such as the calendar period, the physical specifications of the room (room size, ground/upper floor, suite/non-suite, smoking/non-smoking, room service, etc.), the specification of the hotel (location, star rating, hotel brands or independent hotel, amenities, services, number of employees etc.), the market competitors, the duration of stay, the rate of occupancy, and the number and type of guests

The number of employees is of particular importance as the accommodation industry is highly labour intensive sector with relatively low labour productivity that may lead to high labour costs.

Traditional pricing mechanisms aim to cover fixed costs including labour costs firstly and then to generate additional revenue. Therefore, hotels propose fixed room rates according to price determining factors mentioned above. Under traditional pricing mechanisms room rates may vary according to the season, but they do not vary in real time due to changes in demand. This is in contrast to newer dynamic pricing mechanisms.

Market segmentation, high sensitivity of demand and the development of IT tools and electronic sales channels have led to the development of dynamic pricing strategies in the hotel industry. Under dynamic pricing strategies, daily room rates can fluctuate according to demand and the rate for each customer segment in each of the sales channels is controlled by a revenue management system.

Dynamic pricing is one component of revenue management that includes different revenue optimising strategies (also used in the air passenger transportation industry). Revenue management combines price control, revenue flow control, distribution channel control, marketing activities and financial operations etc. (Forgacs 2010, 3). It is of particular relevance in cases where fixed costs are relatively high in comparison to variable costs. Three conditions are essential for revenue management to be applicable: $i$ ) a fixed amount of resource available for sale; ii) the services sold are subject to a time limit, after which they cease to be of value; iii) different customers are willing to pay a different price for using the same services.

The use of dynamic pricing in the hotel industry has led to a range of differentiated pricing mechanisms implying a wide variety of room rates within the same hotel. In other 
words, room rates may behave as a spot market, as the price of the exact same room can differ from one day to another. Indeed, revenue management is a mix of different revenue maximisation strategies and procedures (e.g. pricing mechanisms) that aim to increase the profitability of a hotel. It can be defined as a strategy whereby a hotel sets its prices based on real-time market information and often according to types of customer (business, leisure, group, government etc.) and how much each customer segment is willing to pay at that precise moment. The main pricing mechanisms are presented below:

- The 'Required Rate of Return' mechanism involves the determination of room rates that are sufficient to cover all costs and provide a profit that meets the owners' targeted return on investment;

- The 'Relative Room Size' mechanism involves estimating the number of square metres that will be sold on an average night, and then determining at what rate each square metre must be charged to provide the desired total accommodation revenue;

- The 'Revpar' (revenue per available room) mechanism involves finding the optimal balance between the pursuit of high occupancy levels and a quest for high average room rates charged.

Beyond these three main pricing mechanisms employed by the hotel industry, it is useful to understand how hotels set prices with reference to marketing strategies, under which price adjustments are applied in response to particular market and customer contexts:

- The 'loss leader' approach involves a service price (such as a room) that is advertised at a low in order to attract customers to the point of sale with the hope that they will purchase other product or service lines;

- The 'going-rate pricing' approach involves setting prices in line with competitor prices.

- 'Prestige pricing' occurs when a hotel sets relatively high prices in order to convey or re-enforce a high quality or luxury image.

- 'Product bundle pricing' involves bundling several services (e.g. 'bed and breakfast') into a package and offering it at a discounted rate.

- 'Volume discounts' can be provided to hotel customers who purchase a large number of rooms at one time or over the course of a year (this is primarily relevant to enterprises). Discounts based on time refer to out of season or early booking price reductions.

- 'Last minute pricing' has grown in significance with the advent of widespread internet access.

- 'Price lining' involves pricing different service products in a service range at various levels, dependent on size and features, to increase the size of the target market.

- 'Discounts based on place' refers to the fact that there can be price differentials across different sales channels. 


\subsubsection{Classification aspects}

\subsubsection{Industry classification}

Accommodation services, classified under section I - Accommodation and food service activities, division 55 - Accommodation, of the ISIC classification system includes the provision of short-term accommodation for visitors and other travellers. Some units may provide only accommodation while others provide a combination of accommodation, meals and/or recreational facilities. It also includes the provision of long term accommodation for students, workers and similar individuals. More precisely, division 55 of ISIC is split into:

1. Short-term accommodation activities (e.g. hotels, B\&Bs);

2. Camping grounds, recreational vehicle parks and trailer parks;

3. Other accommodation.

Accommodation excludes activities related to the provision of long-term primary residences in facilities such as apartments typically leased on a monthly or annual basis which are classified under Section L - Real Estate Activities.

A review of the other industry classification systems by activity (NACE, NAICS, and ANZSIC) shows that they closely concord with the ISIC classification. As shown in annex A, it should be mentioned that NACE and NAICS provide a greater level of detail than ISIC. In particular, the NACE classification distinguishes between 55.10 - Hotels and similar accommodation and 55.20 - Holiday and other short-stay accommodation such as cottages, chalets, cabins, etc. In addition, some European countries have created national derivations of the NACE classification to meet their requirements. At the opposite of the spectrum, the ANZSIC classification doesn't distinguish between different types of accommodation services and provides less detail than ISIC.

\subsubsection{Product classification}

The corresponding products for accommodation (ISIC 55) are classified in the groups 631 - Accommodation services for visitors and 632 - Other accommodation services for visitors and others of the CPC. As shown in annex B, the CPA is similar to the CPC although the CPA provides slightly more detail with a separate sub-class for Sleeping cars. The NAPCS is also concordant to the CPC classification.

\subsubsection{Scope of the survey}

Ideally, the survey should capture price changes in the accommodation sector as a whole. However as noted previously, camping grounds, recreational vehicle parks and trailer parks and other accommodation services may be considered economically less significant than those services classified as short-term accommodation activities. Moreover, the collection of price data for these sub-sectors of accommodation services is likely to prove difficult and resource intensive and so a pragmatic decision to cover only hotels may be appropriate. Short-term accommodation activities are therefore the essential component of the SPPI for accommodation with most countries focusing on service activities provided by hotels.

As such, it should be noted that some European countries exclude Holiday and other short-stay accommodation activities (55.20 NACE) from the scope of the survey. For 
example, in Ireland, a sizeable portion of accommodation supply in this class is unregistered. Furthermore, the use of administrative data generated by the taxation system is complicated by the fact that holiday or short-let accommodation services are often provided as a secondary economic activity by sole traders such as farmers. Therefore it is very difficult to identify, survey and compile statistics on these units.

The ideal survey of the hotels sector should track constant quality price change for the full range of service outputs to all end users. Business, households or leisure, government and foreign customers are the main end users of accommodation services. However in Canada it proved difficult to distinguish between government and foreign rates due to a lack of data for these two types of users. From a pragmatic approach, the survey could be produced on a BtoAll, capturing separate price data for the business and household sectors (that is by combining separate price indices for $\mathrm{BtoC}$ and $\mathrm{BtoB}$ ).

Three options are then available to produce a survey on a BtoAll basis with separate price indices for BtoB and BtoC end users: $i$ ) Design a dedicated SPPI survey to compile a full derived SPPI; ii) Design a partial SPPI survey often with the scope limited to business end users to be complemented with CPI data for the BtoC component. In this case, a suitable weighting structure may be applied to weight together both the SPPI and CPI components to produce a BtoAll index; iii) In collaboration with the CPI unit, prices offered to business and household end users are collected as part of the CPI survey.

It should be mentioned that the CPI for accommodation (covering only consumption by households) is used by many countries as a full proxy for the BtoAll SPPI. However, as discussed in chapter 2, CPI price data need to be adjusted so that they are valued at purchasers' prices, to basic prices by deducting any taxes including VAT and trade margins prior to their inclusion in the compilation of SPPIs.

The selection of one of these three approaches should be made with reference to the following questions:

- Do services provided to households and business users follow the same or similar price development? Compiling separate SPPIs for different service end users is an important requirement for the national accounts when price discrimination by type of end user results in heterogeneous price developments. In the particular case of accommodation services, business guests often pay a higher price than private guests, which affects the price levels on weekdays and weekends but not necessarily the price developments of the two. Therefore, it is necessary to assess the potential for business prices to display different trends to those of households. The use of CPI data as a full proxy for the SPPI may result in reduced burden and resource requirements but the resultant index may be of reduced quality;

- Are sufficient resources available to collect data using a dedicated SPPI survey? A full SPPI survey is designed to fully meet the requirements of the SPPI framework. However, it may be costly in terms of resources and burden. A partial SPPI survey (complemented with CPI data) may be designed to collect prices for services not covered by the CPI (conference/meeting, hosting, business customers) and to estimate the split of turnover by product and customer type (business, personal, government); this approach will result in an index of better quality than when only CPI is used. It should also generate considerable efficiencies and cost less than a full SPPI survey. 


\subsubsection{Industry vs. product based SPPI}

In the early stage of development of the SPPI for accommodation, a choice must be made between a product or industry based SPPI. Three questions must be considered:

1. What is the primary objective of the SPPI? As discussed in chapter 1, SPPIs serve two purposes that are normally not in conflict because they can often be reconciled in the SPPI development. If the primary objective for the development of an SPPI is to deflate national accounts data, then a product based SPPI would be preferable for the ideal SPPI survey (either partial or full). On the other hand, if the primary aim of the SPPI is to provide a short-term indicator of price movements then an industry based SPPI will be preferred;

2. Is an adequate sample frame available? One of the main difficulties in compiling a product based SPPI is the unavailability of an adequate sample frame containing turnover data at product level. These data are more generally available at the industry level;

3. What is the importance of secondary activity in the sector? The main advantage of a product based SPPI is its potential to cover all units producing relevant service activities whether these units are classified under accommodation or nonaccommodation industries. However, weighting these different products may be difficult. The industry based SPPI refers to those business enterprises for which accommodation activity is their primary activity. Therefore, any accommodation services produced as secondary activity by business establishments classified outside the accommodation industry is missed.

\subsubsection{Sample design}

First, information on the market structure of the industry (the respective shares of small, large, and chain establishments) should be collected - this can usually be sourced from industry representative associations or tourism statistics. Second, the sample design will depend on whether or not separate indices for different end users are required.

Probability Proportional to Size (PPS) sampling is generally recommended in the compilation of SPPIs. This method could be applied to the accommodation by using total room revenue as the indicator of the size of units. Options for stratifying the sample, by region or size may be used to improve efficiency of the sample. A mixture of nonprobability and random sampling may also be considered. This could ensure that the largest and most important units are always included in the sample, with the remaining units sampled randomly.

For example, in the U.K., the sample frame is stratified according employment size bands. Units from each stratum are sampled randomly except for the stratum containing the largest units which is fully enumerated. Prices may be collected from: $i$ ) an individual hotel which is not part of a chain; $i$ i) the head office of a complete hotel chain - providing data for the whole chain; iii) individual hotels which belong to a chain but return data solely for their hotel; $i v$ ) the head office of a chain where other hotels within the chain were represented individually.

\subsubsection{Collection of information and specification of the service}

As previously discussed, data collection for compilation of an SPPI that covers both business and household users can be conducted in three ways: $i$ ) via either a dedicated 
SPPI survey (e.g. Korea and the U.S.); ii) through the combination of a dedicated SPPI survey that is limited in scope with other existing sources such as CPI data, or iii) as part of the CPI survey (e.g. Canada). Pricing information from a variety of sources can be used to construct a price index for the accommodation sector including administrative data $^{2}$, survey data, prices collected from the internet, and prices collected for the CPI.

\section{Initialisation phase}

Collecting accurate constant quality price data for accommodation services requires that both the characteristics of the representative room(s) and room rate(s) are precisely defined.

First, during the initialisation phase, representative rooms are selected taking into account the following parameters:

- Location (capital city, seasonal location: mountain, seaside, etc.);

- Type of room (standard, executive, suite, etc.);

- Period of occupancy (weekdays, weekends, etc.);

- Date and length of stay;

- Number of guests (Double, single occupancy);

- Additional services included (e.g. breakfast, newspaper, use of leisure complex, etc.).

Second, the definition of the room rate must be fully defined with reference to the following:

1. Type of users: when compiling SPPIs by type of users it is important to define precisely how business and leisure room rates are identified: weekdays versus weekends, single versus double occupancy, business versus private guests;

2. Timing and frequency should be considered, keeping in mind that prices can be volatile. Different options can be used including the collection of an average room rate over the entire period (usually monthly). For the BtoAll SPPI the U.S. uses an average price for guestroom rental that covers the first 21 calendar days of the month, allowing for coverage over a large number of days, while still holding the number of weeknight and weekend nights constant;

3. Sales channels: ideally room rates for each establishment should be collected from each sales channel. However, this may be difficult and costly to implement and the identification of the most representative sales channel for each establishment may be a pragmatic solution;

4. Special events and public holidays.

In the U.K., the type of rate supplied is indicated on the survey form so as to facilitate the collection of prices for constant quality services. Three types of rates are described as follows (note that the U.K. compiles a BtoB SPPI only): i) Corporate Local: This applies to local businesses regularly using the hotel and known personally to the hotel sales staff; ii) Corporate National: This applies to businesses and government departments using the hotel chain nationally; iii) Preferred or Business House: This is the rate listed by booking agencies or travel agents, whereby the hotel pays commission to the agent.

Data collection 
After the survey initialisation phase is completed, each respondent is asked to provide an updated price on an on-going basis for the exact same service (as defined in the initial specification). Updated price information can be provided by respondents by telephone or through survey forms returned by mail, fax, post, or online submission.

Statistics Finland, in co-operation with reservation system software providers, has developed a standardised transmission system for receiving data directly from respondent reservation systems. This automated data transmission has significantly reduced the response burden. The environment for developing an automated data transmission has been favourable in Finland due to the limited number of reservation software providers. A common Nordic approach on automated data transmission has also been designed in cooperation with the other Scandinavian countries. In addition, the EU has shown special interest in promoting the system at the EU level, and has launched an ESSnet project on automated data collection and reporting for accommodation statistics.

\subsubsection{Main pricing methods}

The direct use of prices of repeated services and the unit value pricing methods are most commonly employed for accommodation services.

\subsubsection{Direct use of prices of repeated services}

Collecting list prices is no longer representative of prices charged given the development of reservation systems and pricing strategies in the sector. It is highly recommended therefore, to collect real transaction prices and to distinguish between business and leisure rates when separate SPPIs for different end users are required.

The direct use of prices of repeated services covers actual transactions and quality adjustment is facilitated by the detailed specifications provided for each service activity transaction. However, the method may not allow for the collection of prices that are representative of all transactions that occur in a hotel. As noted previously, prices for the same hotel room can fluctuate on a daily basis and can also be heavily influenced by public holidays and local events. A spot price or repeat service price may not therefore be sufficiently representative. Moreover, the increased use of online booking channels has had a dramatic effect on hotel pricing strategies. Discount bookings made via the Internet may not be taken into account when using the direct use of prices of repeated services. In other words, discounts and promotions available exclusively on the internet may be missed.

\subsubsection{Unit value}

The unit value method is a valuable alternative approach that has been adopted in many countries compiling SPPIs for accommodation services. Typically an average room rate - the total hotel revenue divided by the number of occupied rooms - requires sufficiently homogenous subsets of service outputs including appropriate data on revenues and room numbers for each sub-group. For example, Sweden collects three types of average room rates which distinguish different end-users: $i$ ) average invoiced price per occupied room, business guests; ii) average invoiced price per occupied room, private guests; iii) conference day with full board, single occupancy.

The main advantage of this method is that representative service transactions are recorded for each type of customer. This method is employed in the U.S. in order to 
overcome some of the deficiencies of the direct use of prices of repeated services discussed previously.

Consideration must also be given to the most appropriate reference period during which information is collected. Sweden collects an average rate over an entire month while Finland collects price information between the $10^{\text {th }}$ and $15^{\text {th }}$ day of the month. The U.S. collects an average daily rate (ADR) encompassing the first 21 days of a month in order to hold the number of weekend dates (6) within a referenced month constant from month to month. This is important since rates for weekend dates often exhibit different price behaviour than those for weekdays. Note however, that the U.S. compiles a BtoAll SPPI for accommodation. Some respondents to the U.S. survey find it difficult to report the ADR for specific room types at the property, since the standard industry practice is to track the ADR across all rooms at the property.

Product-mix is therefore the main issue when using unit value. As single and double occupancy rates may be mixed and weekday and weekend rates combined the unit value method does not allow for compilation of SPPIs by end users. Additionally, a change in the mix of room types sold may be interpreted as a price change rather than a quality change. This poses problems in producing a standard quality price index unless appropriate breakdowns of revenues and room types can be obtained.

\subsubsection{Quality issues}

Precise specification of accommodation services is necessary and must be kept constant over time. The control of quality change over time is easier when the direct use of prices of repeated services rather than the unit value method is employed. When collecting average room rates, special attention needs to be paid in the bundling of services. The basic service, the room, is often bundled with other services such as breakfast, room service etc., so care must be taken in accounting for any changes to bundled services.

In the U.S. quality adjustments are performed if the service output has fundamentally changed due to renovations or upgrades to room amenities. If a property undergoes a renovation, producer cost data could be used to determine the percentage of total price change that is attributable to the renovation. However, because it is very difficult to obtain producer cost data from respondents, such quality adjustments have not been implemented in practice.

\subsubsection{Weighting and aggregation}

The sources of weight data vary between countries and are greatly influenced by the target coverage of the SPPI - separate SPPIs for different end-users or a single BtoAll index.

Annual product level turnover data should ideally be used in the weighting schemes of SPPIs. In practice, only a limited number of countries produce annual product level information and therefore industry level data or tourism statistics (e.g. Sweden) tend to be used in the weighting of SPPIs.

\subsubsection{Specific aspects}

Only a limited number of countries compile and publish SPPIs for accommodation service activities. There are two main reasons for this: $i$ ) there is often little demand for a 
detailed SPPI given the availability of a CPI for accommodation services, especially as volume estimates for this sector are usually calculated using the $\mathrm{CPI}$; ii) index compilation faces the following challenges:

1. Costly and burdensome collection of data;

2. Development of alternative distribution channels such as online sales makes it difficult to collect representative prices covering all transactions that occur in the market. In this regard, the development of Mobile Applications designed as easyto-use booking channels should also be mentioned and considered in the future;

3. The bundling of services.

\subsubsection{Overview of national methods \\ Canada}

Canada compiles BtoB, BtoC and BtoAll SPPIs for traveller accommodation services. These SPPIs cover establishments classified as Hotels (except Casino Hotels) and Motels (72110 of NAICS 2007) and Casino Hotels (721120 of NAICS 2007) whose annual sales from accommodation services exceeded 250,000\$ CAD. Only primary activities of establishments are considered, namely the provision of rooms for an overnight or short stay without any meals or other services provided.

By definition the traveller accommodation index should cover leisure, business, government, and foreign client groups as requested by the System of National Accounts for deflation. However, distinguishing government and foreign rates has been a challenging issue due to a lack of data for these two groups. Statistics Canada has then decided to suppress these two indices and only provide SPPIs covering leisure and business groups.

Respondents are selected using the PPS method. Typically, the largest establishments are selected into the sample with a probability of $100 \%$ and the probability of selection for the remaining establishments is proportional to the total room revenue of the establishment in their tourist region.

Data is collected as part of the CPI program, where regional interviewers obtain the necessary information from respondents through visits or by phone. Interviewers visit most respondents when they are initiated into the survey sample. The purpose of the visit is to select two rooms deemed to be representative of the typical rooms rented during the month. In fact, these two rooms should best represent a double-occupancy room for leisure clients, and a single-occupancy room for business clients. After the initial visit, room rate information is collected from each respondent by telephone.

Statistics Canada uses the direct use of prices of repeated services by collecting real transaction prices. As mentioned above, data is collected as part of the CPI program: price data for leisure group are collected and adjusted for other services provided and excluding all indirect taxes; the applicable rate is the weekend rate for the third weekend of the month, booked three weeks in advance. The applicable rate for business group is the weekday rate for the third Wednesday of the month, booked three weeks in advance is surveyed.

All attempts are made to keep the specifications (i.e. type of rates and conditions) constant, so that only pure price changes are recorded. Interviewers request information regarding the reasons for reported price changes and details pertaining to non-standard 
items included in the current price of the room (e.g., meals) that would not have been covered in the price quoted for the previous month. This information is used to adjust room rates so that they always reflect prices for the same services over time.

The direct use of prices of repeated services method has the advantage of measuring effective transactions and facilitating the quality adjustment. However, this methodology doesn't take into account Internet pricing which could miss promotions and discounts.

\section{Finland}

Accommodation services are highly seasonal in Finland. Many accommodation service providers only open for the winter or summer season. In the winter, Northern Finland is very popular for different kinds of snow related activities and, in the summer, summer cottage type accommodation services are more in demand. An interesting characteristic of the Finnish hotel business is that there is no official rating system for the hotels. However, the chaining of hotels has been increased in years. In 2005, only 58\% of the national hotel room capacity was held by hotel chains, whereas in 2010 the share was around $64 \%$ and increasing. Another important characteristic is that domestic (i.e. Finnish) guests account for the majority (over 70\%) of nights spent at accommodation establishments.

Prices of hotel accommodation services are measured by both the SPPI and CPI. The SPPI accommodation price index refers to the price of a single room for one night during a weekday (reflecting representative stays by business guests) while the CPI refers to the price of a double room for a weekend (representing representative stays by private guests).

The direct use of prices of repeated services is the main pricing methods used as it can be employed relatively easily. Both real transaction and list prices are collected. The unit value method has also been considered but Statistics Finland has experienced difficulties with this approach due to the fact that many respondents cannot calculate unit values for different types of rooms (accounting systems do not provide these values automatically). Average price for all rooms were available but these mixed single, double and family rooms as well as weekday and weekend rates. This mix of different service products made it impossible to produce a constant quality price index.

Data are collected monthly between the 10th and 15th day of the month. The CPI team collects both consumer (double room, weekend) and BtoB SPPI (single room, weekday) prices as part of the same data collection process. The CPI is published as a monthly index but the SPPI for accommodation is published as a quarterly figure.

No quality adjustments are performed as it is assumed that there are no quality changes between accommodation services bought from one month to the next. It could be argued that there are differences in quality, especially in respect of holidays. Accommodation services might be more expensive during holidays (Christmas, Midsummer, Easter, etc.) as demand is higher. However, Statistics Finland has chosen to focus on the yearly changes in prices and not to make any quality adjustments.

\section{Japan}

Japan compiles price indices for service provided by hotels (mainly budget hotels), excluding food and beverage services. Japan uses the direct use of prices of repeated services and the unit value method, i.e. monthly revenue per effective room. 


\section{Sweden}

Sweden publishes SPPIs for different end users including business guests, private guests, conference guests, and all users are published for Hotel and similar accommodation services. . This level of disaggregation is required due to the fact that business guests usually pay a higher price than private guests and price development for the two end user types differs. As the rate of occupancy is usually is lower on weekends, and especially around holidays, prices are also lower. Holidays such as Christmas and Easter have a big impact on average monthly prices. There are fewer stays by business and conference guests during the summer season time leading to price reductions during these months. Price increases can be observed in September which is the most popular month for conferences.

Therefore, the three most important price determining characteristics are the type of guests, rate of occupancy and the presence of events that increase demand for accommodation services. Some hotels also refer to the economic downturn and increased competition between hotels as reasons for lower prices.

Given that large price fluctuations, sometimes up to $50 \%$ from one month to the next, can be observed, the Average Room Rate appears to be the best pricing method for hotel rooms. A potential problem could be that single and double occupancy are mixed. Most hotels claim that the mix is constant over time and should not therefore affect price development. Rooms with two beds are often rented to just one person, for the price of single occupancy. Collecting separate prices for single and double occupancy rooms does not necessarily solve this problem.

Hotels with less than 10 employees are excluded from the SPPI sample in order to reduce burden for the smallest hotels.

Statistics Sweden employs the unit value method for pricing accommodation services. An average quarterly invoiced price is collected for the three following categories of room rates:

1. Average invoiced price per occupied room, business guests;

2. Average invoiced price per occupied room, private guests;

3. Conference day with full board, single occupancy.

Weights are derived from the Accommodation Statistics Survey that collects detail on the number of rooms occupied rooms by business, private and conference guests. The Accommodation Statistics Survey also collects the total accommodation revenues and numbers of occupied rooms, which allow for the calculation of average revenue per occupied room, known as the Average Room Rate (ARR). The ARR equates to the average invoiced price per occupied room collected in the SPPI survey. Statistics Sweden also compares the results from the Accommodation Statistics Survey to the total SPPI index as the indices should show a similar development.

\section{United-Kingdom}

According to the United Kingdom Standard Industrial Classification of Economic Activities (SIC) 2007, hotels and similar accommodation service activities are classified under section I, division 55 - Accommodation. SIC 2007 is identical to the NACE at the 4-digit class level and ISIC at the 3-digit group level. 
The U.K. SPPI for hotels and similar accommodation is split into two main categories: "London" and "Rest of the U.K.". "London" has a weight of $84 \%$ within the index and the "Rest of the U.K." has a weight of 16\% (for the base year 2010). Each of these categories is then split into four areas: Bedroom accommodation, daily delegate rate, 24 hour residential rate and conference/exhibition room hire.

The index uses direct use of prices of repeated services where possible, with model pricing used where this is unavailable. After prices are collected, any atypical or extreme measures are queried with the respondent to confirm that reported price changes reflect pure price change, rather than a change in the quality of service defined in the item specification.

Prices for the index are collected via quarterly questionnaires. In the sample selection, a weighted stratified simple random sampling technique is applied; where potential respondents are stratified by size (employment size band) and industry (SIC '07 classification). Turnover data for this index are collected using the Service Turnover Survey (STS).

Prices are collected from a range of hotels. The service transaction descriptions include the type and size of room being priced, facilities included in the price, any food and drink included and booking duration. Where the hotel is part of a chain the specific hotel is also detailed in the description. Currently 374 prices are collected from 126 suppliers.

The requirement to provide separate accommodation service transactions for business customers, rather than private individuals may present a challenge to respondents. Some hotels will have a separate price-list for business guests, and may even provide special reduced rates for businesses. However some hotels may not be able to distinguish between business and private rates for individual rooms. Where this is the case it is assumed that businesses and private transactions are priced in the same way. Another issue found when collecting prices for this index is that often hotels do not utilise set tariffs. Prices can change daily and are dependent on demand, availability and seasonality.

The other three categories included in the SPPI relate more directly to corporate services. For the most part the services priced relate to the hiring of facilities for meetings and conferences and are charged per delegate. Although in the case of the conference/exhibition room hire, it can difficult to collect regular prices as they can be hired out for private functions such as weddings. Where this is the case a model price can be collected.

\section{United States}

The U.S. compiles a BtoAll SPPI for accommodation services for establishments classified as Hotels (except Casino Hotels) and Motels (721110 of NAICS 2007) and Casino Hotels (721120 of NAICS 2007).

The U.S. SPPI covers all services offered to guests and the general public by hotels/motels and casino hotels that are classified as primary activities. Noted that in addition to the provision of lodging, the following activities are also included as primary activities: $i$ ) food and beverage services, including restaurant services, room service, and banquet and catering services; ii) other hotel services, including telephone services, internet access charges, laundry services, parking fees, retail sales of food or merchandise; and iii) casino gaming. Moreover, secondary activities are also covered. 
The only services that are considered secondary to these industries are services that are not provided to the general public, such as the leasing of hotel space to a retail tenant.

Respondents, selected via PPS sampling, provide on a monthly basis price data based on their selling prices to all possible buyers (BtoAll). Consequently, the prices collected include sales to businesses as well as households. During the initial data collection period, items are selected and initial prices are collected through in-person visits by data collectors. In subsequent periods, updated price information is provided by respondents through survey forms returned by mail, fax, or online submission.

The preferred pricing method is the unit value method. As mentioned previously, the ADR for selected room types based on turnover from the provision of lodging in these rooms divided by the paid room nights during a specific time period (such as the first 21 days of the month or all days in the calendar month) is collected monthly. Room nights refer to the sum of the total number of rooms booked for all nights in the reference period. Collecting the ADR allows for the inclusion of all transactions that occurred for a selected room type, during the designated time frame. The rate charged for a specific room can vary dramatically from day to day based on occupancy levels and other market conditions. Collecting an average price based on an extended time period captures all of these transactions and is therefore very representative of on-going price development. However, some respondents may be unable to report the ADR for specific room types at the property since the standard industry practice is to track the ADR across all rooms at the property. Consequently, in instances when an ADR across all room types is collected, changes in the mix of room types sold can impact the movement of the ADR figure.

If ADR figures cannot be reported, transaction or list prices for lodging only are collected. They typically reflect the rate that would be charged on the monthly re-pricing date, which is always the Tuesday of the week containing the 13th of the month. Since these prices are collected for the same room type, price changes typically are not the result of changes in product mix. However, these types of prices are not representative of all transactions produced by an accommodation services provider. While the fees charged to certain groups (such as individual travellers, business travellers, travel agents, $3^{\text {rd }}$ party booking sites, etc.) may stay constant over a period of time, accommodation providers may receive different effective prices by shifting available room inventory between these buyers. For example, if demand is low, hotels may make additional inventory of rooms available to $3^{\text {rd }}$ party booking sites that pay a lower price than individual travellers. While unit value methods capture these effective price changes, transaction and list pricing methods do not. Since the output is the same regardless of the buyer type, the ideal survey should capture these shifts as price changes.

Quality adjustment is performed if the service output has fundamentally changed due to renovations or upgrades to room amenities. If a property undergoes a renovation, producer cost data could be used to determine the percentage of total price change that is attributable to the renovation. However, because it is very difficult to obtain producer cost data from respondents, such quality adjustments have not been implemented in practice.

\subsection{Food and beverage service activities (Anne-Sophie Fraisse, OECD)}

Only a limited number of OECD and European countries compile SPPIs for food and beverages services. The reasons for this are twofold: i) a large component of output from the food and beverage sector goes to final demand, in particular to households. Consequently, the demand for an SPPI for this sector is relatively low because a CPI can 
serve as a suitable proxy. Specifically, the CPI for catering services (group 11.1 of the COICOP classification) which covers consumer food services for restaurant and mobile food services, cafeterias, take-away, beverages (class 11.1.1 - Restaurants, café and the like) and canteens (class 11.1.2 - Canteens) is extensively used by national accountants as a deflator for the sector; ii) Because, over the last decade, the primary focus for development of SPPIs has been on business services, namely services that are mainly aimed at uses other than household consumption.

Nonetheless, as for the accommodation sector, the development of SPPI for food and beverages services may be valuable for countries with an important tourism economy but also to correctly measure the value of these services, both in current and constant prices by covering business service activities that are not covered by the CPI.

\subsubsection{Industry description (ISIC 56)}

The food and beverage service activities division comprises the provision of meals and/or drinks fit for immediate consumption whether in bars, restaurants, cafeterias, or from take away restaurants. The division also includes the provision of meals by event and industrial catering and canteens based on contractual arrangements with the customers, for a specific period of time and/or for a specific event.

The food and beverage industry is dominated by a large number of micro and small sized enterprises (e.g. in Canada micro establishments (1-4 employees) represented $27.7 \%$ and small establishments (5-99 employees) represented $70.5 \%$ of the total establishments in 2011). Franchises (e.g. McDonalds, Starbucks, and Subway) and catering companies (e.g. Compass Group, Sodexho, and Elior) also play an important role in the sector.

\section{Price determining factors, pricing mechanisms and strategies}

The price that a food and beverage service producer charges for a meal or a drink depends on many factors such as the type of meal (i.e. breakfast, lunch, dinner, reception, etc.) or drink (alcoholic, non-alcoholic, etc.), the composition of the meal (e.g. appetizer, entree, dessert, and beverage), the basis of meal selection, (i.e. fixed-price, à la carte, buffet), the ingredients used, the service provided and the specification of the place (location, star rating, the ambience and decor of the establishment, brand (franchise), etc.), the market competitors, the type of end-users, and the number of employees.

Specifically for canteens and catering services, the duration of the contract can vary from a single event (such as banquet or a reception) to years of service (such as canteens for offices, schools, etc.). Since the type of end-user is more likely to be diverse for this type of contractual service, it is desirable to include the type of end-user (households, business, government) as a price determining factor.

Similar to the provision of accommodation services, food and beverage service activities are highly labour intensive and associated with a low apparent labour productivity that may lead to high labour costs reinforced in some instances by a lack of qualified workforce. National regulatory and legislative conditions must also need to be considered when analysing price determining factors in the sector. Likewise, volatility of commodity/input prices and of energy prices largely influenced prices in the sector.

Traditional pricing mechanisms aim to cover fixed costs including labour costs first and then to generate revenue. Therefore, restaurants and other food and beverage service producers propose fixed prices according to the price determining factors mentioned 
above. A specificity of the sector is the reluctance of restaurants to frequently change their menu prices which may lead to little or no price change over consecutives periods. However, restaurants may use alternative pricing strategies such as: $i$ ) "early bird special offers dinner" where specials are used to entice customers to arrive at the restaurant early (bars use "happy hours" as a similar pricing strategy); ii) "coupons" which are used to win new customers who may be more willing to try a restaurant if offered a discounted price; and, iii) daily specials.

\subsubsection{Classification aspects}

\subsubsection{Industry classification}

Food and beverage service activities are classified under section I - Accommodation and food service activities, division 56 - Food and beverage service activities of ISIC classification system. This division includes food and beverage serving activities providing complete meals or drinks fit for immediate consumption, regardless of the type of facility supplying the service; sit-down and take-away restaurants are included, as well as bars, canteens and catering services.

The key criteria for food service activities included in this division is the fact that meals fit for immediate consumption are offered rather than the kind of facility providing them. Leased food-service locations in facilities such as hotels, shopping malls, airports and department stores are included while food service activities that occur within establishments such as hotels, civic and social associations, amusement and recreation parks, and theatres are excluded. In the latter case the food services provided would be considered a secondary activity. The provision of food or drinks that are sold through independent distribution channels, in other words through wholesale or retail trade activities (section G of ISIC) is also excluded.

Division 56 of ISIC classification system covers three main activities:

1. Restaurants and mobile food service activities;

2. Event catering and other food service activities;

3. Beverage service activities (e.g. Bars, pubs, coffee shops, mobile beverage vendors etc.).

As shown in annex A, the NACE classification mirrors that of the ISIC while the NAICS and ANZSIC classifications provide much greater detail for services provided by restaurants. However, ANZSIC does not distinguish between food and beverage service activities.

\subsubsection{Product classification}

The corresponding products for ISIC 56 - Food and beverage activities, are classified in the groups 633 - Food serving services, and 634 - Beverage serving services, of the CPC classification system. As shown in annex B, the CPA is similar to the CPC although the CPA provides slightly more detail. Both of these classifications are organised on an industry-of-origin basis using the criteria of the units providing those services. The more detailed NAPCS, on the other hand, uses the characteristics of the service produced which results in greater product detail. 


\subsubsection{Scope of the survey}

Ideally the SPPI should capture constant quality price changes in the food and beverage services sector as a whole for the full range of output to all end users. It should capture separate price data by type of users for each of the following three main activities: i) Restaurant and mobile food; ii) Catering services; and iii) Beverage serving activities and capture separate price data by type of users.

Restaurant, mobile food and Beverage serving activities (classes 5610 and 5630 of ISIC)

As for accommodation services, business, households or leisure, government and foreign customers are the main end users of food and beverage services. Most surveys however distinguish only two types of end-users, business and households customers. It can reasonably be assumed that restaurant and mobile food service activities (ISIC 5610) and beverage serving activities (ISIC 5630) are not, or only slightly, differentiated by end users. In this case, price movements should not significantly differ for business and household customers (however, the weighting structure may be rather different).

From a practical point of view, it is sensible to design a survey capturing price changes on a BtoAll basis for both of these activities. Two approaches can however be considered: $i$ ) consistent with the SPPI framework described in this Guide, a dedicated SPPI survey covering all types of users can be designed; $i$ ) considering the fact that most OECD and European countries compile a CPI for catering services (consistent with COICOP classification, group 11.1), the CPI may be considered as a reasonable alternative of the SPPI. ${ }^{3}$ The main notable exclusion from the CPI for catering services is the food and drink provided to hospital in-patients. Ideally, according to the share of this service activity, it requires a special treatment within the SPPI framework.

Event catering and other food service activities (classes 5621 and 5629 of ISIC)

A survey for these two service activities would be ideally designed on a business-toall basis (BtoAll), capturing separate price data for households and business sectors. Both households and business are end-users of event catering, while the operation of canteens or cafeteria for factories, offices, hospitals or schools (5629 of ISIC) covers mainly BtoB activities. Here again two approaches can be considered: i) a dedicated SPPI survey would be designed on a business-to-all basis (BtoAll), capturing separate price data for households and business sectors such as canteens or cafeteria for factories, offices, hospitals or schools; ii) a partial SPPI survey for the business-to-business component, perhaps complemented by CPI data for the BtoC component. In this case, a suitable weighting structure may be applied to weight together both the SPPI and CPI components to produce a BtoAll index.

\subsubsection{Industry vs. product based SPPI}

Ideally, the SPPI would be product based as described by the U.K. and U.S. experiences presented under the Overview of national methods.

\subsubsection{Sample design}

First, information on the market structure of the industry (the respective shares of small, large, and chain establishments) should be collected - this can usually be sourced from industry representative associations or business statistics. Second, the sample design will depend on whether or not separate indices for different end users are required. 
Probability Proportional to Size (PPS) sampling is generally recommended in the compilation of SPPIs. The total revenue of units in the sample frame could be used as an indicator of their size. The sample frame may also be stratified to improve the efficiency of the sample. A mixture of non-probability and random sampling may also be considered. This could ensure that largest and most representative units are always included in the sample, with the remaining units sampled randomly.

For example, in the U.K. the sample is stratified according to employment size bands. Units from each stratum are sampled randomly except for the stratum including the largest establishments which is fully enumerated.

\subsubsection{Collection of information and specification of the service}

The approaches to the collection of price data and the specification of service transactions depend on the scope of the survey discussed above.

Restaurant, mobile food and beverage serving activities (5610 and 5630 of ISIC)

Collecting accurate constant quality price data requires that detailed characteristics of the representative meals and/or drinks are precisely defined. Representative service products offered during the initialisation period are selected, taking into account the following parameters:

- Type of meal (i.e. breakfast, lunch, dinner, reception, etc.) or drink (alcoholic, non-alcoholic, etc.);

- Numbers of courses (e.g. appetizer, entree, dessert, and beverage, or may consist of a single fixed price charged for all courses served);

- Basis of meal selection (i.e. fixed-price, à la carte, buffet);

- Any additional provisions (e.g. coffee, soft drinks).

Event catering and other food service activities (5621 and 5629 of ISIC)

For catering services, the additional following parameters need to be taken into account:

- Types of end-users (households and/or businesses) the services are provided to (e.g. reception, banquet, schools, healthcare, etc.);

- Number of people the meal is provided for;

- Number of staff working in the canteen/catering business;

- Duration of contract (e.g. one-off, annual, 5 year);

- Other services supplied (e.g. operation of vending machine, cleaning services).

\subsubsection{Main pricing methods}

The direct use of prices of repeated services method is commonly employed for restaurant and mobile food service activities, beverage serving activities and for event catering activities. Contract pricing may also be considered for other food service activities (5629 of ISIC) where prices are specified under contracts. 


\subsubsection{Direct use of prices of repeated services}

The direct use of prices of repeated services is relatively easy to employ by directly collecting real transaction prices, list or menu prices. Respondents are asked to report menu or transaction prices for a range of specific food and beverage services offered.

It is not recommended to collect an average cheque price or an average price per person to avoid changes in product-mix from period to period. However, menu prices may not include discounting provided under special promotions, redeemable coupons, or to frequent customer or members.

\subsubsection{Contract pricing}

As previously discussed, event catering and other food service activities (562 of ISIC) includes the provision of meals by event and industrial catering and canteens based on contractual arrangements with the customers. The contract pricing method is recommended when contracts with specified prices are used for the provision of constant quality services covering more than one survey period. This applies particularly for BtoB food and beverages services such as industrial catering and the operation of food concessions at sports and similar facilities and operation of canteens or cafeterias (e.g. for factories, offices, hospitals or schools) on a concession basis.

The contract pricing method has the main advantage of allowing for easy identification of pure price change and price change due to changes in the quality the service provided.

\subsubsection{Quality issues}

Precise specification for the selected service transaction is necessary and must be kept constant over time.

Quality adjustments are mainly performed by using explicit methods such as judgemental method. For example in the U.S., quality adjustment is performed when the size of the specified meal has changed or if the foods offered as part of the meal have changed. It is however often difficult for respondents to provide an explicit monetary value associated with changes in quality. If the price of the service has changed along with the quality of the service, respondents can sometimes approximate the value of the quality adjustment by estimating the portion of the price change that directly results from the change in quality.

\subsubsection{Weighting and aggregation}

When developing a SPPI for food and beverage services, it is important to consider the availability of accurate weighting data. First, as mentioned previously, developing a BtoAll SPPI can reasonably be compiled on the assumption that the services provided and their price development, are unlikely to differ significantly between households and businesses. However, there is a possibility that the weighting structure is rather different, e.g. households may consume a greater portion of lower priced services. One of the main compilation challenges is the estimation of an adequate weighting scheme as product and/or end-user level weights may not be available.

Ideally, the weighting scheme for the SPPI should utilise annual product level turnover data, generally collected by means of statistical survey. However, these data are not usually readily available. 


\subsubsection{Overview of national methods}

\section{United-Kingdom}

Under the umbrella of the SPPI for the hospitality sector, the U.K. publishes product based SPPIs for business users covering only CPA class 56.20 - Event Catering and Other Food Services, offered by units classified under the corresponding ISIC group. The CPA class provides a further breakdown: $i$ ) canteen for education; $i$ ) canteen for industrial and office; iii) canteen for healthcare; and $i v$ ) catering services.

The index employs the contract pricing method. After prices are collected any atypical or extreme measures are queried with the respondent in order to confirm that any reported price changes in the price are pure price changes, rather than resulting from changes in the quality of specified service transactions.

Prices are collected quarterly, via questionnaires. Respondents are selected using a weighted stratified simple random sampling technique where units in the sample frame are stratified by size (employment size band) and industry (SIC '07 classification). Turnover data for this index are collected using the Service Turnover Survey (STS).

Prices are collected from a range of canteens and catering firms. Respondents are required to include only services supplied to another business, central or local government. As such, services provided to private individuals are excluded. This might prove problematic for catering companies in particular where services are provided to individuals for private functions.

\section{United-States}

The U.S. compiles two product based SPPIs for food and beverage service activities: i) Food and non-alcoholic beverages, and ii) Alcoholic beverages. Items included in these SPPIs are collected only from firms that are classified in industries outside of NAICS sub-sector 722 - Food services and drinking places. Specifically, food and beverage items are collected from firms classified in Hotels and Motels, Casino Hotels, Amusement and Theme Parks, Golf Courses and Country Clubs, and various retail trade industries.

The U.S. compiles SPPIs covering all services offered to all possible buyers. Consequently, the prices collected include sales to businesses as well as households.

Prices are collected exclusively via a SPPI dedicated survey. The PPS method is used to select respondents. During the initial data collection period, specific service transactions are selected and their initial prices are collected during face to face interviews. In subsequent periods, updated price information is provided by respondents through survey forms returned by mail, fax, or online submission. In most instances, respondents are asked to provide the published menu price for a selected meal offered at the establishment. The selected meal may include multiple individually priced menu options, such as an appetizer, entree, dessert, and beverage, or may consist of a single fixed price charged for all courses served.

For banquet and/or catering services, respondents are asked to create a realistic, hypothetical transaction or select an actual transaction that occurred in the past. In subsequent months, respondents are asked to estimate the price that would be charged to perform the same service in the current month based on current market conditions. In all cases, the price reported by the respondent should include any service fees charged for providing the selected service (such as a service charge for room service) but should exclude taxes and gratuity. 
The direct use of prices of repeated services is the preferred pricing method. Since respondents are asked to report menu or transaction prices for specific food and beverage offerings (rather than an average check price or an average price per person), constant quality prices are reported. However, menu and list prices do not capture discounting that can occur due to special promotions, redeemable coupons, or frequent customer/membership discounts.

Quality adjustment is performed when the size of the meal or $i$ the foods offered as part of the meal have changed. It is however often difficult for respondents to provide an explicit monetary value associated with the change in quality. If the price of the service has changed along with the quality of the service, respondents can sometimes approximate the value of the quality adjustment by estimating the portion of the price change that is directly tied to the change in quality.

\section{Bibliography}

Forgacs, G., (2010), Revenue management: Maximising revenue in Hospitality Operations, American Hotel \& Lodging Educational Institute.

Friedén, M., (2010), Mini presentation - NACE 55.1 Hotels and similar accommodation in Sweden, $25^{\text {th }}$ Voorburg Group meeting, Vienna, Austria, available at: http://www.voorburggroup.org/Documents/2010\%20Vienna/Papers/2010\%20$\% 2041 . p d f$

Hyrkäs, J., (2011), Dynamic pricing agreements of Norwegian hotels from the corporate accounts perspective, Haaga-Helia, University of Applied Sciences.

Joint OECD Eurostat Task Force for the revision of the Methodological Guide for developing Producer Price Indices for Services, (2012), Internal survey on accommodation and food services, non-published.

McMahon, R., (2011), Sector paper on accommodation and food services, $26^{\text {th }}$ Voorburg Group meeting, Newport, U.K., available at:

http://www.voorburggroup.org/Documents/2011\%20Newport/Papers/2011\%20\%2006.pdf

Netessine, S., and Shumsky, R., (2002), Introduction to the Theory and Practice of Yield Management, INFORMS Transactions on Education, Vol. 3, $\mathrm{N}^{\mathrm{o}}$. 1, available at: http://archive.ite.journal.informs.org/Vol3No1/NetessineShumsky/

Nieminen, S., (2010), Mini presentation on SPPI for accommodation and food services in Finland, $25^{\text {th }}$ Voorburg Group meeting, Vienna, Austria, available at: http://www.voorburggroup.org/Documents/2010\%20Vienna/Papers/2010\%20\%2043.pdf

O'Hanlon, N., (2010), Mini presentation on SPPI for accommodation and food services in Ireland, $25^{\text {th }}$ Voorburg Group meeting, Vienna, Austria, available at: http://www.voorburggroup.org/Documents/2010\%20Vienna/Papers/2010\%20-

\%2045.pdf 


\section{Notes}

1. Source Eurostat. In the EU-27, the period 2007-10 showed an average fall of $2.2 \%$ per year for hotels and a rise of $2.3 \%$ per year for campsites. It is likely that the different developments observed for hotels and campsites can be linked to the financial and economic crisis, and the substitution of nights spent in hotels by nights spent in campsites may have been in order to lower the cost of a holiday.

2. As experienced by Finland, administrative data (VAT data) may also be a valuable source especially to separate secondary activities such as food services of accommodation businesses (that may be bundled). Statistics Finland specifies that the VAT tax rates are different for accommodation and food services in Finland (at $8 \%$ and $22 \%$ respectively). This helps to separate these two service groups when administrative data are used.

3. As mentioned previously for accommodation, CPI data, valued at purchasers' prices, need to be adjusted to basic prices by deducting any taxes including VAT and trade margins. 



\section{Chapter 8. Information and telecommunication}

This chapter presents practical guidance as well as main issues and challenges for compiling SPPIs for Publishing of books, periodicals and other publishing activities (ISIC 581), Software publishing (ISIC 5820), Telecommunications (ISIC 61), and Computer programming, consultancy and related activity (ISIC 62). 


\subsection{Publishing of books, periodicals and other publishing activities (Denis Gac, INSEE)}

\subsubsection{Industry description (ISIC 581)}

Publishing is the process of production and dissemination of literature, music, information and other content. Traditionally, the term refers to the distribution of printed works such as books, newspapers and magazines, directories and mailing lists, and other materials such as photos, engravings, postcards, posters and reproductions of works of art. These materials are characterised by the intellectual creativity required in their development and so are usually protected by copyright. The acquisition of copyrights to content (information products) are therefore included in this group, in addition to making this content available to the general public by engaging in (or arranging for) its reproduction and distribution in various forms.

In recent years digital publishing has emerged as important publishing activity. Additionally, free media activities (internet, free newspapers) are an increasingly important component of publishing activity although it is not yet clear as to how they should be treated from the perspective of SPPI compilation.

\section{Characteristics of book, newspaper and magazine markets}

Markets for traditional publishing activities in OECD countries are often dominated by a small number of very large publishers accounting for a very large share of total output. For example, in France the two largest publishing groups account for about 35\% of book sales while the twelve largest publishers account for nearly $80 \%$ of sales.

The market for books is also characterised by a very large diversification of supply with a shorter lifetime of books and a decreasing number of copies of each edition. While the number of copies sold tends to decrease (e.g. $-2.1 \%$ in 2012 in France), the number of editions sold is increasing (e.g. $+3.0 \%$ in 2012 and $+2.0 \%$ in 2013 in France).

Newspaper publishers operate in a two-sided market as they sell news to readers and readers to advertisers. Consequently, traditional sources of publisher revenue are sales of printed newspaper and print advertising; both have however been negatively affected by the economic crisis of 2008. The newspaper market has suffered an erosion of revenue from print newspaper and consequently from advertisers, and also increasing competition from online content. New online and mobile services have (in very many cases) yet to grow into profitable businesses. Even this system is not yet mature in all countries; there is a trend towards development of on-line paperless newspaper such as the Huffington Post, Slate, Mediapart etc.

The magazine publishing sector is highly concentrated with a clear segmentation of supply (TV magazines, specialised journals, women's/men's press, youth press etc.).

\section{Price determining characteristics}

The objective when compiling a SPPI for publishing of books, periodicals and other publishing activities is to analyse the revenue of the publisher. In this respect, four issues should be presented:

1. The intrinsic quality of book or newspaper, such as the number of pages or the reputation of the writer, largely determines its price. If a "fixed book price policy"1 is not applied in a country, the type of distribution channels (for example retailer, club or direct sale by the publisher) may also influence final price of a 
book. However, it is important to note that major publishers groups are often distribute their books via affiliates; As in the case for books, the intrinsic quality of a newspaper and the distribution channels (for example retail shop, home delivery or subscription) influence its final price. While sales by retailers have declined, sales by subscriptions have been the most resilient distribution channel since the economic crisis.

2. The SPPI for publishing activities should measure prices received by publishers, net of transport and retail margins;

3. A large share of a publisher's revenue (especially in the cases of newspaper and magazine publishers) comes from the sale of advertising space. Therefore the SPPI for publishing could be jointly operated with the SPPI for Advertising (ISIC 731);

4. Publishers also generate revenue from the sale of licences, for example to create games or movies from a book. The amounts of revenue generated can be very erratic and the activity is difficult to monitor. Given the measurement challenges and the small share of total industry output resulting from the sale of licences, this activity is often excluded from SPPI coverage.

\subsubsection{Classification aspects}

\subsubsection{Industry classification}

The publishing of books, periodicals and other publishing activities are classified under ISIC section J - Information and communication, division 58 - Publishing activities, group 581. The creation of section J in the ISIC was a major development in the classification system. This new grouping gives coherence to activities focussed on the production of intellectual content which were organised according to the format of dissemination (for example printed vs. online books, printed vs. online newspaper) in previous versions of the classification system. However, it should be noted that the printing and reproduction of recorded media (division 18 of ISIC) is still classified under manufacturing.

The publishing of software (group 582), motion pictures, video and television programme activities (group 591) and sound recording and music publishing activities (group 592) are all classified elsewhere.

The publishing of books, periodicals and other publishing activities are classified under group 581 in the ISIC classification. This group is divided into four classes:

- 5811 - Book publishing;

- 5812 - Publishing of directories and mailing lists;

- 5813 - Publishing of newspapers, journals and periodicals;

- 5819 - Other publishing activities.

The NACE, NAICS and ANZIC classification systems are almost identical to the ISIC classification, the difference in each case being the distinction between the publishing of newspapers and the publishing of journals and periodicals (see annex A). 


\subsubsection{Product classification}

Activities relating to the publishing of books and periodicals, and other publishing activities are classified in the CPC classification system under section 8 - Business and production services, division 89 - Other manufacturing services; publishing, printing and reproduction services; materials recovery services, group 891 - Publishing, printing and reproduction services, class 8911 - Publishing, on a fee or contract basis.

In both the CPA and NAPCS classifications however, the products are classified in line with the NACE and NAICS classifications respectively, reflecting the treatment of publishing activities as information and communication services rather than as manufacturing. These international industry and product classifications therefore provide a consistent hierarchy from industry to service products.

It is interesting to note that in France an alternative nomenclature was developed in order to better approximate the way in which the industry classifies different service activities. According to this alternative nomenclature the output of the publishing industry in France can be disaggregated between:

- Sales of physical books, newspapers, journals, periodicals;

- Sales of on-line books, newspapers, periodicals;

- Sales of advertising space in those books, newspapers, journals and periodicals ${ }^{2}$;

- Sales of licenses for copyrights of original works (4\% of sales for book publishers in France).

\subsubsection{Scope of the survey}

Ideally, the SPPI should track constant quality price change for the full range of output to all end users (such as business, household, exports and government etc.). In practice compilers may limit scope to the activities (and end users of these activities) which account for the largest shares of output. As such, inclusion in the SPPI of ISIC 5812 - Publishing directories and mailing lists, may not be necessary where the class accounts for only a very minor share of the total output of the group and is therefore unlikely to have a significant impact on the overall price index.

Additionally, it is often difficult to separate prices charged to different end-users of publishing services and compilers may instead calculate a single PPI covering all end users. As an example, INSEE aims to calculate all of its SPPIs on both a BtoB and BtoAll basis, and to only compile BtoC and BtoE indices for a limited set of activities. The SPPI for publishing activities is currently published on a BtoAll basis only.

As previously noted, it is not yet clear as to how "free media" activities should be treated within the SPPI framework.

\subsubsection{Sample design}

Ideally, probability proportional to size (PPS) sampling should be employed, using turnover as the size variable. Stratified sampling, using turnover or number of employees as the stratification variable, may be utilised to improve efficiency of the sample by reducing variance. Industry representative organisations may provide advice in respect of how the sample is structured. 
In France, the sample has been developed to reflect the relative importance of different publishing activities. Distinctions are made between:

- Paperback and other books;

- The different distribution channels for books (libraries, schools, bookshops etc.);

- Book themes (accounting for specialists publishers);

- Newspaper types (national, regional, local, free);

- Magazine types.

In order to facilitate the ongoing price measurement of books, it may be helpful to consider three categories of repeatable services:

- Titles which are published repeatedly (e.g. annuals);

- Series of successive books (e.g. encyclopaedias);

- Titles from a well-known author which could reasonably be considered as having the same quality.

\subsubsection{Collection of information and specification of the service}

Representative service products, for each of the different types of service activity, should be identified and adequately specified during the respondent initialisation process. Detailed product specification information facilitates pricing to constant quality in future periods.

Specifications may include the definition or category of the published material (for example, fiction, and crime), the title and author, the size and number of pages, size, and the type of binding.

\subsubsection{Main pricing methods}

Tracking constant quality price change for the full range of publisher output needs to monitor price of books, newspaper and magazine and advertising space sales in newspaper.

It should be noted that the use of CPI prices for publishing services may not be suitable for use in the compilation of the SPPI where trade and transport margins are included in the price paid by the consumer.

\subsubsection{Book publishing}

Prices should be measured at basic prices and therefore exclude taxes and trade and transport margins. The basic price reflects the price paid by the distributer or the retailer, rather than the consumer. The price paid for a book by the distributer or retailer may be $40-70 \%$ less than the list price to the final consumer (Vizner, 2013).

Typically, the direct use of prices of repeated services or contract price methods are employed for the ongoing measure of price development of books. As shown in box 1, when public price is collected, it should be net of taxes, and associated, according to the type of book, with bookseller average discount rate, number of pages and margin of delivery and diffusion. 
Box 8.1.1. French examples of types of prices collected for books

\begin{tabular}{|l|l|l|}
\hline \multicolumn{1}{|c|}{$\mathrm{N}^{\circ}$ of series } & \multicolumn{1}{|c|}{ Definition of price series } & \multicolumn{1}{c|}{ Kind of prices collected } \\
\hline $\mathrm{A}$ & "Tales and legends of Brittany" & Public price \\
\hline $\mathrm{B}$ & "Tales and legends of Brittany" & Average discount rate \\
\hline
\end{tabular}

Price to be used: $A *(1-B)$

\begin{tabular}{|l|l|l|}
\hline \multicolumn{1}{|c|}{$\mathrm{N}^{\circ}$ of series } & \multicolumn{1}{|c|}{ Definition of price series } & \multicolumn{1}{|c|}{ Kind of prices collected } \\
\hline $\mathrm{A}$ & $\begin{array}{l}\text { "Secondary schools / code 004757 / geography / } \\
\text { high school }\end{array}$ & Public price, net of taxes \\
\hline $\mathrm{B}$ & School books & Bookseller average discount rate \\
\hline
\end{tabular}

Price to be used: A * (1-B)

\begin{tabular}{|l|l|l|}
\hline \multicolumn{1}{|c|}{$\mathrm{N}^{\circ}$ of series } & \multicolumn{1}{|c|}{ Definition of price series } & \multicolumn{1}{c|}{ Kind of prices collected } \\
\hline $\mathrm{A}$ & "I learn to draw" / last release & Public price, net of taxes \\
\hline $\mathrm{B}$ & "I learn to draw" / last release & Number of pages \\
\hline $\mathrm{C}$ & "I learn to draw" / last release & Margin of delivery and diffusion \\
\hline
\end{tabular}

Price to be used: $\mathrm{A} * \mathrm{~B}^{-1 / 2} *(1-\mathrm{C})$

For major publishing houses that sell books in large quantities, it may be necessary to distinguish between the different types of retailers (for example supermarkets typically only stock current best sellers). It should be noted that the prices for educational books are often fixed by regulation.

\subsubsection{Newspaper and magazines}

The unit value method is typically employed where large numbers of transactions of homogeneous products occur. Under this method, the price of the publishing service is derived by dividing revenues from sales by volumes of services provided in respect of a large number of transactions. This method is particularly appropriate to the measurement of prices of publication of newspapers and journals, although the compiler should distinguish between the different forms of distribution (for example by dealer or bookseller, posted by subscription, internet subscription). 


\begin{tabular}{|l|l|}
\hline \multicolumn{2}{|c|}{ Box 8.1.2. French examples of types of prices collected for newspapers } \\
\hline \multicolumn{1}{|c|}{ Definition of price series } & \multicolumn{1}{|c|}{ Kind of prices collected } \\
\hline Newspaper day of the week & $\begin{array}{l}\text { Sales in kiosk / net average price for one } \\
\text { issue without retailer trade margin }\end{array}$ \\
\hline $\begin{array}{l}\text { Newspaper day of the 7th day } \\
\text { Subscription 7 days carried home all the year } \\
\text { / 364 issues }\end{array}$ & $\begin{array}{l}\text { Sales in kiosk / net average price for one } \\
\text { issue without retailer trade margin }\end{array}$ \\
\hline $\begin{array}{l}\text { Subscription } 7 \text { days carried home all the year } \\
\text { / 30 issues }\end{array}$ & Net average price for one issue \\
\hline $\begin{array}{l}\text { Posted subscription } 6 \text { days for one year } / 312 \\
\text { issues }\end{array}$ & Net average price for one issue \\
\hline $\begin{array}{l}\text { Posted subscription } 6 \text { days for one year / } 25 \\
\text { issues }\end{array}$ & Net price of the subscription \\
\hline Women & $\begin{array}{l}\text { Net average price (net publisher turnover / } \\
\text { number of issues sold) }\end{array}$ \\
\hline $\begin{array}{l}\text { Television } \\
\text { number of issues sold) }\end{array}$ \\
\hline
\end{tabular}

Subscription prices, especially in the case of newspapers, can vary according to the length of the subscription. Similarly, prices may be reduced for prepaid subscriptions. In order to price constant quality services, the compiler should ensure that representative subscription services are well specified.

\subsubsection{Advertising space in newspaper}

Revenue from sales of advertising space is usually shared between the publisher and the advertising selling agency (usually paid on a commission basis).

Considering the full price for advertising space, quality adjusted, $(\mathrm{P})$ and the commission rate for the seller of advertising space (C), INSEE calculates price indices for both the provision of advertising sales (NACE 73.12), the publishing of directories and mailing lists (NACE 58.13) and the publishing of newspapers, journals and periodicals (NACE 58.14) on the basis of:

Price for NACE $73.12=\mathrm{C}^{*} \mathrm{P}$

Price for NACE 58.13 or NACE $58.14=(1-\mathrm{C}) * \mathrm{P}$

There is often a close collaboration between agencies selling advertising space and newspaper publishers and therefore consideration may be given to jointly surveying these activities.

\subsubsection{Quality issues}

Identifying and maintaining constant quality publishing service activities is challenging. It can also be difficult to identify where a change to service quality occurs and to appropriately quality adjust in response. 
In the case of books, service quality can be linked to the type of book and to its physical characteristics. Therefore when a specific book is no longer offered for sale, a replacement title may be selected, and quality adjusted for, on the basis of, for example; the author, the type or genre of book (literature, science, cooking), the target reader (academics, adults , children), the number of pages, the number of pictures and the type of binding. In the compilation of the SPPI for publishing activities in France, a quality (size) adjusted price is calculated by dividing the price of a book by the square root of the number of pages (following the method used in the compilation of the CPI).

For newspapers, it may be difficult to measure quality and to identify quality change. Changes to format, size, the amount of colour print and the space given over to advertising could all be monitored to identify changes in quality. However, it is unclear as to how the quality of journalism and editorial content can be adjusted for. Newspapers and magazines may periodically include a free gift (for example a $C D$, another publication, book or toy) without a change to the price. Again, it is not clear as to the appropriate quality adjustment that should be performed for these gifts.

\subsubsection{Weighting and aggregation}

The choice of weights used for weighting and aggregation will depend on the availability of reliable source data. Different data sources can be used, such as turnover data collected through a dedicated turnover survey, weighting data provided by an external supplier, National Accounts input/output tables or a combination of the above data sources. Ideally, each service transaction will be assigned its own weight. The weighting structure below industry level will depend on the chosen classification structure, based on standard classifications and perhaps modified or extended to take account of the national organisation of the industry.

\subsubsection{Specific aspects}

Published material is increasingly being sold through electronic format. The growing importance of importance of electronic editions of newspapers and magazines and "ebooks" should be an important consideration in the design and maintenance of the SPPI. For example in France, digital books are now priced separately to paper books.

\subsubsection{Overview of national methods}

A small number of countries (U.S., U.K., Sweden, Slovenia, Japan, and Israel) calculate an SPPI for publishing activities The U.S. is currently the only country that includes prices for licensing activities in its SPPI. Typically compilers focus on books, newspapers, journals and periodicals. The decision as to include or exclude advertising prices depends on whether or not the measure of output of publishing activities includes output generated from advertising activity.

\subsection{Software publishing (David Friedman, U.S. Bureau of Labor Statistics)}

\subsubsection{Industry description (ISIC 5820)}

Business enterprises in this industry engage in computer software publishing, publishing and reproduction, and operations necessary for producing and distributing computer software, such as designing, providing documentation, assisting in installation, and providing support services to software purchasers. They may design and develop software in conjunction with publishing it, or may only publish software without being 
engaged in its design or development. The creation of customised software designed to meet the needs of specific users is excluded from this industry.

Business enterprises in the software publishing industry sell licenses that grant customers the right to use standard (non-customised) software programs. These programs are designed for use on personal computers, servers, portable devices, video game consoles, and a variety of other computing devices. Software may be provided by physical transfer on discs or cartridges or by download. Software publishers provide services such as technical support, product updates, consulting, implementation, and training services in addition to software licenses. Many software publishers offer these services bundled with the software license in the form of a maintenance agreement. Maintenance agreements are often charged as a percentage of the original license price. Most software publishers require customers to purchase one year of maintenance at the time the license is initially purchased. After the first year of maintenance is completed, customers are given the option to renew the maintenance agreement. Since "first-year" maintenance is typically bundled with the initial sale of the software license, first year maintenance and the software license are collected as a single transaction price and are captured in the primary service line corresponding to the appropriate software license category (other application software publishing, etc.). However, sales of renewed software maintenance services are captured in the primary service line entitled Software maintenance, technical support, training, and other services related to software publishing because they are priced separately.

Some software firms may provide technical support, consulting, or training services for third party software. Turnover earned from providing these secondary service activities for third party software are outside the scope of this industry, since the service provider is not the owner or originator of the intellectual property associated with the software. Turnover generated in this way is collected as other receipts.

There are two main categories of software: system software and application software. System software includes programs that instruct computer hardware and other software applications in how to operate. Examples include software for operating systems, networks, database management, and development tools and programming language software. Application software includes programs that complete specific tasks or functions. Examples of application software include word processing, spreadsheet, accounting, and game software.

In recent years, this industry has faced increased competition from firms that provide online access to hosted software on a subscription basis and also firms that provide open source software. Unlike traditional software licenses, open source software source code can be copied, altered, and redistributed free of charge. Firms that offer open source software typically distribute free programs to their customers and earn revenues only by providing support services, such as implementation and consulting.

\subsubsection{Classification aspects}

\subsubsection{Industry classification}

Software publishers are classified in ISIC group 582. This group includes publishing of the following types of ready-made (non-customised) software:

- Operating systems;

- Business and other applications; 
- Computer games for all platforms.

Excluded from this group are the following:

- The reproduction of software without publishing (classified in ISIC 1820);

- The retail sale of non-customised software (classified in ISIC 4741);

- The production of custom software (classified in ISIC 6201);

- The provision of online access to hosted software (classified in ISIC 6311).

Annex A provides classifications from various systems by type of activity.

\subsubsection{Product classification}

Annex B maps the NAPCS product codes for the Software Publishing industry to the CPC structure. The products in the two structures are largely comparable. One substantive difference is that the NAPCS includes more detailed products (crossindustry, vertical market, utilities, and other applications software) for the CPC broad category for other application software. Another difference is that software originals, defined as the sale of copyrighted intellectual property provided on a non-contract basis is included in a separate subject area of the NAPCS structure. This is also the case for on-line games, which are primarily offered by Internet publishers and are included in that portion of the NAPCS structure.

\subsubsection{Scope of the survey}

The ideal survey for software publishing measures price changes for the provision of software on a licensed basis and related services provided by the publisher including software maintenance and technical support. Sales of software are priced on a per license or per transaction basis. The major service lines for which the U.S. calculates SPPIs are System software publishing; Application software publishing; Game software publishing; and Software maintenance, technical support, and other services related to software publishing. The U.S. does not publish indices that distinguish between software sold to business, household, or government clients although ideally separate SPPIs should be available for each of these use categories and for exports.

\subsubsection{Industry vs. product based SPPI}

Although product based SPPIs are most useful for deflating input-output national accounts, an industry based survey for software publishing that delineates primary production from secondary activities can be used as an acceptable alternative. In the U.S., sampling frames are available by 6-digit NAICS industry (not by product) and services that are not primary to the software industry are considered "other receipts" and given a chance of selection at each sampled company. When publication criteria are met, a price index for these "other receipts" is published. These "other receipts" contribute approximately $15 \%$ of total software publishing industry turnover according to the U.S. Census Bureau. Since turnover for secondary activities is significant, it is important that these activities are collected and published separately. Some examples of common "other receipts" for the software publishing industry include the provision of web hosting services, including the provision of access to hosted software, the sale of computer hardware, and technical support, consulting, or training services provided for third party software. 


\subsubsection{Sample design}

Probability proportional to size sampling with turnover or number of employees as the size measure should ideally be employed for this industry. Due to the rapid rate of product innovation inherent in the software publishing industry, it may be necessary to update the sample of firms more frequently than for other industries. An alternative strategy may involve augmenting the initial sample with firms that were either not in existence when the initial sample was drawn or that did not generate significant turnover at that time but have since grown. Surveying firms in the sample periodically to solicit price information for new products (ones that have been introduced since the last sampling) should also be considered.

\subsubsection{Collection of information and specification of the service}

In the U.S., prices are collected directly from respondents. When establishments join the survey, they undergo face to face initialisation interviews with data collectors in order to select representative transactions and collect initial prices. Financial officials at headquarters locations are often the best contacts, particularly when collecting unit value prices.

Data collectors select representative transactions based on products' relative contributions to total firm turnover. The first stage of transaction selection distinguishes between the sale of software licenses and sales of other related services, including training and support services transacted separately from the license sales. For software license items, the next step of probability-proportional-to-size disaggregation is based on the type of software sold (operating system software, database management software, desktop and portable device application software, game software, etc.). Once a type of software is chosen, selection proceeds between individual software programs within the selected category.

The following transaction characteristics are recorded for each software license item:

- Name of software;

- Type of software;

- Type of client purchasing software;

- Software version number;

- Date current software version was introduced: This information is used to help determine when directed substitution to a new software program may be needed. Directed substitution is a strategy that may be employed to update the product sample more frequently. Items that have not had new versions introduced for an extended period typically are products that are experiencing sharply declining sales. These items are the best candidates for a targeted substitution effort, where respondents are asked to provide a newer software program that has gained or is gaining market share in place of the one that is declining in the market;

- Type and number of licenses included: Some transactions may consist of the sales of both server based and client based licenses. The server licenses may be transacted based on the number of central processing units (CPUs) required to run the software program on each server machine on which the software resides; 
- Duration of licensing agreement: Many software sales are for perpetual licenses with no defined term. Other sales may grant the use of a license for only a specified period;

- Bundled services included: One year of software maintenance is often included with certain software license sales. In these cases, the price for the bundled maintenance is included in the item price. Training, documentation, and other services may also be sold in a bundled transaction with the license.

The following transaction characteristics are recorded for sales of services transacted separately from software licenses:

- Type of service provided;

- Duration of service;

- Location where service is provided: This characteristic is particularly important for software training services. Higher prices are typically charged for training services performed at a client's worksite;

- Name and type of software for which that service is provided.

\subsubsection{Main pricing methods}

The most common types of prices collected for this industry are unit value prices, component prices, direct prices of repeated services, and model prices.

\subsubsection{Unit value}

Unit value prices are calculated by dividing the total turnover earned from all sales of a particular type of license for a specified software product made to a given buyer type (end-user, retailer, wholesaler, or original equipment manufacturer) by the total number of these licenses sold to these buyers within a specified period. An alternative way that this price may be calculated is by applying an average discount to the list price for a selected software license sale. The average discount is calculated by comparing the turnover generated from all sales of a specified license to the turnover that would have been generated if each of these transactions were made at the listed price.

The benefit of the unit value method is that it captures all discounting and reflects the period to period changes in software pricing caused by changes in both market demand and firms' marketing and sales strategies. This is especially important for this industry, since software has virtually no marginal production costs and consequently is often heavily discounted in order to generate sales. A significant disadvantage of this method is that it may lead to lags in data reporting, since these unit values are often not available until after the pricing period has been completed. In addition, unit values may change due to shifts in the mix of buyers that purchase the software in each period. While a unit value should be limited to include only sales to a particular type of buyer, there may still be variation within that defined category. For example, a unit value of all perpetual license sales of a specified product sold to original equipment manufacturers may be collected. From period to period, there may be shifts in the mix of large manufacturers and small manufacturers that purchase the product. Since large manufacturers typically receive the lowest prices, unit value prices will tend to fall in periods when they purchase large quantities of the product. 


\subsubsection{Component pricing}

Component prices may be used when pricing software sales to large enterprise endusers. These transactions often consist of the sales of both server based and client based licenses. The server licenses may be transacted based on the number of central processing units (CPUs) required to run the software program on each server machine on which the software resides. In addition to these license sales, a typical enterprise software transaction also includes the sale of a year of software maintenance. An enterprise software transaction priced using the component method may, for example, consist of the sale of eight CPU licenses, 100 client device licenses, and one year of software maintenance.

\subsubsection{Direct use of prices of repeated services}

Prices of repeated services are collected for products that are regularly transacted in each pricing period. This includes sales of mass marketed software offered through the retail distribution channel.

\subsubsection{Model pricing}

Model prices are collected for products that are transacted infrequently or that have significant price variation between different buyers. Since software products may be sold at substantially different prices based on the timing of the sale and the negotiating skill of the buyer, it is often difficult for respondents to estimate the prices that would be charged if a particular software sale were to occur. This is a significant disadvantage of model pricing.

\subsubsection{Combination of the model pricing and the percentage fee methods}

In pricing software maintenance contract renewals, the United States employs a combination of the model pricing method and the percentage fee method. The following characteristics are collected in the base period:

- The software licensed;

- The original license price, including the cost of first year maintenance;

- The month and year of the original sale;

- The percentage of the license price charged for renewed maintenance;

- Any applicable discounts.

In subsequent re-pricing periods, the software licensed is held constant, and the time between the original sale of the software license and the maintenance renewal is held fixed at twelve months. For each reporting period, SPPI compilers escalate the price of the original software license sale and corresponding first year maintenance by the appropriate PPI Software publishing index to provide the respondent with an estimate of what the price of the initial purchase would have been if the selected software license transaction had occurred twelve months prior to the reporting month. For example, a maintenance renewal transacted in October 2012 would reference a software license sold in October 2011; during the November 2012 reporting period, the U.S. provides the respondent with an estimate of what would have been charged for the same software license in November 2011. The respondent uses these escalated values to calculate the 
price that would be charged in the current reporting period to renew maintenance for a second year.

\subsubsection{Quality issues}

Newly released versions of software programs typically have increased functionality and new features, and are not therefore directly comparable to the previous versions. If possible, the price basis of the software is adjusted by using production cost data in order to account for the change in quality when a new software version is released. The production costs for software publishers primarily consist of the research and development (R\&D) costs associated with the enhancements made to new software versions. Note that consumer utility of the increased functionality and new features is appropriately not considered when adjusting the producer price index for quality change. Respondents are asked to estimate the development costs associated with the enhancements made to the new software version. These costs are then divided by the number of units of the new version that are expected to be sold. If this number is not available, the costs are instead divided by the number of units of the previous version that were sold, since this is considered the best available proxy for expected sales of the new version. The calculated per unit development costs are then used to quality adjust the item when the new version is released.

\subsubsection{Weighting and aggregation}

Table 8.2.1 lists the industry indices the U.S. calculates for the Software Publishing industry.

Table 8.2.1. U.S. indices for the Software Publishing industry

\begin{tabular}{|l|l|}
\hline \multicolumn{1}{|c|}{ Index code } & \\
\hline 511210 & Software publishers \\
\hline $511210 \mathrm{P}$ & Primary services \\
\hline 5112105 & Software publishing, except games \\
\hline 511210501 & Systems software publishing \\
\hline 511210502 & Application software publishing \\
\hline 51121050201 & Desktop and portable device application software publishing \\
\hline 51121050202 & Other application software publishing \\
\hline 511210503 & Technical support, training, and other services related to software publishing \\
\hline 5112106 & Game software publishing \\
\hline $511210 S M$ & Other receipts \\
\hline
\end{tabular}

A distinct index for all software publishing with the exception of games is provided to assist with the deflation of gross fixed capital in the national accounts (2008 SNA, p. 207). While the sales of systems and applications software are included in the fixed investment accounts, sales of games software are included only as personal consumption expenditures.

For each of these index series, the lower level indices are aggregated using industry turnover data as weights. Within the lowest level indices, each item is weighted based on company turnover provided at the time of data collection. 


\subsubsection{Specific aspects}

The fast pace of technological change creates a large challenge for pricing constantquality services in this industry. Software publishers are continually updating their service offerings to adapt to changing computing environments. The increased capacity of Internet applications and the rise in the use of portable computing devices have accelerated these changes. As a result, frequent item re-sampling and a strong emphasis on quality adjustment are often employed for software publishing SPPIs.

\subsubsection{Overview of national methods}

\section{Canada}

Canada does not currently collect price information directly. Prices are instead estimated based on the following data collected directly from responding firms: turnover, personnel expenses, and the average annual percentage change in labour rates.

The estimated price is calculated as follows:

$$
\text { Price }=\text { Net Multiplier } * \text { Average } \% \text { change in wages }
$$

Where:

Net Multiplier $\mathrm{t}=\frac{\left(\frac{\text { Turnover }_{\mathrm{t}}}{\text { Wagexpense }_{\mathrm{t}}}\right)}{\left(\frac{\text { Turnover }_{\mathrm{t}-1}}{\text { WageExpense }_{\mathrm{t}-1}}\right)}$

The wage expense in the Net Multiplier is defined to be the total wages of employees and contractors.

The average change in wages is defined to be the weighted average change in wages for employees and contractors and is defined by the following equation:

Average $\%$ change in wages $=$

$$
\begin{aligned}
& { }_{\left(\text {Weight }_{\mathrm{t}}\right.}^{\text {employees } \left._{*} \text { Average_wages_employees }\right)+} \\
& \text { (Weight } t_{t}^{\text {contractors* }} \text { Average_wages_contractors)Where the weights are given as: } \\
& \text { Weight }_{t}^{\text {employees }}=\frac{\text { Wage }_{t}^{\text {employees }}}{\text { wage }_{t}^{\text {employees }}+\text { wage e }_{t}^{\text {contractors }}} \\
& \text { Weight }_{\mathrm{t}}^{\text {contractors }}=\frac{\text { Wage }_{\mathrm{t}}^{\text {contractors }}}{\text { wage }_{\mathrm{t}}^{\text {employees }}+\text { wage }_{\mathrm{t}}^{\text {contractors }}}
\end{aligned}
$$

\section{Germany}

According to a European regulation on short term statistics, Germany is obliged to provide SPPIs for the division 62 and group 63.1 of the NACE classification. As with other SPPIs, the Federal Statistical Office followed a two-phase approach for collecting the necessary data. The first step consisted of a paper based survey designed to validate the sample and to provide the necessary data for the weighting pattern - effectively a respondent initialisation survey. The second phase consists of the survey for the current period price observations. The industry representative organisations were contacted to discuss the organisation of the industry. These contacts confirmed that the services offered by classes $58.29,62.00$, and 63.10 often overlap. In order to capture additional information about the main and secondary activities of the market actors, the first phase 
survey was expanded to a sample of enterprises classified as software publishers. Table 8.2.2. summarises the weighting results for products of the three classes mentioned above.

Table 8.2.2. Weighting results for CPA-products for Other software publishing (NACE 58.29), Computer programming, consultancy and related activities (NACE 62.00), and Data processing, hosting and related activities; web portals (NACE 63.10)

\begin{tabular}{|c|c|c|c|c|}
\hline \multirow{2}{*}{ CPA-Product } & \multirow{2}{*}{ Description } & \multicolumn{3}{|c|}{ Industry (NACE) } \\
\hline & & 58.29 & 62.00 & 63.10 \\
\hline 5829 & $\begin{array}{l}\text { Other software } \\
\text { publishing services }\end{array}$ & $51.8 \%$ & $16.5 \%$ & $17.0 \%$ \\
\hline 6201 & $\begin{array}{l}\text { Computer } \\
\text { programming } \\
\text { services }\end{array}$ & $8.7 \%$ & $23.5 \%$ & $10.6 \%$ \\
\hline 6202 & $\begin{array}{l}\text { Computer } \\
\text { consultancy } \\
\text { services }\end{array}$ & $39.5 \%$ & $34.7 \%$ & $19.9 \%$ \\
\hline 6203 & $\begin{array}{l}\text { Computer facilities } \\
\text { management } \\
\text { services }\end{array}$ & $0.0 \%$ & $9.2 \%$ & $18.9 \%$ \\
\hline 6311 & $\begin{array}{l}\text { Data processing, } \\
\text { hosting and related } \\
\text { services }\end{array}$ & $0.0 \%$ & $16.0 \%$ & $33.6 \%$ \\
\hline
\end{tabular}

As a compromise, the Federal Statistical Office publishes product based SPPIs as well as industry based SPPIs. The product based SPPIs incorporate the price development of service providers from all three of the above mentioned industries. The weighting schemes are derived from a sample including units from each of the three industries. The industry based SPPIs are aggregations of the product based SPPIs - according to their weights within the industry.

\section{Hungary}

Hungary uses a cut-off sampling selection method (with a combination of number of employees and turnover) for large companies. In the case of ISIC class 5820, the sample is expanded by random sampling for smaller enterprises due to smaller companies accounting for greater than $60 \%$ of industry turnover.

Hungary employs the unit value, direct use of prices of repeated services, and component pricing methods for this industry.

Hungary employs two sources of turnover data for weighting. For its product based SPPI, turnover data are obtained at the 6- and 4-digit CPA levels from the annual CPA survey. For its industry based SPPI, turnover data from two years prior are obtained at the 4-digit and higher levels from the Structure Business Statistics (SBS) survey. Weights and samples are updated annually.

Lower level (CPA 6-digit) indices of companies are first calculated as un-weighted geometrical means. Next, the company's class level (CPA 4-digit) aggregates are computed as a weighted arithmetical average, followed by sub-indices for "big" (weighted) and "smaller" (un-weighted) companies, which are aggregated using the turnover share of the industry SBS data. 


\section{Japan}

Japan uses the direct use of prices of repeated services method for their price indices on packaged software. Japan employs the production cost method for quality adjustment.

\subsection{Telecommunications (Christopher Jenkins, Office for National Statistics U.K.)}

\subsubsection{Industry description (ISIC 61)}

Telecommunications is a very dynamic service industry, susceptible to rapid changes in technology and customer movement to new services. It is one of the more challenging services to accurately capture current price changes for. Globally there is movement towards communications convergence, resulting in the integration of telecommunications services with IT services (telephone, computer and television). This makes both an industry-structure model and a representative weighting pattern difficult to establish and maintain.

Business enterprises classified to this division engage in a wide range of activities which include providing telecommunications and/or video entertainment services over networks (which they either own or lease) and client supplied high speed internet connection. Establishments can be classified into one of four industry groups depending on the type of telecommunications services they offer. The first three groups relate to the provision of telecommunications services using transmission facilities and infrastructure that they own or lease. The distinction between these groups is the type of infrastructure that is operated (wired, wireless or satellite). The owners of the infrastructure, known as network operators - sell their services both to final consumers (businesses or households) and as inputs to service providers that resell these services to final users. The fourth group relates to those establishments that primarily provide telecommunications support services.

The industry is capital intensive, with very high start- up costs required to cover the construction of base stations and user networks as well as the acquisition of telecommunications licenses. Consequently, individual markets are often dominated or at least heavily influenced by one or a few large service providers.

Traditionally, telecommunications services were priced according to the duration of service consumption (such as cost per minute). However, as the industry develops and competition increases, telecommunications service providers are developing alternative pricing packages in order to win new customers. Bundled services are becoming a popular way to provide, and thus charge for, telecommunications services. By bundling more than one service product, telecommunications providers can offer customers a price structure that provide financial (or other) benefits that are contingent on the consumption of any or all service elements included in the services bundle.

When measuring the price of a bundle of services, two main alternatives are available to the price index compiler: $i$ ) break down the bundle into separate services and price these separately; or $i$ ) price bundled services together as a single product. Note that the pricing method used in each case will be dependent on what data is available. More detail on the pricing methods used for this industry is provided under Section on pricing method.

Under the first option, it is important not only to specify and price each component separately but also to measure the financial or other benefits provided to customers who subscribe to bundled services. Financial benefits are relatively easy to identify when 
pricing bundled services. However, pricing other benefits is more complicated. In addition, breaking down bundles and pricing each sub-component separately will translate into heavy response and calculation burdens. One possibility for minimising burden involves letting respondents choose the service bundles that are most representative of their business in terms of revenues. The sub-components of these bundles are then priced separately.

Under the second option, only the prices of the bundled services and their corresponding service specifications are required. Since the underlying services are not priced under this approach, the response and calculation burdens are reduced. Keeping the bundles representative over time is a significant concern and requires that bundled services are updated regularly. Updating of bundled services should be accompanied by appropriate quality adjustment. It should be noted that quality adjustment is also required when pricing the service components of the bundle separately (option i).

\subsubsection{Classification aspects}

\subsubsection{Industry classification}

The three main international industrial classifications, ISIC, NACE, and NAICS are fully consistent at the class/group level; however, below this level there are some slight differences in the detail provided.

The most broadly used classifications are the international classification system of economic activities ISIC and NACE. These classification systems are identical for division 61 which is located under section $\mathrm{J}$ - Information and communication, in both hierarchies and includes the activities of providing telecommunications and related service activities, i.e. transmitting voice, data, text, sound and video. The transmission facilities that deliver these activities may be based on a single technology or a combination of technologies. The commonality of activities classified in this division is the transmission of content; the creation of content is excluded. The breakdown of division 61 is based on the type of infrastructure operated (Camus, 2009 ${ }^{3}$ ). In the case of transmission of television signals this may include the bundling of complete programming channels (produced in division 60) into programme packages for distribution.

Under the NAICS classification, the description of class 517 - Telecommunications is identical to the ISIC and NACE descriptions. The first three groups are comprised of providers that operate transmission facilities and infrastructure which they own and/or lease, and provide telecommunications services using those facilities. The distinction among the first three industry groups is the type of infrastructure operated (i.e. wired, wireless, or satellite). The fourth industry group is comprised of providers of support activities, telecommunications reselling services, or many of the same services provided by those in the first three industry groups, but who do not operate as telecommunications carriers. Business enterprises primarily engaged as independent contractors in providing these services may be classified in other sectors (e.g. construction, administrative and support services, food service and drinking places) according to their primary activity.

\subsubsection{Product classification}

The international product classifications are not as closely harmonised. The CPC is the main product classification system applicable for this industry and the relevant categories are: 
- 841 - Telephony and other telecommunications services;

- 842 - Internet communication services;

- 8463 - Broadcasting, programming and programme distribution services.

There are 15 different subclasses for the telecommunications services with a breakdown according to technical criteria.

The product classification for the industry within the European CPA system is more detailed than, broadly comparable to, the CPC

The NAPCS provides an even greater level of detail than the CPA, including products such as installation services for telecommunication networks and network design and development services.

Although the activity and product classifications cover the services of the industry in general, some flexibility is needed to ensure that service products used in SPPI compilation reflect adequately the real service structure of the industry. The current product groupings for telecommunications are largely influenced by marketing, technological and regulatory considerations.

The appropriate level of service product classification for an SPPI often depends on the pricing method applied. When the unit value method is applied, the lowest level of service product detail is dictated by the available revenue and quantity data. Where the component pricing method is applied the structure of published service-rates will dictate the level of service product detail.

\subsubsection{Scope of the survey}

Ideally, the SPPI for the telecommunications industry should cover the production of all resident telecommunications service providers in the economic territory. It should measure constant quality price change for the full range of output to all intermediate and end users (business, household, government and export).

However, the provision and collection of price data for each of these users is likely to prove difficult and resource intensive. With this in mind the compiler may choose to make use of CPI data as a proxy for the BtoC component of a BtoAll index. It should be noted that taxes, such as VAT, are included in the prices collected for a CPI. The compiler will need to balance the conceptual requirements of the 'ideal survey' against the cost and burden of collecting and processing the necessary data.

In Hungary, it is proposed to develop a BtoAll SPPI by weighting together separate price indices for the BtoB component (as collected quarterly in the Hungarian SPPI) and BtoC component (as collected monthly for the CPI). Adjustments are required for the CPI data to convert the prices to a quarterly series and to potentially adjust for any differences in the conceptual basis of CPI price data (such as the inclusion of taxes). This proposal is still under development and evaluation.

\subsubsection{Industry vs. product based SPPI}

If the primary objective for the development of an SPPI is to deflate national accounts data, then a product based SPPI would be preferable for the ideal survey. However, in reality compilers very rarely have a sample frame (or turnover data) according to the products produced in this industry (although in some cases it is possible that an industry regulator will have sufficiently detailed information on revenue by product). This data is 
more typically available at the industry level in which case the statistical agency can produce an industry based price index that covers only the primary output of the telecommunications industry. Whilst this industry based approach is more practical, it has the disadvantage that it will miss any secondary activity of those establishments classified outside the telecommunications industry. In countries where this secondary activity is of a notable industry based index may be biased.

In the early stages of index development it is recommended that the compiler investigates the likely size of secondary activity that would be missing if an industry based approach was taken. Such investigation could involve discussions with industry regulators and those establishments within the industry. Based on this research, the compiler will then need to balance the additional resource and costs in producing a product based index against the concession in quality that an industry based index may produce.

\subsubsection{Sample design}

In countries where the telecommunications industry is well regulated, the regulatory authority should be able to provide the compiler with information on the market structure of the industry and the relative importance of telecommunications service components. The structure of the telecommunications industry is likely to be similar across most countries with a small number of large service providers dominating the market.

With this in mind, the ideal survey for telecommunications would employ PPS sampling. Options for stratified sampling, using turnover (or some other size measure) as the stratification variable, may also be applied to improve the efficiency of the sample through reducing variance. If the telecommunications industry is recognised to be led by a small number of dominant suppliers, a mixture of non-probability and random sampling may also be considered. This could ensure that the most representative and leading service providers are always included in the sample, with the remaining providers sampled randomly.

Due to the rapid rate of technological development in this industry, the sample may need to be updated more frequently than for other service industries. It might, for example, be appropriate to update the sample on an annual basis to ensure the survey remains representative.

In the U.K. where the unit value approach is employed, a census of data is received for each survey period from the U.K. industry regulator "The Office of Communications (Ofcom)". In Hungary, the SPPI sample is selected from Hungarian Central Statistical Office business register at the NACE class level. Hungary uses a cut-off sampling method, where a census of units is taken above a predefined size threshold (based on turnover of the enterprise) and below this level a random sample is used.

\subsubsection{Collection of information and specification of the service}

The timing and frequency of price collection for telecommunications services will depend on a number of factors that the compiler will need to assess when developing the index. An important consideration will be the proposed pricing method and the availability and periodicity of input data. For example, if a compiler chooses to take a survey approach, the timing and frequency of data collection will need to be evaluated against the availability of data and potential burden on those who will be providing the data. Likewise, if administrative data is to be collected from an industry regulator, an 
appropriate frequency for price delivery needs to be negotiated that allows adequate time for data cleaning, analysis and derivation of the price index. In the U.K., administrative data (turnover and volume data) is received from the U.K. telecommunications regulator every quarter in time for the publication of a quarterly SPPI.

\section{Options for data collection}

In order to construct a price index for the telecommunications industry it is necessary to accurately capture specifications for telecommunications services, including the type of price, the unit of measure, the size of, and reason for price change. Administrative data, survey data, prices collected from the internet and prices collected for the CPI can all be used in the calculation of price change for the industry.

\section{Administrative data}

Administrative data can be accessed either directly from establishments or from a third party, such as the industry regulator. The quality of administrative data can vary between periods and may contain a significant number of outliers and erroneous values. A considerable amount of data cleaning might be required. The trade-off between data quality and data availability could prove to be significant. As such, administrative data for constructing a telecommunications services price index may prove to be unreliable and difficult to manage. However, as discussed in the previous section, the data source may be more suitable for sampling and weighting purposes.

\section{Survey data}

The data source used in compiling a price index is often an important determinant of the pricing method employed. For example, administrative data or tax data that contains income statement variables (revenues and expenses) might be more suited to a unit value methodology whereas transactions prices can be collected directly from a survey. Of the countries currently producing price indexes for the telecommunications industry, 21 of 25 collect price data through a survey while 5 countries compute unit values, although in the U.S. and Germany these data (turnover and quantity) used to compute a unit value are collected through a survey (survey data and unit value methods are not mutually exclusive). In the case of the U.S., both the transaction and unit value approaches are employed. 
Table 8.3.1. Summary of the Pricing Method for Telecommunications SPPI

\begin{tabular}{|l|l|l|}
\hline \multicolumn{1}{|c|}{ Price Method } & Number of countries using the method & \multicolumn{1}{c|}{ List of countries using the method } \\
\hline Transaction & 8 & $\begin{array}{l}\text { AUS, FIN, HKG, JPN, KOR, NOR, } \\
\text { CHN \& U.S. }\end{array}$ \\
\hline Unit Value & 3 & $\begin{array}{l}\text { CAN, ESP,FRA U.K., DNK, GER, U.S. } \\
\text { \& AUT }\end{array}$ \\
\hline Transaction \& Model & 1 & CHE \\
\hline List & 4 & CZE, POL, SVK \& SVN \\
\hline List or Transaction & 4 & MEX, NZL, SWE \& ITA \\
\hline Model/Unit Value/List & 1 & NLD \\
\hline Total & 26 & \\
\hline $\begin{array}{l}\text { Note - this table has been compiled using the most up-to-date information available at the time of writing this } \\
\text { Guide. It may not accurately reflect the latest situation in each country listed. }\end{array}$
\end{tabular}

These statistics and the shortcomings of the administrative data (described in the previous section) suggest that a price survey approach is often the most appropriate method for collecting price information in this industry. The survey approach will allow the compiler full control over the level and periodicity of data collected. Due to the complex nature of telecommunications products it is strongly recommended that the compiler considers an initial face-to-face meeting with respondents during the respondent initialisation process in order to select representative items and collect the initial price specification and base price (if using survey method).

\section{Internet pricing}

An alternative to conducting a survey is to use data that is readily available from the internet. Although a considerable amount of data are available on-line, they are often list prices rather than actual transaction prices (taking account of discounts etc.). Another concern around the use of internet pricing is the potential for service providers to change the content or presentation of the information they provide on their website. This implies a potential risk to regular index production.

\subsubsection{Main pricing methods}

There are a number of pricing methods that could be employed for the telecommunications industry - each with positive and negative aspects. According to the Voorburg Group Sector Paper on telecommunications (Camus, 2009) the most commonly used pricing methods for this industry are the component pricing method (bill or rate) and the unit value method. In this section, the merits of each method are considered. Other methods which the compiler may wish to consider when developing an SPPI for the industry are also introduced.

\subsubsection{Component pricing}

The component pricing with fixed service structure (or bill) method assumes that a set of representative telephone bills and prices is available throughout the lifetime of a business telecoms index. The bills in a base year could be used to define the set of services used in a base year and generate the weighting pattern. This approach is valid if the price changes are the only movement in the index and there is no change in the service use. The respondent would be asked to provide the price updates on the bill and the associated discount information. A disadvantage of this approach is that the use of one service on the bill may affect the discount (and hence price) of another service on the bill 
(particularly with bundled services) which would require informed (and unlikely) knowledge on the part of the respondent. This approach places a large burden on the survey respondent and has been shown to bias the survey response to smaller, less complex bills.

If the bill method of component pricing is likely to prove too burdensome then the 'rate method' is an acceptable alternative. The concession with the rate method is that respondents no longer have to re-evaluate bills for individual service components, but instead provide updated tariffs or rates for a completely specified service (with the price determining characteristics held constant over time). The disadvantages of the rate method are the same as for the bill method (but the respondent's burden is lower). A further disadvantage of both component pricing methods is the assumption of no change in service in this industry, which is quite unrealistic considering the pace of technological change of telecommunications services.

\subsubsection{Unit value}

The unit value method is implemented by obtaining a unit value price at the lowest level of aggregation, which is the ratio of revenues to quantity for a homogeneous group of products. The unit value method can only be applied if the homogeneity requirement can be satisfied. In some cases confirming and maintaining this homogeneity can be difficult. To achieve a unit value, the revenue of a specified service is divided by the appropriate quantity for the service (i.e. minutes, number of flat rates, gigabytes). The yielded unit value is multiplied by its base weight and aggregated within service groups. In effect, the unit value method can be considered to be the component pricing method on a 'per unit of service' basis. As with rate information, telecommunications providers record the value and volume measures for their own analysis, which minimises the respondent burden of the survey. Value and volume data may also be provided by regulatory authorities.

Compared to the component pricing with fixed service structure, a benefit of the unit value method is that it generates no bias towards smaller accounts caused by respondents favouring the reporting of less complex bills. The unit value approach also offers advantage over the component pricing in that it captures price change when services are bundled together. Neither version of component pricing captures these price changes, when the service price varies depending on usage.

A disadvantage of the unit value method is that the mix of service-products in groups does not satisfy the strict requirements of a Laspeyres index. A unit value approach will not guarantee a pure measure of price change, but will provide an approximation. The unit value method also requires cooperation of telecommunications services providers and/or industry regulators for the supply of data. A further complication to consider where administrative data is the main data source is maintaining homogeneity of services provided over time. For example, differences in access, technology, upload and download speed and changes in monthly download limits can be difficult to assess within the unit value method. These changes should be properly accounted for in index compilation.

\subsubsection{Direct use of prices of repeated services}

The main advantage of this pricing method is that it surveys real transaction prices (which may also be list prices) and in dynamic industries it can easily identify any potential changes in quality. This method can only be applied when services can be directly observed or measured, which should be the case in the telecommunications 
industry. Prices can be collected either via a traditional survey approach or internet pricing. A key point with using this method is that the product specification identified in the initial collection period needs to be as detailed as possible to ensure the price determining characteristics are captured and held constant over time. This is especially important in the telecommunications industry where a typical service being measured will likely include a bundle of options (such as a fixed amount of talk time, download limits etc.). By ensuring the specification adequately captures this information the compiler can maintain the constant quality of the item over time or, where changes to the specification have to be made, adjust the price using an appropriate method of quality adjustment. However, the nature of the services offered in this industry requires the compiler to continually review the representativeness of the specification being priced. New service plans are introduced regularly by service providers, which represent more competitive prices for customers as opposed to changing the price of existing plans. Therefore the compiler needs to ensure it adequately captures this move to new products through regular review of the service specification by monitoring 'too stable prices'. This concept is discussed further at section below on quality issues.

\subsubsection{Use of CPIs as proxies}

As discussed earlier, this method of price collection could be used for services provided to the household sector if the compiler requires a BtoAll price index.

In many countries, sections of the telecommunications industry are covered by the CPI (such as wired, wireless activities including services via Internet etc.). Assuming there are resource constraints in producing a business-to-all SPPI, the CPI should provide the compiler with a useful proxy for the measurement of price change for all output.

The compiler should consider any potential adjustments to CPI data that may be required to make them suitable for use in the calculation of an SPPI. Particularly, the price data may need to be adjusted to account for a difference in periodicity (for example, CPI prices are collected on a monthly basis in the U.K. but SPPI is a quarterly index) or any changes to tax rates that are included in the price (for example changes in VAT).

The main advantage of using CPI data is the low cost to the compiler. These data are already being collected and should therefore be relatively easy to obtain and process for inclusion in an SPPI. The obvious disadvantage is the difference in conceptual basis on which the prices are collected - there is a risk that CPI price data will not capture the discounting that takes place in the business-to-business market.

\subsubsection{Quality issues}

One of the most challenging aspects of developing a price index for the telecommunications industry is to ensure that constant quality is maintained for the price data which is collected. As previously noted, the telecommunications industry is dynamic and susceptible to both rapid changes in technology and customer movement to new services. It is therefore imperative that the compiler takes the necessary steps to ensure any change in quality is both identified and treated appropriately.

The method of quality adjustment used will depend on the chosen pricing method. When considering those pricing methods that measure actual transaction prices (such as component or direct use of repeated services) it is essential that the initial price specification is as detailed as possible to ensure the price determining characteristics are identified and fixed. The subsequent collection of regular price updates should then 
attempt to identify any price change that has occurred as a result to the change in the service being offered. This could be carried out in a number of ways. The compiler can simply ask the respondent to report any change in the service specification since the previous period. The compiler may need to follow up with the respondent to fully record the new specification and its impact on the service price. This information can then be used to make an appropriate quality adjustment to the price data.

Alternatively the compiler could choose to use price change as an indicator of potential change in service specification. For example in the United Kingdom SPPI, any price movement of $7.5 \%$ or more is queried with the respondent to ensure the price change is genuine and not a result of a change in service. If a change in service has occurred, then the appropriate details are recorded to facilitate the necessary quality adjustment.

The compiler should also take care to check that prices move in line with expectations for the industry. In such a dynamic industry, the expectation should be that prices of telecommunications services are rarely static. It is important therefore to monitor prolonged "no price change" (that is, service prices which have not shown any price change for a number of periods) to ensure that the specification is still representative and the respondent is providing accurate and meaningful price information each period. As a guide, in the United Kingdom SPPI program, any price which has not shown a price movement for 6 periods (the United Kingdom SPPI is quarterly) is queried with the respondent. This period of "no price change" can be set to meet the needs of the price index being developed and initial consideration should be given to likely price variation in the industry. If the price is no longer representative (or the service is no longer provided) then a replacement service is identified and the necessary quality adjustment is carried out.

A final quality consideration for a telecommunications price index is how and when to introduce new services and remove old services from the index. New telecommunications services and new bundles of services are frequently introduced and a regular assessment of the weighting structure used in the compilation of the index is essential to keep up with these developments. When using a base-year Laspeyres index, the introduction of a new service and generation of an associated weight can be difficult, with turnover data sometimes not available for the base year. Equally, exclusion of new services or inclusion of older non-representative services can create a bias in the index which may increase with time. The unit value method can partially reduce the need for a quality adjustment methodology as the use of average, weighted prices can accommodate migrations between services within product classes.

\subsubsection{Weighting and aggregation}

The weighting and aggregation of a price index is constrained by the availability of reliable data (such as turnover) with which the compiler can reasonably create a representative weighting structure. For an industry such as telecommunications, where it is recommended that weights are updated on an annual basis, identifying a timely supply of data may prove to be problematic.

There are two main sources of potential data for reweighting a telecommunications price index. A compiler could choose to collect the information directly from the respondent (which is likely to prove burdensome, expensive and untimely) or from the industry regulator (again, this source of data is unlikely to be timely). 
In reality, a compiler is unlikely to be able to update the weighting structure as frequently as recommended. Therefore a decision is required that balances the quality of the price index against the availability of data. This may lead to a telecommunications price index that is reweighted more frequently than the standard approach of every five years, but less frequently than the recommended approach of annual updating.

In the U.K., two sources of weights are used to aggregate the SPPI. Firstly, at the elementary aggregate level, a dedicated turnover survey of all respondents providing price data to the SPPI is carried out to collect the corresponding turnover generated for these services in the base period. As the U.K. SPPI is a base weighted Laspeyres type price index, this source of turnover is collected every five years (with the latest survey collecting data in respect of 2010). Due to resource constraints, there are no plans to increase the frequency of this survey.

This source of turnover is used to calculate elementary aggregate weights, which in turn are then used to weight together the elementary aggregate price relatives to produce higher-level indices, up to and including the industry level aggregate.

At the industry level, the U.K. uses national accounts data to derive industry level weights (input/output tables). These weights are then used to aggregate the industry level price movements together to calculate a 'service sector' SPPI, although it should be noted that this aggregate is only representative of the industries which are currently collected by the U.K. This aggregate SPPI is produced on both a gross and a net basis through the adjustment of the industry weights which are calculated. Each industry will be allocated a net industry weight (the net weight for any industry relates only to transactions between that sector and other industries, sales and purchases within industry are excluded) and a gross weight (this covers all transactions).

\subsubsection{Specific aspects}

Business telecommunications services change rapidly in their specification. Corporate usage of telecommunications services can also change quickly. An SPPI for the industry should therefore undergo frequent quality assurance to ensure that it remains representative. The following issues could apply:

- Re-weight the service products on a more frequent basis to capture rapid changes in service consumption;

- Research methods of capturing the prices of bundled service products (with discounts) which are increasingly prevalent. These bundled services may include both telecommunications and IT services;

- Pricing bundled services is further complicated where hardware (such as a new phone, router or modem) is included in the final bundle. The bundle should be priced excluding of hardware so that the price index is only capturing services;

- Consideration of what is classified as export (non-domestic) and international services should be carried out. International telecommunications services are usually provided by a host service provider in the external country, but payments are made directly to the host service provider in the host country. For example, if a U.K. customer of a U.K. telecommunications service provider travels to France, any service used in France will be provided by a French service provider. However, the U.K. customer continues to pay for this service via the U.K. 
telecommunications provider, who in turn passes on payment to the French provider;

- A final challenge for the methodological development of SPPI for this industry is to consider how to capture the reselling of network capacity as part of other telecommunications activities. This issue seems to be quite similar to those encountered in developing a price index for the wholesale and retail trade services, specifically which pricing method should be used and should a gross or net approach be considered?

\subsubsection{Overview of national methods}

A selection of recent and representative references is provided in the Voorburg sector paper for telecommunications (Camus 2009).

\section{Austria}

In Austria, Statistics Austria, with the help of the Austrian Regulatory Authority for Telecommunications and Broadcasting (RTR GmbH), calculates a quarterly overall SPPI for telecommunications services which comprises fixed link telecommunications, mobile telecommunications services as well as broadband services and leased lines. Satellite telecommunications services have not been taken into account due to their minor market relevance. Due to the structure of the data provided, the index compilation is based on a unit value approach, starting at the most detailed level of aggregation. The unit value obtained, depending on the surveyed service product, is defined as the ratio of revenues in Euro to volume in minutes. The RTR provides quarterly data for the index calculation at the most detailed level possible, as well as the requisite weighting information.

\section{Hungary}

In Hungary, data for business-to-business transactions are collected via questionnaires which are completed by market-leader service providers. The general methodology was developed with the active contribution of respondents and an individual questionnaire for each respondent is produced taking into account the services provided. The survey started in 2007 for fixed line telephony and mobile services, and was expanded in 2010 to include the providers of satellite and other telecommunications services (as a pilot). For the majority of services, the unit value or a combination of unit value and component pricing for well specified services is used to capture price data. For satellite and other telecommunications activities, the contract pricing approach (e.g. for reselling network capacity) and direct use of prices of repeated services are used. Price indices for BtoB services are computed and transmitted to Eurostat whilst business-to-all services are under development. For calculation of a BtoAll index, Hungary proposes to use reprocessed CPI data to capture the BtoC component and then weight these data together with the SPPI data (using yearly turnover share captured via a special part of the Structural Business Statistics Survey SBS).

Japan

Japan compiles price indices on telecommunications services including wired/wireless telecommunications and interconnection services for network providers. Indices are focused on BtoB transactions. For wired telecommunications a mix of the direct use of prices of repeated services and unit values methods are used for: fixed telephone services, leased circuits, Internet connection services, and wide area network services. For wireless telecommunications, the model pricing method is employed and 
coverage extends to cellular phone services and PHS services. For interconnection services for network providers, the prices of access charges are measured using the direct use of prices of repeated services method.

\section{United Kingdom}

The U.K. index for business telecommunications comprises fixed line and mobile telephony services. Fixed line activity is dominated by a single service provider with other suppliers using the infrastructure of the main supplier. U.K. mobile services are supplied by a small number of evenly sized businesses with their own networks. Other mobile suppliers provide virtual networks by securing airtime from one of the major providers. The U.K. telecommunications SPPI has not been reviewed or updated in recent years. The index is based on a unit-value method. It is compiled from the aggregation of unit-values defined as the ratio of revenue to volume for each homogeneous group of products. Turnover and volume data for the whole market is sourced from the U.K. communications regulator (Ofcom) providing full coverage. The unit-value approach provides a proxy estimate suitable for the telecommunications industry. In addition to minimising bias, it solves the problem of service bundles and escalating tariffs by negating the need to constantly adjust for quality.

\section{United States}

The United States calculates price indices for both wired and wireless telecommunications. For wired services, with the exception of public switched toll service (long distance), the direct use of repeated prices method is used to measure the change in actual transaction prices for specified service packages including all features. If there is a change to any service feature, such as call waiting or the number of video channels, the associated change in provider cost is used to adjust for the change in quality. For public switched toll service, a unit value is the preferred price. The unit value is calculated by dividing total turnover by total minutes for a specified type of call.

For traditional cellular (voice and data) services, the unit value price is calculated as the average turnover per line. To calculate the average turnover, respondents initially provide a user profile based on a specific market area. This profile is based on all service features provided across all rate plans in the given area. Features typically included in the user profile are average local air minutes, roaming minutes and other recurring services. This profile becomes the fixed service being prices, as the average number of minuets for each service feature is held constant in subsequent months. Using the same features in the user profile, each respondent calculates the average turnover per access line for each feature in subsequent periods. Each average turnover value is then multiplied by the corresponding feature in the user profile to derive the average turnover per line. As wireless service providers move from regional pricing plans to nationwide plans in the U.S., prices are to be calculated using nationwide data when available.

\subsection{Computer programming, consultancy and related activity (Ruth Vizner, Central Bureau of Statistics Israel)}

\subsubsection{Industry description (ISIC 62)}

Computer services activities comprise of hardware and software-related services and data processing services. Included are hardware and software consultancy and implementation services, maintenance and repair of computer and peripheral equipment; disaster recovery services, provision of advice and assistance on matters related to the 
management of computer resources; analysis, design and programming of systems ready to use and technical consultancy related to software; development, production, supply and documentation of customised software, including operating systems and other support services such as training provided as part of consultancy; data processing services, such as data entry, tabulation and processing on a time-sharing basis; web page hosting services and computer facilities management. Excluded from computer services is the selling of packaged (non-customised) software.

Although there has been a spectacular growth in the provision of computer services over the last decade or so, this has been from a low base, and it remains a relatively small sector in total world trade and income. In 2008, computer and information services comprised $4.6 \%$ of total OECD service exports and 3.0\% of total OECD service imports. In 2012 the two most dominant countries in the export of computer services were India ( $\$ 47.134$ billion in exports and only $\$ 2.096$ billion imports) and Ireland ( $\$ 46.751$ billion exports and only $\$ 604$ million imports), far more than the U.K. (\$11.479 billion exports and $\$ 5.562$ billion imports) and Israel ( $\$ 11.329$ billion exports and no imports). Germany has a high level of exports, but also a high value of imports in computer services $(\$ 19.981$ billion exports and $\$ 17.149$ billion imports). ${ }^{4}$ The leading countries in the importation of computer services are Germany, the Netherlands and the U.K. The fact that Ireland, although a small country, has gained such a prominent position in this market underscores that trade in computer services is still relatively small in total world trade and income. However, it is a fast growing industry showing an average annual growth of $17.0 \%$ in OECD exports between 2000 and 2008(with only financial services and construction growing faster), and it is the fastest growing industry in respect of OECD service imports, with an annual average growth of $18.7 \% .^{5}$ Developments in information and communication technology are probably the most important drivers of growth in trade in this industry.

Globalisation or "international economic integration" has expanded trade opportunities and influenced business enterprises in both developed and developing countries. Globalisation has become a fundamental force for growth in computer services as providers attempt to maximize profits and gain competitive advantages, such as reducing labour costs, through geographic arbitrage. Three of the most popular terms used to describe this business model are offshoring, outsourcing and near shoring:

- Offshoring is defined as the movement of a business process performed by a company in one country to a subsidiary or other type of affiliate company in another country. The reason for relocation is almost always a lower cost of operations in the new location. The motivation for offshoring includes access to qualified personnel abroad and an increased speed to market as well;

- Outsourcing refers to the process by which an organisation contracts part of its work to another firm/organisation in another country;

- Near shoring refers to outsourcing service activities to a foreign affiliate or external company that is geographically close.

Offshoring of services has increased in recent times, driven by the liberalisation of services sectors and by technological advances. Improvements in technology, standardisation, infrastructure growth and decreasing data transmission costs have all facilitated the utilisation of services from aboard. Rapid advances in Information Communication Technology (ICT) have also increased the tradability of many service activities and created new kinds of tradable services. In particular, "knowledge work" 
such as data entry and information processing services, and research and consultancy services, can easily be carried out via the internet and e-mail and through video conferencing.

The mostly frequently offshored activities are computer services such as software development and Information Technology (IT) services, with more than $50 \%$ of companies offshoring their functions. ${ }^{6}$ Very often the first jobs to be outsourced were low skilled, such as help desk, back-office and data entry operation. However, over time more skilled jobs and tasks of greater strategic importance for the firms such as network administration, programming, software development and testing, design and system integration have been offshored

The offshoring and outsourcing of Computer Programming and Related Services activities are also important although surveys of multi-national enterprises in several countries (France, U.S., Sweden and Ireland) show that they still only account for a relatively small share of total production. ${ }^{7}$

The three most important motivations for offshoring are: labour cost savings, increased organisational flexibility and access to qualified personnel. Some of the main risks associated with offshoring include: the quality of service, high employee turnover in the offshore service center and concerns about data security.

India's low-cost labour and availability of a large pool of English speaking and technically proficient personnel has made it an offshoring destination for global firms such as HP, IBM, Accenture, Intel, AMD, Microsoft, Oracle Corporation, Cisco, SAP, and BEA. However, wage inflation in India and several other established offshoring destinations has begun to reduce their attractiveness as offshore destinations. India's popularity as the go-to location for product or software development work is declining, while many new destinations, such as China, Canada and Central America (Mexico), are becoming increasingly popular.

\subsubsection{Classification aspects}

\subsubsection{Industry classification}

Under the ISIC classification, division 62 - Computer programming, consultancy and related activities, is an aggregation composed of three industries. Under the NAICS classification, group 54151 - Computer system design and related services, (comparable to ISIC division 62) is an aggregation composed of four industries. The NACE classification for computer programming, consultancy and related activities, is similar to the ISIC classification although it provides more detail (see details in annex A)

While all three classification systems are similar, both the NACE and NAICS classifications specify 'computer facilities management services' as a separate industry, while under the ISIC classification this business activity is combined with computer consultancy.

ISIC 6201 - Computer programming, can be thought of as the production of customised software. Computer programmers write, modify, test, maintain and support software to meet the needs of a particular customer. Services provided may also include customising packaged software to meet a client's specific needs, such as interfacing with other software or business processes. Note that software publishing (pre-packaged or packaged software, which includes licensing the right to use most operating systems, 
office suites, utilities and games as well as support and software updates) is not part of ISIC 62, but instead is included as part of division 58 - Publishing activities.

The primary services classified under ISIC 6202 - Computer consultancy, can be described as planning, designing, advising or offering expert opinion on computer systems that integrate hardware, software and communication technologies. Computer consultants may provide the hardware and software components for their design or these components may be provided by third parties. Computer consultants may also install a system, train and support users of the system, and provide advice and procedures for enhancing systems security.

This industry also includes computer facilities management activities which provide on-site (including remote access) management, operation and support services for clients' computer systems and/or data processing facilities. Note that establishments providing computer data processing services at their own facilities are not included in this industry, but instead are classified under ISIC Group 631 - Data processing, hosting and related activities; web portals.

ISIC 6209 - Other information technology and computer service activities, includes outputs as diverse as computer disaster recovery services, installation of personal computers and software installation.

It is clear therefore, that turnover for computer programming, consultancy and related activities is generated from a wide range of services.

\subsubsection{Product classification}

The corresponding products for Computer programming, consultancy and related activities (ISIC 62) are classified in CPC as follows:

- 831 - Management consulting and management services; information technology services;

- 8313 - Information technology (IT) consulting and support services (corresponds to ISIC 6202 - Computer consultancy and computer facilities management activities);

- 83131 - IT consulting services;

- 83132 - IT support services;

- 8314 - Information technology (IT) design and development services (corresponds to ISIC 6201 - Computer programming activities);

- 83141 - IT design and development services for applications;

- 83142 - IT design and development services for networks and systems;

- 83143 - Software originals;

- 8316 - IT infrastructure and network management services;

- 83161 - Network management services;

- 83162 - Computer systems management services;

- 873 - Installation services (other than construction);

- 8733 - Installation services of office and accounting machinery and computers (corresponds to ISIC 6209 Other information technology and computer service activities);

- 87332 - Installation services of personal computers and peripheral equipment; 
A comparison between the CPC and NAPCS classifications shows that NAPCS is much more detailed (see annex B).

Practices in the provision of computer services vary across countries. However, to the extent allowed by market conditions, it is recommended that national product classifications are developed such that they will accord to the generally accepted breakdowns included above. This will increase international comparability, while at the same time facilitating the customised measurement of different products and product groups, where necessary.

\subsubsection{Scope of the survey}

The ideal survey will capture price changes in computer programming, consultancy and related activities as a whole, covering ISIC sub-divisions 6201, 6202 and 6209. The decision on partial coverage of the sector depends on the market structure in the country. In most countries group 6201 - Computer programming activities, accounts for the largest share of the total output of the division followed by group 6202 - Computer consultancy and computer facilities activities. Group 6209 - Other information technology services, usually accounts for the smallest share. In practice, most countries that compile a SPPI for the industry cover all three groups with a minority covering only the first (6201) and second (6202) groups.

\subsubsection{Sample design}

Sampling can be organised over several levels, meaning that the price observation under consideration may have been chosen as a result of more than one sample selection. For example, a sample of business enterprises is drawn first, followed by a sample of representative services and finally of contracts. Probabilistic, stratified or random, sampling can be used at all levels of sampling.

The Business Register is typically used as the sample frame for SPPI, although the samples for short-term and structural business surveys can also be used as the frame for selecting units. The sample is usually selected at the class level. Stratified sampling, which involves the independent sampling of different subgroups within the frame, can be applied. Units can be selected using various methods such as PPS sampling, random sampling and non-probability sampling. These sampling methods allow for differences in unit sizes to be taken into consideration. In some cases only cut-off sampling is used, in which only units above a certain size are included. By including the larger units, coverage of a significant share of the turnover can be achieved. Probability and non-probability sampling methods can often be successfully combined.

The size criterion for selection of unit is usually either turnover or number of employees or a combination of both. The correlation between the number of employees and the net turnover is often relatively high, which indicates that the number of employees is a reasonable proxy for the net turnover.

The size of the sample is, in practice, determined either by statistical methods or according to available resources. Because of the diversification in services, the sample design should include medium and small size units to cover all kind of services. When regional differences are observed in a price change, the use of geographic area as a stratification variable can be considered. 


\subsubsection{Collection of information and specification of the service}

It is important to ensure that respondents provide accurate and representative data. The information provided should represent the diversity of services in the industry and their price development. Ideally, respondent contacts should be senior managers, who command a broad overview of the relevant services and of the industry as a whole. This will help to ensure a high quality and representative index for the industry.

The specification of specific service transactions should include:

- The type and kind of service (e.g. software analysis, software programming, software installation, hardware consultancy);

- Details of staff: profession and skill level (e.g. senior database programmer, senior system engineer, PC technician), experience (e.g. less than 2 years, between 2-5 years, more than 5 years);

- Other specification of the services such as kind of software language (e.g. Java);

- Customer type.

Special efforts should be made to identify any changes to the service transaction between the current and previous period. If there has been a change in the service transaction, a quality adjustment should be made to account for this change.

\subsubsection{Main pricing methods}

The selection of the pricing method must take into account the special characteristics of the pricing mechanisms used in the industry. Business enterprises providing computer programming, consultancy and related activities usually charge their clients according to the time spent in providing the service. Charges cover salaries and other costs, and also profit.

\subsubsection{Time based methods}

The most commonly used pricing method in this industry, employed in the majority of countries, is the time base method. This method surveys the amount of money charged to a service purchaser for a standard amount of work (e.g. one hour or one day) by an employee of the producer, who contributes to the provision of that service.

When using time based methods such as charge out rates, the service specification should be sufficiently detailed and might include the profession level of the staff, their skills and experience, and the project and client types.

The charge out rate is an acceptable method although it does not capture changes in productivity. It is relatively easy for respondents to report hourly rates and respondent burden is minimised. Time based methods are commonly employed for computer programming activities, as they are unique non-repeatable services provided to a specific client.

\subsubsection{Model pricing}

Model pricing can also be employed for the provision of unique services. Under this method a standardised representative service is identified in cooperation with the respondent who will then provide a price estimate for the standardised service in each survey period. The model can be based on an actual service provided (ideally recently 
provided) or on a fictitious one. When estimating the price for the model, the expert might consider real transaction prices, hours worked, wages, revenues and any other input data

\subsubsection{Direct use of prices of repeated services and contract pricing}

For the other groups - Computer consultancy and Computer facilities activities and other information technology services - which have more regularly provided services (such as data processing or the operation of hardware systems), other pricing methods can be used. The direct use of prices of repeated services and contract pricing methods are employed for more regular services, such as security services for networks.

Table 8.4.1. Pricing methods for computer programming, consultancy and related activity

\begin{tabular}{|l|l|l|}
\hline \multicolumn{1}{|c|}{ Pricing method } & \multicolumn{1}{c|}{ Example } & \multicolumn{1}{c|}{ Sub-group } \\
\hline Time based & Hourly charge-out rates for chief programmer for analysis & 6201 \\
\hline Time based & $\begin{array}{l}\text { Hourly charge-out rate for senior database programmer for } \\
\text { design and development of the database }\end{array}$ & 6201 \\
\hline $\begin{array}{l}\text { Direct use of prices for } \\
\text { repeated services }\end{array}$ & Security services for network & 6209 \\
\hline Percentage fees & Percentage of software licenses & 6202 \\
\hline
\end{tabular}

\subsubsection{Globalisation effects on SPPIS}

The outsourcing or offshoring of computer services activities presents SPPI compilers with difficult measurements challenges. When part or all of a service activity previously produced in-house (domestically) is outsourced, it is often to a lower cost country, resulting in a change to the transaction price, margin or both. The use of geographic labour arbitrage is not a concern from a SPPI perspective. The question is - has output changed as a result of the shift from internal to external production? As long as the outputs are unchanged, the primary interest of an SPPI is to record transaction prices that are tied to the firm revenue function. If a component of a computer service activity is outsourced offshore, resulting in lower costs for the same service in period 2 compared to the service produced in period 1 , the price change should be recorded as a pure price change. If a job or component of a job is outsourced and results in qualitatively different inputs then a quality adjustment to account for the change in output quality is needed. Outsourcing of services has no implication for the classification of the principal companies, even if all of the production process is outsourced. Therefore, the classification of the principal company remains as if they were carrying out the complete service activity in contrast to the outsourcing of the manufacture of products (in which case the classification of the principal company is dependent on whether part or all of the manufacturing is outsourced and on the ownership of the material inputs).

In order to facilitate a better understanding of the effects of globalisation on the SPPI for computer services it may be necessary to collect more information from multinational enterprises, perhaps as part of the SPPI survey. This information might include: the type of services offshored; the process of offshoring; comparison of the quality of the outsources and domestically produced services; the proportion of their production that is outsourced; the motivation for outsourcing and the identification of other factors that influence the prices of and profit margins for outsourced services. 


\subsubsection{Quality issues}

Estimating the value of change in output quality is one of the most challenging measurement problems faced by SPPI compilers. The output of computer programming, consultancy and related activities is dynamic and tends to be customised to the needs of the client. Thus, the initial specification of the service or job that is repeatedly priced will become less representative over time. The ability to explicitly and accurately value quality changes remains challenging.

Implicit quality adjustments are the most commonly used methods for quality change valuations. These include the overlap method and the overall mean, targeted mean and class mean methods. Hedonic techniques do not appear to be a practical option due to a lack of resources, the complexity of consultancy outputs, and the lack of sufficient data. ${ }^{8}$

Changes in the time based prices generally include not only pure price changes but also changes in productivity which should ideally be accounted for in the measurement of price development. In order to facilitate the identification of changes in productivity it is vital that charge out rates must be based on detailed specifications of the work, the type, skills level and experience of staff, the client as well as profit and overhead.

Much work remains to improve the current methods for valuing output quality and compiling constant quality output price indices. Future improvements will require a combination of research, efforts to improve respondent cooperation and more extensive use of expert advice.

\subsubsection{Weighting and aggregation}

The sources of weight data vary among countries. Most countries use data from annual surveys like Structural Business Surveys and Annual Surveys of Services for Computer Services. In some countries, weight data are collected by a specific SPPI survey which is usually conducted as part of the respondent initialisation process. Some countries use National Accounts data and data from input-output tables.

\subsubsection{Specific aspects}

In addition to the measurement issues discussed in the previous section - outsourcing, quality change and the non-observable productivity changes when using hourly rates there are a number of other issues that present challenges for compilers of SPPIs for this industry.

Intra-enterprise pricing is one such issue. An enterprise may set up an establishment to provide IT services to other units within the enterprise. It can be difficult to collect prices for these intra-enterprise services and they may be of dubious value if they do not parallel the price development for market transactions.

The rapid consolidation of large business enterprises, through mergers and acquisitions presents further challenges. Additionally, the dynamic nature of the services produced may create sampling and classification problems, as well as the need for frequent updating of the sample of business enterprises and the types of services, and a greater need for a quality valuation model.

The export share of the industry is relatively high compared to other industries, and further complicated by the activities of foreign branches and subsidiaries particularly in the context of offshoring, subcontracting and outsourcing. 


\subsubsection{Overview of national methods}

\section{Austria}

In Austria, the collection of prices is by e-mail, fax, post and telephone. Hourly charge out rates by level of staff and type of service are provided by respondents (for example: chief programmer for analysis, senior consultant for consultancy, junior consultant for planning and chief programmer for training). Close contact is maintained with respondents to facilitate the identification of changes in the quality of services.

\section{Canada}

In Canada, the prices collected for the IPSPI (Informatics Professional Services Price Index) represent the input costs of labour and the realised profit for the firm. The labour cost is calculated as the weighted average of the firm's contract fees and wage rates for the year, while the profit portion reported is used to derive the realised net multiplier. Both of these inputs are multiplied to arrive at a total price index. Prices are collected annually by e-mail. The potential for using model prices on a quarterly basis to replace the current labour/profit pricing method will be explored in the future.

\section{Czech Republic}

In the Czech Republic, monthly prices are collected by e-mail. Charge out rates type of service and type of job are collected; level of skill and experience will also be accounted for in the future.

\section{Finland}

In Finland, charge out rates are collected using an online questionnaire, and by email.

\section{Germany}

In Germany, the time based (hourly rates) method is employed for computer programming, while the time based and contract price methods are used for computer consultancy and computer facilities activities. The percentage fee method is used for software support (percentage of software licenses). The overlap method is used to quality adjust services.

\section{Hungary}

In Hungary, prices are collected via the internet. The most commonly used pricing method is based on working time (hourly rates or charge per day), taking into account the type of software, and the education and experience levels of staff. For regularly provided services, such as data processing or the operation of hardware systems for the specified period, contract pricing or the direct use of prices of repeated services methods are used. For some other services, such as data backup, the unit value method (or average prices based on contracts) is employed.

\section{Ireland}

In Ireland, hourly rates by staff grade, experience and type of work are collected by email. Implicit quality adjustment methods are employed.

\section{Japan}

In Japan, average charge out rates for specified clients are used to measure the price change of custom software development activities. The direct use of prices of repeated services, the unit value and time based (average charge out rates) pricing methods are 
employed for system management and operation services activities. The direct use of prices of repeated services method is used for security services for networks activities.

\section{Korea}

In Korea, the SPPI covers group 6201 - Computer programming activities, and group 6202 - Computer consultancy and computer facilities management activities. The model pricing method is employed for computer programming activities and fee percentages are collected for computer facilities management activities.

\section{The Netherlands}

The Netherlands compiles a quarterly SPPI covering Group 6202 Computer consultancy and computer facilities management activities. Prices are collected using a paper questionnaire and non-response is followed up by email and phone. Realised hourly tariffs (with reference to turnover and the concomitant hours), stratified to function, skill level and experience are used to measure price development.

Norway

Norway compiles a quarterly SPPI on the basis of average hourly charge out rates by skill level. Prices are collected via the internet.

\section{Slovakia}

In Slovakia, the experimental SPPI for computer programming employs the time based pricing method. Charge-out rates according to professions and skill level of staff are collected. Both paper and online questionnaires are used in the collection of prices.

\section{Slovenia}

In Slovenia, quarterly prices are collected by e-mail. A mixture of direct price of repeated services and time based methods (by type of software, project, and experience and skill level of staff) are employed.

\section{Spain}

In Spain, prices for computer programming activities are collected on a quarterly basis, mostly by email. The time based method (hourly rate) is employed. Distinction is made between different skills and experience of staff, and different products where relevant. The overlap method and expert judgement are used to quality adjust prices.

\section{Sweden}

In Sweden, prices are collected electronically and the time based pricing method is employed, taking account of the experience and skill level of staff. When a service change results in non-comparability, the overlap quality adjustment method is applied. 


\section{Bibliography}

\section{Publishing of books, periodicals and other publishing activities:}

Gac D. and Gallais A., (2013), Mini presentation on publishing activities in France (turnover and SPPI), $28^{\text {th }}$ Voorburg Group meeting, Tokyo, Japan available at: http://www4.statcan.ca/english/voorburg/Documents/2013\%20Tokyo/Papers/4002paper36.pdf

Ginsburgh V. and Throsby D., (2006), Handbook of the Economics of Art and Culture, North-Holland, coll. « Handbooks », volume 1, chapter 21.

Sulc J., (2013), SPPI for Publishing of books, periodicals and other publishing services in the Czech Republic, $28^{\text {th }}$ Voorburg Group meeting, Tokyo, Japan available at: http://www4.statcan.ca/english/voorburg/Documents/2013\%20Tokyo/Papers/4010paper41.pdf

Vizner R., (2013), Mini-Presentation on SPPI for ISIC4 Group 581 Publishing of books, periodicals and other publishing activities, $28^{\text {th }}$ Voorburg Group meeting, Tokyo, Japan available at:

http://www4.statcan.ca/english/voorburg/Documents/2013\%20Tokyo/Papers/4008-paper40.pdf

\section{Software publishing:}

Swick, R., Bathgate D., and Horrigan, M., (2006), Services Producer Price Indices: Past, Present, and Future, Paper prepared for the National Bureau of Economic Research, 36 Conference on Research in Income and Wealth Summer Institute, Cambridge, MA, 83 p., available at: http://www.bls.gov/bls/fesacp1060906.pdf

Hirakata, N., Kouju, A., Utsunomiya, K., (2004), Quality Adjustment Method in Prepackaged Software in Japan's 2000 Base Corporate Service Price Index, $19^{\text {th }}$ Voorburg Group meeting, Ottawa, Canada, available at: http://www.voorburggroup.org/Documents/2004\%20ottawa/papers/2004-045.pdf.

\section{Telecommunications:}

Camus, B., (2009), Sector Paper on Industry ISIC 61 Telecommunications, $24^{\text {th }}$ Voorburg Group meeting, Oslo, Norway, available at:

http://www4.statcan.ca/english/voorburg/Documents/2009\%20Oslo/Papers/2009\%20\%2002.pdf

\section{Computer programming, consultancy and related activity:}

Camus, B., Gac, D., (2007), SPPI for IT industries in France, $22^{\text {nd }}$ Voorburg Group meeting, Seoul, South Korea available at: http://www.voorburggroup.org/Documents/2007\%20Seoul/papers/16.pdf

Gac, D., Nieminen, S., Norman, V., Varjonen, S., (2008), Average daily charge out rates in the context of offshore outsourcing, 23rd Voorburg Group meeting, Aguascalientes, Mexico available at:

http://www.voorburggroup.org/Documents/2008\%20Aguascalientes/Papers/2008\%20-

$$
\text { \%2001.pdf }
$$


Gac, D., Prioux, H., (2009), Effect of globalization on services producer price index change in the IT industry, $24^{\text {th }}$ Voorburg Group meeting, Oslo, Norway available at: http://www.voorburggroup.org/Documents/2009\%20Oslo/Papers/2009\%20\%2011.pdf

Holdway, M., (2008), Sector Paper on Computer Programming, Consultancy and Related Activities, $23^{\text {rd }}$ Voorburg Group meeting, Aguascalientes, Mexico available at: http://www4.statcan.ca/english/voorburg/Documents/2008\%20Aguascalientes/Papers/ 2008\%20-\%2003.pdf

Holdway, M., (2009), Effect of Globalization on IT services, $24^{\text {th }}$ Group meeting, Oslo, Norway available at:

http://www.voorburggroup.org/Documents/2009\%20Oslo/Papers/2009\%20\%2005.pdf

Norman, V. (2008), The Charge Out Rates Applied to the Swedish Computer Services, 23rd Voorburg Group meeting, Aguascalientes, Mexico available at: http://www.voorburggroup.org/Documents/2008\%20Aguascalientes/Papers/2008\%20\%2023.pdf

OECD, (2008), OECD Statistics on International Trade in Services, Volume I, Detailed tables by service category, Paris, France.

Vizner, R., (2012), Updated Sector paper on Computer Programming, Consultancy, and Related Activities, $27^{\text {th }}$ Voorburg Group meeting, Warsaw, Poland available at: http://www.voorburggroup.org/Documents/2012\%20Warsaw/Papers/1018\%20\%20updated_Sector_Paper_on_\%20ISIC_62_Computer_Programming.pdf

\section{Notes}

1. In 2011, 13 European countries plus Korea, Japan, and Mexico, operated fixed book price policies for cultural reasons. For more detail on fixed book price policies, see Ginsburgh and Throsby (2006), volume 1, chapter 21.

2. This activity can account for up to half of the revenue of the publisher. Publishers can engage external advertising agencies (73.11 NACE) to sell the advertising space, or (more rarely) sell the space themselves.

3. This section borrows heavily from the 2009 Voorburg Group sector paper on Telecommunications.

4. Source: World Trade Organization, 2012.

5. Source: OECD, 2008.

6. Source: Offshoring Research Network U.S. Survey.

7. Source: Gac, D., et ali (2008).

8. Quality adjustment for PPIs in discussed in detail in Chapter 7 of the PPI Manual. 



\section{Chapter 9. Financial and insurance activities}

This chapter presents practical guidance as well as main issues and challenges for compiling SPPIs for Monetary intermediation activities (ISIC 6419), Investment banking (ISIC 6499), Security and commodity contract brokerage (ISIC 6612), and Insurance (ISIC 651). 


\subsection{Monetary intermediation activities (David Friedman, U.S. Bureau of Labor Statistics)}

\subsubsection{Industry description (ISIC 6419)}

This industry class includes the receiving of deposits and/or close substitutes for deposits and extending of credit or lending funds. The granting of credit can take a variety of forms, such as loans, mortgages, credit cards, etc. These activities are generally carried out by monetary institutions other than central banks, such as banks, savings banks, and credit unions.

Included in these activities are both direct and indirect financial intermediation services. Indirect services include convenience, liquidity, security, and facilitation in borrowing and lending funds. These services do not have an explicit price and this presents a challenge in measuring banking output. Interest is a primary source of bank turnover. The spread (or difference) between interest earned on loans and interest paid to depositors is used to measure prices for these indirect services. This concept of financial intermediation services indirectly measured or FISIM is the recommended method for pricing loan and deposit banking services in the SNA.

There are a few countries that are either developing or have practical experience calculating an SPPI for banking services and, from this experience and research, a number of different ways to implement FISIM pricing has emerged. At the core of the different methods is the differing definitions of the service that financial intermediaries provide, specifically the activities they undertake to manage risk. Default risk and term risk are the two broad types of risk. Default risk covers the risk that a borrower will default, while term risk covers the risk that interest rates contracted to be paid on deposits or charged on loans will become misaligned with market rates during the term of the contract.

In the U.S., no explicit attempt is made to exclude interest payments that cover the defaults of others, thereby supporting the underlying concept that banks are assuming the risk of default. Adopting the risk assumption concept for banking is consistent with the U.S treatment of risk in the insurance industries.

In contrast, if it is assumed that banks set interest rates that not only support the loan services provided but also cover expected losses from defaulting loans, the risk is transferred (or pooled) and not assumed and is, therefore, not considered production by the financial intermediary. Non-production activities must be removed from FISIM prices and that is done through selection of an effective interest rate and selection of an appropriate reference rate. Ultimately, the reference rate selection and the determination of whether or not to attempt to adjust for loan write-offs will depend on which of these risk concepts is adopted.

\subsubsection{Classification aspects}

Monetary intermediation activities excluding central banking are classified in ISIC class 6419 . This group includes the following activities:

- Receiving deposits;

- Extending credit or lending funds;

- Postal giro and postal savings bank activities; 
- Credit granting for house purchase by specialized deposit-taking institutions; ${ }^{1}$

- Money order activities.

\subsubsection{Industry classification}

Annex A provides various industry classifications for each type of activity. A major difference between the NAICS and ISIC definitions is the treatment of credit unions. Under NAICS, credit unions are classified in their own industry, NAICS 522130. Specialised depository institutions that grant credit for house purchases are similar to savings and loan associations, which are classified in NAICS 522120. The U.S. equivalent of postal giro is automated clearing, classified in NAICS 522320. NAICS 522110 and 522120 include finance leasing services which are classified in ISIC 6491.

\subsubsection{Product classification}

Annex B maps the NAPCS product codes to the CPC structure for classes 7112 and 7113.

\subsubsection{Scope of the survey}

Ideally, as in the U.S., the banking indices should measure price change for both consumer and business transactions. Detailed service line indices reflect the major loan categories. By definition, each service line is either entirely consumer or entirely business in nature. All other indices include a mix of consumer and business transactions.

\subsubsection{Industry vs. product based SPPI}

Each U.S. banking sub-industry (Commercial Banking; Savings Institutions) is inclusive of the full range of banking products, which allows the flexibility to capture a representative sample of products from establishments classified in each industry for calculating industry based price indices. The similarity of products across these industries allows for the calculation of approximate product based indices as well. In the U.S., price data are collected by industry, but used for calculating both industry based and approximate product based indices for banking.

\subsubsection{Sample design}

It is ideal to sample the banking industries using probability proportional to size with turnover as the size measure. In the U.S., banks are sampled at the headquarters level. The U.S. Federal Deposit Insurance Corporation (FDIC) maintains a comprehensive list of commercial banks and savings institutions, as well as turnover data for each entity.

The industries are concentrated with the large banks being dominant. However, there are a large number of small banks. In the U.S., the largest banks are separated into three different sample units that correspond to the following banking activities:

- Loans;

- Deposits;

- Other banking services.

This strategy forms the basis for stratification and, in many cases, creates multiple reporting units for a single bank. Often, large banks will have separate officials and 
separate records for these specific types of services. Each of the smaller banks is given a chance of selection as a single sample unit, and it is typical to have one official at these smaller banks that can provide the pricing information for all services offered within the bank.

Since item selection is restricted to a single type of service for larger banks, prices are not collected for secondary activities. For the smaller banks that are sampled by the entire business enterprise, little to no turnover is generated from secondary activities. Therefore, only services primary to the industry appear in the published indices in the United States.

\subsubsection{Collection of information and specification of the service}

In the U.S., the unique item that is priced for loans and deposits is a homogeneous portfolio of accounts (for example, all 15-year fixed rate residential mortgages or all 1year certificates of deposit). Trusts and other banking services are priced by selecting an individual transaction.

For initial data collection, representative portfolios and transactions are selected during a personal visit with respondents. The price determining characteristics are then captured for accurate pricing over time. The following characteristics are common for most banking services:

- Type of service - for example, mortgage loans, money market savings account, corporate trusts, etc.;

- Term of service - for example, 15-year loan, 5-year certificate of deposit, etc.;

- Type of fees - for example, late payment, automatic teller machine, early withdrawal penalty, etc.

In Australia, for the compilation of a banking index for the CPI, a sample of products is selected from each institution to represent each major product category. Each product is assigned a weight to represent the entire product group.

\subsubsection{Main pricing methods}

The primary challenge presented by the banking industry is measuring financial intermediation services indirectly measured or FISIM as defined in the United Nations System of National Accounts (SNA). Banks often provide services for which they do not explicitly charge by paying or charging different rates of interest to lenders and borrowers. The margin between the rates charged to borrowers and the rates paid to depositors represents the indirect price of the intermediation services, including safekeeping, recordkeeping, and risk management. The resulting net revenues of interest are used to defray bank expenses and provide an operating surplus. This scheme of interest rates avoids the need to charge customers individually for services provided and leads to the pattern of interest rates observed in practice.

As a result, it is necessary to develop a methodology that not only captures directly priced services, but also reflects services priced indirectly. This methodology must allow for the calculation of prices for loans and deposits such that output can be allocated to both services. 
Figure 9.1.1. Calculation of prices for loans and deposits

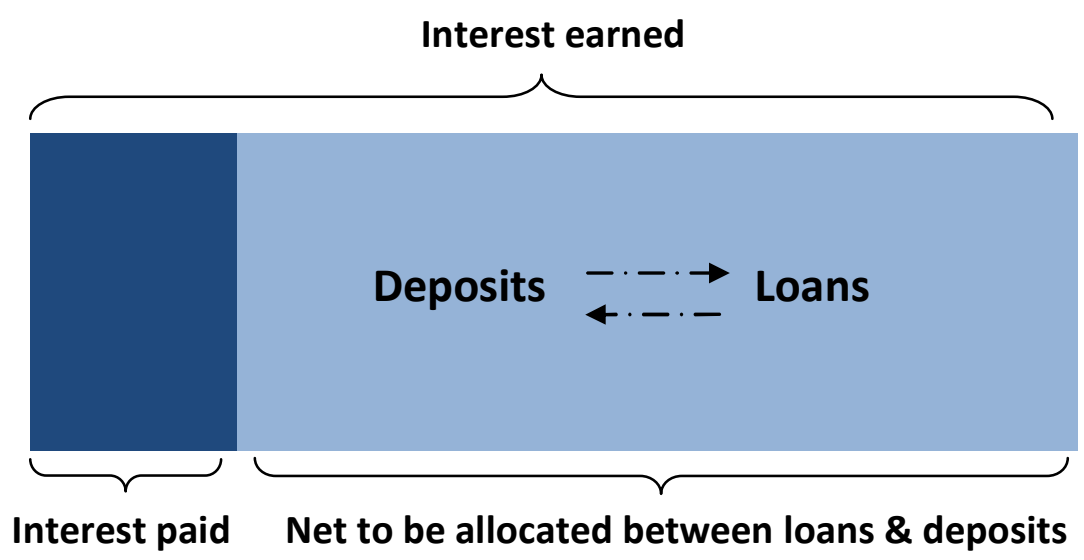

The user cost methodology is implemented in the U.S. The user cost for a financial service is the difference between the turnover it generates and the sum of its implicit and explicit costs. To measure these implicit costs, interest is allocated between loans and deposits by means of a "reference rate." A single reference rate that includes a mix of maturities is recommended for calculating output for both loans and deposits. The Intersecretariat Working Group on National Accounts (ISWGNA) Task Force on FISIM continues to investigate various methods for calculating reference rates. ${ }^{2}$ The reference rate is the pure cost of borrowing funds that does not include any intermediation services. In theory, the price of intermediation services associated with a loan is equal to the asset holding rate less a reference rate. The asset holding rate for a portfolio of loans is equal to the interest received plus service charges divided by the portfolio balance. For deposits, the price of the intermediation service is equal to a reference rate less the liability holding cost rate. The liability holding cost rate for a portfolio of deposits is equal to the interest paid to depositors less service charges divided by the portfolio balance.

Figure 9.1.2. Asset holding income rate

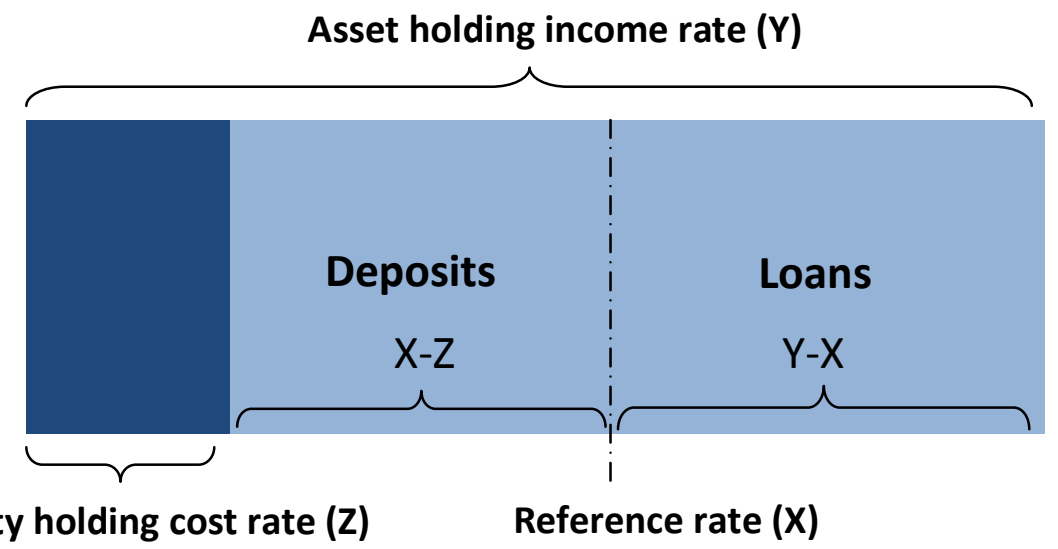




\subsubsection{Unit value}

In practice, the price of these services can be expressed as a unit value as shown below.

- For loans:

$$
\begin{aligned}
& \text { Price of loan portfolio } \\
& \qquad\left\{\left(\frac{\text { Interest income }+ \text { fees }}{\text { Average loan balance }}\right)-\text { Reference rate }\right\} \\
& \times \text { fixed monetary value }
\end{aligned}
$$

Interest income includes all interest earned in a given month for the portfolio of loans being priced. This includes interest earned on both old and new loans. The average loan balance is calculated by averaging the ending daily balances of all loans in the portfolio over the month.

- For deposits:

Price of deposit portfolio

$$
\begin{aligned}
& =\left\{\text { Reference rate }-\left(\frac{\text { Interest payments }- \text { fees }}{\text { Average deposit balance }}\right)\right\} \\
& \times \text { fixed monetary value }
\end{aligned}
$$

Interest payments include all interest paid to depositors on the funds held in the portfolio in a given month. Fees include all fees earned by the bank, such as those for ATM withdrawals or insufficient funds. Again, the deposit balance is calculated by taking the average of the ending daily balances of the portfolio.

For both equations presented above, the calculation within the outer brackets results in a rate. This rate is multiplied by a fixed monetary value, such as $\$ 1000$ in the U.S., to convert the rate to the dollar value used in index calculation. When the price is positive, the service is considered an output. However, whenever the price is negative, the service is considered an input and the price is excluded from index calculation until it becomes positive.

Every month, banks provide the monthly interest, fees, and average balances from the previous month for each portfolio. A new reference rate is calculated each quarter. Because each bank manages their assets, liabilities, and low or no risk securities holdings differently to maximize profits, a bank-specific reference rate is preferred. The use of this rate in calculating prices is likely to eliminate the incidence of negative prices as well. The preferred reference rate is calculated for each bank by the dividing the quarterly interest income that the bank earns on U.S. Treasury securities and U.S. government agency obligations (excluding mortgage-backed securities) by the balance of these securities held by the bank. The rate on U.S. Treasury securities is used since these are considered the most free of risk. The reference rate is always lagged by one quarter, which is the period of time necessary for banks to adjust to changes in their investment portfolios. The bank-specific rate is calculated using quarterly Federal Deposit Insurance Corporation (FDIC) regulatory data. When FDIC data are not available for certain banks, a reference rate is estimated based on the weighted average rate of all sampled banks for which FDIC data is available. A separate average rate is calculated for each NAICS industry. In the U.S., calculating bank-specific reference rates, as opposed to use of national reference rate, is a recent development. 
Since data reported to the FDIC is quarterly, the reference rate is converted to a monthly rate to correspond to the monthly data reported by the banks using the following formula:

$$
\text { Monthly rate }=(1+\text { Quarterly rate })^{1 / 3}-1
$$

This monthly rate is used for a three-month period.

Australia used a conceptually similar method in calculating a FISIM price in their CPI. A sample of products (weighted to represent the entire product group) is chosen and an interest rate margin for each product is calculated from the difference between the product yield and the reference rate. These margin rates are then applied to the balances on a series of sampled accounts to compute the dollar value of the margin. The balances are updated each period using a four quarter moving average of the all groups CPI to preserve the quantities associated with these balances.

\subsubsection{Percentage fee method}

In addition, in the U.S., the percentage fee method is used for pricing services for which the price is based on the value of assets, such as the management of trusts. Banks provide the actual value of the assets in the trust in addition to the fee percentage charged. The value of these assets is held constant over time and the current percentage fee, reported by the bank, is applied to this fixed value to obtain the price.

\subsubsection{Direct use of prices of repeated services}

Finally, in the U.S., the direct use of prices of repeated services method is used for all other banking services, such as sale of money orders and rental of safe deposit boxes. With this method, banks report the actual fee charged for performing the service.

\subsubsection{Quality issues}

A fundamental issue in pricing banking services is keeping monetary values stated in constant terms. Periodically, certain values included in the price calculations are adjusted to account for the time value of money. For example, the fixed monetary value used in calculating loan and deposit prices is adjusted once a year by the annual change in the gross domestic purchases price index calculated by the U.S. Bureau of Economic Analysis (BEA). For services such as trust management services, the value of the assets is adjusted by the rate of return earned on the fixed assets. 


\subsubsection{Weighting and aggregation}

\subsubsection{Industry based indices}

Table 9.1.1. provides the U.S. PPI industry based publication structures for the banking industries.

Table 9.1.1. U.S. PPI industry based publication structures for the banking industries

\begin{tabular}{|c|c|}
\hline 522110 & Commercial banking \\
\hline $522110 \mathrm{P}$ & Primary services \\
\hline 5221101 & Loan Services \\
\hline 522110101 & Residential real estate loans, except home equity \\
\hline 522110102 & Non-residential real estate loans \\
\hline 522110103 & Home equity loans \\
\hline 522110105 & Commercial, industrial, and agricultural loans \\
\hline 522110106 & New and used auto and truck loans \\
\hline 522110107 & Credit cards, overdraft credit, and related plans \\
\hline 522110108 & Other loan services \\
\hline 5221102 & Deposit services \\
\hline 522110201 & Demand deposits \\
\hline 522110202 & Time and other deposits \\
\hline 5221103 & Trust services \\
\hline 5221104 & Other banking services \\
\hline 522120 & Savings institutions \\
\hline $522120 \mathrm{P}$ & Primary services \\
\hline 5221201 & Loan Services \\
\hline 522120101 & Residential real estate loans, except home equity \\
\hline 522120102 & Non-residential real estate loans \\
\hline 522120103 & Home equity loans \\
\hline 522120105 & Commercial, industrial, and agricultural loans \\
\hline 522120106 & New and used auto and truck loans \\
\hline 522120109 & Credit cards, overdraft credit, and related plans \\
\hline 522120111 & Other loan services \\
\hline 5221202 & Deposit services \\
\hline 522120201 & Demand deposits \\
\hline 522120202 & Time and other deposits \\
\hline 5221203 & Trust and other banking services \\
\hline 5221204 & Other banking services \\
\hline
\end{tabular}

For each index series, the lower-level indices are aggregated using industry turnover data as weights. Although the indices are calculated using the Laspeyres formula, these weights are updated approximately every five years. Within the lowest level indices, each bank and the items selected within the bank are weighted using turnover provided by the bank at the time of data collection. These weights remain fixed throughout the life of the sample.

\subsubsection{Product based indices}

Table 9.1.2. provides the U.S. SPPI product based publication structures for the banking industries. The U.S. covers only a portion of the banking output, thus weights represent only partial coverage. 
Table 9.1.2. U.S. PPI product based publication structures for the banking industries

\begin{tabular}{|l|l|}
\hline \multicolumn{1}{|c|}{39} & \\
\hline 391 & \multicolumn{1}{c|}{ Credit intermediation services (partial) } \\
\hline 3911 & Loan services (partial) \\
\hline 3912 & Business loans (partial) \\
\hline 391201 & Consumer loans (partial) \\
\hline 39120101 & Residential real estate loans (partial) \\
\hline 39120102 & Residential real estate loans, except home equity (partial) \\
\hline 391202 & Home equity loans (partial) \\
\hline 391203 & Vehicle loans (partial) \\
\hline 3913 & Credit cards, overdraft credit, and related plans (partial) \\
\hline 392 & Other loans and loan services (partial) \\
\hline 393 & Deposit services (partial) \\
\hline
\end{tabular}

As with the industry based series, indexes are aggregated using turnover data for each product line regardless of the product's industry of origin.

\subsubsection{Specific aspects}

The 2008 SNA states that no service element should be included in the reference rate, but does not refer to the reference rate as being risk-free. ${ }^{3}$ The choice of an appropriate reference rate is likely the most significant methodological consideration in developing an SPPI using the FISIM concept, as the reference has a significant influence on price changes. In the U.S., the reference rate is chosen such that the risk premium is eliminated to the greatest extent possible. This is consistent with the assertion that banks receive transaction payments for the assumption of risk, including the risk of default. Note that this is also consistent with the treatment of risk in the U.S. pricing methodology for the insurance industries for which output there is defined as the assumption of risk as well. For banking, financial intermediation is defined as the assumption of risk that arises from taking money from depositors and lending it to borrowers.

Alternative methods for calculating the reference rate include the following: ${ }^{4}$

- Market interest rate such as LIBOR, EURIBOR - A market rate is directly observed and theoretically consistent, but it could include a risk premium. In addition, it would be difficult to find a single rate that is appropriate and that would not lead to negative prices;

- Average interest rate on funds borrowed by financial institutions from other financial institutions - An average rate broadly reflects the average maturity of loans and deposits, but the calculation requires detailed balance sheet $(\mathrm{B} / \mathrm{S})$ and profit and loss $(\mathrm{P} / \mathrm{L})$ data. There is little risk of negative prices;

- Mid-point rate - The average of deposit interest rates and loan interest rates. Australia has used the mid-point of weighted average borrowing and lending rates for each institution in the calculation of FISIM for the CPI. The midpoint represents a rate that would have been struck in the absence of financial intermediaries. The risk of negative prices using this rate is minimal.

\section{Negative prices}

The potential for negative prices can be problematic in pricing banking services. If the price for a service is perpetually negative, then that service is considered an input to the production process. These services do not present a measurement challenge, since they are not priced as output. However, there are instances when the price for a particular 
banking service is negative in some months and positive in others. It is this type of negative price that presents a measurement challenge. Current U.S. index calculation methodology does not accommodate negative prices, and therefore, the negative price is excluded from calculation. A likely cause of the occasional negative price is the use of an industry-wide reference rate. Theoretically, collecting a bank-specific rate would likely diminish the number of negative prices significantly, since it is a more narrowly defined rate that is more closely aligned with the bank's business strategy. The U.S. recently began attempting to collect bank-specific reference rates when they are available.

Other sources of negative prices and potential solutions include the following: ${ }^{5}$

- Mismatch in timing for collecting B/S and P/L data - Careful treatment of data and corrections are recommended;

- Accounting anomalies - Careful treatment of data and corrections are recommended;

- Differences in the speed of adjusting various interest rates - Smoothing of interest rates, such as calculating a moving average, is a possible solution;

- Cross-subsidization or service bundling - Banks may use certain products as a loss-leader and compensate by charging a higher price for other products. Aggregating the products could resolve the negative price issue;

- Official subsidization - Some government-owned banks offer significantly lower rates for specific policy purposes. Using the same reference rate for these banks as used for privately owned banks could lead to negative prices. The calculation of separate reference rates or the estimation of government subsidies is recommended.

\section{Average Prices}

The variation in the number of days in a month contributes to some volatility in banking prices. For example, considering no other factors, banks have 31 days in January to collect fees and interest on a loan compared to 28 days in February. Loan balances can also change in the additional four days. The impact is unclear, since more loans could be paid off in the additional time and/or more loans could be made.

\subsubsection{Overview of national methods}

\section{Australia}

The Australian Bureau of Statistics (ABS) currently excludes the financial services industry from its suite of PPI; however, the ABS may consider expanding the current scope of industries represented within the PPI in the longer term.

The Australian CPI introduced the FISIM methodology with the release of the 15th series CPI in the September quarter 2005 and that experience is relevant to SPPIs as well so it is presented here and was taken directly from the paper presented by the ABS at the $25^{\text {th }}$ Voorburg Group meeting on Services Statistics in September 2010.

The deposit and loan facilities index includes a mid-point reference rate for each institution (as mentioned previously) to proxy the service-free rate. To calculate the indirect service charge in this index, monthly balance and interest flow data are obtained from financial institutions for each of their consumer products and in aggregate. For each sampled financial institution, a sample of products is selected to represent each of the 
major product categories: current accounts, savings accounts, investment accounts, term deposits, retirement accounts, fixed and variable rate housing loans, personal loans, and credit cards. The specific product selected from each group (e.g. the sampled home loan product) is assigned a weight to represent the entire product group (e.g. housing loans).

The interest margin for each sampled product is calculated from the difference between the product yield and the reference rate. Because percentages (such as margin rates) are not prices, the latest period margin rates have to be applied to some monetary amounts (e.g. balance of the home loan account) in order to calculate the current period prices (the dollar margins). To preserve the quantities supporting the values of the account balances in the base period, the balances used to derive the dollar margins are updated to reflect a four-quarter moving average of the CPI All-groups.

The CPI Deposit and loan facilities index is calculated by weighting the indices for the sampled products according to the weight of the product group. To minimise the effect of any short-term accounting anomalies (such as posting of effects and adjustments of various types), the ABS constructs a three-month moving average of balances and interest flows and derives the required interest rates, reference rates, and margin rates from the smoothed data.

A particular challenge that has arisen in regards to sampling products is the presence of fixed rate products in the index. Within the Australian Financial industry, the high proportion of variable rate products (e.g. variable house loans) means that these dominate the reference rate. Effective yields on fixed rate products move at a much slower rate than the calculated reference rate. This induces a high level of price rate volatility on fixed rate products. There are three main problems associated with this: the possibility of negative prices, sensitivity to errors, and determining appropriate weights for these products.

\section{Canada}

Statistics Canada is currently developing an SPPI for banking services. This experimental work includes only chartered banks and focuses on traditional loan and deposit products offered by federally regulated banks that report to Canada's regulatory agency for financial institutions, the Office of the Superintendent of Financial Institutions (OSFI). Statistics Canada's Industrial Organization and Finance Division (IOFD) collects similar data on a "booked-in-Canada" basis (i.e. all those service activities that generate revenue recognised by Canadian business enterprises and therefore excluding activities they recognise as revenue for their foreign subsidiaries). These data, along with some financial market data, are used to estimate the SPPI and to test alternative assumptions in order to inform the final data collection and SPPI estimation strategy for this industry.

In the simplest form, the price of a unit of deposit for the Canadian SPPI is the difference between the reference rate and the effective rate banks pay on deposits, plus explicit fees per unit of deposit. The price of a unit of lending is the spread between the effective loan rate and the reference rate, plus explicit fees. To calculate the effective rate, interest income (expenditure) is divided by the outstanding balance. In order to keep the unit of measure constant, the outstanding balance is discounted ${ }^{6}$ by the reference rate, which is assumed to be the opportunity cost for the banks.

The reference rates used are obtained mostly from the Bank of Canada (CANSIM table 176-0043) and the banks' financial statements. The use of financial statements allows for the construction of firm-specific reference rates. Since interest income or expenditure reported in the current period reflects interest rates set in the previous period, the market reference rates obtained from CANSIM are lagged by one period in order to 
produce more appropriate results. Lagging one period assumes that financial institutions react quickly to changes in market rates.

Fitness of use is the primary limitation of the administrative data. The data are based on financial statements that use accounting conventions to satisfy the regulatory requirements imposed on banks by the Office of the Superintendent of Financial Institutions. Periodically, these requirements change resulting in changes to the data that may or may not reflect actual changes in business conditions. Also, the use of accounting conventions often results in data anomalies from a price measurement perspective that may be acceptable from an accounting perspective. Thus, there are many cases of negative prices, negative revenues, or abnormally large or small numbers as well as significant and unrealistic levels of volatility. Furthermore, there is an issue with the level detail for explicit fees being different from that of interest income and expense. This makes it difficult to systematically allocate explicit fee income between products.

Canada continues to explore methods of using the administrative data that are currently available in order to produce a high quality banking SPPI, while exploring the possibility of developing a survey for collecting prices for banking services.

\subsection{Investment banking (David Friedman, U.S. Bureau of Labor Statistics)}

\subsubsection{Industry description (ISIC 6499)}

This industry class includes other financial service activities primarily concerned with distributing funds other than by making loans, such as factoring activities, the writing of swaps, options and other hedging arrangements, the activities of viatical settlement companies, and own-account investment activities.

Within ISIC 6499, the U.S. calculates and publishes SPPIs for investment banking services (NAICS 523110). The U.S. does not calculate or publish SPPIs for factoring activities or the activities of viatical settlement companies. Own-account investment activities, also primary to ISIC 6499, constitute proprietary trading and are considered out of scope for formulating U.S. SPPIs, since no market output is generated from this activity. $^{7}$

Investment banking services include the underwriting of securities, in which investment banking firms aid corporations, governments, and other institutions in raising capital through the issuance of debt and equity.

Investment banking firms also engage in the underwriting of securitised products such as mortgage-backed securities (MBS), asset-backed securities (ABS), and collateralised debt obligations (CDOs), whose values are derived from the values of other underlying securities. The creation of derivative securities is similar to the creation of equity and debt securities except that individual asset-backed securities are grouped into tranches or distinct groups. These tranches are sold individually to investors. The tranches resemble either a form of debt or equity depending on their risk profile.

Investment banking firms also engage in the writing of hedging arrangements, including the origination of swaps and forward rate agreements (FRAs).

In the U.S., investment banking services also include mergers and acquisition (M\&A) advisory services, though these services are also offered by firms operating in other industries, such as management consulting firms. According to the concordance between 
ISIC and CPC, M\&A advisory services are an activity primary to ISIC 6619 - Other activities auxiliary to financial service activities, and are not covered in this section.

Business enterprises that offer investment banking services often also operate as trading principals who buy and sell securities on the behalf of clients but in doing so take legal possession of the securities and thereby assume trading risk. Banks operating as principals in securities trades generate turnover by earning the spread (or difference) between the price at which they purchase a security (the bid or offer price) and the price at which they sell that same security (the ask price). The bid-ask spread is used to measure prices for principal securities trades. Securities dealing activities on the behalf of others is considered primary to ISIC 6612 - Security and Commodity Contracts Brokerage. ${ }^{8}$

\subsubsection{Classification aspects}

Other financial service activities, except insurance and pension funding activities, not elsewhere classified, are classified in ISIC group 6499. This group includes the following activities:

- Other financial service activities primarily concerned with distributing funds other than by making loans:

- Factoring activities

- Writing of swaps, options, and other hedging arrangements

- Activities of viatical settlement companies

- Own-account investment activities

\subsubsection{Industry classification}

Annex A provides various industry classifications for each type of activity. There are several notable differences between the NAICS and ISIC classification structures.

- Within NAICS 523110 - Investment banking and securities dealing, there are five major service lines: Mergers and acquisition (M\&A) advisory services; Underwriting and placement services; Securities dealing services (principal trades on the behalf of clients); Reverse repurchase agreements; and Securities lending services. Of these service lines, underwriting and placement services are considered activities primary to ISIC 6499. As mentioned in the industry description section, M\&A advisory services are primary to ISIC 6619 and securities dealing services are primary to ISIC 6612. It should also be noted that reverse repurchase agreements and securities loans can be executed by business enterprises that are classified in a number of industries. Discussion of these lending activities is referenced in the chapter for ISIC 6612.

- Additionally, under NAICS, factoring activities are considered to be nondepository credit intermediation, not elsewhere classified, and are classified in NAICS 522298 - All other nondepository credit intermediation.

- The purchasing, pooling, and repackaging of loans for sale on the secondary market, classified in ISIC 6499, is classified in its own industry, NAICS 522294 Secondary Market Financing. 
- The activities of viatical settlement companies are classified in NAICS 523910 Miscellaneous Intermediation. Own-account securities and commodities trading is also considered activity primary to NAICS 523910 - Miscellaneous Intermediation, though firms classified in a number of industries (particularly in the finance and insurance sector) also engage in proprietary own-account trading. As mentioned in the Industry description section, own-account trading is not considered in-scope activity for purposes of formulating SPPIs.

\subsubsection{Product classification}

Annex B maps the NAPCS product codes to the CPC structure for subclasses 71190 and 71200 .

\subsubsection{Scope of the survey}

The ideal survey for investment banking services should measure the change in fees received by business enterprises for providing underwriting services, including advising the issuing entity on the terms of the offering, purchasing the securities from the issuer or assisting the issuer in selling the securities, and distributing the securities to public or private investors. Investment banking firms may act alone in an underwriting and perform all roles - advisement, underwriting, and sales - or they may act as part of an underwriting syndicate of firms and serve a smaller role, such as operating strictly as the selling firm. Underwritings fall into two categories of arrangements: $i$ ) firm commitment; and $i$ ) best-efforts. In a firm commitment arrangement, the investment bank purchases the securities from the issuing company and then resells them to the public at a higher public offering price. The difference in price, or the gross spread, serves as compensation to the underwriter. In a best-efforts arrangement, the underwriter merely agrees to assist the issuing firm in selling the securities, but does not necessarily take possession of the entire issue. In this case, the underwriter acts only as an intermediary. In such an arrangement, the underwriter earns a percentage fee of the money raised for the client. Once securities are underwritten, they may be placed into public markets (public placement), or distributed only to a selected group of private investors such as insurance companies, investment companies, and pension funds (private placement). The type of market into which securities are placed can be price-determining, with private placements sometimes carrying lower fees, since the buyer pool may be known prior to placement, mitigating risk to the underwriter.

When banks underwrite asset-backed securities, they purchase specified types of assets that get pooled into tranches. For example, when underwriting a Mortgage-backed security (MBS), banks will purchase mortgages. Other types of assets that may comprise an Asset-backed security (ABS) include: credit card receivables, home equity loans, student loans, and automobile loans. The cash flows from the loan payments go to pay the holders of the securities. Collateralised debt obligations (CDOs) are also similar to ABS except that CDOs are backed by other debt securities like investment grade bonds or high yield bonds.

In the case of interest rate swaps in which two parties exchange fixed rate obligations for floating rate obligations (or vice versa), the fixed rate is agreed upon by both parties before they enter into the swap and is referred to as the "price" of originating the swap. Investment banks quote swap spreads in terms of the difference between the fixed rate they would accept (the ask) and the fixed rate they would pay (the bid) for the specified floating rate (e.g. the 3-month London Interbank Offered Rate or LIBOR). In pricing the 
origination of swaps in the U.S., responding firms provide this bid-ask spread, which is then multiplied by a specified notional value of the swap to derive the price used in SPPI calculation. Similarly, forward rate agreements (FRAs) are forward contracts quoted in terms of interest rates in which two parties agree to exchange floating and fixed rate obligations at a specified time in the future, with payments determined by an underlying notional value. As with swaps, banks quote spreads on FRAs in terms of fixed interest rates, and the U.S. prices FRAs using the quoted bid-ask spread multiplied by the notional value.

\subsubsection{Industry vs. product based SPPI}

In the U.S., many of the largest financial institutions offer services primary to each of the largest sub-industries in the financial services sector, including commercial banking, investment banking, securities brokerage, portfolio management, and investment advice. Apart from investment banking, these services are secondary activities for business enterprises in this sub-industry.

However, because the U.S. samples by NAICS industries, which within the financial services sector are narrowly defined, a publication structure based strictly on NAICS industry definitions would necessarily need to support a vast array of secondary activity. For this reason, the U.S. employs the strategy of producing industry based indexes that cover only investment banking activities. In practice, the U.S. creates sample units that represent specified activities, i.e., investment banking activities only, in order to ensure that companies are properly included in the sampling frame for this industry. Therefore, secondary activities are not considered. Due to the exclusion of secondary activities in the U.S., there is no functional distinction between the industry based and approximate product based SPPIs for investment banking services. The sample design described below supports this strategy.

\subsubsection{Sample design}

It is ideal to sample the investment banking industry using probability proportional to size (PPS) with turnover as the size measure. Due to difficulties in obtaining figures for in-scope turnover prior to data collection, the U.S. conducts a PPS sample using employment as the size measure.

For all respondents, initial data collection occurs at their headquarters. Typically, underwriting services are provided by large financial institutions that offer services primary to several industries within the financial services sector. In the U.S., the largest banks are separated into several different sample units that correspond to the following banking activities:

- Investment banking (ISIC 6499);

- Securities dealing (ISIC 6612);

- Securities brokerage (ISIC 6612);

- Other securities dealing services* (ISIC 6612);

- Commercial banking (ISICS 6419);

- Portfolio management (ISIC 6630);

- Investment advice (ISIC 6619). 
* Refers to reverse repurchase agreements and securities lending services.

This strategy forms the basis for stratification and, in many cases, creates multiple reporting units for a single bank. Often, large banks will have separate officials and separate records for these specific types of services. Each of the smaller banks is given a chance of selection as a single sample unit, and it is typical to have one official at these smaller banks that can provide the pricing information for all services offered within the bank.

Because the largest business enterprises are sampled by service line rather than on an industry basis, the U.S. does not collect secondary production from any industry firms, and only services primary to the industry appear in the published U.S. industry SPPIs.

\subsubsection{Collection of information and specification of the service}

\section{Underwriting and placement services}

At initial data collection, a recently completed underwriting transaction is selected during a personal visit with company officials. The respondent must select an underwriting transaction for which he/she can estimate the gross spread percentage and retained percentage fees in future periods. The following characteristics are typically collected for underwriting transactions and are held constant throughout the survey period:

- Type of underwriting - public, private;

- Type of client - based on industry, firm-client relationship, and other characteristics;

- Type of issue - initial offering, secondary offering;

- Type of offering - firm commitment offering , best efforts offering;

- Role of investment bank - all roles, underwriter, manager/co-manager, sales group;

- Type of securities issued - exchange-listed equity, corporate debt, municipal debt, etc.

Additionally, the following values are collected and are updated during the survey period:

- Size of offering - escalated by U.S. SPPI staff; see section on Pricing Methods for more details;

- Gross spread percentage - updated by respondent;

- Fee percentages for each role in which the bank served - all roles, underwriter, manager/co-manager, sales group - updated by respondent.

\section{Writing of hedging arrangements}

At initial data collection, a recently originated hedging arrangement (e.g. swap, FRA) is selected. The following characteristics are collected and held constant throughout the survey period:

- Referenced security, rate, or index; 
- Number of months until settlement (FRAs);

- Duration of contract (swaps).

Additionally, the following values are typically collected and are updated during the survey period:

- Notional value - escalated by U.S. SPPI staff;

- Fixed rate bid-ask spread - updated by respondent;

\subsubsection{Main pricing methods}

\subsubsection{Underwriting and placement services}

In collecting prices for underwriting and placement services, the U.S. employs a hybrid of the model pricing and percentage fee methods.

Because each transaction of underwriting services is unique and non-recurring, it is necessary to employ model pricing to capture prices for this service line. Fees earned for underwriting services are typically derived from the total value of the issue being underwritten, so application of the percentage fee method in conjunction with model pricing is appropriate. During initial data collection, the U.S. asks survey respondents to identify a recently completed underwriting transaction for which the respondent can estimate both the gross spread and percentage fees in future periods. It is critical that, during the life of the survey, the respondent be able to estimate the gross spread and the percentage fees earned.

In order to reflect changes in the value of securities over time the U.S., implemented a procedure in which the values of the underwriting transactions are periodically updated by U.S. SPPI staff. For example, the values of equity security offerings are adjusted based on a broad index measure of the overall U.S. equity market.

The values of debt securities offerings are adjusted based on index measures of the overall changes in prices of the selected type of debt security.

\section{Box 9.2.1. Example of a firm commitment equity underwriting transaction}

\section{Period 1 (base period):}

Item Description: Public underwriting. Client ID: Company B. Client industry: insurance. Percentage fee. Firm commitment initial offering. Price represents role of manager and underwriter. Exchange listed equity.

\begin{tabular}{|l|l|}
\hline Size of Offering: & $\$ 50,000,000$ \\
\hline Gross spread $\%:$ & $3 \%$ \\
\hline Dollar value of gross spread: & $\$ 1,500,000(=\$ 50,000,000 * 3 \%)$ \\
\hline Manager fee: & $20 \%$ \\
\hline Underwriter fee: & $20 \%$ \\
\hline Total Fee: & $\$ 600,000(=\$ 1,500,000 * 20 \%+\$ 1,500,000 * 20 \%)$ \\
\hline
\end{tabular}




\section{Box 9.2.1. Example of a firm commitment equity underwriting transaction, continued}

\section{Period 2:}

Item Description: Public underwriting. Client ID: Company B. Client industry: insurance. Percentage fee. Firm commitment initial offering. Price represents role of manager and underwriter. Exchange listed equity.

\begin{tabular}{|l|l|}
\hline Size of Offering: & $\$ 52,500,000$ \\
\hline Gross spread \%: & $3 \%$ \\
\hline Dollar value of gross spread: & $\$ 1,575,000(=\$ 52,500,000 * 3 \%)$ \\
\hline Manager fee: & $20 \%$ \\
\hline Underwriter fee: & $25 \%$ \\
\hline Total Fee: & $\$ 708,750(=\$ 1,575,500 * 20 \%+\$ 1,575,500 * 25 \%)$ \\
\hline
\end{tabular}

Between periods 1 and 2, the value of securities traded in the U.S. equity market has increased by 5 percent; this change has been reflected in the updated value of the size of the offering. The respondent updates the gross spread percentage and the percentages retained for all roles in which the firm acted. In this example, the business enterprise serving as the underwriter in the referenced underwriting transaction now retains a fee of $25 \%$, while the gross spread percentage and the manager's fee remain unchanged. The changes in both the estimated value of the securities and the change in the fee are both shown as price changes.

\subsubsection{Writing of hedging arrangements}

In collecting prices for the writing of hedging arrangements, the U.S. employs model pricing.

While firms may originate hedging arrangements in each survey period, it is unlikely that specific transactions of the same value (in real terms), duration (in the case of swaps), and referenced rate or security will recur in each period. For this reason, the swap or forward rate agreement specified in the base period serves as the basis for re-pricing in future periods, consistent with application of the model pricing method.

In order to reflect changes in the time value of money, the U.S. implemented a procedure in which the notional value referenced in FRA and swap contracts is periodically updated based on changes in a broad measure of U.S. inflation.

During each survey period, respondents are asked to estimate the bid and ask rates they would quote for entering into a swap or FRA with the characteristics specified in the contract selected at initial data collection. 


\section{Box 9.2.2. Example of an interest rate swap}

\section{Period 1 (base period):}

Item Description: Interest rate swap. Referenced interest rate: 3-month LIBOR. Notional value of swap: $\$ 1,000,000$. Duration of contract: 5 years.

\begin{tabular}{|l|l|}
\hline Ask price & $2.50 \%$ \\
\hline Bid price & $2.49 \%$ \\
\hline Quoted Spread & $0.01 \%$ \\
\hline Notional Value & $\$ 1,000,000.00$ \\
\hline Dollar Value of Quoted Spread: & $\$ 100.00\left(=\$ 1,000,000.00^{*} 0.01 \%\right)$ \\
\hline
\end{tabular}

\section{Period 2:}

Item Description: Interest rate swap. Referenced interest rate: 3-month LIBOR. Notional value of swap: $\$ 1,004,264.76$. Duration of contract: 5 years.

\begin{tabular}{|l|l|}
\hline Ask price & $2.65 \%$ \\
\hline Bid price & $2.64 \%$ \\
\hline Quoted Spread & $0.01 \%$ \\
\hline Notional Value & $\$ 1,004,264.76$ \\
\hline Dollar Value of Quoted Spread: & $\$ 100.43(=\$ 1,004,264.76 * 0.01 \%)$ \\
\hline
\end{tabular}

Between periods 1 and 2, the U.S. inflation measure has grown by roughly $0.4 \%$; this change has been reflected in the escalated notional value of the swap. The respondent updates the bid and asks prices, holding all other characteristics constant.

\subsubsection{Quality issues}

An important methodological issue compilers developing SPPIs for this industry must address is whether the deal values upon which investment banks typically assess fees should be updated in future periods, and if so, which measures should be used as the basis for these updates. If the deal values are not updated, changes in investment banking turnover that result solely from changes in constant-quality deal valuations will be reflected directly in the measures of real output. This may lead to highly volatile output figures, as market valuations can fluctuate severely.

In the U.S., the values of underwriting transactions are updated based on broad index measures of security valuations. Indices that measure changes in the average values of new underwritings were considered, but ultimately rejected since the types of deals that occur in each period are highly variable. The broad security value indices were determined to be the most appropriate measure to estimate the level at which the securities offered in the originally selected underwriting transaction would be valued in the current period if they were to be re-transacted.

Because of the non-recurring nature of underwriting transactions, responding firms may find it difficult to estimate the fees earned for assisting in the hypothetical transaction of a previously completed underwriting. This issue, however, is not unique to investment banking and is evidenced among respondents for most industries in which services are unique and non-recurring. 


\subsubsection{Weighting and aggregation}

\subsubsection{Industry based indices}

Table 9.2.1. provides the U.S. PPI industry based publication structures for the investment banking and securities dealing industry.

Table 9.2.1. U.S. PPI industry based publication structures for the investment banking and securities dealing industry

\begin{tabular}{|l|l|}
\hline \multicolumn{1}{|c|}{523110} & \\
\hline 5231102 & Dealer transactions \\
\hline 523110201 & Dealer transactions, equity securities \\
\hline 523110202 & Dealer transactions, debt securities and all other trading \\
\hline 5231103 & Investment banking services \\
\hline 5231104 & Other securities dealing services \\
\hline 523110 SM & Other receipts \\
\hline
\end{tabular}

For each index series, the lower-level indices are aggregated using industry turnover data as weights. Although the indices are calculated using the Laspeyres formula, these weights are updated approximately every five years. Within the lowest level indices, each bank and the items selected within the bank are weighted using turnover provided by the bank at the time of data collection. These weights remain fixed throughout the life of the sample.

\subsubsection{Product based indices}

Table 9.2.2. provides the U.S. PPI product based publication structures for investment banking services.

Table 9.2.2. U.S. PPI product based publication structures for investment banking services

\begin{tabular}{|l|l|}
\hline \multicolumn{1}{|c|}{403} & \\
\hline 4031 & Investment banking \\
\hline 403101 & Investment banking \\
\hline 40310101 & Investment banking \\
\hline
\end{tabular}

As with the industry based series, indices are aggregated using turnover data for each product line regardless of the product's industry of origin.

It should be noted that both the U.S. industry based and approximate product based SPPIs for Investment banking include transactions of underwriting services and mergers and acquisition (M\&A) advisory services.

Additionally, the approximate product based SPPI for Securities brokerage and dealing related services includes transactions of margin lending services and fees earned from the sale and distribution of mutual funds in addition to reverse repurchase agreements and securities lending services. For more details, please see the Security and Contracts Brokerage Services section in this Guide.

\subsubsection{Specific aspects}

Transactions in this industry are technically complex, due both to the actual mechanics of underwriting securities and the industry terminology used to describe the specifics of a given transaction. As stated in Section 3, Scope of survey, the provision of 
underwriting and placement services for a given service may in practice be executed by one or more business enterprises acting as an underwriting syndicate, and depending on the sampled firm's level of seniority in the syndicate, in future periods the respondent may or may not be able to estimate the fee that would be earned for performing its role in the underwriting. The potential involvement of business enterprises other than the one sampled in performing underwriting services adds a degree of complication for data collectors. In order to ensure that only underwriting transactions in which the sampled business enterprise can estimate the gross spread and its percentage fee in future periods would be collected, the U.S. devoted additional resources to training data collectors for this industry. Extensive computer based training materials were prepared and presented in order to familiarise data collectors with industry terminology and collection procedures.

\subsubsection{Overview of national methods}

The U.S. is currently the only country in the member states of the task force that worked on this version of the Guide that develops and publishes price indices in this industry. The methods and practices are discussed throughout this section.

\subsection{Security and commodity contracts brokerage (Hina Kikegawa, Bank of Japan)}

\subsubsection{Industry description (ISIC 6612)}

Business enterprises in this industry class engage in buying or selling securities on the behalf of individual and institutional clients. Transactions in which securities firms take legal possession of the securities being traded and thereby assume trading risk are referred to as principal transactions. For principal transactions, business enterprises in this industry generate turnover from the spread (or difference) between the price at which they purchase a security and the price at which they sell that security. Transactions in which securities firms do not take legal possession of the securities being traded but instead act as agents (i.e. brokers) are referred to as agency transactions. For agency transactions, business enterprises in this industry generate turnover on a transaction fee or commission basis.

Securities firms may also engage in lending transactions such as reverse repurchase agreements and securities loans. Repurchase agreements, commonly referred to as repos, are short-term lending agreements in which the borrowing party sells securities to the lending party with an explicit agreement to repurchase the securities at a specified time in the future (typically the next day). Reverse repurchase agreements refer to repurchase agreements, though from the perspective of the lender of the funds. In these arrangements, the lending party generates turnover through lending interest. The U.S. SPPI only captures prices for this lending activity. Securities lending transactions are arrangements in which one securities dealer loans securities to another dealer in exchange for collateral, typically cash or other securities. Securities loans provide the borrowing dealer with specific securities necessary for trade settlement. As with reverse repurchase agreements, the lending party in securities lending arrangements generates interest turnover. The U.S. SPPI captures prices for securities loans from the perspective of the lending party only.

\section{How the service industry is organized}

The deregulation of financial markets which took place in most advanced countries liberalised market entry and opened the market to a variety of securities companies. These include bank-affiliated, foreign based, and online securities companies, which have 
expanded the range of channels through which financial products can be sold. Furthermore, the liberalisation of stock brokerage commissions has greatly impacted the operations of securities companies. As online brokerage services grew, commission rates were reduced significantly. Deregulation resulted in mergers between securities companies and tie-ups between securities companies and financial groups. This industry is concentrated in a small number of large firms in most countries.

The price mechanisms and price determining factors

For principal transactions, securities companies earn spreads or mark-up from the purchase and sale of securities. Examples of price determining characteristics are:

- Type of securities - corporate bonds, municipal bonds, government debt, domestic and foreign equities, options, futures, etc.;

- Price of the security;

- Price volatility of the security;

- Trading volume of the security;

- Bond rating (for debt securities);

- Time to maturity (for debt securities);

- Bond provisions (for debt securities).

For agency transactions, securities companies mainly charge flat fees or value based commissions. Examples of price determining characteristics are:

- Flat fees

- Type of securities - domestic stocks, foreign stocks, options, exchange-traded funds (ETFs), bonds;

- Type of client - institutional investor, retail investor;

- Size of the client;

- Method used to place trade order - online, by telephone, in person;

- Trading volume of the client.

- Value based commissions

- Type of securities - domestic stocks, foreign stocks, options, ETFs, bonds;

- Type of client - institutional investor, retail investor;

- Size of the client;

- Method used to place trade order - online, by telephone, in person;

- Trading volume of the client;

- Market value of the traded securities;

- Role of the firm - originating broker, non-originating broker;

- Type of order placed - market order, limit order, stop order. 


\subsubsection{Classification aspects}

\subsubsection{Industry classification}

Security and commodity contracts brokerage services are classified in ISIC class 6612. This group includes the following activities:

- Dealing in financial markets on behalf of others (e.g. stock broking) and related activities;

- Securities brokerage;

- Activities of "bureaux de change";

- Commodity contracts brokerage etc.

This class excludes the following activities:

- Dealing in markets on own account (ISIC 6499);

- Portfolio management, on a fee or contract basis (ISIC 6630).

Note that the exclusion of own-account dealing refers to proprietary trading in which a firm is not executing trades on the behalf of clients, but rather on the behalf of the firm's own investment account.

Annex A provides various industry classifications for each type of activity.

\subsubsection{Product classification}

Annex B maps the NAPCS product codes to the CPC structure for classes 7152 and 7159.

\subsubsection{Scope of the survey}

For "Securities brokerage services," "Dealing in financial markets on behalf of others," and "Activities of bureaux de change," services are provided to all customers. Therefore, SPPIs should ideally measure the price changes for all customers (BtoB, government, consumers, and export).

For securities brokerage services, respondents may easily distinguish prices for enterprises and households, because they usually have different business units for different types of customers. In the U.S., securities brokerage services for both enterprises and households are covered. In Japan, only brokerage services for enterprises are covered, while in Korea, only retail brokerage services are covered. Canada plans to cover retail initially and include institutional as development progresses.

"Commodity contracts brokerage" services are primarily provided to institutional investors. However, in certain countries with large agricultural markets, these services are also provided to individual farmers. In such cases, coverage should extend to service activities provided to these customers.

For reverse repurchase agreements, the interest rates charged by lenders vary across the classes of securities to be repurchased. In the U.S., there are distinct market rates for reverse repurchase agreements involving debt securities issued by the U.S. Treasury, U.S government-sponsored enterprises, and private corporations, with transactions involving Treasury securities typically carrying the lowest rates. Due to differences in market repo 
rates, the ideal survey would capture a representative sample of these different reverse repurchase agreements. Similarly, the lending rates for securities lending transactions in which other securities are posted as collateral vary according to both the securities loaned and the securities posted as collateral, and the ideal survey would capture securities lending transactions involving a diverse pool of securities.

\subsubsection{Industry vs. product based SPPI}

Many of the largest financial institutions offer services primary to each of the largest industries in the financial services sector, including commercial banking, investment banking, securities brokerage, portfolio management, and investment advice.

Apart from securities brokerage, these activities are the secondary activities for business enterprises in this industry. If the secondary activities are significant, these activities should be considered.

In practice, however, countries such as the U.S. create sample units that represent specified activities, i.e., securities brokerage activities only, in order to ensure that companies are properly included in the sampling frame for this industry. Therefore, secondary activities are not considered. Canada currently compiles product based SPPIs, which facilitate deflation of the national accounts.

\subsubsection{Sample design}

Non-probability sampling and PPS sampling are common approaches;

- Japan, Korea and Canada use the non-probability sampling approach. The market is concentrated in a small number of large firms. The main criteria for selection are the market share of companies and the services they provide.

- The U.S. uses the PPS sampling with employment as the measure of size for sampling $\mathrm{s}$ and value of shipments and receipts obtained from sampled $\mathrm{s}$ used for selection of individual items.

\subsubsection{Collection of information and specification of the service}

In Japan, the U.S., and Korea, data are collected from the respondents on a monthly basis. For initial data collection, representative transactions and price determining characteristics are specified with respondents' assistance.

The following characteristics are usually specified for this industry:

- Securities brokerage services:

- Types of securities - domestic stocks, foreign stocks, options, ETFs, bonds, etc.;

- Types of clients - institutional investors, retail investors;

- Size of the clients;

- Method used to place the trade orders - online, by telephone, in person;

- Trading volume of the clients;

- Execution price of securities traded;

- Underlying security or rate (derivatives only); 
- Type of contract - call, put (options only);

- Months to expiry (options only);

- Description of the strike price (options only).

- Securities selling or dealing services:

- Types of securities - stocks, bonds, stock investment trusts, options;

- Type of client - firms, individual investors;

- Method used to place the trade orders - online, by telephone, in person;

- Trading volume of the clients;

- Offered prices of securities traded;

- Bond rating - AAA, Aa1, etc. (bonds only);

- Time to maturity (bonds only);

- Underlying security or rate (derivatives only);

- $\quad$ Type of contract - call, put (options only);

- Months to expiry (options only);

- Description of the strike price (options only).

- Mutual fund sales:

- Types of mutual funds - active funds, passive funds;

- Types of loads - front-end loads, back-end loads;

- Purchased or redemption values of the funds.

In the U.S., a special case exists for the collection of trades of options securities. To maintain constant quality pricing in each survey period, several additional characteristics need to be held fixed. When an option is selected, in addition to its type, underlying asset, and time to expiry, a description of the strike price is also collected. This description includes its position (whether it is in or out of the money) and its degree of moneyness (the extent to which the strike price of the option differs from the current price of the underlying asset). For example, a call option, which represents the right to purchase the underlying asset at a specified price, may be transacted on security $\mathrm{X}$, which has a current price of $€ 27,960$. The option may, for example, expire in 3 months and carry a strike price of $€ 30,000$. This option would be out of the money, since the option execution price of the call is higher than the current market price. This option would be the third-closest out of the money option as the call options with strike prices of $€ 28,000$ and $€ 29,000$ would be the first- and second-closest, respectively. When a dealer transaction for this option is collected in the U.S., in each survey period the respondent is asked to provide the bid-ask spread for the third-closest out of the money call option on a specified security that has a time to expiry of three months. When a brokerage transaction for this option is collected in the U.S., in each survey period the respondent is asked to provide the premium on the third-closest out of the money call option on a specified security that has a time to expiry of three months and the commission rate that would be charged for executing the trade. The premium is multiplied by the number of contracts traded and the commission rate charged to obtain the total commission. 
- Reverse repurchase agreements and securities lending services:

For reverse repurchase agreements, the type of security to be repurchased is identified. For securities lending transactions, the type of security loaned and posted as collateral is collected. Respondents do not reference specific securities, but instead provide general rate information for all transactions of the selected type of security.

The following characteristics are collected for reverse repurchase agreements and securities lending transactions and are held constant throughout the survey period:

- Type of service - reverse repurchase agreement, securities lending;

- Type of client;

- Type of collateral posted - debt, equity (securities lending only);

- Type of security loaned - U.S. Treasury, mortgage-backed security, U.S. government sponsored enterprise bond, U.S. equity, global equity, etc. (securities lending only);

- Duration of loan/agreement (in days);

- Type of security to be repurchased - U.S. Treasury, mortgage-backed security, U.S. government sponsored enterprise bond, corporate bond (reverse repurchase agreements only).

Additionally, the following values are collected and updated during the survey period:

- Value of the securities loaned/to be repurchased - escalated by U.S. SPPI staff; see section on Pricing Methods for more details;

- Lending fee percentage - updated by respondent (securities lending only);

- Repo interest rate - updated by respondent (reverse repurchase agreements only).

- Commodity brokerage services, foreign currency exchange:

No member state of this task force currently compiles price indices for these services.

\subsubsection{Main pricing methods}

The selection of the pricing method will depend on the type of pricing mechanisms used for a particular service, i.e. whether 'flat fees' or 'value based commissions' are used:

- When securities companies charge 'flat fees', data on the single fixed fee for the specified service should be collected. In this case, the direct use of prices of repeated services is the appropriate method;

- When securities companies charge 'value based commissions', the combination of the model pricing method and the percentage fee method is the appropriate method. Due to the differences in the definition of the unit transaction, methods to estimate prices vary; ${ }^{9}$

- For principal transactions on a spread or mark-up basis, the direct use of prices of repeated services is the appropriate pricing method; 
- For lending transactions in which securities are posted as collateral, such as reverse repurchase agreements and securities loans, a combination of the model pricing method and the percentage fee method is appropriate.

\subsubsection{Flat fees: Direct use of prices of repeated services}

When direct use of prices of repeated services is employed, the respondent specifies a representative transaction at the start of the survey.

For Securities brokerage services, flat fees are typically based on the value of the customer's trading accounts or the amount of trades they have made in the past. For example, a broker may charge $€ 10$ per trade for customers with less than $€ 100,000$ in their account and $€ 5$ per trade for customers with more than $€ 100,000$ in their account. The compiler, in consultant with the respondent, selects the representative transactions, i.e., the representative customer groups and then tracks changes in the standard fee.

\subsubsection{Value based commissions: combination of model pricing and percentage fee method}

The U.S., Korea, and Japan use the combination of the Model pricing method and the Percentage fee method. However, the practical methods to estimate prices vary according to the definition of the unit transaction.

The compiler should choose how the representative unit transaction is defined. The definition of the unit transaction will have an impact on the volume measurement (as discussed in Section 8).

There are three ways in which the unit transaction could be defined:

1. The nominal value of traded securities;

2. The number of traded securities - the U.S. and Korean approach;

3. The real value of traded securities - the Japanese approach;

In the second approach, the nominal value of traded securities is divided into "the number of traded securities" and "the price of those securities." The number of traded securities is held constant while changes in the value of commissions received by brokers as a result of changes in the valuation of traded securities are considered as price changes. In the U.S. the number of traded securities is held constant at the sample price level, while in Korea the number of traded securities is implicitly held constant by using the average market price index (e.g., KOSPI, KOSDAQ) as the inflator to adjust changes in traded securities values.

In the third approach, the nominal value of traded securities is discounted by the inflation rate of general prices. Increases in general prices result in deterioration in the quality of services provided, since the same transaction amount in nominal terms in two periods implies smaller amount of transaction in the real terms in the second period. The inflation rate of general prices thus can be taken as the rate of quality deterioration.

\subsection{The nominal value of traded securities approach}

During the respondent initialisation process, respondents should specify the following two components in order to set the model services:

- The nominal value of traded securities; and 
- The percentage fee charged for commission.

In subsequent months, respondents should update only the percentage fee. Prices are estimated as:

$$
\begin{aligned}
& P_{t=0}=\text { nominal value of traded securities } s_{t=0} \times \text { percentage fee }_{t=0}(\%) \\
& P_{t=n}=\text { nominal value of traded securities } s_{t=0} \times \text { percentage fee } e_{t=n}(\%)
\end{aligned}
$$

Changes in estimated prices are a function of changes in the broker's commission percentage only.

Box 9.3.1. is an example of the nominal value of traded securities approach

\section{Box 9. 3. 1. Example: a customer would like to purchase securities at time 0}

- Nominal value of traded securities is $€ 2,000$

- $5 \%$ charged for commission

$\rightarrow$ The price at time 0 is estimated as: $\mathrm{Pt}=0=€ 2000 \times 0.05=€ 100$

- At time1, the percentage fee has been increased to 9 percent.

$\rightarrow$ The price at time 1 is estimated as: $\mathrm{Pt}=1=€ 2000 \times 0.09=€ 180$

\subsection{The number of traded securities approach}

During the respondent initialisation process, respondents should specify the following three components, in order to set the model services:

- The number of traded securities;

- The securities price; and

- The percentage fee charged for commission.

In subsequent months, respondents should update only the percentage fee and the securities price. The number of securities traded is held constant over time.

Prices are estimated as:

$$
P_{t=0}=\text { nominal value of traded securities } t_{t=0} \times \text { percentage fee }_{t=0}(\%)
$$

$P_{t=n}=$ number of securities ${ }_{t=0} \times$ securities price $_{t=n} \times$ percentage fee $_{t=n}(\%)$

Changes in estimated prices are a function of changes in both the broker's commission percentage, and the prices of the underlying securities, i.e., market value of the particular securities selected. To ensure that these selected securities are representative of the market at the time of sampling, the U.S. uses a process in which the securities are statistically selected based on their market capitalization.

Box 9.3.2. is an example of the number of traded securities approach. 


\section{Box 9. 3. 2. Example: a customer would like to purchase 100 shares of stock at time 0}

- 100 shares of stock

- $€ 20$ per share

- 5 percent charged for commission

$\rightarrow$ The price at time 0 is estimated as: $\mathrm{Pt}=0=100 \times € 20 \times 0.05=€ 100$

- At time1, the share price has doubled and the percentage fee has been increased to 9 percent.

$\rightarrow$ The price at time 1 is estimated as: $\mathrm{Pt}=1=100 \times € 40 \times 0.09=€ 360$

\subsection{The real value of traded securities approach}

During the respondent initialisation process, respondents should specify the following two components in order to set the model services:

- The nominal value of traded securities;

- The percentage fee charged for commission; and

- The inflation rate of general prices: In addition, the inflation rate of general prices is used as the rate of quality change in order to hold the real value of traded securities constant.

In subsequent months, respondents should update only the percentage fee. The NSI should update the inflation rate of general prices. Prices are estimated as:

$$
\begin{aligned}
& P_{t=0}=\text { nominal value of traded securities } t_{t=0} \times \text { percentage fe } e_{t=0}(\%) \\
& \frac{P_{t=n}}{1+\pi_{t=n}}=\text { nominal value of traded securities } t_{t=0} \times \text { percentage fe } e_{t=n}(\%)
\end{aligned}
$$

With: $\pi_{t=n}$ stands for the inflation rate from $t=0$ to $t=n$

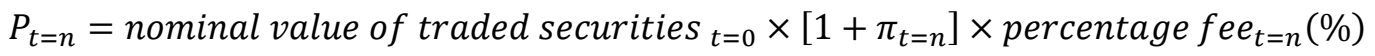

Changes in estimated prices are a function of changes in both the broker's commission percentage, and the inflation rate of general prices.

Box 9.3.3. is an example of the real value of traded securities approach.

\section{Box 9. 3. 3. Example: a customer would like to purchase securities at time 0}

- Nominal value of traded securities : $€ 2,000$

- 5 percent charged for commission

$\rightarrow$ The price at time 0 is estimated as: $\mathrm{Pt}=0=€ 2000 \times 0.05=€ 100$

- At time1, general prices have risen by 3 percent and the percentage fee has been increased to 9 percent.

$\rightarrow$ The price at time 1 is estimated as: $P_{t=1}=€ 2000 \times 1.03 \times 0.09=€ 185.40$. 


\subsubsection{Spreads and mark-ups: Direct use of prices of repeated services}

For securities trades that are transacted on a spread basis, respondents first select a security type (e.g. corporate bond, government bond, stock option) and then select a specific security within that group. For the specific selected security, the respondent provides the price at which the firm would purchase the security (the bid or offer price) and the price at which the firm would sell the security (the ask price) as of the market open on the pricing reference date. The quoted spread, or the difference between the ask price and the bid price, is the price used in index calculation. In subsequent survey periods, the respondent provides the bid and ask prices for the selected security as of the open of the market on the pricing reference date in the given survey month.

In some instances, rather than providing bid and ask prices, respondents will instead provide the current market price of the selected security and the amount by which it marks up the security for sale. In these cases, the dollar value of the mark-up is the price used in index calculation.

\subsubsection{Lending interest: Combination of the Model pricing method and the Percentage fee method}

While firms may transact reverse repurchase agreements and securities lending transactions involving the same broad classes of securities in each period, it is unlikely that specific transactions of the same duration and value (in real terms) will recur in each period. For this reason, the reverse repurchase agreement or securities lending transaction specified in the base period serves as the basis for re-pricing in future periods, consistent with application of the Model pricing method. Fees earned by lenders in reverse repurchase agreements and securities lending transactions are derived from the value of the securities loaned or to be repurchased, so application of the percentage fee method is appropriate as well.

In order to reflect changes in the time value of money, the U.S. implemented a procedure in which the values of securities involved in reverse repurchase agreements and securities lending transactions are periodically updated based on changes in a broad measure of U.S. inflation.

Fees for reverse repurchase agreements are calculated by multiplying the value of the securities to be repurchased first by the repo interest rate for the referenced class of security and then by the term (in days) of the agreement, divided by 360 . In some countries, standard practice may be to instead divide by 365 in order to obtain a daily rate of interest.

Box 9.3.4. is an example of a reverse repurchase agreement. 


\section{Box 9.3.4. Example of a reverse repurchase agreement}

\section{Period 1 (base period):}

- Reverse repurchase agreement. Client: other securities dealer. Overnight repo. Treasury security.

Value of assets/securities traded: $\quad \$ 275,000,000$

Repo interest rate:

$0.1236 \%$

Term (Days/360):

$1 / 360$

Total fee:

\section{Period 2:}

- Reverse repurchase agreement. Client: other securities dealer. Overnight repo. Treasury security.

Value of securities traded:

$\$ 276,172,810$

Repo interest rate:

$0.1529 \%$

Term (Days/360):

Total fee:

$\$ 1,172.97$

Between periods 1 and 2, the inflation measure that is used has increased by roughly 0.4 percent; this change has been reflected in the escalated value of the securities traded. The respondent updates the repo interest rate while holding all other values fixed, including the term of the agreement.

Fees for securities lending transactions are calculated by multiplying the value of the securities loaned first by the lending fee percentage and then by the term (in days) of the loan, divided by 360

\subsubsection{Quality issues}

\subsubsection{The definition of the unit transaction and its impact on the volume measurement}

The definition of the unit transaction has an impact on the volume measurement in this industry. Let us compare the effect of the three different approaches, using the situation presented in table 9.3.1.

Table 9.3.1. Definition of the unit transaction

\begin{tabular}{|l|l|l|l|l|l|}
\hline & $\begin{array}{c}\text { Number of } \\
\text { securities traded }\end{array}$ & $\begin{array}{c}\text { Securities } \\
\text { Price }\end{array}$ & Percentage fee & Nominal output & \multicolumn{1}{|l|}{$\begin{array}{c}\text { Inflation rate of } \\
\text { general prices }\end{array}$} \\
\hline Time 0 & 100 & $€ 20$ & $5 \%$ & $€ 100$ & -- \\
\hline Time 1 & 300 & $€ 40$ & $9 \%$ & $€ 1080$ & $3 \%$ \\
\hline
\end{tabular}


Table 9.3.2. shows the nominal output and also the results of the estimated real output based on the three approaches.

Table 9.3.2. Results of the estimated real output based on the three approaches

\begin{tabular}{|l|l|l|l|l|}
\hline \multirow{2}{*}{} & \multirow{2}{*}{ Nominal output } & \multicolumn{3}{|c|}{ Real output (time 0=€100) } \\
\cline { 3 - 5 } & & $\begin{array}{c}\text { Nominal value of } \\
\text { traded securities } \\
\text { approach }\end{array}$ & $\begin{array}{c}\text { Number of traded } \\
\text { securities approach }\end{array}$ & $\begin{array}{c}\text { Real value of traded } \\
\text { securities approach }\end{array}$ \\
\hline Time 0 & $€ 100$ & $€ 100$ & $€ 100$ & $€ 100$ \\
\hline Deflator $\left(P_{0} / P_{1}\right)$ & -- & $\begin{array}{l}€ 100 / € 180 \\
=1 / 1.8\end{array}$ & $\begin{array}{l}€ 100 / € 360 \\
=1 / 3.6\end{array}$ & $\begin{array}{l}€ 100 / € 185.40= \\
1 / 1.854\end{array}$ \\
\hline Time 1 & $€ 1080$ & $€ 1080 \times 1 / 1.8=€ 600$ & $€ 1080 \times 1 / 3.6=€ 300$ & $\begin{array}{l}€ 1080 \times 1 / 1.854= \\
€ 582.52\end{array}$ \\
\hline
\end{tabular}

In the first approach, changes in the number of securities and the price of securities are reflected in the volume measurement.

In the second approach, changes in the number of securities are reflected in the volume measurement.

In the third approach, changes in the real value of traded securities are reflected in the volume measurement.

\subsubsection{Maintaining constant quality of service over time for principal transactions of debt securities}

The spread or mark-up earned on a given debt security is dependent on a number of underlying characteristics of that security that may change over time. For example, the bid-ask spread on a bond with a AAA credit rating may behave markedly differently if the credit rating were to be downgraded. Similarly, as debt securities approach their maturity dates, spreads typically narrow. In order to ensure that the underlying characteristics of debt securities remain constant over time, when fundamental spreaddetermining characteristics such as credit rating and time to maturity change, the U.S. asks respondents to provide substitute securities with time to maturity and credit rating closest to that of the original selected security. To facilitate the ease of substitution, during initial data collection, the U.S. asks respondents to provide spreads on debt securities from entities (i.e. companies, municipalities) that regularly issue debt.

\subsubsection{Weighting and aggregation}

Both in the U.S. and Japan, the lower level indices are aggregated using industry turnover data as weights. Korea currently publishes "Securities brokerage commissions" price indices only. The index formula is the fixed-weight Laspeyres formula.

The U.S. uses the total revenue of this industry in the Economic Census for the lower index weight calculation. These weights are updated approximately every five years. Within the lowest level indices, each security company is weighted by its own turnover provided at the time of data collection. These weights remain fixed throughout the life of the sample.

Japan uses two sources for weight calculation: $i$ ) the intermediate transaction value estimated in the Input-Output Tables for the "Major group" and "Group" weights 
calculation; and $i$ i) the results from statistics published by industry organizations for the "Items" weights calculation. These weights are updated every five years.

Korea mainly uses the Input-Output tables for weight calculation.

Table 9.3.3. provides the U.S. SPPI publication structures for securities brokerage services.

Table 9.3.3. U.S. SPPI publication structures for securities brokerage services

\begin{tabular}{|l|l|}
\hline \multicolumn{1}{|c|}{ Index code } & \\
\hline 523120 & Securities brokerage \\
\hline $523120 \mathrm{P}$ & Brokerage services, equities, and ETFs \\
\hline 5231201 & Brokerage services \\
\hline 523120101 & Brokerage services, exchange-listed equities \\
\hline 523120102 & Brokerage services, all other securities \\
\hline
\end{tabular}

Table 9.3.4. provides the U.S. SPPI publication structures for principal securities transaction services.

Table 9.3.4. U.S. SPPI publication structures for principal securities transaction services

\begin{tabular}{|l|l|}
\hline \multicolumn{1}{|c|}{ Index code } & \\
\hline 5231102 & Dealer transactions Index title \\
\hline 523110201 & Dealer transactions, equity securities \\
\hline 523110202 & Dealer transactions, debt securities and all other trading \\
\hline
\end{tabular}

The U.S. also publishes product based services indexes for securities brokerage and dealing services as shown in the table 9.3.5.

Table 9.3.5. U.S. SPPI product based for securities brokerage and dealing service

\begin{tabular}{|l|l|}
\hline \multicolumn{1}{|c|}{ Index code } & \\
\hline 4011 & Securities brokerage, dealing, investment advice, and related services \\
\hline 401101 & Securities brokerage, dealing, and investment advice \\
\hline 40110101 & Securities brokerage, dealing, and investment advice \\
\hline 401102 & Securities brokerage and dealing related services \\
\hline 40110201 & Securities brokerage and dealing related services \\
\hline
\end{tabular}

Table 9.3.6. provides the Japan's CSPI (Corporate Services Price Index) publication structures for the securities and commodity brokerage services. The shaded "Items" are classified as falling into some other industries. 
Table 9.3.6. Japan's CSPI for securities and commodity contracts brokerage

\begin{tabular}{|c|c|c|c|}
\hline \multicolumn{4}{|l|}{ Major group } \\
\hline & \multicolumn{3}{|l|}{ Group } \\
\hline & & \multicolumn{2}{|l|}{ Subgroup } \\
\hline & & & Item \\
\hline \multicolumn{4}{|c|}{ Finance and insurance } \\
\hline & \multicolumn{3}{|c|}{ Financial services } \\
\hline & & \multicolumn{2}{|c|}{ Financial services } \\
\hline & & & Domestic money transmission and receipt \\
\hline & & & Account services \\
\hline & & & Securities brokerage services \\
\hline & & & Underwriting services \\
\hline & & & Securities selling services \\
\hline & & & Securities issuance, transfer and related services \\
\hline & & & Financial agency services \\
\hline & & & Safe deposit box services \\
\hline & & & Credit guarantee \\
\hline & & & Credit card interchange fees \\
\hline & & & ATM interchange fees \\
\hline
\end{tabular}

\subsubsection{Specific aspects}

\section{Treatment of bundled services}

For securities brokerage services, many of the large full-service securities companies provide their clients with a range of services in addition to executing their buy and sell orders such as the provision of investment advice and financial planning services, which are classified in some other industries. Examples of these bundled services are "wrap accounts" and "prime brokerage."

The inclusion of the prices of these bundled services depends on: $i$ ) whether the service is primarily included in this service and/or $i$ ) whether only charges for securities brokerage services can be distinguished.

Following these criteria, "wrap accounts" are not included in the U.S. securities brokerage industry price indices because "wrap accounts" are considered primary to NAICS 523930 - Investment Advice (ISIC 6619 -Other activities auxiliary to financial service activities). "Prime brokerage" can be included because the charges for the brokerage services, as the components of the prime brokerage, can typically be distinguished.

\subsubsection{Overview of national methods}

The U.S., Korea, and Japan are currently the only countries publishing price indices for the security and commodities brokerage industry. The methods and practices applied in each of these countries are discussed throughout this sub-chapter. 
Canada is currently developing an SPPI for securities brokerage based on the unit value method.

\subsection{Insurance (David Friedman, U.S. Bureau of Labor Statistics)}

\subsubsection{Industry description (ISIC 651)}

Business enterprises in this industry group engage in underwriting annuities and insurance policies (assuming the risk, assigning premiums, and so forth) and investing premiums to build up a portfolio of financial assets to be used against future claims (financial intermediation). Insurance services are defined in terms of the type of risk being insured against, such as death, loss of employment because of age or disability, and/or property damage. Contributions and premiums are set on the basis of actuarial calculations of probable pay-outs based on risk factors from experience tables and expected investment returns on reserves.

Over the past ten years, the advent of new underwriting tools has helped insurers to better estimate the risk of future claims. One such tool is credit scoring, which enables insurance companies to differentiate between low- and high-risk policyholders, allowing them to charge the appropriate premium for the assumed risk. Most companies now use credit scoring, which has fostered competition in the industry and provided the consumer with more choices.

\subsubsection{Classification aspects}

\subsubsection{Industry classification}

Insurance activities are classified in ISIC group 651. This Group includes the following types of insurance:

- ISIC 6511 - Life insurance:

- Life insurance;

- Annuities;

- Disability insurance;

- Accidental death and dismemberment insurance;

- ISIC 6512 - Non-life insurance:

- Accident and fire insurance;

- Health insurance;

- Travel insurance;

- Property insurance;

- Motor, marine, aviation and transport insurance;

- Pecuniary loss and liability insurance.

Annex A provides classifications from various systems by type of activity. Note that, in both the U.S. NAICS and ANZSIC systems, health insurance is classified separately from the other non-life insurance activities. In addition, accident insurance and fire insurance are classified separately in NAICS. NAICS 524127 - Title Insurance, and 
NAICS 524128 - Other direct insurance (except life, health, and medical) carriers, are also covered by ISIC 6512 . Included in NAICS 524128 are warranty insurance carriers and bank deposit insurance carriers.

In Canada, NAICS 524121 includes establishments that underwrite a combination of automobile, property, and liability insurance, with no one of the three types accounting for more than 70 percent of the nominal output. Each of the other NAICS insurance industries comprises establishments in which more than 70 percent of nominal output is derived from underwriting a particular type of insurance classified in that industry.

\subsubsection{Product classification}

Annex B maps the NAPCS product codes to the CPC Ver.2 structure for classes 7132 and 7133 .

The U.S. SPPI also includes accidental death and dismemberment with life insurance services, but there is no NAPCS code for this service. Freight insurance falls under the NAPCS code that includes inland marine insurance. NAPCS products for multiple peril insurance can include both property and liability coverage, so the NAPCS codes for these products correspond to $\mathrm{CPC}$ codes for both general liability and property insurance.

\subsubsection{Scope of the survey}

The U.S. SPPI also includes accidental death and dismemberment with life insurance services, but there is no NAPCS code for this service. Freight insurance falls under the NAPCS code that includes inland marine insurance. NAPCS products for multiple peril insurance can include both property and liability coverage, so the NAPCS codes for these products correspond to CPC codes for both general liability and property insurance.

\subsubsection{Industry vs. product based SPPI}

The broad ISIC definition of the insurance industries (ISIC 6511 and 6512) that is inclusive of a wide range of insurance products allows for the flexibility to survey by industry and capture a representative sample of products from companies classified in the industry. The various NAICS industries are, conversely, more narrowly defined. In the U.S., insurance companies tend to offer insurance policies across these industries so an industry based publication structure would necessarily need to support a vast array of secondary activity. To insure that the largest business enterprises are represented in each 6-digit NAICS insurance industry in which they operate, the U.S. produces industry based indices that cover only the primary services for each insurance industry. As a result, the industry based and approximate product based insurance SPPIs are exactly the same in the U.S. The sample design described below supports this strategy.

\subsubsection{Sample design}

The ideal sampling strategy for the insurance industries is to sample using probability proportional to size with premium turnover as the size measure. In the U.S., many companies operate in more than one insurance industry, but may not operate separate profit maximizing centres (PMCs). This is especially true for companies that offer life and health insurance. Therefore, it is necessary to create separate PMCs, when they do not already exist, and give the company a chance of selection in each specific NAICS industry. For property and casualty insurance, the PMC is further broken down by line of insurance (e.g. private passenger auto, homeowners, etc.), and this forms the basis for 
stratification. Since item selection is restricted to a single type of insurance, rather than inclusive of all activities of the business enterprise, secondary activities are excluded. Therefore, only services primary to the industry appear in the published indices in the United States. The number of items to be collected for each survey unit is determined by turnover. Within the survey unit, the number of items to collect for each service line is determined by the relative importance of each service line.

\subsubsection{Collection of information and specification of the service}

The policy underwritten by the insurer represents the unique service transaction. The policy lists the coverages for which restitution would be made to the policyholder to cover claims. The amount of risk being transferred to the insurer is clearly stated in terms of covered benefits (and benefits not covered) and the policy obligates the insurer to pay claims for all such occurrences.

For initial data collection, representative policies are selected following consultation with respondent representatives, typically from the actuarial department. It is necessary to capture detailed policy characteristics to facilitate constant quality pricing over time. The following policy characteristics are captured:

- Life insurance:

- Type of policy - whether the policy is term, whole life, universal, etc. will have an effect on the premium amount. The premium for a term policy tends to be lower;

- Age of insured - the older the insured, the higher the premium due to increasing mortality;

- Sex of insured - premiums tends to be higher for males than for females;

- Face amount of policy - the premium will increase as the amount of coverage increases in order to cover potential claims;

- Smoker/non-smoker - the premium tends to be higher for people who smoke due to increased health risks which increase mortality;

- Health of insured - the healthier the insured, the lower the premium will be since chance of premature death is expected to be lower;

- Duration of the policy - this refers to the nth year of the policy (i.e. 1st year, 5 th year, etc.). The premium or fees may change depending on how the long the policy has been in force;

- Riders - a policy may have a provision for additional coverage called a rider. A rider may provide additional coverage for spouse or children of the insured and will increase the premium otherwise payable.

- Property insurance:

- Type of property or insured risk - provides the characteristics of the insured property or specific risk covered;

- Type of coverage - provides the physical damages and liabilities covered by the policy; 
- Dollar limit of coverage - maximum amount of money the insurer is legally obligated to pay in the event of a claim;

- Coinsurance clause - percent of the value of the property to be reimbursed by the insurer;

- Deductible - the insured bears the first part of any loss covered by the policy up to a specified amount;

- Length of policy period - time frame for which the policy is in effect;

- Perils covered - specific risks that the insurer assumes;

- Location of the insured property - risks vary by geographic location;

- Past loss experience - generally, the premium is lower if the insured has a past record of making fewer claims;

- Valuation of insured property - either the actual cash value of the property, which adjusts for depreciation, or the replacement cost;

- Valuation of risk exposure - monetary value for liability coverage.

- Health insurance:

- Type of coverage - underwriters will require different information in order to provide prices for medical service plans, long-term care, and other services;

- Amount of coverage (richness of benefits) - includes the number of covered services, the dollar amount of coverage for each service, and the maximum dollar amount of coverage;

- Rate class - prices for the same service within the same group will differ according to the rate class. Generally, a family will pay a higher premium than an individual within the same group plan;

- Voluntary vs. non-voluntary (contributory vs. non-contributory) - voluntary (contributory) group policies are policies for which the employee pays $100 \%$ of the premium. Non-voluntary (non-contributory) group policies are policies whereby the employer pays $100 \%$ of the premium. The percentage contribution of the employer or the employee can vary anywhere between $0 \%$ and $100 \%$;

- Group composition - the combination of gender and age ranges is an important factor in determining the premium. Therefore, companies require the age and gender of each person covered by the policy, including spouses and children;

- Medical history - a previously healthy person will generally pay a lower premium than one who has a record of health care utilisation;

- Occupation - a person employed in a dangerous occupation will generally pay more than one in a sedentary, low risk occupation. The classification code of the industry is usually used for underwriting purposes;

- Geographic location - people who live in areas in which natural disasters often occur and/or pollution is a problem will generally pay higher premiums than those who do not. For large groups, or small groups which are geographically 
dispersed, several geographic regions may apply. However, a national rate may be used if a group is very well dispersed throughout the nation;

- Earnings - As incomes rise, utilisation rates tend to increase. Thus, premiums tend to increase as income increases as well. Earnings will be most important in determining a price for accident insurance. Maximum benefits paid are usually based on income;

- Smoking Status - Smokers generally pay higher premiums than non-smokers.

\subsubsection{Main pricing methods}

\subsubsection{Type of prices}

In the U.S. service producer price index program, the primary output of the insurance industries is the assumption of risk, or transfer of risk from the policyholder, and financial intermediation. Financial intermediation represents the investments made to partially offset the size of the premium payment. The primary type of price for measuring this output is the premium plus the return on investment. This price can be expressed as:

$$
\text { Price }=\text { Premium }(1+r)
$$

Where $r$ is the annual return on the invested portion of the premium for the particular type of insurance that is being priced. This rate is stated as a percentage of all premiums paid. This type of price is collected for all property and health insurance services and any life insurance service for which the policyholder pays a set premium.

Mutual companies, whose policyholders are also the stockholders of the company, typically pay out a dividend to the policyholders on an annual basis. In such cases, the dividend would be subtracted from the premium to obtain a net transaction price. This price can be expressed as:

\section{Price $=$ Premium $(1+r)-$ Dividend}

For some types of life insurance, premiums may vary at the discretion of the policyholder, making them an inaccurate measure of the output. Instead of obtaining premiums, the various fees charged to administer the policy are collected as a proxy for the premium, taking the total fees and investment return as the price.

For universal and variable life insurance policies, the price collected is expressed as follows:

$$
\text { Price }=(M C+E X P+P+C)(1+r)
$$

Where $\mathrm{MC}=$ mortality costs, $\mathrm{EXP}=$ expenses, $\mathrm{P}=$ profits, $\mathrm{C}=$ contingency allowances and $\mathrm{r}=$ earned rate on investments

For annuities, companies receive a consideration (premium) that is variable, but they only retain a portion of it. All money invested in the annuity, net of any fees and/or interest retained by the insurance company, is intended to be returned to the annuitant. The outputs from annuities are measured by fees and/or interest.

For variable deferred annuities, the fee methodology used for universal and variable insurance was adapted to measure the output of these annuities. Fees charged for provision of these annuities are generally set as a percentage of the account value. These fees cover expenses, mortality risks, and investment management. 
For fixed-rate annuities, a company's turnover is the difference in the interest that they earn and interest that they credit to the annuitant. The difference is applied to the account value. In addition to this interest spread, companies may charge a flat administrative fee.

The price measure for immediate annuities is the actuarial rate. This is the rate at which the provider derives the premium or consideration. It is calculated as the present value of the payment of one dollar every month for the expected duration of the annuity.

\subsubsection{Pricing approach}

The U.S. SPPI uses model pricing to track price movement over time. Companies provide estimated premiums or fees for a "frozen" policy. Initially, the type of policy to be priced is selected by probability proportionate to size item sampling at the establishment. Respondents then choose actual policies of the selected type that are representative of their business in terms of price movement and coverage. Subsequently, the premium determining characteristics are held constant, while the policy is priced on an annual or semi-annual basis. The respondent estimates the current premium for this "frozen" policy by using current charges applied to the policy characteristics of the policy. This premium remains unchanged until the policy is priced again.

In order to hold the real values of coverage constant, periodic adjustments are made to account for inflation. For homeowners' insurance, the dollar limit of coverage is adjusted annually to account for construction price inflation. The assumption is that the policyholder is insuring to secure a constant flow of services from the insured property. If there is price inflation affecting the cost of repair or replacement of the damaged property, the coverage limit should be escalated to reflect this increase. This adjustment is made annually on the anniversary date of the policy. This reflects what actually occurs; companies make these coverage adjustments at the time of policy renewal. For sampled policies, spreading policy anniversary dates throughout the year smoothes overall industry price behaviour.

The data sources used for these adjustments vary based on the type of coverage. For example, in the case of worker's compensation insurance, the workforce in the group is held constant (same number of people in the same jobs), but the wage rates are adjusted using the Bureau of Labor Statistics' Employment Cost Index to account for general wage inflation.

An alternative to model pricing is to follow the selected policy over time using the direct use of prices of repeated services method. With this method, respondents are asked to provide the actual premium charged to the policyholder and to identify any modifications to the policy each year on the anniversary (or renewal) date. Any changes in benefits over time must be factored out so that index movements reflect only changes in price and not changes due to additional benefits. To maintain constant quality, the companies must be able to provide the value of the risk change associated with any change to the policy characteristics.

\subsubsection{Quality issues}

A fundamental issue in pricing insurance services is identifying and adjusting for changes in risk. For changes in explicitly endogenous risk factors such as changes in coverage or deductibles, respondents typically have suitable cost data to allow for meaningful cost based quality adjustment. ${ }^{10}$ However, for changes in exogenous risk 
factors that go beyond the scope of policy negotiations, such as an increased incidence of theft or a severe hurricane season, a particular business enterprise is not likely to have sufficient data to definitively quantify risk. Only data sources external to the business enterprise will be robust enough to identify short-term vs. long-term changes in risk and, in most cases, it is not practical to obtain this information and use it for quality adjustment. One exception is for private passenger auto insurance. The U.S. obtains information used to quality adjust for changes in auto insurance risk from an external data source. ${ }^{11}$

However, it is not always clear when a shift in underlying risk occurred. Decisions must be made in real time, and sufficient data may not be available in the current time period to identify and quantify the effect of these changes.

Another issue related to quality is new item bias. This is especially problematic when pricing a frozen policy. Over time, this policy may no longer be representative. Mandated coverages may change or new insurance products may be introduced. Although bias may not be as prevalent when following an actual policy, it can occur if the general population has changed their preferences for the type of insurance product that they purchase or if the policy represents a smaller portion of the company's business. To minimise new item bias, the insurance industries may require more frequent sampling than other industries. In addition, many mandated coverage changes are captured during normal pricing activities.

\subsubsection{Weighting and aggregation}

Table 9.4.1. provides the U.S. SPPI industry publication structures for the insurance industries.

Table 9.4.1. U.S. PPI industry publication structures for the insurance industries

\begin{tabular}{|l|l|}
\hline \multicolumn{1}{|c|}{ Index code } & \\
\hline \multicolumn{1}{|c|}{524113} & \\
\hline $524113 \mathrm{P}$ & Primary services \\
\hline 5241131 & Life insurance polices \\
\hline 524113101 & Individual life insurance policies life insurance carriers \\
\hline 52411310101 & Term life insurance policies \\
\hline 52411310102 & Whole life insurance policies \\
\hline 52411310103 & Universal life insurance policies \\
\hline 52411340104 & Other individual life insurance policies \\
\hline 524113102 & Group life insurance policies \\
\hline 5241132 & Annuities \\
\hline 524113201 & Variable deferred annuities \\
\hline 524113202 & Fixed-rate deferred annuities \\
\hline 524113203 & Immediate annuities \\
\hline 5241133 & Disability insurance policies \\
\hline
\end{tabular}


Table 9.4.1. U.S. PPI industry publication structures for the insurance industries, continued

\begin{tabular}{|l|l|}
\hline \multicolumn{1}{|c|}{524126} & \\
\hline $524126 \mathrm{P}$ & Primary services \\
\hline 5241261 & Private passenger auto insurance \\
\hline 5241262 & Homeowners insurance \\
\hline 5241263 & Commercial auto insurance \\
\hline 5241264 & Non-auto liability insurance \\
\hline 524126402 & Medical malpractice insurance \\
\hline 524126403 & Product liability and other non-auto liability insurance \\
\hline 5241265 & Commercial multiple peril insurance \\
\hline 5241266 & Workers compensation insurance \\
\hline 5241267 & Other property and casualty insurance \\
\hline & \\
\hline 524114 & \\
\hline $524114 \mathrm{P}$ & Primary services \\
\hline 5241141 & Medical service plans \\
\hline 524114101 & Comprehensive medical service plans \\
\hline 52411410101 & Group managed care medical service plans \\
\hline 52411410102 & Group fee-for-service medical service plans \\
\hline 52411410103 & Individual comprehensive medical service plans \\
\hline 524114103 & Non-comprehensive medical service plans \\
\hline 52411410301 & Dental service plans \\
\hline 52411410302 & Supplemental Medicare service plans \\
\hline 52411410303 & Other medical service plans \\
\hline 5241142 & Health insurance \\
\hline
\end{tabular}

For each of these index series, the lower level indices are aggregated using industry turnover data (premiums plus investment income) as weights. Although the indices are calculated using the Laspeyres formula, these weights are updated approximately every five years. Within the lowest level indices, each insurance company is weighted by its own turnover provided at the time of data collection. These weights remain fixed throughout the life of the sample.

The U.S. also publishes product based services indices for insurance as shown in the table 9.4.2. below.

Table 9.4.2. U.S. product based services indices for insurance

\begin{tabular}{|l|l|}
\hline \multicolumn{1}{|c|}{ Index code } & \\
\hline 411101 & Life insurance \\
\hline 411102 & Disability insurance, including accidental death \\
\hline 411103 & Health and medical insurance \\
\hline 41110 & Property and casualty insurance \\
\hline 412101 & Annuities \\
\hline
\end{tabular}

\subsubsection{Specific aspects}

While individual policies may vary, most transaction characteristics and terminology are standard throughout the industry (i.e. a policy that is medical malpractice at one company would be considered a malpractice policy at another company).

However, one problematic situation in property insurance is that a sampled policy may include two lines of insurance. For example, it is not uncommon for a homeowner's policy to include inland marine coverage, which is a service line in itself, in addition to the regular homeowner's coverage. Another difficulty is that companies may also vary on 
how they categorise motorcycle (auto vs. other) and motorhome insurance (auto vs. homeowners).

Recordkeeping practices dictate how the policies are categorized and priced in both situations. In the first, the premium for inland marine coverage is excluded from the price if the company separates the premiums in their records; otherwise it is included. In the second case, the policy's categorisation will depend on that of the company.

\subsubsection{Overview of national methods}

\section{Canada}

Canada is currently developing indices for non-life insurance activities. Indices will be calculated for each 5-digit NAICS industry. Depending on the approach recommended, commercial insurance could be excluded. For auto and property insurance, which represent the bulk of net premiums written, the portion of commercial coverage within each line represents approximately 5\% and 10\%, respectively. Each industry will be sampled at the establishment level with no stratification.

\section{Japan}

Japan compiles price indices on Property and Casualty insurance services, including Fire insurance, voluntary motor vehicle insurance, compulsory motor vehicle insurance, and marine and other transportation insurance services. Indices are focused on business to business transactions. The model pricing method is mainly used.

Since Japan defines the unit transaction in insurance service as the real value of coverage, the nominal value of coverage is discounted by the inflation rate of prices of the insured property. For example, the inflation rate of the Building Construction Cost Index is used for adjustments in the nominal value of building damage coverage.

\section{Netherlands}

In the Netherlands, public service sectors like health care and insurance are characterized by regulated tariffs. Statistics Netherlands has developed a statistical method for price and volume measurement of non-life insurance services using the net measurement approach. The general idea behind this approach is that the insurance industry retains a margin for the provision of services or activities (e.g. policy administration). For the net approach, nominal value is expressed as

$$
P_{i, t}+E S_{t}-E L_{t}
$$

$P_{i, t}$ denotes total premiums earned for product group $i$ in year $t, E S_{t}$ denotes the expected investment income to premium ratio in year $t$, and $E L_{t}$ denotes expected loss (claims) in year $t$. Dutch data is used to estimate yearly expectations of loss and investment income.

In the model, premiums are set according to expected loss, to which insurers may add their expectation about investment income. ${ }^{12}$ Expected loss and its "relative handling cost" are used to characterize insurance services which have different values depending on the type of non-life insurance. Expected loss is expressed as follows:

$$
\mu_{i}^{p} P_{i, t}+\mu_{i}^{s} P_{i, t} E S_{t}
$$

Premiums and investment income are distributed over risk and handling costs, so parameters $\mu_{i}^{p}$ and $\mu_{i}^{s}$ denote the fractions of premiums and expected investment income, 
respectively, that cover total expected loss for product group $i$. Parameters $\mu_{i}^{p}$ and $\mu_{i}^{s}$ are set to values between 0 and 1 .

$\mu_{i}^{p}$ is expected to take some value smaller than 1 , while $\mu_{i}^{S}$ could be equal to 1 . In that case, investment income is entirely used to cover expected loss, so that handling cost exclusively consists of (a fraction of) premiums. In this model version, different sources of risk arising from loss and investment income are combined and premiums are set through the handling cost parameter $\mu_{i}^{p}$. The idea behind this model version is that investment income is used to compensate (a part of) losses incurred. Model versions where the $\mu_{i}^{s}$ are equal to zero imply that investment income is assigned to handling cost and that a part of the premiums is used to cover losses.

\section{Bibliography}

\section{Monetary intermediation activities:}

Auer, J., and Kazuhiko I. (2011), Banking and Credit, Reference Rate and Negative Prices, $26^{\text {th }}$ Voorburg Group meeting, Newport, United Kingdom available at: http://www4.statcan.ca/english/voorburg/Documents/2011\%20Newport/Papers/2011 $\% 20-\% 2002 . p d f$

Bathgate, D. (2009), United States Producer Price Index for Banking, $24^{\text {th }}$ Voorburg Group meeting, Oslo, Norway, available at: http://www4.statcan.ca/english/voorburg/Documents/2009\%20Oslo/Papers/2009\%20\%2025.pdf

Swick, R., Bathgate D., and Horrigan, M., (2006), Services Producer Price Indices: Past, Present, and Future, Paper prepared for the National Bureau of Economic Research, 36 Conference on Research in Income and Wealth Summer Institute, Cambridge, MA, 83 p., available at: http://www.bls.gov/bls/fesacp1060906.pdf

Barosevic, M., Lewis C., and Cullen, D., (2011), Financial Intermediation Services Indirectly Measured (FISIM) in the CPI, 58th World Statistics Congress of the International Statistical Institute, Dublin, Ireland available at: http://2011.isiproceedings.org/papers/650260.pdf

Apsitis, M., and Morgan, M., (2010), The Australian Perspective on Financial Intermediation Services, $25^{\text {th }}$ Voorburg Group meeting, Vienna, Austria, available at: http://www4.statcan.ca/english/voorburg/Documents/2010\%20Vienna/Papers/2010\%2 $\underline{0-\% 2050 . p d f}$

\section{Investment banking:}

Barosevic, M., Lewis C., and Cullen, D., (2011), Financial Intermediation Services Indirectly Measured (FISIM) in the CPI, 58th World Statistics Congress of the International Statistical Institute, Dublin, Ireland available at: http://2011.isiproceedings.org/papers/650260.pdf 
U.S. Bureau of Labor Statistics, (2008), PPI Fact Sheet for Producer Price Indexes for Security and Commodity Contracts Intermediaries and Brokerages - NAICS 5231, BLS Website, available at:

http://www.bls.gov/ppi/ppinaics5231.htm

Investment banking:

Barosevic, M., Lewis C., and Cullen, D., (2011), Financial Intermediation Services Indirectly Measured (FISIM) in the CPI, 58th World Statistics Congress of the International Statistical Institute, Dublin, Ireland available at:

http://2011.isiproceedings.org/papers/650260.pdf

U.S. Bureau of Labor Statistics, (2008), PPI Fact Sheet for Producer Price Indexes for Security and Commodity Contracts Intermediaries and Brokerages - NAICS 5231, BLS Website, available at:

http://www.bls.gov/ppi/ppinaics5231.htm

Security and commodity contracts brokerage:

Ribe, M., (2003), Financial Services in Swedish Price Indices, $7^{\text {th }}$ Ottawa Group meeting, Paris, France available at:

http://www.ottawagroup.org/Ottawa/ottawagroup.nsf/home/Meeting+7/\$file/2003\%20

7th\%20Meeting\%20-\%20Ribe $\% 20$ Martin $\% 20$ -

\%20Financial $\% 20$ Services $\% 20 \mathrm{in} \% 20$ Swedish $\% 20$ Price $\% 20$ Indices.pdf

\section{Insurance:}

Bathgate, D., (2004), Price Indexes for Property and Casualty Insurance, Voorburg Group Metting, Ottawa, Canada available at:

http://www4.statcan.ca/english/voorburg/Documents/2004\%20ottawa/papers/2004030.pdf

Bathgate, D., (2011), United States Producer Price Indexes for Non-Life Insurance, Voorburg Group meeting, Newport, United Kingdom available at: http://www4.statcan.ca/english/voorburg/Documents/2011\%20Newport/Papers/2011 \%20-\%2036.pdf

Swick, R., Bathgate D., and Horrigan, M., (2006), Services Producer Price Indices: Past, Present, and Future, Paper prepared for the National Bureau of Economic Research, 36 Conference on Research in Income and Wealth Summer Institute, Cambridge, MA, 83 p., available at: http://www.bls.gov/bls/fesacp1060906.pdf

Chessa, A. G., (2011), A New Method for Price and Volume Measurement of Non-Life Insurance Services: A Statistical Approach, Voorburg Group meeting, Newport, United Kingdom available at:

http://www.voorburggroup.org/Documents/2011\%20Newport/Papers/2011\%20\%2031.pdf 


\section{Notes}

1. Credit granting for house purchasing by specialised non-deposit taking institutions are in ISIC Class 6492. Credit card transaction processing and settlement activities are in ISIC Class 6619.

2. Source: Preliminary Report of the ISWGNA Task Force on FISIM

3. Source: Preliminary Report of the ISWGNA Task Force on FISIM

4. See Auer, J., and Kazuhiko I., (2011).

5. Ibid.

6. Present value discounting is required in order to maintain a constant unit of measure. Since the outstanding balances are period-end values and since the real value of money is eroded over time, the nominal balances must be reduced so that they are reflective of their real value in the base period. The nominal values are discounted through multiplication by a discount factor $[1 /(1+r)]$; where $r$ is the discount rate, which is the opportunity cost of capital. For the purpose of the Canadian Banking SPPI, the discount rate has been primarily the relevant reference rate.

7. As discussed under Classification Aspects, there are significant differences between how ISIC and NAICS treat these activities but ISIC 6499 appears to be the closest match

8. For more details, please see the Security and Commodity Contracts Brokerage section in this Guide.

9. See section 9.3.7.2.

10. Examples of these kinds of factors include the addition of a terrorism clause to property and casualty insurance policy and, for health insurance, the removal of lifetime maximums.

11. See Bathgate (2011).

12. See Chessa (2011). 


\section{Chapter 10. Real estate activities}

This chapter presents practical guidance as well as main issues and challenges for compiling SPPI for Real estate activities (ISIC 68). 


\subsection{Real estate activities with own or leased property (Aspasia Papa, Office for National Statistics United Kingdom)}

\subsubsection{Industry description (ISIC 68)}

Real estate activities encompass a range of services relating to the provision of property, i.e. buying, selling and renting of commercial and residential properties or land. This division also includes the activities of real estate agents intermediating in buying, selling, letting or managing real estate.

\subsubsection{Classification aspects}

\subsubsection{Industry classification}

The ISIC classification identifies separately two main industry groups, namely 681 Real estate activities with own or leased property, and 682 - Real estate activities on a fee or contract basis. The former includes buying, selling, and operating of self-owned or leased property whereas the latter encompasses the provision of real estate activities on a fee or contract basis.

The other international industry classifications provide further delineations. Indeed, ANZSIC identifies separate classes for 6711 - Residential property operators and 6712 Non-residential property operators. NACE distinguishes 68.10 - Buying and selling of own real estate, from 68.20 - Renting and operating of own or leased real estate. In addition, NACE divides the provision of real estate activities into 68.31 - Real estate agencies, and 68.32 - Management of real estate on a fee or contract basis. Finally, NAICS identifies separate industries for lessors of residential buildings and dwellings, lessors of non-residential buildings (except mini warehouses) and lessors of mini warehouses and self-storage units. It also makes a distinction between residential property management and non-residential property management and identifies a single industry for all real estate appraisal services.

\subsubsection{Product classification}

The CPC classification follows closely the industry classification and includes two groups, namely 721 - Real estate services involving own or leased property and 722 Real estate services on a fee or contract basis. The former includes rental or leasing of residential and non-residential property. This group also encompasses trade services, where the property, either residential or non-residential, is treated as sales of trading stock by the seller as opposed to disposals of fixed assets of the selling unit. The second group consists of residential and non-residential property management and real estate appraisal services. In addition, this group includes building as well as land sales on a fee or contract basis.

One area of growing importance is that of time-share properties. Indeed, the CPC classification identifies time-share property subclasses in each of the two groups. It should be noted that the term time-share has a dual meaning, since it can refer to both a deeded partial ownership as well as a prepaid authorisation for use of accommodation services. In this context, the CPC refers to the deeded partial ownership and related services; whereas the prepaid accommodations and time share exchange services are included in groups 855 - Travel arrangement, tour operator and related services and 631 Accommodation services for visitors. ${ }^{1}$ 
CPA and NAPCS have structures and details comparable to CPC. The commission sales activities for residential and non-residential property, the fee based property management services for residential and non-residential property, and other fee based products, such as appraisal services, are also separately identified in each of these product classifications. NAPCS consists of more than 50 detailed products which separate residential and non-residential real estate services. It also provides a further delineation of rental of real estate by purpose of use (e.g. commercial, industrial, manufacturing, mini warehouses, etc.) and breaks down the appraisal services by opinion of value and quality of real estate and taxation appraisal services.

\subsubsection{Scope of the survey}

The ideal survey would track constant quality price change for the full range of output to all end users (such as business, household and government etc.). It is important that compilers consider the extent to which different service activities, and even similar activities provided to different end users, may follow comparable or different price development over time. The pricing mechanisms employed for different service activities, their relative size in output terms, and the availability of data, should also be considered in setting the scope of the survey.

The survey should cover both the provision of real estate activities with own or leased property and the provision of real estate activities on a fee or contract basis as they are likely to have different drivers of price development.

The 2009 Voorburg Group "Revisited Status Report" for the industry, highlighted a problem of partial coverage of the industry arising in the majority of reporting countries because only non-residential rental and leasing were covered.

The U.K. SPPI publishes two indices, distinguishing between the provision of services to property owners and purchasers, and the letting of non-residential property, and provision of associated services, by property owners namely:

- An index for Real Estate Agency services covering selling, letting and acquisitioning activities and act as a proxy for all real estate agency activities (including property management services). The services are mainly provided to the property owners although some are to prospective purchasers.

- An index for Property Rental relating to the renting or leasing of self-owned nonresidential property. In practice, this can also include other services, such as use of utilities, ground leases, maintenance changes and business rates.

It should be noted that whilst the selling and buying of self-owned real estate is included in the classification, it is not listed here on the basis that it does not contain a corporate element. Similarly, price changes in dwellings are often proxied by CPI information, although a number of countries (e.g. Australia) include the price change of residential properties in the compilation of their SPPI for real estate.

The development of building projects for sale is classified under construction activity and therefore falls outside the scope of the SPPI survey for this industry.

The services related to real estate generally do not cover all of the activities that are associated with real estate ownership transactions. Activities classified elsewhere including the activities of surveyors, title researchers, and attorneys are not included in real estate service activities. 


\subsubsection{Sample design}

The source data for the sampling frame, the sample structure and size and sampling techniques must be considered in the context of the availability of data and resources, the overall importance of the industry and the level of homogeneity or otherwise of price development.

Typically, the national business register will provide a potential sample frame. However, consideration must be given to the extent to which the frame covers the entirety of real estate activities. Many buildings are owned and rented by business enterprises with a primary activity other than the provision of real estate services. For example, a law firm might own a building that not only accommodates its offices but also provides additional office space that the firm rents out to other tenants. The establishment would therefore appear on a business register as a law firm rather than a lessor of non-residential property. Compilers need to review and analyse property ownership patterns in their country to determine the most appropriate sampling frame.

\subsubsection{Real estate agency services}

The U.K. sample of real estate agency service providers is structured so as to take account of:

- Region;

- The type of property - office, retail, industrial and other;

- The type of primary estate agency activity - selling, letting and acquisition.

The population frame is obtained from the business register. The sample selection follows a multi-stage process where the population is stratified according to employment band and the number of questionnaires sent is determined by the turnover share. Establishments with less than 10 employees are not included in the sample. For each component of the sample structure two elements are surveyed separately, namely a commission rate and a rental or capital value index.

\subsubsection{Property rental payments (non-residential)}

The data used to compile this index is derived from a sample of over 1,000 properties which are independently valued each month. The sample is designed to include representative coverage of office, retail, industrial and other property types. Properties included have been purchased for investment purposes - mainly relating to insurance and pension funds. The index is compiled from valuation and management records for individual buildings in complete portfolios, collected directly from investors. Valuations are conducted on the sample of properties by qualified valuers working according to industry guidelines and reflect the value that each of the properties would attract if put on the market for rent or sale.

\subsubsection{Collection of information and specification of the service}

The U.K. Real Estate Agency Services index requires data on commission rates which are collected from real estate agents via a quarterly survey. A paper questionnaire is sent every quarter to those real estate agents included in the panel. Most of the data are returned by telephone using the Telephone Data Entry system. Contributors dial a given number and, using the touch-tone facility, input their individual identifier and supply data 
for each of the index reference numbers on their questionnaire. Voice messages can be left to explain any changes or to provide details of any new information. Input data are stored in a database which can then be loaded into the main SPPI database.

Capital values and rental values are provided by a third party data supplier, namely the Investment Property Databank - IPD. The same supplier also provides an index of the rental income from investment properties. These data are obtained on a monthly basis, as part of a continuing agreement, and are sent in a spreadsheet format.

\subsubsection{Main pricing methods}

There is a variety of pricing mechanisms used within the real estate services industry giving rise to a requirement for different pricing methods.

Prices for commission based real estate agency services, including buying, selling, leasing or renting of real estate have two primary components, the commission rate and the value of the real estate or total value of the lease or the rental value of price. Both these parameters must be accounted for when developing price indices to avoid bias. Indeed, a price index only capturing average commission rates, would not necessarily fluctuate in the same direction or magnitude as the actual value being received for the services being provided. This rationale is in line with the recommendations of the National Accounts Working Party's Task Force on Price and volume measures for real estate, renting and business services which indicate that: "Monitoring estate agents' margins only could produce misleading results, e.g. if margins remained constant at $5 \%$ say, the index would remain constant. However, if property prices are increasing then the income earned would be increasing - and so this needs monitoring too to enable a true measurement of estate agents' charges."

An example follows of an index of estate agents' margins (average commission rates) with an index of average property prices (for selling property):

Table 10.1.1. Index of estate agents margins

\begin{tabular}{|l|l|l|l|}
\hline \multicolumn{1}{|c|}{ Period } & \multicolumn{1}{|c|}{ Average property price } & \multicolumn{1}{|c|}{ Property price index } & \multicolumn{1}{|c|}{ Estate agents' margins } \\
\hline 1 & $£ 70,000$ & 100.0 & $5.0 \%$ \\
\hline 2 & $£ 74,000$ & 105.7 & $5.1 \%$ \\
\hline 3 & $£ 78,000$ & 111.4 & $5.2 \%$ \\
\hline 4 & $£ 82,000$ & 117.1 & $5.3 \%$ \\
\hline 5 & $£ 86,000$ & 122.9 & $5.4 \%$ \\
\hline
\end{tabular}

Table 10.1.1. Index of estate agents margins, continued

\begin{tabular}{|l|l|l|l|}
\hline \multirow{2}{*}{ Period } & Index of agents' margins & Estate agents' charges & $\begin{array}{c}\text { Index of estate agents' } \\
\text { charges }\end{array}$ \\
\hline 1 & 100.0 & $£ 3,500$ & 100.0 \\
\hline 2 & 102.0 & $£ 3,774$ & 107.8 \\
\hline 3 & 104.0 & $£ 4,056$ & 115.9 \\
\hline 4 & 106.0 & $£ 4,346$ & 124.2 \\
\hline 5 & 108.0 & $£ 4,644$ & 132.7 \\
\hline
\end{tabular}


In the above example, both the average property prices and estate agents' margins are rising, so the increase in estate agents' charges would be underestimated if only one of the component indices was used.

Index compilers should also be aware of various incentives that are used in leasing and renting. These can include "free" months of rent, moving or outfitting allowances, and other incentives given in lieu of discounts that should be accounted for in the current estimate of the lease value.

In order to avoid collecting average commission rates, data can be collected on representative commission rates. "A representative commission rate" is defined as a rate which reflects as far as possible any movement in commission rates for the sector as a whole. Where there is a range of rates for a market sector then the predominant or median rate can be provided.

Property management contracts tend to be fixed fee based, with the fee and specific duties and responsibilities explicitly listed in the management contract. Alternatively, property management fees can be based on a percentage of the lease amount, building revenue, or other variables. For these variable fee contracts, the price program should track the commission rate and the current value of the variable component, either rent or building revenues.

Fee based real estate services pose less of a problem. Certain activities, including valuations, escrow contracts, and listing services are generally repeated services and can be tracked periodically using actual transaction prices. For services provided on an hourly basis, such as real estate consulting (e.g., zoning studies, market studies, expert witness services, etc.), hourly charge-out rates can be tracked

\subsubsection{Quality issues}

As is generally the case, any fluctuation in the price index should be free from quality changes. As such, the quality of real estate services and property rentals should remain constant over time. Problems can be caused by respondents misinterpreting what constitutes a representative commission rate. For example, a respondent might take an average of 10 transactions for each market sector and calculate the average commission rate for each of the selected properties. However, quarter on quarter changes could be caused by changes in the mix of properties in those samples rather than market pressures. The respondent should therefore be asked to select representative and specific transactions for each market sector and should report on these each quarter. Transaction specifications may include the type, size, location and fit-out quality of property.

An alternative approach used to overcome quality issues is to apply a hedonic model. In Finland, hedonic price indices for constant quality rent of shops and offices have been developed to decompose changes in arithmetic mean prices into quality adjustment factors and price change standardised for quality. The variables impacting price include floor area and location. Commission rates could subsequently be applied to estimate the actual revenue received for commission based leasing services by real estate agents.

\subsubsection{Weighting and aggregation}

The sources of weight data vary between countries. Most countries use data from annual surveys like Structural Business Surveys or Annual Sectoral Surveys. In some countries, weight data are collected by a specific SPPI Survey. 
For the U.K. real estate agency services index, price relatives for each component for each contributor are derived by combining the commission rate figure with the appropriate capital value or rental index value. The index values as provided are used which means the actual capital or rental values do not need to be used in the calculation. Price relatives for each component across all contributors are then calculated. The weights used to aggregate the price relative are obtained from a turnover survey exercise which is carried out quinquennially. Indices for each region and the country overall are also calculated using the relevant weights for each component, also derived from the turnover survey.

\section{Property rental payments (non-residential)}

The capital value index is derived from figures for capital growth: the change in capital value from one valuation to the next, net of any capital flows, divided by capital employed. In this context, capital employed is defined as the capital value at the start of the year plus half of any net capital flow, and half of income receivable, i.e. flows of capital and reinvested income are assumed to be spread evenly throughout the year. The rental value index is based on estimates of rental growth which are the percentage changes in the rental value used in the valuations from one year to the next. The gross income index used for property rental payments is derived from calculating the changes in gross rent receivable.

\subsubsection{Specific aspects}

One of the issues to be addressed in the compilation of an SPPI for the industry is the bundling of services which can affect both prices and turnover data. Indeed, there is an increasing tendency for larger business enterprises to diversify, both horizontally and vertically, and expand the scope of their activities to include a number of services ranging from conveyancing, facilities and asset management, to financial and legal services and project management. In a similar vein, units primarily renting space to others on a fee basis often have income from a variety of sources. This can include the gross rents received for the provision of space, as well as net capital gains from the sale of real estate, interest, dividends, royalties, and other sources of revenue. It is strongly recommended to separate out the sources of income so as to facilitate the identification of the revenue received from primary real estate agency activities as opposed to other activities.

Beyond the separate identification of gross rents, separate breakdowns for residential rents and non-residential rents are also recommended. The reason is twofold. First, rents charged in residential and non-residential rental markets often move in different directions or with different magnitudes based on local and national market conditions. Second, residential rents are a component of final demand while commercial or other non-residential rents are a component of intermediate demand.

\subsubsection{Overview of national methods}

\section{Australia}

In Australia, non-residential property operators consist of units mainly engaged in renting or leasing non-residential properties. Primary activities include:

- Agricultural land renting or leasing;

- Commercial or industrial property renting or leasing; 
- Commercial property body corporation;

- Commercial property strata corporation;

- Factory renting or leasing;

- Office Space renting or leasing;

- Self-storage renting or leasing;

- Shopping centre renting or leasing;

- Warehouse renting or leasing;

Potential respondents are selected by non-probability sampling (based on market share or turnover) and then interviewed to establish whether they are suitable for inclusion in the survey and to determine which of their service activities are most representative for on-going pricing. Locations sampled include capital cities in all Australian states and territories.

Respondents report a price for one or more specified service products on a quarterly basis. Reasons for reported changes in prices are also provided at this point. This information is valuable to the process of validation of prices by the compiler. Each specification for non-residential property operators has its own weight. These weights are based on the amount of turnover and market share of the business, which is established during the respondent initialisation process.

Non-residential property operators provide basic prices. The survey questionnaire specifies that the price should exclude goods and services tax. Pricing of services provided by non-residential property operators is carried out with reference to full day rates or provided by price per square metre.

On occasion, inadequate reasons for a price change are provided. In these instances further investigation and follow up with the provider is undertaken. When suitable, or supporting, evidence for a price change cannot be obtained the observation may be imputed if it does not correlate with other data collected.

The ABS compiles an SPPI for real estate services (ANZSIC class 6720, ISIC 6820), which measure changes in the prices of services offered by real estate agents to their clients. This class consists of units mainly engaged in valuing, purchasing, selling (by auction or private treaty), managing or renting real estate for others. Primary activities include:

- Broking service (real estate);

- Real estate agency service;

- Real estate auctioning service;

- Real estate management service;

- Real estate rental agency service;

- Time share apartment management service;

- Valuing service (real estate).

The measurement of real estate agency services requires a different approach to that used for other services within this class. The commission rate is estimated and then 
applied to an estimate of the value for a sample of houses, which is calculated using a regression model. The model is developed each quarter and uses real estate data on the sale price and location of property. By applying the commission rate to the value of property, a dollar amount representing the price charged for the service activity is calculated and used to measure price change for each capital city.

Respondents for the real estate agency service sample are selected by non-probability sampling, taking into account factors such as their location and the representativeness of the services they provide. Once selected, respondents undergo a telephone interview to confirm their willingness to participate in the survey. The sample of houses used to estimate property price change is randomly selected, by the House Price Index (HPI) team from property transactions which took place over a 12 month period. A similar approach is taken for the other real estate services in this class measured by the Australian Bureau of Statistics (ABS), with data obtained for the most representative services offered in every capital city in the current quarter.

Real estate agency services data is collected from respondents on a quarterly basis through a quarterly survey questionnaire (Survey of Producer Prices). These questionnaires are tailored specifically for real estate respondents. All real estate respondents have the option to provide 1 to 6 property sales per month, over a three month period. The different sections of the real estate questionnaire consists of the month, post code of the property, price of a particular property, fees for services excluding advertising and total amount charged for advertising costs. Data on other services provided by real estate agents, in respect of both retail and residential properties, is provided separately for both retail and commercial properties along with any changes in the value of these properties.

The prices collected for real estate agency services relate to the amount received by respondents for the provision of specified services exclusive of any advertising fees. These prices obtained from a sample of properties in the same location every quarter are then analysed using a regression model where estimates of the commission rates are obtained. These commission rates are then applied to the prices of this sample of properties to get the dollar figures for the current quarter. For other real estate services prices are collected for residential and commercial properties. Respondents provide information on any changes or reasons for price movements from the previous quarter.

\section{Finland}

In Finland, rents on residential space have been published since 1964. The statistics are produced as a combination of a register and a sample survey. Data is collected in a rather unique way; the data of the annual statistics on rents of residential space are compiled from the interview data collected in connection with the Labour Force Survey for the quarterly statistics on rents as well as from the data in the Social Insurance Institution's Housing Allowance Register. The pricing method combines stratification and hedonics. In regional regression models variables impacting price include area of dwelling and its square root, age of dwelling and its square root, type of building and number of rooms, as well as a dummy variable indicating the time the data relate to.

Apart from the annual statistics on rents of residential space, Statistics Finland also publishes quarterly statistics on rents. The main difference between the two sets of statistics is that in addition to interview data, the annual statistics utilize data from the Housing Allowance Register, which are not used in the quarterly statistics. 
Work began on the compilation of hedonic price indices for constant quality rents of shops and offices in 2005, although the time series goes back to 1996. The results of this work can be used to estimate the constant quality price change of leases. The data is provided by a private organisation. Variables impacting price include size, age after basic renovation, and location. The actual age of a shop or an office was found to be a poor indicator of the quality of the space as older buildings are often renovated to meet modern demands (e.g. ICT capacity, lighting).

\section{Japan}

Japan compiles price indices on real estate services including Office Space Rental, Sales Space Rental, Hotel Rental, and Parking Space Rental. Japan mainly uses the unit value method. Average monthly rents per square meter for specified real estates are used for the unit value method. For Office Space Rental, a new quality adjustment technique that allows for correction of time-dependent service deterioration due to aging of equipment is applied. Samples are stratified into four categories, namely Tokyo, Nagoya, Osaka, and Other Areas to account for geographical heterogeneity.

\section{United States}

In the U.S., information on the lessors of non-residential buildings industry is collected from property management business enterprises. These business enterprises serve as proxy reporters for the building owners. This strategy was enacted because many of the private investors, insurance companies, pension funds, and other investment pools that own non-residential buildings are often unable to provide regular updates on the detailed rents for their owned properties. The property managers are responsible for compiling and maintaining this information. Industry samples are drawn from a universe of all leased non-residential properties clustered by property management firms, with units selected based on their total leasable area managed. The measure of leasable area is adjusted based on aggregate turnover statistics from the U.S. Census Bureau to give a greater chance of selection to those properties that typically generate larger amounts of turnover per occupied area.

Unit value prices are collected. These prices are calculated by dividing the total rents received for all leased areas with similar characteristics within a property by a measure of the physical size of these occupied areas. Vacant areas are excluded from the price calculations. Total rents include base rents plus all billed operating expenses and common area maintenance charges. It is preferable that rents are provided on an accrual basis reflecting when services are rendered rather than when payments are actually collected. This can avoid data volatility associated with delinquent tenants, tenants on distinct payment schedules, and periodic operating expense charges. Reporting of unit values is often delayed since final calculated data are not available until the month following the reporting period. When it is not possible to collect unit values, a contract price for a single leased area is collected.

For real estate brokerage services, model prices are collected. In the initial data collection period, a specific property transaction is selected. In subsequent periods, respondents are asked to estimate the amount they would receive if they were to assist with the purchase or sale of the property specified in the original transaction. Since prices are typically set as a percentage of the value of the transacted property, respondents must estimate both the current market value of the real estate and the percentage commission fee they would charge. Many respondents had difficulty in providing updated estimates, particularly for the property market values. To assist respondents with this effort, the U.S. 
introduced a procedure to update the market value of each property based on statistics published by private real estate data providers. These estimates are then presented to the respondents on the survey forms and they are asked to either confirm the estimates or update them based on their knowledge of local market conditions. This procedure has led both to an increased survey response and an increase in the number of respondents that actively engage in updating property values.

\section{Bibliography}

Eurostat, (2000), Report of the task force price and volume measures for real estate, renting and business services, meeting of the Working Party on National Accounts, Luxembourg.

Nieminen, S., and Murpphy, J. (2009), Revised Revisited Sector Paper on: ISIC 6810 Real estate activities with owned or leased property and ISIC 6820 Real estate activities on a fee or contract basis, Voorburg Group meeting, Oslo, Norway available at:

http://www.voorburggroup.org/Documents/2009\%200slo/Papers/2009\%20-

\%2068.pdf

Palmer, N., and Jones, K., (2001), Price Indices for Real Estate Services, Draft Principal Paper, Office for National Statistics, Voorburg Group meeting, Örebro, Sweden available at

http://www.voorburggroup.org/Documents/2001\%20orebro/papers/2001-026.pdf

Suoperä, A., (2009), Some new perspectives on price aggregation and hedonistic index methods: Empirical application to rents of office and shop premises, Statistics Finland, Prices and Wages, available at:

http://tilastokeskus.fi/org/tut/dthemes/papers/survey_on the rents_of_office-

business premises.pdf

\section{Notes}

1. Namely, subclasses 85522 -Time-share exchange services and 63113 - Room or unit accommodation services for visitors, in time-share properties. 



\section{Chapter 11. Professional, scientific and technical activities}

This chapter presents practical guidance as well as main issues and challenges for compiling SPPIs for Legal activities (ISIC 68), Accounting, bookkeeping and auditing activities; tax consultancy (ISIC 6920), Management consultancy (ISIC 7020), Architectural activities and engineering services and related technical consulting services (ISIC 7110), Technical testing and analysis (ISIC 7120), Advertising (ISIC 7310) and Market research and public opinion polling (ISIC 7320). 


\subsection{Legal activities (Christopher Jenkins, Office for National Statistics, United Kingdom \& Maria Schuch, Statistics Austria)}

\subsubsection{Industry description (ISIC 6910)}

The actors of the legal services industry can be differentiated between lawyers, barristers and solicitors, notaries and patent attorneys. Lawyers, barristers and solicitors deal with advising clients in legal matters as well as disputes (consulting in non-forensic affairs, mediation) and represent them in courts of law and other legal agencies. Most lawyers specialise in legal activity fields such as civil, commercial, criminal, family, fiscal, insurance, labour, renting, social, traffic law etc. Notaries are responsible for stating legal situations in the field of family, company and real estate rights such as real estate contracts, partner inscription in company registers etc. Patent attorneys accompany their clients from the invention, over the declaration of a patent for the innovative product or services, the protection of the product or services from competitors' patents until the prolongation of a patent. The three groups differ in their training and professional qualifications: from notaries with the most wide-ranging education of law to patent attorneys with a more technological and science background.

National legal systems can usually be categorised into one of two legal systems; the continental European legal system and the Anglo-Saxon legal system. ${ }^{1}$ The differences between the systems are considerable and give rise to further differences in the way in which the markets for legal services function. Legal practice in the continental European legal system follows laws and acts where-as in Anglo-Saxon legal system it is based on precedent cases. Consequently the legal services systems in countries following the continental European model are more tightly regulated than in those which follow the Anglo-Saxon system. In the continental European system legal services' fees are set on the basis of scales of fees, where-as in Anglo-Saxon system fees are usually agreed after free price negotiations and sometimes on a success basis. However, legal services in all countries are overseen by regulatory bodies (such as law societies or bar associations) which coordinate the functioning of the legal market. In smaller countries regulations concerning the legal market are uniform throughout the whole country while in larger countries they may have been established separately at the regional level.

A generalised business model of the legal industry identified that a common feature of legal industries in different countries is that a small number of large firms tend to provide a range of services to corporate clients and a much larger number of small firms service the household and small business clients. ${ }^{2}$

\subsubsection{Classification aspects}

\subsubsection{Industry classification}

In the ISIC classification the activities of legal service providers are classified under class 6910 - Legal activities, which include activities such as the legal representation of one party's interest against another party, general counselling and advising, preparation of legal documents and other activities of notaries, bailiffs, arbitrators, examiners and referees. NACE aligns perfectly with ISIC. In NAICS, legal service activities are classified under class 5411 - Legal services whilst ANZSIC classifies legal services under class 6931. The NAICS classification disaggregates legal services into the activities of offices of lawyers, offices of notaries and other legal services (comprising title abstract 
and settlement offices and all other legal services). The ANZSIC classification consists of similarly defined services as for ISIC and NACE.

The aforementioned classifications differ in that law court activities are specifically excluded from the ISIC and NACE classifications (they are instead classified under class 8423), whereas no specific exclusion of this class is mentioned in either NAICS or ANZSIC.

\subsubsection{Product classification}

The CPC identifies a similar level of detail for group 82.1 - Legal services as provided by the counterpart industry classifications. It classifies the following products for legal services: legal advisory and representation services concerning criminal law, other fields of law, legal documentation and certification services and other legal services (split into arbitration and conciliation services and other legal services n.e.c.).

The CPA provides a similar level of detail to the CPC although it provides a fuller breakdown of services in the legal advisory and representation class. The CPA also specifically includes products for notarial services and auction legal services.

The NAPCS has a much more detailed classification compared to either CPC or CPA. The NAPCS group 5411 - Legal services identifies five detailed sub groups for criminal/civil law, arbitration \& conciliation services, patent services, legal support and other related services under which approximately 50 detailed products are defined.

\subsubsection{Scope of the survey}

Ideally a SPPI for legal services should cover all domestic production and be disaggregated by destination of output. However in practice, the compiler will need to balance the conceptual requirements of the 'ideal survey' against the associated implications for resources and respondent burden.

The compiler may need to utilise a pricing method that will not provide the most conceptually appropriate measure of price change. For example, 'charge-out' rates used in the legal industry (normally readily available from respondents) could be used to calculate a meaningful price index even though it may not be as accurate as a price index compiled using the direct use of prices of repeated services (more difficult to collect from respondents). Similarly, is may not be feasible to collect sufficiently detailed data to all for a distinction of services (and their prices) by end user and so the compiler may choose to calculate a single price index for the all service users. When developing a SPPI for the industry the compiler should consider, with the assistance of industry representative organisations or respondents, how adequately they could measure the 'ideal survey' before deciding on any concessions that may need to be made.

\subsubsection{Industry vs. product based SPPI}

As detailed elsewhere in this manual, there are potentially three options for the compilation basis of SPPIs. These are industry based, product based and approximate product based. Conceptually a product based SPPI is preferable if its primary purpose if deflation of the national accounts. However, this requires that a suitable product detail sampling frame is available that provides details on the products respondents produce. In reality an industry based SPPI will perhaps be easiest to define and produce. For industry based SPPIs firstly each establishment is classified to a 4-digit ISIC (or equivalent) heading based on its principal activity. A sample of establishments is then drawn from 
within each heading (in this case ISIC 6910) and a selection of representative transactions is priced from each sampled unit. All of the output of these sampled units is represented in theory (even secondary activity output classified under other industries in the international classification systems) and aggregated to form these 4-digit industry level indices. On this basis, legal services provided as secondary activity in other industries may be missed. However, the legal industry is usually highly regulated, which can mean that the amount of secondary legal activity in other industries is small. In such cases an industry based SPPI may be adequate.

\subsubsection{Sample design}

In order to gain insight into the structure of the legal services industry it is recommended to contact the represent organisations for lawyers, notaries and patent attorneys. Information on the structure of the industry could help the compiler to better understand how a representative sample should be designed.

A random stratified sampling approach using turnover as the size variable is considered to be the most adequate method. The sample could include with certainty the larger service providers that generally account for a significant share of industry revenue and are often price drivers within the market.

In the U.K., the sample for the legal services SPPI is selected by stratified random sampling. Units are stratified five "employment by size" classes; 0-9 employed, 10-49 employed, 50-99 employed, 100-299 employed and 300+ employed. Those units in the largest employment "employment by size" class are selected with certainty (i.e. all are selected) whilst the sample sizes for each of the other classes are distinguished according to their relative size (based on the total turnover of all units in the class).

\subsubsection{Collection of information and specification of the service}

The appropriate timing and frequency of data collection will depend on a number of factors. These will include the choice of pricing methodology to be employed and the relative availability of the data which respondents will be required to supply. For example, information on hourly charge-out rates can be collected on a regular basis via a short questionnaire whereas other methods such as model pricing require more resources from both the respondent and compiler.

In the U.K., a detailed research phase is carried out in the early stages of SPPI development to identify the most suitable pricing method and to develop a data collection instrument that will facilitate timely response. For legal services, this involved face-toface visits with a sample of respondents from within the industry to assess what data would be available and the extent to which these data would meet the needs of a price index. Following this process a questionnaire is developed to collect the first set of data needed for index compilation.

It is essential that detailed information, which will be used to facilitate pricing to constant quality in future periods, is collected during the respondent initialisation process. In the U.K. SPPI, an initial base period service product specification that attempts to fix the price determining characteristics of the service being offered is collected. This includes for example:

- The area of legal services to which the service refers (such as notarial services, patents etc.); 
- The grades and experience of staff delivering service;

- Further (and fuller) details relating to the specific service being covered (for example, customer type).

Once the service product specification has been agreed, it is sent to the respondent in each survey period (in the U.K. a quarterly frequency is used) for pricing. Any significant change to the price or specification of a service product is queried to identify the reason for change. Where a change in price has been caused by a change in service specification, the appropriate quality adjustment is carried out to ensure the service remains representative and at a constant quality.

\subsubsection{Main pricing methods}

It has been recognised by McKenzie (2001) and Matulska-Bachura \& Jones (2010) that most forms of pricing mechanisms within the legal industry are based on the cost of time spent in service provision, and can vary depending on the mix of staff and experience of staff that are involved in the service delivery. However, the legal system and degree of regulation in a country will determine which billing methods are most commonly used. In countries following the Anglo-Saxon system, fees are often determined by negotiation and or on a success basis. In countries following the continental European system, scales of fees still play an important role in price setting. However, some deregulation of price setting can be observed, in particular very specialised lawyers and those legal establishments with sufficient market power may choose to set their prices in free contract negotiations. Before assessing the relative merits of the main pricing methods used in the construction of a SPPI for legal services, it is worth revisiting the pricing mechanisms considered.

1. Freely contracted fees: these are charge-out rates, ad valorem or flat rates.

- Charge-out rates (hourly rates)

The client pays an amount that equals the multiplication of a person day - usually eight hours - with the hourly rate. The rate itself can be negotiated between lawyer and client. The hourly rate may be independent of the field of legal activity. Lawyers may expect a certain compensation for their work irrelevant of what tasks they have to fulfil for their clients.

Many mid and large sized establishments use a list of hourly rates for different staff levels and functions (legal or support). Smaller establishments may charge a single hourly rate.

\section{- Ad valorem prices}

In many countries, especially those following the Anglo-Saxon legal system, ad valorem pricing can be observed. Fees are set either as a proportion of the value of a claim or with reference to the value of claim (value of claim size class). Therefore the client does not negotiate the amount of the value of claim but rather the proportion or factor that relates to it.

- Flat rates

Flat rates that integrate all modules for a complete case are also charged - here time and the single service expenditures are not exactly calculated. Flat rates occur more often in the Anglo-Saxon countries than in the others. 


\section{- Success-correlated fees}

In those following the Anglo-Saxon legal system, free price negotiations are common. Fees based on success are also permitted, but these are not allowed in other countries.

2. Scales of fee: scales of fees that exist in Central European countries have their origin in the legislative and regulate the market prices.

- Fixed fees

The scale of fees lists fixed fees relating to precisely defined legal services. They apply to standard and routine matters that do not require a detailed and elaborate occupation with the case and client (e.g. signature authentication).

- Ad valorem prices

Ad valorem prices represent the most important type of fee derived from the scales of fee. The size of fee increases stepwise. It does not rise proportionally with growing values of a claim. The proportion of the fee corresponding to the value of a claim decreases as the value of a claim rises.

In most cases legal advisers either set charge-out rates after free price negotiations or charge ad valorem prices according to the scales of fee.

Having considered the main pricing mechanisms in the legal industry, the 2010 Voorburg Group legal services sector paper identified a number of different pricing methods that have been adopted by compilers of SPPIs for the legal industry. ${ }^{3}$ The relative merits and disadvantages of each method are considered in the following section.

\subsubsection{Hourly charge-out rates}

As law firms and legal advisers usually do not publish prices of their hourly rates or services these rates have to be surveyed via direct inquiry. It is important to ensure that rates are obtained for all categories of staff billed for by the firm (e.g. partners, associates, juniors etc.). It is also important to establish whether or not support staff is specifically billed for, and to collect their charge-out rates if they are. Price relatives for each category of staff should then be weighted together based on the proportions of turnover generated by each staff category. These proportions of turnover must also be collected from the respondent. ${ }^{4}$ They should be split by the different types of legal services the respondent establishment performs in accordance with the elementary aggregate structure of services products used in the compilation of the SPPI.

It is essential to verify whether the reported charge-out rates reflect actual (or approximate) transaction prices prevailing in the market within the survey period or are simply list or reference prices. List prices tend to be reviewed less frequently (e.g. annually) and generally do not represent real market prices. The charge-out-rate approach offers the advantage of allowing for relatively short and easily understood questionnaires. However, from a methodological perspective hourly rates are considered a less than optimal approach as they do not account for the quality or success of the service provided. Therefore, the output of the service provided is not defined precisely as is generally required in the measurement of price statistics. A further issue with the use of charge-out rates for legal services SPPI is the potential to misstate price change due to productivity increases. For example, typically as a legal representative becomes more experienced, his productivity improves. Effectively this will mean he can produce more services in an hour - or an improvement in the quality of the service he provides. If this is 
not captured and adjusted for then the use of charge-out rates has the potential to misstate price change. It is acknowledged that both capturing and adjusting for productivity change can be difficult, and this is discussed further under section on quality issue.

\subsubsection{Percentage fee method}

Legal service providers may also employ a pricing mechanism based on a scale-ofcharge system. In response, the compiler may calculate the price for a specific model case using the scale-of-charge. A model case may specify criteria such as activity field, nature of client action, case participants, value of claim, date etc. When the percentage fee method is applied, price development tends to be driven by changes to the scale of charge and in the values of claims. The legal scales of charge as they exist in countries following the Central European system are based in legislation designed to regulate market prices. They contain two types of pricing mechanisms:

Fees may be fixed, in which case they can be centrally collected. The compiler simply has to identify when the scales of charge are updated and record the resulting price developments.

More commonly, fees are based on ad valorem prices. Measurement of change in ad valorem prices is more difficult and price observations should be carefully analysed before they are included in index compilation. Changes in ad valorem prices most frequently depend on changes in the values of claims. The other main contributor to price development, changes in the legal scales of fees, seldom occurs.

In practice, it is often difficult to define representative claim values as legal cases differ from client to client and over time. Estimates of price change of legal services provided in various activity fields are often based on the use of adequate reference price indices. Such a price index may for example, be a residential property price index. Before selecting representative cases, a classification of legal service activities should be established. Price relatives for each category of legal service activity should be weighted together based on their respective shares of turnover. These turnover shares must also be collected from the respondent. ${ }^{5}$ In the case of patent attorneys is can be difficult to develop a weighting pattern for various activity fields. The patent attorney usually represents the client throughout the product life-time and it may not be possible to distinguish between the different patent phases making the different activity fields difficult to identify.

\subsubsection{Model pricing}

In this method the respondent is asked to define the activities involved in a representative legal service they perform (e.g. obtaining an injunction) and to re-price this service in each subsequent reporting period (even though the exact same service may never be repeated). Unlike the percentage fee method, no fee scale is available for use in price estimation, rather the price is assumed to be based on negotiation between lawyer and client. The benefit of this method is that it can be implemented where there are difficulties in identifying representative or repeated services. Effectively the compiler asks the respondent to provide a hypothetical price quotation in each period and it is therefore essential that the respondent provide a detailed service specification. When estimating the updated 'model' price in each subsequent period the respondent should consider factors such as labour costs, overheads and profit margins. With this in mind, the compiler may need to periodically review each model price to ensure that the specification remains representative. The model price method may result in the under- 
reporting of price change if the respondent seeks to minimise burden by reporting no price change. This in turn may lead to an increase in burden as the compiler seeks to clarify and quality assure non-movement of prices. However, a clear advantage to employing this pricing method over the use of hourly charge-out rates, in the compilation of SPPIs for legal services, is that the respondent should take account of labour productivity in the reporting of prices in each period.

\subsubsection{Quality issues}

Generally speaking, quality changes in the legal industry are difficult to identify. Technological progress in the information and communication sector (e.g. IT hardware or customised administration software) impacts on the work of lawyers and notaries, but not to such an extent that it would lead to a new input/output relationship. On the contrary, legislation is of a very complex nature. On-going changes to complex legal systems may well cancel out any efficiency gains from technological progress or quality changes in legal works. Both capturing and measuring these changes in quality represents an ongoing challenge.

Productivity change gives rise to a quality concern in respect of the collection and measurement of charge-out rates. However, it is very difficult to identify and make appropriate adjustments for change in productivity. In the U.K., respondents are asked each period if there have been any productivity changes during the period under survey. If the respondent confirms that productivity has improved (or declined) they will be contacted by telephone to discuss the potential change in quality and the adjustment that may be required. However, it is acknowledged that this could be a difficult assessment for the respondent to make.

When collecting model prices, the main quality concern relates to their representativeness. Extra care must be taken by the compiler to ensure that the respondent is taking the necessary steps to accurately re-price the model specification each period. In the U.K., a quality assurance process is used (across a number of industrial SPPIs) which monitors 'too stable' prices. Where a price change has remained static for a number of periods, the respondent is contacted to check that the service specification is still representative and that the price remains correct. This is especially important to carry out when model pricing is used so as to ensure the respondent does not simply return the same price for each period.

\subsubsection{Weighting and aggregation}

In general the methodology used to weight and aggregate the SPPI will depend on the availability of reliable source data with which the compiler can reasonably create a weighting structure (such as turnover data).

In the U.K., two sources of weights are used to aggregate the SPPI. Firstly, at the elementary aggregate level, a dedicated turnover survey of all respondents providing price data to the SPPI is carried out to collect the corresponding turnover generated for these services in the base period. As the U.K. SPPI is a base weighted Laspeyres price index, this source of turnover is collected every five years (with the latest survey collecting data in respect of 2010). This source of turnover is used to calculate elementary aggregate weights, which in turn are then used to weight together the elementary aggregate price relatives to produce higher-level indices, up to and including the industry level aggregate. At the industry level, the U.K. uses national accounts data to derive industry level weights (input/output tables). These weights are then used to aggregate the 
industry level price movements together to calculate a 'service sector' SPPI, although it should be noted that this aggregate is only representative of the industries which are currently collected by the U.K. This aggregate SPPI is produced on both a gross and a net basis through adjustment of the industry. Each industry will be allocated a net industry weight (the net weight for any industry relates only to transactions between that sector and other industries, sales and purchases within industry are excluded) and a gross weight (covering all transactions).

\subsubsection{Specific aspects}

When developing a price index for the legal services industry, exports are generally not relevant as the legal system is country specific. For international cases the lawyer collaborates with corresponding partner law companies.

Legal cases often last several survey periods, sometimes taking more than a year. In this situation due attention should be paid that the accrual principle is followed, as closely as possible, in the index compilation.

\subsubsection{Overview of national methods}

Austria

Austria started work on the construction of an SPPI for legal activities in 2002. Since 2006 an SPPI is published for legal representation using the scale of legal fees, and in 2010 coverage was expanded to include provision of legal advice which is surveyed through charge-out rates per qualification category. Notaries and patent attorneys are not surveyed.

\section{Finland}

In Finland, hourly charge-out rates for legal services are surveyed since 2002.

\section{France}

In France, data collection started in 2006. The index for lawyers consists of the following components: global turnover divided by number of hours $(3 \%)$, turnover by sector divided by number of hours $(4 \%)$, price of real services $(15 \%)$, services for identified customers (4\%), charge-out rates by sector $(16 \%)$, charge out rates by qualifications $(52 \%)$, and global charge out rates $(6 \%)$. A new index for notaries is under development. The new index will be a BtoAll index based on different components of turnover, such as successions, advises, registrations of acts when buying houses, etc. As most of the turnover of notaries is earned with reference to the scale of fees, different indices (such as the CPI) will be used in the calculation of this SPPI.

\section{Germany}

In Germany, data collection started in 2004. Lawyers generate the majority of turnover classified in NACE 69.1. Both lawyers and patent attorneys have the right to practice once they are approved by their local chamber. There are many very small establishments with few employees and therefore the market is not heavily concentrated. Lawyers can either charge according to the scale of legal fees or negotiate their charges with clients. Small establishments often bill in accordance with the scale of legal fees, whereas larger establishments tend to negotiate fees for their services. The percentage fee method is used in the measurement of regulated fees. The case studies used for the method have been defined in cooperation with the relevant legal chamber. Hourly charge- 
out rates are collected for negotiated fees. A weighting scheme structured by billing method and field of law is used to aggregate the different results according to the CPA classification. The share of the different fields of law could be derived from the "Turnover by product type and residence of client survey" which supplements the "Survey on structural statistics for business". The shares of regulated and negotiated fees in every field of law have to be determined by additional surveys conducted every five years.

A local accreditation is required in order to open a notary practice and the number of local accreditations is restricted. Notaries must use the official scale of fees for notaries and therefore the percentage fee method is employed. The representative cases specified for notaries were defined in cooperation with the relevant chamber.

\section{Ireland}

In Ireland, data collection started in 2005. Respondents can choose to be surveyed with reference to hourly billing rates, model pricing or contract pricing. However, some respondents have difficulty in maintaining constant quality of services provided within the model and contract pricing approaches. Consequently the design of the survey is under currently review.

\section{Japan}

Japan compiles price indices on legal activities including Attorney Services, Patent Attorney Services and Judicial Scrivener Services. The direct use of prices of repeated services and the unit value methods are employed. The quality of services can differ depending on the experience and other individual characteristics of attorneys. In order to partially control for quality differences, both types of services and the seniority of attorneys are specified for the purposes of price collection. The index for legal activity services has been published since 1985 .

\section{Netherlands}

In the Netherlands, data collection started in 2003. Lawyers are surveyed on the basis of hourly rates as they charge on an hourly basis. For notarial services model pricing was initially employed for all establishments. However, only the smaller establishments charge per service delivered. The larger establishments charge according to hourly rates. Therefore, since 2006, the smaller establishments receive a questionnaire based on model pricing (price per standard service delivered) while the larger establishments receive a questionnaire based on realised hourly rates.

\section{Poland}

Prices of legal services have been surveyed in Poland since 2010. Data collection is conducted quarterly by electronic questionnaire. The survey is based on a purposively selected sample based on expert judgment. About 21 enterprises are included in the sample and they provide a total of approximately 150 price quotations per quarter. The use of hourly charge-out rates is the main method employed. Some respondents provide also prices of repeated services or average prices for a few comparable services. The first publication of the index for legal services in Poland was planned for 2013.

\section{Slovenia}

In Slovenia, data collection started in 2006. Prices are collected directly from the attorney tariff list published on the website of the Bar Association of Slovenia, and from the notary tariff list published on the website of the Slovenian Notary Chamber. 


\section{Sweden}

In Sweden, price collection has been carried out since the first quarter of 2003. Price information is based the average invoiced hourly rate for the following categories of staff; part owner, associate with 0-2 years, 3-5 years and 6 years and more professional experience. The SPPI is based on a rotating sample with $20 \%$ of the firms replaced per annum.

\section{United States}

The United States began publishing an industry based SPPI for Offices of Lawyers in December 1996 and a product based SPPI for Legal Services in March 2009. Data is collected monthly via fax, mail and online survey. The U.S. has had good experience employing a hybrid charge-out rate/model pricing method wherein the model is specified using professional identifiers (e.g. attorney 1, legal assistant 1, partner 1), the hours billed on a given project and the hourly charge-out rates for each individual professional specified. Respondents update the hourly charge-out rates and any other associated flat fees on a regular basis, while holding the number of hours billed fixed for each professional. For standardised legal services such as the writing of wills, the U.S. also employs the method of direct use for repeated prices.

\subsection{Accounting, bookkeeping and auditing activities; tax consultancy (André Loranger, Statistics Canada)}

\subsubsection{Industry description (ISIC 6920)}

Business enterprises classified to this industry generally produce the following types of services: preparation of financial statements, financial accounting and management accounting reports, the review and auditing of accounting records, the development of budgets, the design of accounting systems ${ }^{6}$, the provision of advice on matters related to accounting, bookkeeping, billing and payroll services, the recording of commercial transactions from businesses or others, the examination of accounts and the certification of their accuracy, the preparation of personal and business income tax returns, and advisory activities and representation on behalf of clients before tax authorities.

Large accounting firms concentrate more on tax advisory and auditing services while the smaller firms tend to focus more on accounting and bookkeeping services.

Prices for accounting services are determined primarily on the basis of the time required to complete the particular accounting engagement. For example, many accountants will combine, for each level of professional whose time is charged to the particular engagement, a time based rate (i.e. hourly/daily rate) with the amount of time billed (i.e. chargeable time) in order to arrive at the total price for a particular accounting engagement. Less influential price determining characteristics may include: the complexity of the work, the volume of the work for a particular client (lower hourly rates for large-volume clients), and the reputation of the firm (anecdotal evidence suggests that new firms' prices 'catch-up' to those of more experienced firms as they establish themselves in the market and adjust their human resources and utilisation). 


\subsubsection{Classification aspects}

\subsubsection{Industry classification}

In the ISIC classification, class 6920 includes activities such as the recording of commercial transactions from businesses or others, preparation or auditing of financial accounts, examination of accounts and certification of their accuracy, preparation of personal and business income tax returns, advisory activities and representation on behalf of clients before tax authorities.

Under the NAICS classification, industry 5412 comprises establishments primarily engaged in the preparation of financial statements, preparation of management accounting reports, the review and auditing and accounting records, the development of budgets, the design of accounting systems, the provision of advice and assistance on matters related to accounting, tax return preparation services, bookkeeping, and billing or payroll processing services.

Note that ISIC class 6920 excludes activities such as the designing of accounting systems, cost accounting programmes, and budgetary control procedures, which are considered to be management consulting activities. Conversely, NAICS 5412 includes activities relation to the design of accounting systems.

The NACE classification is derived from ISIC and used by European Member States. NACE class 69.20 - Accounting, bookkeeping and auditing activities; tax consultancy corresponds to ISIC 6920 and at this level of detail the NACE covers and defines virtually the same activities as the ISIC.

Also, the ANZSIC class 6932 - Accounting Services, consists of similar defined service activities as the ISIC and NACE. It includes units primarily engaged in providing services such as auditing of accounting records, preparing financial statements, preparing tax returns and bookkeeping.

The four industry classifications broadly cover and define the same activities within accounting services, with some notable differences. NAICS includes services such as payroll processing and billing, whereas ANZSIC classifies these services elsewhere. Also, ISIC and NACE exclude bill collection activities from accounting services. Furthermore, NAICS includes services such as designing of accounting systems, which both ISIC and NACE classify under management consulting activities.

\subsubsection{Product classification}

The CPC identifies the following accounting services: financial auditing, accounting, bookkeeping and payroll services, corporate tax consulting and preparation services, individual tax preparation and planning services, and insolvency and receivership services.

The CPA, the European version of $\mathrm{CPC}$, follows virtually the same breakdown and definitions for accounting services as the CPC.

The North American Product Classification System (NAPCS) includes three relevant groups: $i$ ) 541021 - Auditing and other assurance services; ii) 541022 - Tax preparation and representation services; and iii) 541023 - Bookkeeping, financial statement compilation, and payroll services. 


\subsubsection{Scope of the survey}

An ideal survey would cover the service production (i.e. output) of a sample of resident producers. It would also track the price of the industry's service output intended for sale to any and all types of clients, or end users. In practice, it might be difficult for a compiler to collect and publish data according to the range of end users as described above. First, the greater the level of detail at which indexes are published, the more data and respondent burden that is required of survey respondents. Second, because sampling frames typically do not exist that classify establishments according to the end users that they serve, the resulting indices might not be sufficiently reliable for publication.

Statistics Canada produces an output price index comprised of a sample of resident producers. The sampling frame used for this survey is comprised of all service producers that are classified to NAICS industry 5412 - Accounting, Tax Preparation, Bookkeeping and Payroll Services. The prices collected for inclusion in the index are valued at basic prices (i.e. they do not include any margins or other taxes collected for remittance to a government agency).

Statistics Canada makes no distinction between accounting services sold to business, household, and government clients, either in the data collection or in the index publication. ${ }^{7}$ Although exported accounting services are technically in-scope in an 'ideal' survey, we know from other Statistics Canada surveys that in 2009, exports constituted only $1.8 \%$ of total industry sales (Statistics Canada 2011). Note that the largest global accounting firms tend to have separate subsidiaries in each of the major countries in which they operate, which likely accounts for why exports are such a small proportion of total industry sales. In the U.S., for example, the 2007 Economic Census indicates that exports accounted for only $0.1 \%$ of total industry revenue.

\subsubsection{Industry vs. product based SPPI}

As the principal application of an SPPI is for deflation of the national accounts, the SPPI should ideally be product based rather than industry based. This is because inputoutput accounts are typically deflated along the product, and not the industry dimension. Despite the usefulness of product based SPPIs, they are rarely produced in practice due to the fact that compilers rarely have available sampling frames that group establishments according to the products they produce.

The reader should note that the potential for developing "approximate product based" SPPI as discussed at chapter 3. An alternative may be to produce industry based indices that cover only the primary output of the target industry. For example, an industry based index for the accounting industry would cover only accounting services, despite the fact that accounting firms also sometimes engage in consulting, finance \& insurance, and legal activities.

Statistics Canada's Accounting Services Price Index (ASPI) is an industry based survey that prices only the industry's primary output (i.e. accounting services). In particular, the index does not target the prices of secondary or ancillary activities of this industry. In using this approach, the compiler does not depend on the profiling of the sample units in order to identify secondary and/or ancillary activities before the questionnaire is mailed. Since all units in the sample offer accounting services, the same survey questionnaire can be mailed to all respondents (i.e. the survey questionnaire does not need to be customised according to the secondary activities offered by particular sample units). Note that the survey does collect and publish data according to the 
following types of accounting services: $i$ ) audit, review and related services; $i i)$ other assurance services; iii) bookkeeping, compilation and general accounting services; $i v$ ) tax preparation services for corporate clients; and $v$ ) tax preparation services for individuals and unincorporated businesses.

\subsubsection{Sample design}

The sample design that is implemented will depend on the type of index to required. Non-probability sampling and probability proportional to size (PPS) sampling design are common approaches. When using the PPS approach, a size related variable such as revenue is used to select the firms into the sample.

Statistics Canada uses a PPS sampling design to select the primary sample unit, the firm. Revenue is used as the size variable in the selection of firms. The current sample was drawn from a frame of all firms classified to NAICS 5412 - Accounting, Tax Preparation, Bookkeeping and Payroll Services.

As noted in the previous section, Statistics Canada publishes separate indices for five different product lines. For each product line offered by a particular firm, the survey asks that the respondent choose a representative engagement that he/she will re-price over time. The accounting firms that are selected in the sample choose and report prices for engagements that are representative of the type of service they offer and represent a substantial proportion of the firm's revenue. In order to be able to follow these engagements from year-to-year, firms are asked to report prices for engagements that are likely to be renewed in the years following the initial survey.

\subsubsection{Collection of information and specification of the service}

The timing and frequency of price collection will typically depend on the pricing method that is adopted. When either pricing based on working time or model pricing are used, the compiler will typically have more flexibility in terms of the timing and frequency of price collection. This is because these two pricing methods do not rely on transaction prices. When the direct use of prices of repeated services is used, on the other hand, the compiler will typically match the timing of price collection with the timing and pattern of the service transaction. Statistics Canada has found that a variety of accounting services (for example, tax preparation services) are transacted at annual intervals (i.e., during tax season). This, in addition to the fact that the agency has adopted the direct use of prices of repeated services, explains the annual collection frequency that it has adopted.

Statistics Canada has recently adopted an internet based reporting tool for this survey. An e-mail invitation is sent to the survey respondent, containing a link to the survey questionnaire. The e-mail invitation is typically sent out in July since the "tax season" has ended by this time. It is addressed to either the respondent's controller or managing partner. Once data is submitted through the on-line reporting tool, regular follow-up can address issues such as inconsistent or missing survey data.

Statistics Canada's survey questionnaire asks respondents to provide the price charged to a particular client (net of taxes) for a specific accounting engagement provided during both of two consecutive years (so that a year-over-year price comparison can be made). In order to adjust for any changes in the quality of the service between the two comparison years, the questionnaire asks the respondent to exclude from the year-overyear price change any value that is attributable to a change in the characteristics of the 
service offered between the two consecutive years. Because Statistics Canada collects prices once annually, it is possible to directly use the prices of repeated services in the index. Many accounting services, such as auditing and tax preparation services, are provided to clients by the same firm at the same time each year (i.e. during tax season), and therefore it is generally not difficult for firms to identify services that will be billed each year. On the other hand, this method could not be used if the compiler wishes to collect and/or publish data at a frequency greater than once per year. Statistics Canada's survey is mandatory.

First time respondents to the survey will be contacted by telephone prior to receiving the e-mail invitation as part of the respondent initialisation process. Statistics Canada will confirm with the respondent that the firm does in fact provide accounting services and the most appropriate person within the firm to receive and complete the questionnaire will be identified (i.e., somebody within the firm that has access to invoicing or that is familiar with pricing policy and/or contract pricing).

The respondent is asked to select a number of representative accounting engagements that have been invoiced in the past and that are expected to be repeated in the future for the same client. The respondent will provide the invoiced price for this engagement each year, while also providing an estimate of the value of any change in quality from year-toyear. The respondent will typically make this quality adjustment based on the number of hours worked on the engagement during the two comparison years. The survey form provided below shows how the respondent provides the prices and corresponding quality adjustment for a particular accounting engagement.

Figure 11.2.1. Example of Price Form (Statistics Canada - Accounting Services Price Index)

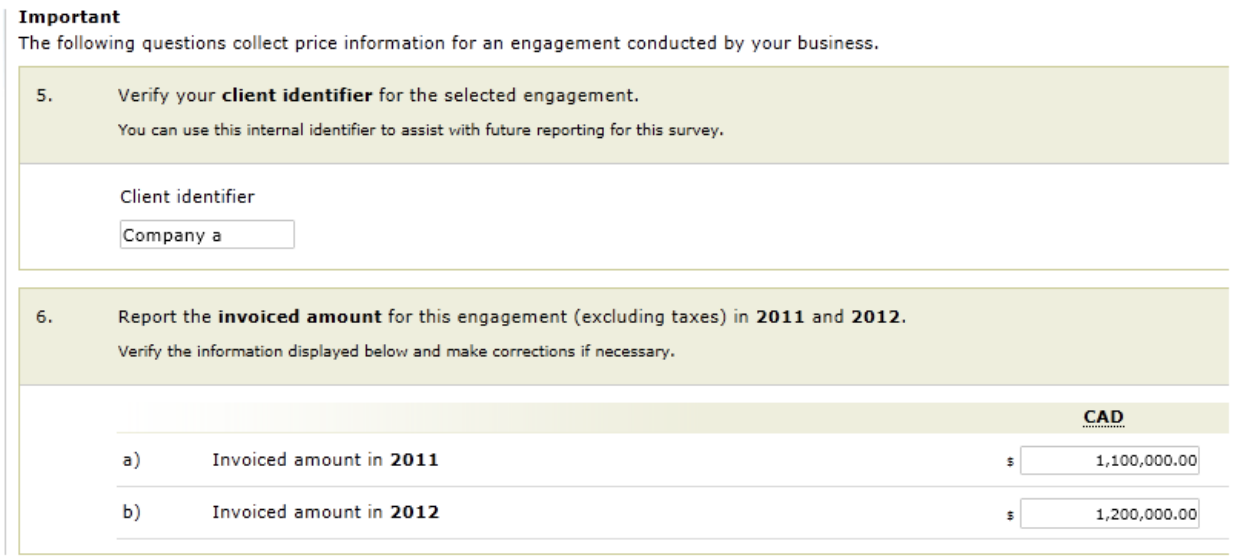


Figure 112.2.2. Example Quality Change Form (Statistics Canada - Accounting Services Price Index)

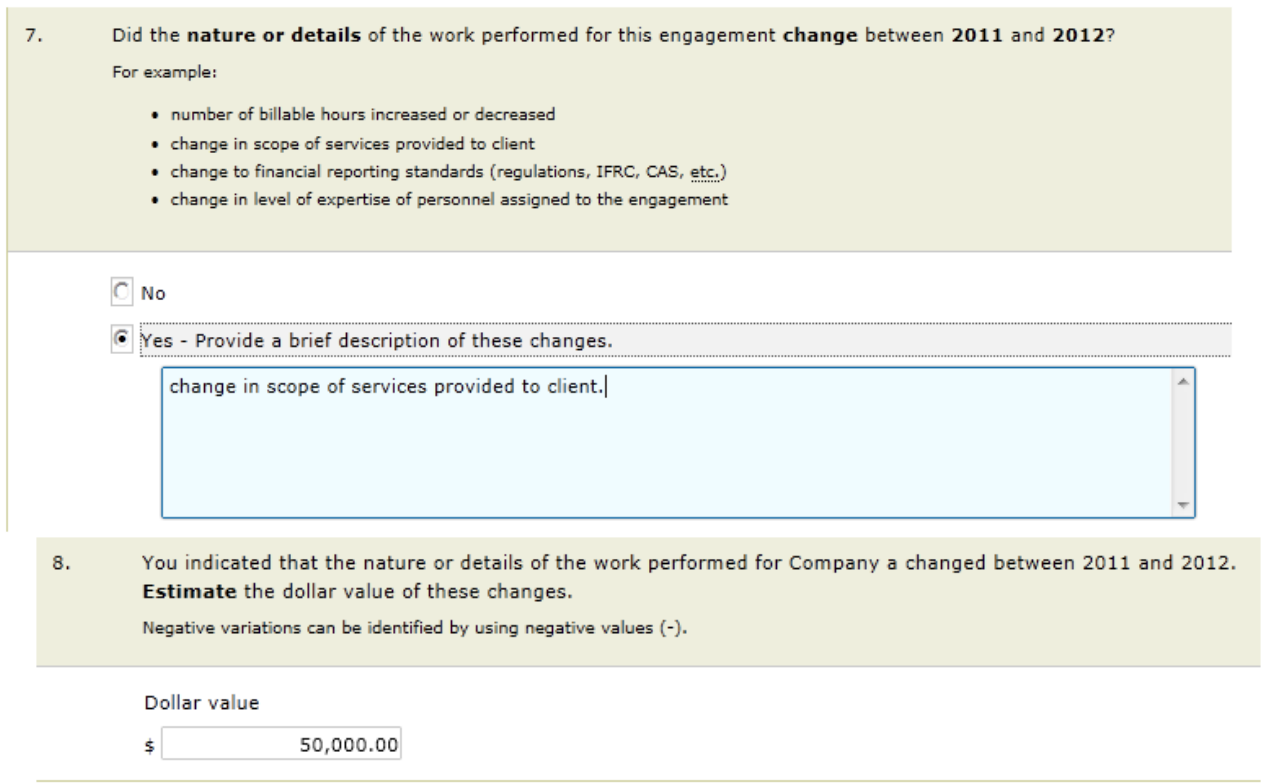

Follow-up calls are made to verify suspect data with respondents (for example, when larger-than-normal price changes are identified). Telephone interviewers also attempt to identify the reasons behind outlier price movements and confirm that pure price changes have not been mistaken for quality changes (i.e. change in service characteristics).

The following are other collection issues that have been encountered:

- Some firms do not offer accounting services that are repeated with the same client each year. An example is that of forensic accounting services, where the service is truly unique and not at all amenable to the type of contract pricing methodology adopted by Statistics Canada;

- A portion of the sample is typically made up of accounting subsidiaries of companies not classified to the accounting industry. Because the services performed by these subsidiaries are not explicitly charged for (i.e. they are not based on market prices), it is impossible to include these prices in the index;

- The follow-up telephone calls made to respondents in order to verify data are not made by price statisticians who are familiar with the often subtle difference between price- and quality-change: at Statistics Canada, personal visits with respondents are neither practical nor affordable. Additionally, collection activities are centralised with the collection arm of the Agency acting as the intermediary between the respondent and the price statisticians (Draper and Loranger, 2011).

\subsubsection{Main pricing methods}

The first edition of the SPPI Guide described two main pricing methods for this industry: model pricing and pricing based on working time (i.e., hourly charge-out rates). We add a third pricing method to this version of the Guide: direct use of prices of repeated services. Each of these pricing methods is considered in turn below. 


\subsubsection{Direct use of prices of repeated services}

Under this method, the respondent chooses during the first period of data collection a set of accounting engagements that are likely to recur on a regular basis with the same client. The respondent will then report the prices charged for the engagements for each pricing period that they are carried out. Schoultz and Zetterberg (2008) note that "the method of collecting [the] actual price of repeated services gives an accurate price index that is representative for the industry and is hence regarded as the best practice." Statistics Canada uses this pricing method for its Accounting Services Price Index by asking respondents to choose accounting engagements that are likely to be renewed with the same client each year. Of course, accounting engagements, even those performed for the same client, are unlikely to be identical from year to year. For example, an individual who has his/her tax return completed by the same accountant each year may have more or less complicated returns to complete each year. Shoultz and Zetterberg (2008) note that "even a long-lasting [firm-client relationship] with the same client is bound to change as the client's [revenue] grows or diminishes, the client changes its business structure or face new legal claims." The precise way in which quality adjustments can be made in this context will be discussed in the next section.

\subsubsection{Model pricing}

The model pricing method is employed when it is hard to find representative services that are frequently repeated. In using this method, the respondent will either construct a model service that accurately reflects its business, or select a broadly representative service that was transacted in a recent period. For each reporting period, the respondent is then asked to make an estimation of what the price would have been if the service had actually been provided. When making the estimation, it is important that the respondent takes labour costs, overhead and gross profit margin into account. As the labour costs are being recalculated each period, productivity is being considered, and from this perspective makes this method more appealing than a method that is based on working time only (to be considered below). However it should be noted that the model pricing method involves significant respondent burden and requires close contact between the respondent and compiler. It is also important to update the models so that they remain representative for the responding establishment.

\subsubsection{Pricing based on working time}

The pricing based on working time method is employed when it is hard to specify the service that is actually provided. Instead the time spent on providing the service is used as a proxy. The service is assumed to correspond directly to the chargeable time (i.e., hours, days, etc.) actually worked for the client. A problem with this method is that changes in service quality and productivity are not reflected in the measures. From a deflation perspective, if the price index measures the price of hourly rates, the resulting volume measure is the number of working hours and not the volume of the service itself. This makes it a less suitable method in industries where the technological development is fast. Within the accounting services industry there has been a rapid change in productivity during the last 10-15 years as computers and accounting software have developed. Furthermore, this productivity change is likely to continue. Hence, pricing based on working time cannot be considered best practice in this industry. When calculating price indices for accounting services, it is common to divide the staff into different categories of work experience and field of expertise. In this way, the quality is held constant to some, but the productivity change within each category is still not considered. 
The advantage of this method is that the price is easy to observe for the respondent and as a result the response burden is kept low. It is not uncommon that the required data already are available within the respondents' accounting systems. This method also allows for the capture of unique services in the price index.

\subsubsection{Quality issues}

The way in which quality adjustments are considered and carried out in practice will depend on the pricing method that is used. The pricing methods that were considered in the previous section are again considered here with regards to how quality adjustments may be made in each case.

\subsubsection{Direct use of prices of repeated services}

As mentioned above, it is unlikely in practice that an accounting firm will provide an identical service to a particular client each period. For example, even though an individual might use the same accountant to complete his/her tax returns each year, it is unlikely that the number of documents requiring processing and the complexity of the returns will be identical each year. In this case, the respondent should provide an estimate of the value of the difference in service between the two comparison periods. This value can then be subtracted from the total change in price as reported by the respondent. In practice, the respondent will estimate the value of any difference in service between the two comparison periods by comparing the amount of working time spent in each of the two periods. Because the value of the quality change is estimated directly by the respondent, the compiler is often unaware of the method used by the respondent to estimate it. The compiler should query the respondent in order to discuss and verify the reported data, especially in the presence of extreme outliers or inconsistent data. In order to ensure that the selected service transactions remain representative over time, the compiler should allow respondents to replace 'old' transactions with newer, more representative ones. A final quality aspect regarding this pricing method is that because the respondent may be limited to selecting contracts that will be repeated on an annual basis, certain types of unique services, such as forensic accounting or one-time audits services, are likely to be excluded from the price index.

Statistics Canada controls for changes in price due to changes in service characteristics by asking the respondent to indicate, for each service transaction, how much of the year-over-year price variation is due to a change in service and how much is attributable to pure price change. In other words, it is left to the respondent to indicate how much of the change in price is due to changes in the nature of the transaction and how much is due to pure price change. At this point, there is no alternative but to rely on respondents in making this estimation.

In the example given in Figures 1 and 2, the respondent identifies the transaction by the ID\#: Company a. The respondent indicates that the invoiced price of the transaction increases from $\$ 1.1$ million in 2011 to $\$ 1.2$ million in 2012. But, the respondent also indicates that the value of the service increased by $\$ 50,000$. Then, in this case, the yearover-year percentage change in the quality-adjusted price is given by: $(\$ 1,200,000$ $\$ 50,000) / \$ 1,100,000=1.045$.

\subsubsection{Model pricing}

One feature of this approach is that, because the quality of the service is held constant by definition, no explicit adjustment should be required. However, when model pricing is 
used, it is essential to ensure that the model service engagement remains representative and that the respondent realistically and accurately prices it. If prices remain flat for several periods, then the compiler should query the respondent. In addition, it is important that the respondent understands that in addition to the relevant prices, the amount of working time (i.e. billed time) required to complete the contract must also be updated. By not accounting for changes over time in the amount of working time required, this method will suffer from some of the same problems associated with the method of pricing based on working time (see below).

\subsubsection{Pricing based on working time}

As the price of the service output is not followed directly over time, it becomes difficult to make adjustments for quality when using this method.

\subsubsection{Weighting and aggregation}

Two sources of weights are used in the Canadian Accountancy Services Price Index: i) the total revenue of each sampled firm is derived from Statistics Canada's central frame database; and ii) a percentage breakdown of each firm's total revenue across the five accounting service lines is reported by the respondent on the survey questionnaire. Together, these data provide the amount of revenue attributable to each service line, for each firm.

- Elementary aggregates: As stated in Section 3, the survey collects prices for five different types of accounting services. In the event that a firm provides more than one price quote (i.e., contract) for a particular service line, these price relatives will be combined using a geometric mean index formula.

- Service-line indexes: All of the price relatives belonging to a particular service line are aggregated together (i.e., across firms) to form the service line indexes. For weighting purposes, the revenue associated with a particular service line and a particular firm is given by the product of two numbers: $i$ ) the firm's total revenue; and $\mathrm{ii}$ ) the proportion of the firm's total revenue attributable to the particular service line.

\subsubsection{Specific aspects}

Statistics Canada has found that a significant portion of the sampling frame for this industry is comprised of accounting and/or finance arms of firms that are otherwise not classified to the accounting industry. These accounting divisions provide accounting and financial services to their companies but do not charge explicit, market based prices for these services. This is an example of intra-company transfer pricing and it would be nearly impossible for a compiler to attempt to price these services. A solution to this problem would be to contact the respondent during an initialisation process to ensure that the selected company is able to provide prices for services that are appropriate for inclusion in the index.

\subsubsection{Overview of national methods}

\section{Germany}

In Germany, separate SPPIs for auditing and tax consultancy services (including bookkeeping and accountancy) have been calculated since 2004. For business enterprises primarily engaged in producing auditing services the standard pricing method is time 
based, utilising realised hourly rates differentiated by four different degrees of professional expertise and three activity fields (auditing, tax consultancy and management services). Price collection therefore takes place on a basis. Business enterprises that primarily engage in the production of tax consultancy services are typically small or medium sized. The percentage fee method, based on a legally set scale of fees, is used for these service activities. This scale of fees determines prices for almost $90 \%$ of revenue in the tax consultancy sector. A survey is not needed but the Federal Statistical Office calculates the prices for an elaborate set of model service transactions by desk research. The model service transactions are defined by criteria such as activity field and differences in the gross value used in the calculation of tax liability. Detailed data from tax statistics and additional information from a survey of tax consultancy firms serve as inputs to the development of the model service transactions. The percentage fee method considers two price components: i) the change in the percentage (i.e. the fee of the scale of charge); and ii) the change in the value to which the fee relates (i.e. the anticipated gross value over time). Different indices were chosen for each model case and included in the annual pricing.

\section{Hungary}

Hungary currently produces a product based index for this industry. Data are collected via a mandatory quarterly survey. The pricing method used in Hungary is selected in close cooperation with respondents, taking into account the pricing mechanisms, and accounting and controlling systems they use. In other words, the pricing method that applies to one respondent may be different to that applying to another. Because this industry is characterised by a range of unique services that are not comparable over time (e.g. auditing activities, tax consultancy), the pricing based on working time method is commonly employed for this industry. Alternatively, identical services that are repeatedly provided to the same client are handled using either the contract pricing method or the direct use of prices of repeated services. For other cases the unit value method is applied, but in this case the observed item should be as homogeneous as possible.

\section{Japan}

Japan compiles price indices for accounting services for both Certified Public Accounting services and Licensed Tax Accounting services. For the former, the unit value method is used to compute an average hourly rate for auditing services. For the latter, the direct use of prices of repeated services is used. Typically, expected total auditing fees are paid at the beginning of the contract and any difference is reconciled at the end of the contract. Therefore, the primary index is likely to be subject to revisions.

\section{Netherlands}

Statistics Netherlands uses realised hourly rates (i.e. unit value method) where respondents report their revenue with the associated hours, specific to each work function and level of experience. It has been found that this method results in a relatively low burden on respondents as many already compile this type of data. A disadvantage of this approach is that the hours and the revenue do not always correspond, due to projects that are running but not yet paid for.

\section{United Kingdom}

Accounting firms in the U.K. typically charge for services in a number of ways, but two main pricing methods are employed in response: 
- An indirect method using charge out rates for a particular service line. This method can be employed when the price for a particular accounting service transaction is a function of the amount of time billed and the hourly/daily rates for the different levels of professionals whose time was billed to the engagement;

- A direct method which captures a fixed fee for the service provided.

For the larger accountancy firms, the indirect method of price collection using realised charge out rates is used. For smaller accountancy firms the direct prices for regular and repeatable services offered are collected. The accountancy price index is then calculated based on the weighted movement in both the indirect and direct price data. Price data are collected for three distinct service activities:

- Audit and assurance;

- Accounting and bookkeeping;

- Tax consultancy.

For the indirect price collection, standard hourly charge out rates for specific grades of staff working on the particular service activities in the period are collected. Additional data relating to the hours billed by each grade and the total billed in the period are also collected to calculate the realisation adjustment.

Where respondents are unable to provide the data in sufficient detail, a concession is made and average hourly charge out rates per grade of staff for each service line is used.

\section{United States}

The United States employs model pricing as its primary pricing method. It is used instead of direct prices of repeated services because the same exact services are not typically provided to the same or similar clients in each monthly pricing period. Note that because repeated services are more likely to be observed with the same client on an annual basis (i.e. at tax season), Statistics Canada's annual survey is able to use the prices of repeated services in its index for this reason. Prior experience in the U.S. indicates that model pricing is more effective than direct prices of repeated services in holding service requirements constant. For example, the highly customised nature of accounting services makes it difficult to compare direct prices charged for different client engagements over time. For the largest firms in the industry only, the U.S. uses an approach that combines elements of model pricing and the unit value method. For these transactions a representative accounting contract is selected during the initial data collection period. The selected contract is used only to determine the relative contributions of the professionals whose time is billed in the contract. Respondents then provide the average billing rates for each professional level (e.g. senior accountant, partner, associate, etc.) specified in the contract. These average billing rates are calculated by dividing the total turnover earned by all individuals within a particular professional level by the total amount of hours these individuals billed. It is strongly preferred that distinct averages are provided for the major practice areas of tax, audit, and accounting advisory services. An advantage of incorporating the unit value method is that it is often easier for respondents to provide unit value data than contract-specific data. This approach is also consistent with record keeping practices at the large U.S. accounting firms, where average billing rate data is used as the primary metric for tracking price change. Unit value data represents many transactions across many individual firm locations and can be collected from a single point of contact, allowing for more efficient data collection. 


\subsection{Management consultancy (Denis Gac, INSEE)}

\subsubsection{Industry description (ISIC 7020)}

The principal output of management consulting firms is the provision of advice, guidance and assistance on management to businesses and other organisations. Consultancy services are frequently provided in respect of high level strategic and organisational planning, business financing, budgeting, marketing and production and logistics. Consultancy outputs are typically delivered in the form of written and verbal advice and recommendations and management consultants may assist in the implementation of their recommendations.

The industry is made up of two very different sub-industries: the production of management consulting services and the production of public relations services. In France, the weights of these two sub-branches are approximately $90 \%$ (management consulting services) and 10\% (public relations services), respectively. Public relations services are far less developed in France than in the U.S. or U.K., for example.

Management consulting services consist of a wide range of activities such as; business strategy studies and advice, financial consulting, auditing of marketing functions and proposal for improvement, auditing and proposals related to the organisation of the staff and studies to improve productivity.

Due to the increasing overlap between management consulting and Information Technology (IT), one of the main challenges for compilers is to distinguish between management consulting and IT consulting activities. This problem is especially pronounced in the case of large service producers, which often refer to management consulting in the broad sense, including IT consulting.

Public relations services provide support in improving the image or perception of a business, a group or a person; they are clearly differentiated from services linked to implementation such as advertising (Camus and Wallace, 2007).

\subsubsection{Classification aspects}

\subsubsection{Industry classification}

The industry includes business enterprises mainly involved in the production of a diverse range of business and management consultancy activities including; strategic consulting, financial management consulting, customer relations management consulting, human-resources management consulting and supply-chain management consulting.

Business management consultancy is classified in section $\mathrm{M}$ - Professional, scientific and technical activities, division 70 - Activities of head offices; management consultancy activities of the ISIC classification system.

A review of other main international classification systems by activity (NACE and NAICS) shows that they are more detailed than the ISIC classification. The NACE classification distinguishes between Public relations and communication activities and Business and other management consultancy activities, while the NAICS classification provides a much more detailed disaggregation namely; Administrative management and general management consulting services, human resources consulting services, marketing consulting services, process, physical distribution, and logistics consulting services, and public relations agencies. 
Under the ANZSIC, management consulting services and public relations services belong to the same class 6962 - Management advice and related consulting services.

\subsubsection{Product classification}

The corresponding products for ISIC 7020 - Business management and consulting activities, are classified in classes 8311 - Management consulting and management services, and 8312 - Public relations services and other business consulting services of the CPC. Management consulting and management services are further disaggregated according to the branches of consulting (financial, marketing, supply chain) and the functions of consulting (strategic, operations and business process). Public relations services and other business consulting services are disaggregated between public relations consulting and a residual subclass for other business consulting services.

The CPA classification follows a very similar structure to the CPC although it contains an additional class covering other project management services, except construction project management services. The NAPCS differs primarily in that it includes additional products allowing for the bundling of consultancy and implementation activities which are excluded from ISIC 7020. The NAPCS also provides more detail in respect of public relations service activities.

\subsubsection{Scope of the survey}

Ideally the survey should measure price changes for constant quality business management consultancy activities provided to all end users. Management consulting is an activity which by definition relates primarily to businesses, but governments and other organisations are also important buyers of these services. By definition these service activities are not provided to households.

IT consultancy service activities should be excluded although it may be difficult to clearly define the borderline between IT consultancy and management consultancy activities.

It may, at least in theory, be possible to calculate indices including intra-group turnover (from affiliate companies) but in practice indices are based only on extra-group turnover (at market prices)

\subsubsection{Industry vs. product based SPPI}

Industry based indices measure the transaction prices of activities produced by establishments classified to the industry. Product based indices measure the transaction prices of relevant service activities produced not only by establishments classified to the industry but also the transaction prices of relevant activities produced by establishments classified elsewhere as a complimentary or secondary activity.

The survey sample is usually industry based (due to the unavailability of a product level sample frame) and structured to reflect the operational practices of each part of the industry. On this basis, the price development of secondary activities relating to business management implementation services and/or IT consultancy services may be included in the index even though they are appropriately classified elsewhere. 


\subsubsection{Sample design}

This industry has traditionally comprised of many small and medium service producers. However, there are also a few very large multinational enterprises present in very many countries. In the 1970s there was talk of "big 8" and later a "big 6". Now there is a "big 4" comprising of Price Waterhouse Coopers (PwC), Deloitte, Ernst \& Young and KPMG. The most important service producers, where they are much larger in size than other producers, should always be included in the sample.

In France, about $53 \%$ of the turnover of this industry is generated by small units (less than 10 persons), although an opposite pattern is observed in Canada where a small number of large consulting firms generate the majority (75\%) of industry revenue.

Samples for service industries are usually drawn from business registers using probability proportional to size, cut-off or stratified sampling techniques. It may however be advisable in some cases (e.g. when business registers do not differentiate between establishments operating providing business management and IT consulting services) to combine business registers with data from other sources such industry representative associations.

If there is a requirement for compilation and dissemination of two separate indices for management consulting services and public relations services then it may be necessary to select two distinct samples, due to the variation in the typical size of establishments between the sub-industries (i.e. public relations companies tend to be smaller).

In France, the cut-off method is applied for public relations service activity producers, and a mix of cut-off and expert opinions (from the industry representative association) for business and other management consultancy activity producers. Both samples are focused on the larger business enterprises (more than 20 persons), as quotations from these respondents tend to be more stable and credible over the time.

\subsubsection{Collection of information and specification of the service}

Management consultancy services cover a large heterogeneous range of consulting activities. The services produced by this industry tend to be customised and unique to each client. It is important to distinguish between the different types of service activities produced, such as strategy, business financing and budgeting as they may be subject to different price determining characteristics and different levels of charge-out rates.

Respondent initialisation surveys should therefore be employed to identify the different types of service activities, their respective pricing mechanisms and representative transactions (including their respective weights based on relative contributions to total establishment turnover). Representative transactions are then priced on an on-going basis, usually quarterly. In France, the respondent initialisation surveys are conducted by field surveyors who specialise in service activities.

It should be noted that some service producers set prices according to the sector of the clients, in addition to, or rather than, the type of service provided to those clients.

\subsubsection{Main pricing methods}

\subsubsection{Pricing Mechanisms}

As noted in Chapter 2, SPPI compilers may have to use a number of different pricing methods to track price changes in service products, with the methods typically depending 
on the pricing mechanisms used. It is therefore appropriate to examine the various pricing mechanisms employed for the production of management consulting services.

- The fixed price is a classical pricing mechanism for labour based service activities and is commonly employed in this industry. In order to calculate the price of a service, the service producer uses a cost analysis for each category of staff employed in its delivery, e.g. it multiplies unit cost by the estimated time spent on the project. This gives the cost of the project to which a target profit margin is applied. The price initially proposed to the client will be negotiated, which roughly amounts to negotiating the service producer's profit margin. Some producers may charge a risk coefficient to take into account the uncertain nature of the "time-spent" estimates. Finally, a large number of producers use list-prices according to qualifications linked to experience in order to set their fixed prices.

- Invoicing on a time-spent basis is used in a minority of cases. This pricing mechanism may be employed, for example, when the management consultancy service producer provides staff at the client firm's premises. Clients are increasingly negotiating for fixed price invoicing rather than time-spent contracts. Fixed price invoicing provides greater security to the client than invoicing on time-spent basis, which can spiral.

- For major clients, the referencing system is used. The purchasing departments of major firms favour this system. It involves defining daily rates according to qualifications and a system of discounts for large volumes. When the service producer uses this system, the client can call on it for a given project. Prices charged are those defined in the referencing system. In practice, prices can however be renegotiated.

Statistics Canada found during questionnaire/focus-group testing for its Consulting Services Price Report survey that the "Referencing System" is used most often in consulting relationships with public-sector clients. It was also found that for service producer who use this system, price movements are likely to be very flat/stable over time (and are less likely to respond to market supply/demand conditions). This is because the rates that are agreed to in a particular "referencing system" are in effect for at least one year. Of course, this may vary from country to country.

- Although still marginal, the use of success fees (alternatively known as "outcome based fees" or "contingency-fees") as a pricing mechanism is growing, particularly when the client is in a manufacturing industry. Under this mechanism, part of the price is dependent on the success or outcome of the consultancy service provided. For example, a service producer may recommend actions to improve productivity. Part of the price may depend on the resulting productivity change. Statistics Canada found (2010) almost 30\% of large consulting service producers $(100+$ consultants), use outcome based fees at least sometimes, up from just $10 \%$ two years previously. Financial and operational consultants are the most likely to propose outcome based fees - business lines where setting targets and measuring performance can be more straightforward. However, consultants rarely, if ever, use this pricing mechanism for the majority of their business.

- For the provision of public relations services, annual contracts may be signed with regular clients. Invoices are issued on a fixed price basis with an estimate of the time spent over the course of the 12 months of the contract. Even for regular 
clients, it appears that services provided change from one year to another, making it difficult to monitor contracts over time. A special kind of pricing mechanism involves a starting price which is paid even if very little service activity is provided. Additional fees may be charged depending on the amount of service activity provided as measured on a time-spent basis.

\subsubsection{Pricing based on working time}

For the production of business management consultancy services, monitoring of average charge out rates according to the qualification levels of staff is both relevant and possible. Staff engaged in the production of these services generally complete time sheets of their billable hours and this practice can facilitate the use of a range of pricing methods based principally on time spent. The simplest example is the monitoring of average unit of time charges (e.g. hourly, daily) per qualification at an aggregate (e.g. respondent) level. In general, time sheets are not completed within the public relations consulting profession. In this industry prices are not set with reference to time worked (for example in the case of crisis reporting). This feature can also be observed in advertising agencies.

Even when time sheets are completed, the service producer may calculate average charge out rates according to qualifications on a contract-client basis only - rather than at a more aggregate level.). In these cases it is possible to monitor average charges according to qualifications by selecting specific client contracts. Average charge out rates according to qualifications could be monitored across a sample of representative client contracts.

Another approach is to approximate prices from the turnover per staff member, corrected for variations in activity rates. Ideally, turnover excluding subcontractors, number of productive staff on a full-time equivalent basis and the activity rate should all be considered. The activity rate is an indicator that is widely monitored within the profession. However, in view of its highly aggregated nature, this method is inferior to the previous two methods described. It does however attempt to reflect development of actual market prices, unlike list type rates. For this approach to be relevant, the mix of qualifications among staff in a respondent firm must remain stable over time. This approach may also be used in public relations consulting services, replacing turnover with the gross margin. In fact, this method may often be one of the few options for estimating the price development of public relations services. Methods which follow costs/charges per qualification cannot usually be applied for this industry as times sheets are rarely used.

Note that when applying time based methods for service contracts covering several survey periods, payments do not necessarily correspond to actual service production in each period. For example, with an annual contract, the client might pay a fixed amount every month (total for the annual contract divided by 12) even though less services may be produced during holiday periods. However, this situation does not suggest that prices are fluctuating, but that payments are made to a fixed schedule rather than following the accrual principle. Differences between the pattern of payments and actual service production should not be reflected in the SPPI.

\subsubsection{Model pricing}

Considering the unique nature of the services produced, the model pricing approach could, at least in theory, be recommended. As in other industries, care must be taken to ensure that prices reflect the prevailing market situation. Therefore one can, for example, 
ask the respondent for its average margin in the period which could be applied to the total cost for the "model service".

There are two classic pitfalls that must be avoided: monitoring of list prices (as discounting of list prices can be substantial, especially during recessionary periods) and monitoring charge out rates for all experience/qualification levels considered as a whole (as changes occurring within the structure of the work force will not be accounted for). It appears that monitoring charge out rates for all qualifications considered as a whole poses less of a problem than in the IT industry. According to management consulting service producers, it appears that the mix of staff by qualification tends to remain relatively stable over time, contrary to what is observed in the IT consulting industry in particular. Some large business enterprises even have a target qualification pyramid (which remains stable over time), which they endeavour to achieve through staff losses and recruitment.

\subsubsection{Quality issues}

Identification and adjustment for quality changes must be carefully considered. When charge-out rates are used to measure price development, it is very difficult to adjust for changes in the quality of the services produced. When a respondent reports a price increase due to labour cost, it is impossible to know what portion of that is due to providing a better service and what portion is due to market forces. As a result, the index likely shows more than pure price change (York, 2005).

Two problems remain in relation to the monitoring of average charge out rates according to qualifications. Firstly, changes in productivity within each qualification group are not taken into account. Secondly, average rates according to qualifications are calculated on the basis of time actually spent (from time sheets) and not from time estimates (as invoiced) in the context of the initial fixed charge which determined the price.

For some consultancy services in the area of cost reduction, fees may be paid on the basis of the reduction in costs (such as taxes, salaries and rent). In France, it was found to be too problematic to identify and price constant quality transactions and consequently these activities are not included in the SPPI.

\subsubsection{Weighting and aggregation}

Typically, two levels of weights are required for the aggregation of the SPPI: a weight for each sampled unit and a transaction level weight for each observed price. The weight for each sampled unit will generally be derived from the turnover of that unit, and each observed price will be, in so far as possible, representative of different service activities that it produces. The weight of the unit will equal the sum of the weights for its observed prices.

The source of weights varies between countries. Most countries use data from annual structural business or sectorial surveys. In some countries, weights are collected using a specific SPPI survey. During the first phase of weighting it is recommended that each individual transaction should be assigned a weight based on its share of sales of a service product. Upper-level indices are compiled by weighting together lower level indices through progressive levels of aggregation defined by the classification structure. 


\subsubsection{Specific aspects}

The business management consultancy industry is self-regulated, with a small number of strong representative associations (such as the European Federation of Management Consultancy Associations). These associations aim to increase the performance standards of consulting activity producers, to implement quality standards through professional regulations, and to positively influence the economic and legal framework conditions of the sector.

Experiences in both German and France demonstrated the usefulness of cooperating with representative associations in the development of SPPIs for the sector.

\subsubsection{Overview of national methods}

Compilers from France, Germany and U.S. presented papers on management consultancy services at the 2006 Voorburg Group meeting. ${ }^{8}$ In the 2013 Voorburg country progress report, 15 countries indicated that they compile an SPPI for this industry.

For pricing methods, the charge-out rate is widely used in Australia, New Zealand, Germany and France. Specifically, the U.S., France and Germany use "realised chargeout rate", which in general means that an average rate is calculated from several contracts, based on time actually spent and revenue received. Australia calculates the charge-out rate on the basis of "bill rate and a percentage of realised rate". Of course the charge-out rate method does not take into account of the evolution of productivity in the labour force.

The model pricing method is employed in Germany and the U.S. An estimated price is calculated for a fictitious service or for a service that has been directly observed in the past, but not during current pricing periods.

\section{Germany}

In Germany, the market for management consultancy is highly concentrated. Data collection started in 2005 and about 150 business enterprises are surveyed each quarter by paper based questionnaire; an online survey is under construction. The standard pricing method is time based using realised hourly rates, differentiated by four degrees of professional expertise and four activity fields (products). These activity fields are mainly structured according to the CPA-/CPC-product classifications.

Survey experience has shown that in Germany is only necessary to distinguish between four management consulting service products namely; consulting in strategy (accounting for $27.1 \%$ of the total industry weight, consulting in organisation/management/processes $(51.1 \%)$, consulting in human resources $(6.9 \%)$, and consulting in IT issues (7.2\%). It should be noted that $7.7 \%$ of the total weight is assigned to travel expenses. Price adjustments of travel expenses are calculated using a model pricing approach with CPI data (prices for hotel, flights and railway travel).

Because of the small size of the public relations consulting industry in Germany, it is not included in the current management consultancy index.

\section{United States}

The U.S. employs a pricing method that combines elements of the model pricing and unit value approaches. First, a type of consulting, such as strategy, human resources, or marketing, is selected. Next, professionals that are tracked in each service transaction are 
selected and weighted based on the aggregated turnover that they generated in the most recent completed year. If there are more than five professional groups (for example, partners, associates, analysts, etc.) that billed time for the chosen type of consulting, the transaction is limited to the five groups that generated the most turnover. If turnover data are not available, the professional groups that billed the most hours are selected. The relative contributions of each of these professional groups are held constant using the base year data.

For each pricing period, respondents provide the average billing rates that each of the selected professional groups earned on all projects of the selected type. These average billing rates are calculated by dividing the total turnover earned by all individuals within a particular professional level by the total amount of hours these individuals billed. Collecting distinct average prices for each major type of consulting project is preferred. The U.S. experience with large professional service producers indicates that they find it easier to provide average billing rate data rather than contract-specific data. When pricing specific contracts, the U.S. has also had difficulty holding output constant, as management consultancy service producers regularly offer different services to individual clients each pricing period. The approach of collecting average billing rate data also allows for the collection of robust, broadly representative price information with fewer transactions than if contract-specific prices were used, and thereby reducing respondent burden.

\subsection{Architectural activities (Marcel Spanjaard, Statistics Netherlands)}

\subsubsection{Industry description (ISIC 7110)}

Architectural activities generally encompass the aesthetical and functional design of buildings, cities and landscapes. ${ }^{9}$ The main characteristic of architectural services, from the perspective of a SPPI compiler, is their uniqueness: most specific services are produced only once. Furthermore, services produced range over different fields, from design of buildings to equipment and infrastructure. Examples of services that illustrate their diversity include: planning and design of a large city; design of a large highway; design of different types of buildings; planning a construction project; arranging building permits and landscape advisory; etc.

Architects categorise their customers into three main groups: private households, private enterprises and public institutions. The pricing mechanisms employed for each of these groups appear to differ. The main difficulty in measuring price change in this industry is the fact that architects do not design the same object in successive periods. Every service they produce is unique, and therefore cannot be compared exactly to services previously produced. Nevertheless, several countries have experienced varying levels of success in using model pricing to collect price data for this industry.

Prices of architectural services are influenced by a wide range of factors, some of the most important being:

- Type of costumer (private households, private enterprises and public institutions);

- Hours worked;

- Type of building / object designed;

- Complexity of design; 
- Supply of and demand for architectural services;

- Prestige versus routine projects;

- "Main service" versus "extra work";

- Total construction costs;

- Size of project in $\mathrm{m}^{2}$.

Architects primarily engage in the production of design services. However, they may also undertake a number of secondary activities including; project management, securing of building permits, and research and surveying of sites. The assignment of responsibilities for the architect is often expressed as a percentage of the total project. A " $100 \%$ project" means that the architect performs all the designing, planning and arrangement services. In residential project in particular, " $80 \%$ projects" are commonplace, with the client performing some limited activities (such as arrangements) so as to reduce the total cost.

Part of the output of architects is included in gross fixed capital formation in national accounts. The contribution made by the industry to the GDP of the Netherlands in 2008 was $0.7 \%$.

\subsubsection{Classification aspects}

\subsubsection{Industry classification}

In the ISIC classification, Architecture is one of the industries classified under section M - Professional, scientific and technical activities, division 71 Architectural and engineering activities; technical testing and analysis. The most detailed breakdown of this division in ISIC is class 7110 - Architectural and engineering activities and related technical consultancy. Other international industry based classifications provide more detail. The NACE classification for example identifies a class for architectural activities (71.11) separate to engineering activities and related technical consultancy (71.12). The NAICS provides a further delineation between architectural services and landscape architectural services.

Annex A shows how the international industry classifications differ in respect of the detail provided.

\subsubsection{Product classification}

The various international product classifications provide considerable detail and it is unlikely that SPPIs could be produced to the most detailed product levels. Instead, the finest levels of the product classifications could be used to measure prices for homogenous groups of services, which could then be aggregated to form a robust price index. The CPC classification divides architectural services into three classes: 8321 Architectural services and advisory services, 8322 - Urban and land planning services and 8323 - Landscape architectural services and advisory services. Further breakdowns are provided for each of these classes. The NAPCS has similar delineations as the CPC but also adds a fourth category for project site master planning services.

It is common to use and focus on the industrial classifications when measuring turnover. Therefore, it may not be possible to compile a product level SPPI. Either approximate product level indices, or industry level indices may be more practical. 


\subsubsection{Scope of the survey}

The industry itself makes a sharp distinction between architectural and engineering services and most countries produce separate SPPIs for each. However, the various international industry classifications only make this distinction at lower levels and it is possible that it is not accurately made in national business registers or structural business surveys. It is recommended that architectural and engineering service activities are treated separately for the purposes of SPPI compilation in recognition of their differing characteristics.

As product classifications clearly distinguish between architectural and engineering services it should be possible to correctly assign business enterprises to the respective industries if product level turnover data is available.

It is possible that business enterprises cannot be easily assigned to architectural or engineering services if the industrial classification provided is not detailed enough or if product level turnover data is not available. This can create difficulties during sample selection, as it will not be possible to separately sample architectural or engineering services. In such cases, the sample could be selected at a higher aggregate level. Sampled units can be assigned to either architectural or engineering services during the respondent initialisation process.

Architects produce services for households, businesses, government and export. The largest share of turnover is typically generated from services produced for businesses and government. In that sense, the SPPI for architectural activities might be described as primarily a BtoB index.

\subsubsection{Industry vs. product based SPPI}

Architects mainly produce architectural services. However, engineers may also produce some architectural services as secondary activity. Thus, with an industry approach, one can presume that mainly architectural services are measured. Although the secondary activity of engineers is not included in the industry based index, it can reasonably be expected that such an index will provide an effective measure of price change for architectural services.

The advantage of a product based SPPI lies in the inclusion of the secondary activity of engineers.

\subsubsection{Sample design}

The most popular sampling approach is the PPS sampling. This is often combined with a cut-off limit which excludes the smallest units and includes all of the largest. The size criterion on which the PPS sampling is based is usually turnover or number of employees. Turnover should be considered first, especially if the aggregation weights are also based on turnover.

The sample design in the Netherlands is as follows:

- The SPPI is product based. The sampling frame is based on product level (CPA) turnover data. Units are selected according to PPS-sampling for the elementary levels (which are based on corresponding CPA services) with turnover as the criterion for size (units with a higher turnover will have a higher chance of inclusion in the sample). Potential sampling error is reduced as information about the type of services produced by each unit is available. Furthermore, respondents 
may be asked to supply prices for more than one activity type on the basis of how their turnover is generated.

- The number of units in the sample (at the elementary level) are based on three considerations: $i$ ) the total number of units to be sampled across the entire SPPI program; ii) the relative weight of the industry in question; and iii) the variability of prices reported for the industry (where larger variability in prices is observed within a sampling stratum, the size of that sample may be increased).

\subsubsection{Collection of information and specification of the service}

The timing of price collection depends on the pricing method used. Measurements at either the midpoint or end of the reference period are common approaches. Statistics Netherlands uses model pricing to measure price changes. The price of a service model is collected at the midpoint of each quarter. The extra benefit of collection at the midpoint of the quarter is that price changes which are effective over the entire quarter can be estimated early. This may facilitate the compilation of provisional national accounts results.

Running a pilot SPPI is recommended. Statistics Netherlands found this useful in helping to identify price determining factors, market conditions and the most appropriate pricing method.

In the Netherlands, the first contact with respondents is via an introductory letter. This letter includes a sample model and a blank page on which the respondent can describe his own representative model. Respondents select and describe representative models for ongoing pricing and often with assistance from the compiler. Most respondents need to complete the questionnaire over a number of periods before they fully understand the requirements of model pricing. This period of "education" is important, and it is recommended to maintain close contact with the respondent during this phase.

The service transaction chosen for model pricing will be a virtual one. It should be representative of the type of service activities provided by the respondent. In the Netherlands, the respondent chooses the model and the compiler checks it to make sure it is suitable for on-going price measurement. An example of a model is presented in box 11.4.1.

\section{Box 11.4.1. Model pricing for architectural activities}

Model contract utility: Residential buildings, "extra work"

Project: New to build houses in Amsterdam; $100 \%$ project

Project number: 0012

Assignment: Design of a new house front within a running project

Complexity: Normal

Planned duration: 1 month

Persons and hours to working for the project: Design and architecture, 64 hours

Including advances

Total price including discounts 


\subsubsection{Main pricing methods}

The main pricing methods employed are hourly charge out rates and model pricing. Charge out rates can be distinguished by staff type, type of service activity or by type of customer. An index based on hourly charge out rates may follow market price development very accurately. Larger firms in particular, tend to price their services on the basis of worked hours. The downside of the use of hourly charge out rates is that they may suffer from productivity bias. When productivity increases, the time worked to produce the service may shorten and the quality of services might change. Thus, SPPIs based solely on time worked for clients tend to be positively biased.

To overcome the productivity bias, model pricing can be employed. This method also fits the architectural services industry well since the activities performed are mostly unique. A detailed model service is agreed with the respondent. The model (or models) should be representative of the main activities performed by the respondent. In the case of architectural services the diversity of services can make this a difficult task. A disadvantage to the use of model pricing in this industry is that respondents are often unwilling to provide detailed models for on-going pricing. Developing models is very time consuming for the respondent, and only a limited number of employees may be qualified to carry out the task. Furthermore, a virtual model is difficult to price since there is not much to gain or lose when setting a model price for the purposes of survey completion. In comparison, under real market conditions, price setting is complex and very important for the firm. Attempts by the U.S. to lower the response burden, whilst still using the model pricing method, are detailed under section 11.4.11.

There are alternative pricing methods, including; percentage fee (Germany, France and Spain) and contract pricing (Hungary). Many architects in the Netherlands use percentage fee (of the total construction cost) as a check to see if the price of their service correlates with general market conditions.

\subsubsection{Quality issues}

Constant quality services are hard to identify in this industry because of the uniqueness of individual service transactions. Using model pricing provides a solution, since the quality of the model service transaction is kept constant. Therefore, the problem of quality change is more or less circumvented. However, quality change will have to be addressed periodically, when an out-dated service needs to be replaced by a more representative one. The choice of method of quality adjustment for linking the new service transaction to the old can have a large influence on the price index. Statistics Netherlands mostly uses the "overlap method" when replacing out-dated models. Respondents may not be able to accurately price out-dated services (which by definition will also be unrepresentative), so it is important to contact them whenever such an occasion arises. To maintain quality of data, respondents should also be contacted whenever large price changes are reported.

Advances in technology result in quality change. One can think of the ever improving software tools, which allow, for example, for drawings to be created faster. New 3-D visualisation techniques have been developed and these have become increasingly easier to use and thus accessible - there are even free tools available online. Productivity is likely to increase as a result of improved technology and compilers must take care to take account of this trend. 


\subsubsection{Weighting and aggregation}

A common approach to aggregation is to use turnover data (usually from structural business statistics) for weights. These can be used at business enterprise level and also for subsequent aggregation to higher level indices. Weights for individual transactions should, if possible, be collected during the respondent initialisation process.

Statistics Netherlands does not use weights at the individual transactions level. Where a respondent reports prices for multiple models of a specific service activity, the price changes are geometrically averaged for each activity group. At the business enterprise level, turnover data from either structural business statistics or collected directly from the respondent is used. At this and higher levels, a weighted arithmetic average is used for aggregation. All the higher aggregation levels have weights that are based on aggregated turnover data.

The SPPI for architectural services is then further aggregated within the overall SPPI.

\subsubsection{Specific aspects}

CPIs do not always include architectural services as they are a relatively minor expense category for households and are related to investment rather than consumption by their nature. Therefore a dedicated SPPI survey of the sector is required to facilitate deflation of the National Accounts.

\subsubsection{Overview of national methods}

\section{Austria}

Austria surveys charge-out rates for specific services from different qualifications of employees in building construction, city and regional planning and interior design. The chamber of architects and charted engineering consultants supported the development of a suitable questionnaire and provides weighting information for every level of aggregation.

\section{Canada}

Statistics Canada is currently developing a quarterly Architectural, Engineering and related Services Price Index (AESPI) to succeed the longstanding Consulting Engineering Price Index (CESPI). This industry based survey expands coverage to include NAICS 541310 - Architectural Services and 541320 - Landscape Architectural Services, 541330 Engineering Services, 541360 - Geophysical Surveying and Mapping Services and 541370 - Surveying and Mapping (except geophysical) Services. Respondents have been selected from Statistic's Canada Business Register (BR) frame using a Probability Proportional to Size (PPS) sampling mechanism. The survey is mandatory and price collection began in the $3^{\text {rd }}$ quarter 2012 reference period.

Preliminary research on fee setting guidelines published by various professional bodies indicate that time based pricing mechanisms are most prevalent. Furthermore, projects undertaken by business enterprises in this industry are predominantly unique. Consequently the model pricing method has been adopted for the survey. Respondents are instructed to select a recently completed contract and estimate the fee that they would charge if bidding for the same contract as of a specific reference date in the current quarter. The selected contract should be representative of the respondent's pre-determined business activity which is based on industry classification and confirmed early in the respondent initialisation process. All applicable fee components such as direct labour costs, overheads, profit and reimbursable expenses should be revised based on prevailing 
firm and market conditions as of the reference date. The reference date is typically the mid-point of the current fiscal quarter.

Field testing of the questionnaire was conducted in the spring of 2012 in order to evaluate the questionnaire and the survey methodology. Results indicate that relevant pricing data are available and respondents are able to provide updated fee estimates for recently completed contracts. External costs such as sub-consultant expenses however, are burdensome to estimate on an ongoing basis and therefore a decision was made not to collect this information. It is also apparent that adequately preparing respondents for the survey will significantly reduce response burden. Statistics Canada will undertake several measures towards this end: $i$ ) prior to sending out the first survey forms, targeted survey respondents (project managers, architects, engineers or surveying and mapping professionals) will be identified through initial phone calls; $i$ ) additional documentation will be made available to respondents to address frequently asked questions and elaborate further on the survey; and iii) subject matter officers will follow-up with respondents to resolve misunderstanding in the early stages of the survey cycle. Feedback from field testing suggests that the response burden associated with this survey should decrease over time as respondents become more accustomed to the survey.

\section{Germany}

Germany is one of the few countries in Europe that utilises a scale of fees for architects (Honorarordnung für Architekten und Ingenieure, HOAI). The HOAI refers to services in the construction sector. It describes in detail the services of architects for several fields of activities which, together with a key for the complexity of the building, define a range within which the payment for the architect should be.

\section{United States}

Due to the non-recurring nature of architectural services, the U.S. employs model pricing as its main pricing method. Some architectural business enterprises in the U.S. set their fees as a percentage of the total cost of construction. In these instances, respondents are asked to estimate the cost of construction and their percentage fee in order to determine the estimated fee received if they were to provide the same service to the same client in subsequent months. The U.S. has found that it is often difficult for respondents to update the cost of construction, so in order to provide an estimate from which a percentage fee can be derived, the cost of construction is instead escalated by an appropriate PPI or construction cost index. For example, the cost of construction for an educational facility is escalated by the PPI for New School Building Construction. Respondents can change the escalated value if necessary each time they report; if they do not, the PPI escalated value will be used to estimate the percentage fee received. This escalation practice eases respondent burden as respondents can focus on updating changes, if any, to the percentage fee they charge.

\subsection{Engineering services and related technical consulting services (Marcel Spanjaard, Statistics Netherlands)}

\subsubsection{Industry description (ISIC 7110)}

Engineering services activities involve applying physical laws and principles of engineering in the design of machines, materials, instruments, structures, processes and systems and the provision of consulting activities in respect of heating and air conditioning, energy, electricity, industrial engineering, project management, 
construction and installation (site engineering), and even meteorological services and geodetic studies.

Engineering activities, therefore, encompass a wide variety of services some of which are closely related to the construction sector.

Most engineering services are unique, in part because of the research and development aspects of the activities produced. Additionally, even "common" engineering activities are generally customised to the unique requirements of specific clients. These two aspects make it very difficult to compare prices for constant quality engineering service activities over time. Furthermore, the complexity of the engineering industry is increased by pricing mechanisms employed within the industry (such as "fee strategy" and "competitive bids"), by technological change and by government regulation. These factors are described below.

Some engineering service producers adopt a fee strategy to calculate their prices for the provision of services for construction projects. The fee comprises of a percentage of the total construction budget, where the construction budget can be predetermined (fixed fee) or not (non-fixed fee). Prices can also be based on hours worked.

Engineers make competitive bids for contracts for work. These bids may not reflect the final price, which may be very different due to interim change orders and unforeseen circumstances.

As in the case of other industries, new technologies, resulting in productivity increases, are an important characteristic.

More than in other industries, the construction sector is subject to changes in building codes and other regulation by government. Engineering services that are closely connected to the construction sector are therefore confronted with changes in, for example, safety and environmental regulations.

Engineering service producers often price according to standard hourly rates based on costs and margins which are calculated annually. These rates are standard list prices which provide the basis for each tender offer. When the business enterprise tenders for a project, it estimates how many hours of work will be needed (by grade of employees used). A standard price is achieved by multiplying the hours with the standard rates. The final price that is charged, however, is subject to negotiation based on the circumstances of the tender bid. Furthermore, a large portion earnings from a project may be through "extra work", additional to the agreed service specification.

Part of the output of engineers is included in gross fixed capital formation in national accounts. The contribution to GDP of engineers in the Netherlands (excluding construction) was $1.1 \%$ in 2008 .

\subsubsection{Classification aspects}

\subsubsection{Industry classification}

Engineering is one of the industries included under division 71 of ISIC. The most detailed breakdown of ISIC in this division is 7110 - Architectural and engineering activities and related technical consultancy. Other international industry based classifications include some additional detail. The NACE classification, for example, identifies a class for engineering services and related technical consulting services (71.12) separate to architectural services (71.11). The NAICS has a further breakdown into 
engineering services, drafting services, building inspection services, geophysical surveying and mapping services, and surveying and mapping services (except geophysical mapping).

The industrial classifications therefore are broadly similar, differing only in respect of the level of detail provided.

\subsubsection{Product classification}

Most of the international product classifications are very detailed, and probably more detailed than the level at which SPPIs are published. However, detailed product classifications can be used to facilitate the identification of homogenous service activities groups for ongoing pricing, which can be aggregated into a robust price index.

The CPC breaks engineering services into three groups: $i$ ) Engineering advisory services; ii) Engineering services for specific projects; and iii) Project management services for construction projects. The second group (specific projects) is then broken down further. Other international classifications are similarly organised.

In many countries, turnover is measured at industry level. However, if turnover data is available at the product level it would provide a useful starting point for developing the SPPI.

\subsubsection{Scope of the survey}

The industry makes a sharp distinction between engineering and architectural services. It is recommended that architectural and engineering service activities are treated separately for the purposes of SPPI compilation in recognition of their differing characteristics. As product classifications clearly distinguish between architectural and engineering services it should be possible to correctly assign units to the respective industries if product level turnover data is available. However, because the distinction between the two services only occurs at a very detailed level, it is possible that the industries may not be properly delineated in the Business Register or the relevant turnover survey(s).

The product classifications offer better opportunities to correctly delineate between architectural services and engineering services. The Netherlands collects turnover data at a product level which is comparable with the CPA classification. From these data, units are assigned to either the engineering services or architectural services industry

Engineers produce services for households, enterprises, public institutions and for export. A large share of their services is typically provided to the construction sector and a much smaller share provided to households.

\subsubsection{Industry vs. product based SPPI}

Engineering service producers also engaged in a wide range of secondary activities such as architectural services. They may also provide bundled services, particularly to the construction sector. Bundled activities may include for example, design, project management, arranging of permits and actual construction.

On the other hand, very little engineering services are likely to be produced as secondary activity by firms in other industries. Architects might provide some engineering services, however these will typically account for only a minor part of their 
turnover. Therefore, an industry based SPPI may effectively measure price change for engineering service activities.

The advantage of a product based SPPI is the possibility it offers fin respect of improved sampling. When units can be selected based on all their activities (rather than only on their main activity), the elementary levels are more homogenous and more detailed - and the resulting SPPI will be more robust. When a more detailed SPPI, with multiple lower aggregates, is required, a sufficiently large sample will be needed.

\subsubsection{Sample design}

PPS sampling is commonly employed. This is often combined with a cut-off limit which excludes the smallest units and/or includes all of the largest units. Turnover or number of employees is typically used to determine the size of units. Turnover should be considered first, especially if the weights used for aggregation are also based on turnover.

The Netherlands compiles product based SPPIs. Turnover data at product level (based on the CPA classification) provides the sample frame. This allows for the identification and surveying of secondary activities.

The number of respondents in the sample could be based on considerations such as:

- The total allowable sample size, both for the industry and the overall SPPI bearing in mind available resources and respondent burden;

- The relative importance of weight of the industry index;

- The variability of prices (when it is known that there is a large variability in prices for a certain aggregate, the sample should be larger).

\subsubsection{Collection of information and specification of the service}

Prices are usually collected at the midpoint or end of each measurement period (quarter) but the periodicity of price collection can depend on the pricing method used. In the case of model pricing, the price of a service model could be collected at the midpoint of the quarter. However, for engineering activities, the time based method is often employed and therefore price collection may take place at the end of the quarter.

The choice of pricing method will also influence the amount of time needed for respondents to complete the survey and for the compiler to process the returns. Questionnaires based on model pricing typically requires more time to complete and to process.

It is very important to identify the appropriate contact that will complete the survey within each responding business enterprise. For model pricing, the contact person should be qualified to deal with both the specification and billing of activities. A time based questionnaire will probably be completed within the respondent's finance unit.

When developing an SPPI, Statistics Netherlands conducts a preparatory review and a respondent initialisation process. These allow for the identification of the price determining factors, mainly through contact with industry representative organisations and business enterprises from within the sector. Price determining factors for engineering services include:

- Total construction cost;

- Construction service or non-construction service; 
- Complexity of the service;

- Duration of the project;

- Contract variation (fixed or non-fixed);

- Whether the project a prestige project;

- How much of the entire project is performed;

- Type of customer (private households, private enterprises or public institutions);

- Reputation;

- Which other companies are participating in the bidding;

- New or existing customer;

- Negotiation results.

It is important to maintain on-going contact with respondents to ensure the quality and representativity of the prices collected. Model pricing and time based pricing methods can suffer from considerable variability in this industry and on-going close contact with respondents is necessary.

\subsubsection{Main pricing methods}

\subsubsection{Model pricing}

The model pricing method can be a particularly effective method for industries where service outputs are predominantly unique. In addition to being mostly unique, engineering services are subject to changes in productivity which cause difficulties for constant quality pricing. Model pricing can cope with changes in productivity, when up to date representative models are used.

However, model pricing can be problematic for a number of reasons: $i$ ) if models are not representative; ii) if respondents are unwilling to estimate model prices due to the higher levels of respondent burden involved; and iii) if prices are estimated with considerable a degree of subjectivity.

1. It is difficult to generate representative models for engineering services. The activities of engineers are both diverse and unique. There is also a danger that models can quickly become unrepresentative. Many engineering service activities are provided as part of large projects which can last over a number of years. These activities are not always suitable for model pricing as the activity must be delivered over a shorter time scale in order for the reported prices to be meaningful. Therefore, model pricing is more appropriate to smaller short-term projects which may not be representative of the service activities provided by larger respondents;

2. Respondents in the engineering industry may be unwilling to estimate model prices. This is typically due to the high respondent burden involved and the requirement for the contact person to be qualified to deal with model specification, billing for activities and the application of discounts;

3. It is possible that different people within one respondent business enterprise will be involved in completing the survey. This may lead to inconsistencies in pricing, 
as there may be elements of subjectivity involved. While this is a general problem for model pricing, it appears to be a particular challenge measurement of the engineering industry due to the complexity of projects.

\subsubsection{Time based pricing methods}

Even though in theory time based pricing methods may not be considered the most appropriate method for measuring prices of engineering service activities, they are commonly employed in practice. These methods are relatively practical and involve reduced levels of respondent and processing burden. Realised charge-out rates are a commonly used time based pricing method. Contact persons need to know the amount of hours that are worked together with the associated turnover or output. This requirement tends not to present significant burden for the financial units of responding business enterprises.

The downside of the charge-out rate method is that it does not account for changes in quality of the service activities provided or for changes in productivity. When charge-out rates are used, the implicit volume measure is "hours worked". No adjustment is made for varying levels of quality of work performed.

In practise, charge-out rates classified by type of labour should be collected. Sometimes, hourly list prices are collected; however these should be adjusted to take account of discounts offered.

\subsubsection{Percentage fee method}

A method based on the percentage fee of construction costs can be used for construction engineering services. The engineering services producer will ask for a fee relative to the total construction costs. The change in fee, together with the change in construction costs, is then used in the calculation of the price index. A construction output price index can provide a measure of the change in construction costs. However, as previously noted, there are many factors that influence the price of engineering services and the percentage fee method may not adequately reflect actual prices received.

Other methods for measuring price development of engineering services have been used with varying levels of success. One example is the use of hedonics to adjust for the changes in quality of services produced from period to period. This method was tested in Norway but ultimately the use of charge out rates was considered a better option (Kruger Enge, 2000). More information about alternative pricing methods used for the engineering services industry can be found in Rosenbaum (2000) and Goldhammer (2008).

\subsubsection{Dutch Experience}

The Netherlands currently uses realised hourly tariffs to compile an SPPI for engineering services activities. The respondent is asked to detail the number of hours worked and the associated turnover or output. These data are stratified by type and level of staff grade and sometimes by specific project types. A realised hourly tariff is then calculated to measure changes in tariffs every quarter. Survey forms are typically completed by a respondent contact located in the finance unit. In general, the resulting price index appears to reflect the longer term market situation. However, a number of problems can be observed in respect of the short term movement of the index. It is quite volatile due to the fact that the number of worked hours registered does not always 
synchronise with the financial reporting system - there may be "work in progress". Other practical problems include the "function mixture" (the same type of work is performed by a member of staff of a different grade and tariff) and "working within a project" (the project is fixed fee and the amount of actual worked hours will affect the resulting hourly tariff). Additionally, productivity changes and differences in the quality of the service produced are not measured by the realised hourly tariff method.

Because of the practical and theoretical issues described above, the Netherlands has attempted to move to use of the model pricing method. However, the unwillingness of respondents, and in particular larger respondents, to provide model prices presented a significant challenge.

However, smaller respondents appear willing to complete the survey. These respondents tend to provide services for smaller projects that occur more frequently and this suits model pricing very well. The Netherlands is therefore moving towards a combined pricing method. Larger respondents will complete a survey based on realised hourly tariffs at the end of the each quarter. Smaller respondents will complete a survey form based on model pricing in the middle of the quarter. The full design of this combined pricing method has yet to be finalised at the time of writing.

\subsubsection{Quality issues}

Model pricing is the preferred pricing method for engineering services activities due to its ability to capture productivity change over time. However, this method involves a higher respondent burden and care must be taken to ensure that the models remain representative and estimate actual transaction prices.

Model pricing attempts to price a constant quality output, but it is difficult to achieve a fixed input/output price index for the industry as work processes continuously change and services are usually unique. As automated systems are an important component of engineering services, IT developments have a potentially strong effect on the industry. A problem arises in the use of model pricing when an outdated service is replaced by a newer one; the choice of method of quality adjustment procedure used in linking the old and new services can have a significant impact on the index. Statistics Netherlands tries to use the overlap method in other service industries where model pricing is in use.

Respondents may find it difficult to accurately price out-dated services, so it is important to identify replacement models. It might be difficult however to recognise an outdated service. Large price changes and prolonged periods of no price change should be queried in order to the maintain quality of data, and to identify out-dated models.

\subsubsection{Weighting and aggregation}

Turnover data is commonly used in the aggregation of indices. These can be used at the respondent level and additional levels of aggregation. Product level weights may need to be collected as part of the respondent initialisation process.

Statistics Netherlands does not use weights at the product level. Where respondents provide prices for multiple models, the price changes are averaged across each service activity group by use of a geometric mean. Turnover data, usually provided by a structural business statistics survey, is used to weight at the level of business enterprise and subsequent levels. 
The SPPI for engineering services activities is then further aggregated within the overall SPPI.

\subsubsection{Specific aspects}

Sub-contracting is common in the production of engineering services. This does not represent a particular problem where the main goal of SPPIs is to provide a price index for national accounts purposes. Because output is measured on a gross basis, so too should SPPIs - meaning that sub-contractors should be included in the survey. Separate indices for contracts and sub-contracts are in principle needed for deflation of National Accounts, but only one kind of index is normally produced. Further discussion of this issue can be found in chapter 1 .

Exports can represent a significant share of output, as in the case of France. The survey should take account of services produced for exports where they are significant For example, the survey of average charge-out rates could explicitly allow for the reporting of prices of exported service activities.

The timing of pricing also presents an issue for the compilation of an SPPI for engineering services. There can be large delays between the closing of a contract, the delivery of the service and the making of payments. This can have implications for the recording of prices on the accrual basis as discussed in chapter 1 .

As industries evolve, new types of services are created for which new statistical treatments may have to be considered. In the engineering services industry, so-called "design-build contracts" are becoming more commonplace. These are bundled packages of services that include architectural, engineering, and construction services in a single contract. When engineering and architectural business enterprises win these contracts, they often subcontract the construction activity. Design-build contracts are typically classified to the construction sector, because the construction component of the bundle accounts for the major part of the value added. Consequently, design-build contracts tend not to be included in the SPPI for engineering service activities; in fact engineering service producers focusing on these types of contracts should be reclassified to the construction sector.

In the U.S., many major engineering business enterprises enter into contractual agreements in which they provide both design and construction services, with the construction services often subcontracted out. Business enterprises, having a core competency of engineering rather than construction, may therefore be classified within the construction sector. When determining the industry classification of design-build firms, the U.S. first examines turnover from non-design-build projects. If the majority of respondent turnover from non-design-build projects is derived from engineering, the respondent is classified under the engineering industry. If the respondent only generates turnover from design-build projects, it is asked if its in-house staff is primarily involved in either engineering or construction work. If the respondent indicates that their in-house staff is primarily involved in producing engineering services, it is classified under the engineering industry. In all cases, all construction output, including that from designbuild contracts, is considered out of the scope of the survey. 


\subsubsection{Overview of national methods}

\section{Austria}

In Austria, respondents report charge-out rates for different staff grades for specific services in infrastructure and civil engineering, structural and building services engineering, water, waste management and environment and space-oriented services. The industry representative associations provided advice on survey design and also weighting information.

\section{Hungary}

In Hungary, pricing based on working time (charge-out rates or realised charge-out rates by categories of employees) is the most commonly applied pricing method, followed by simple models based on contracts, created in close cooperation with respondents. Elementary indices are compiled at the CPA 6-digit level.

\section{United States}

The U.S. employs model pricing as its primary pricing method for compiling SPPIs for engineering services activities. An entire contract serves as the basis for model pricing, although if a responding firm is unwilling to provide an actual contract, a hypothetical contract may be used. Engineering business enterprises employ three primary fee structures: the time and materials structure, in which they estimate the amount of labour needed for a project, the hourly billing rate with realised profits incorporated for each engineering professional, and any incurred material costs; the costplus fixed fee structure, in which the they estimate labour costs, material costs and a fixed fee or multiplier to account for profits; and the fixed fee structure, in which the they estimate a single negotiated price for the entire service provision, inclusive of all labour, materials, overhead, and profits. The U.S. uses specified model contracts to measure prices based on each of these fee structures.

\subsection{Technical testing and analysis (Ildiko Holocsy, Hungarian Central Statistical Office)}

\subsubsection{Industry description (ISIC 7120)}

The purpose of technical testing and analysis services is usually to meet legal requirements or otherwise confirm safety and reliability of business enterprises products and procedures. These services include the performance of physical, chemical and other analytical testing and inspection as well as measuring, certification and validation of all types of materials and products.

Technical testing and analysis services are mainly business orientated. Periodic roadsafety testing of motor vehicles is however a notable exception. Business enterprises providing periodic road-safety testing of motor vehicles offer standard set of tests for different kinds of vehicles having usually tariff systems for these different kinds of vehicles. These services are provided to both consumers and businesses, especially in the case of cars, when periodic inspection is required by law. For the testing of cars the price is usually set on the basis of vehicle size, irrespective however of whether it is for business or personal use. Other vehicles are mainly used for business purposes.

Typically, the industry will comprise of few major business enterprises and large number of smaller testing and analysis services producers. The smaller producers usually 
focus on specific areas of testing and analysis, while larger units often offer a wider range of services.

One of the main characteristics of this industry is the wide variety of services offered. For example, the testing of a certain characteristic of a product can often be carried out in a number of different ways. Similar tests may be performed according to different standards since competing standards exist (there is however, a trend toward international harmonisation of testing standards). Therefore testing laboratories may produce a large number of different services. Finding the most representative services can be a major challenge. In this respect, industry representative organisations such EUROLAB (European Federation of National Associations of Measurement, Testing and Analytical Laboratories) can provide important information on the organisation of the industry.

The industry is also affected by both globalisation and international harmonisation.

Many of the larger business enterprises are subsidiaries of multinational corporations or holdings. The major business decisions (for example in respect of pricing) are often made centrally for all of the subordinated units in these holdings.

Certification of product services includes a series of standard product safety tests. Certification is granted to products that comply with quality/safety requirements. Certification may be nationally or internationally orientated although there is a growing trend towards international harmonisation. It has extended from individual products to include certification of systems. However, certification of systems has not yet been included in the ISIC classification.

\subsubsection{Classification aspects}

\subsubsection{Industry classification}

The classification of technical testing and analysis under the ISIC and the European NACE systems are fully consistent and comparable.

In both the ISIC and NACE classifications, class 7120 - Technical testing and analysis services is classified under section M - Professional, scientific and technical activities and division 71 - Architectural and engineering activities and technical testing and analysis activities. ${ }^{10}$ While class 7120 is not further subdivided in the above international classifications, the covered activities have been additionally broken down into sub-classes in the national classification systems of a number of countries. ${ }^{11}$

Class 7120 - Technical testing and analysis services includes the performance of physical, chemical and other analytical testing of all types of materials and products, includes:

- Acoustics and vibration testing;

- Testing of composition and purity of minerals etc.;

- Testing activities in the field of food hygiene, including veterinary testing and control in relation to food production;

- Testing of physical characteristics and performance of materials, such as strength, thickness, durability, radioactivity etc.;

- Qualification and reliability testing; 
- Performance testing of complete machinery: motors, automobiles, electronic equipment etc.;

- Radiographic testing of welds and joints;

- Failure analysis;

- Testing and measuring of environmental indicators: air and water pollution etc.;

- Certification of products, including consumer goods, motor vehicles, aircraft, pressurized containers, nuclear plants etc.;

- Periodic road-safety testing of motor vehicles;

- Testing with use of models or mock-ups (e.g. of aircraft, ships, dams etc.);

- Operation of police laboratories.

This class excludes:

- Testing of animal specimens, see ISIC 7500;

- Diagnostic imaging, testing and analysis of medical and dental specimens, see ISIC 8690.

The NAICS classification is not fully comparable with the ISIC/NACE classifications. It covers 54.138 - Testing laboratories which comprises business enterprises primarily engaged in providing physical, chemical and other analytical testing services. The testing activities may occur in a laboratory or on-site. Business enterprises primarily engaged in the following activities are however excluded:

- Performing laboratory testing the veterinary;

- Performing clinical laboratory testing for the medical profession;

- Auto emission testing. ${ }^{12}$

It should be noted that business enterprises producing technical testing and analysis services may also engage in very significant secondary activities, perhaps completely different from their main activity, and therefore assigning the correct industry classification to these establishments may be difficult. In many European countries (for example Hungary and Finland) a large number of laboratories are classified under NACE class 72.1 - Research and experimental development on natural sciences and engineering. Furthermore, many business enterprises under NACE division 45 - Wholesale and retail trade and repair of motor vehicles and motorcycles offer periodic road-safety testing of motor vehicles as a secondary activity. On the other hand, for some business enterprises classified under "technical testing and analysis" a significant share of their total turnover is generated from secondary activities, such as NACE class 72.19 - Other research and experimental development on natural sciences and engineering, class 46.1 - Wholesale on a fee or contract basis, and class 74.90 - Other professional, scientific and technical activities.

The degree of concentration within the industry varies between countries. For example, in Hungary it is dominated by micro- and small establishments (those with less than 20 employees account for more than $95 \%$ of the total number of establishments and more than $60 \%$ of the total turnover). However, in Norway the industry is dominated by a few large and global actors and establishments with 50 or more employees account for $80 \%$ of the total turnover. 


\subsubsection{Product classification}

As shown in annex B, both the CPC and the CPA divide technical testing and analysis services into five product sub-classes, including:

- Composition and purity testing and analysis services;

- Testing and analysis services of physical properties;

- Testing and analysis services of integrated mechanical and electrical systems;

- Technical inspection services of road transport vehicles;

- Other technical testing and analysis services.

\subsubsection{Scope of the survey}

The ideal survey will track price changes for the full range of services provided to all end users. However, technical testing services are mainly provided to businesses, with the exception of the testing of motor vehicles. Therefore, most technical testing services can be covered with respect to BtoB transactions only.

Compilers should note that if the consumer price index (CPI) already includes price collection for technical inspection services of road transport vehicles (71.20.14) especially for cars, these prices could also be used in the compilation of the SPPI. In this case, it is important to note that the prices should be made exclusive of VAT when they are used in the compilation of the SPPI.

\subsubsection{Industry vs. product based SPPI}

The primary purpose of the SPPI is to facilitate the deflation of national accounts to constant prices, ideally on a product rather than industry basis. In many cases however, product based SPPIs are not feasible and approximate product based or industry based indices are compiled.

As noted in chapter 1, the larger the share of industry turnover generated from the provision of secondary service activities the stronger the argument for compiling product based SPPIs. In Hungary, because of the high levels of secondary activity in the industry and testing services performed as secondary activity outside the industry, approximate product based indices are compiled, as described under chapter 3.

\subsubsection{Sample design}

In many countries the sampling frame consists of all business enterprises classified to the technical testing and analysis service industry in the national business register. The sample can be selected using one of several different sampling methods of which PPS sampling is the most popular (e.g. Norway), followed by random stratified sampling (e.g. Germany) and cut-off based on size (usually turnover or employment), as well as combination of these methods (e.g. Hungary). Irrespective of the methodology employed, the market-leader service producers are usually selected.

In the case of cut-off sampling, when only the largest units are included in the sample, it is assumed that they control the evolution of prices and account for a large share of the total output of the industry (for example more than $80 \%$ ). This method can minimise both the cost of price collection and also the response burden on smaller units. 
As already noted, in Hungary the survey frame is based on the national business register, and the reporting units are enterprises. A combination of cut-off and random sampling are employed. A census of units is taken above a size threshold (companies with more than 19 employees and a specified turnover value) and a random sample of smaller enterprises below the cut-off line (with between 10-20 employees) is selected. Larger enterprises account for around $40 \%$ of the share of turnover sampled, with smaller enterprises accounting for around $60 \%$.

Units classified to other industries may be selected for inclusion in the survey of this industry, if they generate sufficient turnover from the secondary activity of technical testing and analysis services. Requesting prices for relevant secondary as well as primary activities allows for compilation of both industry and approximate product based SPPIs.

In countries where the share of turnover generated by sales of services to households is relatively low, an index limited in scope to BtoB transactions should closely approximate the BtoAll. The CPI (for example in the case of the sub-index for periodic road-safety testing of motor vehicles) may also provide a good source of price data. Therefore, when designing the sample the compiler should take of account the market structure, the availability of existing data and respondent burden.

In Finland, sampling was conducted in two stages. The sampling frame was first divided into inspection of motor vehicles and other testing and analysis services. The national CPI already partly covers periodic road-safety testing of motor vehicles, and so provided a natural starting point for data collection. The CPI survey was expanded to cover SPPI relevant data. ${ }^{13}$ The sample of other testing and analysis services producers was selected using compiler discretion (i.e. non-probability sampling) because not all units classified as technical testing and analysis services producers in the business register are actually in this industry and also because there are subsidiary establishments that provide services to a parent company only and thus their prices are unlikely to follow the market prices.

Samples are usually updated annually or every five years although some countries carry out continuous updating or ad hoc maintenance. It is important to ensure that the SPPI is representative of the industry as a whole and therefore the survey should cover all significant product groups.

\subsubsection{Collection of information and specification of the service}

The main source of price data for the compilation of an SPPI for technical testing and analysis services activities is often a dedicated survey. Prices, usually for regulatory based tests, may also be collected from service producer price lists via the internet. However, internet pricing can give rise to quality issues if price discounting, such as volume discounts, are offered. As previously noted, in some countries prices collected for the compilation of the CPI are also used in the compilation of the SPPI (after any necessary adjustments have been made).

Data collection is usually compulsory and conducted on a quarterly basis, although some countries collect prices each month. Prices for technical testing and analysis services tend to remain relatively stable.

Several countries use a standard product list, mainly for administratively regulated prices, as well as a product list for freely negotiated prices identified in cooperation with respondents. Ongoing contact with the industry regulator, industry representative 
organisation and perhaps the largest service producers can be helpful in ensuring that the SPPI remains representative.

As the services producer can be quite heterogeneous a relatively open questionnaire, leaving space for different types of services and representative items (for example those questionnaires used in Germany or Hungary) might be recommended.

It is unlikely that pre-existing product level turnover data is available and for this reason, it is recommended that the product groups and their respective turnover, as well as representative prices for them, are identified for each respondent during the respondent initialisation process.

A number of countries collect product level turnover/revenue on an annual basis to ensure representative weights are used in the calculation of the index (for example Finland, Hungary, the Netherlands). In France field-officers visit each sampled unit to collect the required information.

Price determining characteristics include: the type of client (new/existing, resident/non-resident, large/small); type and complexity of service (test/analysis/certification); type of object tested (materials/cars/etc.); size of the item(s) being tested (in number, weight, depth, and/or volume); and time spent. These characteristics should be held constant to ensure constant quality pricing.

It may be however useful to refer to the following service activities (organised according to CPA subcategories) during the respondent initialisation process so as to help identify relevant service product lines.

- 712011 - Composition and purity testing and analysis services

Analysis of chemical and biological properties of materials such as:

- Cereals (quality control);

- Food and chemicals (fats, sugar, microbiology, bacteriology, vitamins...);

- Environment (soil, air, water, waste, ...);

- Metals (precious metals...).

- 712012 - Testing and analysis services of physical properties services

Analysis of physical properties of materials such as:

- Tests for tension, hardness, strength;

- Electrical conductivity;

- Radioactivity;

- High-temperature effects.

- 712013 - Testing and analysis services of integrated mechanical and electrical systems

Analysis of mechanical and electrical characteristics of:

- Machinery, motors, automobiles;

- Tools, appliances;

- Communication equipment.

- 712014 - Technical inspection services of road transport vehicles 
Periodical technical inspection services (general inspection and emissions tests) for:

- Automobiles, motorcycles;

- Buses;

- Lorries, trucks;

- Other road transport vehicles.

- 712019 - Other technical testing and analysis services

Testing and analysis services of a technical or scientific naturel not elsewhere classified (technical testing of lifts, bunkers, tanks, certification of products, ...)

\subsubsection{Main pricing methods}

A wide range of services are offered by the technical testing and analysis industry due to the large variety of products and characters being tested, and in testing methods and standards. Choosing the most applicable pricing method(s) depends on the service produced, the availability of alternative data sources and on the level of response burden the statistical office can impose on respondents.

\section{Recommendations for collection of prices}

The direct use of prices of repeated services, contract pricing and model pricing - or appropriate combinations of each - appear to be the most usable pricing methods for this industry. A distinction should be made between administratively regulated and freely negotiated prices. Periodic road-safety testing of motor vehicles constitutes an exception however. Inspection of motor vehicles is usually a repeated standard service.

- The most appropriate pricing methods may be:

- Contract prices for the large and representative customers of a dominant market-leader services producer: prices for a standardised and repeated test/analysis, for the same type of tested object with the same price determining factors;

- Average prices/charge out rates for a strictly defined type of test (per test/analysis, per time unit (e.g. hour/day/month for personnel and machinery ), per ton, per service package);

- Selected representative tariffs with good estimation of discounts;

- Very precise and detail model pricing (with the appropriate coverage of services provided and turnover accounted).

- Second best:

- Tariffs without any discount;

- Averages prices per unit of measure for a relatively openly defined type of test.

\subsubsection{Periodic road-safety testing of motor vehicles}

As periodic road-safety testing services are rather simple and non-unique, the direct use of prices of repeated services is the most appropriate pricing method. Existing tariff systems on the most important testing services can be used as price quotations and this 
pricing method is simple and effective. As previously mentioned, prices collected for the compilation of the CPI could also be used for the compilation of the SPPI.

\subsubsection{Other testing and analysis services}

Although other testing and analysis services are often unique service products, it is possible to find services that are provided on a reoccurring basis. These may include, for example, food production control, purity tests, and air and water pollution tests. In cases where the same tests and analysis are performed regularly with the same testing methods and standards, the direct use of prices of repeated services or contract pricing methods are appropriate. If services are complex and unique services, the model pricing method is more appropriate. Under this method, the specified service (model) does not need to be transacted in the current period, as it can be priced by expert estimation.

\section{Direct use of prices of repeated services}

The direct use of prices of repeated services method utilises real transaction prices for specific constant quality services with are transacted over time. List prices may be used to approximate real transaction prices for service activities for which discounts are not typically offered. Generally, prices can be obtained from online price information, in particular in the case of administratively regulated prices (for example for periodic roadsafety testing services). In certain cases, the use of list prices can be an efficient method of collecting prices.

\section{Contract pricing}

The contract pricing method refers to the use of prices in long term contracts for the repeated delivery of the same (or a very similar) service and is therefore, a special case of using real transaction prices. Prices may be fixed for the entire duration of the contract or subject to change according to the specific conditions set out in the contract.

Although contract pricing utilises real transactions prices it can be difficult to apply to the full range of services provided by the industry, in particular for unique services. As noted in chapter 2 , the method should be used with caution because individual contract prices agreed in a previous period for future periods may not be representative of current price development in the industry. Therefore in applying the method, it is important to consider how well the resulting price index reflects price development in the industry concerned.

\section{Model pricing}

The model pricing method can be recommended for obtaining prices of complex and/or unique services. The main advantage of model pricing is that improvements in productivity can be identified and accounted for. However, it is necessary to ensure that models remain representative, and allow for the reporting of discounts applied during the reporting period. The model pricing method can result in significant respondent burden; particularly if models are complex and ongoing pricing requires expert judgement.

\section{Pricing based on working time}

Time based pricing methods can be employed for service activities which are priced according to worked time, or charge out rates for personnel and machinery. In some cases it may be appropriate to combine the pricing based on working time method with other methods (e.g. Germany and Austria combine model pricing, direct use of prices of repeated services and charge-out rates). Pricing based on worked time can, however, be a 
poor indicator of price development if productivity improvement is a feature of the industry.

\subsubsection{Quality issues}

Technical testing and analysis services evolve with technology and new services replace older ones. This industry is however, characterised by the production of services according to regulatory standards. The likelihood of quality issues arising is reduced where service transactions selected for ongoing pricing are well defined. The price of a test or analysis service transaction depends on the item being tested, the testing method and standard used among other things. As the range of services produced by this industry is extremely wide, it is essential to carefully define all the factors that influence pricing and to collect prices for those services that are most representative of the industry generally. It is also important that the compiler maintains the representativeness of the index by taking account of new services and declining demand for older services.

In Hungary, quality adjustment is most commonly performed using the overlap method. This can be applied where new and older services are sold simultaneously. Comparable adjustment and quantity adjustment methods are also used. If most services are performed on an ongoing basis, quality adjustment should only be needed infrequently.

In the case of temporarily missing prices, countries often carry forward the price from the previous period ideally adjusting it with reference to the average price development of similar products or establishments (mean class imputation).

In order to maintain the quality of the index, significant price changes and changes to existing service specifications should be queried with respondents. The compiler should also monitor prolonged periods of "no price change reported" (that is, service prices which have not shown any price change for a number of periods) to ensure that the specification is still representative and the respondent is providing accurate price information in each period. This period of "no price change" can be set to meet the needs of the price index being developed and initial consideration should be given to likely price variation in the industry. If the price is no longer representative (or the service is no longer provided) then a replacement service is identified and the necessary quality adjustment is carried out. It is also recommended that compilers compare price development with other relevant sources such as regulatory data or SPPIs in neighbouring countries.

\subsubsection{Weighting and aggregation}

Possible sources of data for the weighting structure include turnover data collected directly from respondents, or from other statistical sources such as structural business statistics or the national accounts. Alternatively it may be possible to derive weights from information provided by the regulatory authority.

\subsubsection{Specific aspects}

Technical testing and analysis services encompass an extremely wide range of services, many of which are unique. A move towards the global harmonisation of different standards may facilitate more comparable price measurement in the future.

As previously noted, the total output of this industry may include a sizeable element of secondary activity. This could give rise to significant differences between industry and 
product based indices. Compilers should therefore take account of the organisation of the industry in their country when developing the SPPI.

An additional challenge encountered when developing an SPPI for technical testing and analysis is that many of the major business enterprises are subsidiaries of multinational enterprises and provide services only for the parent company. Consequently their prices are unlikely to follow market prices.

\subsubsection{Overview of national methods}

\section{Austria}

Austria combines the model pricing, direct use of prices of repeated services and charge-out rates methods in the compilation of the SPPI for technical testing and analysis services activities. The industry questionnaire covers composition and purity testing and analysis services, testing and analysis services of physical properties, testing and analysis services of integrated mechanical and electrical systems and technical inspection services of road transport vehicles. Prices for one standard test or charge-out rates for personnel or machines can be quoted. The intermediate aggregation of collected data is made at a respondent level.

\section{Finland}

In Finland, technical testing and analysis services activities are divided into periodic road-safety testing of motor vehicles and other testing and analysis services. Periodic road-safety testing of motor vehicles covers more than $30 \%$ of the total industry turnover. There are a few major business enterprises and a large number of smaller testing and analysis service producers in the industry. A large number of laboratories are classified to the Research and experimental development on natural sciences and engineering (NACE 72.1), which causes difficulties in obtaining both representative services and data suppliers.

The SSPI sample was conducted in two stages. The national CPI already partly covers periodic road-safety testing of motor vehicles, so price collection was extended to cover SPPI relevant transactions (with the appropriate adjustment for VAT). The sample of other testing and analysis services producers was selected purposively. The direct use of prices of repeated services and model pricing methods are employed. Data collection includes an annual collection of lower level weights for each service category which ensures that the index remains representative.

\section{Germany}

Germany introduced the SPPI for technical testing and analysis services activities in 2008. The service groups follow the corresponding product classification in the CPA. Additionally, three fields of testing and analysis services of integrated mechanical and electrical systems were identified, namely technical testing of large scale plants, technical testing and analysis of machinery and small installation, and technical testing and analysis for the certification on products and prototypes. A mixture of pricing methodologies is employed (direct use of prices for repeated services, model pricing and charge-out rates). Only technical inspection services of road vehicles, which are regulated, are priced according to the direct use of prices of repeated services exclusively. The use of openly designed questionnaires leaving space for many different types of services/price quotations has facilitated price collection in what is a highly heterogeneous industry. This approach, however, comes at the cost of increased respondent and data collection 
burdens. All enterprises with an annual turnover of more than $€ 25$ million are included in the permanent price collection and these are supplemented by a random stratified sample of enterprises with an annual turnover up to $€ 25$ million.

\section{Hungary}

In Hungary, prices are collected via a compulsory quarterly SPPI questionnaire since 2007. The sample is selected according to a cut-off sample of all units with 20 employees or more, complemented with a random sample of smaller business enterprises (with between 10-19 employees), giving a total sample size of between 50 and 60 units. A quite open general questionnaire which includes a standard product list was developed in close cooperation with respondents. Customised survey forms are then developed for each respondent on the basis of the first return that they make. Each customised questionnaire takes account of both the detailed specifications of selected service transactions and the respondent accounting system. Prices for secondary activities are also collected allowing for the calculation of both approximate product based and industry based indices.

Prices are partly influenced by the Euro and U.S. dollar exchange rates since some services are priced at foreign currency rates for non-resident customers. Product level turnover data is collected in the first quarter of each year from respondents so as to ensure that the index weights remain representative. The contract pricing, direct use of repeated services and model pricing methods, or combinations of these methods, are employed.

\section{Netherlands}

In the Netherlands, a large variety of testing services are classified according to three main clusters; "health and safety tests", "tests of materials and equipment" and "environmental inspections". The model pricing methodology is employed for "tests of materials and equipment" and "environmental inspections". The first cluster is dominated by government agencies and does not therefore involve open market prices. Model pricing is employed as the services produced by the industry are predominately unique. Some prices for services that are exported, or prices that are set by a head office located abroad, are partly influenced by exchange rates.

\section{Norway}

In Norway, the technical testing and analysis industry is dominated by a few large and global business enterprises. Almost $80 \%$ of the total industry turnover is generated by business enterprises with more than 50 employees. The current sample of 80-90 business enterprises, covering about $85 \%$ of the total turnover of the industry was selected by PPS sampling. The direct use of prices of repeated services is employed. The CPA classification was used as a starting point for decomposing the industry into more homogeneous sub-groups. However, some adjustments have been made and discussions with the industry have contributed to the development of a more general activity classification.

\section{United Kingdom}

The U.K. index for technical testing is based on prices charged to businesses for testing and analysis services. Technical testing services are mainly sought in order to introduce a recognised level of safety to a particular product or service. Some examples include: the safety testing of motor vehicles, ships, aircraft, pressurised containers and nuclear plants; the safety testing of electrical power tools; material strength/shrinkage testing in the textiles industry; testing steel for strength and impact in the building industry; testing the quality of water and air, measuring radioactivity and pollution; food 
hygiene testing for disease or levels of pesticide. The U.K. first published an SPPI for technical testing in 2000. The main pricing methods employed are model pricing and contract pricing since most activity is of a specialist, tailor-made nature.

\subsection{Advertising (Johanna von Borstel, Destatis)}

\subsubsection{Industry description (ISIC 7310)}

In general, advertising services can be divided into creative and media placement activities. Creative activities comprise of planning, designing, creating and placing of advertising products. Business enterprises primarily engaged in the production of these services are labelled "advertising agencies". Media placement involves the sale of media space and time by media agencies and media marketers. The media agency buys media space on behalf of its client in order to achieve better conditions than the client could achieve on its own. The media marketer purchases media space in bulk from the media and then re-sells it. Media marketers may offer additional planning and consulting services as secondary activities.

The division of advertising activities is not always reflected in the various national and international industry classification systems (which are described in section 11.7.2). Moreover, the nature of media placement services varies significantly between countries. To account for these differences, further delineation between services is necessary. The Voorburg group agreed upon an alternative nomenclature which focuses more on the different types of business model regardless of what the advertising firms actually call themselves or how they are classified in the industrial classifications. A distinction is made between "brokers" who are primarily engaged in the negotiation and purchase of media space/time on behalf of their client, and "resellers" who primarily purchase and resell media space/time.

It is important to note that the legal status of resellers varies across countries. An institution which has no legal obligation to its customers in case of price fluctuations might be described as a wholesaler. This is for instance, the prevalent model in the U.K. Here, the customer bears the risk of any price change. On the other hand, an institution that manages a portfolio of advertising space/time might be described as a portfolio manager as it has a similar function to a stock market portfolio manager. The institution bears the risk of any price decline within its portfolio as it is obliged to quality adjust its service products by giving discounts in case of lower-than-expected numbers of spectators. ${ }^{14}$ This is the prevailing model in Germany. In addition, these business models differ in respect of the billing methods that are typically applied. The net basis where the agency charges purely for the service of negotiating the best rate with the media owner, is generally only applicable to broker-type advertising firms. The gross basis is used by both broker-type and reseller. Here the client has to pay both the service fee and for the price of the media space.

Identifying which of the business models is prevalent in a national industry is essential for the accurate measurement of turnover of the industry. The broker can charge on both net and gross basis. Turnover should be calculated on the net basis, because only the broker's value added (which is generated from negotiation etc.) constitutes output of the advertising sector (ISIC 731). However, in practice it may be difficult to distinguish between net and gross turnover. 
The reseller on the other hand always charges on a gross basis and turnover should also be calculated on the gross basis. This is because the service produced by the reseller cannot be separated from the advertising service or product bought in bulk.

Industry concentration ratios seem to vary between countries. In Germany, the industry is not dominated by larger business enterprises. In 2009, the largest 3 firms in the advertising industry accounted for only $5.4 \%$ of the total sales and the largest 50 firms accounted for only $27 \%$ of the total sales. ${ }^{15}$ However, the creative advertising services industry (i.e. advertising agencies) has a lower concentration ratio than the media placement industry (i.e. media marketers and media agencies). On the other hand, the advertising agency industry in the U.S. is somewhat concentrated. The four largest firms in NAICS 541810 - Advertising agencies control $24 \%$ of total industry turnover and the 50 largest firms control almost $40 \%$ of industry turnover. ${ }^{16}$ Firms engaged in media reselling (NAICS 541830 - Media Buying Agencies) are even more concentrated, as the four largest firms control 36 percent of industry turnover while the 50 largest firms control 73 percent of total industry turnover. ${ }^{17}$ The Czech Republic reports that in 2009 the largest 3 and the largest 50 advertising agencies accounted for $8 \%$ and $47 \%$, respectively, of the total sales of CPA category 73.11 - Services provided by advertising agencies. However, in the media placement industry, the largest 3 and the largest 50 firms accounted for $27 \%$ and $90 \%$, respectively, of the total sales of CPA 73.12 - Media representation services. The degree of industry concentration should be considered when choosing the sample size.

The amount of advertising revenue generated is closely related to the business cycle. As economies grow, advertising revenues increase. Conversely, during a tightening of the economy or a recession, advertising revenues decline. Advertising is also created and placed by in-house advertising departments which are departments within a business enterprise specifically created to design, prepare and place advertising for the parent enterprise. As these in-house departments do not receive payment for their services but are salaried operations, only non-market economic output is generated. Therefore, these departments are not in-scope of the SPPI.

\subsubsection{Classification aspects}

\subsubsection{Industry classification}

Most of the international classification systems have a similar design for the advertising services sub-sector. In the ISIC classification advertising is classified under class 7310 - Advertising. This class includes:

Creation and realization of advertising campaigns conducting marketing campaigns and other advertising services aimed at attracting and retaining customers.

Whereas ISIC does not distinguish between creative and sales type activities, this approach is reflected in the ANZSIC classification. In class 6940 - Advertising services, different types of agencies such as advertising agency and advertising material preparation service are specified. The ANZSIC classification also considers sample distribution services as advertising services. In the NACE classification system advertising is classified under group 73.1. Class 73.11 - Advertising agencies, is almost identical to ISIC 7310. However, class 73.1 additionally contains subclass 73.12 - Media representation, which includes media placement. 
In the NAICS classification, the subdivision is slightly different from the abovementioned classifications. Industry group 5418 - Advertising, public relations, and related services is divided into the following industries:

- 54181 - Advertising Agencies;

- 54182 - Public Relations Agencies;

- 54183 - Media Buying Agencies;

- 54184 - Media Representatives;

- 54185 - Display Advertising;

- 54186 - Direct Mail Advertising;

- 54187 - Advertising Material Distribution Services;

- 54189 - Other Services Related to Advertising.

\subsubsection{Product classification}

The international product classifications differ considerably more than the industrial classification systems. The CPC classification delineates on basis of accounting method used: group 836 - Advertising services and provision of advertising space or time is divided into:

- 8361 - Advertising services;

- 8362 - Purchase or sale of advertising space or time, on commission;

- 8363 - Sale of advertising space or time (except on commission).

In the CPA classification, the division of group 73.1 - Advertising services is based on pre-defined services:

- 73.11 - Services provided by advertising agencies:

- 73.11.1 - Services provided by advertising agencies;

- 73.11 .11 - Full service advertising services;

- 73.11 .12 - Direct marketing and direct mailing services;

- 73.11 .13 - Advertising design and concept development services;

- 73.11 .19 - Other advertising services.

- 73.12 - Media representation services:

- 73.12.1 - Sale of advertising space or time on a fee or contract basis;

- 73.12.2 - Re-sale of advertising space or time on a fee or contract basis.

The NAPCS distinguishes between different types of agencies:

- 54181 -Advertising Agencies;

- 54182 - Public Relations Agencies;

- 54183 - Media Buying Agencies;

- 54184 - Media Representatives; 
- 54185 - Display Advertising;

- 54186 - Direct Mail Advertising;

- 54187 - Advertising Materials Distribution Services;

- 54189 - Other Services Related to Advertising;

Within the different types of agencies the activities are further distinguished by types of services offered - similar to the CPA classification but in more detail.

\subsubsection{Scope of the survey}

Firstly, the nature of the media placement activity should be determined using either expert market information or a dedicated survey (especially when both billing methods prevail). In some countries like Spain and Germany, a substantial part of price information can be collected from administrative sources or industry representative associations.

Although it might be difficult to collect the necessary information, discounts effectively shape real transaction prices and should not be ignored. ${ }^{18}$

Advertising services activities are mainly used in intermediate consumption. Businesses are the main users of these activities, with government using much smaller amounts. In 2009, about $5 \%$ of German advertising activities were exported. ${ }^{19}$ Germany conducts a BtoAll SPPI, which is considered a suitable and cost-effective way to provide national accounts with price indices that are representative of all advertising activities. Australia also follows a BtoAll approach.

Depending on billing and business modalities prevalent in the country, the focus of the SSPI might vary. For instance, the media buying (reselling) industry in the U.S. is much smaller in terms of turnover than the advertising agency industry. Total industry turnover in 2007 for media resellers accounted for only $15 \%$ of total turnover earned by the Advertising Agency industry. ${ }^{20}$ As a result, the U.S. only produces a price index for the Advertising Agencies industry (NAICS 541810). The U.S. does not produce price indexes for media resellers (classified under NAICS 541830 Media Buying Agencies) or for any other advertising activities found within NAICS industry group 5418 Advertising, public relations, and related services. However, in Germany more than $60 \%$ of advertising turnover was generated by media placement. Therefore, Germany compiles price indices for both creative advertising and media placement.

\subsubsection{Industry vs. product based SPPI}

Sales of advertising can occur in many different industries: The most substantial component is the sale of media space in industries like newspaper, publishing, television broadcasting etc., in other words, where the media space is produced. Sales by a producer of media space are not considered part of advertising services, but of their respective industry, unless the producer establishes a subsidiary company for their media placement. Thus, the organisational structures of major (gross accounting) market players can have a large effect on industry output (and subsequently of the SPPI weighting scheme).

The substantial amount of advertising services produced as secondary activity leads also to a large discrepancy between industry and product based SPPIs. The former excludes, among other activity types, all classified advertising in newspapers. Whereas national accountants will usually accept an industry based index, a product based index is 
preferred by industry experts and representatives. To solve this problem, Germany and the Czech Republic currently compile both industry and product based SPPIs for advertising activities. The U.S. compiles distinct product based SPPIs for both advertising agency services and sales of advertising space and time, by media type. SPPI.

Self-produced advertising activities, as non-market output, are not in scope of the

\subsubsection{Sample design}

A PPS based sampling technique is recommended for this sector. Turnover data (revenue) or employment data should be used as the size measure. A comprehensive and detailed business register or similar source of establishment level data should be used as the frame for the sample. The frame should not be clustered by enterprise if it can be assumed that the clients and pricing structure differ between affiliate offices and pricing decisions are made at the local level. The sample size should be designed efficiently and smaller sample sizes may suffice for homogenous markets and markets with high concentration rates.

Some international examples of sample design follow:

- Germany employs PPS sampling for the creative advertising service industry. Units with a turnover below the threshold of $€ 250,000$ are not surveyed in order to lower their administrative burden. All units with turnover above $€ 25,000,000$ are selected the sample. All in all, Germany selects about 80 units from 7 strata $(.25-.5, .5-1,1-2,2-5,5-10,10-25,>25 € \mathrm{Emil})$ to cover a total industry turnover of $€ 21$ billion in 2009.

- The U.S. sampling process for advertising agencies differs slightly from that of Germany. The U.S. implements a PPS sampling technique using employment as the size measure but does not exclude firms below a predetermined size from the sample. Additionally, the U.S. selects from a single stratum.

- In the Czech Republic turnover is used as the size measure. A mixture of nonprobability and PPS sampling is employed; the largest units accounting for the significant share of the total turnover in specific groups of service activities are selected with certainty. The remaining sample is then proportionally selected from small and medium sized companies.

- Australia employs judgemental sampling. Respondents are chosen based on their market share and revenue. The accounting or finance departments of respondent units are asked to complete the survey as they are most likely to have access to the relevant data.

Concerning the sample frame, the U.S. clusters advertising agencies by company, with all data collected at the headquarters location where records are located and prices are set. Subsampling to one local office is allowed in the unusual event that pricing data is unavailable at the headquarters location. This also has the additional benefit of allowing for more efficient data collection. Based on its experience the U.S. has found that collection at the local level is not necessarily required since firm headquarters locations can provide transaction information for activities performed by local offices. However, since different industry practices may apply in other countries, no prior assumptions should be made prior to sample design. Collection of prices from a central office that itself collects prices from its regional branches and submits them (rather than sets them) 
can make follow-up queries difficult (i.e. when seeking explanations of price changes or quality change).

A major source of non-sampling error can be the incompleteness of the sampling frame. Its main source (often a business register) should be checked from other available (e.g. market player listings from market observers, online check on address information, etc.).

\subsubsection{Collection of information and specification of the service}

Respondent initialisation visits can facilitate the selection of representative service transactions (i.e. contracts or charge-out rates). Where feasible, PPS sampling could be used in this process. Alternatively, the respondent could select transactions to represent the most important service activity types.

As a first step, information about the different pricing mechanisms typically used in the industry should be obtained. Price collection questionnaires should be designed to reflect the pricing mechanisms employed. Germany conducted a dedicated survey of respondents in order to identify their main service activity types (e.g. drafting creative advertising), billing mechanisms (e.g. net) and employed personnel (e.g. 100\% Art Director (senior)). Information collected during this survey was used to develop customised survey forms for respondents.

Several countries use external sources for data collection. Industry representative associations may be able to provide information on market characteristics and the pricing mechanisms typically employed in the industry. In Germany, the industry representative association also provides the unit value data for advertising space in television and radio.

While commission based pricing for advert placement services has declined significantly among U.S. advertising agencies in recent years, some responding firms still earn revenue through this compensation model. In these instances, respondents are asked to estimate the media cost and their commission percentage in order to determine the estimated commission amount received if they were to place the same type of advertising for a similar client in subsequent months. The U.S. has found that it is extremely difficult for respondents to update the media cost in subsequent months since advertising agencies themselves do not determine these rates. In order to estimate media costs over time, the price of the media placement is instead escalated by an appropriate SPPI media index. For example, the price of placing advertising on local radio is escalated by the SPPI for local radio time sales. Respondents can change the escalated value if necessary each time they report; if they do not, the SPPI escalated value will be used to estimate the commission amount received. This escalation practice eases reporter burden as respondents can focus on updating changes, if any, to the commission percentage they charge. However, this method can only be implemented if: $i$ ) the advert placement transaction collected is isolated to a specific type of media; and $i$ ) a SPPI which tracks advertising for that specific medium is available.

Examples for price determining characteristics of advert placement services are:

- For radio or television:

- $\quad$ Length of the ad (15, 30, 60 seconds);

- Time of day/ week ad is aired;

- Ad aired around features or popular seasons; 
- Quantity of commercials bought;

- Discounts (volume/ frequency);

- Geographic and demographic targeting;

- National versus local advertising;

- Popularity of show (high versus low rating).

- For newspapers or magazines:

- Size of the ad;

- Placement (position) of the ad;

- Black and white versus colour;

- Number of colours in the ad;

- Size of circulation;

- Geographic and demographic targeting;

- Section of newspaper (main news, sports, real estate, business, etc.).

Discounts are an important feature of the pricing of advertising services and it is crucial that they are taken into account so as to accurately measure the actual fees received for the provision of the service of media purchase or sale.

There are generally two types of discounting applied in the sale of advertising space:

1. Discounts that are given as a result of successful negotiations, as in many other industries;

2. Discounts given to clients as compensation for failure to achieve predicted audience figures. Due to the size of discounts given in the industry, the latter is seen as only a minor factor contributing to the overall discounts that are used as an instrument to strategically discriminate prices, to skim consumer surpluses and to react on the overall economic situation. Discounts need to be taken into account for the SPPI calculation.

It may be difficult to identify the true value of discounts as they are commercially sensitive. Moreover, a discount can be given with a considerable time lag. The actual transaction price is, therefore, observed retrospectively. Until then the price index is provisional. In Germany, an annual supplementary survey on discounts asks for the percentage change of given discounts in the current year in relation to the previous year. The published (preliminary) price indices of the previous four quarters are corrected accordingly. Preliminary results are based on forecasted discounts.

Capturing discounts for advertising services can be problematic in the U.S. and this problem is also experienced in other countries. When collecting prices for advertising agency services, the U.S. attempts to capture discounting implicitly by requesting that respondents estimate the price that would be charged to provide the same service to the same type of client in subsequent months. While an actual dollar value of the discount amount is not reported each month, the price reported still reflects discounting since it is an estimate of the negotiated price that would be charged to that client based on prevailing market conditions. 
Only in the case of a reseller acting as wholesaler should discounts given as audience compensation (in this case by the media space producer) not be taken into account. As a result, price changes can be measured directly in the case of wholesalers.

In the case of portfolio managers on the other hand, only retrospective measurement of price change is possible as portfolio managers give discounts in retrospect to adjust for quality changes (as described under Section 6).

Greater emphasis should be placed on the internet advertising sub-sector, which represents $16 \%$ of advertising expenditure in the U.K. (Advertising Statistics Yearbook 2008). The growth of internet advertising influences both the creative and the placement activity sectors. Generally there are two ways of measuring price changes in this sector. If clients pay their agencies per click on advert, calculation is straightforward and could for example be based on price per click or per thousand clicks. Industry research firm eMarketer indicates that spending on internet advertising accounted for $17 \%$ of total U.S. advertising expenditures among major media types (television, internet, newspapers, radio, directories, magazines, outdoor) in 2010 and is projected to grow to $26 \%$ by 2015 . In the U.S., internet advertising space can be sold in a variety of ways, such as directly by the media or through ad exchanges or ad networks. Internet advertising is often priced on a cost per click (CPC) or cost per 1000 impressions (CPM) basis. Other countries may use the abbreviation CPT instead of CPM.

\subsubsection{Main pricing methods}

\subsubsection{Model pricing}

Model pricing can be used for the advertising services activities of advert creation and media placement services:

For creative advertising services activities, the respondent is requested to provide a price and description for a fictitious single service or a price based on a service provided in the recent past. As personnel typically constitute the highest cost factor in the creative sector, labour costs (type of staff, number of hours and hourly rates) constitute the main factor in the model contract. In successive periods respondents are asked to estimate how the prices for the characteristics specified in the original contract have changed, or if any of the features in the contract or staff information is no longer applicable. To maintain constant quality, the services characteristics should be specified in considerable detail. The price provided by the respondent is an estimate of the service fee.

For media placement services, hourly rates or staff hours are not usually listed in contracts. The price provided by respondents is the monthly (or quarterly) fee or commission received for the placement of the ads in a specified contract (depending on the billing method the price for the media space might be added). If the price is a commission, it is based on the total monetary value of the placed advertisements. If the publication structure for advertising services has detailed indices for media placement for different media, then the model should be limited to a single type of media. For example, the contract should only contain adverts placed in newspapers and not adverts placed on television or radio.

In order to obtain a full transaction price for these models, the two service lines may have to be bundled together for the provision of a media placement service that includes advert creation. In this bundled service, respondents often charge for only the placement 
of the advert and include the advert creation service for 'free' (or vice versa). In this situation, the description of the service provided must include both these activities.

\subsubsection{Unit value method}

The unit value method is mainly used in the media placement industry. Unit values can be appropriate for highly homogeneous services.

When advertising space or time is purchased, it is traditionally done so on cost-perthousand (CPT) viewers basis. The CPT can be calculated with reference to either expected or achieved audience figures.

The unit value method intrinsically contains a quality adjustment by audience size which is problematic for brokers and wholesalers.

Depending on the legal framework in the respective country, the media placement agency might have to compensate for underachieved audience figures by providing retrospective discounts. If such a discount has been provided, it is imperative that this refund is deducted from the price originally charged, since the final price received by the agency or marketer lower than the originally billed price. SPPIs should always measure changes in the price actually received by the service producer.

Alternatively, one could obtain unit value prices by dividing commission received by the number of adverts placed in a certain homogenous time slot for television such as prime time viewing.

If the unit value method is employed across different clients and advertisements the index may suffer from bias. Therefore, it is vital that the method should only be employed for fully homogenous services.

\subsubsection{Component pricing}

Under the component pricing method the respondent chooses a representative contract, which is broken down into a number of key components. One or more of the key components are then priced in future periods. Although this may make pricing easier for the respondent, discounting and other price changes may not be captured as reported prices are not based on complete contracts.

\subsubsection{Pricing method based on working time}

Pricing methods based on working time are mainly used in the creative sector as the mechanism for pricing is the time that professionals work in order to create the advert. For example, average hourly charge-out rates for specific advert creation professionals can be priced. In most cases, these professionals are staff members, for example a graphic artist. It is advisable to categorise and identify staff by grade or profession and level of experience.

Hourly charge-out rate lists should not be used for on-going pricing. A bias may arise due to changes in productivity, particularly where the relationship between labour and output is not fixed. Furthermore, hourly charge-out rate lists are usually only updated once a year. 


\subsubsection{Fixed fee}

A fixed fee can be used for more regular services that have few components. However, this fee would be considered a list price if the service varies in quality from period to period. List prices for advertising services are not appropriate as most prices in advertising are negotiated, highly variable and heavily discounted.

\subsubsection{Quality issues}

Creative advertising activities are generally not quality adjusted. However, the quality adjustment of media placement services is a much discussed issue.

Changes in the price of a service can be considered to be made of two components: pure price change and quality change. Only the pure price change should be reflected in the price index. Quality changes should not be considered as part of the price change. However, measurement of quality change in media placement activities is problematic. Depending on the particular market settings in a country, changes in audience size can be interpreted as changes in quality. Here, it is important to consider the differences that result from any legal obligation that the service producer has to its customer. Where an agency charges its client purely for the service of purchasing the media space and where the fee is based on the number of hours worked, this fee is clearly not linked to the achieved audience size.

On the other hand, media marketers or media agencies can act as portfolio managers who manage bought media space in order to achieve a certain audience size for their customer. Here, the fee will be reduced if the achieved audience size is lower than expected and vice versa.

Thus, whether audience size can be used for quality adjustment depends on industry conventions. It is applicable in those industries that supposedly add value beyond the wholesale activity (by managing a portfolio of space to achieve higher audience). Here, the effect of a change in achieved audience size should be removed to attain the pure price change.

\subsubsection{Weighting and aggregation}

Weights for lower level indices are optimally drawn from a single turnover or employment structure that includes all chosen service activity types. Higher level indices can be compiled by aggregating these elementary indices according to their respective weights.

In practise however, more than one data source is often used. . For example, turnover data may be supplemented with available market structure information on the service category (i.e. industry representative association data on distribution of TV advertisement turnover across broadcaster and time-slot for gross TV media placement). The sources for the latter can include dedicated surveys, administrative data or other non-official industry information.

In Germany, weights are compiled from a combination of a dedicated survey and information provided by industry representative organisations.

The weights should mirror the measurement of the turnover in the industry. If net turnover is collected, weights generated from the net turnover structure should be used.

Weights should be updated regularly and at least every 5 years. 


\subsubsection{Specific aspects}

As the advertising services industry changes over time, so too may pricing mechanisms. The types of prices collected should be updated as industry standards change. In recent years the U.S. has seen a move away from commission based pricing for advert placement services towards fee based compensation. A survey conducted by the Association of National Advertisers (ANA) in 2010 found that fee based pricing accounted for $75 \%$ of all U.S. compensation plans, while commission based pricing accounted for only $3 \%$ of all plans.

\subsubsection{Overview of national methods}

As previously mentioned, there are significant differences between countries in regard to prevailing business models (brokers or resellers).

Austria

In Austria, hourly rates are surveyed for the SPPI for Advertising Agencies. Respondents define a typical average customer for whom average hourly charge-out rates are priced for 11 specific advert creation professionals (for example Creative Director or Etat Director). Indices per professional category are aggregated to form the SPPI for Advertising Agencies. This index is further aggregated with an index for Media Representation Services, which monitors the price of advertising space or time in different areas and media types, to obtain an overall index for NACE 73.1.

\section{Czech Republic}

In the Czech Republic, media marketers (resellers) charge on a gross basis. The SPPI covers media representation services only. List and invoiced prices are collected for predefined advertisements (e.g. for print media the price of $1 / 2$ page on a Thursday in black and white is monitored).

\section{France}

In France media agencies are brokers and are not allowed to act as wholesalers; they only can buy space or time for specific customers (Sapin Law 1993 aiming at transparency in media space prices). However, turnover is still collected on a partly gross basis. Unit prices are calculated for media space sellers (subsidiaries of media business enterprises). Examples of specific service transactions include; prices for a column in a newspaper, and prices for 30 seconds TV advertising. Commission rates differ substantially across media types.

\section{Germany}

In Germany, a mixture of resale and brokerage is common and pricing mechanisms vary between agencies. Resellers act as portfolio manager and generally give retrospective discounts to adjust for actually achieved audience sizes. The unit value pricing method is employed in Germany. Unit values are calculated by subtracting discounts from the price of the advertisement (e.g. 30 seconds in a certain time frame aired by a certain broadcaster), correcting for achieved audience figures and actually given discounts. The SPPI is preliminary until the discounts are incorporated.

\section{Hungary}

The pricing methods used in Hungary are selected in close cooperation with respondents, taking into account the market structure, pricing mechanism, accounting and 
controlling system. For service providers other than media agencies, the unit value method is the most common methodology employed, followed by pricing based on working time.

\section{Japan}

Japan employs a mixture of methods: direct use of prices of repeated services (for radio commercials, outdoor advertising, advertising in traffic facilities, leaflet advertising, direct mail, and internet advertising) and the unit value method (for television commercials, newspaper advertising, magazine advertising, and free newspaper \& magazine advertising). For the unit value method, average monthly rate for specified time $\&$ program or for specified size and position is surveyed. The audience size is regarded as a key factor determining the quality of the advertising services. Therefore, audience size is considered in the calculation of the indices for television commercials, leaflet advertising, direct mail, internet advertising, and free newspaper \& magazine advertising.

\section{Spain}

Spain compiles a SPPI for Media Representation Services only. A unit value approach is employed by dividing turnover by number of minutes or advertising pages respectively.

\section{United-Kingdom}

In the U.K., media agencies act like wholesalers, meaning that they purchase media in bulk. Therefore turnover is collected on a gross basis (see also section 1). However, media agencies never actually own the media space themselves. This results in a mismatch with the ISIC and NACE classifications which refer to the "Sale of advertising space or time", as in practice this activity does not take place in the U.K. The U.K. currently compiles two separate SPPIs for advertising. The first covers the placement part of the industry (i.e. the cost of actually placing an advertisement in various forms of media). For this index the U.K. uses two sets of administrative data to compute unit value prices. The first data set provides information on rate cards and circulation figures for the newspaper and magazine industry. The second dataset provides revenue and audience figures for television advertising which allows a cost per thousand (CPT) viewers price to be derived. These unit value prices are then weighted together to calculate an aggregate price index for advertising placement services. This SPPI is published on a quarterly basis.

The second U.K. SPPI for the advertising industry is currently in development and focuses on the creation and media buying side of the industry. For this index, the U.K. is using a more traditional survey based approach to collect price information. A time based pricing method is being piloted, where respondents are asked to provide realised hourly rates for any relevant personnel across a number of different advertising services. This realised hourly rate should be the average amount received for the service (per hour) after discounting has taken place. Movements in these rates are weighted together to create an aggregate price index for the industry.

\section{United States}

In the U.S., advertising agencies act strictly as brokers and charge their clients only for their services. Therefore advertising agency turnover is collected on a net basis. Model pricing is the prevalent pricing method employed. The BLS typically collects transaction price for selected projects. Survey respondents are asked to estimate the price that would be charged to perform the same project in subsequent months. The transaction 
description may include the total amount billed for labour (labour rates multiplied by number of hours worked by each individual involved in the project) plus any additional non-labour fees charged (for example, mark-ups on services provided by outside vendors, travel, and administrative fees).

\subsection{Market research and public opinion polling (Aspasia Papa, Office for National Statistics United Kingdom)}

\subsubsection{Industry description (ISIC 7320)}

Market Research involves the systematic collection, analysis, interpretation and presentation of data with the aim of providing an increased understanding of target markets or consumers. Market research activities help to support and inform business decisions and therefore refer to a process of gathering information rather than selling a product.

Market research can take on a number of forms and structures depending on the business needs of the customer. Traditional vehicles for market research such as telephone and face to face interviews are still employed by market research organisations. Additionally, newer methods that use up-to date technology (such as television panels, internet tracking and e-forums) can be observed.

\subsubsection{Classification aspects}

\subsubsection{Industry classification}

Both ISIC and NACE classify market research and public opinion polling under section M - Professional, scientific and technical activities, which includes division 73 Advertising and market research. Group 732 - Market research activities, contains a single class 7320 - Market research and public opinion polling. The class entails investigation into market potential, familiarity of product and consumer buying habits as well as collective opinion of the public on political and socioeconomic matter. It also includes statistical analysis of the data gathered.

Both ANZSIC and NAICS classifications have similar structures in that they also include only one class. However, both provide an alternative definition of the industry, as comprising establishments primarily engaged in systematically gathering, recording, tabulating and presenting marketing and public opinion data. ANSIC explicitly includes statistical bureau operation as a primary activity.

\subsubsection{Product classification}

The CPC classification includes one group (837) and class (8370) for Market research and public opinion polling services. The CPA classification, however, provides a more detailed delineation by dividing the class into 6 subcategories. Indeed, the CPA distinguishes between qualitative and quantitative surveys, carried out either on an ad-hoc or continuous basis. The CPA also identifies separate sub-categories for market research services carried out on secondary data as well as other market research services and public opinion polling.

The NAPCS classification has two main industries, marketing research services and public opinion polling services and related products. The first industry delineates market research services by survey instrument, i.e. telephone, internet, mail and focus groups and 
other face to face methods. It also distinguishes media audience research services and market research services not elsewhere classified (e.g. analysis of secondary data). Finally, it separately identifies sampling and survey design and data collection by means other than telephone.

The second industry, public opinion polling services and related products, is disaggregated by data collection through the phone, data processing and publication and by own-account custom-made software and other related products.

\subsubsection{Scope of the survey}

This industry includes the entire spectrum of the research and opinion polling value chain, ranging from survey design and pilot testing of the survey instrument to sample design and analysis as well as report writing and presentation.

It should be noted that ISIC section M, division 72 - Scientific research and development activities refers to research and experimental development activities on natural sciences and engineering as well as social sciences and the humanities. The principal difference between these activities and market research and opinion polling activities is that the latter are more standard and continuous in nature.

Research and analytical services that are predominantly associated with the purchase of media space are outside the scope of this survey as they are classified under media planning and buying services.

\subsubsection{Sample design}

Sampling is generally conducted with reference to national business registers. More often than not, these registers will not include sufficient detail to specify the individual services produced by each business enterprise on the register. The population frame may therefore be supplemented by membership lists from industry representative associations.

In order to achieve a representative sample, it is advisable to use a stratified sampling scheme, either single or multi-stage, where the stratum criterion could be the service being offered and/or the business enterprise size. Larger business enterprises tend to have more scope for conducting extensive research with the latest technology, such as television program tracking boxes. Smaller business enterprises tend to concentrate their services on traditional market research methods such as telephone and face to face interviews. The sample size of each could be determined with reference to the total turnover attributed to each stratum.

\subsubsection{Collection of information and specification of the service}

Prices are typically collected through a quarterly survey. Respondents are asked to identify contracts that they expect to be repeated or models that are representative of the market research services they produce. Respondents are then asked to provide a current period price for each contract or model. The quality for service specified in each contract or model should be kept as consistent as possible.

When quoting prices, respondents should be required to take into account the following price determining characteristics:

- Staff, travel and subsistence costs;

- Mode of data collection and associated costs (e.g. telephone interviewing); 
- Hours involved in analysing and producing final products;

- Number and length of interviews or number of respondents;

- Additional outputs (e.g. presentations).

Completed surveys are typically returned by telephone, post or fax. Large and atypical price changes require explanation from the respondents. Respondents should also provide justification for changes to contracts and models.

\subsubsection{Main pricing methods}

\subsubsection{Model pricing}

Model pricing is commonly employed for the market research and opinion polling services industry reflecting the fact that the services produced by this industry are often unique and priced as packages.

The model pricing methodology necessitates close monitoring to ensure respondents are able to provide consistent and representative price quotes for each survey period, and to identify any changes in the way in which services are delivered. Models that become unrepresentative of the services produced should be promptly replaced with representative services. Model pricing can result in greater respondent and processing burdens than other methodologies and it is important to maintain regular contact with respondents to ensure that the prices reflect adequately the evolution of the market situation.

\subsubsection{Time based methods}

Time based methods may also be employed for this industry. These methods have the advantage of involving reduced levels of respondent burden. Respondents may be asked to provide the average achieved (or realised) hourly charge-out rate for a specific period for the activity and grade concerned. This is the hourly charge out rate, averaged across projects, actually achieved after taking into account any discounts and any hours written off during the period. Alternatively, respondents could be asked to supply the standard charge-out rate adjusted by a realisation rate for the period.

Whilst obtaining information on staff grades and worked time within each project is relatively straightforward, the main disadvantage of collecting hourly charge-out rates is that the methodology fails to capture other variables that impact on pricing within the industry. Indeed a change in an indirect variable such as the price of telecommunication costs for telephone interviewing will not be captured as charge out rates would remain constant. Furthermore, time based methods do not account for changes in quality of the service activities provided or for changes in productivity. When charge-out rates are used, the implicit volume measure is "hours worked". No adjustment is made for varying levels of quality of work performed.

\subsubsection{Quality issues}

Quality problems arise when models become outdated and are therefore no longer representative of normal practice within the industry. This is particularly apparent in the market research industry where the dynamic nature of technology surrounding the industry can simultaneously lead to improvements in quality and lower prices. It is important that compilers ensure that models remain representative by monitoring business 
practices within the market research industry and keeping in regular contact with respondents.

\subsubsection{Weighting and aggregation}

The weighting structure should be generated by establishing an aggregation structure for the output or turnover generated by the different types of service activities produced by the industry. Suggested categories at the elementary level include:

- Group discussion;

- Tracking study;

- Hall test, i.e. opinion polling;

- Other interview, attitude and survey work;

- Other market research.

Price relatives are calculated at the elementary level and weighted using turnover information. Detailed turnover data may need to be collected through a dedicated survey or as part of the respondent initialisation process.

\subsubsection{Specific aspects}

One of the major challenges presented by the market research industry is the apparent reporting gap between actual transaction prices and those derived from charge-out rates. Every client and project combination is unique. Discounting does not seem to be applied on an average basis but tends to depend on the importance of the client and the monetary value of the project.

Other issues facing the industry include: the off-shoring of market research call centres to countries with lower labour costs; the growing importance of research carried out via the internet and the corresponding decrease of mail based research.

\subsubsection{Overview of national methods}

\section{Austria}

In Austria, an SPPI for the market research and public opinion polling sector is estimated using a combination of model pricing, direct use of prices of repeated services and charge-out rates. The sector is divided into qualitative research, quantitative research as well as time based services (i.e. daily charge-out rates per qualification category). For each field a product index is aggregated and these sub-indices are combined to give the total SPPI for this sector.

\section{Australia}

In Australia, market research and statistical services are classified under ANZSIC division M, subdivision 69 - Professional, scientific and technical services (except computer system design and related services).

Non-probability sampling is used whereby respondents are chosen on the basis of their market share. Interviews with prospective respondents are then conducted to assess their suitability to participate in the survey and to determine the most representative services for on-going pricing. The sample is confined to the states of New South Wales and Victoria, where the majority of the industry in Australia is based. 
Data is collected by survey questionnaire from respondents via mail on a quarterly, bi-annual or annual basis. Each respondent is asked to provide the price for their specified service product transactions and the reason(s) for any reported changes in price. This allows compilers to validate reported prices.

Basic prices are used for output price indices. Respondents are asked to provide the price they receive exclusive of goods and services tax. Both model pricing and times based methods are employed. Each specification is assigned a weight based on the share of revenue that that service generates for the respondent and the respondent's share of total industry revenue.

Product descriptions are well specified to ensure respondents are able to provide prices for the same quality service every quarter. Should a quality issue arise, the respondent is queried by phone. This normally occurs when there is a change in the respondent's contact as the new contact may not be aware of how the previous contact derived the reported prices. Quality issues can also occur when there are changes to the services produced.

Challenges in collecting data for this index include:

- Respondents not completing surveys in time for compilation;

- A new respondent contact who is not familiar with the survey or the manner in which the previous contact estimated prices;

- Inadequate reasons provided for price change, thereby requiring further investigation. Occasionally it is difficult to contact respondents and if valid reasons for significant price changes cannot be obtained, it may be necessary to impute prices.

\section{Germany}

In Germany, the industry is split into secondary-research and consultancy projects, quantitative ad-hoc-research projects, qualitative research projects and quantitative panel research.

The Federal Statistical Office business register is used to identify all units in the survey population according to their size by turnover with two modifications. Firstly, all businesses enterprises with turnover of at least $€ 10$ million are included in the survey. Secondly, businesses enterprises with turnover below $€ 500,000$ are excluded from the survey in order to reduce the bureaucratic burden.

The realised charge-out-rate method is employed for the secondary research and consultancy fields sub-industries, and the component or model pricing methods are employed for the remaining sub-industries.

\section{Japan}

Japan compiles a SPPI for market research and public opinion polling service activities. The index covers market surveys and public polls by means of face-to-face interviews, internet surveys and hall tests. Japan uses the direct use of prices of repeated services, the unit value method and the model pricing method. 


\section{Bibliography}

\section{Legal activities:}

McKenzie, R., (2001), Producer Price Index for the Legal Services Industry, $16^{\text {th }}$ Voorburg Group meeting, Sweden, Norway available at:

http://www.voorburggroup.org/Documents/2001\%20orebro/papers/2001-033.pdf

Matulska-Bachuira, A., and Jones, T., (2010), Revisited Sector Paper on Legal Services, 25th Voorburg Group meeting, Vienna, Austria available at: http://www.voorburggroup.org/Documents/2010\%20Vienna/Papers/2010\%20\%2013.pdf

Accounting, Bookkeeping and Auditing Activities; tax consultancy:

Bordé F., and Garneau G., (2001), A Producer Price Index for Accounting Services, $16^{\text {th }}$ Voorburg Group meeting, Örebro, Sweden available at: http://www.voorburggroup.org/Documents/2001\%20orebro/papers/2001-036.pdf

Draper, C., and Loranger, A., (2011). Initializing New Respondents in Price Surveys, Presented at the Joint OECD-Eurostat Task Force for the Revision of the Methodological Guide for Developing Producer Price Indices for Services, Paris, April 2011.

Kennesey A. et al., (2007), Thesaurus of Producer Price Indices for Services (SPPI's), $22^{\text {nd }}$ Voorburg Group meeting, available at:

http://www.voorburggroup.org/Documents/2007\%20Seoul/papers/03.pdf

Schoultz, Ch., and Zetterberg, K., (2008), Revised Sector Paper on: ISIC 6920 Accounting, Bookkeeping and Auditing Activities; tax consultancy, $23^{\text {rd }}$ Voorburg Group meeting, Aguascalientes, Mexico available at:

http://www.voorburggroup.org/Documents/2008\%20Aguascalientes/Papers/2008\%20\%2016.pdf

Statistics Canada, (2009), Services Bulletin: Accounting Services, Catalogue nº 63-256-X available at:

http://www.statcan.gc.ca/pub/63-256-x/63-256-x2012001-eng.htm

\section{Management consultancy:}

Baer, A., (2006), The U.S. Producer Price Index for Management Consulting Services (NAICS 541610), 21st Voorburg Group meeting, Wiesbaden, Germany available at: http://voorburggroup.org/Documents/2006\%20wiesbaden/papers/28.pdf

Buisson, B., (2005), The French SPPI on business and management consultancy, $20^{\text {th }}$ Voorburg Group meeting, Helsinki, Finland available at: http://voorburggroup.org/Documents/2005\%20helsinki/papers/2005-17.pdf

Camus, B, and Wallace, M.E., (2007), Sector Paper on Management Consultancy (ISIC 7020), $22^{\text {nd }}$ Voorburg Group meeting, Seoul, Korea available at: http://voorburggroup.org/Documents/2007\%20Seoul/papers/08.pdf

Ciolek, A., and Williams, D., (2005), Producer Price Indexes for Business Management Services within Australia, $20^{\text {th }}$ Voorburg Group meeting, Helsinki, Finland available at: 
http://voorburggroup.org/Documents/2005\%20helsinki/papers/2005-18.pdf

Gac, D., (2006), The French SPPI on business and management consultancy, $21^{\text {st }}$ Voorburg Group meeting, Wiesbaden, Germany available at: http://voorburggroup.org/Documents/2006\%20wiesbaden/papers/24.pdf

Lorenz, S., Roemer, P., and Stroh, A., (2005), SPPI for Business and Management Consultancy Activities in Germany, $20^{\text {th }}$ Voorburg Group meeting, Helsinki, Finland available at: http://voorburggroup.org/Documents/2005\%20helsinki/papers/2005-20.pdf

Lorenz, S., and Ritter, L., (2006), SPPI for Business and Management Consultancy Activities in Germany, $21^{\text {st }}$ Voorburg Group meeting, Wiesbaden, Germany available at:

http://voorburggroup.org/Documents/2006\%20wiesbaden/papers/26.pdf

York, J., (2005), Pricing Business and Management Consulting: the New Zealand Experience, $20^{\text {th }}$ Voorburg Group meeting, Helsinki, Finland available at: http://voorburggroup.org/Documents/2005\%20helsinki/papers/2005-27.pdf

\section{Architectural activities:}

Krüger Enge, A., (2000), Developing PPIs on Architectural and Civil Engineering Services: the Norwegian Experience, $15^{\text {th }}$ Voorburg Group meeting, Madrid, Spain available at:

http://www.voorburggroup.org/Documents/2000\%20madrid/papers/2000-016.pdf

Goldhammer, B., (2008), ISIC Rev. 3.1 4421/Rev. 47110 Architectural and engineering activities and related technical consultancy, Voorburg Group meeting, Aguascalientes, Mexico available at:

http://www.voorburggroup.org/Documents/2008\%20Aguascalientes/Papers/2008\%20\%2032.pdf

\section{Engineering services:}

Krüger Enge, A., (2000), Developing PPIs on Architectural and Civil Engineering Services: the Norwegian Experience, $15^{\text {th }}$ Voorburg Group meeting, Madrid, Spain available at:

http://www.voorburggroup.org/Documents/2000\%20madrid/papers/2000-016.pdf

Goldhammer, B., (2008), ISIC Rev. 3.1 4421/Rev. 47110 Architectural and engineering activities and related technical consultancy, Voorburg Group meeting, Aguascalientes, Mexico available at:

http://www.voorburggroup.org/Documents/2008\%20Aguascalientes/Papers/2008\%20\%2032.pdf.

Rosenbaum, A. (2002), Price Indexes for Engineering Services - Measuring Output Prices for Engineering Services in the United States, Voorburg Group meeting, Nantes, France available at:

http://www.voorburggroup.org/Documents/2002\%20nantes/papers/2002-007.pdf

\section{Technical testing and analysis:}

Papa A. (2012), Updated Sector Paper on industry ISIC 712 Technical testing and analysis, $22^{\text {th }}$ Voorburg Group meeting, Warsaw, Poland available at: http://www.voorburggroup.org/Documents/2012\%20Warsaw/Papers/1002\%20-

\%20Update_Technical testing_sector_paper.pdf 
Hungarian Central Statistical Office (2012), A szolgáltatási kibocsátási árak alakulása (The development of Service Producer Prices, 2011), available at (Hungarian only): http://www.ksh.hu/docs/hun/xftp/idoszaki/pdf/szolgkiboar11.pdf

Borstel von J. (2011), SPPI for Technical testing and analysis in Germany, $23^{\text {th }}$ Voorburg Group meeting, Newport, United Kingdom available at: http://www.voorburggroup.org/Documents/2011\%20Newport/Papers/2011\%20\%2027.pdf

Holilokk S.E., Kalko J. (2011), Price index for services in technical testing and analysis in Norway, $23^{\text {th }}$ Voorburg Group meeting, Newport, United Kingdom available at: http://www.voorburggroup.org/Documents/2011\%20Newport/Papers/2011\%20$\% 2029 . p d f$

Spanjaard M. (2011), SPPI for Technical testing and analysis in the Netherlands, $23^{\text {th }}$ Voorburg Group meeting, Newport, United Kingdom available at: http://www.voorburggroup.org/Documents/2011\%20Newport/Papers/2011\%20\%2026.pdf

Eidman U. (2010), A comparison of methods used to compile PEEIs in short-term business statistics, Statistics in Focus 52/2010, Eurostat, Luxembourg available at: http://epp.eurostat.ec.europa.eu/cache/ITY_OFFPUB/KS-RA-12-005/EN/KS-RA-12005-EN.PDF

Rémond-Tiedrez I. (2008), Service producer price indices (SPPIS): a new European economic Indicator, Statistics in Focus 103/2008, Eurostat, Luxembourg available at: http://epp.eurostat.ec.europa.eu/cache/ITY_OFFPUB/KS-SF-08-103/EN/KS-SF-08-103EN.PDF

Kennesey A. et al, (2007),. Thesaurus of Producer Price Indices for Services (SPPS), $22^{\text {nd }}$ Voorburg Group meeting, Seoul, South Korea available at: http://www.voorburggroup.org/Documents/2007\%20Seoul/papers/03.pdf

\section{Advertising:}

The first country-specific experiences in gathering data on pricing mechanisms in the advertising industry were presented at Voorburg Group meetings in Örebro in 2001 and in Nantes in 2002.

Voorburg papers 2008 - 2010 sum up the current discussion after agreement as to how to deal with several issues that differ significantly across countries.

Pegler, K., Berger, M. and Šulc, J. (2009), Revisited Sector Paper on ISIC 7310 Advertising. 24th Voorburg Group meeting, Oslo, Norway available at: http://www.voorburggroup.org/Documents/2009\%200slo/Papers/2009\%20\%2066.pdf

Wirsing, M. (2009), The new producer price indices for advertising and market research. Wirtschaft und Statistik 7, Destatis, Wiesbaden, Germany.

Pegler, K. and von Borstel, J. (2010), Quality Adjustment Paper on ISIC 7310 Advertising, 25th Voorburg Group meeting, Vienna, Austria available at: http://www.voorburggroup.org/Documents/2010\%20Vienna/Papers/2010\%20\%2088.pdf 


\section{Market research and public opinion polling:}

Stroh, A. and Lorenz, S., (2005), Producer price indices for services, SPPI for market research in Germany, $20^{\text {th }}$ Voorburg Group meeting, Helsinki, Finland available at: http://www.voorburggroup.org/Documents/2005\%20helsinki/papers/2005-24.pdf

\section{Notes}

1. Matulska-Bachura and Jones, 2010.

2. McKenzie, 2001.

3. Matulska-Bachuira and Jones, 2010.

4. It is recommended to review these proportions with the respondent on an annual basis and adjust aggregation weights accordingly.

5. It is recommended to review these proportions with the respondent on an annual basis and adjust aggregation weights accordingly.

6. Differences exist between the various international classification systems. This section is designed to give the reader a general overview of the types of services provided by the sector and does not refer to any one particular classification system. A comparison of the different international classifications will be given in sub-section "classification aspects" of this section.

7. Tax preparation services are separated into two categories: $i$ ) Tax preparation services for corporate clients; and ii) Tax preparation services for individuals and unincorporated businesses.

8. See Ciolek, and Williams (2005), Buisson (2005), Lorenz et al.. (2005), Lorenz and Ritter (2006), and York, (2005).

9. See Goldhammer (2008).

10. NACE 71 - Architectural and engineering activities; technical testing and analysis, 7111 - Architectural activities, 7112 - Engineering activities and related technical consultancy, 7120 - Technical testing and analysis

11. For example in Polish classification: 7120A - Food quality related testing and analysis, $7120 \mathrm{~B}$ - Other technical testing and analysis;

In the Dutch classification: 71201 - Testing and analysis of agricultural products and food, 71202 - Technical testing and analysis of machinery, equipment and materials, 71203 - Other technical testing and analysis.

12. Source: Statistics Canada (http://www.statcan.gc.ca/concepts/)

13. Even though the price definitions of these two indicators are different in theory, in Finland that does not present a problem in practice, as long as prices are adjusted to basic prices (the effects of subsidies or taxes are removed).

14. See also the section 11.7.10. on Specific aspects.

15. Source: German business register 
16. Source: 2007 U.S. Economic Census

17. Source: 2007 U.S. Economic Census

18. For more information, see sections on price collection and weighting.

19. Source: German service statistics 2009.

20. Source: 2007 U.S. Economic Census. 



\section{Chapter 12. Administrative and support service activities}

This chapter presents practical guidance as well as main issues and challenges for compiling SPPIs for Employment activities (ISIC 78), Security and investigation activities (ISIC 80), and Cleaning activities (ISIC 812). 


\subsection{Employment activities (Dorothee Blang,Destatis)}

\subsubsection{Industry description (78 ISIC)}

The provision of employment services plays a particularly central role in the functioning of the labour market, especially during periods of high employment growth. Employment activities are varied and complex and so the measurement of the value of these services, both in current and constant prices, is challenging.

\section{Structure of the market and recent developments}

Employment activities comprise all services relating to the search for and selection of candidates, supplying workers to clients' businesses for limited periods of time (i.e. temporary employment agencies) and other kinds of human resources provision. These activities have grown at a rapid pace in recent years because they allow businesses more flexibility in adapting to changes in economic conditions. This is particularly true for the services provided by temporary employment agencies which are strongly linked to changes in economic conditions and are often an early indicator of broader economic developments. Thus over the last ten years, the number of temporary workers being placed by agencies has consistently grown, reflecting more flexible patterns of work.

Businesses enterprises engaged in employment activities encounter low barriers to entry in the market and have relatively small capital requirements. As a consequence, there may be a large number of small service producers although the majority of turnover is often generated by large and/or international business enterprises. The existence of a large number of service producers in a market can lead to significant differentiation in the products offered. Large service producers take advantage of their size, length of experience, and international networks while smaller producers often focus on regional, sectorial or occupational "niches". A wide range of services are offered across the division, from staffing to payroll services, outplacement, outsourcing and search and selection.

The industry is sensitive to structural changes in the market; for example, in respect of the ageing population in Europe or changes in the regulation of the labour market. Alongside the more traditional activities of employment placement and temporary employment agencies, new activities have emerged, particularly outsourcing and the services of so-called "umbrella-companies" - both classified within ISIC group 783 Other human resources provision:

- Outsourcing: The client outsources the employment activity to a service producer that supplies workers to the client for a longer period of time. In practice these workers function as regular employees of the client even though they are legally and officially on the service provider's payroll.

Producers of outsourced employment activity services are either legally independent entities (known as Professional Employer Organisations - PEOs) or subsidiaries of business enterprises which transfer the administration of their personnel to this intra-group service producer and subsequently lease them back on a long-term or permanent basis. The service producer therefore becomes the official and legal employer of the workers, even though they remain under the direct supervision of their initial employer - the client.

PEOs often specialise in a single specific sector, such as medical, wholesale or construction, rather than diversifying into several sectors. This allows PEOs to 
realise specialisation effects and economies of scale thereby enabling them to offer reduced prices to clients and enhanced benefits and administrative services to personnel.

The importance of intra-group-PEOs has grown in recent times. Many business enterprises, particularly larger ones, have created PEO subsidiaries to outsource the employment of their workers. This allows them to bypass labour agreements particular to the sectors in which the workers are actually engaged, thereby reducing costs.

- Umbrella companies: The activities of so-called "umbrella companies" function as official employers for actual freelancers and supply them to clients on a temporary basis, usually to run a specific project. They provide freelancers with services in implementing employment contracts and payroll accounting. The freelancers benefit fiscally and professionally from being employed by such an umbrella company (as in the case of the U.K.) or can avoid legal burdens concerning their self-employment (as in the case of France).

\section{Price determining factors and pricing mechanisms}

Differentiation of products, competitive markets, and the emergence of outsourcing and umbrella companies can make the measurement of price change challenging. The price of employment activities can depend on many factors including, the level of qualification or skill that the workers must possess, the length and type of contracts, the numbers of hours worked, the contract between the employment agency and the client, and the geographical location.

In order to effectively measure the change in prices of employment activities, it is crucial to firstly consider how the workers are paid. Different relationships between the service producer, the worker (i.e. the recruited employee), and the client may lead to different pricing mechanisms; reflecting the type of services offered and the way in which the workers are paid.

In this respect, the two following distinct cases should be considered:

1. Workers are employed and paid directly by the client

This case is of particular relevance for placement agencies that provide services in respect of the search for and selection of candidates, and all ancillary services such as skills assessment. These services involve drawing up descriptions of positions to be filled, searching for and selecting candidates. Placement agencies may use advertisements (increasingly online), a direct approach ("headhunting") or a combination of the two in the search for candidates.

Several pricing mechanisms can be employed by placement agencies, including a fixed price, a price based on a percentage of the salary of the placed workers or re-invoicing of costs with profit. Pricing based on a percentage of the annual salary of the placed worker appears to be the most common mechanism. In this case, the placement agency records only the recruitment costs on which the price charged to the client is based; the salaries of placed workers are paid directly to them by the client and therefore the fees paid to agencies should be treated on a net basis.

2. The client pays the service producer, who in turn pays the worker 
This case applies for both the activities of temporary employment agencies and other human resources provision such as outsourcing and umbrella companies. Here, the definition of the output services is an essential part of the SPPI compilation process and should be consistent with national accounting practice.

- The activities of temporary employment agencies relates to the supply of replacement or supplementary workers to clients for limited periods of time. The temporary workers are recruited and remunerated by temporary employment agencies according to the legal conditions in a given country.

The service activity provided by temporary employment agencies to clients is the supply of a defined amount of work according to a certain level of qualification and not the output of the labour performed by the placed workers. The value of output of temporary employment agencies amounts to all payments received by the agency, including those covering the compensation of temporary employees as well as "net fees".

The pricing mechanism involves applying a multiplier coefficient to the temporary worker's hourly gross salary in order to obtain a price per hour. This hourly salary is negotiable between the temporary employment agency and the client, according to the temporary worker's qualifications and market conditions. All other things being equal, changes in salaries result in changes in prices. The size of the multiplier coefficient is a key pricing consideration for the temporary employment agency. It may depend on a number of factors including the temporary worker's qualifications, the client type or the length of assignment. The longer the assignment or the higher the number of hours to be worked, the lower the multiplier coefficient is - particularly if the work is for unskilled employees.

In the provision of temporary employment services, framework contracts for major/regular clients are common. These contracts specify the hourly rates to be charged according to various categories of worker qualifications. Framework contracts tend to be honoured even when there is a change in the general economic situation. The values of the multiplier coefficients for specific clients appear to remain quite stable over time.

- The pricing mechanism typically employed for the provision of other human resource services can be assumed to be similar to the mechanism employed by temporary employment agencies. In fact umbrella companies, as well as PEOs, mostly receive their remuneration by a multiplier coefficient of the salary of the placed worker.

However, subsidiaries functioning as the intra-group supplier of the workforce may set the price for their services simply by summing the wages with overhead expenses without considering any market price for their activities.

\subsubsection{Classification aspects}

\subsubsection{Industry classification}

Employment activities, classified under section N - Administrative and support service activities, division 78 Employment activities, of the ISIC classification system, covers the following three classes: 
1. 7810 - Activities of employment placement agencies, includes listing employment vacancies and referring or placing applicants for employment, where the individuals referred or placed are not employees of the employment agencies;

2. 7820 - Temporary employment agency activities, includes the supply of workers to clients' businesses for limited periods of time to temporarily replace or supplement the working force of the client;

3. 7830 - Other human resources, are typically provided on a long-term or permanent basis and the units classified here may perform a wide range of human resource and personnel management duties associated with this provision. The units classified here represent the employer of record for the employees on matters relating to payroll, taxes, and other fiscal and human resource issues, but they are not responsible for direction and supervision of employees.

As shown in annex A, the ISIC and NACE classifications have the same structure. NAICS has a similar structure although the equivalent of class 7810 is split into two groups namely 561311 - Employment placement agencies, and 561312 - Executive search services. The concordance between ISIC and ANZSIC is less effective since group 721 Employment services, is separated into two classes only: 7211 - Employment placement and recruitment services, and 7212 - Labour supply services, which consists of units mainly engaged in supplying their own employees to clients' business on a fee or contract basis. Additionally, ISIC class 7830 corresponds to activities classified outside the ANZIC group 721, such as management advice and related consulting services or office administrative services.

\subsubsection{Product classification}

The corresponding products for ISIC 78 - Employment activities are classified in the CPC classification under group 851 - Employment services. This group is divided into two classes, 8511 - Personal search and referral services and 8512 - Labour supply services, which are defined as follows:

- 8511 - Personal search and referral services which is further split between:

- 85111 - Executive/retained search services, covering the provision of services such as formulation of job descriptions, specialized search and screening and testing of applicants;

- 85112 - Permanent placement services, other than executive search services, including the provision of services in respect of the testing, interviewing and referring of candidates.

- 8512 - Labour supply services which is further delineated by the specific nature of contracts between the client and service provider:

- 85121 - Contract staffing services, consisting of the search for and referral of a candidate to fill a specific position in the client company. Conditions and terms of employment are pre-assigned in the contract between client and staffing company and the service provider maintains legal rights and duties with respect to the individual worker;

- 85122 - Temporary staffing services including the supply of workforce to clients on a temporary basis in order to resolve shortage of manpower; 
- 85123 - Long-term staffing (payrolling) services covering the supply of personnel for extended work assignments. Under the terms of this arrangement, the client may recruit the person or persons hired by the staffing firm and assigned to their place of work, or transfer a portion of their existing workforce to the staffing firm. Long-term employees are placed on the payroll of the staffing firm, which is legally responsible for their actions, but when working they are supervised by the client. This service includes labour leasing, staff leasing, employee leasing, extended employee staffing and payrolling. The services of Professional Employer Organizations (PEOs) are not included;

- 85124 - Temporary staffing-to-permanent placement services covering the supply of personnel for temporary employment with the expectation of permanent work at the end of a trial period with the client. The employee remains on the payroll of the temporary help staffing firm until the hiring decision is made at which time he or she becomes an employee of the client or, if not, returns to the temporary help staffing firm. This service may include training, counselling, assessment, and resume upgrading;

- 85125 - Co-employment staffing services covering the supply of personnel through a staffing arrangement in which a PEO co-employs a client's workforce. The PEO and the client enter into a contractual agreement whereby the rights and responsibilities in respect of co-employees are shared or allocated, with the service provider assuming responsibility for certain activities as agreed with the client. These range from basic to full-service packages.

The CPC does not therefore distinguish the kind of activity the employee is hired out to, but the kind of service the agency is providing to the client. However, as shown in table 2 of the annex, the corresponding products of the CPA classification, namely 78.20 Temporary employment agency services, and 78.30 - Other human resources provision services, are both further subdivided into the fields of work the employee is hired out to, distinguishing between computer and telecommunications, other office support, commercial and trade, transport, warehousing, logistics or industrial, hotels and restaurants, medical staff, other fields.

Challenges might arise when distinguishing between agencies providing temporary workers and PEOs or intra-group service providers. In order to distinguish between the two, agencies should be asked to identify whether their services involve repeatedly referring and providing workers to clients on a temporary basis or providing staff over a long or open-end period, during which the services provided by the agency are restricted to the administration of the supplied personnel.

Further detail on the structuring of service products in the most common product classifications are presented at the annex B.

\subsubsection{Scope of the survey}

In theory at least, the ideal survey will track price changes for the full range of services provided to all end users across each of the three groups presented under ISIC division 78. However, in practice a number of features of the industry will influence the scope of the survey. 
First, employment services are almost entirely provided to business customers and the provision of these services to private consumers is negligible. Additionally, the share of turnover generated by services for customers abroad is - with about 4\% in 2010 in Germany - relatively small compared to other service industries. Therefore, a disaggregation of the SPPI by destination of output may not be necessary and the survey can be compiled solely on a single BtoB basis.

Second, as noted in chapter 1, intra-group services should only be included in the compilation of the SPPI if their prices reflect basic market prices. Non-market prices that do parallel open market prices should be excluded.

Third, the question of a gross or net treatment of prices underlying the SPPI should also be discussed, ideally with the compilers of the national accounts. From a national accounting perspective, a pure net approach is considered to be appropriate when collecting price data for employment placement agencies, since the agency's services ends with the hiring and the placed worker becomes a regular employee of the client company that pays and administrates him. On the other hand, a gross approach is preferred over the net procedure when collecting price data for temporary employment services and other human resources provision. Although the personnel services of companies providing other human resources are also intended to have a permanent or at least long-lasting effect on the client company, the client does not pay the hired-out worker his salary directly, but only pays the agency for its service. This payment therefore consists of the worker's wage and the agency's remuneration. Consequently, the output of the other human resources providing companies has to be calculated by using these gross-fees, as in the sector of temporary employment. These gross and net treatments should be reflected in the weights used to aggregate the index.

\subsubsection{Industry vs. Product SPPI based SPPI}

Business enterprises classified under ISIC groups 781,782 or 783 rarely offer secondary activities classified outside division 78, except perhaps consultancy relating to employment services (classified under group 702 - Management consultancy activities n.e.c.). However, they often provide a mix of services across a range of employment activities; for example employment placement agencies may also provide human resources services. Therefore the weighting schemes for each of the industry based SPPIs should include a certain percentage of services classified as main activities of the other 3digit industries within the division.

Product based SPPIs measure the price development of all output of a service product irrespective of the industry in which the service producer is classified. In Germany labour supply services are often produced as secondary activities in the management consultancy, IT and engineering industries. Product based SPPIs will include the price development of human resources services produced by these industries.

\subsubsection{Sample design}

Business registers often provide the sample frame, even though they may not always provide all of the information needed for a targeted sample selection. Furthermore, business registers might not be fully up to date and some business enterprises may be incorrectly classified, especially in respect of the distinction between temporary employment agency activities and the provision of other human resources. 
Therefore as a first step, the content of business registers should be verified with other sources of information on the industry such as industry representative associations. This applies particularly to the largest service producers in the market.

Probability proportional to size (PPS) sampling, perhaps supplemented by stratification, can be recommended, ideally with reference to turnover or number of employees. However, if the sample frame does not contain information on the range of services offered by each unit then a combination of PPS and purposive sampling may yield a sample that comprehensively covers all of the service products offered by the industry. Market information gathered from industry representative associations, respondents and market reports can help to inform the purposive selection.

Another option - if a small number of business enterprises account for a significant share of the total output of the industry (or in other words, if the industry is highly concentrated) - is to include only the largest units based on turnover or number of employees in the sample (cut-off sampling). The employment services industry is often relatively highly concentrated and the largest units may accurately represent the evolution of prices in the industry as whole.

\subsubsection{Collection of information and specification of the service}

It is recommended that the compiler establishes on-going cooperation with the industry representative organisation in order to develop a better understanding of the organisation of the industry and to encourage sampled units to participate in the survey. However, as in other industries, some respondents can be hesitant in divulging sensitive price information.

The appropriate level of specification of services and their price-determining characteristics are dependent on the main activity of the respondent. Different pricing mechanisms are employed for different service activities and these will determine the most appropriate pricing method and way in which services should be specified.

In Germany, although the very first request for reporting of prices is conducted by mail, telephone advice and assistance are also provided. Telephone contact with the reporting unit can help to identify the "best" contact person. Respondents then receive a questionnaire which details the service products for which prices are to be reported on an ongoing basis. Respondents are requested to supplement the products specifications (thereby providing transaction specifications) and to notify the corresponding prices for the current and previous reporting period.

\section{Employment placement agencies}

Respondents should be facilitated in reporting prices according to the pricing mechanisms that they typically employ. Information on the appropriate pricing mechanisms and the information required to support on-going pricing should be collected during the respondent initialisation process. Respondents should also be asked to provide information on the share of their total turnover generated by different employment service activities, if this information is not already available to the compiler.

Employment placement agencies use various pricing models. The price of a service is often set as a percentage of the annual salary for a given post. Alternatively, the price may be calculated on the basis of the hourly rate of the employee who provides the employment service and the number of hours needed for the recruitment process. The questionnaire is therefore customised to the pricing method employed by the respondent. 


\section{Temporary employment agency activities and other human resources provision}

From the perspective of price data collection and the price determining characteristics required, the difference between temporary employment activities and other human resources provision is primarily in respect of the length of contracts. Provision of personnel other than on a temporary basis mainly occurs between clients and intra-group service providers. Thus, it might be necessary to identify if the service provider is active in the market (if the price of the service is negotiated between agency and customer), or if it is only an internal price.

Both types of agencies also offer on-site management services. Usually these services are included in the price of providing the hired-out worker. Nevertheless it should be clarified if on-site management is part of the service, if it is invoiced separately and if so, the share of turnover it accounts for.

For temporary employment services and other human resources provision the specification of services and their price determining characteristics also depend on the underlying product classification. As the CPA classification system is used in Germany, for temporary and long-term staffing services the profession and qualification of the provided employee is an important feature of the price. The prices of provided services are usually established on the basis of gross hourly rates which differentiate between different types of workers. As the temporary worker is paid by agency, the final fee for the provided service covers the associated hourly wage rate including the social insurance contribution, other overheads of the agency and the margin of agency. The margin is usually set as a percentage of the gross hourly rate of the temporary worker.

\subsubsection{Main pricing methods}

As previously noted, the pricing mechanisms employed by service providers will vary depending upon the industry subsector and the nature of the services and these will determine the most appropriate pricing method.

\subsubsection{Employment placement agencies}

Employment placement agencies usually set the price of the service as a percentage of the annual salary for a given post. As noted previously, the price may also be calculated on the basis of the hourly rate of the employee who provides the employment services and the number of hours needed for the recruitment process. Fees are often paid by instalment, reflecting the progression of the placement through the different stages of the recruitment process, rather than on the basis of the final outcome of the recruitment process.

The most commonly used pricing methods are the charge-out rate, percentage fee and direct used of prices of repeated services where the survey aims to capture prices of employment placement agencies.

The direct use of prices of repeated services is the appropriate method when standard net-fee prices are available. Alternatively, when prices are based on a commission netfee, which is a proportion of the recruited employee's salary, the percentage fee method can be employed. However, commission net-fees are less straightforward because salaries vary among recruited workers and as a result it may be necessary to average earnings for different categories of occupation. The percentage fee applied generally remains stable and price changes usually result from movements in average earnings for the occupation group used as a reference. Therefore, earnings (or average earnings) must be measured in 
addition to percentage fees. It is important that the average earnings for occupation groups, used in the calculation of service transaction prices, match the types of positions placed by the employment placement agencies.

Finally, the pricing method based on working time could also be employed. Under this method, the hourly rate of the agency's employee (the person responsible for providing the specified service) is multiplied by the number of hours needed for providing the service.

\subsubsection{Temporary employment agencies}

The charge-out rate method is commonly used in the measurement of price change for temporary employment services. Hourly invoicing rates are calculated with reference to the level of qualification of the place worked, the client industry/sector, gross hourly salaries and multiplier coefficients. In all cases, the price of employment services is heavily influenced by the type of temporary worker and their rate of pay. However, it is important that each service transaction is sufficiently well specified to ensure constant quality pricing. Given that the price of employment services may be negotiated between the agency and client depending on specific parameters, these should also be taking into account. Prices are mainly influenced by the following factors:

- Underlying collective labour agreement;

- Type and salary of actual work performed;

- Level of required qualifications - the more qualified worker the higher price;

- Geographical location - e.g. placement in capital cities or wealthier regions may attract higher rates;

- Kind of advertised post depending on the rate of pay (if fixed) - the higher the rate of pay, the higher the price;

- Performed hours (in case of temporary employment) - the more hours performed, the lower price;

- Relationship between the agency and client (employer) - one-off contracts attract higher prices relative to longer-term agreements;

- Margin of the agency;

- Length of contract - the longer the contract, the lower the price;

- Bonus at the end of the year;

- General economic conditions.

Representative placements are selected taking account of the level of qualification required, the client sector/industry and the relationship between agency and client. An average charged hourly rate is calculated based on the number of hours invoiced. These data should be readily available from the management information systems used by larger temporary employment agencies. However, small or medium sized respondents may not compile these data for their own purposes and in such cases the hourly prices charged might be calculated by relating the total transaction price to the total quantity of the transaction, i.e. the number of workers or performed hours. 
Alternatively a single representative average wage rate could be used to track the average rates for similar types of work, if it can reasonably be assumed that changes in this average wage rate adequately represent changes in charge-out rates.

In general, only qualifications and clients that are representative of the temporary employment company's business should be monitored. Furthermore, the compiler must ensure that these types of services can be monitored in subsequent survey periods (regular client, qualification typically required by this client).

\subsubsection{Other human resources provision}

The pricing mechanisms employed for the provision of other human resource services are similar to those used for the provision of temporary employment services. Therefore similar pricing methods can be applied. The charge-out rates and percentage fee methods can also be applied for the human resources provision services of PEOs and umbrella companies. However, when PEOs and umbrella companies provide workers on a longterm or permanent basis, the direct use of prices of repeated services or the contract pricing method could also be applied.

For monitoring prices for intra-group services it is necessary to consider how the supplying subsidiaries determine their prices, i.e. if they are supposed to generate revenue or not. It can be assumed that in many cases such intra-group providers of employment services are reimbursed only for the wages they pay to the supplied workers and some overhead costs. If the development of the supplied workers' wages is expected to be similar to changes in the regular workers' salaries, then the usage of national wage indices of a specific sector could be considered.

\subsubsection{Quality issues}

As discussed previously, the output of temporary work and other human resources services is defined as the provision of labour and not the result of the labour performed by the placed workers. Consequently, prices of working hours of temporary workers do not need to be quality adjusted. In particular, changes in the productivity of place workers do not require quality adjustments of the services produced by the employment agency.

Employing the percentage fee method for placement agencies can however be problematic where reliable and frequent time series of average earnings by detailed occupational group are not available. The use of indices of wage rates at more aggregate levels may result in a reduced quality index. This can be a particular problem for executive recruitment or "head hunting" services.

\subsubsection{Weighting and aggregation}

The SPPI for the employment services industry represents the average price development of all employment activities covered by the survey. To reflect the relative importance of each service product in the price index, each individual price observation should, where possible, be weighted. This may require a dedicated survey of turnover by service product, which is often conducted as part of the respondent initialisation process.

During the development of the SPPI survey in Germany, respondents were required to provide detail on the types of services produced and the share of turnover attributed to them. These data allowed for the calculation of respective weights for the services of employment placement services and provision of personnel services. Additionally, for 
search and placement services, weights were also formed for each of the pricing mechanisms- minimum fee, percentage fee or commission charged on gross salaries.

For EU member states, the supplementary survey to the structural statistics on business services "Turnover by product type and residence of client" offers an excellent data source for revenue share of products for business enterprises in the industry. Additional data may only be needed therefore in respect of the relative importance of the various pricing mechanisms.

Germany publishes SPPIs for group 781 and the sum of groups 782 and 783 . These indices are aggregated to a division level index, on the basis of their respective share of total turnover for the division. The sum of groups 782 and 783 has a relatively high weight in the overall index due to the fact that the wages of placed workers are included in the measurement of turnover.

\subsubsection{Specific aspects}

An increasing number of business enterprises outsource the tasks of personnel management to subsidiaries or contractors. In some cases, placed workers are not paid on hourly basis. Instead, fixed-price contracts are concluded for specific work and as a result, the employment services agency must provide the client with not only the working hours but also successful completion of the work. These service contracts help to circumvent certain employment regulations and thereby facilitate a more flexible workforce - including workers from non-EU countries. Although the supply of temporary workers to the construction sector is permitted only on a very limited basis, this restriction can be circumvented by specific service contracts. The growth in importance of these types of contracts will pose new challenges for price measurement.

\subsubsection{Overview of national methods}

\section{Austria}

Austria uses a combination of model pricing, direct use of prices of repeated services and charge-out rates. The survey covers activities of employment placement agencies, temporary employment agency activities and "try \& hire" activities in different fields of application, i.e. crafts and trades, industry and transport or trade. Weighting information is provided by the trade association for all levels of aggregation.

\section{France}

In France, the contract pricing and charge-out rate methods are the main methods used to measure the evolution of prices of employment activities. About $85 \%$ of the turnover of the division is generated by the activities of temporary employment agencies. This group is highly concentrated (with eight service providers accounting for $80 \%$ of the activity), allowing for a small sample of the largest producers. On the other hand, the number of business enterprises classified under other employment activities is growing in France. These business enterprises are mainly subsidiaries of large groups or large corporations and only support the payment of employees within their parent corporation. Thus far, the only solution found for monitoring the prices of other employment activities is to monitor indicators of wage levels in the industries of the parent corporations.

\section{Japan}

Japan compiles price indices for temporary employment agency services including the recruitment of part-time workers and the provision of personnel services. The unit 
value method is the most commonly employed pricing method. Under this approach an average monthly rate for specified occupation, region and type of contract is monitored. Service types are stratified into multiple categories based on government regulations. A wide range of service types such as the provision of workers engaged in bookkeeping, software development and manufacturing are covered.

\section{United States}

In the U.S., the employment agency industry is divided into three main groupings. Since many U.S. firms offer services classified in two or more of these industries, a single sample of employment placement, temporary help, and executive search firms was used to create SPPIs for each of these service lines, similar to the strategy described in section 12.1.4 (Industry vs. Product based SPPI).

The delineation between employment placement services (formerly contingency payment recruiting) and executive search services (formerly retained executive recruiting) is no longer based on method of payment as was the case in NAICS 2002. While both services provide for the placement of applicants in permanent employment positions in exchange for a commission based on salary, Executive search services only provide for the placement of senior level executive positions.

For employment placement services, the U.S. approach combines elements of model pricing and the percentage fee method. During the initial data collection period a particular placement is selected and in subsequent periods the respondent estimates the price they would charge if they were to make a similar placement with a similar client. Since prices are typically set as a percentage of the value of the first-year compensation of the placed employee, respondents must estimate both the current market compensation for the selected type of worker and the percentage commission fee they would charge. Many respondents had difficulty in providing updated estimates, particularly for the market compensation. To assist respondents with this effort, the U.S. introduced a procedure to update the value of the workers' compensation based on Bureau of Labour Statistics (BLS) employment cost data. These estimates are then presented to the respondents on the survey forms and they are asked to confirm the estimates or update them based on their knowledge of local market conditions. With this approach price variation resulting from the switching of clients is excluded.

For temporary help services, the U.S. collects unit value prices from the largest companies. For these respondents, prices are calculated by dividing the total monthly turnover received for the provision of all temporary workers within a specified job classification by the total number of these labour hours billed. With this methodology, it is essential that the job classification code is defined as narrowly as possible to avoid changes in client or worker mix being shown as price change.

\subsection{Security and investigation activities (Anne-Sophie Fraisse, OECD)}

\subsubsection{Industry description (80 ISIC)}

This division includes security-related services such as: investigation and detective services; guard and patrol services; picking up and delivering money, receipts, or other valuable items with personnel and equipment to protect such properties while in transit; operation of electronic security alarm systems, such as burglar and fire alarms, where the activity focuses on remote monitoring these systems, but often involves also sale, installation and repair services. The security and investigation industry has grown 
strongly over the past decade or so, and continues to do so, giving rise to a wide and varied range of economic activities in both the government domain and the business sector.

In recent years the industry appears to be increasingly overlapping with public law enforcement and national security as governments has become significant customers. Increasingly, specialised firms are providing governments with security services including activities traditionally produced by police forces. The industry will continue to grow as this trend continues although in many countries it will necessitate legislative changes, as well increasing regulation of the industry (OECD, 2004).

Subcontracting of security service activities by business enterprises has also contributed to the growth of the industry.

The main consumers of security and investigation services are other business enterprises and government and the turnover of the whole industry comes almost entirely from the services bought by them. Households account for only a minor part of the industry's total output although the increasing range of services offered is contributing to growing demand.

Despite the strong growth of the industry, its market structure has remained relatively stable. At a national level the industry usually comprises of a few large and medium-size firms and a host of small operators. The larger firms generate a considerable proportion of the total turnover of the industry. They are often major international business enterprises and market leaders in the countries in which they operate. The smaller firms are usually minor local operators. Larger firms offer a more diverse range of services while the smaller firms tend to provide more traditional investigation and security services. Significant changes in market share are relatively rare and often a consequence of business take-overs. Consequently the five-year cycle for reviewing weights employed by many compilers can generally be regarded as satisfactory.

The main services provided by the industry involve the guarding of people and property, which generate the vast majority of its turnover. The total share of industry turnover generated by the provision of investigation services is very small, although smaller firms may specialise in providing these activities. This section focuses on the measurement of price development for security activities as it accounts for the bulk of industry output.

\subsubsection{Classification aspects}

\subsubsection{Industry classification}

In recent years, advances in technology have allowed the services produced by the industry to develop significantly. Larger firms in particular have exploited technological advances effectively, for example through the provision of emergency call centre services covering extensive geographical areas. Smaller local operators are unable to provide services of similar scale because of the substantial fixed costs involved. Partly for this reason many smaller firms have concentrated on providing specialised services over much smaller geographic areas. The development of the industry has not, thus far, resulted in the provision of service activities classified to other industries.

Business enterprises engaged in investigation and security service activities can be adequately and exhaustively classified according to ISIC. It is the most frequently used classification, which many countries have adapted and improved to suit the special 
national characteristics of different industries. These national adaptations must always be thoroughly taken into account in the compiling and reviewing of a price index for the industry.

Security and investigation activities, classified under section N - Administrative and support service activities, division 80 of the ISIC classification system include securityrelated services such as:

- Surveillance, guarding and other security services;

- Transport of valuables;

- Body guarding;

- Surveillance and street patrolling of residential buildings, offices, factories, construction sites, hotels, theatres, amusement venues, sport stadiums, shopping centres, etc.;

- Public transport safety procedures, such as security checking of luggage and passengers at airports and security guarding of trains and underground trains;

- Store detective services;

- Operation of service telephone lines or the like for remote monitoring of mechanical equipment;

- Screening of alarms (to identify false alarms) and calling of police, fire or ambulance services as necessary;

- Consultancy on household and public sector security systems, including background security vetting of individuals;

- Destruction of data from any data carrier;

- Private investigation activity.

Providers of investigation and security services usually specialise in specific service activities, supplying almost exclusively only those services that relate to their own industry. This makes the classification of service providers relatively straightforward. Division 80 of ISIC is split into three groups:

1. 8010 - Private security activities (e.g. security guard, bodyguard, armoured car services);

2. 8020 - Security systems service activities (e.g. monitoring of burglar and fire alarms);

3. 8030 - Investigation activities (e.g. detective, private investigators).

The other international industry classification systems by activity (NACE, NAICS, and ANZSIC) are broadly comparable in the area of security activities with the ISIC classification. As shown in the annex, NACE provides the same structure of the sector as ISIC, with the industry split into three classes. It should be noted that NAICS structures the sector into two main classes: 56161 - Investigation, guard, and armoured car services, and 56162 - Security systems services, but makes finer delineations within these industries and identifies particularly two separate industries for security systems services: 561621 - Security systems services (except Locksmiths), and 561622 - Locksmiths. The 
ANZSIC classification doesn't distinguish between different types of service and investigation activities and provides a lower level of detail than ISIC.

\subsubsection{Product classification}

The corresponding products for security and investigation activities (division 80 of ISIC) are classified under group 852 - Investigation and security services, of the CPC classification. As shown in annex B, the CPA classification is similar to the CPC. However, differences occur for security consulting services: the CPC classification includes security consulting services whereas the CPA classification includes these under 74.9 - Other professional, scientific and technical services n.e.c.

The NAPCS classification generally follows a similar breakdown for the group 1, investigation and security services. In addition a second group for investigation and security related products is identified (see group 2 Related products below). The NAPCS product list for NAICS 5616 is as follows:

- 1 - Investigation and security services:

- 1.1 - Investigation services;

- 1.2 - Security guard and patrol services;

- 1.3 - Bodyguard services;

- 1.4 - Armored car services;

- 1.5 - Building security system monitoring services;

- 1.6 - Building security system and lock installation and repair services;

- 1.7 - Other security system and lock services.

- 2 - Related products:

- 2.1 - Security consulting services;

- 2.2 - Security training services;

- 2.3 - Reselling services for merchandise, retail;

- 2.4 - Rental of locks, security systems, safes, and other security equipment;

- 2.5 - Architectural armoring services;

- 2.6 - Vehicle armoring services;

- 2.7 - Cash handling and management services for business;

- 2.9 - Other related products.

Each of the international product classifications is very detailed. ${ }^{1}$ When compiling statistical data according to such detailed structures, the survey sample size is large enough to generate reliable results. It is unlikely that SPPIs for each detailed product will be published. Instead compilers may publish aggregated indices.

\subsubsection{Scope of the survey}

Naturally, the ideal starting point is to capture price changes in the security and investigation division as a whole, namely ISIC groups 8010,8020 and 8030 . The decision 
on full or partial coverage of the division should be made with reference to the market structure in the country. Indeed, most countries focus on the first ISIC group 801 - Private security services, which usually generate the vast majority of the turnover for the division. It is noted that the availability of price data for money transport services maybe an issue. Furthermore, only a few countries, such as the U.K. and Sweden, include investigation and security system services.

Business and government are the main end users of security and investigation services. As households account for only a minor part of the industry's total demand the survey could be produced on a BtoB basis.

\subsubsection{Industry vs. Product SPPI based SPPI}

Conceptually, product based SPPI for security and investigation services is the preferred approach, ensuring better coverage of secondary activities where relevant. Security and investigation companies sometimes offer services classified to other industries such as cleaning services. Where secondary activities are significant a productbased SPPI can be recommended.

The detailed product classifications for the industry facilitate the compilation of a product based SPPI. However, it is advisable to collect the price information via survey used to collect turnover data for the security and investigation services.

\subsubsection{Sample design}

In many countries the investigation and security services industry is comprised of a large number of smaller firms and a much smaller number of medium and large sized firms. The collection of price data from smaller firms is often minimised, for reason of response burden, so cut-off sampling can be used to reduce the size of the sampling frame. For example a cut-off threshold of one per cent could be applied, that is all the firms with turnover accounting for less than one per cent of the total turnover of the industry are excluded from the frame. However, it should be noted this will mean that the sample is not representative of the entire industry. However, in practice this may not give rise to significant unrepresentativeness. Nevertheless, smaller firms that are close to the threshold and growing in size could be included in the sample.

Either stratified sampling according to company size or PPS sampling are typically employed for this industry. These methods allow for selection of different sized firms. The size of the sample is, in practice, determined according to statistical methods and/or available resources.

Non-probability and probability sampling methods can often be successfully combined. For example, if an industry is dominated by a small number of firms, these can be formed into a single stratum from which all units are selected. The remaining firms form the other stratum to which either PPS or random sampling is applied. If necessary, a sampling design with more than one dimension can be used. If, for example, regional differences in price development are observed, stratification according to region may be considered.

Sampling can be conducted on several levels For example, a sample may have been drawn first from enterprises, then from representative services and finally from contracts. 


\subsubsection{Collection of information and specification of the service}

In order to ensure the provision of accurate, representative and complete data it is important that responding firms assign survey contact duties to appropriately qualified staff. The experts representing the industry must be from upper management of companies, commanding a broad overview of the services concerned and of the industry as a whole. This will ensure high quality and representativeness of the index for the industry.

In order to ensure constant quality pricing, the following information should be collected about the representative service transactions selected for pricing:

- Type of service activity;

- Customer type;

- The time and the location of the service is provided;

- Details of staff: skills, experience and equipment, transportation (e.g. guard type and professional level, age, experience, training, skills, equipment (armed/unarmed);

- Details of equipment;

- Special conditions of contracts;

- Possible quality changes.

In practice however, respondents should not be subjected to excessive burden as this can endanger the quality of the reported data. It may not be possible therefore in all cases to capture in full the ideal set of data on an on-going basis. It may be necessary to prioritise collection of certain data over others, perhaps on a case-by-case basis.

\subsubsection{Main pricing methods}

The choice of pricing method must take into account the pricing mechanisms employed in the industry. Long-term contracts for provision of very specific service activities tailored to customer needs are typical in the investigation and security service industry. These negotiated contracts are especially prevalent among larger firms.

\subsubsection{Contract pricing}

Contract pricing is the most commonly employed pricing method for this industry. Representative contracts are selected in cooperation with respondents. Well selected contracts give an accurate picture of real transaction price movements. Compilers must however, ensure that the selection of contracts adequately represent price development over time. ${ }^{2}$ Furthermore, compilers may have to quality adjust renewed contracts when the specific services provided for under the contract have changed.

A drawback of the contract pricing method is that it requires a considerable initial effort from the respondent to ensure that representative contracts are selected in a statistically correct and efficient manner. In addition, all of the price determining characters must be specified in the sample contracts. On the other hand, once the contracts have been selected the contract pricing method does not involve a significant burden for the respondent or compiler. 


\subsubsection{Direct use of prices of repeated services}

The direct use of prices of repeated services using list prices may also be employed. List prices, if available, are often the quickest and least labour-intensive way to obtain prices for service activities. In practice however, the list prices published by service producers may not represent the actual real prices they receive Large customers may be able negotiate lower prices. Discounts may also be offered in order to win new business. However smaller customers may expect to pay close to list prices.

\subsubsection{Other pricing methods}

As shown in table 12.2.1. below, model pricing and time based methods can also be employed for certain security and investigation activities. In the case of time-based methods, it is necessary to divide the staff into different categories according to professional level, skills, experience, age, training and equipment (armed/unarmed).

Table 12.2.1. Example of pricing methods in Security and investigation activities

\begin{tabular}{|l|l|l|}
\hline \multicolumn{1}{|c|}{ Pricing method } & \multicolumn{1}{|c|}{ Example } & Sub Group \\
\hline Contract pricing & $\begin{array}{l}\text { Cash delivery of all subsidiaries of the client; 538 stops per } \\
\text { month 1 stop is calculated at 5 minutes, 2 employees }\end{array}$ & Armoured car \\
\hline Contract pricing & $\begin{array}{l}\text { Uniformed guards, mobile site costumer x 2 visit per night, } 7 \\
\text { days a week, price per week }\end{array}$ & Security guard \\
\hline Model pricing & $\begin{array}{l}\text { Security of building A } \\
\text { Object: 2 exits, 20 people working } \\
\text { Activities: opening \& closing rounds } \\
\text { Time: 7:00-19:00 } \\
\text { total price: }\end{array}$ & Security of building \\
\hline Time based methods & Average price per hour for bodyguard & Guard security \\
\hline $\begin{array}{l}\text { Prices of repeated } \\
\text { services }\end{array}$ & Investigation for private customer for one tracking & Investigation \\
\hline
\end{tabular}

\subsubsection{Quality issues}

In the investigation and security service industry, changes in quality mainly arise from variation in the composition of the agreed services. Constant quality service transactions are required for on-going pricing and changes to the quality of service transactions should be quality adjusted.

Ideally, when a contract expires or changes it should be substituted for by a new contract for identical service activities. In this case care should be taken to avoid a possible 'sales bias' in the replacement contract. ${ }^{3}$ Substitute contracts for identical services can often be found for standard contracts. However, it is generally the case that very large contracts contain such detailed specifications that finding substitutes for them may be difficult or even impossible.

It may also be possible to quantify a change in the quality of a service. If a contract is revised, it is sometimes possible to quantify and adjust for the change in quality of the service provided. If the revised contract is for the same service activities but a quantifiable factor has been changed (such as size of premises, number of hours or number of guards), a quantity conversion can be performed. In this case, the revised contract can be used, but only after an adjustment has been made for the change in the quantifiable factor. Another option is to use differences in production costs, (particularly 
labour costs given the nature of the industry) for quality adjustment. In practice, however, quality changes can be difficult to quantify.

\subsubsection{Weighting and aggregation}

Ideally, product level turnover data collected by surveys should be used in the aggregation of the survey. Most compilers use structural business statistics turnover data (turnover data by products from annual surveys) while other sources of data include turnover data from business registers, dedicated SPPI turnover surveys, administrative data (such as taxation records) or expert/industry representative information. Where alternative sources of information are used for the aggregation of the index it is recommended that these are supplemented, as necessary, with additional information collected from respondents.

Many countries use a five year cycle for updating the weights because of the relatively stable structure of the market.

\subsubsection{Specific aspects}

The industry tends to be highly concentrated, that is, a few large firms account for a considerable proportion of the total turnover of the industry. Smaller firms are numerous, but individually they have very minor shares of the total turnover of the industry. Major contracts are usually awarded among the largest firms, because they can offer a broad range of services. Long-term contracts are also characteristic of this industry. The duration of contracts is often relatively long, because the quality of the service activities remain stable for and the demand for the services is continuous.

Labour is the largest input into investigation and security service activities and therefore labour costs are the main determinant of price development. Wages and salaries tend to be rigid and, often change only annually. For this reason for services provided under contract often change annually - as a result of pay reviews. In order to ensure that the index is representative of current market conditions it is important to achieve a balance between older and new contracts.

\subsubsection{Overview of national methods}

\section{Czech Republic}

The Czech Republic collects contract prices from approximately 30 respondents. The SPPI for the industry is published monthly. For the moment price data are collected for only one service, which therefore represents the whole industry. When changes to specific service transactions are reported, respondents are asked to estimate the proportion of the change in the service price resulting from the change in quality and the proportion that represents genuine price change.

\section{Finland}

In Finland, data on real contract prices are collected from the largest companies in the industry who collectively account for the majority of the turnover of the industry. These companies primarily offer only guarding services. Prices are monitored quarterly and the index is calculated as a chained Laspeyres type index. 


\section{Israel}

In Israel, a time-based method (the hourly rate) is most commonly employed. The specific components of services, including the customer and customer field of activity, location, guards' professional level and type of equipment are kept fixed. The index is compiled quarterly using a Laspeyres type formulation.

\section{Japan}

Japan compiles an SPPI for the industry using contract prices. The collected service prices are inclusive of an excise duty. The index calculated using a Laspeyres formulation and published monthly. Quality changes are dealt with on a case-by-case basis using the method most appropriate to the particular situation.

\section{United Kingdom}

The U.K. SPPI for security services is compiled using prices collected from four broad security categories: manned security; CCTV; secure transport; and other. Manned security is the largest component of the index with a weight of around $70 \%$. This in turn is split between: static uniform, mobile uniform, aviation security; and operation/response. The U.K. first published an SPPI for security services in 2000. The main methods of price collection are contract prices and discounted list prices.

\section{United States}

In the U.S., the SPPI is compiled with reference to charge out rates. Respondents determine the charge-out rates for specific, well specified contracts. Each contract specifies characteristics such as the level of skill of personnel, benefits, equipment and transportation needs. The charge-out rates are hourly rates. The index is compiled on a monthly basis

Portugal, France, New Zealand, Mexico and Australia also calculate SPPIs for the investigation and security service industry. The contract price method is employed in France, New Zealand and Australia, whereas Mexico uses mark-up pricing.

\subsection{Cleaning activities (Marcel Spanjaard, Statistics Netherlands)}

\subsubsection{Industry description (812 ISIC)}

This industry group includes the activities of general interior cleaning of all types of buildings, exterior cleaning of buildings, specialised cleaning activities for buildings or other specialised cleaning activities, cleaning of industrial machinery, cleaning of the inside of road and sea tankers, disinfecting and extermination activities for buildings and industrial machinery, bottle cleaning, street sweeping, snow and ice removal.

The relative size of the industry group, and its structure, are largely determined by the level of outsourcing of cleaning activities. In countries where outsourcing of cleaning is commonplace, the industry is relatively significant. Where outsourcing is less important, cleaning personnel are often employed directly by property owners and the cleaning industry is therefore smaller.

The type of labour used also differs between countries: in some countries workers are directly employed by cleaning firms, while in other countries a larger share of workers is hired from temporary employment agencies. 
The industry has become increasing professionalised and organised. There is a higher degree of comparability between the service products of the industry relative to some other business services. Increasing professionalism within the industry has led to the introduction of standards, norms and professional codes, including advanced quality assessment and control systems.

Comparability of service products and competition in the market has resulted in increases in efficiency and technical developments have also impacted upon the industry. Cleaning brokers can help identify requirements and select service providers, particularly for long term contracts. Long-term contract with occasional price escalation (renegotiation) is the main pricing mechanism employed in the industry.

The largest input is labour costs. Other, less significant, inputs include materials, work clothes and equipment. The price determining factors are the objects to be cleaned (e.g. entire buildings, floors, and windows), the level of cleaning required, type of client, the timing of payment up front compared to delivery of service, and the length of the contract. A large share of services production is generated by the cleaning of buildings, and in particular office buildings.

\subsubsection{Classification aspects}

\subsubsection{Industry classification}

Cleaning activities are classified under ISIC division 81 - Services to buildings and landscape activities. Other industry groups in this division are 811 - Combined facilities support activities, and 813 - Landscape care and maintenance service activities.

The cleaning activities group is split into two classes:

- 8121 - General cleaning of buildings; and

- 8129 - Other building and industrial cleaning activities.

The NACE classification deviates slightly from ISIC, since there is an extra class, 8122 - Other building and industrial cleaning activities. This leaves 8129 as Other cleaning activities.

The ANZSIC and NAICS classifications both have an extra class in the form of pest control services, while exterminating services are classified under 8129 in both ISIC and NACE.

\subsubsection{Product classification}

The product classifications are very detailed and could be used to identify homogenous groups of service activities pricing.

The CPC classification recognises four classes under group 853 - Cleaning services:

- 8531 - Disinfecting and exterminating services;

- 8532 - Window cleaning services;

- 8533 - General cleaning services;

- 8534 - Specialised cleaning services.

The CPA classification has a different structure; Cleaning services are classified under group 812 and further broken down into: 
- 8121 - General cleaning of buildings;

- 8122 - Other building and industrial cleaning services;

- 8129 - Other cleaning services.

Each of these classes in turn is further broken down into more detailed categories and subcategories.

Furthermore, the CPA classification also includes group 811 - Combined facilities services. The services in this group are bundled, such as general interior cleaning, maintenance, trash disposal, guarding and security.

The NAPCS classification provides a very detailed classification. Cleaning services products are mainly covered in industry group 56172 - Cleaning services, which is further broken down into:

- 56172.1 - Residential interior cleaning services;

- 56172.2 - General-purpose and comprehensive commercial cleaning services (with further splits);

- 56172.3 - Cleaning services for window exteriors;

- 56172.4 - Cleaning services for building exteriors;

- 56172.5 - Damage restoration and cleaning services;

- 56172.6 - Hard-surface floor care services;

- 56172.7 - Cleaning services for carpets, rugs, and upholstery (with further splits);

- 56172.9 - Other specialized cleaning services (with further splits).

Furthermore, cleaning services are also found in 56179.12 - Cleaning services for commercial and industrial machinery and equipment, 56179.14 - Cleaning services for parking lots and driveways, and 56179.15 - Cleaning services for aircraft, railcar, and ship interiors. Pest control services are classified under 56171.

\subsubsection{Scope of the survey}

Cleaning companies typically categorise their customers into three groups: private households, private enterprises and public institutions. Cleaning services for private enterprises and public institutions will account for the majority of total output. Cleaning services for private households are also covered in the CPI and can be quite difficult to measure. Therefore, SPPI measurements usually focus on service activities provided to enterprises. The CPI can provide source data for service activities provided to households where measurement is required.

Ideally, the SPPI for cleaning services should measure the prices of cleaning activities only. However, these services may be bundled with services such as security and therefore correctly classified as group 811 - Combined facility support services. Note however, that groups 811 and 812 will not form a homogenous group in respect of price measurement, and therefore need be treated separately. It is possible that cleaning service activities will in the future be increasingly bundled with other services and therefore classified under group 811 . Hence, a price index for group 811 may be a mixture of mostly cleaning and security services activities. 


\subsubsection{Industry vs. Product SPPI based SPPI}

The SPPI for cleaning services should ideally be product based. Many business enterprises classified under cleaning activities will also produce combined facilities support activities and vice versa, and a product based SPPIs will capture these secondary production activities. A further advantage of a product based SPPI is the possibility it offers for improved sampling. When establishments can be selected based on all of their activities (rather than on their main activity only), the resultant lower level indices are more homogenous and detailed - and the resulting SPPI will be more robust. A more detailed SPPI, with multiple lower level indices will of course require a sufficiently large sample.

An industry based SPPI will not cover relevant cleaning service activities produced by business enterprises classified under combined facilities support activities.

\subsubsection{Sample design}

On the one hand, a relatively small sample size can suffice when the market for cleaning activities is both transparent and competitive. On the other hand, different submarkets exist with potentially different price development trends and in some countries the industry is unconcentrated. An explicit choice may have to be made whether to include subcontracting, if it is a large share of production. The specialisation of firms may make it necessary to sample by submarket to ensure the inclusion of respondents offering different types of service activities. Depending on the structure of the industry within a country, PPS sampling or stratified sampling (ideally with turnover as the measure of size) variable can be recommended.

The SPPI for cleaning activities in the Netherlands is product based. The business register, which is supplemented with product level turnover detail collected for structural business statistics, provides the sample frame sampling frame of the SPPI is the sample that the turnover statistics use. Units are selected by PPS sampling based on turnover at product level. Respondents may be required to provide prices for more than one service product if they generate sufficient turnover from a number of service products.

The size of the sample for each product activity is determined by:

- The total number of units to be included in the sample for the industry (bearing in mind response burden);

- The weight of the service product type within the industry;

- The variability of prices reported for the industry (where larger variability in prices is observed within a sampling stratum, the size of that sample may be increased).

The Netherlands samples 100 units for the SPPI for cleaning activities. On average each respondents provides prices for four models (or contracts).

\subsubsection{Collection of information and specification of the service}

The timing of price collection depends on the pricing method used but typically takes place at the end or the midpoint of the measurement period. In case of model pricing, the price of a service model could be asked at the midpoint of the reporting period allowing for early compilation of indices. The choice of pricing method has a significant bearing on the size of respondent burden. Model pricing for example, involves significantly more 
time for survey compilation and processing while time based pricing methods takes less time. It is vital that specifications are sufficiently detailed to ensure constant quality pricing over different survey periods. Contract pricing involves a significantly reduced respondent burden, although contracts need to be replaced periodically.

The model pricing method is employed in the Netherlands. An example of a model is presented in box 12.3.1. The example demonstrates the requirement for a very detailed specification of the service transaction.

\section{Box 12.3.1. Model for CPA 8121 - General cleaning of buildings}

- Model 1 (office building):

- Total cleaning area: $4568 \mathrm{~m} 2$; from which: $3198 \mathrm{~m} 2$ offices, $457 \mathrm{~m} 2$ committee rooms, $457 \mathrm{~m} 2$ toilets, $228 \mathrm{~m} 2$, parking, $228 \mathrm{~m} 2$ canteen;

- Frequency: parking: 156 days/year, committee rooms: 208 days/year, offices, canteen and toilets: 260 days/year;

- Amount of employees in building: 121;

- Year of construction: 2005, Floor type: diverse;

- Cleaning between: 09.00 hours and 17.00 hours;

- 15 percent of cleaning personnel are youths.

- Price for an existing customer

\subsubsection{Main pricing methods}

Cleaning activities are usually unique. No building, floor or room is exactly the same, and neither are the individual needs of the various customers. The price of a cleaning service depends heavily on cost of labour, except perhaps where large cleaning machines are employed.

\subsubsection{Contract pricing}

Prices for cleaning service activities are typically set, by contract, for a fixed period of time (often a year). The contract pricing method can be employed in such cases. It is important to select contracts that are representative of the business of the respondent.

\subsubsection{Model pricing}

The model pricing method is appropriately employed when service outputs are predominately unique. Statistics Netherlands employs this method in the compilation of the SPPI for cleaning activities It is important to note that model prices are virtual prices - the model should resemble, or be based on, existing contracts but the price does not have to be paid (as in the case of transaction prices). It is also important to ensure that the model is representative of service activities produced by the respondent in the specified period. A model should reflect an activity for which a contract would normally be signed. Furthermore, all the price determining parameters should be specified in the model. 


\subsubsection{Time-based methods}

Time-based methods could, at least in theory, also be employed for cleaning activities since prices may be heavily influenced by changes in wage rates. In fact, the wage rate itself (for cleaning services) could be used to approximate price change in this industry in the absence of an SPPI for the industry. The disadvantage of the time-based method is that "quality change" and "productivity change" are not accounted for. Quality and productivity changes are not likely to significantly on this industry as it is largely "labour based". However, there are some mechanised cleaning service activities and these may display different price development to labour-based cleaning activities. Therefore the time-based method cannot be recommended for all cleaning service activities.

\subsubsection{Quality issues}

Quality change and productivity change are not significant issues in the compilation of SPPIs for cleaning activities, especially when contract pricing or model pricing methods are employed. However, productivity change must be considered for cleaning activities that become mechanised or when machinery becomes more efficient.

The quality of cleaning activities delivered on the basis of a contract is assumed to be fixed. However, when contracts are revised or replaced, or new contracts are secured quality adjustment will be required. Whenever a model contract is becomes outdated and is therefore no longer representative a replacement model must be introduced. Techniques such as the overlap method or comparable replacement method can be employed in these cases.

When using a time-based method (such as hourly charge-out rates or realised hourly rates), appropriate treatment of quality change is important. Adjustment may be required for example, for the differing levels of experience of workers and the changes in the types of cleaning activity.

Respondents may have difficulty in pricing out-dated services and so it is important to contact them to identify replacement service transactions as necessary. Respondents should also be contacted to confirm and provide explanations for reported large price changes.

\subsubsection{Weighting and aggregation}

Turnover data is commonly used in the aggregation of SPPIs. Ideally these data should be used at the service transaction level and for all additional levels of aggregation. Typically turnover data is not available at product level but can be collected as part of the respondent initialisation process

Statistics Netherlands does not employ weighting at the service transaction level and price changes in each service activity group for individual respondents are averaged by the use of a geometric mean. Turnover data, usually provided by a structural business statistics survey, is used to weight at the business enterprise and subsequent levels. Lowest level weights are updated each year while higher level weights are updated every five years. Cleaning services is one of many service industries that are further aggregated to a total SPPI covering a broad range of service industries. 


\subsubsection{Specific aspects}

Exports are not very relevant for cleaning services. Potentially, large international enterprises are represented by cleaning 'outlets' at a national level.

The price development of cleaning service activities are more easily measured than those for more complex service activities produced by professionals such as engineers and lawyers. Similarly, it is easier for clients to compare tenders and this can lead to increased competition. For example, a client can exactly compare tenders for cleaned single well defined service product. It is much harder to make a full comparison between the services provided by different lawyers. There is a higher pressure to increase productivity in less complex industries; a cleaning firm will try to deliver a defined service in as few hours' work as possible, whereas professionals may simply try to sell as many billable hours as possible.

As previously mentioned, cleaning activities are heavily reliant on labour and therefore changes to wage rates have a significant impact on price development in the industry. In the Netherlands, employees in the cleaning industry are subject to a collective employment agreement. This agreement affixes annual wage increases and therefore has a direct impact on the price index.

\subsubsection{Overview of national methods}

\section{Austria}

In Austria, data on NACE 81.2 - Cleaning activities, are collected from business enterprises operating in all three subclasses of this group. Prices are collected for general cleaning, chimney sweeping and specialised cleaning services. Model pricing and the direct use of prices of repeated services methods are employed. Survey questionnaires were designed in cooperation with the relevant industry representative associations. In the case of specialised cleaning services customised survey questionnaires were developed in cooperation with respondents who provided information on the pricing mechanisms they employ.

\section{France}

The French SPPI for cleaning activities is based on prices of representative contracts. The panel of 130 respondent firms was selected according to a stratified sample (with firms stratified according to turnover). A total of 917 prices are collected in each survey period. Prior research suggested that it can be difficult for respondents to provide ongoing prices for a representative model contract; they prefer to provide prices for an existing contract.

The timing of billing compared to delivery is a price determining factor; prices can change as a consequence of a change in the timing of payment. Service producers can offer discounts of up to $20 \%$ to acquire new contracts. Once a contract has been secured, the price for a specific service product then rises stepwise towards the normal market price. This business strategy can make SPPI compilation difficult.

Contracts are split into categories based on client type and object type according to:

- Total cleaning, 8120 ISIC (sum of $8121,8122,8129$ ):

Breakdown by type of client:

- Cleaning in public sector (8120); 
- Cleaning in private sector (8120).

- Detailed disseminated indices:

Breakdown by type of object

- Offices (8121);

- i. Public (8121);

- ii. Private (8121);

- Manufacturing:

- $i$. Manufacturing equipment (8121);

- ii. Manufacturing, standard (8121);

- iii. Manufacturing, sensitive areas (8122);

- Commercial property (8121);

- Public space (8121);

- Communal areas in dwellings (8121);

- Specialised cleaning (health equipment, incinerators, chimneys) (8122);

- Industrial disinfection, rat control, insect control (8122).

The various types of cleaning contracts are assigned different weights. Respondent level weights are based on turnover figures measured in a separate survey.

INSEE collects transaction prices of long running contracts. The contracts are distinguished according to the above specified objects. Respondents can distinguish between general price change and price changes result from changes to the quality/conditions of service transactions. INSEE usually contacts respondents by phone to verify prices changes of more than $10 \%$ in a quarter. Large price changes often result from changes to the terms of the contract (such as a change in the size of the area to be cleaned). Prices are often lower during the summer time because of vacancies.

\section{Bibliography}

\section{Employment activities:}

Matulska-Bachura, A., (2009), Revisited Sector Paper on Employment activities, $24^{\text {th }}$ Voorburg Group meeting, Oslo, Norway available at:

http://www4.statcan.ca/english/voorburg/Documents/2009\%20Oslo/Papers/2009\%20\%2062.pdf

Broderick, R., (2002), U.S Producer Price Index for Help Supply Services, $17^{\text {th }}$ Voorburg Group meeting, Nantes, France available at: http://www4.statcan.ca/english/voorburg/Documents/2002\%20nantes/papers/2002020.pdf 
Buisson, B., (2004), The French PPI for provision of temporary workers and labour recruitment, $19^{\text {th }}$ Voorburg Group meeting, Ottawa, Canada available at:

http://www4.statcan.ca/english/voorburg/Documents/2004\%20ottawa/papers/2004061.pdf

Buisson, B., (2005), The French SPPI on recruitment and provision of temporary workers, $20^{\text {th }}$ Voorburg Group meeting, Helsinki, Finland available at:

http://www4.statcan.ca/english/voorburg/Documents/2005\%20helsinki/papers/2005-

04.pdf

Lorenz, S., (2008), Development of producer price indices for labour recruitment and provision of personnel, project report, Destatis.

Security and investigation activities:

Lorenz, S., and Vizner, R., 2009, Sector paper on Security and investigation activities, $18^{\text {th }}$ Voorburg Group meeting, Oslo, Norway, available at:

http://www.voorburggroup.org/Documents/2009\%20Oslo/Papers/2009\%20-

\%2064.pdf

OECD, 2004, The security economy, OECD Publication, Paris.

Cleaning activities:

Hansen, J. A., (2010), Mini Presentation SPPI for Industrial Cleaning in Norway, $25^{\text {th }}$ Voorburg Group meeting, Vienna, Austria available at:

http://www4.statcan.ca/english/voorburg/Documents/2010\%20Vienna/Papers/2010\%2 $\underline{0-\% 2026 . p d f}$

Spanjaard, M., (2011), SPPI for Industrial Cleaning in the Netherlands, Supplementary paper for the Voorburg Group meeting in 2010, Statistics Netherlands, the Hague.

\section{Notes}

1. The NAPCS provides more detailed products separating out types of investigation, security guard, armored car, monitoring systems and other services. A full list of products is available at:

http://www.census.gov/eos/www/napcs/finalized/web 5616 final reformatted edited US052009.pdf

2. See chapter 2 .

3. See chapter 2 . 



\section{Chapter 13. Human health activities}

This chapter presents practical guidance as well as main issues and challenges for compiling SPPIs for Human health activities (ISIC 86). 


\subsection{Human health activities (Bonnie Murphy, U.S. Bureau of Labor Statistics)}

\subsubsection{Industry description (ISIC 86)}

ISIC division 86 includes activities of short- or long-term hospitals, general or specialty medical, surgical, psychiatric and substance abuse hospitals, sanatoria, preventoria, medical nursing homes, asylums, mental hospital institutions, rehabilitation centres, leprosaria and other human health institutions which have accommodation facilities and which engage in providing diagnostic and medical treatment to inpatients with any of a wide variety of medical conditions. It also includes medical consultation and treatment in the field of general and specialised medicine by general practitioners and medical specialists and surgeons. It includes dental practice activities of a general or specialized nature and orthodontic activities. Additionally, this division includes activities for human health not performed by hospitals or by practicing medical doctors but by paramedical practitioners legally recognized to treat patients. Note that residential care activities with some level of nursing services are included in ISIC 87 - Residential care activities, and strictly are not considered human health activities as classified in ISIC 86.

The division 86 is further divided into the following ISIC groups:

- 861 - Hospital activities;

- 862 - Medical and dental practice activities;

- 869 - Other human health activities.

Human health activities may be characterised as having either marketed or nonmarketed output. Output is considered market production when transactions have economically significant prices associated with them. Nonmarket production is characterized by the lack of observed prices. Price indices for human health activities industries can only be calculated if observable prices exist.

The U.S. healthcare market is comprised of two types of economically significant prices:

1. Market value prices paid by private payers, including private insurance companies and individual patients that pay directly (known as out-of-pocket payers); and

2. Market value prices paid by public or government payers.

In the U.S., public payers can be separated into two main categories, Medicare and Medicaid. Medicare is a federally funded program for persons over age 65. Medicaid is a state administered, jointly funded (federal and state) program for the indigent. Price indices are calculated for transactions with both types of payers as prices are observable in both cases.

In developing SPPIs for health activities, it is important to consider what types of transactions reflect marketed output and are measureable. Health care is financed differently among countries and development of an SPPI in this important area should not be limited to financing considerations only.

U.S. hospital activities and medical practices are not very concentrated. Relatively large hospital systems exist in the U.S. but do not dominate. Medical and dental practices exhibit even less concentration, as these industries are predominantly composed of small single-location establishments. For the other human health activities group, medical laboratories, diagnostic imaging centres, and blood and organ banks are very 
concentrated, and the dominant providers have significant price-making power for some payers. Due to the highly complex and expensive machinery that is needed in these classes, economies of scale are evident.

The U.S. measures changes in the values that human health providers expect to receive from all payers for the services they provide. This is referred to as the "expected reimbursement" and may differ significantly from the amounts that appear on a patient's medical bill due to both pre- and post-billing negotiations and delinquent accounts.

The major price determining factors for hospital activities include the following:

- Principal diagnosis, often represented by a Diagnosis Related Group (DRG ${ }^{1}$ ) in the U.S;

- Principal procedure;

- Type of payer;

- Inpatient or outpatient;

- Length of stay (inpatients only).

These characteristics are the main components of the total service package that a hospital patient receives during their entire length of stay from admission to discharge. In the U.S., the two most important price determining characteristics are the DRG and the type of payer. The DRG is often the basis for pricing in general medical and surgical hospitals, while the principal diagnosis is used for pricing in psychiatric hospitals and most specialty hospitals.

The major price determining factors for medical and dental practice activities include the following:

- Type of service, often represented by the Current Procedural Terminology (CPT) code for physicians and the Current Dental Terminology (CDT) code for dentists in the U.S.;

- Type of payer;

- Setting where service is provided (in a physician's office, hospital, etc.);

- Geographical location where service is provided;

- Specialty of physician providing service.

The two most significant price determining characteristics are the type of service and the type of payer. The range of services provided in this industry is quite large so it is important to specify what services are being priced on a monthly basis. Types of payers are also important due to the relationship between payers and providers and the prices they are able to negotiate.

The major price determining factors for other human health activities include the following:

- Type of payer;

- Type of test, panel, profile or automated multichannel test for Medical laboratories and Diagnostic imaging centres;

- Type of blood product, organ, or tissue for blood and organ banks; 
- Type of service such as medical care, hospice care, or home infusion therapy for home health care.

\subsubsection{Classification aspects}

\subsubsection{Industry classification}

In the area of human health activities, the main difference between ISIC and NAICS is that ISIC classifies activities by who is providing the counselling which is not done in NAICS. If a medical professional provides the counselling, the activity is classified in Medical and dental practices. If a non-medical professional provides the counselling, the activity is classified in other human health activities.

\subsubsection{Product classification}

In general, the NAPCS codes are much more detailed then the CPC counterparts, as each NAPCS code is based upon an International Classification of Disease (ICD) chapter that describes a disease or major body system. Examples of NAPCS titles include Surgical interventions, diseases of the digestive system, inpatient; Non-surgical interventions, diseases of the skin and subcutaneous tissue, inpatient; and Diagnosis and treatment services for diseases of the skin and subcutaneous tissue. The U.S. currently publishes price indices for General medical and surgical hospitals by detailed NAPCS product lines and is researching the feasibility of publishing detailed service line indexes for additional health service industries in a similar manner.

\subsubsection{Scope of the survey}

Ideal human health activities SPPIs measure all relevant marketed output, including transactions to private and public payers. In the U.S., as mentioned in section on industry description, detailed service line indices for general surgical and medical hospitals are published for services related to the treatment of specified diseases and disorders. Additional indices are also published for all hospital services by type of payment: Medicare patients, Medicaid patients and all other patients. For physician services, detailed service line indices are published based on type of practice, i.e. one or two physician practices or single specialty group practices vs. multispecialty group practices. Within the former type of practice, service line indices are further broken down by specialty such as general/ family practices, paediatrics, internal medicine, etc. For dental services, detailed service line indices are published by major lines of services provided, i.e. dental visits and consultations, dental surgical intervention services, and dental nonsurgical intervention services.

\subsubsection{Industry vs. product based SPPI}

The U.S. calculates and publishes approximate product based SPPIs in addition to industry based SPPIs. Although product based SPPIs are most useful for deflating inputoutput national accounts, an industry based survey for health services that delineates primary production from secondary activities can be used as an acceptable alternative. In the U.S., sampling frames are available by 6-digit NAICS industry (not by product) and services that are not primary to the actual health service industry where the company is classified are considered "other receipts" and given a chance of selection at each sampled company. When publication criteria are met, a price index for these "other receipts" is published. These "other receipts" contribute between $1 \%$ and $7 \%$ of U.S. industry 
turnover in this division depending on the specific NAICS industry. Some examples of common "other receipts" include parking at hospitals, food and beverage sales, sales of goods like toothbrushes and medical equipment, and physical therapy services performed at a physician's office.

The U.S. publishes approximate product based indices using the same items that are sampled by industry and used to calculate the industry based SPPIs but organised somewhat differently and with considerably less detail. For the health service industries, distinct product based indices are published for patient care services provided in an inpatient setting and those provided in an outpatient setting. This distinction is not available for the industry based SPPIs, so these indices allow for additional analysis. Detailed indices by payer type are also available within the approximate product based indices.

\subsubsection{Sample design}

The appropriate sample design to employ for classes in this division will vary greatly by country depending on the availability of administrative data. The information below details how the U.S. SPPI sampled various classes.

The U.S. survey for hospitals includes general medical and surgical, psychiatric, and specialty hospitals. Although many hospitals within the U.S. operate as part of integrated health systems made up of multiple hospitals, the sample units are generally individual hospitals. This is because prices are usually set at each individual hospital. For physicians, the sample units are practices, which may include an individual physician or a group of physicians that work together in a single practice.

For all health care classes, probability proportionate to size selection is ideal. For hospitals, firms may be selected based on turnover. If this is not available, hospital expenses, number of patient admissions, or number of beds are potential alternative sampling size measures. For medical and dental practices, number of physicians may be used if turnover data are unavailable. For other human health activities, such as medical laboratories, employment may be used as an alternative size measure.

Distinct strata based upon type of hospital may be used to ensure a representative sample for this activity. The U.S. survey is stratified by these hospital types:

- Large/Small Urban;

- Large/Small Rural;

- Large/Small Metropolitan.

Distinct strata based on physician specialty may be used to ensure a representative sample for this activity. The U.S. survey is stratified by these specialty types:

- General/Family;

- Internal Medicine;

- General Surgery;

- Paediatrics;

- Obstetrics/Gynaecology;

- Anaesthesia; 
- Radiology;

- Pathology;

- Other Specialty;

- Multiple Specialties.

\subsubsection{Collection of information and specification of the service}

For initial data collection, representative healthcare services are selected in consultation with respondents. Respondent representatives are typically employees from the healthcare firms' billing departments, since these individuals have access to pricing records. Items are typically selected based on each service's relative contribution to total firm turnover. For hospitals, however, services are statistically selected prior to the data collection visit based upon national turnover data organized by DRG. This is done to ensure that the item sample represents the national DRG distribution and not just the local DRG distribution.

During the collection visits, each of the major price determining characteristics outlined in section 1 are recorded and described for each selected item. This information is listed as the item specification and is used to accurately re-price the item.

In many cases, prices received by providers from public payers may be publicly disclosed so respondent contact may not be needed to collect this information. In these cases, prices are collected via administrative data.

\subsubsection{Main pricing methods}

Prices for human health activities should ideally reflect the total amounts providers receive for providing services to all patients. The provision of medical or health services to patients is the primary output. This includes all payments received from patients paying directly, and all payments from third parties, such as private insurance companies and government institutions paying on behalf of patients. More specifically, total reimbursement to a provider for a specified medical service may include payments from multiple payers making pricing more complicated. For example, Medicare may pay the hospital for part of a hospital stay and the patient's supplemental private insurance company may pay for the remaining portion of the medical services not covered by Medicare.

\subsubsection{Model pricing}

Model pricing is the ideal type of price to collect for most human health activities because the exact item specification data collected at initiation will not be observed on a recurring basis in almost all cases due to unique patient characteristics. For transactions priced according to this method, individual patient bills are selected and the billed services are held constant over time. In subsequent periods, respondents are asked to provide the price they would charge if they were to offer the same services to a similar patient. In this way, hypothetical transactions based on those prevalent in the market are priced over the life of the sample.

Though model pricing is often the most appropriate pricing method for most types of health services, there are nevertheless some inherent problems with this methodology, for which mitigation strategies need to be considered. Some respondents may have difficulty providing accurate price estimates as some insurance providers do not release 
reimbursement information without actual claims (transactions) taking place. Additionally, the respondent burden required by this method is very high. This is mitigated by the standardisation of procedural terminology by various medical associations, professionals and classification experts, which allows for consistency of billed services. Therefore substitutions are only necessary if new procedures replace current procedures to increase treatment effectiveness. This type of adjustment is rare.

Substitutions are more likely to occur when a particular insurance or health plan is no longer accepted by a provider. In these cases, the expected reimbursement from the new payer is substituted.

In the U.S., prices negotiated between third party payers and healthcare providers typically change once per year. Medicare, for example, reimburses using fixed, predetermined amounts. This is referred to as a Prospective Payment System (PPS) and greatly simplifies price index calculation as prices are fixed by law for an exact amount of time. Item prices can be directly observed using this administrative data without the need for direct respondent contact.

\subsubsection{Direct use of prices of repeated services}

An alternative to model pricing is to follow the selected patient bill over time using the direct use of prices of repeated services method. This is most commonly used for other human health activities transactions where standard prices are often charged to all patients. These providers often can provide the prices they receive directly from a standard fee schedule.

In the U.S., urgent care (also called emergency care) must be provided to all citizens. This can complicate the accurate measurement of healthcare price change as some patients may not have to pay the entire reimbursement amount or they may default on all or a portion of their healthcare debt. In the former case, providers may at times discount their services if the patient is indigent and this discount will vary depending upon the patient's income. Transactions with these patients are eligible for selection. When selected, the patient's income range and the applicable discount in the item specification are recorded. In future periods the respondent updates the discount and income range as needed when reporting the current price. Because the U.S. uses the "expected reimbursement" as the transaction price, individual patient default on healthcare payments does not affect index levels.

\subsubsection{Quality issues}

In the U.S., the health outcomes of patients are not specifically assessed for potential quality adjustment as changes in these outcomes are indicative of changes in consumer utility but do not necessarily represent changes in the nature of the services provided. Quality adjustment is only undertaken when the nature of the production changes. In these cases, it is appropriate to use producer costs to quantify the quality change. Differences in quality and competence among medical practitioners are extremely difficult to measure accurately, and as a result, it is generally not possible to use these factors as a basis for quality adjustment.

However, the U.S. has developed systematic quality adjustment methods in several healthcare classes. As part of this effort, a quality adjustment method to account for changes in a selection of patient treatments performed at hospitals is now employed. This quality adjustment procedure is discussed in further detail in the paper titled "Proposal for 
Adjusting the General Hospital Producer Price Index for Quality Change" listed in the bibliography of this section. The U.S. Department of Health and Human Services (DHHS) created a Hospital Compare (HC) database to compare the service quality across hospitals. The database contains measures (from data provided by the vast majority of U.S. hospitals) of service quality for the treatment of some major conditions (heart attack, heart failure, pneumonia, or surgery). These measures are services that medical experts (based on scientific evidence) deem are important for optimal recovery. When hospitalspecific data from the HC database indicate that the percentage of patients within a DRG that have received these specific services changes, DHHS-provided cost data are used to quantify and adjust for these changes in service. This procedure is currently used for transactions that cover patients diagnosed with heart failure, heart attack, and pneumonia. If, for example, DHHS data indicate that an increased percentage of heart failure patients at a sampled hospital are given an evaluation of their left ventricular systolic (LVS) function, then this percentage increase is applied to the average cost of treating these patients. The resulting figure is used as the basis for explicit quality adjustment. When a particular hospital evaluates a higher percentage of their patients for LVS function, quality is considered (by the medical experts who were consulted in developing the quality measures) to be increased and the price index will decline after this adjustment is applied (assuming no reported price change).

The U.S. also systematically quality adjusts transactions in the Nursing care facility industry (NAICS 623110) using the Nursing Home Compare database that was also developed by DHHS. This database contains staffing level information. Medical experts have determined that the quality of production at nursing homes is affected by facility staffing levels. As a result, quality adjustment is performed to account for reported changes in staffing levels. This quality adjustment procedure is discussed in further detail by Lucier and Agliata (2003).

As more data are released by DHHS, the U.S. will research and develop additional systematic quality adjustment methodologies. Additionally, the opinions of medical experts in published documentation will continue to be assessed in order to determine which changes in production correspond with changes in the quality of the output.

\subsubsection{Weighting and aggregation}

For each of these U.S. SPPI index series, the lower level indices are aggregated using industry turnover data as weights. Although the indices are calculated using the Laspeyres formula, these weights are updated approximately every five years. Within the lowest level indices, each health care company is weighted by its own turnover provided the time of data collection. These company weights remain fixed throughout the life of the sample.

The following are three examples of U.S. SPPI publication structures for industry based outputs which are classified in human health activities (table 13.1.1). The specific structure that is chosen for publication depends on many factors, some of which include requests from industry specific data users, the availability of turnover data to accurately weight the lowest level indices, and the needs of national accountants to create accounts according to disease. 
Table 13.1.1. U.S. PPI industry based publication structures for the human health activities

\begin{tabular}{|c|c|}
\hline SPPI Code & Industry based index title \\
\hline 621111 & Offices of physicians (except mental health) \\
\hline $621111 \mathrm{P}$ & Primary services \\
\hline 6211114 & One and two physician practices and single specialty group practices \\
\hline 621111411 & General/family practice \\
\hline 621111412 & Internal medicine \\
\hline 621111413 & General surgery and other surgical specialties \\
\hline 621111414 & Pediatrics \\
\hline 621111415 & Obstetrics/gynecology \\
\hline 621111419 & Other specialty \\
\hline 6211115 & Multispecialty group practice \\
\hline $621111 S M$ & Other receipts \\
\hline 621511 & Medical laboratories \\
\hline $621511 P$ & Primary services \\
\hline 6215112 & Medical laboratory services \\
\hline 62151123 & Medicare patients \\
\hline 62151124 & Medicaid patients \\
\hline 62151125 & Private insurance patients \\
\hline 62151126 & All other patients \\
\hline $621511 S M$ & Other receipts \\
\hline 622110 & General medical and surgical hospitals \\
\hline $622110 \mathrm{P}$ & Primary services \\
\hline 622110101 & Diseases and disorders of the nervous system \\
\hline 622110103 & Diseases and disorders of the ear, nose, mouth, and throat \\
\hline 622110104 & Diseases and disorders of the respiratory system \\
\hline 622110105 & Diseases and disorders of the circulatory system \\
\hline 622110106 & Diseases and disorders of the digestive system \\
\hline 622110107 & Diseases and disorders of the hepatobiliary system and pancreas \\
\hline 622110108 & Diseases and disorders of the musculoskeletal system and connective tissue \\
\hline 622110109 & Diseases and disorders of the skin, subcutaneous tissue and breast \\
\hline 622110111 & Endocrine, nutritional and metabolic diseases and disorders \\
\hline 622110112 & Diseases and disorders of the kidney and urinary tract \\
\hline 622110113 & Diseases and disorders of the male reproductive system \\
\hline 622110114 & Diseases and disorders of the female reproductive system \\
\hline 622110115 & Pregnancy, childbirth and the puerperium \\
\hline 622110116 & Newborns and other neonates with conditions originating in the perinatal period \\
\hline 622110117 & Diseases and disorders of the blood and blood forming organs and immunological disorders \\
\hline 622110118 & Myeloproliferative diseases and disorders and poorly differentiated neoplasms \\
\hline
\end{tabular}


Table 13.1.1. U.S. PPI industry based publication structures for the human health activities, continued

\begin{tabular}{|l|l|}
\hline \multicolumn{1}{|c|}{622110} & \multicolumn{1}{c|}{ General medical and surgical hospitals } \\
\hline 622110119 & Infectious and parasitic diseases \\
\hline 622110122 & Alcohol/drug use and alcohol/drug induced organic disorders \\
\hline 622110123 & Injury, poisoning and toxic effects of drugs \\
\hline 622110125 & Factors influencing health status and other contacts with health services \\
\hline 622110126 & Multiple significant trauma \\
\hline 622110127 & Human immunodeficiency virus infections \\
\hline 622110128 & Other diseases and disorders \\
\hline $622110 S M$ & Other receipts \\
\hline
\end{tabular}

Table 13.1.2. lists the approximate product based index structure for the U.S.

Table 13.1.2. U.S. PPI product based publication structures for health care services

\begin{tabular}{|c|c|}
\hline 51 & Health care services \\
\hline 511 & Outpatient care (partial) \\
\hline 5111 & Outpatient care (partial) \\
\hline 511101 & Physician care \\
\hline 51110102 & Medicare patients: physician care \\
\hline 51110103 & Medicaid patients: physician care \\
\hline 51110104 & Private insurance patients: physician care \\
\hline 51110105 & All other patients: physician care \\
\hline 511102 & Medical laboratory and diagnostic imaging center care \\
\hline 51110201 & Medical laboratory care \\
\hline 511102011 & Medicare patients: medical laboratory care \\
\hline 511102012 & Medicaid patients: medical laboratory care \\
\hline 511102013 & Private insurance patients: medical laboratory care \\
\hline 511102014 & All other patients: medical laboratory care \\
\hline 51110202 & Diagnostic imaging center care \\
\hline 511102021 & Medicare and Medicaid patients: diagnostic imaging center care \\
\hline 511102022 & Private insurance patients: diagnostic imaging center care \\
\hline 511102023 & All other patients: diagnostic imaging center care \\
\hline 511103 & Home health and hospice care \\
\hline 51110301 & Home health and hospice care \\
\hline 5111030101 & Medicare and Medicaid patients: home health and hospice care \\
\hline 51110301011 & Medicare patients: home health and hospice care \\
\hline 51110301012 & Medicaid patients: home health and hospice care \\
\hline 5111030102 & Private insurance and all other patients: home health and hospice care \\
\hline 51110301021 & Private insurance: home health and hospice care \\
\hline
\end{tabular}


Table 13.1.2. U.S. PPI product based publication structures for health care services, continued

\begin{tabular}{|c|c|}
\hline 511 & Outpatient care (partial) \\
\hline 51110301022 & All other patients: home health and hospice care \\
\hline 511104 & Hospital outpatient care \\
\hline 51110401 & Hospital outpatient care \\
\hline 511105 & Dental care \\
\hline 51110501 & Dental care \\
\hline 512 & Inpatient care \\
\hline 5121 & Inpatient care \\
\hline 512101 & Hospital inpatient care \\
\hline 51210101 & Hospital inpatient care \\
\hline 512101011 & Hospital inpatient care, general medical and surgical hospitals \\
\hline 5121010111 & Medicare patients: hospital inpatient care, general medical and surgical hospitals \\
\hline 5121010112 & Medicaid patients: hospital inpatient care, general medical and surgical hospitals \\
\hline 5121010113 & Private insurance \& all other patients: hospital inpatient, general medical and surgical hospitals \\
\hline 51210101131 & Private insurance patients: hospital inpatient care, general medical and surgical hospitals \\
\hline 51210101132 & All other patients: hospital inpatient care, general medical and surgical hospitals \\
\hline 512101012 & Hospital inpatient care, psychiatric \& substance abuse hospitals \\
\hline 5121010121 & Hospital inpatient care, psychiatric hospitals \\
\hline 51210101211 & Medicare patients: hospital inpatient care, psychiatric hospitals \\
\hline 51210101212 & Medicaid patients: hospital inpatient care, psychiatric hospitals \\
\hline 51210101213 & Private insurance and all other patients: hospital inpatient care, psychiatric hospitals \\
\hline 512101013 & Hospital inpatient care, specialty hospitals. \\
\hline 5121010131 & Medicare patients: hospital inpatient care, specialty hospitals \\
\hline 5121010132 & Medicaid patients: hospital inpatient care, specialty hospitals \\
\hline 5121010133 & Private insurance and all other patients: hospital inpatient care, specialty hospitals \\
\hline 512102 & Nursing home care \\
\hline 51210201 & Nursing home care \\
\hline 5121020101 & Medicare and Medicaid patients: nursing home care. \\
\hline 51210201011 & Medicare patients: nursing home care. \\
\hline 51210201012 & Medicaid patients: nursing home care. \\
\hline 5121020102 & Private insurance and all other patients: nursing home care. \\
\hline 51210201021 & Private insurance patients: nursing home care. \\
\hline 51210201022 & All other patients: nursing home care. \\
\hline 512103 & Intellectual and developmental disability centre care \\
\hline 51210301 & Intellectual and developmental disability centre care \\
\hline 5121030101 & Medicaid patients: Intellectual and developmental disability centre care \\
\hline 5121030102 & Medicare, private ins. \& all other patients: Intellectual \& develop. disability centre care \\
\hline 513 & Sales of blood and blood products, organs, and tissues \\
\hline 5131 & Sales of blood and blood products, organs, and tissues \\
\hline 513101 & Sales of blood and blood products, organs, and tissues \\
\hline 51310101 & Sales of blood and blood products, organs, and tissues \\
\hline
\end{tabular}




\subsubsection{Specific aspects}

Since most payments for human health activities in the U.S. are made by parties other than the individual patients, adjustments are applied to ensure that medical expenditures data reflect the ultimate recipient of the services. The U.S. shifts transactions reimbursed by public payers (such as Medicare and Medicaid) from the government consumption account to the personal consumption expenditure (PCE) account. Transactions reimbursed by private insurance companies are similarly shifted from the private business investment account to PCE.

PPI data is used to deflate human health activities output in the national accounts, where available. For areas where PPI data is not calculated, PCE price indices prepared by the U.S. Bureau of Economic Analysis are used.

The U.S. is currently developing a satellite account that organizes health care expenditures based on disease episodes, rather than spending on specified services in separate industries. A disease based concept combines, for example, all prescription drug, inpatient, and outpatient medical services provided for a specified medical condition. This approach is designed to provide greater clarity on the sources of changes in health care spending, and to evaluate the return on medical treatments. A disease based approach necessitates price index deflators that are also organized by disease. The U.S. is currently developing price indexes that can be used for this purpose.

\subsubsection{Overview of national methods}

The U.S. is the only country participating in the compilation of this manual that produces SPPIs in the human health activities division.

\section{Bibliography}

Swick, R., Bathgate D., and Horrigan, M., (2006), Services Producer Price Indices: Past, Present, and Future, Paper prepared for the National Bureau of Economic Research, 36 Conference on Research in Income and Wealth Summer Institute, Cambridge, MA, 83 p., available at: http://www.bls.gov/bls/fesacp1060906.pdf

Hospital Quality Valuation Team, (2008), Proposal for Adjusting the General Hospital Producer Price Index for Quality Change, U.S. Bureau of Labor Statistics. February 15, 2008, available at: http://conference.nber.org/confer/2008/si2008/PRCR/murphy2.pdf

Lucier, J., and Agliata, M., (2003), A New Quality Adjustment Methodology for Nursing

Home Price Indexes, U.S. Bureau of Labor Statistics. August 8, 2003 available at: http://www4.statcan.ca/english/voorburg/Documents/2003\%20tokyo/papers/2003065.pdf 


\section{Notes}

1. DRGs are used to classify patients by the resources they consume during treatment. 



\section{ANNEX A. CLASSIFICATION SYSTEMS BY INDUSTRY}

The United Nations International Standard Industrial Classification of all Economic Activities (ISIC), Rev.4 is a coherent and consistent classification structure of economic activities based on a set of internationally agreed concepts, definitions, principles and classification rules. It provides a comprehensive framework within which economic data can be collected and reported in a format that is designed for purposes of economic analysis, decision-taking and policy-making. The classification structure represents a standard format to organise detailed information about the state of an economy according to agreed economic principles.

The fourth edition, released in 2008, enhances the relevance of the classification by better reflecting the current structure of the world economy, recognising new industries that have emerged over the past 20 years and facilitating international comparison through increased comparability with existing regional classifications.

The annex A presents correspondence tables of ISIC with the other three main regional classification systems by activity:

- The Classification of Economic Activities within the European Communities (NACE);

- The North American Industrial Classification System (NAICS);

- Australian and New Zealand Standard Industrial Classification (ANZSIC).

The correspondence tables, presented for the 31 service industries discussed in this Guide, are presented in excel format and are available at the following address: http://dx.doi.org/10.1787/888933175812

In particular, correspondence tables are available for the following service industries:

E - Water supply; sewerage, waste management and remediation activities:

37 - Sewerage;

38 - Waste collection, treatment and disposal activities; materials recovery;

39 - Remediation activities and other waste management services.

G - Wholesale and retail trade; repair of motor vehicles and motorcycles:

46 - Wholesale trade, except of motor vehicles and motorcycles;

47 - Retail trade, except of motor vehicles and motorcycles.

\section{H - Transportation and storage:}

4923 - Freight transport by road;

501 - Sea and coastal water transport;

51 - Air transport; 
5210 - Warehousing and storage;

5224 - Cargo handling;

53 - Courier and postal activities.

I - Accommodation and food service activities:

55 - Accommodation;

56 - Food and beverage service activities.

J - Information and communication:

581 - Publishing of books, periodicals and other publishing activities;

5820 - Software publishing;

61 - Telecommunications;

62 - Computer programming, consultancy and related activity.

K - Financial and insurance activities:

6419 - Monetary intermediation activities;

6499 - Investment banking;

6612 - Security and commodity contracts brokerage;

651 - Insurance.

L - Real estate activities:

68 - Real estate activities with own or leased property.

M - Professional, scientific and technical activities:

6910 - Legal activities;

6920 - Accounting, bookkeeping and auditing activities; tax consultancy;

7020 - Management consultancy;

7110 - Architectural activities and engineering and related technical consulting services;

7120 - Technical testing and analysis;

7310 - Advertising;

7320 - Market research and public opinion polling.

$\mathbf{N}$ - Administrative and support service activities:

78 - Employment activities;

80 - Security and investigation activities;

812 - Cleaning activities.

\section{Q - Human health and social work activities:}

86 - Human health activities. 


\section{ANNEX B. CLASSIFICATION SYSTEMS BY PRODUCT}

The United Nations Central Product Classification (CPC) Ver.2 is a coherent and consistent classification based on the physical characteristics of goods or on the nature of the services rendered. Each type of good or service distinguished in the CPC is defined in such a way that it is normally produced by only one activity as defined in ISIC. The CPC covers products that are an output of economic activities, including transportable goods, non-transportable goods and services.

Annex B presents correspondence tables of CPC with the Classification of Products by Activity (CPA) - the CPC equivalent European Union classification.

Correspondence tables are available in excel format for the corresponding product of service industries presented in annex A. They are available at the following address: http://dx.doi.org/10.1787/888933175821 



\section{Glossary}

\section{Accrual accounting}

Accrual accounting records flows at the time economic value is created, transformed, exchanged, transferred or extinguished; this means that flows which imply a change of ownership are entered when ownership passes, services are recorded when provided, output is entered at the time products are created and intermediate consumption is recorded when materials and supplies are being used.

Some services are special in the sense that they are characteristically supplied on a continuous basis. Examples are operating leasing, insurance and housing services (including those of owner-occupied dwellings). These services are recorded as provided continuously over the whole period the contract lasts or the dwelling is available.

\section{Acquisition and selling prices}

Acquisition and selling prices refer to a data type in a price survey. The difference between the two allows for calculation of a margin price. The acquisition price is the cost to purchase a good or a service from the supplier excluding any taxes and rebates while the selling price is the cost to the purchaser excluding any taxes and transport charges.

\section{Aggregate}

A set of transactions relating to a defined flow of goods and services, such as the total output produced by resident establishments in a given period, or the total purchases of intermediate inputs made by resident establishments in a given period. The term "aggregate" also is used to mean the value of the specified set of transactions.

\section{Aggregation}

The process of combining or adding, different sets of transactions to obtain larger sets of transactions. The larger set is described as having a higher level of aggregation than the sets from which it is composed. The term "aggregation" also is used to mean the process of adding the values of lower-level aggregates to obtain higher-level aggregates. It also is used to mean the process by which price indices for lower-level aggregates are averaged, or otherwise combined, to obtain price indices for higher-level aggregates.

\section{Ancillary activity}

A supporting activity undertaken within an enterprise in order to create the conditions within which the principal or secondary activities can be carried out.

\section{Base period}

The base period generally is understood to be the period with which other periods are compared and whose values provide the weights for a price index. However, the concept of the "base period" is not a precise one and may be used to mean rather different things. Three types of base periods may be distinguished: 
1. The price reference period, that is, the period whose prices appear in the denominators of the price relatives used to calculate the index; or

2. The weight reference period, that is, the period usually a year, whose values serve as weights for the index. However, when hybrid expenditure weights are used in which the quantities of one period are valued at the prices of some other period, there is no unique weight reference period; or

3. The index reference period, that is, the period for which the index is set equal to 100.

The three reference periods may coincide but frequently do not.

\section{Basic price}

The basic price is the amount receivable by the producer from the purchaser, for a unit of service produced as output, minus any taxes on services payable, and plus any subsidies receivable by the producer as a consequence of its production or sale. The basic price includes any applicable discounts, rebates, and surcharges that may apply to customers. It excludes any transport charges invoiced separately by the producer.

\section{Billable hours (Billable working hours)}

The number of hours used to produce a good or service billed to the client. Revenue for the service divided by billable hours results in a unit value (also known as realised hourly rates and fee income per grade of worker). Billable hours are used in pricing methods based on working time.

\section{Bundle (bundling of services)}

Bundling is also referred to as package tie-in and tends to occur when one product is sold in combination with another as a requirement for the sale.

Bundling of products may be a source of economies or efficiencies for the producer, part of which may be reflected in a lower composite price for the buyer than if all the different products were supplied or bought separately. However, bundling may also make it difficult for firms to enter different product segments of the market.

The competition implications of bundling, including that of tied selling generally, are complex and need to be evaluated on a case by case basis adopting a rule of reason approach.

\section{Business enterprise}

An enterprise is a term in the commercial world used to describe a project or venture undertaken for gain. It is often used with the word "business" as in "business enterprise". Usually, by extension, it refers to the business entity carrying out the enterprise and is thus synonymous with "undertaking", "company" or "firm".

\section{Chain indices}

Chain indices are obtained by linking price (or volume) indices for consecutive periods; the short-term movements which are linked are calculated using weighting patterns appropriate to the periods concerned.

\section{Chain linking}

Joining together two indices that overlap in one period by rescaling one of them to make its value equal to that of the other in the same period, thus combining them into a 
single time series. More complex methods may be used to link together indices that overlap by more than period. Also known as "chaining".

\section{Charge-out rate}

The price charged per unit in pricing based on working time methods. Normally this is an hourly rate charged to a client for services and designed to recover all costs of providing the service.

\section{Component pricing}

Component pricing is a pricing method that divides a service into a number of key output sub-components of which one or more are then priced separately.

\section{Contract pricing}

Contract pricing is a pricing method that uses real transaction prices when the same producer for the same client repeats the services across survey periods. Prices of contracts are agreed for more than one period when the contract is signed or renewed.

\section{Data type in the survey}

Typical data surveyed by a compiler from a respondent: real transaction price, list price, revenue and amount sold, acquisition and selling prices, percentage fee and related value, expert estimate, and input data. The pricing method transforms these data into prices ready for standard PPI compilation procedures.

\section{Deflation}

The division of the value of some aggregate by a price index - described as a "deflator" - to revalue its quantities at the prices of the price reference-period or to revalue the aggregate at the general price level of the price reference period.

\section{Double-deflation}

A method whereby gross value added at constant prices is derived by subtracting the value of intermediate inputs at constant prices from the value of output at constant prices. The method is feasible only when the values at constant prices are additive such as those calculated using a Laspeyres' formula (either fixed-base or for estimates expressed in the previous year's prices).

\section{Derived prices}

A price that is not observed but rather calculated based on other variables. When developing margin price indexes for wholesale trade services and retail trade services, the margin price is derived from variables such as cost of goods sold and gross sales.

\section{Direct use of prices of repeated services}

Direct use of prices of repeated services refers to a pricing method that represents the ideal of using real transaction prices or, less preferably, list prices, of the same service product in successive survey periods.

\section{Domestic production}

GDP (Gross Domestic Production) is intended to be a measure of the value created by the productive activity of resident institutional units. Although for the kinds of technical reasons just given, it may not be identical with the sum of the gross values added of resident producers it nevertheless consists mainly of the latter. 
It should be noted, however, that GDP is not intended to measure the production taking place within the geographical boundary of the economic territory. Some of the production of a resident producer may take place abroad, while some of the production taking place within the geographical boundary of the economy may be carried out by non-resident producer units. For example, a resident producer may have teams of employees working abroad temporarily on the installation, repair or servicing of equipment. This output is an export of a resident producer and the productive activity does not contribute to the GDP of the country in which it takes places. Thus, the distinction between resident and non-resident institutional units is crucial to the definition and coverage of GDP. In practice, of course, most of the productive activity of resident producers takes place within the country in which they are resident. However, producers in service industries which typically have to deliver their outputs directly to their clients wherever they are located are increasingly tending to engage in production in more than one country, a practice which is encouraged by rapid transportation and instantaneous communication facilities. Geographical boundaries between adjacent countries are becoming less significant for mobile service producers, especially in small countries bordered by several other countries.

\section{Elementary aggregate}

This is the lowest level of aggregation for which value data are available and used in the calculation of the SPPI. Elementary aggregates consist of relatively homogeneous sets of goods or services. Their values are used as weights when averaging the elementary price indices associated with them to obtain indices for higher level aggregates. They also may serve as strata from which the products selected for pricing are sampled.

\section{Enterprise}

An enterprise is an institutional unit in its capacity as a producer of goods and/or services. From the European point of view, the enterprise is the smallest combination of legal units that is an organisational unit producing goods or services, which benefits from a certain degree of autonomy in decision-making, especially for the allocation of its current resources. An enterprise carries out one or more activities at one or more locations. An enterprise may be a sole legal unit. The enterprise thus defined is an economic entity which can therefore, under certain circumstances, correspond to a grouping of several legal units.

\section{Establishment}

An establishment is an enterprise or part of an enterprise that is situated in a single location and in which only a single (non-ancillary) productive activity is carried out or in which the principal productive activity accounts for most of the value added. Establishments are sometimes referred to as local kind-of -activity units (local KAUs).

\section{Expert estimate}

An expert estimate refers to a data type in a survey where a price is based on the potentially subjective judgment of an expert in the responding company who completes the survey. The estimate can reflect different types of units, for instance only components of an entire service, or prices per working time and per product.

\section{Exports}

Exports of goods and services consist of transactions in goods and services (sales, barter, or gifts or grants) from residents to non-residents. 


\section{Family tree}

A family tree in SPPI is a classification of services. In most cases, the classification comes from a specific survey in a particular services sector or from an industry representative organisation.

\section{Fictitious service}

A fictitious service is a service that is devised for a price survey only and used in model pricing.

\section{Final consumption}

Final consumption consists of goods and services used up by individual households or the community to satisfy their individual or collective needs or wants.

\section{Gross Domestic Product (GDP)}

GDP is the standard measure of the value of final goods and services produced by a country during a period. GDP can be measured in three different ways: expenditure measure, income measure and production measure.

\section{Globalisation}

The term globalisation is generally used to describe an increasing internationalisation of markets for goods and services, the means of production, financial systems, competition, corporations, technology and industries.

Amongst other things this gives rise to increased mobility of capital, faster propagation of technological innovations and an increasing interdependency and uniformity of national markets.

\section{Gross sector output}

Gross sector output is the sum of the sales of output of the establishments in the sector including the sales of output among themselves, to other sectors in the economy, and within the sector.

\section{Hedonic method}

The hedonic method is a regression technique used to estimate the prices of qualities or models that are not available on the market in particular periods, but whose prices in those periods are needed in order to be able to construct price relatives. It is based on the hypothesis that the prices of different models on sale on the market at the same time are functions of certain measurable characteristics and so regression methods can be used to estimate by how much the price varies in relation to each of these characteristics.

\section{Hourly charge-out rate}

The term refers to the price of one hour of work by an employee of the producer that contributes to the production or provision of a service.

\section{Imports}

Imports of goods and services consist of transactions in goods and services (purchases, barter, or receipts of gifts or grants) from non-residents to residents. The treatment of exports and imports in the System of National Accounts is generally identical with that in the balance of payments accounts as described in the Balance of Payments Manual. 


\section{Industry SPPIs}

An SPPI for an industry is compiled based on prices of all outputs of sampled establishments belonging to the industry concerned including prices of secondary activities.

\section{Input data}

A data type in the survey which corresponds to the prices of all (or a number of) input components needed to make a set amount of output. The profit margin is always to be included as an important input component. Input data can be taken from respondent records based on real transactions or be estimated by an expert.

This practice is best known from the pricing method pricing based on working time which multiplies an hourly wage with a coefficient to include overhead costs and mark-up to arrive at an hourly charge-out rate. The other pricing method using this data type in the survey is model pricing.

Strictly speaking, the input prices can be taken from a list, estimated by an expert or calculated as an average from real transactions. However, an input price is set apart as it is not an output price, unlike every standard data type in the survey.

\section{Intra-enterprise transfer price}

The value assigned on a per unit or per shipment basis to goods or services transferred from one establishment of an enterprise to another. It may or may not be economically significant. However, it is not a market price since ownership of the good or services does not change hands.

\section{Kind-of-activity unit}

A kind-of-activity unit (KAU) is an enterprise, or a part of an enterprise, which engages in only one kind of (non-ancillary) productive activity or in which the principal productive activity accounts for most of the value added.

\section{List prices}

List price refers to a data type in a price survey. The price of a product is quoted from the producer's price lists, catalogue, Internet site, etc.

\section{Local kind of activity unit (LKAU)}

See "Establishment"

\section{Loss leader}

Loss-leader selling is a marketing practice of selling a good or service at a loss in order to attract customers to buy other products at regular prices. Although this practice is illegal in some jurisdictions, in others it is viewed benevolently as a promotional device that has the pro-competitive effect of increasing total sales.

\section{Local unit}

A local unit is an enterprise, or a part of an enterprise, which engages in productive activity at or from one location. 


\section{Margin (trade)}

A trade margin is the difference between the actual or imputed price realised on a good purchased for resale (either wholesale or retail) and the price that would have to be paid by the distributor to replace the good at the time it is sold or otherwise disposed of.

\section{Margin (transport)}

A transport margin consists of those transport charges paid separately by the purchaser in taking delivery of the goods at the required time and place.

\section{Margin pricing}

Margin pricing is a pricing method that applies where the value of the service can be measured as the difference between the observed acquisition and selling prices of a given product.

\section{Market prices}

Market prices for transactions are the amounts of money willing buyers pay to acquire something from willing sellers.

\section{Mark-up}

The mark-up is an amount added to the cost price to determine the selling price.

\section{Model pricing}

Model pricing refers to a pricing method that is typically applied in cases where the service provided is unique. The approach specifies a standardised service product ("model") which is not transacted in the survey period but is sufficiently representative of the type of service provided; survey respondents are asked to provide a price quote for this standardised service product.

\section{Net sector output}

Net sector output refers to the sum of the sales of output of the establishments in the sector to other sectors of the economy. It is calculated as gross sector output for the sector less the sales of the sector's output within the sector.

\section{Non-probability sampling}

The selection of a sample of producers and products is non-random but based on expert knowledge of judgment. Non-probability sampling is also known as "non-random sampling", "purposive sampling" and "judgmental sampling".

\section{Non-resident}

A unit is non-resident if its centre of economic interest is not in the economic territory of a country.

\section{Output}

Output consists of those goods or services that are produced within an establishment that become available for use outside that establishment, plus any goods and services produced for own final use. 


\section{Output PPI}

Output producers price indices seek to measure the change in the trading price of products sold by domestic producers on the domestic market and the non-domestic market.

\section{Percentage fee and related values}

Percentage fee and related values refer to a data type in a price survey. They are data on both the value of a good or service, and percentage fee from which an actual fee (price) can be calculated. The percentage fee could in practice be taken from a list, estimated by an expert or calculated as an average from real transactions. The related value refers to an underlying good or other product to which the service relates.

\section{Percentage fee method}

The percentage fee method is a pricing method that calculates the value of the service as the product of the percentage fee and value of the product to which the fee relates.

\section{Period prices}

Period prices are an estimate of the price across a given period and so is an average price for the period.

\section{Point-in-time prices}

Point-in-time prices prevail on a particular day of the month.

\section{Producer Price Index (PPI)}

PPI is a measure of the change in the prices of goods and services either as they leave their place of production or as they enter the production process.

\section{PPS}

Probability proportional to size is a sampling procedure whereby each unit in the universe has a probability of selection proportional to the size of some known relevant variable. In the case of establishments, size is usually defined in terms of employment or output.

\section{Price} service.

The price of a good or service is the value that will purchase one unit of that good or

\section{Price index}

A price index is a measure reflecting the average of the proportionate changes in the prices of a specified set of goods and services between two periods of time.

\section{Price observation}

The price collected or reported for a sampled product or item.

\section{Price reference period}

The price reference period is the period with which prices in the current period are compared. 


\section{Price relative}

A price relative refers to a product surveyed within the business enterprise for which a micro index has been estimated. The micro index is made up of one of several price quotations for similar services.

\section{Pricing mechanism}

Corresponds to charging arrangements put in place by economic operators.

\section{Pricing method}

Pricing method is a procedure put in place by compilers to make price data eligible to be entered in an index. The pricing method is largely determined by the characteristics of the data available to the compiler.

\section{Pricing point}

The pricing point is the moment in the production or distribution process to which the price refers. For an output PPI, the pricing point is generally where the product leaves its place of production - hence, farm gate or factory gate price.

\section{Principal activity}

The principal activity of a producer unit is the activity whose value added exceeds that of any other activity carried out within the same unit (the output of the principal activity must consist of goods or services that are capable of being delivered to other units even though they may be used for own consumption or own capital formation).

The "principal activity" is identified by the "top-down" method as the activity which contributes most to the total value added of the entity under consideration.

\section{Probability sampling}

The random selection of a sample of producers and/or products from a universe of activity in which each producer and/or product has a known non-zero probability of selection.

\section{Producer's price}

A producer's price is the amount receivable by the producer from the purchaser for a unit of a good or service produced as output minus any VAT, or similar deductible tax, invoiced to the purchaser; it excludes any transport charges invoiced separately by the producer.

\section{Product SPPIs}

Product based SPPIs are created from samples of products and so should, in theory, be compiled on the basis of output information at product level from each establishment.

\section{Productivity}

Productivity is understood as a change in working time in the provision of the same service product in two periods. Change in productivity may be a result of improved labour or capital productivity or of the switch in the use of labour and capital.

\section{Products}

Products, also called "goods" and/or "services", are the result of production; they are exchanged and used for various purposes: as inputs in the production of other goods and services, as final consumption or for investment. 


\section{Product specification}

The (service) product specification is a detailed list of the characteristics that identify an individual sampled (service) product. Its purpose is to ensure the consistency of the price collection through time. The specifications cover both the (service) product and the transaction.

\section{"Pure" price change}

The change in the price of a good or service whose characteristics do not change over time. When some characteristics do change, that is to say a change in quality occurs, the "pure" price change is the price change remaining after eliminating the contribution of the change in quality to the observed price change.

\section{Quality adjustment}

The process - or the result of the process - of estimating what the market price of a replacement product would be if it had the characteristics of the product it replaces and with whose price its price is to be compared.

The process requires estimating the market value of any differences in the pricedetermining characteristics of the two products and adjusting - by addition, subtraction or multiplication by a coefficient - the observed price of the replacement product.

The adjustment is made in order that the price comparison between the two products reflects "pure" price change only.

\section{Real transaction price}

Real transaction price refers to a data type in a price survey. It is the price of a service actually paid in the market, taking the form of a receipt, bank statement or electronic database; it represents the actual price paid (inclusive of any discounts, surcharges or rebates) for an individual transaction that can be observed repeatedly.

\section{Representative item}

A representative item is a product selected for pricing within an elementary aggregate because of its significance in terms of turnover.

\section{Resident}

An institutional unit is resident in a country when it has a centre of economic interest in the economic territory of that country.

\section{Revenue}

The value of output sold. The value of invoiced sales of goods or services supplied to third parties during the reference period. The term is often used interchangeably with "sales" and "turnover".

\section{Revenue and amount sold}

Revenue and amount sold refer to a data type in a price survey. They allow for calculation of an average price over a large number of transactions. These data may be used in several pricing methods (unit value, component pricing, model pricing, and hourly charge-out rates). The revenue corresponds to the value of output sold or the value of invoiced sales of goods or services supplied to third parties during the reference period; the amount sold is a measure of the quantity of homogeneous services. 


\section{Re-weighting}

It is the introducing of a new set of weights into the index.

\section{Sampling frame}

The sampling frame is the list of the units (producers of services) in the universe from which a sample of units is to be selected. The sampling frame provides the details required to pick the sample, such as turnover, size, and main industry. The business register is the main sampling frame used in SPPIs although it may be supplemented by other sources as structural surveys or industry representative organisations.

\section{Secondary activity}

A secondary activity is an activity carried out within a single producer unit in addition to the principal activity and whose output, like that of the principal activity, must be suitable for delivery outside the producer unit.

A secondary activity is an activity carried out within a single producer unit in addition to the principal activity and whose output, like that of the principal activity, must be suitable for delivery outside the producer unit. The value added of the secondary activity must be less of than that of the principal activity, by definition of the latter. The output of the secondary activity is a secondary product. Most producer units produce at least some secondary products.

\section{Service industry}

The terms service industry(ies), service sector(s) or simply service(s) are generally used to refer to economic activities covered by Sections G to M of ISIC Rev. 4, and the units that carry out those activities.

\section{Services}

Services are outputs produced to order and which cannot be traded separately from their production; ownership rights cannot be established over services and by the time their production is completed they must have been provided to the consumers; however as an exception to this rule there is a group of industries, generally classified as service industries, some of whose outputs have characteristics of goods, i.e. those concerned with the provision, storage, communication and dissemination of information, advice and entertainment in the broadest sense of those terms; the products of these industries, where ownership rights can be established, may be classified either as goods or services depending on the medium by which these outputs are supplied.

\section{Spot (market) price}

Spot price is a generic term referring to any short-term sales agreement as opposed to prices in a long-term contract. It generally refers to a single provision of an uncustomized service, reflecting current (efficient) market conditions.

\section{Sub-contractor}

A sub-contractor is a person or firm contracted by a main contractor or employer to carry out work or deliver services, labour or materials as part of a larger project.

\section{Subsidy on product}

A subsidy on a product is a subsidy payable per unit of a good or service produced, either as a specific amount of money per unit of quantity of a good or service or as a 
specified percentage of the price per unit; it may also be calculated as the difference between a specified target price and the market price actually paid by a buyer.

\section{Tax on product}

A tax on a product is a tax that is payable per unit of some good or service, either as a specified amount of money per unit of quantity or as a specified percentage of the price per unit or value of the good or service transacted.

\section{Time-based method}

Time-based method refers to a pricing method where the price is directly or predominantly based on prices for a set amount of time's work (e.g. one hour's work) charged by the service provider.

\section{Transaction}

A transaction refers to the buying and selling of a product on terms mutually agreed by the buyer and seller.

\section{Transfer price}

A price adopted for bookkeeping purposes used to value transactions between affiliated enterprises integrated under the same management at artificially high or low levels in order to effect an unspecified income payment or capital transfer between those enterprises.

In the case of trade between a unit and another unit abroad of the same enterprise group, the invoiced price may well be a transfer or disposal price whose evolution may not always reflect the price changes for a client not within the same enterprise group

\section{Unit price}

The price of the product is expressed per some quantity unit of that product.

\section{Unit value method}

The unit value method is a pricing method that constructs a price index based on observed revenue and quantity data (unit value price). The unit value method as defined in this Guide is limited to cases where price observations refer directly to service output.

\section{Unit value "mix" problem}

Unit values "mix" problem refers to bias in price index construct by using unit value method that may attribute to changes in the mix of heterogeneous service products.

\section{Unit value price}

The price is calculated by dividing revenues from sales of services by quantity of delivered services.

\section{Value added - gross}

Gross value added is the value of output less the value of intermediate consumption; it is a measure of the contribution to GDP made by an individual producer, industry or sector; gross value added is the source from which the primary incomes of the SNA are generated and is therefore carried forward into the primary distribution of income account. 


\section{Value added - net}

Net value added is the value of output less the values of both intermediate consumption and consumption of fixed capital.

\section{Value added tax (VAT)}

A value added tax (VAT) is a tax on products collected in stages by enterprises; it is a wide-ranging tax usually designed to cover most or all goods and services but producers are obliged to pay to government only the difference between the VAT on their sales and the VAT on their purchases for intermediate consumption or capital formation, while VAT is not usually charged on sales to non-residents (i.e. exports).

\section{Weights}

Weights are a set of numbers used to weight price relatives, or elementary price indices, when these are averaged to obtain price indices or higher-level indices.

\section{Bibliography}

European Commission, IMF, OECD, UN and World Bank (eds.) (2009), System of National Accounts 2008, United Nations, New York.

Eurostat (2002), Methodology of short-term business statistics. Interpretation and guidelines", European Union, Luxembourg.

Eurostat (2013), European system of accounts - ESA 2010, European Union, Luxembourg.

ILO, IMF, OECD, UNECE, Eurostat, World Bank (eds.) (2004 a), Consumer Price Index Manual, Theory and practice, International Labour Office, Geneva.

ILO, IMF, OECD, UNECE, Eurostat, World Bank (eds.) (2004 b), Producer Price Index Manual, Theory and practice, International Monetary Funds, Washington, DC.

ILO, IMF, OECD, UNECE, Eurostat, World Bank (eds.) (2009), Export and Import Price Index Manual, Theory and Practice (XMPI Manual), International Monetary Funds, Washington, DC.

IMF (2009), Balance of Payments and International Investment Position Manual (BPM6), International Monetary Funds, Washington, DC.

OECD, OECD Glossary of Statistical Terms available on-line at: http://stats.oecd.org/glossary/

Eurostat, Ramon, Eurostat metadata server, available on-line at: http://ec.europa.eu/eurostat/ramon/index.cfm?TargetUrl=DSP PUB WELC)

Voorburg Group, (2009), Glossary of “Voorburg Group” terminology for MiniPresentations, Sector Papers, and Revisited Sector papers available at: http://www.voorburggroup.org/Documents/2009\%20Oslo/Papers/2009\%20\%2004.pdf 


\section{ORGANISATION FOR ECONOMIC CO-OPERATION AND DEVELOPMENT}

The OECD is a unique forum where governments work together to address the economic, social and environmental challenges of globalisation. The OECD is also at the forefront of efforts to understand and to help governments respond to new developments and concerns, such as corporate governance, the information economy and the challenges of an ageing population. The Organisation provides a setting where governments can compare policy experiences, seek answers to common problems, identify good practice and work to co-ordinate domestic and international policies.

The OECD member countries are: Australia, Austria, Belgium, Canada, Chile, the Czech Republic, Denmark, Estonia, Finland, France, Germany, Greece, Hungary, Iceland, Ireland, Israel, Italy, Japan, Korea, Luxembourg, Mexico, the Netherlands, New Zealand, Norway, Poland, Portugal, the Slovak Republic, Slovenia, Spain, Sweden, Switzerland, Turkey, the United Kingdom and the United States. The European Union takes part in the work of the OECD.

OECD Publishing disseminates widely the results of the Organisation's statistics gathering and research on economic, social and environmental issues, as well as the conventions, guidelines and standards agreed by its members. 


\section{Eurostat-OECD Methodological Guide for Developing Producer Price Indices for Services}

\section{Contents}

Producer Price Indices for Services

Part I. Methodological aspects

Chapter 1. General aspects of Service Producer Price Indices compilation

Chapter 2. Main pricing methods for Service Producer Price Indices

Chapter 3. Practical aspects of the development process

Part II. Producer Price Indices for specific service industries

Chapter 4. Waste management

Chapter 5. Wholesale and retail trade services

Chapter 6. Transportation and storage

Chapter 7. Accommodation and food service activities

Chapter 8. Information and telecommunication

Chapter 9. Financial and insurance activities

Chapter 10. Real estate activities

Chapter 11. Professional, scientific and technical activities

Chapter 12. Administrative and support service activities

Chapter 13. Human health activities

Annex $A$. Classification systems by industry

Annex $B$. Classification systems by product

Glossary

Consult this publication on line at http://dx.doi.org/10.1787/9789264220676-en.

This work is published on the OECD iLibrary, which gathers all OECD books, periodicals and statistical databases. Visit www.oecd-ilibrary.org for more information.

OECDpublishing www.oecd.org/publishing

ISBN 978-92-64-22066-9

$302014061 \mathrm{P}$ 